\title{
Stadtgestaltung durch örtliche Bauvorschriften
}

\author{
Dissertation \\ zur Erlangung des Doktorgrades \\ der Juristischen Fakultät \\ der Universität Regensburg
}

\section{UBR UBR UBR UBR UBR}

069008307563

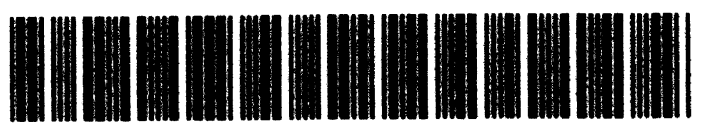

vorgelegt von

Gerrit Manssen 


\author{
Erstberichterstatter: Prof. Dr. Udo Steiner \\ Zweitberichterstatter: Prof. Dr. Rainer Arnold \\ Tag der mündlichen Prüfung: 22. Februar 1990
}




\section{GERRIT MANSSEN}

Stadtgestaltung durch örtliche Bauvorschriften 


\title{
Schriften zum Öffentlichen Recht
}

\author{
Band 583
}




\title{
Stadtgestaltung durch örtliche Bauvorschriften
}

\author{
Von
}

Gerrit Manssen

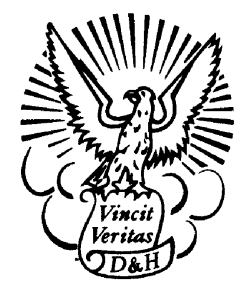

Duncker \& Humblot · Berlin 
CIP-Titelaufnahme der Deutschen Bibliothek

Manssen, Gerrit:

Stadtgestaltung durch örtliche Bauvorschriften / von Gerrit

Manssen. - Berlin: Duncker u. Humblot, 1990

(Schriften zum Öffentlichen Recht; Bd. 583)

Zugl.: Regensburg, Univ., Diss., 1990

ISBN 3-428-06926-9

NE: GT

Alle Rechte vorbehalten

(C) 1990 Duncker \& Humblot $\mathrm{GmbH}$, Berlin 41

Fotoprint: Berliner Buchdruckerei Union $\mathrm{GmbH}$, Berlin 61

Printed in Germany

ISSN 0582-0200

ISBN 3-428-06926-9 


\section{Vorwort}

Die vorliegende Untersuchung wurde im Wintersemester 1989/90 von der Juristischen Fakultät der Universität Regensburg als Dissertation angenommen. Die Arbeit ist im November 1989 abgeschlossen worden, bis März 1990 erschienene Rechtsprechung und Literatur wurde jedoch in den Fußnoten weitgehend berücksichtigt.

Bedanken möchte ich mich an dieser Stelle zunächst und vor allem bei Herrn Prof. Dr. Udo Steiner. Er hat die Untersuchung des Themas angeregt, mir im Rahmen der Tätigkeit an seinem Lehrstuhl genügend zeitliche Dispositionsmöglichkeiten belassen, sowie die Anfertigung der Arbeit mit seinem fachlichen Rat und persönlichem Engagement gefördert.

Ein weiterer Dank gebührt meiner Frau Heike, zum einen für fleißiges Kontroll- und Korrekturlesen, zum zweiten dafür, daß sie mir manch interessanten Aspekt aus ihrer beruflichen Ausbildung und planungspraktischen Erfahrung vermitteln konnte.

Gedankt sei schließlich auch Herrn Prof. Dr. Rainer Arnold für die zügige Erstellung des Zweitgutachtens.

Widmen möchte ich die Arbeit meinen Eltern.

Regensburg, im April 1990

Gerrit Manssen 


\section{Inhalt}

A. Örtliche Bauvorschriften zwischen Bauplanungs- und Bauordnungsrecht

I. Offene Fragen bei der kompetenzrechtlichen Einordnung

von örtlichen Bauvorschriften. 19

1. Einleitung und Darstellung des weiteren Vorgehens...................................................... 19

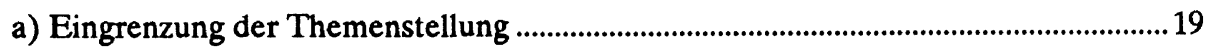

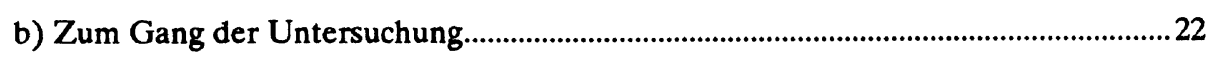

2. Die einzelnen Regelungsbereiche örtlicher Bauvorschriften und ihre kompetenzrechtliche Einordnung.......................................................................24

a) Die "baugestalterischen" Vorschriften........................................................................24

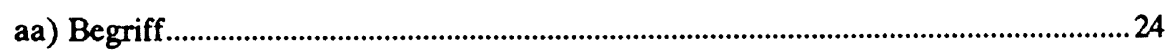

bb) Die Verfolgung "städtebaulicher Absichten" als Kompetenzproblem................26

cc) Anforderungen in baugestalterischen Vorschriften im Verhältnis zu Festsetzungen nach $\$ 9$ Abs. 1 BauGB ..................................... 28

b) "Schutzvorschriften" für bestimmte Straßen, Plätze etc. ...........................................31

aa) Schutzvorschriften und baugestalterische Vorschriften ........................................31

bb) Schutzvorschriften und Denkmalschutz............................................................... 32

cc) Schutzvorschriften und Bauplanungsrecht .............................................................. 34

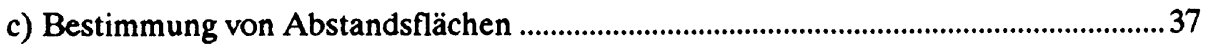

aa) Allgemeines zum Abstandsflächenrecht in den Landesbauordnungen...............37

bb) Abstandsflächenrecht und Bauplanungsrecht .....................................................3 37

cc) Die funktionelle Bedeutung abstandsmodifizierender örtlicher Bauvorschriften ...........................................41

d) Sonstige Regelungsbereiche und ihr Verhältnis zum Bauplanungsrecht...................44

aa) Weitere gestalterische Vorschriften ....................................................................44

bb) Einschränkungen für die Errichtung von Stellplätzen und Garagen .................. 45

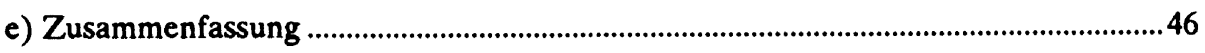

II. Die Abgrenzung zwischen Bauordnungs- und Bauplanungsrecht ....................................47

1. Allgemeines zur Kompetenzabgrenzung im Baurecht ..................................................4 47

a) Kompetenzaufteilung im Baurecht und Schutz der Länderzuständigkeiten ...........47

b) Die Bedeutung der Eigentumsgarantie

für die Kompetenzaufteilung im Baurecht 
2. Das Rechtsgutachten des BVerfG. .51

a) Wesentliche Aussagen und Wirkungen des Gutachtens ...............................................51

b) Kritik an den Abgrenzungsformeln des BVerfG...........................................................53

c) Länderkompetenzen im Baurecht und materieller Polizeibegriff.............................57

3. Der städtebauliche Bezug als tatsächlich verwendeter Abgrenzungsmaßstab ..............59

a) Das Beispiel der Stadterhaltungssatzungen ............................................................59

b) Schwierigkeiten bei der Bestimmung des städtebaulichen Bezugs am Beispiel der Stadtgestaltung....................................................................................6 63

c) Das BauGB und der Begriff der geordneten städtebaulichen Entwicklung ............67

aa) Kompetenzrechtliche Begrenzungsnormen im BauGB.........................................67

bb) Konkretisierung des verfassungsrechtlichen Abgrenzungsmaßstabes

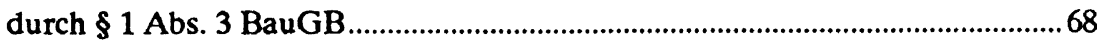

cc) Konkretisierung des verfassungsrechtlichen Abgrenzungsmaßstabes

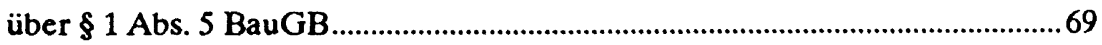

(1) Öffentliche Belange und Planrechtfertigung.....................................................69

(2) Private Belange und Planrechtfertigung .......................................................... 76

(3) Folgen für die finale Abgrenzung zwischen Bauordnungsund Bauplanungsrecht

dd) Die geschichtliche Entwicklung des Bauplanungsrecht und die Kompetenz "Bodenrecht"

ee) Konkretisierung der aufgrund der Bodenrechtskompetenz zulässigen Festsetzungen

III. Übertragung des gefundenen Ergebnisses auf die Kollisionsprobleme bei örtlichen Bauvorschriften .

1. Probleme bei den "baugestalterischen Vorschriften" .....................................................91

a) Die Verfolgung "städtebaulicher" Absichten ...............................................................91

b) Überschneidungen von möglichen Festsetzungen ......................................................93

2. Probleme bei den denkmalschützenden Vorschriften ........................................................95

3. Bauleitplanung und Abstandsflächen...................................................................................97

a) Das Problem der Ersatzbauleitplanung .........................................................................97

b) Zur Ermöglichungsfunktion von örtlichen Bauvorschriften ...................................98

4. Kompetenzrechtliche Qualifikation von örtlichen Bauvorschriften ............................102

\section{B. Die Garantie der gemeindlichen Selbstverwaltung und Stadtgestaltung}

I. Die Einordnung des Erlasses von örtlichen Bauvorschriften in die Aufgabensysteme nach den Kommunalgesetzen der Länder.

1. Dualistisches und monistisches Modell. 
2. Die Regelungen in den Landesbauordnungen im Hinblick auf die Frage des Wirkungskreises. . .110

II. Der verfassungsrechtliche Spielraum bei der Einordnung von örtlichen Bauvorschriften

1. Problemstellung 113

2. Alternative Konzeptionen zur Auslegung des Art. 28 Abs. 2 GG

3. Örtliche Bauvorschriften und Kernbereich der kommunalen Selbstverwaltungsgarantie.

a) Die Rechtsprechung des BVerfG zum Problem des Kernbereichs der kommunalen Selbstverwaltung 118

b) Das Problem der Zuordnung der Bauleitplanung zum Kernbereich........................ 118

4. Die Bedeutung des Gesetzesvorbehaltes in Art. 28 Abs. 2 S. 1 GG ............................ 128

a) Problemstellung..............................................................................................................128

b) Die Aufgabenqualifikation durch den formellen Gesetzgeber................................131

c) "Rahmen der Gesetze" nach Art. 28 Abs. 2 S. 1 GG und Gesetzesvorbehalt........ 134

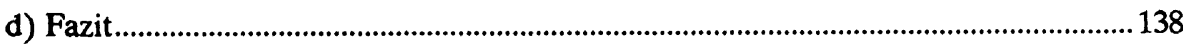

III. Gemeindliche Gestaltungsbefugnisse und Wirkungskreiszuordnung...............................139

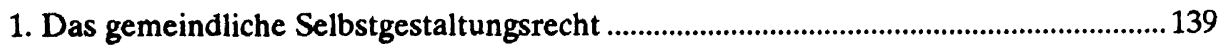

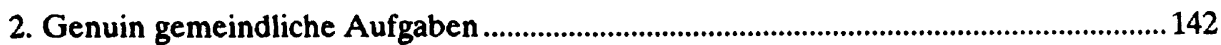

3. Gemeindliche Individualität und kommunales Aufgabensystem .................................144

4. Satzung und Rechtsverordnung als Instrumente gemeindlicher Selbstgestaltung .... 146

a) Die mögliche Relevanz der Unterscheidung für den Bereich örtlicher Bauvorschriften

b) Die Verwendung von Rechtsverordnungs- und Satzungsermächtigungen in der Rechtsordnung.

c) Zur Frage der verfassungsrechtlichen Zulässigkeit der festgestellten landesrechtlichen Regelungen.................................................................................. 150

d) Weitere Abgrenzungsversuche außerhalb von Art. 80 Abs. 1 S. 2 GG.................... 152

e) Von Art. 80 GG ausgehende Abgrenzungsversuche....................................................154

C. Örtliche Bauvorschriften und baugestalterische Generalklauseln ........................................ 165

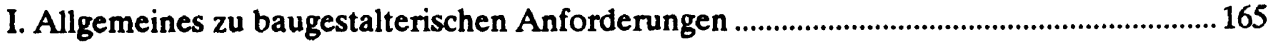

1. Bestandsaufnahme der baugestalterischen Anforderungen in den

Landesbauordnungen .165

a) Übersicht über die gesetzlichen Regelungen 165

b) Der Einfluß der Rechtsprechung des BVerwG zu § 1 BaugestVO auf die Ausformung der gesetzlichen Gestaltungsanforderungen 
2. Das Problem des fehlenden Konsenses in ästhetischen Fragen.......................................170

3. Der maßgebliche grundrechtliche Prüfungsmaßstab ....................................................... 173

II. Die umgebungsunabhängigen Anforderungen an die Baugestaltung ................................ 176

1. Umgebungsunabhängige Anforderungen und Sozialbindung des Eigentums .............176

2. Kulturgestaltungsmacht des Staates und Förderung der Bauästhetik ...........................180

3. Der Maßstab für die Beurteilung einer Verunstaltung ...................................................... 183

a) Zutreffendes an der Argumentation mit dem Topos "gebildeter Durchschnittsbetrachter" 183

b) Versuche einer Konkretisierung des "gebildeten Durchschnittsbetrachters"..

4. Relevanz der umgebungsunabhängigen gestaltungsrechtlichen Generalklauseln für das Institut der örtlichen Bauvorschriften

III. Formellgesetzliche umgebungsabhängige Anforderungen an die Baugestaltung und ihre Relevanz für den Bereich der örtlichen Bauvorschriften

1. Umgebungsabhängige Gestaltungsanforderungen und Eigentumsgarantie.

a) Umgebungsabhängige Forderungen und Bauästhetik.

b) Versuche der Absicherung umgebungsabhängiger Anforderungen an die Baugestaltung aufgrund verfassungsrechtlicher Determinierung.

2. Die Reichweite der umgebungsabhängigen Anforderungen an die Baugestaltung .. 197

a) Schutz des bestehenden Straßen-, Orts- und Landschaftsbildes

aa) Die Regelungen in den Landesbauordnungen 197

bb) Unterschiede und Gemeinsamkeiten bei der Auslegung im Vergleich zum umgebungsunabhängigen Maßstab

cc) Konkretisierungsmöglichkeiten durch örtliche Bauvorschriften 200

b) Der Schutz der beabsichtigten Gestaltung des Straßen-, Orts- und Landschaftsbildes. 202

aa) Die formulierungsmäßigen Differenzen ................................................................202

bb) Das Problem der rechtssatzmäßigen Konkretisierung .......................................203

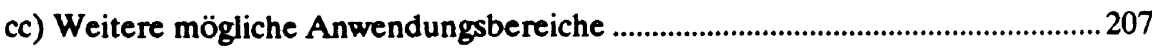

dd) Beabsichtigte Gestaltung und "positive Gestaltungspflege" ............................... 208

c) Eine bayerische Besonderheit: Art. 12 Abs. 3 BayBO................................................210

D. Erweiterter Umgebungsschutz und positive Gestaltungspflege durch örtliche

Bauvorschriften

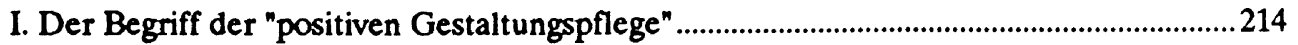

1. Positive Gestaltungspflege durch baugestalterische Vorschriften ....................................214

2. Positive Gestaltungspflege durch Schutzvorschriften 
II. Zur verfassungsrechtlichen Zulässigkeit einer positiven Gestaltungspflege ......................217

1. Die eigentumsrechtliche Zulässigkeit positiver Gestaltungspflege ...................................217

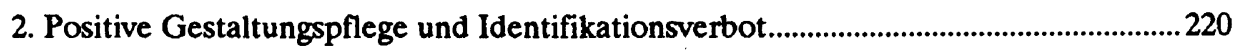

3. Positive Gestaltungspflege und Bestimmtheitsgrundsatz ................................................222

a) Bestimmtheit der Satzungsbestimmungen .........................................................222

b) Bestimmtheit der Ermächtigungsgrundlagen ...........................................................224

E. Das Normenerlaßverfahren bei örtlichen Bauvorschriften - materiellrechtliche und

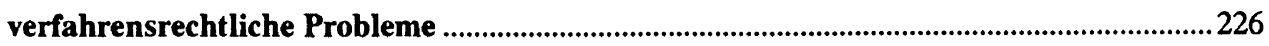

I. Die Aufnahme von örtlichen Bauvorschriften in den Bebauungsplan ..............................226

1. Die Bedeutung des § 9 Abs. 4 BauGB.....................................................................................226

a) Formelle oder materielle Deutung des $\$ 9$ Abs. 4 1. HS BauGB...............................226

b) Die Anforderungen bei der Aufnahme von örtlichen Bauvorschriften in den Bebauungsplan ................................................................................................................2231

aa) Die Auslegung des $\S 9$ Abs. 4 2. HS BauGB..........................................................231

bb) Die Anforderungen im einzelnen ..........................................................................232

c) Das Normenkontrollverfahren gegen örtliche Bauvorschriften als Bestandteile von Bebauungsplänen .................................................................................................... 236

2. Die Verweisungen in den Landesbauordnungen auf das BauGB / BBauG .................237

a) Das Maß der Ausschöpfung der Ermächtigung des $\$ 9$ Abs. 4 BauGB durch die Landesbauordnungen...................................................................................................237

aa) Abweichungen bei verfahrensrechtlichen Fragen ...................................................237

bb) Zum Problem der Abwägung ..................................................................................2239

cc) Folgen aus einer Nichterfüllung des "Pflichtprogramms" ...................................243

b) Die Inbezugnahme des BBauG durch die Landesbauordnungen als "Verweisungsproblem" ...................................................................................................24

aa) Die grundsätzliche Problemstellung ..................................................................244

bb) Terminologische Vorfragen ..................................................................................246

c) Bedenken gegen die Annahme einer dynamischen Verweisung durch die Landesbauordnungen auf Bundesbaurecht ....................................................................250

d) Inhalt und Bestimmtheit der Verweisungen in den Landesbauordnungen auf das BBauG

II. Der Erlaß von örtlichen Bauvorschriften als einfache Satzungen

Х1. Verfahrensrechtliche Anforderungen an den Erlaß einer Satzung über örtliche

Bauvorschriften.

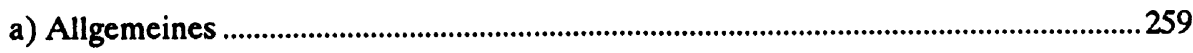

b) Versuche zur Ableitung einer Begründungspflicht für örtliche Bauvorschriften.. 261

$\chi$ aa) Begründungspflicht und Abwägungsgebot. 
bb) Begründungspflicht aus Art. 20 Abs. 3 GG ..........................................................2.

cc) Begründungspflicht aus Art. 19 Abs. 4 GG .........................................................265

dd) Grundrechtliche Ableitung einer Begründungspflicht .......................................2.266

(1) Allgemeines zur Ableitung von Verfahrensanforderungen aus den

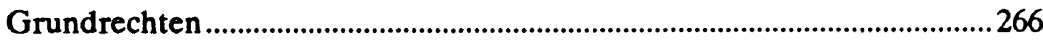

(2) Art. 14 GG und Begründungspflicht bei örtlichen Bauvorschriften.........269

2. Materiellrechtliche Anforderungen an den Erlaß örtlicher Bauvorschriften..............2271

a) Das Abwägungsgebot bei örtlichen Bauvorschriften ...................................................271

aa) Die Konzeptionen der Oberverwaltungsgerichte ................................................271

bb) Die Rechtsprechung des BVerwG zur Vorgangs- und Ergebniskontrolle bei Abwägungsprozessen

cc) Abwägungsvorgangs- und Abwägungsergebniskontrolle in der

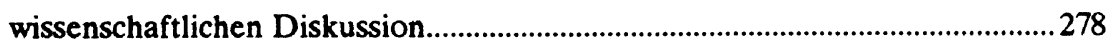

dd) Abwägung und Abwägungskontrolle bei örtlichen Bauvorschriften.................222

b) Die Wahl zwischen der Aufnahme örtlicher Bauvorschriften in den Bebauungsplan und dem Erlaß einer einfachen Satzung............................................2.287

3. Satzungen über Ortsgestaltung ohne rechtsverbindliche Festlegungen .........................290

a) Zusammenfassung der Schwierigkeiten bei einer Ortsgestaltung durch rechtsverbindliche Festlegungen

b) Privatrechtliche Durchsetzung von Gestaltungsabsichten und Schutz der Eigentümerinteressen 291

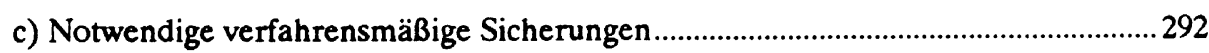

F. Zusammenfassung der wichtigsten Ergebnisse

Literatur. .304

Stichwortregister 331 


\section{Abkürzungen}

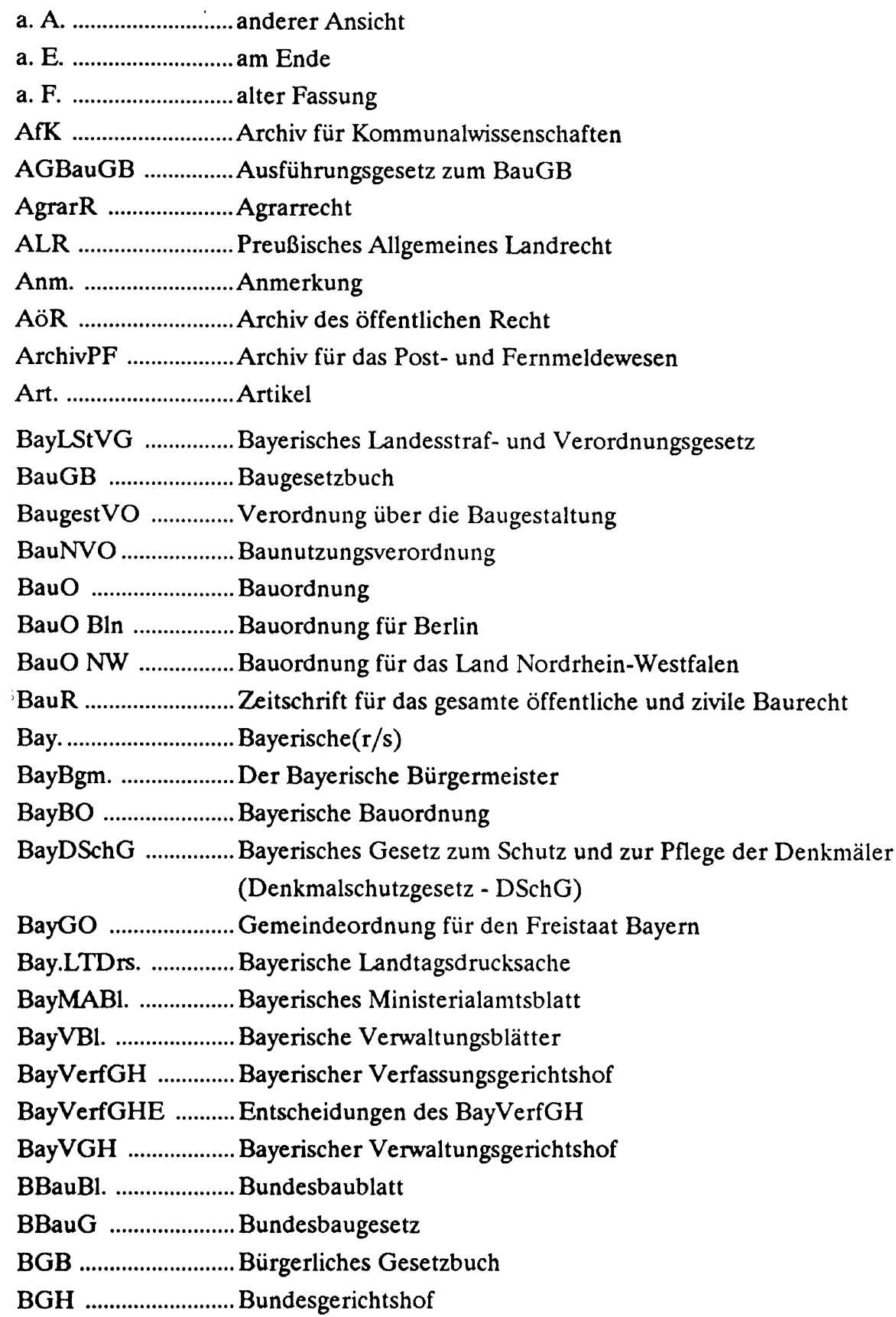


BImSchG Bundesimmissionsschutzgesetz

BK Kommentar zum Bonner Grundgesetz

BremDSchG Bremisches Gesetz zur Pflege und zum Schutz der Kulturdenkmäler (Denkmalschutzgesetz - DSchG)

BremLBauO Bremische Landesbauordnung

BRS Baurechtssammlung

BT-Drs. Bundestagsdrucksache

Buchh. Buchholz, Sammel- und Nachschlagewerk der Rechtsprechung des BVerwG

BV Verfassung des Freistaates Bayern

BVerfG ................... Bundesverfassungsgericht

BVerfGE ..................Entscheidungen des BVerfG

BVerwG ................. Bundesverwaltungsgericht

BVerwGE ................ Entscheidungen des BVerwG

BWDSchG ............... Baden-Württembergisches Gesetz zum Schutz der Kulturdenkmale (Denkmalschutzgesetz - DSchG)

BWLT-Drs. .............. Baden-Württembergische Landtagsdrucksache BWVGH .................. Baden-Württembergischer Verwaltungsgerichtshof

DAR Deutsches Autorecht

DB Der Betrieb

ders. derselbe

difu Deutsches Institut für Urbanistik

DJT Deutscher Juristentag

DÖV Die Öffentliche Verwaltung

DSchG Bln. Gesetz zum Schutz von Denkmalen in Berlin (Denkmalschutzgesetz Berlin)

DSt. Der Städtetag

Drs. Drucksachen

DSchPfG Rh.Pf. ...... Rheinland-Pfälzisches Landesgesetz zum Schutz und zur Pflege der Kulturdenkmäler (Denkmalschutz- und -pflegegesetz - DSchPflG - )

DVBayBO .............. Durchführungsverordnung zur BayBO

DVB1. ...................... Deutsche Verwaltungsblätter

DVerwPr. ................ Deutsche Verwaltungspraxis

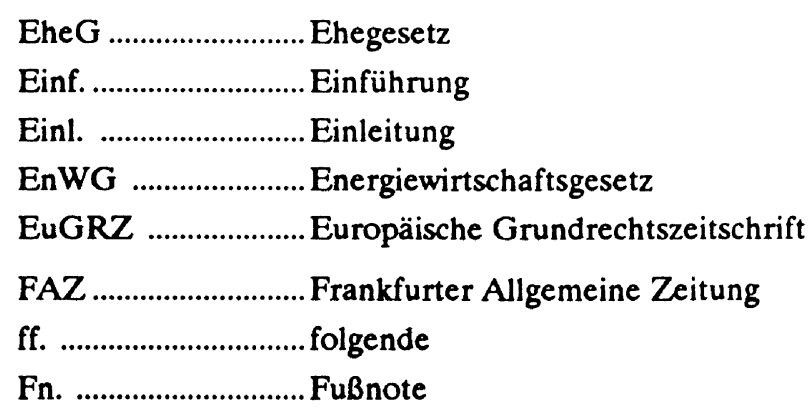

GemO BW .. Gemeindeordnung für Baden-Württemberg 


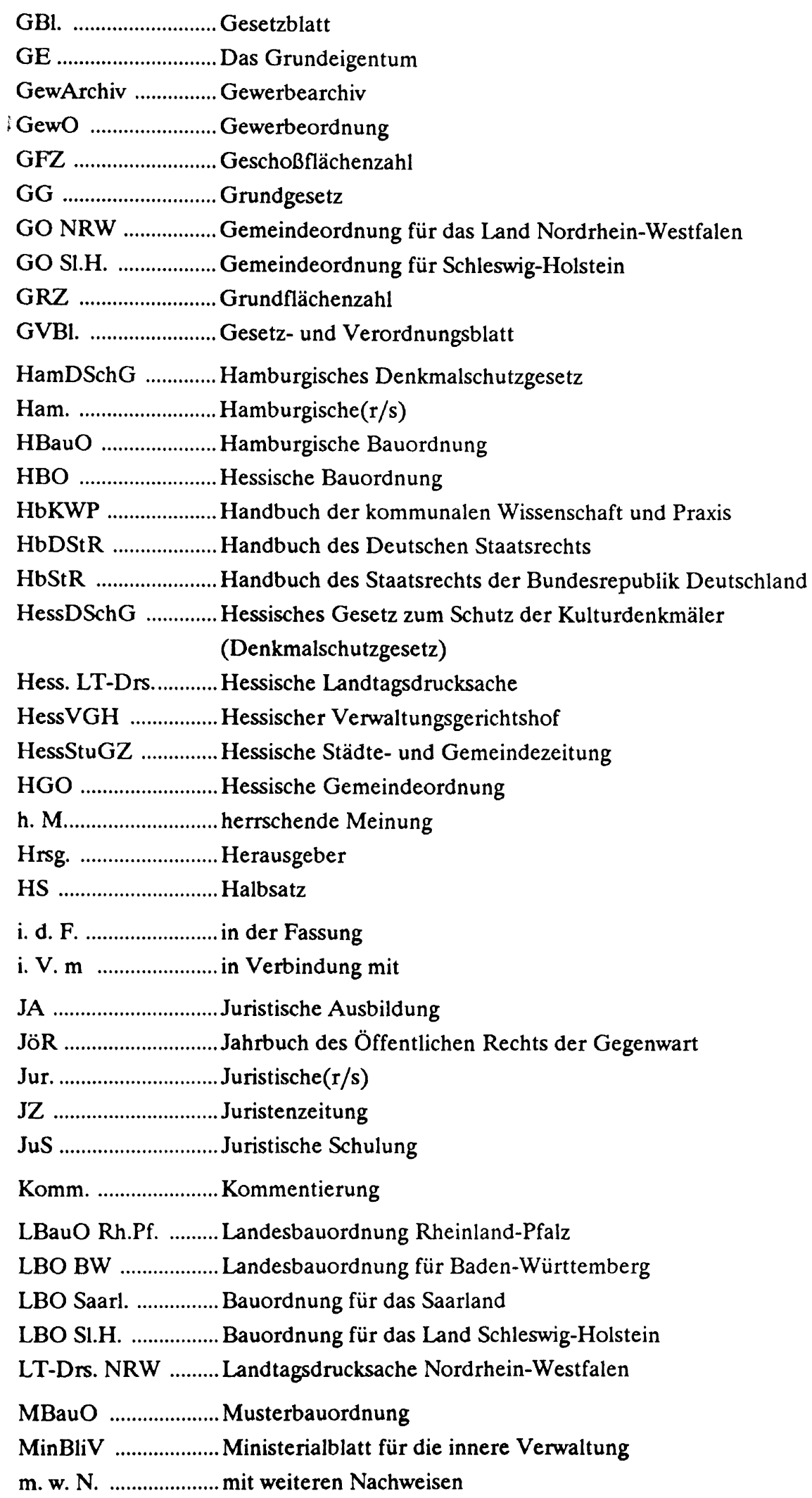


n. F. neuer Fassung

NBauO Niedersächsische Bauordnung

NDSchG . Niedersächsisches Denkmalschutzgesetz

NGO Niedersächsiche Gemeindeordnung

NJW Neue Juristische Wochenschrift

NRW Nordrhein-Westfalen

NuR Natur und Recht

NVwZ Neue Verwaltungsrechtszeitschrift

NVwZ-RR Neue Verwaltungsrechtszeitschrift - Rechtsprechungsreport

NWDSchG Gesetz zum Schutz und zur Pflege der Denkmäler im Lande Nordrhein-Westfalen (Denkmalschutzgesetz - DSchG)

NWVB1. Nordrhein-Westfälische Verwaltungsblätter

$\mathrm{Nr}$. Nummer

OLG Oberlandesgericht

OVG Oberverwaltungsgericht

PrGS Preußische Gesetzsammlung

PrOVG Preußisches Oberverwaltungsgericht

PrOVGE Entscheidungen des PrOVG

RArbBI. Reichsarbeitsblatt

\{́RdErl. Runderla $B$

|RGBI. Reichsgesetzblatt

Rh.Pf.GemO Gemeindeordnung für Rheinland-Pfalz

$\mathrm{Rn}$. Randnummer

ROG Raumordnungsgesetz

S. Seite

SDschG . Gesetz Nr. 1067 zum Schutz und zur Pflege der Kulturdenkmäler im Saarland (Saarländisches Denkmalschutzgesetz)

SaarlKSVG Saarländisches Kommunalselbstverwaltungsgesetz

Sl.H. Schleswig-Holstein

S1.H.DSchG ..Schleswig-Hosteinisches Gesetz zum Schutze der Kulturdenkmale StrG BW Baden-Württembergisches Straßengesetz

u. a. und andere

UPR Umwelt- und Planungsrecht

VBIBW Verwaltungsblätter für Baden-Württemberg

Verf. BIn Verfassung von Berlin

Verf. Bremen Landesverfassung der Freien Hansestadt Bremen

Verf. BW Verfassung des Landes Baden-Württemberg

Verf. Hessen Verfassung des Landes Hessen

Verf. HH Verfassung der Freien und Hansestadt Hamburg

Verf. NRW Verfassung für das Land Nordrhein-Westfalen

Verf. Rh.Pf. Verfassung für Rheinland-Pfalz

Verf. Saarl. Verfassung des Saarlandes 
Verf. Sl.H. Landessatzung Schleswig-Holstein

VerwArchiv Verwaltungsarchiv

VerwRundschau ...... Verwaltungsrundschau

vgl. vergleiche

VO Verordnung

Vorl.Nieders.Verf. Vorläufige Niedersächsiche Verfassung

Vorb. Vorbemerkung

VR Vermessungswesen und Raumordnung

VVDStRL Veröffentlichungen der Vereinigung der Deutschen Staatsrechtslehrer

VwGO Verwaltungsgerichtsordnung

VwVfG Verwaltungsverfahrensgesetz

WiVerw. Wirtschaft und Verwaltung

WRP Wettbewerb in Recht und Praxis

WRV Weimarer Reichsverfassung

z. B. zum Beispiel

ZfBR Zeitschrift für deutsches und internationales Baurecht

ZG Zeitschrift für Gesetzgebung

ZPO Zivilprozeßordnung

I ZRP Zeitschrift für Rechtspolitik

ZSSD Zeitschrift für Stadtgeschichte, Stadtsoziologie und Denkmalschutz 



\section{A. Örtliche Bauvorschriften zwischen Bauplanungs- und Bauordnungsrecht}

\section{Offene Fragen bei der kompetenzrechtlichen Einordnung von örtlichen Bauvorschriften}

\section{Einleitung und Darstellung des weiteren Vorgehens}

a) Eingrenzung der Themenstellung

Die heute in der Bundesrepublik geltenden Landesbauordnungen sehen die Möglichkeit zum Erlaß von ortsrechtlichen Vorschriften in Ergänzung zu den allgemeinen Bestimmungen der Bauordnungen vor ${ }^{1}$. Die Begriffe, mit denen diese Vorschriften in den Landesbauordnungen bezeichnet werden, sind nicht ganz einheitlich. Vor allem verwenden § $76 \mathrm{BauO} \mathrm{Bln}, \S 118$ HBO und $\S 81 \mathrm{HBauO}$ den von den anderen Landesbauordnungen gewählten Begriff "örtliche Bauvorschriften" nicht. Zur Vereinfachung der Terminologie soll im folgenden jedoch stets von "örtlichen Bauvorschriften" gesprochen werden, wenn die genannten Vorschriften der Landesbauordnungen gemeint sind.

Die Rechtsprechung der Oberverwaltungsgerichte hatte sich in der Vergangenheit regelmäßig mit Satzungen über örtliche Bauvorschriften zu beschäftigen ${ }^{2}$. Dies dürfte ein deutlicher Hinweis darauf sein, daß örtliche Bauvorschriften als Instrument zur Stadtgestaltung durchaus praktische Bedeutung haben und dabei häufig auch rechtliche Probleme auftreten ${ }^{3}$. Deren literarische Behandlung beschränkte sich lange Zeit weitgehend auf die jeweiligen Kommentierungen zu den Landesbauordnungen ${ }^{4}$. In jüngerer Zeit sind nun auch einige Monographien erschienen, die auf ein gestiegenes wis-

\footnotetext{
${ }^{1} \S 73$ LBO BW; Art. 91 BayBO; $\S 76$ BauO Bln und $\S 7$ AGBauGB vom 19.12.1987, GVBI. 1987, S. 2731 f.; § 110 BremLBauO; § $81 \mathrm{HBauO;} 118 \mathrm{HBO}$; $56 \mathrm{NBauO}$; $81 \mathrm{BauO}$ NW; § 86 LBauO Rh.Pf.; § 83 LBO Saarl.; § 82 LBO Sl.H.

${ }^{2}$ Siehe dazu die Nachweise im Text zu den einzelnen Sachbereichen.

${ }^{3}$ Zur praktischen Relevanz siehe Jaeger, ZSSD 1979, S. 302.

${ }^{4}$ Siehe insoweit die weiteren Nachweise im Text und im Literaturverzeichnis.
} 
senschaftliches Interesse hinweisen ${ }^{5}$. Desweiteren ist das Thema "örtliche Bauvorschriften" nicht nur juristisch von Relevanz. Mit ihm beschäftigen sich auch andere Disziplinen, etwa der Forschungsbereich "Stadtgestaltung"6.

In der vorliegenden Untersuchung wird es - ohne daß Stellungnahmen aus anderen Bereichen ignoriert werden sollen - vor allem um die juristischen Fragestellungen gehen. Ziel der Arbeit kann es nicht sein, die Planungspraxis darüber zu belehren, ob und in welchen Zusammenhängen der Erlaß von örtlichen Bauvorschriften sinnvoll ist. Selbst für die Frage, ob durch "planenden Eingriff" überhaupt "gestalterische Qualität" erreicht werden kann ${ }^{7}$, soll keine erschöpfende Antwort gesucht werden ${ }^{8}$. Aufzuzeigen ist vor allem der rechtliche Rahmen, in dem sich der Erlaß von örtlichen Bauvorschriften bewegen kann. Ob sich damit stadtgestalterisch ansprechende Ergebnisse erzielen lassen, kann nur der entscheiden, der dies in der Praxis ausprobiert'.

Aber auch bei den juristischen Fragestellungen ergeben sich eine Reihe von Selbstbeschränkungen. Die vorliegende Untersuchung wird sich auf die grundlegenden Probleme konzentrieren und sich dabei vor allem auch solcher Themen annehmen, die zwar schon ausgiebig in allgemeinen Zusammenhängen untersucht worden sind, bei denen das Beispiel örtlicher Bauvorschriften aber in aller Regel außer Betracht blieb. Genannt seien Probleme der Auslegung des Art. 28 Abs. 2 GG $^{10}$, solche der Begründungspflicht $^{11}$ und der Abwägungslehre ${ }^{12}$, sowie die Problematik der Zulässigkeit sogenannter dynamischer Verweisungen ${ }^{13}$. Mit Anspruch auf allgemeine Richtigkeit auftretende Lösungskonzepte müssen sich auch an rechtlichen

${ }^{5}$ Keller, Örtliche Bauvorschriften nach Art. 91 BayBO, 1986; Seybold, Bauästhetisches Ortsrecht, 1987; Moench / Schmidt, Die Freiheit der Baugestaltung, 1988.

${ }^{6}$ Zum Selbstverständnis dieser Disziplin siehe Jaeger, ZSSD 1979, S. 298.

${ }^{7}$ Siehe Adrian, HbKWP Band 3, S. 363; Klipper, S. 35 ff.

${ }^{8}$ Sehr skeptisch zur Erreichung gestalterischer Qualität durch Bebauungspläne oder Gestaltungssatzungen Pernice, DSt. 1989, S. 383; weiterhin Ortlieb, S. 16 ff. Kritisch auch schon Baumeister, S. 266: "Concurrenz und Bedürfnis führen sicherer zur Schönheit als amtliche Controle."

${ }^{9}$ Siehe dazu vor allem die Beiträge in Flagge (Hrsg.), Gestaltung und Satzung: Baufreiheit oder verordnete Baugestaltung, 1982. Vergleiche auch Bächer, S. 29 f. und Baur, S. 95.

${ }^{10}$ Unten $B$.

${ }^{11}$ Unten E II 1 b.

12 Unten E II 2 a.

${ }^{13}$ Unten E 12. 
Instituten bewähren, die gelegentlich bei der Diskussion von Grundsatzfragen etwas außerhalb des juristischen Bewußtseins liegen. Es wird sich in einigen Fällen die Notwendigkeit zeigen, neuen oder zumindest von der herrschenden Meinung abweichenden Lösungsansätzen zu folgen, um auch die bei örtlichen Bauvorschriften auftauchenden Probleme angemessen lösen zu können.

Die ausführliche Auseinandersetzung mit grundsätzlichen Problemen zwingt dazu, viele weniger wichtige Aspekte etwas im Hintergrund zu belassen. So kann es bei einer monographischen Untersuchung von örtlichen Bauvorschriften nicht darum gehen, zu möglichst allen von den Befugnisnormen in den Landesbauordnungen aufgeworfenen Fragen Stellung zu nehmen. Dieser Aufgabe nehmen sich die entsprechenden Kommentare in hinreichender Weise an. Auch sollen zwar alle in der Bundesrepublik erlassenen Bauordnungen einigermaßen gleichmäßig Berücksichtigung finden. Eine Ausnahme gilt aber für die Bauordnungen der Stadtstaaten, weil sich dort die schwerpunktmäßig behandelten Fragen der Einschaltung der Gemeinden in den Baurechtsvollzug nicht stellen.

Auf eine geschlossene Darstellung der mit dem Thema "Werbeanlagen" verbundenen Probleme wird ebenfalls verzichtet. Die mit diesem Komplex zusammenhängenden Fragen sind allerdings auch im Zusammenhang mit örtlichen Bauvorschriften vielschichtig ${ }^{14}$. Ein "Erkenntnistransfer" aus dem Bereich Werbeanlagen auf das Recht allgemeiner baulicher Anlagen ist aber meistens nicht möglich. Dazu sind die dort angebotenen Lösungen angesichts der unterschiedlichen Arten von Werbeanlagen oft zu spezifisch. Soweit aus Stellungnahmen in Literatur und Rechtsprechung jedoch allgemeine Erkenntnisse gezogen werden können, soll dies an den entsprechenden Stellen geschehen.

Umgekehrt sind die Aussagen, die in dieser Untersuchung allgemein meist am Beispiel von Satzungen über Anforderungen an Gebäude getroffen werden, auf Satzungen für Werbeanlagen übertragbar. Zwar taucht im Zusammenhang mit der Frage der Anwendung baurechtlicher Bestimmungen auf Werbeanlagen oft sehr schnell die Frage auf, ob und inwieweit es sich hierbei um bauliche Anlagen handelt ${ }^{15}$. Gerade diese Frage spielt aber bei örtlichen Bauvorschriften keine Rolle. Anforderungen an Werbeanlagen

${ }^{14}$ Siehe Engelmann, Der baurechtliche Verunstaltungsbegriff bei Anlagen der Außenwerbung, 1986; Simon, WiVerw. 1983, S. 194 f., ders., BayBO, Art. 91 Rn. 5 ff., jeweils m. w. N.

${ }^{15}$ Instruktiv dazu Kersting, VerwRundschau 1982, S. 84 ff. 
sind von den Befugnisnormen zum Erlaß von örtlichen Bauvorschriften expressis verbis vorgesehen ${ }^{16}$, es kommt nicht darauf an, ob es sich um eine bauliche Anlage handelt oder nicht.

Keine gesonderte Darstellung erfahren schließlich auch die historischen Vorläufer der heutigen Bestimmungen über örtliche Bauvorschriften ${ }^{17}$. Auch dieser Verzicht dient vor allem der Übersichtlichkeit, denn bei einer geschichtlichen Darstellung müßte noch stärker als heute nach den unterschiedlichen landesrechtlichen Bestimmungen differenziert werden. Geschichtliche Entwicklungen werden deshalb nur dort dargestellt, wo sie im Zusammenhang mit der Auslegung des heutigen Rechts relevant sind.

\section{b) Zum Gang der Untersuchung}

Die Befugnis zum Erlaß von örtlichen Bauvorschriften steht in einer Art Spannungsfeld zwischen zwei nach überwiegender Auffassung nebeneinander stehenden und grundsätzlich voneinander zu trennenden Bereichen, und zwar auf der einen Seite dem Städtebaurecht oder genauer Bauplanungsrecht und auf der anderen Seite dem Bauordnungsrecht. Während die Bauleitplanung eine Aufgabe ist, die die Gemeinde zumindest aufgrund einfachgesetzlicher Anordnung in eigener Verantwortung wahrzunehmen hat ( $\$ 2$ Abs. 1 S. 1 BauGB) und die im allgemeinen zum Bereich der "Wohlfahrtspflege" gezählt wird, wird das Bauordnungsrecht immer noch vor allem als Gefahrenabwehrrecht verstanden ${ }^{18}$. Dies scheinen die Landesbauordnungen dadurch zu bestätigen, daß sie unisono in ihrer allgemeinen Generalklausel den Satz an die Spitze stellen, daß bauliche Anlagen die öffentliche Sicherheit und Ordnung nicht gefährden dürfen ${ }^{19}$.

Allerdings gehören aus der Sicht der Praktiker in den gemeindlichen Planungsämtern beide Befugnisse zusammen. Die Gestaltungsvorschriften werden in der Regel nach $\S 9$ Abs. 4 BauGB in den Bebauungsplan aufgenommen, häufig ohne daß man den Eindruck hätte, daß den verschiedenen

\footnotetext{
${ }^{16}$ Vgl. nur Art. 91 Abs. 1 Nr. 1 BayBO: "... über besondere Anforderungen an die äußere Gestaltung baulicher Anlagen und an Werbeanlagen..."

${ }^{17}$ Der Versuch einer solchen Darstellung findet sich z. B. bei Keller, S. 4 ff. Instruktiv Baumeister, S. 261 ff., besonders zu den Preußischen Verunstaltungsgesetzen Baltz / Fischer, S. 176 ff.; Oelker, S. 158 ff.; Heine, S. 73 ff.

${ }^{18}$ Grosse-Suchsdorf / Schmaltz / Wiechert, Vorb. Rn. 23; Proksch, S. 163; Förster / Grundei / Steinhoff / Dageförde / Wilke, Einführung, S. 3.

${ }^{19} \$ 3$ Abs. 1 S. 1 LBO BW, BauO Bln, BremLBauO, HBauO, HBO, BauO NW, LBauO Rh.Pf., LBO Saarl., LBO Sl.H.; Art. 3 Abs. 1 S. 1 BayBO; 1 Abs. 1 S. 1 NBauO.
} 
Rechtsgrundlagen irgendwelche Bedeutung beigemessen wird. Der Erlaß von Bebauungsplänen und der von örtlichen Bauvorschriften ist in der Praxis der meisten Gemeinden ein weitgehend einheitliches Instrument für die Beeinflussung der baulichen Gestaltung des Gemeindegebietes. Dabei erscheinen die erlassenen örtlichen Bauvorschriften oft als weniger wichtiges Beiwerk des eigentlichen Bebauungsplans, das bei Satzungserlaß ohne größere Diskussionen mitbeschlossen wird ${ }^{20}$.

Aber nicht nur die Planungspraxis sondern auch die Juristen tun sich schwer, aus der Trennung zwischen Bauplanungs- und Bauordnungsrecht überzeugende Folgerungen zu ziehen. So entsprechen einige Festsetzungen, die üblicherweise in örtlichen Bauvorschriften getroffen werden, den nach Art. 9 Abs. 1 BauGB möglichen Festsetzungen im Bebauungsplan ${ }^{21}$. Die dafür vorgebrachten Erklärungsversuche überzeugen vielfach nicht. Umgekehrt werden Probleme in die Auslegung des einfachen Rechts hineingetragen, die sich bei unbefangener Lektüre des Gesetzestextes nicht ergeben, aber aus kompetenzrechtlichen Gründen folgen sollen ${ }^{22}$.

Gerade die kompetenzrechtliche Einordnung ist nun vorgreiflich für eine Reihe von anderen Fragen, die sich im Zusammenhang mit dem Erlaß von örtlichen Bauvorschriften stellen. So läßt sich etwa das vor allem in Bayern kontrovers behandelte Problem, ob die Satzungen nach Art. 91 BayBO im "eigenen" oder "übertragenen" Wirkungskreis erlassen werden, kaum sinnvoll diskutieren, wenn nicht feststeht, ob es sich nicht schon deshalb um eine Materie des übertragenen Wirkungskreises handeln muß, weil es sich beim Bauordnungsrecht wegen der Aufteilung des Baurechts nur um "Polizeirecht" handeln kann. Betont man etwa die Herkunft der örtlichen Bauvorschriften aus dem Bauordnungsrecht, kommt man zum übertragenen, sieht man eher die Verwandtschaft mit der Bauleitplanung zum eigenen Wirkungskreis. Deshalb wird zunächst die Frage des Umfangs von Bundes- und Länderkompetenzen im Baurecht erörtert. Erst im Anschluß hieran kann auf die Rolle der Gemeinden bei der Ausübung der Befugnis zum Erlaß von örtlichen Bauvorschriften vor dem Hintergrund des Art. 28 Abs. 2 GG und damit auch auf die Frage des Wirkungskreises eingegangen werden.

Nach dieser verfassungsrechtlichen Grundlegung soll dann auf der Ebene des einfachen Rechts schwerpunktmäßig das Verhältnis zwischen den An-

\footnotetext{
${ }^{20}$ Kritisch dazu Kuhn, DVBI. 1968, S. 498.

${ }^{21}$ Siehe dazu unten A 12 a cc.

${ }^{22}$ Siehe dazu unten A I 2 b cc.
} 
forderungen der gestaltungsrechtlichen Generalklauseln und den Bestimmungen über den Erlaß von örtlichen Bauvorschriften erörtert werden. Danach können abschließend die verfahrensrechtlichen und materiellrechtlichen Anforderungen dargestellt werden.

\section{Die einzelnen Regelungsbereiche örtlicher Bauvorschriften und ihre kompetenzrechtliche Einordnung}

a) Die "baugestalterischen" Vorschriften

aa) Begriff

Die Landesbauordnungen enthalten als ersten möglichen Regelungsbereich für örtliche Bauvorschriften den Erlaß von "besonderen Anforderungen an die äußere Gestaltung von baulichen Anlagen oder Werbeanlagen"23. Diese Befugnis wurde vereinzelt als solche zum Erlaß von "Bauästhetischem Ortsrecht" in Form von "gebietsbezogener Gestaltungspflege" bezeichnet ${ }^{24}$. Eine solche Bezeichnung verengt jedoch von vornherein den Anwendungsbereich der Befugnis auf einen möglichen Teilaspekt, nämlich den Schutz der Bauästhetik. Anforderungen an die äußere Gestaltung sind aber auch aus anderen Gründen zumindest denkbar. So sind etwa schon örtliche Bauvorschriften aufgrund der genannten Bestimmungen erlassen worden, die Werbeanlagen mit Ausrichtung auf Bundesfernstraßen auszuschließen, um die Sicherheit des Verkehrs zu gewährleisten ${ }^{25}$. Für die Beschränkung von Dachantennen werden von den Gemeinden teilweise fernmelderechtliche oder medienpolitische Gründe ins Feld geführt ${ }^{26}$. Weiterhin hatten sich die Oberverwaltungsgerichte wiederholt mit Problemen der Aufgabe der Flachdachbauweise zu befassen. Örtliche Bauvorschriften, in denen zunächst Flachdächer zwingend vorgeschrieben waren, wurden dahingehend geändert, daß auch geneigte Dächer zulässig sein sollten, weil sich die Flachdachkonstruktionen als untauglich und die Flachdächer als undicht erwiesen

${ }^{23} \S 73$ Abs. 1 Nr. 1 LBO BW; Art. 91 Abs. 1 Nr. 1 BayBO; $\$ 76$ Abs. 7 BauO Bln; $\S 110$ Abs. 1 Nr. 1 BremLBauO; $\S 81$ Abs. 1 Nr. 5 HBauO; $\S 118$ Abs. 1 Nr. 1 HBO; $\S 81$ Abs. $1 \mathrm{Nr}$. $1 \mathrm{NWBauO}$; $56 \mathrm{Nr}$. 1 NBauO; $\$ 86$ Abs. $1 \mathrm{Nr} .1$ LBauO Rh.Pf.; $\S 83$ Abs. 1 Nr. 1 a LBO Saarl.; $\$ 82$ Abs. 1 Nr. 1 LBO Sl.H. Im folgenden werden vor allem die Anforderungen an bauliche Anlagen diskutiert.

24 Seybold, S. $31 \mathrm{ff}$.

${ }^{25}$ Vergleiche die Nachweise bei Beckmann, WRP 1978, S. 694; Vogel, BayVBI. 1978, S. 587.

${ }^{26}$ Hermann, S. $37 \mathrm{ff}$. 
hatten ${ }^{27}$. Da die Planänderungen offensichtlich auf Wunsch der Mehrzahl der betroffenen Eigentümer und weniger oder überhaupt nicht aus gestalterischen Gründen erfolgte, sah sich allerdings das OVG Lüneburg veranlaßt, die fragliche Änderungssatzung mangels eines "städtebaulichen Anliegens" für nichtig zu erklären ${ }^{28}$. In einem sehr ähnlich gelagerten Fall kam dagegen der BWVGH zu der Auffassung, daß für die äußere Gestaltung baulicher Anlagen nicht nur ästhetische Gründe eine Rolle spielen, sondern auch sonstige bauordnungsrechtliche Gesichtspunkte ${ }^{29}$. Die Rechtslage war in beiden Fällen vergleichbar. Zwar enthält § 73 LBO BW - anders als die LBO Sl.H. den Passus "im Rahmen dieses Gesetzes" für die Beschreibung des zulässigen Regelungsumfanges örtlicher Bauvorschriften, und verweist damit auf die Generalklausel, die den Schutz der öffentlichen Sicherheit und Ordnung vorsieht ( $\$ 3$ Abs. 1 S. 1 LBO Rh.Pf.) $)^{30}$. Dieser Passus ist jedoch eine Beschränkung der nachfolgenden Befugnisse und erklärt sich in seiner jetzigen Fassung daraus, den Erlaß von örtlichen Bauvorschriften nicht auf den Verunstaltungsschutz zu beschränken, sondern auch eine "positive Gestaltungspflege" zuzulassen ${ }^{31}$. Er kann also nicht als ein Argument für die Erweiterung der Befugnisse der Gemeinden etwa im Vergleich zur Ermächtigung nach der LBO Sl.H. verwendet werden.

Unabhängig von der Frage, inwieweit dem BWVGH oder dem OVG Lüneburg zu folgen ist, ob etwa zumindest auch ein ästhetischer Gesichtspunkt die Festsetzung mit beeinflussen muß, zeigt dieses Beispiel besonders prägnant, daß der Begriff "Bauästhetisches Ortsrecht" zumindest als Arbeitsbegriff für eine Untersuchung des Instituts örtliche Bauvorschriften ungeeignet ist. Durch ihn wird der mögliche Anwendungsbereich in eine bestimmte Richtung festgelegt, der vom Gesetzeswortlaut nicht unbedingt vorgegeben ist. Auch die von den meisten Bauordnungen geforderte "baugestalterische Absicht", die dem Erlaß von Anforderungen an die äußere Gestaltung zugrunde liegen soll ${ }^{32}$, führt nicht zwingend zur Beschränkung auf bauästheti-

${ }^{27}$ OVG Lüneburg, Beschluß vom 30.06.1987, BauR 1988, 307 ff.; BWVGH, Beschluß vom 30.07.1987, BRS Band 47, Nr. 11 S. 35 ff., Urteil vom 07.05.1987, BauR 1988, 310 ff. = BRS Band 47 Nr. 12 S. 39 ff.; HessVGH, Beschluß vom 24.09.1987, BauR 1988, S. 312 ff.

${ }^{28}$ OVG Lüneburg (Fn. 27), S. 309.

${ }^{29}$ BWVGH, Beschluß vom 30.07.1987, (Fn. 27) S. 38.

${ }^{30}$ Dies erwähnt auch der BWVGH (Fn. 29).

${ }^{31}$ Schlez, LBO BW, $\S 73 \mathrm{Rn}$. 2. Zum Begriff der "positiven Gestaltungspflege" siehe unten D I.

${ }^{32} \S 73$ Abs. 1 Nr. 1 LBO BW; $§ 76$ Abs. 7 BauO Bln; $\$ 110$ Abs. 1 Nr. 1 BremLBauO; $§ 81$ Abs. 1 Nr. 4 HBauO; $\S 118$ Abs. 1 Nr. 1 HBO; $\S 81$ Abs. 1 Nr. 1 NWBauO; $\S 82$ Abs. 1 Nr. 1 
sche Fragen. Diese Formulierung läßt durchaus Raum für unterschiedliche Deutungen. Wenn baugestalterische Anforderungen - denn nichts anderes sind Anforderungen an die äußere Gestaltung von Gebäuden - zur Durchsetzung baugestalterischer Absichten erlassen werden sollen, ist das Regelungsinstrumentarium gleichzeitig auch Regelungsziel und damit möglicherweise gar kein Regelungszweck eindeutig vorgegeben. Verwenden die Bauordnungen nur oder zumindest auch den Begriff "städtebauliche Absichten $^{\text {"33 }}$, so läßt sich schon gar nicht von einer zwingenden Beschränkung auf Fragen der Bauästhetik ausgehen. Im folgenden wird deshalb nicht von "Bauästhetischem Ortsrecht" gesprochen. Stattdessen wird der Begriff "baugestalterische Vorschriften" verwendet.

\section{bb) Die Verfolgung "städtebaulicher Absichten" als Kompetenzproblem}

Die einzelnen Landesbauordnungen verwenden für die Umschreibung des mit den baugestalterischen Vorschriften zu verfolgenden Ziels - wie schon angedeutet - verschiedene Begriffe. Teilweise sprechen sie von "baugestalterischen Absichten" ${ }^{34}$, 88 Abs. 1 Nr. 1 LBauO Rh.Pf. verlangt "gestalterische Absichten", Art. 91 Abs. 1 Nr. 1 BayBO "städtebauliche" und § $56 \mathrm{NBauO}$ "baugestalterische oder städtebauliche" Absichten. Aber nicht nur die gegenwärtige Terminologie der Landesbauordnungen ist unterschiedlich. Aufgrund einiger Novellierungen hat sie auch innerhalb der einzelnen Bauordnungen gewechselt. So verwendet § 111 LBO Sl.H. vom 09.02.1967 genau wie heute die BayBO den Begriff "städtebauliche Absichten"35 und § 111 LBO BW vom 06.04.1964 wie heute die LBauO Rh.Pf. den der "gestalterischen" Anforderungen ${ }^{36}$.

Es läßt sich nicht erkennen, daß mit diesen Gesetzesänderungen die Absicht verbunden war, eine inhaltliche Änderung herbeizuführen ${ }^{37}$. Es gibt auch keinen Anhaltspunkt dafür, daß die Landesgesetzgeber mit den unterschiedlichen Begriffen etwas Unterschiedliches ausdrücken wollten. Der

LBO Sl.H.; $\$ 86$ Abs. 1 Nr. 1 LBauO Rh.Pf. und $\$ 83$ Abs. 1 Nr. 1 LBO Saarl. sprechen von "gestalterischen Absichten". Anders noch § 113 Abs. 1 Nr. 1 LBO Saarl. vom 27.12.1974, Amtsblatt 1975, S. 85 ff.

${ }^{33}$ Art. 91 Abs. 1 Nr. 1 BayBO; $\$ 56$ NBauO.

${ }^{34}$ Siehe die Nachweise oben Fn. 32.

${ }^{35}$ GVBI. S. 51.

${ }^{36}$ GBI. S. 151.

37 Siehe Schleswig-Holsteinischer Landtag, Drs. 7/1003, S. 64, zu Nr. 89 a; BadenWürttembergischer Landtag, Drs. V 5399, S. 27 und S. 42 zu Art. 1 Nr. 72 b. 
Begriff der "städtebaulichen Absicht" geht vor allem zurück auf $\S 2$ der BaugestVO vom 10. November $1936^{38}$. Diese Vorschrift war bis zum Erlaß der Landesbauordnungen in den sechziger Jahren Grundlage für den Erlaß von baugestalterischen Vorschriften ${ }^{39}$. Daß die meisten Landesbauordnungen trotzdem den Begriff "städtebauliche Absichten" vermieden und stattdessen den nicht sehr klaren ${ }^{40}$ Ausdruck "baugestalterische Absicht" verwendeten, dürfte vor allem darauf zurückzuführen sein, daß "städtebaulich" auf "Städtebaurecht" hinweist und der Begriff "Städtebaurecht" wiederum mehr und mehr als Synonym für den Kompetenztitel "Bodenrecht" nach Art. 74 Nr. 18 GG gebraucht wurde ${ }^{41}$.

Die Gesetzgebungskompetenz des Bundes für das Bodenrecht soll jedoch abschließend ausgeschöpft sein ${ }^{42}$. Diese Absicht kommt etwa in den Gesetzesmaterialien zum neugefaßten $\S 9$ Abs. 4 BBauG 1976 zum Ausdruck. Dort wird die Befugnis des § 9 Abs. 4 BBauG 1976 dahingehend erläutert, daß die Landesgesetzgeber durch die Möglichkeit, auf Landesrecht beruhende Regelungen in den Bebauungsplan aufzunehmen, nicht ermächtigt würden, über den Katalog des $\S 9$ Abs. 1 BBauG hinausgehende bodenrechtliche Festsetzungsmöglichkeiten zu schaffen ${ }^{43}$. Dem Vorwurf vorzubeugen, sich unzulässigerweise in eine vom Bund verfassungsgemäß in Anspruch genommene Kompetenz einzumischen, dürfte somit ein wesentlicher Grund gewesen sein, von der Terminologie der BaugestVO abzuweichen, ohne jedoch etwas anderes aussagen zu wollen.

Auslegungsbemühungen um das Merkmal "städtebauliche Absichten" kennzeichnen sich parallel hierzu durch den Versuch, trotz unterschiedlichen Wortlauts gegenüber den anderen Bauordnungen zu einer gleichen oder ähnlichen Aussage zu kommen. So wird für die BayBO der Versuch unternommen, Art. 91 Abs. 1 Nr. 1 BayBO in verfassungskonformer Weise im Sinne von "baugestalterischer Absicht" zu interpretieren ${ }^{44}$. Im Bereich

\footnotetext{
${ }^{38}$ RGBI. I S. 938.

${ }^{39}$ Seybold, S. 5.
}

${ }^{40}$ Dazu siehe oben A I 2 a aa.

${ }^{41}$ Zur Gleichsetzung der Begriffe "Bodenrecht" und "Städtebaurecht" siehe Henke, S. 22 m. w. N.; Steiner, Verkehrsplanung, S. 42; von Arnim, in: Schlotterbeck / von Arnim, Einf. Rn. 3; Erbguth, Bauplanungsrecht, S. 1 Rn. 2.

42 Gaentzsch, Berliner Kommentar, § 1 Rn. 9; Dyong, Der Landkreis 1971, S. 87; Kummer, DÖV 1980, S. 839 Fn. 4; OVG Lüneburg, Urteil vom 19.12.1979, DÖV 1980, S. 837 ff.

${ }^{43}$ BT-Drs. 7/2496, S. 41 und S. 71.

${ }^{44}$ Koch / Molodovsky / Rahm, Art. 91 Anm. 2.2. Dieser Kommentierung folgt Seybold, S. 35 . 
der NBauO überwiegt die Ansicht, städtebauliche und baugestalterische Absichten seien nicht scharf voneinander trennbar, da der Städtebau auch die Stadtgestaltung einschließe ${ }^{45}$. Ein Erlaß des Niedersächsischen Sozialministers von 1975 bemüht sich zwar um eine Definition von baugestalterischen und städtebaulichen Absichten ${ }^{46}$, enthält dann aber die Feststellung, eine genaue Abgrenzung sei in der Regel nur schwer möglich ${ }^{47}$. Für die letztgenannte Auffassung läßt sich immerhin anführen, daß die Gestaltung des Ortsbildes ein abwägungserheblicher Belang nach $§ 1$ Abs. 5 S. 2 Nr. 4 BauGB ist und der Schutz des Ortsbildes auch im Nichtplanbereich nach $\S 34$ Abs. 1 S. 2 BauGB und $\S 35$ Abs. 3 Schrägstrich 6 BauGB eine Rolle spielt. Der Ansicht, wonach letztlich eine klare Grenzziehung nicht möglich sei, scheint auch das OVG Lüneburg zu sein, wenn es in seiner bereits angeführten Flachdachentscheidung davon spricht, daß "baugestalterische" Absichten dann nicht verfolgt würden, wenn kein "städtebauliches" Anliegen vorliege $^{48}$. Es läßt sich daher der Schluß ziehen, daß die Landesbauordnungen trotz zum Teil unterschiedlichen Wortlauts das gleiche Regelungsziel für den Erlaß von baugestalterischen Vorschriften vorsehen wollen. Die terminologischen Differenzen weisen aber deutlich auf die Unsicherheit bezüglich der Frage hin, in welchem kompetenzrechtlichen Rahmen sich die Landesgesetzgeber bewegen dürfen. Weitgehend liegt den Bauordnungen die Auffassung zugrunde, da $ß$ die Ziele des Bauplanungsrechts nicht solche des Bauordnungsrechts sein dürfen.

cc) Anforderungen in baugestalterischen Vorschriften im Verhältnis zu Festsetzungen nach $\$ 9$ Abs. 1 BauGB

In den meisten Landesbauordnungen werden die in baugestalterischen Vorschriften möglichen Anforderungen nur dadurch spezifiziert, daß damit solche Anforderungen gemeint sind, die die "äußere Gestaltung" von baulichen Anlagen betreffen ${ }^{49}$. Präzisierungen enthalten zwar für bauliche Anlagen $\S 56 \mathrm{Nr} .1 \mathrm{NBauO}$ und die meisten anderen Landesbauordnungen im

\footnotetext{
${ }^{45}$ Grosse-Suchsdorf / Schmaltz / Wiechert, § 56 Anm. 6.

${ }^{46}$ Runderlaß vom 01.08.1975, abgedruckt bei Burger / Gutschow / Krause, S. 295, Nr. 4.2.1.: "Städtebauliche Absichten kommen vor allem in Bauleitplänen zum Ausdruck." Weiterhin Nr. 4.2.2.: "Baugestalterische Absichten sind Bestrebungen, die vor allem auf eine ästhetische Stadtgestaltung gerichtet sind."

${ }^{47}$ Runderlaß Nr. 4.2.3. (Fn. 46).

${ }^{48}$ Beschluß vom 30.06.1987, BauR 1988, S. 309. Siehe dazu auch oben A I 2 a aa.

${ }^{49}$ Siehe die Nachweise oben A I 2 a aa, Fn. 23.
} 
Hinblick darauf, daß sich Anforderungen an Werbeanlagen auch auf deren Art, Größe und Anbringungsort beziehen dürfen ${ }^{50}$. Auch im Bereich der BayBO besteht aber kein Zweifel darüber, daß insofern Anforderungen an Werbeanlagen gestellt werden können ${ }^{51}$. Festlegungen von Dachneigung, Gebäude- und Geschoßhöhen, die etwa § 56 Nr. 1 NBauO nennt, sind auch im Bereich der anderen Bauordnungen zulässig ${ }^{52}$. Auf jeden Fall hat kein Landesgesetzgeber abschließend umschrieben, was man sich unter Anforderungen an die äußere Gestaltung vorzustellen habe.

Daraus resultieren gewisse Abgrenzungsschwierigkeiten in bezug auf die in $\S 9$ Abs. 1 BauGB und in der BauNVO geregelten bauplanungsrechtlichen Festsetzungsmöglichkeiten. Ein gutes Beispiel hierfür ist das Problem, ob örtliche Bauvorschriften die Firstrichtung von Gebäuden bestimmen können. Der Erlaß von baugestalterischen Vorschriften dient nach allgemeiner Auffassung zumindest hauptsächlich dazu, eine optisch ansprechende Gebietsgestaltung zu erreichen. Die Bestimmung der Firstrichtung beeinflußt in wesentlicher Weise den optischen Eindruck eines Baugebietes $^{53}$, ihre Festlegung wird insofern konsequent als eine Anforderung an die äußere Gestaltung im Sinne der genannten Vorschriften der Landesbauordnungen aufgefa $\mathrm{t}^{54}$. Unterschiedlich sind nur die Begründungen, mit denen dies im Hinblick auf $\S 9$ Abs. 1 Nr. 2 BauGB gerechtfertigt wird. Teilweise wird schlicht der Eindruck erweckt, die Tatsache, daß auch über § 9 BauGB die Firstrichtung festgesetzt werden könne, habe nicht weiter zu beunru-

${ }^{50}$ Nach $\S 73$ Abs. 1 Nr. 1 LBO BW gilt dies auch für Automaten. Im übrigen $\S 76$ Abs. 7 BauO BIn; $\S 110$ Abs. 1 Nr. 1 BremLBauO; $\$ 81$ Abs. 1 Nr. 5 HBauO; 118 Abs. 1 Nr. 1 HBO; 56 Nr. 2 NBauO; $\S 81$ Abs. 1 Nr. 1 BauO NW; $\S 85$ Abs. 1 Nr. 1 LBauO Rh.Pf.; $\$ 82$ Abs. 1 Nr. 1 LBO Sl.H.

${ }^{51}$ Koch / Molodovsky / Rahm, Art. 91 Anm. 2.2.

${ }^{52}$ Für die BayBO Simon, Art. 91 Rn. 6 und Koch / Molodovsky / Rahm, Art. 91 Anm. 2.2.; für die BauO NW Rößler, S. 485; für die LBO BW Schlotterbeck, in: Schlotterbeck / von Arnim, $\$ 73$ Rn. 7.

${ }^{53}$ Siehe die Abbildungen und Nachweise bei Boeddinghaus, Stadterhaltung, S. 100 Rn. 263.

54 So Moench / Schmidt, S. 43; Schlotterbeck, in: Schlotterbeck / von Arnim § 73 Rn. 7; Simon, Art. 91 Rn. 7; Koch / Molodovsky / Rahm, Art. 91 Anm. 2.2.; Grosse-Suchsdorf / Schmaltz / Wiechert, §56 Rn. 17. Beispiele für die Festlegung der Firstrichtung in örtlichen Bauvorschriften finden sich bei Burger / Gutschow / Krause, S. 182. Gegen die Möglichkeit der Festlegung der Firstrichtung in enger Anlehnung an die gestaltungsrechtliche Generalklausel Rößler, $\S 81$ S. 485: "nur auf die in $\S 12$ genannten Gegenstände" und im Ergebnis auch Gädtke / Böckenförde / Temme, § 81 Rn. 14. Schlichter / Stich / Tittel, § 9 Rn. 6, vertreten schließlich die Auffassung, daß die Firstrichtung nur in Bebauungsplänen aufgrund der Vorschrift des $\S 9$ Abs. 1 Nr. 2 BauGB und nicht in örtlichen Bauvorschriften festgelegt werden könne. 
higen $^{55}$. Andere scheinen von einer Art Subsidiarität der Festsetzungen in örtlichen Bauvorschriften gegenüber Festsetzungen im Bebauungsplan auszugehen ${ }^{56}$. Schließlich werden gleiche Festsetzungen in Bebauungsplänen und örtlichen Bauvorschriften für zulässig gehalten oder es wird bezweifelt, daß $\$ 9$ Abs. 1 Nr. 2 BauGB auch die Firstrichtung betreffe ${ }^{57}$.

$\mathrm{DaB} \& 9$ Abs. 1 Nr. 2 BauGB auch die Festlegung der Firstrichtung ermöglicht, ist heute jedoch fast allgemeine Meinung ${ }^{58}$, und zwar zu Recht, denn das Merkmal "Stellung der baulichen Anlage" hätte sonst kaum eine praktische Bedeutung. Die Bestimmung, welche Grundstücksteile zu überbauen bzw. überbaubar sind, kann bereits durch die Festlegung der Baulinien, Baugrenzen und Bauweise hinreichend erfolgen. Die Festlegung der Firstrichtung ist zudem nicht nur ein gestalterisches Mittel, sondern berührt auch die Interessen der Nachbarn. Es ist daher anzunehmen, daß die Gemeinden in $\S 9$ Abs. 1 Nr. 2 BauGB auch zu deren Festlegung und nicht nur zu etwas ermächtigt werden, was sie bereits nach anderen Vorschriften hinreichend beeinflussen können.

Die Frage, ob es denkbar ist, daß etwa die Firstrichtung sowohl durch den Erlaß eines Bebauungsplan als auch durch den einer Satzung über baugestalterische Vorschriften festgesetzt werden kann, führt wiederum zum Problem der Abgrenzung zwischen Bauplanungs- und Bauordnungsrecht. Es stellt sich noch in einigen weiteren Fällen. Ein Beispiel ist die in $\S 73 \mathrm{Abs} .1$ Nr. 7 LBO BW ausdrücklich vorgesehene, aber auch nach den anderen Landesbauordnungen für zulässig gehaltene Festlegung der Gebäudehöhe ${ }^{59}$. Die Festsetzung der Gebäudehöhe ist nach § 9 Abs. 1 Nr. 1 BauGB i. V. m. § 16 Abs. 3 BauNVO auch im Bebauungsplan möglich. Ähnliches gilt für die in $\S 73$ Abs. 1 Nr. 8 LBO BW vorgesehene Festlegung der Gebäudetiefe. Durch die Festsetzung von Baulinien und Baugrenzen nach $\S 23$ BauNVO läßt sich der gleiche Effekt erzielen. Zwar kann man sich in der Praxis damit

${ }^{55}$ So Schlotterbeck, in: Schlotterbeck / von Arnim, $\$ 73$ Rn. 7.

${ }^{56}$ Simon, Art. 91 Rn. 7: "sofern nicht schon durch Bebauungsplan geschehen".

${ }^{57}$ Grosse-Suchsdorf / Schmaltz / Wiecher, \$ $56 \mathrm{Rn} .17$.

58 Schlichter / Stich / Tittel, \$9 Rn. 6; Schmaltz, VR 1983, S. 220; Simon, Art. 12 Rn. 3; Zuck, S.134. Gelzer wendet sich in Rn. 93 nur gegen die Ansicht, wonach sich der Begriff "Stellung der baulichen Anlage" allein auf die Firstrichtung beziehe. In Rn. 200 hält Gelzer aber die Festlegung der Firstrichtung aus planerischen ( = nicht gestalterischen) Gründen für möglich, ebenso Zuck, ebenda. Leichte Zweifel allerdings bei Boeddinghaus, BauR 1987, S. 638, sowie bei Grosse-Suchsdorf / Schmaltz / Wiechert (Fn. 57).

${ }^{59}$ Zur Zulässigkeit der Festlegung der Gebäudehöhe nach Art. 91 Abs. 1 Nr. 1 BayBO siehe Simon, Art. $91 \mathrm{Rn} .7$. 
helfen, da $\beta$ man von der Rechtsgrundlage her zweifelhafte Festsetzungen auf jeden Fall in den Bebauungsplan aufnimmt und offen läßt, ob dies aufgrund von $\S 9$ Abs. 1 oder Abs. 4 BauGB geschieht ${ }^{60}$. An der grundsätzlichen Abgrenzungsproblematik ändert dies aber nichts.

Als Lösungsmöglichkeit bietet sich wiederum an, daß Bauordnungs- und Bauplanungsrecht wegen ihrer unterschiedlichen Zielrichtungen zulässigerweise die gleichen Festsetzungsmöglichkeiten vorsehen können ${ }^{61}$. So ist wohl das Argument zu verstehen, die Festsetzung der Gebäudehöhe sei deshalb auf beiden Wegen zulässig, weil sie sowohl bodenrechtliche als auch gestalterische Qualität habe ${ }^{62}$. Ist eine solche Begründung jedoch nicht möglich, muß entweder $\S 9$ Abs. 1 Nr. 2 BauGB oder der Begriff "besondere Anforderungen an die äußere Gestaltung" aus kompetenzrechtlichen Gründen anders interpretiert werden als dies bisher geschehen ist. Unabhängig von diesem erst nach Darstellung der Kompetenzabgrenzung lösbaren Problem läßt sich allgemein feststellen, daß einige Anforderungen an Gebäude sowohl als Anforderung nach $\S 9$ Abs. 1 BauGB als auch in baugestalterischen Vorschriften für denkbar gehalten werden. Dies weist auf eine enge Verwandtschaft zwischen Baugestaltungs- und Städtebaurecht hin ${ }^{63}$.

b) "Schutzvorschriften" für bestimmte Straßen, Plätze etc.

aa) Schutzvorschriften und baugestalterische Vorschriften

Einen zweiten wichtigen Anwendungsbereich für den Einsatz des Instituts "örtliche Bauvorschriften" bildet das Aufstellen von "besonderen Anforderungen" zum Schutz bestimmter Bauten, Straßen, Plätze oder Ortsteile ${ }^{64}$. Zu diesem Komplex gehört auch die in $\S 73$ Abs. 1 Nr. 3 LBO BW und $\S 86$ Abs. 1 Nr. 6 LBauO Rh.Pf. ausdrücklich genannte Möglichkeit der Einschränkung von Antennenanlagen. Diese Vorschriften dienen ebenfalls dem

\footnotetext{
${ }^{60}$ Schmaltz, VR 1983, S. 222.

${ }^{61}$ So ausdrücklich etwa Schlotterbeck, in: Schlotterbeck / von Arnim, § 73 Rn. 31.

${ }^{62}$ Schmaltz, VR 1983, S. 220; auch Gelzer, Rn. 200; Moench / Schmidt, S. 43; "Alte Städte alte Dörfer", S. $15 \mathrm{f}$.

${ }^{63}$ Ähnlich Gaentzsch, DSt. 1969, S. 373, wonach baugestalterische Vorschriften einen starken Bezug zum Städtebaurecht haben.

${ }^{64} \S 73$ Abs. 1 Nr. 2 LBO BW; Art. 91 Abs. 1 Nr. 2 BayBO; $\S 110$ Abs. 1 Nr. 2 BremLBauO; § 118 Abs. $1 \mathrm{Nr}$. $2 \mathrm{HBO}$; §56 Nr. $1 \mathrm{NBauO}$ allerdings beschränkt auf den Schutz von "Bauten"; § 86 Abs. 1 Nr. 2 LBauO Rh.Pf.; $§ 83$ Abs. 1 Nr. 1 b LBO Saarl.; $\$ 82$ Abs. 1 Nr. 2 LBO Sl.H.
} 
Schutz wertvoller Ortsbilder ${ }^{65}$. Soweit die anderen Landesbauordnungen eine ausdrückliche Ermächtigung nicht enthalten, werden Antennenverbote auf die allgemeine Klausel gestützt ${ }^{66}$.

Eine wichtige Gemeinsamkeit zwischen Schutzvorschriften und baugestalterischen Vorschriften besteht darin, daß sich die möglichen Festsetzungen weitgehend decken. Beide Arten von Vorschriften können sowohl für bestehende als auch für zu errichtende Gebäude erlassen werden. Es ist trotzdem aus eigentumsrechtlichen Gründen eine strikte Unterscheidung vorzunehmen. Durch Schutzvorschriften sind in weiterem Umfang Beschränkungen der Eigentümerbefugnisse möglich. Ein Indiz hierfür ist, daß der Gesetzeswortlaut - anders als bei baugestalterischen Vorschriften - auch den vollständigen Ausschluß von Werbeanlagen zuläßt $t^{67}$. Weil Schutzvorschriften vor allem der Bewahrung historischer Stadtbilder dienen, erscheinen Satzungen über Schutzvorschriften eigentumsrechtlich trotzdem in vielen Fällen unproblematischer als solche über baugestalterische Vorschriften $^{68}$.

\section{bb) Schutzvorschriften und Denkmalschutz}

Mit der Ermächtigung zum Erlaß von "Schutzvorschriften" erhalten die Gemeinden ein Instrument in die Hand, um zumindest in gewissem Rahmen in eigener Verantwortung Denkmalschutz zu betreiben ${ }^{69} . \mathrm{Da} \beta$ es sich beim Erlaß von Schutzvorschriften um ein Instrument des Denkmalschutzes handelt, ergibt sich zum einen daraus, da $ß$ die in den Bestimmungen der Landesbauordnungen in bezug genommenen "Bauten, Straßen, Plätze und Ortsteile von geschichtlicher, künstlerischer oder städtebaulicher Bedeutung $^{70}$ auch unter dem Schutz der jeweiligen Landesdenkmalgesetze stehen, also die Schutzobjekte identisch sind. Das Denkmalschutzrecht erstreckt sich heute nicht mehr nur auf einzelne Bauten, sondern auch auf das sog.

${ }^{65}$ Schlotterbeck, in: Schlotterbeck / von Arnim, § 73 Rn. 12.

${ }^{66} \mathrm{Zu}$ Art. 107 Abs. 1 Nr. 2 BayBO a. F. siehe BayVerfGH, Entscheidung vom 27.09.1985, NJW 1986, S. 833 ff.

${ }^{67}$ Vgl. etwa $\$ 73$ Abs. 1 Nr. 2 LBO BW.

${ }^{68}$ Siehe ausführlich dazu unten, C III 1.

${ }^{69}$ Stadler / Baumgartner / Wiebel, BayBO, 21/10a Art. 3 Anm. 2.4.; Eberl / Martin / Petzet, Erl.DSchG Rn. 39; BayMABl. vom 27.08.1984, Nr. 16 S. 421 ff.

${ }^{70}$ So $\S 73$ Abs. 1 Nr. 2 LBO BW; Art. 91 Abs. 1 Nr. 2 BayBO; $\S 110$ Abs. 1 Nr. 2 BremLBauO; $\S 118$ Abs. 1 Nr. 2 HBO; $\$ 81$ Abs. 1 Nr. 2 BauO NW; $\S 86$ Abs. 1 Nr. 2 LBauO Rh.Pf.; $\$ 83$ Abs. 1 Nr. 1 b LBO Saarl.; $\S 82$ Abs. 1 Nr. 2 LBO Sl.H. 
Ensemble $^{71}$. Zum anderen wird die Denkmaleigenschaft weitgehend durch Merkmale konstituiert, die auch Voraussetzungen für den Erlaß von Schutzvorschriften sind, nämlich künstlerische, geschichtliche oder städtebauliche Bedeutung $^{72}$. Konsequenterweise bestimmt sich die Auslegung der entsprechenden Merkmale für den Bereich der Schutzvorschriften in Anlehnung an das Denkmalschutzrecht ${ }^{73}$.

Zum zweiten ergibt sich die enge Verwandtschaft mit dem Denkmalschutzrecht daraus, daß sich die Art des Schutzes teilweise entspricht. Die meisten Denkmalschutzgesetze machen nicht nur die Denkmäler selbst zum Gegenstand einer rechtlichen Regelung, sondern sehen auch Genehmigungspflichten vor für die Änderung, Beseitigung oder Errichtung von baulichen Anlagen, soweit sich diese Maßnahmen auf Bestand oder Erscheinungsbild des Denkmals auswirken ${ }^{74}$. Die Berliner Rechtslage macht den Zusammenhang zwischen örtlichen Bauvorschriften in Form von Schutzvorschriften und dem Denkmalschutzrecht besonders deutlich. Dort findet sich nicht mehr in der Bauordnung, sondern in § 17 DSchG die Ermächtigung zum Erlaß von Schutzvorschriften ${ }^{75}$.

Die Anforderungen in Schutzvorschriften treten kumulativ zum staatlichen Denkmalschutzrecht hinzu. Für die Ansicht, wonach die nach Erlaß der Landesbauordnungen in Kraft getretenen Denkmalschutzgesetze den Ermächtigungsumfang zum Erlaß solcher Vorschriften dahingehend modifiziert haben, daß örtliche Bauvorschriften nur noch solche bauliche Anlagen betreffen, die von den staatlichen Denkmalschutzgesetzen nicht erfaßt wer$\operatorname{den}^{76}$, gibt es weder einen Anhaltspunkt im Gesetz noch sonst plausible Gründe. Das Argument, daß sonst die Gemeinden ein staatliches Gesetz

\footnotetext{
${ }^{71}$ Vgl. Hoppe, Festschrift für Klein, S. 193: "entscheidende Erweiterung".

${ }^{72} \S 2$ Abs. 1 BWDSchG; Art. 1 Abs. 3 BayDSchG; § 2 Abs. 2 DSchG Bln; $\$ 2$ Abs. 1 Nr. 2 BremDSchG; § 2 Abs. 1 Nr. 2 und 3 HamDSchG; $₹ 2$ Abs. 1 HessDSchG; $\$ 3$ Abs. 3 NDSchG; $\S 2$ Abs. 1 NWDSchG; $\S 4$ Abs. 1 Nr. 2, 5 DSchPfG Rh.Pf.; 22 Abs. 1 SDschG. In $\S 2$ Abs. 1 BremDSchG und $\S 2$ Abs. 1 HamDSchG fehlt allerdings die städtebauliche Bedeutung.

${ }^{73}$ Koch / Molodovsky / Rahm, Art. 91 Anm. 2.3.; Simon, Art. 91 Rn. 9; Rößler, S. 486; Eberl, BayVBI. 1987, S. 355.

${ }^{74} \S 15$ Abs. 3 BWDSchG, der sich jedoch nur auf bauliche Anlagen bezieht. Da Werbeanlagen weitgehend keine "baulichen Anlagen" sind - siehe § 2 Abs. 1 und 8 LBO BW -, kommt für den Umgebungsschutz bei Werbeanlagen insoweit nur der Erlaß von Schutzvorschriften in Betracht. Siehe weiterhin Art. 6 Abs. 1 S. 2 Abs. 2 S. 2 BayDSchG; $\$ 16$ Abs. 1 DSchG Bln.; §§ 2 Abs. 1 Nr. 5, 10 HamDSchG; § 16 Abs. 2 HessDSchG; $\$ 10$ Abs. 1 Nr. 4 NDSchG; $\S 9$ Abs. 1 b) NWDSchG; $\S 4$ Abs. 1 S. 2 und 5 DSchPfG Rh.Pf.; $\S 12$ Abs. 2 SDschG; $\$ 9$ Abs. 1 c) Sl.H.DSchG.

${ }^{75}$ Seit dem 01.01.1978. Kritisch zu dieser Zersplitterung Groth, GE 1985, S. 331.

${ }^{76}$ So Eberl, BayVBl. 1987, S. 355.
} 
"ändern" können ${ }^{7}$, behauptet nur das, was es zu begründen gilt, daß nämlich die Denkmalschutzgesetze insoweit Vorrang vor dem Ortsrecht der Gemeinden beanspruchen wollen. Denn von "ändern" kann man nur dann sprechen, wenn das staatliche Gesetz grundsätzlich Geltung beansprucht. Genauso gut ist es aber denkbar, daß das staatliche Gesetz eben in gewissem Maße zur Disposition des Ortsgesetzgebers stehen will. Dies ist durchaus kein ungewöhnlicher Vorgang. Auch im Bereich der baugestalterischen Vorschriften modifizieren die Gemeinden in gewissem Maße die in den allgemeinen gestaltungsrechtlichen Generalklauseln enthaltenen Anforderungen $^{78}$. Noch weniger überzeugt das zweite Argument, wonach der Erlaß von örtlichen Bauvorschriften neben dem Denkmalschutzgesetz dem Gleichheitssatz widersprechen würde, weil es häufig vom Zufall abhinge, ob die Gemeinden örtliche Bauvorschriften erlassen ${ }^{\text {t9 }}$. Auf diese Weise ließe sich die gesamte kommunale Rechtssetzung als gleichheitswidrig qualifizieren. Unbestritten liegt häufig eine Ungleichbehandlung vor. Sie ist jedoch von der kommunalen Selbstverwaltungsgarantie sanktioniert ${ }^{80}$. Schutzvorschriften können somit auch für Gebäude erlassen werden, die vom staatlichen Denkmalschutzgesetz erfaßt werden.

Unter kompetenzrechtlichen Gesichtspunkten ist die Aufnahme einer Ermächtigung zum Erlaß von denkmalschutzrechtlichen Regelungen in die Landesbauordnungen zunächst unbedenklich. Denkmalschutzrecht ist nach allgemeiner Ansicht Ländersache ${ }^{81}$.

\section{cc) Schutzvorschriften und Bauplanungsrecht}

Den gestalterischen Anforderungen an bauliche Anlagen und dabei vor allem den baugestalterischen Vorschriften wird häufig nachgesagt, sie hätten stets eine Position zwischen Bauplanungs- und Bauordnungsrecht eingenommen ${ }^{82}$. Die Verwandtschaft zwischen den zum Denkmalschutzrecht zu

\footnotetext{
${ }^{n}$ Eberl, BayVBI. 1987, S. 355.

${ }^{78}$ Siehe hierzu die Einzelheiten unten $C$ und D.

${ }^{79}$ So aber Eberl, BayVBI. 1987, S. 355.

${ }^{80}$ Dies gilt unabhängig davon, ob man den Erlaß von örtlichen Bauvorschriften dem eigenen oder übertragenen Wirkungskreis zurechnet, weil sich die Gemeinde richtiger Auffassung nach in beiden Fällen auf die Garantie des Art. 28 Abs. 2 S. 1 GG berufen kann. Zur Begründung siehe unten, vor allem B II 2 a.

${ }^{81}$ Grosse-Suchsdorf / Schmaltz / Wiechert, DSchG, § 1 Rn. 7 f.; Henke, S. 27 m .w. N.

82 Schmidt-Aßmann, in: Ernst / Zinkahn / Bielenberg, BBauG, §1 Rn. 238; OVG Lüneburg, Urteil vom 10.10.1982, DÖV 1983, S. 387 (388).
} 
zählenden Schutzvorschriften und dem Bauplanungsrecht ist nicht weniger stark ausgeprägt. So gehören die Belange des Denkmalschutzes seit der BBauG-Novelle von 1976 zum Zielkatalog der Bauleitplanung (jetzt §1 Abs. 5 S. 2 Nr. 5 BauGB) $)^{83}$. Auch bildet gerade die Bauleitplanung oft eine besondere Bedrohung für den optischen Eindruck etwa eines historischen Stadtbildes $^{84}$. In $\S 9$ Abs. 1 BauGB sind Festsetzungsmöglichkeiten enthalten, die denen des Denkmalschutzrechtes und damit auch denen der Schutzvorschriften entsprechen. Ein Beispiel hierfür ist die Frage der Festlegung der Firstrichtung ${ }^{85}$.

Der Bundesgesetzgeber hat desweiteren den Denkmalschutz an anderer Stelle auch instrumentell einer städtebaulichen Regelung unterworfen, und zwar in den Bestimmungen über Erhaltungssatzungen nach den $\S \S 172 \mathrm{ff}$. BauGB. Danach darf neben dem Abbruch und der Nutzungsänderung die Errichtung oder Änderung baulicher Anlagen auch zum Schutz des Ortsbildes unter Genehmigungsvorbehalt gestellt werden ( $\$ 172$ Abs. 1 S. 1 und S. 2, Abs. 3 BauGB).

Die Verhinderung der Beseitigung von schützenswerten Teilen baulicher Anlagen ist nach $\S 73$ Abs. 1 Nr. 2 LBO BW möglich. Hier ergibt sich - wie bei den baugestalterischen Vorschriften - wiederum das Problem, daß sowohl Landes- als auch Bundesgesetzgeber zu einer identischen Festsetzung zu ermächtigen scheinen. Die Aufnahme des Schutzes vor Beseitigung von schützenswerten Teilen baulicher Anlagen läßt sich auch nicht damit rechtfertigen, daß die $\S \S 172 \mathrm{ff}$. BauGB allein die bauliche Anlage, nicht aber Ausstattungsdetails schützten ${ }^{86}$. Zwar wird teilweise verlangt, die Änderung einer baulichen Anlage falle nur dann unter die $\S \S 172 \mathrm{ff}$. BauGB, wenn sie "bodenrechtlich relevant" $\mathrm{sei}^{87}$. Es läßt sich aber kein Grundsatz des Inhalts aufstellen, daß die Änderung von Ausstattungsdetails "städtebaulich nicht relevant" ist ${ }^{88}$.

\footnotetext{
${ }^{83}$ Battis / Schmittat, S. 107.

${ }^{84}$ Instruktiv OVG Koblenz, Urteil vom 27.05.1987, NVwZ 1988, S. 371 f. Vgl. dazu etwa FAZ vom 30.07.1987, S. 7: "Oberwesels schutzwürdiges Stadtbild gerettet".

${ }^{85}$ Siehe "Alte Städte - alte Dörfer", S. 15.

${ }^{86}$ So aber Schlotterbeck, in: Schlotterbeck / von Arnim, § 73 Rn. 11 und die Gesetzesbegründung, siehe BW LT-Drs. 8/3410, S. 117.

${ }^{87}$ Krautzberger, in: Battis / Krautzberger / Löhr, § 172 Rn. 4 m.w. N.

88 Siehe etwa den Fall des OVG Lüneburg, Urteil vom 25.04.1983, NJW 1984, S. 2905 (2909), bei dem es um die Entfernung von Spitzgiebeln über Haustüren als Merkmal friesischer Bauart ging.
} 
Abgesehen von dieser Überschneidung ergänzen sich die Möglichkeiten zum Erlaß von Schutzvorschriften und Erhaltungssatzungen bei unbefangener Lektüre des Gesetzestextes sinnvoll ${ }^{89}$. Die Gemeinden können sowohl über das Instrument örtliche Bauvorschriften als auch über den Weg der Erhaltungssatzung oder kumulativ auf beiden Wegen versuchen, etwa ein erhaltenswertes Stadtbild zu schützen. Dabei kommt der Gemeinde beim Erlaß einer Erhaltungssatzung eher eine passive Rolle zu. Sie ist darauf beschränkt, im Genehmigungsverfahren unter den Voraussetzungen des § 172 Abs. 3 BauGB gegebenenfalls die Genehmigung zu versagen oder ihr Einvernehmen zu verweigern ( $\$ 173$ Abs. 1 S. 1 und S. 2 BauGB). Dagegen kann sie beim Erlaß einer örtlichen Bauvorschrift vorschreiben, welche Änderungen sie zulassen will und welche nicht und damit den Grundstückseigentümern einen festen Rahmen für etwaige bauliche Änderungen vorgeben.

Diese nach einfachem Recht sinnvolle Ergänzung beider Instrumente leidet aber unter verfassungsrechtlichen Interferenzwirkungen, die sich aus der Kompetenzabgrenzung im Baurecht ergeben. Entsprechend der bereits wiedergegebenen Ansicht, daß Bauordnungs- und Bauplanungsrecht sich nach ihrem Regelungsziel unterscheiden sollen ${ }^{90}$, findet sich die Auffassung, daß örtliche Bauvorschriften und Erhaltungssatzungen gerade keine verschiedenen Instrumente zur Erreichung eines einheitlichen Ziels seien. Vielmehr zielten örtliche Bauvorschriften als Institut des Bauordnungsrechts aus kompetenzrechtlichen Gründen auf das Einzelbauwerk, Erhaltungssatzungen als Institut des Bauplanungsrechts dagegen auf den Gebietscharakter ${ }^{91}$.

Träfe diese Ansicht zu, wäre das nach einfachem Recht zunächst mögliche sinnvolle Zusammenwirken von Erhaltungssatzung und örtlichen Bauvorschriften gestört. Schutzvorschriften könnten nur mittelbar auch zum Schutz eines Gesamteindrucks eingesetzt werden. Ähnlich wie bei der Frage, ob durch baugestalterische Vorschriften "städtebauliche Absichten" verfolgt werden können ${ }^{92}$, führt auch hier das Problem der Kompetenzaufteilung im Baurecht zu Auslegungsproblemen im Hinblick auf das einfache Recht.

\footnotetext{
${ }^{89}$ Siehe auch die Stellungnahme der Vereinigung der Landesdenkmalpfleger in der Bundesrepublik Deutschland, Deutsche Kunst und Denkmalpflege 1981, S. 193.

${ }^{90}$ Siehe oben A I 2 a bb und cc.

${ }^{91}$ OVG Lüneburg, Urteil vom 10.10.1982, DÖV 1983, S. 387 (389).

${ }^{92}$ Siehe oben A I 2 a bb.
} 
c) Bestimmung von Abstandsflächen

\section{aa) Allgemeines zum Abstandsflächenrecht \\ in den Landesbauordnungen}

Neben den baugestalterischen und den denkmalschützenden Vorschriften ist der Bereich der Einflußnahme auf Abstandsflächen eine dritte wichtige Befugnis, die den Gemeinden über den Erlaß von örtlichen Bauvorschriften eingeräumt wird. Diesen Anwendungsbereich zu würdigen, ist aus einer Reihe von Gründen nicht ganz einfach. Die einzelnen Bestimmungen in den Landesbauordnungen weichen erheblich voneinander $a b^{93}$. Die Übersicht wird dadurch erschwert, daß das Abstandsflächenrecht selbst in den Landesbauordnungen ebenfalls sehr uneinheitlich gestaltet und dadurch schwer überschaubar ist ${ }^{94}$. Immerhin entspricht es im Anschluß an die Musterbauordnung von 1981 der neueren Rechtsentwicklung, die Unterscheidungen zwischen "Bauwich", "Abständen" und "Abstandsflächen" aufzugeben und nur noch Regelungen über Abstandsflächen, d. h. über Flächen, die vor überirdischen Gebäuden auf dem Grundstück liegen müssen, zu treffen ${ }^{95}$. Im folgenden wird daher aus Gründen der Übersichtlichkeit von der Modifizierung von "Abstandsflächen" gesprochen. Die Ausführungen gelten jedoch entsprechend auch für den "Bauwich"96.

\section{bb) Abstandsflächenrecht und Bauplanungsrecht}

Das Abstandsflächenrecht ist eines der klassischen Regelungsmaterien in den Landesbauordnungen. Die Zugehörigkeit des Abstandsflächenrechts zum Bauordnungsrecht wird trotzdem mit der Begründung bestritten, es handele sich um "Planungsrecht" ${ }^{197}$. Andere hingegen betonen, wesentliches

${ }^{93}$ Siehe $\S 73$ Abs. 1 Nr. 6 LBO BW; Art. 91 Abs. 1 Nr. 5 und 6 BayBO; $§ 110$ Abs. 1 Nr. 5 BremLBauO; § 118 Abs. 1 Nr. 6 HBO; $\S 81$ Abs. 1 Nr. 5 BauO NW; $\S 86$ Abs. 1 Nr. 4 LBauO Rh.Pf.; § 83 Abs. 1 Nr. 3 LBO Saarl.; § 82 Abs. 1 Nr. 4 LBO Sl.H. S. 4.

94 Ortloff, NVwZ 1988, S. 399, ders., Abstandsflächenrecht, S. 1. Boeddinghaus, BauR 1989,

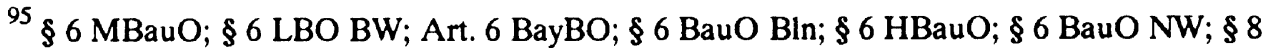
LBauO Rh.Pf.; § 6 LBO Saarl.; § 6 LBO Sl.H. Zu dieser Entwicklung und den Gründen siehe Groth GE 1985, S. 327; Moog / Schmidt, Einl. S. VIII; Ley, NVwZ 1983, S. 600; Ortloff, Abstandsflächenrecht, S. 1; Stich, in: Neues Städtebaurecht, S. 122; LT-Drs. NRW 9/2721, S. 76. Die UnterscheiJung von Bauwich und Abstandsflächen findet sich vor allem noch in $\S \S 7,8$ HBO. Siehe dazu Steinberg, Baurecht, S. 270.

\footnotetext{
${ }^{96}$ Vergleiche $\$ 118$ Abs. 1 Nr. 6 HBO.

${ }^{97}$ Lenz, BauR 1972, S. 261.
} 
Ziel der Vorschriften über Abstandsflächen sei die Sicherstellung von ausreichender Belichtung, Belüftung und Besonnung, so daß das Abstandsflächenrecht zum "Sicherheitsrecht" gehöre ${ }^{98}$.

Dieser Einordnungsstreit hat grundsätzliche Bedeutung. Wären die Bestimmungen über Abstandsflächen in den Landesbauordnungen quasi Landesbauplanungsrecht, so käme den Bestimmungen des Bundesbauplanungsrechts gegenüber den entsprechenden Bestimmungen über Abstandsflächen möglicherweise der Vorrang zu. Denkbar wäre dies dann, wenn entgegen der ganz überwiegenden Meinung ${ }^{99}$ der Bund seine Bodenrechtskompetenz aus Art. 74 Nr. 18 GG nicht vollständig in Anspruch genommen hätte. So ließe sich auf einer solchen Grundlage durchaus die Ansicht vertreten, daß ein Vorhaben auch dann nach § 34 BauGB zulässig ist, wenn die Abstandsflächenbestimmungen der Landesbauordnungen nicht eingehalten werden, soweit das Vorhaben sich in die nähere Umgebung einfügt. Auch die Aufstellung von Bebauungsplänen könnte ohne Rücksicht auf die Abstandsflächenbestimmungen geschehen. Eine Bindung ließe sich nur in der Weise herleiten, daß man annimmt, die Gemeinden seien bei der Durchführung der Bauleitplanung auch an Landesbauplanungsrecht gebunden, weil der Bundesgesetzgeber sie hiervon in $\S \S 1 \mathrm{ff}$. BauGB nicht freistellen wollte. Folgt man dagegen der herkömmlichen sicherheitsrechtlichen Deutung der Abstandsflächenbestimmungen, so sind die entsprechenden Bestimmungen der Landesbauordnungen nach $\S 29$ S. 4 BauGB neben den bauplanungsrechtlichen Bestimmungen anwendbar. Festsetzungen in Bebauungsplänen, die sich wegen entgegenstehender landesrechtlicher Abstandsflächenbestimmungen nicht ausführen lassen, wären nichtig ${ }^{100}$.

Die im Grundsatz also durchaus wichtige Frage über die Rechtsnatur von Abstandsflächenbestimmungen wird jedoch durch einfachgesetzliche Bestimmungen in den Landesbauordnungen weitgehend entschärft. Diese enthalten im allgemeinen die Regelung, daß dann, wenn nach bauplanungsrechtlichen Vorschriften an die Grundstücksgrenze gebaut werden darf oder muß, Abstandsflächen nicht eingehalten werden müssen ${ }^{101}$. Damit ist der wichtigste Kollisionsfall auf einfachgesetzlicher Ebene gelöst, nämlich der,

\footnotetext{
${ }^{98}$ Etwa Proksch, S. 157.

${ }^{99}$ Siehe die Nachweise oben A I 2 a bb, Fn. 42.

${ }^{100}$ Weyreuther, BauR 1972, S. 1 ff.; Knaup / Stange, S. 199.

${ }^{101} \S 6$ Abs. 1 S. 2 LBO BW; Art. 6 Abs. 1 S. 2 BayBO; 6 Abs. 1 S. 2 BauO Bln; $\$ 7$ Abs. 2 BremLBauO; $\S 6$ Abs. 1 HBauO; $\S 7$ Abs. 2 HBO; $\$ 8$ NBauO; $\S 6$ Abs. $1 \mathrm{~S}$. 2 BauO NW; $\S 8$ Abs. 1 S. 2 LBauO Rh.Pf.; § 6 Abs. 1 S. 2 LBO Saarl.; 6 Abs. 1 S. 2 LBO Sl.H.
} 
daß die Gemeinde im Bebauungsplan eine geschlossene Bauweise nach $\S 22$ Abs. 3 BauNVO festsetzt oder daß im unbeplanten Innenbereich ( $\$ 34$ BauGB) eine geschlossene Bauweise vorherrscht ${ }^{102}$.

Vorschriften, nach denen an die (seitliche) Grenze gebaut werden darf oder muß, sind jedoch nicht Festsetzungen nach $\S 22$ Abs. 2 und 3 BauNVO. Baulinien und Baugrenzen haben keinen direkten Bezug zur Grundstücksgrenze $^{103}$. Auch solche Festsetzungen können aber dazu führen, daß eine Planung nur dann durchgeführt werden kann, wenn keine Abstandsflächen eingehalten werden. Problematisch ist das Verhältnis zwischen Festsetzungen in einem Bebauungsplan und den Abstandsflächenbestimmungen in den Landesbauordnungen weiterhin dann, wenn lediglich ein geringerer Abstand eingehalten werden soll, als er sich aus den landesgesetzlichen Bestimmungen ergibt. Solche geringeren Abstandsflächen können sich vor allem aus der Festsetzung von Baulinien ( $\$ 23$ Abs. 2 BauNVO) sowie aus zwingenden Festsetzungen über Geschoßzahl und Gebäudehöhe ergeben ${ }^{104}$. Für diese Fälle sehen die einzelnen Landesgesetzgeber recht unterschiedliche Lösungen vor:

(1) Von den Abstandsflächenvorschriften kann ein Dispens erteilt werden $^{105}$. Die Landesbauordnungen geben damit zu erkennen, daß die Landesgesetzgeber von der grundsätzlichen Geltung der landesrechtlichen Abstandsbestimmungen auch neben zwingenden Festsetzungen eines Bebauungsplans ausgehen.

(2) Zwingende Festsetzungen in Bebauungsplänen haben gegenüber den Abstandsbestimmungen Vorrang ${ }^{106}$. Je nachdem, welcher Auffassung über die Einordnung der Abstandsflächenregeln man folgt, kommt man hier zu einem konstitutiven Zurücktreten oder zu einer nur deklaratorischen Feststellung dessen, was ohnehin gilt. Die LBauO Rh.Pf. und die LBO Saarl. dürften von einem konstitutiven Zurücktreten ausgehen, da als Voraussetzung für den Vorrang der Festsetzungen im Bebauungsplan die ausrei-

${ }^{102}$ Simon, Art. 6 Rn. 13.

${ }^{103}$ BayVGH, Urteil vom 07.04.1987, BayVBl. 1988, S. 274. Siehe auch von Arnim, in: Schlotterbeck / von Arnim, § 6 Rn. 10; Simon, Art. 6 Rn. 13.

${ }^{104}$ Boeddinghaus / Hahn, § 6 Rn. 313; LT-Drs. NRW 9/2721, S. 77.

${ }^{105} \S 7$ Abs. 3 LBO BW; 88 Abs. 8 BremLBauO; $§ 13$ Abs. 3 NBauO; $\S 6$ Abs. 12 LBO Sl.H.

${ }^{106} \S 6$ Abs. 15 BauO NW; $\$ 6$ Abs. 12 HBO; 88 Abs. 12 LBauO Rh.Pf.; $\$ 7$ Abs. 5 LBO Saarl. Dies ist auch die Lösung der MBauO 1981, siehe $\S 6$ Abs. 13. 
chende Belichtung und Belüftung sowie ausreichender Brandschutz aufgeführt werden.

(3) "In Bebauungsplänen" können abweichende Abstandsvorschriften festgelegt werden ${ }^{107}$. Diese Formulierung ist insofern unglücklich, als daß die Festsetzungen, die in einem Bebauungsplan getroffen werden können, in $\S 9$ Abs. 1 BauGB und der BauNVO geregelt sind, dort aber eine eigentliche Regelung von Abstandsflächen nicht vorgesehen ist ${ }^{108}$. Daher ist zweifelhaft, was mit der Formulierung "in Bebauungsplänen" gemeint ist. Zum einen kommt in Betracht, daß es sich dabei um örtliche Bauvorschriften handelt, die eben nur - nach Art. 91 Abs. 3 BayBO und $\S 9$ Abs. 4 BauGB in den Bebauungsplan aufgenommen werden ${ }^{109}$. Gegen ein solches Verständnis spricht aber, da $B$ dann eine ausdrückliche Bestimmung bei den Abstandsflächenregelungen, wonach andere Abstandsflächen auch durch die Aufnahme von örtlichen Bauvorschriften in Bebauungspläne festgesetzt werden können, vollkommen überflüssig ist, weil sich dies bereits aus Art. 91 Abs. 3 BayBO ergibt. Weiterhin wird vorgeschlagen, Art. 7 Abs. 1 S. 1 BayBO dahingehend zu verstehen, daß hier der Landesgesetzgeber die Gemeinden zur Abänderung von Abstandsvorschriften ermächtigt, ohne sie an die einschränkenden Voraussetzungen vor allem des Art. 91 Abs. 1 Nr. 6 BayBO zu binden ${ }^{110}$. Einschränkende rechtliche Voraussetzungen würden sich vielmehr aus $\S 1$ Abs. 3, 4 und 5 BauGB ergeben ${ }^{111}$. Diese Voraussetzungen gelten aber weitgehend auch bei Aufnahme von örtlichen Bauvorschriften in den Bebauungsplan ${ }^{112}$. Es wäre zudem ein gesetzgeberischer Widerspruch, auf der einen Seite in Art. 91 Abs. 1 Nr. 6 BayBO bestimmte Voraussetzungen für die Verringerung von Abstandsflächen vorzusehen, nach Art. 91 Abs. 3 BayBO die Aufnahme solcher Bestimmungen in den Bebauungsplan zu ermöglichen und von diesen Voraussetzungen in Art. 7 gerade für den Fall der Aufnahme der örtlichen Bauvorschrift in einen Bebauungsplan wieder abzusehen. Art. 7 Abs. $1 \mathrm{~S} .1 \mathrm{BayBO}$ dürfte daher so zu

\footnotetext{
${ }^{107}$ Art. 7 Abs. 1 BayBO.

${ }^{108}$ Boeddinghaus / Hahn, § 6 Rn. 313 m. w. N.; Boeddinghaus, Bau R 1989, S. 5.

${ }^{109}$ So Koch / Molodovsky / Rahm, Art. 7 Anm. 2.3.; Boeddinghaus, BauR 1989, S. 6.
}

${ }^{110}$ Dies ist wohl die ganz überwiegende Meinung, siehe Koch / Molodovsky / Rahm, Art. 7 Anm. 2.3.1., Art. 91 Anm. 4.3.1.; Stadtler / Baumgartner / Wiebel, Komm. BayBO 21/10a, Anm. 2.1.; Simon, Art. 7 Nr. 2 b, Art. 91 Rn. 19.

${ }^{111}$ Simon, Art. 7 Nr. 2 b, Art. 91 Rn. 19; einschränkend allerdings Stadler / Baumgartner / Wiebel, Komm.BayBO 21/10a, Anm. 2.4., dies allerdings gegen den Gesetzeswortlaut.

${ }^{112}$ Art. 91 Abs. 3 S. 2 BayBO. Ebenso Stadler / Baumgartner / Wiebel, Komm.BayBO 21/10a, Anm. 2.4. 
verstehen sein, daß die Festsetzung von geringeren Abstandsflächen nach Art. 7 BayBO zwar nicht an die Voraussetzungen des Art. 91 Abs. 1 Nr. 6 BayBO gebunden ist, jedoch auch nicht quasi beliebig erfolgen kann, sondern nur als Reaktion auf eine zwingende Festsetzung in dem betreffenden Bebauungsplan.

Der BayVGH versucht dagegen, den Art. 7 Abs. 1 BayBO dahingehend restriktiv auszulegen, daß Abstandsflächenverringerungen nicht pauschal für ein ganzes Plangebiet, sondern wegen des Ausnahmecharakters der Vorschrift nur für einzelne, genau bestimmte Grundstücke oder bauliche Anlagen zulässig $\operatorname{sind}^{113}$. Gegen diese Auffassung spricht jedoch, daß Art. 7 Abs. 1 BayBO gerade ein normatives Abweichen und nicht ein Abweichen im Einzelfall erlaubt ${ }^{114}$. Immerhin zeugt aber Art. 7 BayBO davon, daß auch der bayerische Gesetzgeber von der grundsätzlichen Geltung der Abstandsflächenregelungen neben planungsrechtlichen Bestimmungen ausgeht.

(4) Schließlich findet sich in Hessen (noch) keine gesetzgeberische Regelung dieses Kollisionsfalls. Gerade hier wird die Frage der richtigen Einordnung der Abstandsvorschriften besonders relevant.

\section{cc) Die funktionelle Bedeutung abstandsmodifizierender örtlicher Bauvorschriften}

Die Bedeutung, die die Modifizierung von Abstandsvorschriften für die gemeindlichen Planungsmöglichkeiten hat oder - soweit man sich der Auffassung, daß Abstandsflächenbestimmungen nicht neben bauplanungsrechtlichen Zulässigkeitstatbeständen zur Anwendung kommen ${ }^{115}$ - nicht hat, ergibt sich aus den oben dargestellten Bestimmungen der Landesbauordnungen, die das Verhältnis zwischen Bauplanungsrecht und Abstandsflächenrecht regeln. Dabei ist zu unterscheiden zwischen der Vergrößerung und der Verringerung von Abstandsflächen.

Soweit die Gemeinde über den Weg des Erlasses einer örtlichen Bauvorschrift größere Abstandsflächen festlegt, ist der Streit um die Einordnung

\footnotetext{
${ }^{113}$ BayVGH, Beschluß vom 20.11.1986, BayVBl. 1987, S. 337 (338), ohne dabei auf Art. 91 Abs. 1 Nr. 6 BayBO einzugehen.

114 Jäde, BayVBI. 1987, S. 339; kritisch auch Boeddinghaus, BauR 1989, S. 4 f. Richtiger wäre es in dem vom BayVGH entschiedenen Fall wohl gewesen, einen Abwägungsfehler anzunehmen, wenn pauschal im Bebauungsplan die Abweichung von den Abstandsflächenbestimmungen erlaubt wird, ohne sich über die Auswirkungen auf die einzelnen Grundstücke Gedanken zu machen. So auch Jäde, ebenda.

${ }^{115}$ Siehe dazu oben A I 2 c aa.
} 
als Boden- oder Sicherheitsrecht irrelevant. Strebt die Gemeinde eine stärker aufgelockerte Bebauung an, als sie sich aus den Abstandsflächenbestimmungen ergibt, kann sie - soweit die Bauordnungen dies vorsehen ${ }^{116}$ eine örtliche Bauvorschrift erlassen. Größere Freiflächen zwischen Gebäuden können aber auch über die Festlegung einer Baulinie oder Baugrenze ( 23 Abs. 2 und 3 BauNVO) erreicht werden. Da Baulinien und Baugrenzen ohne Rücksicht auf die Grundstücksgrenze festgelegt werden, ist dies jedoch ein wesentlich umständlicheres Verfahren als der Erlaß einer örtlichen Bauvorschrift. $\mathrm{Da} \S 73$ Abs. 1 Nr. 6 LBO BW für die Vergrößerung der Abstandsflächen "städtebauliche Gründe" verlangt ${ }^{117}$, zeigt, daß die Möglichkeit der Vergrößerung eine Ergänzung zu oder sogar einen Ersatz für bauplanungsrechtliche Festsetzungsmöglichkeiten bildet. Den Gemeinden bietet sich so die Möglichkeit einer erleichterten und sachgerechteren Ersatzbauleitplanung ${ }^{118}$.

Differenzierter ist dagegen die Funktion abstandsmodifizierender örtlicher Bauvorschriften zu sehen, wenn es um die Verringerung von Abstandsflächen geht und zwar aufgrund der unterschiedlichen Art und Weise, wie die Landesbauordnungen den möglichen Konflikt zwischen Abstandsflächenrecht und bauplanungsrechtlichen Bestimmungen regeln. So kann nach $\S 73$ Abs. 1 Nr. 6 LBO BW und $\S 83$ Abs. 1 Nr. 3 BauO Saarl. auch die Verringerung von Abstandsflächen aus "städtebaulichen" Gründen erfolgen. In diesen Fällen ist der Begriff "städtebaulich" wohl im gleichen Sinn wie in § 1 Abs. 5 BauGB gemeint ${ }^{119}$. Die Gemeinde erhält - die Verfassungsmäßigkeit der Vorschriften unterstellt - auf diese Weise die Möglichkeit, ihre bauplanungsrechtlichen Vorstellungen auch gegenüber den formellen landesgesetzlichen Abstandsbestimmungen durchzusetzen. Zwar bietet $\$ 7$ Abs. 4 LBO BW auch die Möglichkeit des Dispenses von den Abstandsvorschriften. Gerade bei Gemeinden, die nicht selbst Baugenehmigungsbehörde

${ }^{116}$ Die Möglichkeit der Vergrößerung von Abstandsflächen sehen vor: $§ 73$ Abs. 1 Nr. 6 LBO BW, Art. 91 Abs. 1 Nr. 5 BayBO, § 110 Abs. 1 Nr. 5 BremLBauO, $\S 86$ Abs. 1 Nr. 4 LBauO Rh.Pf.

${ }^{117} \mathrm{Zu}$ den Problemen mit der Verwendung des Begriffs "städtebaulich" in einer Landesbauordnung siehe schon oben A I 2 a bb.

${ }^{118}$ Koch / Molodovsky / Rahm, Art. 91 Anm.2.7.; Simon, Art. 91 Rn. 18 verlangt allerdings, $\mathrm{daB}$ eine solche Erweiterung sich an der baurechtlichen Generalklausel orientieren müsse.

${ }^{119}$ Schlotterbeck, in: Schlotterbeck / von Arnim, \& $73 \mathrm{Rn}$. 27. Zum ähnlich gelagerten, aber nach verbreiteter Ansicht anders zu entscheidenden Fall des Art. 91 Abs. 1 Nr. 1 BayBO, siehe oben A I 2 a bb. 
$\operatorname{sind}^{120}$, ist dieser Weg zur Durchsetzung eigener Planungsvorstellungen aber notwendigerweise unsicher.

Auch die Verringerung von Abstandsflächen aus "bauhistorischen Grün$\operatorname{den}^{\text {n121 }}$ ist ein Komplementärinstitut zum Bauplanungsrecht. Wichtigster Anwendungsfall hierfür ist die Erhaltung von Traufgassen oder "engen Reihen" in historischen Altstadtkernen ${ }^{122}$. Die Bebauung mit Traufgassen, die häufig nicht breiter als $80 \mathrm{~cm}$ waren, war über Jahrhunderte hinweg in vielen Städten üblich ${ }^{123}$. Die Erhaltung solcher Gassen erscheint heute vor allem wegen ihrer Bedeutung für den optischen Charakter einer Altstadt in vielen Fällen wünschenswert ${ }^{124}$. Versucht man, die Bebauung mit Traufgassen im Hinblick auf die Bauweise nach § 34 BauGB und § 22 BauNVO zu qualifizieren, so wird man zu dem Ergebnis kommen müssen, daß es sich um einen Fall der offenen Bauweise handelt ${ }^{125}$. Gegen die Annahme, es handele sich bei einer Bebauung mit Traufgassen um eine geschlossene Bauweise ${ }^{126}$, spricht vor allem, daß dies langfristig zu einem Verschwinden der Traufgassen führen würde ${ }^{127}$. Denn wenn es sich um geschlossene Bauweise handelte, wäre im unbeplanten Innenbereich jeder Neubau an die Grundstücksgrenze zu setzen. Wenn die Grundstücksgrenze in der Mitte der Traufgasse verläuft, führt dies zu einer Halbierung der Gasse, was wesentlich problematischer sein dürfte als die Beibehaltung des ursprünglichen Abstandes ${ }^{128}$. Sollen planungsrechtlich Traufgassen "abgesichert" werden, so ist daher zunächst im Bebauungsplan offene Bauweise festzusetzen ( $\$ 22$ Abs. 2 BauNVO). Als zweites müßte - ebenfalls im Bebauungsplan - eine Baulinie festgesetzt werden ( $\$ 23$ Abs. 2 S. 1 BauNVO). Damit würde sichergestellt, daß die ursprüngliche Breite der Traufgasse erhalten bleibt und nicht etwa vergrößert wird. Schließlich wären, soweit nicht die Abstandsvorschriften

\footnotetext{
${ }^{120} \mathrm{Vgl} . \$ \$ 48$ ff. LBO BW.

${ }^{121} \S 73$ Abs. 1 Nr. 6 LBO BW; Art. 91 Abs. 1 Nr. 6 BayBO; $\$ 118$ Abs. 1 Nr. 6 HBO; $\S 81$ Abs. 1 Nr. 5 BauO NW; $§ 86$ Abs. 1 Nr. 4 LBauO Rh.Pf.; $\$ 83$ Abs. 1 Nr. 4 LBO Saarl.; $\$ 82$ Abs. 1 Nr. 4 LBO Sl.H.

${ }^{122}$ Burger / Gutschow / Krause, S. 260.

${ }^{123}$ Boeddinghaus, BauR 1987, S. 639.

${ }^{124} \mathrm{Vgl}$. dazu die Ausführungen des OVG Lüneburg, Urteil vom 25.01.1978, BRS Bd. 33, Nr. 53, S. $116(118)=$ BauR 1978, S. 460.

${ }^{125}$ Im Ergebnis auch Boeddinghaus, Bau R 1987, S. 641.

${ }^{126}$ So das OVG Lüneburg, BRS Band 33, S. 117; Schmaltz, VR 1983, S. 221.

127 Siehe OVG Lüneburg (Fn. 126): Grenzbebauung ist der erste Schritt zur Sanierung unzureichender Grenzabstände.

${ }^{128}$ Boeddinghaus, BauR 1987, S. 641.
} 
A. Örtliche Bauvorschriften zwischen Bauplanungs- und Bauordnungsrecht

zwingenden bauplanungsrechtlichen Bestimmungen weichen ${ }^{129}$, über den Erlaß einer örtlichen Bauvorschrift die Abstandsflächen entsprechend zu verringern ${ }^{130}$.

Die funktionelle Bedeutung der Befugnis zur Modifizierung von Abstandsflächen läßt sich also folgendermaßen zusammenfassen: Die Vergrößerung von Abstandsflächen ist eine sinnvolle Ergänzung der bauplanungsrechtlichen Festsetzungsmöglichkeiten zur Schaffung einer aufgelockerten Bebauung. Die Möglichkeit der Verringerung von Abstandsflächen ist ein notwendiges Komplementärinstrument zur Bauleitplanung vor allem bei spezifischen Problemen der Erhaltung des optischen Eindrucks historischer Altstadtkerne, soweit man vom bauordnungsrechtlichen Charakter der Abstandsvorschriften ausgeht, die deshalb nicht zur Disposition der Bauleitplanung stehen.

d) Sonstige Regelungsbereiche und ihr Verhältnis zum Bauplanungsrecht

\section{aa) Weitere gestalterische Vorschriften}

In den Landesbauordnungen finden sich noch eine Reihe weiterer Regelungsmöglichkeiten für die Anwendung des Instituts "örtliche Bauvorschriften". Viele hängen eng mit der Befugnis zum Erlaß von baugestalterischen Vorschriften zusammen und lassen sich mit diesen unter den Begriff "gestalterische Vorschriften" zusammenfassen. Mit den baugestalterischen Vorschriften haben sie gemeinsam, daß sie vor allem in Neubaugebieten zur Anwendung kommen und den Gemeinden Einflußmöglichkeiten in einem Bereich bieten, in dem über den Erlaß eines Bebauungsplans mangels einer in $\S 9$ Abs. 1 BauGB vorgesehenen geeigneten Festsetzung eine normative Regelung sonst nicht zulässig ist. Sie ermöglichen insoweit eine Regelung en detail, die allein mit Mitteln der Bauleitplanung nicht zu erreichen wäre. Hierzu zählen vor allem Anforderungen an die Gestaltung von nichtbaulichen Anlagen, Grundstücksfreiflächen und Einfriedungen ${ }^{131}$.

\footnotetext{
${ }^{129}$ Dazu siehe oben A I 2 c bb.
}

${ }^{130}$ Ein Beispiel ist insoweit der bei Burger / Gutschow / Krause auf S. 31 wiedergegebene Bebauungsplan der Stadt Freudenberg: "Zur Wahrung der erhaltenswerten Eigenart des Stadtkerns Freudenberg werden für den Geltungsbereich des Bebauungsplans geringere als die in $\$ \S$... BauNVO vorgeschriebenen ... Abstandsflächen ... zugelassen. Die Maße bestimmen sich durch die im Bebauungsplan festgesetzten Baulinien und Baugrenzen."

${ }^{131} \S 73$ Abs. 1 Nr. 5 LBO BW; Art. 91 Abs. 1 Nr. 3 und 5 BayBO; $\S 110$ Abs. 1 Nr. 3 und 4 BremLBauO; $\S 118$ Abs. 1 Nr. 3 - 5 HBauO; $\S 56$ Nr. 3, 5, 6 NBauO; $\S 81$ Abs. 1 Nr. 3 und 4 
Kompetenzrechtliche Probleme ergeben sich daher nur aus dem Regelungsziel, das in den Landesbauordnungen nicht näher bestimmt ist. Dadurch stellt sich erneut die Frage, ob damit etwa nur gestalterische Anliegen verfolgt werden dürfen und sich die primäre Zielrichtung auch auf den Gebietscharakter beziehen darf oder nur auf die einzelne Anlage, insgesamt also Probleme, die keine Besonderheiten gegenüber denen aufweisen, die bereits bei den baugestalterischen und den Schutzvorschriften aufgetaucht sind.

\section{bb) Einschränkungen für die Errichtung von Stellplätzen und Garagen}

In den Bestimmungen über örtliche Bauvorschriften finden sich desweiteren Vorschriften über die Einschränkung oder Untersagung der Herstellung von Stellplätzen und Garagen ${ }^{132}$. Werden örtliche Bauvorschriften nach diesen Bestimmungen erlassen, so kann dies funktionell unter zwei Gesichtspunkten geschehen. Zum einen kommt in Betracht, daß damit ähnlich wie bei der Verringerung von Abstandsflächen bauplanungsrechtliche Festsetzungen ermöglicht werden sollen. Denn der Bundesgesetzgeber hat sich dem Problem der Verbannung des Individualverkehrs vor allem aus den Innenstädten auch durch $\S 12$ Abs. 6 BauNVO angenommen. Der dort enthaltene Vorbehalt zugunsten des Landesrechts wird durch den Erlaß von örtlichen Bauvorschriften ausgefüllt. Ohne eine entsprechende Ermächtigung in den Landesbauordnungen läuft das bundesrechtliche Instrument des $\S 12$ Abs. 6 BauNVO leer. Zum zweiten bietet sich für die Gemeinden die Möglichkeit der Ersatzbauleitplanung ähnlich wie bei der Vergrößerung von Abstandsflächen ${ }^{133}$. Ohne Einhaltung des Verfahrens zum Erlaß eines Bebauungsplans wird eine Einschränkung des Individualverkehrs möglich durch den Erlaß einer Satzung über eine örtliche Bauvorschrift. Wie beim Erlaß eines Bebauungsplans ist ein planerisches Konzept und eine Interessenabwägung notwendig ${ }^{134}$, nur das Verfahren ist weniger kompliziert und aufwendig. Besonders deutlich wird diese Doppelfunktion an Art. 91 Abs. 2 Nr. 4 BayBO. Dort sind für die Einschränkung der Stellplatzherstellung zwei Arten von Gründen genannt. Zum einen kann dies geschehen in Anlehnung

BauO NW; $\S 86$ Abs. 1 Nr. 3 LBauO Rh.Pf.; $\S 83$ Abs. 1 Nr. 2 LBO Saarl.; $\S 82$ Abs. 1 Nr. 3 LBOSI.H.

/ $\$ 73$ Abs. 1 Nr. 10 LBO BW; Art. 91 Abs. 2 Nr. 4 BayBO; $§ 86$ Abs. 3 LBauO Rh.Pf.; § 83 Abs. 1 Nr. 4 LBO Saarl.

\footnotetext{
${ }^{133}$ Dazu siehe oben A I 2 c cc.

${ }^{134}$ Schlotterbeck, in: Schlotterbeck / von Arnim, § $73 \mathrm{Rn} .34$.
} 
an einen Bebauungsplan, aber auch quasi eigenständig aus Gründen des Verkehrs und des Städtebaus. Diese Bestimmung zeigt, daß zumindest die BayBO davon ausgeht, daß bauordnungsrechtliche Instrumente auch aus städtebaulichen Gründen eingesetzt werden können ${ }^{135}$. Die Bedenken, die im Rahmen des Art. 91 Abs. 1 Nr. 1 BayBO sogar zum Vorschlag einer verfassungskonformen Interpretation führten ${ }^{136}$, würden aber zunächst auch hier gelten.

\section{e) Zusammenfassung}

Insgesamt lassen sich nach den bisherigen Untersuchungen folgende Feststellungen über offene Fragen im Verhältnis der örtlichen Bauvorschriften zum Bauplanungsrecht treffen:

1. Der Erlaß von örtlichen Bauvorschriften ermöglicht in wesentlichen Bereichen eine Feinsteuerung bei der Einwirkung auf die bauliche Gestaltung des Gemeindegebietes. Die Notwendigkeit einer solchen Feinsteuerung ergibt sich daraus, daß mit den Festsetzungen, die $\S 9$ Abs. 1 BauGB zuläßt, nicht alle notwendigen Anforderungen gestellt werden können.

2. Probleme für das Zusammenwirken von Bauleitplanung und dem Erlaß örtlicher Bauvorschriften folgen aus der verbreiteten Auffassung über die Aufteilung des Baurechts in Bauordnungs- und Bauplanungsrecht. Zum einen ergeben sich Unsicherheiten in bezug auf die möglichen Festsetzungen, zum anderen auf die Regelungsziele, zu denen örtliche Bauvorschriften eingesetzt werden können. Vor allem bei den Schutzvorschriften wird so ein sinnvolles Zusammenwirken von örtlichen Bauvorschriften mit den Stadterhaltungssatzungen nach $\S 172 \mathrm{ff}$. BauGB erschwert.

3. Die Möglichkeit zum Erlaß von örtlichen Bauvorschriften bietet den Gemeinden in gewissen Bereichen die Möglichkeit zur Ersatzbauleitplanung, d. h. sie können über den Erlaß einer örtlichen Bauvorschrift Wirkungen erzielen, für die sie sonst einen Bebauungsplan aufstellen müßten. Fraglich ist, ob dies im Hinblick auf Art. 72 Abs. 1 i. V. m. 74 Nr. 18 GG zulässig ist.

${ }^{135}$ Dies ist auch eine Bestätigung der Rechtsprechung des BayVGH, wonach bei der Ermessensausübung für die Stellplatzablösung nach Art. 56 Abs. 1 BayBO die Verbesserung der städtebaulichen Qualität eines Gebietes berücksichtigt werden darf, siehe Urteil vom 10.12.1985, BayVBl. 1987, S. 85 ff.

${ }^{136}$ Siehe oben A I 2 a bb. 
4. Örtliche Bauvorschriften ermöglichen die Verwirklichung von Festsetzungen in Bebauungsplänen, indem sie angenommene Hindernisse aus dem Nebeneinander von Bauordnungs- und Bauplanungsrecht beseitigen.

\section{Die Abgrenzung zwischen Bauordnungs- und Bauplanungsrecht}

\section{Allgemeines zur Kompetenzabgrenzung im Baurecht}

a) Kompetenzaufteilung im Baurecht und Schutz der Länderzuständigkeiten

Nach dem System der Art. 70 ff. GG ist dem Bund die Gesetzgebungskompetenz für bestimmte "Angelegenheiten" oder "Gebiete" übertragen. Im übrigen obliegt die Gesetzgebung den Ländern (Art. 70 Abs. 1 GG). Die Zuweisung einer bestimmten Angelegenheit führt vor allem dann zu Abgrenzungsschwierigkeiten, wenn ein nach natürlichem Verständnis einheitlicher Bereich aufgeteilt und somit kompetenzrechtlich durchschnitten wird. Die bauliche Nutzung von Grundstücken ist zumindest ein soziologisch einheitlicher Tatbestand ${ }^{137}$. Zwar hat sich die in den fünfziger Jahren geführte Diskussion darüber, ob das Baurecht auch juristisch eine eigenständige und einheitliche Materie und deshalb eine Kodifikation sinnvoll ist ${ }^{138}$, durch die Rechtsentwicklung zunächst erledigt. Eine getrennte Normierung von Bauordnungs- und Bauplanungsrecht mußte nach dem Baurechtsgutachten des BVerfG $^{139}$ stattfinden. Schwierigkeiten ergeben sich jedoch nach wie vor. Sie bestehen heute vor allem in einem Punkt, der für das Verhältnis von örtlichen Bauvorschriften zum Bauplanungsrecht von besonderer Bedeutung ist, daß nämlich das Städtebaurecht die Berücksichtigung von Belangen vorschreibt, die bei sondergesetzlicher Normierung als Ländersache angesehen werden. Als Beispiele wurden bereits die Ortsbildgestaltung und der Denkmalschutz genannt.

Diese Verschränkungen des Städtebaurechts mit sondergesetzlichen Materien, deren Regelung den Ländern obliegt, haben nun zu Versuchen verleitet, eine strikte Grenzziehung zwischen diesen Materien zu unterlas-

\footnotetext{
${ }^{137}$ Werner, DVB1. 1952, S. 264.

${ }^{138}$ Verneinend etwa Werner, DVBI. 1952, S. 264; bejahend Westermann, BBauBl. 1952, S. $140 \mathrm{ff}$.

${ }^{139}$ Vom 16.06.1954, E 3, 407 ff. Siehe dazu ausführlich unten A II 2 a.
} 
sen. So findet sich etwa die Feststellung, eine "scharfe Grenzziehung" zwischen den Bereichen Denkmalschutzrecht und Städtebaurecht sei nicht mehr möglich ${ }^{140}$. Statt einer Grenzlinie bestehe eine Grenzzone aus Überschneidungen und Überdeckungen von bundes- und landesrechtlichen Vorschriften ${ }^{141}$. $\mathrm{Zu}$ einer gewissen Aufweichung einer strikten kompetenzrechtlichen Aufteilung der gesetzgeberischen Zuständigkeiten kommt es auch, wenn etwa in bezug auf den Schutz des Ortsbildes von einer "gemeinsamen Verantwortung" von Bundes- und Landesgesetzgeber gesprochen wird ${ }^{142}$.

Solchen Tendenzen ist entgegenzutreten. Dies gilt zunächst für die Annahme der Unmöglichkeit einer scharfen Grenzziehung. Gerade im Bereich der städtebaulichen Planung, bei der eine Vielzahl von Belangen zu berücksichtigen ist (siehe $\S 1$ Abs. 5 S. 2 BauGB), bedarf es einer exakten Abgrenzung der Bundeszuständigkeit. Andernfalls besteht die Gefahr des Hineinwucherns der Bundeszuständigkeit für das Bodenrecht (Art. 74 Nr. 18 GG) in Bereiche, für die sich der Bund auf keinen Kompetenztitel berufen kann. Desweiteren zeigen die oben dargestellten Auslegungsprobleme im Bereich des einfachen Rechts, wie sehr es auf eine genaue Trennung von Bundesund Landesrecht ankommt. Nur eine exakte Interpretation der verfassungsrechtlichen Kompetenzabgrenzung ermöglicht die Auslegung des einfachen Rechts.

Auch beim Begriff der "gemeinsamen Verantwortung" ist Vorsicht geboten. Grundsätzlich fordert eine Kompetenzaufteilung nach Sachbereichen, wie sie das GG in den Art. 70 ff. vornimmt, eine getrennte und damit alleinige Verantwortung des jeweiligen Gesetzgebers für seinen Bereich. Die Art. 70 ff. GG mit der Normierung der Zuständigkeit der Länder bei fehlendem Kompetenztitel des Bundes bezwecken den Schutz der Gesetzgebung und damit letztlich der Staatlichkeit der Länder. Es handelt sich um eine zumindest grundsätzliche Entscheidung gegen eine gemischte und damit auch häufig verwischte Verantwortlichkeit. Die strikte Einhaltung der Kompetenzordnung der Art. 70 ff. GG ist schließlich auch die Grundvoraussetzung dafür, dem vielfach beklagten Verlust an Aufgaben für die Länder ${ }^{143}$

${ }^{140}$ Stich, ZfBR 1983, S. 61 (63). Ähnlich Watzke, ZfBR 1981, S. 10, wonach die Grenzziehung "problematisch" sei.

${ }^{141}$ Stich, in: Neues Städtebaurecht, S. 117.

142 Henke, S. 103.

${ }^{143}$ Zum fortschreitenden Aufgabenverlust siehe Wiecher, ZRP 1985, S. 239 m. w. N.; Pestalozza, NJW 1981, S. 2084. Zum Funktionsverlust der Landesparlamente Hufen, BayVBl. 1987, S. 515 m. w. N.; Kisker, NJW 1977, S. 1316; Eicher, S. 76 f. 
und der damit verbundenen Erosion ihrer Eigenständigkeit ${ }^{144}$ Einhalt zu gebieten. Im übrigen sind auch aus rechtsstaatlichen und demokratischen Erwägungen Kompetenzüberschneidungen und Doppelzuständigkeiten zu vermeiden, denn sie führen zu Rechtsunsicherheiten und Verwischung der parlamentarischen Verantwortlichkeit ${ }^{145}$.

b) Die Bedeutung der Eigentumsgarantie für die Kompetenzaufteilung im Baurecht

Neben diesen allgemeinen Überlegungen für die Frage der Lösung von Problemen bei der Kompetenzaufteilung zwischen dem Bund und den Ländern spielt speziell für das Baurecht die Eigentumsgarantie des GG als primär einschlägige grundrechtliche Gewährleistung eine besondere Rolle. Gerade Art. 14 GG verlangt eine strikte Einhaltung der Kompetenzordnung und eine intensive Suche nach praktikablen Abgrenzungsmaßstäben. Das folgt daraus, daß gerade der Grundrechtsträger Grundeigentümer sich in einer spezifischen Gefährdungslage im Hinblick auf übermäßige Beschränkungen seines Eigentums befindet. Diese spezifische Gefährdungslage ergibt sich aus folgenden Überlegungen: Die Schrankenbestimmung des Eigentums nach Art. 14 Abs. 1 S. 2, Abs. 2 GG verlangt eine Abwägung zwischen der Wertentscheidung des GG zugunsten des Privateigentums und den Anforderungen einer sozialgerechten Eigentumsordnung ${ }^{146}$. Dabei wird vor allem dem Grundeigentum eine gesteigerte Sozialpflichtigkeit zugewiesen, die sich aus der Unentbehrlichkeit und Unvermehrbarkeit von Grund und Boden ergibt ${ }^{147}$. Die gesteigerte Sozialpflichtigkeit umschreibt vor allem der Begriff "Situationsgebundenheit"148. Dieser erweiterte Spielraum zulasten des Grundeigentümers wird nicht nur vom förmlichen Landes- oder Bundesgesetzgeber ausgeschöpft, sondern auch von der Verwaltung, die über Satzungen wie etwa den Bebauungsplan oder durch Rechtsverordnungen Inhalts- und Schrankenbestimmungen für das Eigentum vornehmen ${ }^{149}$. Ohne eindeutige Kriterien dafür, welcher Gesetzgeber die Verwaltung in

\footnotetext{
${ }^{144}$ So Soell, Festschrift für Forsthoff, S. 398.

${ }^{145}$ Brohm, DÖV 1983, S. 525.

${ }^{146}$ Kimminich, Art. 14 GG, Rn. 98; Papier, in: Maunz / Herzog / Dürig / Scholz, Art. 14, Rn. 254; Wendt, S. $306 \mathrm{ff}$.

${ }^{147}$ Wendt, Eigentum, S. 384.

${ }^{148}$ Wendt, Eigentum, S. 389.

149 Hoppe, DVBI. 1964, S. 167; Rengeling, AöR 105 (1980), S. 434, mit Hinweisen auf die Rechtsprechung des BVerfG; Conrad, BayVBI. 1970, S. 390.
} 
welchem Bereich aus welchen Gründen wozu ermächtigen darf, entsteht die Möglichkeit, daß verschiedene Gesetzgeber die Verwaltung zu gleichen oder ähnlichen inhalts- und schrankenziehenden Maßnahmen ermächtigen, dabei aber unterschiedliche Eingriffsvoraussetzungen vorsehen. Ein Beispiel ist die Möglichkeit der "Ersatzbauleitplanung" durch örtliche Bauvorschriften, also die Tatsache, daß die Gemeinden Normierungen, für die sie sonst einen Bebauungsplan aufstellen müßten, auch mit dem einfacheren Weg des Erlasses einer Satzung über eine örtliche Bauvorschrift erreichen können ${ }^{150}$. Der Eigentümer muß dann eine Maßnahme gegen sich gelten lassen, obwohl ein anderer Gesetzgeber eigentlich zu seinen Gunsten weitergehende formelle oder materielle Voraussetzungen vorgesehen hatte.

Weiterhin besteht bei einer unklaren Kompetenzlage die Möglichkeit, daß Bundes- und Landesgesetzgeber die Verwaltung zu unterschiedlichen Maßnahmen ermächtigen und bei jeder dieser Maßnahmen derselbe Aspekt zulasten des Eigentümers berücksichtigt wird, es also zu einer Multiplizierung desselben öffentlichen Interesses zulasten des Grundstückseigentümers kommt. Wer etwa in einer historischen Altstadt ein Gebäude besitzt, muß kumulativ mit denkmalschutzrechtlichen Beschränkungen, einer örtlichen Bauvorschrift in Form einer Schutzvorschrift und einer Stadterhaltungssatzung rechnen. Jede Maßnahme für sich mag eine zulässige Eigentumsbindung sein, nicht hingegen in jedem Fall ihre Kumulierung. Die Forderung, daß beispielsweise beim Erlaß einer Satzung berücksichtigt wird, was dem Eigentümer nach anderen Rechtsvorschriften auferlegt wurde, dürfte sich auch nicht immer effektiv durchsetzen lassen. Ohne Klarheit darüber, welcher Gesetzgeber für die Geltendmachung welches öffentlichen Belangs gegenüber dem Grundeigentum zuständig ist, droht damit eine Art "Salamitaktik" zulasten des Grundeigentümers, d. h., daß die Verwaltung mit unterschiedlichen Maßnahmen unter Umständen unterschiedlicher Verwaltungsträger das Grundeigentum beschränkt, obwohl nur eine Beschränkung einer angemessenen Abwägung entsprechen würde ${ }^{151}$. Gerade für das Grundeigentum stimmt die Feststellung, daß Sozialbindungen die Tendenz haben, sich fortlaufend $\mathrm{zu}$ vermehren ${ }^{152}$, und zwar nicht unbedingt immer in hinreichend kontrollierter und abgestimmter Weise.

${ }^{150}$ Siehe dazu das Beispiel der Erweiterung von Abstandsflächen und des Ausschlusses der Herstellung von Stellplätzen und Garagen, oben A I $2 \mathrm{c}$ und A I d bb.

${ }^{151}$ Leisner, HbStR, Band IV, S. 1083 Rn. 153, spricht von "Sozialbindungskumulation".

${ }^{152}$ Maunz, DÖV 1975, S. 1. 
Man wird deshalb verlangen müssen, daß solche Vermehrungen nur unter strikter Wahrung der Kompetenzordnung und nicht aus Gründen geschehen, die bereits an anderer Stelle zu einer Sozialbindung geführt haben $^{153}$. Das BVerfG hat im "Bad-Dürkheimer-Gondelbahnfall" betont, die Verwaltung dürfe bei einer Enteignung nach Art. 14 Abs. 3 S. 2 GG nur das Enteignungsgesetz anwenden, daß der nach der Kompetenzordnung zuständige Gesetzgeber erlassen habe ${ }^{154}$. Für die Bestimmung der Sozialbindung, die zwar nicht final auf einen teilweisen oder völligen Rechtsentzug gerichtet ist, dafür aber in der Regel auch nicht mit der Wohltat eines Geldausgleichs verbunden ist, muß dies in noch verstärktem Maße gelten.

Als Ergebnis bleibt festzuhalten, daß Art. 14 GG noch einmal verstärkt das verlangt, was sich aus den Art. $70 \mathrm{ff}$. GG im Grundsatz auch schon ergibt, daß nämlich eine genaue Kompetenzabgrenzung nötig ist und möglich sein muß. Solche Klarheit ist vor allem für die Frage erforderlich, welcher Gesetzgeber die Verwaltung zu welchen inhalts- und schrankenziehenden Eigentumsregelungen ermächtigen darf.

\section{Das Rechtsgutachten des BVerfG}

a) Wesentliche Aussagen und Wirkungen des Gutachtens

Am Anfang fast jeder Erläuterung zur Zweiteilung des Baurechts in Bauplanungs- und Bauordnungsrecht und den damit verbundenen kompetenzrechtlichen Fragen steht das Rechtsgutachten des BVerfG vom 16. Juni $1954^{155}$. Hierbei soll es sich um die Grundlage und den Ausgangspunkt jeder Prüfung handeln, ob eine baurechtliche Teilmaterie dem Bauordnungs- oder dem Bauplanungsrecht zuzuordnen sei ${ }^{156}$. Die im vorliegenden Zusammenhang wesentlichen Aussagen des BVerfG lassen sich wie folgt zusammenfassen: Das BVerfG lehnte es zunächst ab, aus einer Gesamtschau der in Art. 74 Nr. 18 GG enthaltenen Kompetenztitel dem Bund eine Kompetenz

153 Auch Bartlsperger, DVB1. 1981, S. 288, spricht sich dagegen aus, das Übermaß an Dynamisierung und Labilität urbanen Grundeigentums weiter zu erhöhen.

${ }^{154}$ BVerfG, Urteil vom 10.03.1981, E 56, 249 (262).

${ }^{155}$ E 3, 407 ff. Vgl. etwa Gaentzsch, Berliner Kommentar, § 1 Rn. 5; Krebsbach, HbKWP Band 3, S. 549; Steinberg, Baurecht, S. 266; Krebs, Baurecht, S. 382; Ley, Baurecht, S. 380 Rn. 10.

${ }^{156}$ Gelzer, Rn. 2. Siehe auch Steiner, Verkehrsplanung, S. 41. 
für das gesamte Baurecht zuzugestehen ${ }^{157}$. So betreffe der Titel "Wohnungswesen" schon vom Wortlaut her nur Wohnzwecken dienende Gebäude ${ }^{158}$. Auch dem Argument, daß sich aus der Kompetenz "Siedlungswesen" eine Bundeskompetenz für den Bereich der Baugestaltung ergebe ${ }^{159}$, folgte das BVerfG nicht. Zwar sei die Baugestaltungsverordnung vom 10.11.1936 ${ }^{160}$ aufgrund des $\S 1$ des Gesetzes über das Siedlungswesen ${ }^{161}$ erlassen worden. Die Praxis der nationalsozialistischen Regierung im Hinblick auf die Auslegung von Verordnungsermächtigungen sei jedoch unmaßgeblich ${ }^{162}$. "Siedlungswesen" umfaßt nach Auffassung des Gerichts nur die Begründung neuer Wohnstätten in Verbindung mit der Zuteilung von Grund und Boden zu landwirtschaftlicher oder gärtnerischer Nutzung ${ }^{163}$.

Zur entscheidenden Größe für die Bestimmung der Kompetenz für das Baurecht wurde damit der Kompetenztitel "Bodenrecht". Das BVerfG legte den Begriff dahingehend aus, daß diese Kompetenz den Erlaß solcher Vorschriften erfasse, die den Grund und Boden unmittelbar zum Gegenstand haben, die also die rechtlichen Beziehungen des Menschen zum Grund und Boden regeln ${ }^{164}$. Insbesondere hebt das BVerfG die städtebauliche Planung hervor, die die "rechtliche Qualität des Bodens" bestimme ${ }^{165}$. Demgegenüber gehöre der Teil des Baupolizeirechts, der übrig bleibe, wenn man das Planungsrecht herausnehme, in die Kompetenz der Länder ${ }^{160}$.

Die Wirkung dieses Gutachtens und der darin enthaltenen Formeln war einschneidend. Die Materien, von denen die Bundesregierung aufgrund des Gutachtens annahm, sie gehörten zur Kompetenz "Bodenrecht", wurden im Bundesbaugesetz geregelt ${ }^{167}$. Desweiteren wurde eine Musterbauordnungskommission gebildet. In Abstimmung zum neuen Städtebaurecht sollte eine

\footnotetext{
${ }^{157}$ BVerfGE 3, 416.

${ }^{158}$ BVerfGE 3, 416.

${ }^{159}$ So Büge / Zinkahn, S. 19.

${ }^{160}$ RGBI. I, S. 938.

${ }^{161}$ Vom 03.07.1934, RGBI. I, S. 568.

${ }^{162}$ BVerfGE 3, 417.

${ }^{163}$ BVerfGE 3, 417.

${ }^{164}$ BVerfGE 3, 424. Eine ausführliche Wiedergabe des Gutachtens findet sich bei Plate, S. 39 ff und Giese, AöR 80 (1955/56), S. 213 ff.

${ }^{165}$ BVerfGE 3, 424.

${ }^{166}$ BVerfGE 3, 432.

${ }^{167}$ Gelzer, Rn. 7.
} 
einheitliche Regelung des Bauaufsichtsrechts erarbeitet werden ${ }^{168}$. Die Länder erließen dann in weitgehender Anlehnung an die Musterbauordnung ihre Landesbauordnungen ${ }^{169}$.

b) Kritik an den Abgrenzungsformeln des BVerfG

Die Tatsache, daß die Abgrenzungsformeln des BVerfG auch heute noch ständig zur Lösung von Abgrenzungsfragen herangezogen werden ${ }^{170}$, daß das Gutachten sogar als "Bestandteil des bundesdeutschen Bauplanungsund Städtebaurechts" angesehen wird ${ }^{171}$, dürfte eben auf die einschneidenden Spuren zurückzuführen sein, die es in der deutschen Rechtslandschaft hinterlassen hat. Die Popularität vor allem der Unmittelbarkeitsformel und der Formel von der Bestimmung der "rechtlichen Qualität des Bodens"172 steht jedoch in krassem Gegensatz zu ihrer praktischen Brauchbarkeit.

Abgrenzungskriterien, die auf den Gegensatz mittelbar / unmittelbar abstellen, geben ohnehin meist mehr Probleme auf als sie Zweifelsfragen beantworten. Mit der Unmittelbarkeitsformel des BVerfG ist das nicht anders. So mag man die Festlegung der Grundflächenzahl nach § 19 Abs. 1 BauNVO als ein Instrument ansehen, das unmittelbar Grund und Boden betrifft. Immerhin wird damit festgelegt, daß z. B. nur $60 \%$ eines Grundstücks überbaut werden dürfen. Dagegen kann man bei der Festlegung der Geschoßflächenzahl nach $\S 20$ Abs. 1 BauNVO schon dafür eintreten, dies betreffe nur mittelbar Grund und Boden. Denn die Frage, welcher Anteil des Bodens überbaut werden darf, ergibt sich nur aus dem Zusammenhang mit anderen Festsetzungen. Die Festlegung der Anzahl der zulässigen Geschosse ( $\S 17,18$ BauNVO) betrifft auf jeden Fall zunächst einmal das Gebäude. Es fällt schwer zu begründen, warum die Geschoßzahl unmittelbarer den Grund und Boden berührt als z. B. die Frage der Dachform. Welche Dachform zulässig ist, wird aber durch örtliche Bauvorschriften bestimmt, also gemeinhin dem Bauordnungsrecht zugerechnet.

${ }^{168}$ B. Schulte, S. 72.

${ }^{169}$ Vgl. BVerfG, Beschluß vom 28.10.1975, E 40, 261 (266).

${ }^{170}$ Siehe aus neuerer Zeit etwa Bülow, S. 81 ff. Weiterhin z. B. Evers, DVBI. 1968, S. 6; Brohm, DÖV 1983, S. 529; Steinberg, NJW 1981, S. 551.

${ }^{171}$ Pfaff, Planungsrechtsprechung, S. 144.

${ }^{172}$ Diese Formel wird vom BVerfG wieder aufgenommen z. B. in der Entscheidung zur Verfassungsmäßigkeit des $\S 12$ S. 3 BBauG, siehe Beschluß vom 22.11.1983, NVwZ 1984, S. 430. 
Dieses Dilemma bei der Anwendung der Unmittelbarkeitsformel läßt sich auch keinesfalls dadurch lösen, daß man dahingehend argumentiert, es mache kompetenzrechtlich keinen Unterschied, ob eine Anforderung unmittelbar Grund und Boden oder unmittelbar die bauliche Anlage betreffe, da nach dem "Rechtsbewußtsein" bauliche Anlagen wesentliche Bestandteile der Grundstücke seien ${ }^{173}$. Dann käme man dazu, daß grundsätzlich alle Vorschriften, die Gebäude betreffen, also auch solche über Aufenthaltsräume, Dicke der Wände etc. zum Bauplanungsrecht gehören, was auf jeden Fall nicht die Ansicht des BVerfG im Baurechtsgutachten war. Geht man aber davon aus, daß gesetzliche Bestimmungen, die zunächst nur das Gebäude betreffen, sich nicht unmittelbar auch auf Grund und Boden beziehen, so gibt es schon im Rahmen des $\S 9$ Abs. 1 BauGB eine Reihe von Festsetzungsmöglichkeiten, die bei einem solchen Verständnis nicht unter die Bundeskompetenz "Bodenrecht" fielen ${ }^{174}$.

Ein weiteres instruktives Beispiel sind die Bestimmungen über Abstandsflächen. Mit dem Argument, Abstandsflächenbestimmungen dienten vor allem der Sicherung von ausreichender Belichtung, Belüftung, Besonnung und dem Brandschut ${ }^{175}$, lassen sich diese Regeln nicht für das Bauordnungsrecht "retten". Denn für die Frage der Unmittelbarkeit spielt dies keine Rolle. Daß Abstandsflächen unmittelbar Grund und Boden betreffen, läßt sich aber - soweit man der Unmittelbarkeitsformel noch irgendeinen subsumierbaren Inhalt zugestehen will - nicht bestreiten, denn diese Vorschriften legen fest, daß z. B. in einem Bereich von $3 \mathrm{~m}$ zwischen der Außenwand eines Gebäudes und der Grundstücksgrenze im Grundsatz keine Gebäude errichtet werden dürfen und bestimmen damit die rechtliche Qualität bestimmter Grundstücksteile. Vollkommen konsequent wurden deshalb die Abstands- und Bauwichbestimmungen kurz nach Erscheinen des Baurechtsgutachtens von einem sicherlich profunden Baurechtskenner zum Bauplanungsrecht gezählt ${ }^{176}$, und auch heute kommt man zur Zugehörigkeit der Abstandsbestimmungen zum Bauplanungsrecht, soweit man sich wirklich um eine Subsumtion unter die Unmittelbarkeitsformel bemüht ${ }^{17}$. So stimmt

\footnotetext{
${ }^{173}$ So aber J. Ziegler, DVB1. 1984, S. 380.

${ }^{174}$ Siehe die Beispiele bei J. Ziegler, DVB1. 1984, S. 380.

175 Proksch, S. 157, 163; Plate, S. 46 ff.

${ }^{176}$ Und zwar von Ernst, DVBl. 1955, S. 411.

${ }^{17}$ So etwa J. Ziegler, DVBI. 1984, S. 379.
} 
auch dreieinhalb Jahrzehnte nach Erlaß des Gutachtens immer noch die Feststellung, daß man ausgehend vom Abgrenzungsversuch des BVerfG bei jeder Vorschrift darüber streiten kann, ob sie dem Bundesrecht zugänglich ist oder nicht ${ }^{178}$.

Die Formel, wonach es beim Bauplanungsrecht um die "rechtliche Qualität des Bodens" gehen soll ${ }^{179}$, macht diesen Befund noch eindeutiger. Warum in den genannten Fällen bei Anwendung dieses Maßstabs eine $\mathrm{Zu}$ rechnung zum Bodenrecht oder zum Ordnungsrecht erfolgt, läßt sich höchstens anhand des gewünschten Ergebnisses erklären. Gleiches gilt für die weitere Formulierung im Baurechtsgutachten, wonach das "Bodenrecht" die rechtlichen Beziehungen des Menschen zu Grund und Boden regele. Es ist nicht erklärbar, warum die Frage, ob jemand drei- oder viergeschossig bauen darf, auf seiner rechtlichen Beziehung zum Grundstück beruht, die Frage, ob er ein Spitzdach errichten darf, aber nicht.

Die einschneidenden Wirkungen des Baurechtsgutachtens verbunden mit der Untauglichkeit der vom BVerfG verwendeten Abgrenzungskriterien führen dazu, daß bei kompetenzrechtlichen Abgrenzungsschwierigkeiten häufig das gewünschte oder für richtig gehaltene Ergebnis als Behauptung in den Raum gestellt wird und als Schein einer Begründung dazu das Gutachten zitiert wird. Die unpräzisen Formeln des BVerfG lassen sich als Beleg für fast jedes gewünschte Ergebnis anführen. Ein gutes Beispiel hierfür liefert eine Entscheidung des BVerwG, die die Frage der Vereinbarkeit eines landesrechtlichen Uferbauverbotes mit $\S 35$ BBauG betraf ${ }^{180}$. Danach soll es sich beim "funktionellen Landschaftsschutz", also beim Schutz des Außenbereichs zur Erhaltung und Schaffung von Erholungsmöglichkeiten, um eine Regelung handeln, die Grund und Boden unmittelbar zum Gegenstand hat, während dies beim "optischen Landschaftsschutz", also dem Schutz des Außenbereichs vor ästhetischer Beeinträchtigung, nicht der Fall sei ${ }^{181}$. Diese Entscheidung dürfte im Ergebnis durchaus zutreffend sein. §35 BBauG / BauGB läßt sich dahingehend auslegen, daß in bezug auf den "funktionellen Landschaftsschutz" eine abschließende Regelung vorliegt, während für den "optischen Landschaftsschutz" Raum für eine landesrechtliche Regelung

${ }^{178}$ Werner, DVBI. 1954, S. 484.

${ }^{179}$ BVerfGE 3, 424.

${ }^{180}$ BVerwG, Urteil vom 24.02.1978, E 55, 272 ff. Ein weiteres Beispiel für einen typischen Fall von Nichtsubsumtion bilden die Ausführungen von Hönes, S. 37.

${ }^{181}$ BVerwGE 55, 275. 
bleibt. Durch die Unmittelbarkeitsformel läßt sich aber zu dieser Erkenntnis nichts beitragen ${ }^{182}$.

Das BVerfG hat in seinem Baurechtsgutachten versucht, die Bundeskompetenz im Baurecht objektiv zu umschreiben. Die Festsetzungsmöglichkeiten und sonstigen gesetzlichen Bestimmungen wurden von ihrer Wirkungsweise her umschrieben. Dabei hatte das Gericht vor allem Bestimmungen über die Art der baulichen Nutzung im Auge ${ }^{183}$. Allein dadurch, daß man versucht, die Maßnahmen zu bestimmen, die unter die Bundeskompetenz fallen, läßt sich das Kompetenzproblem aber nicht lösen. Es ist heute anerkannt, daß ähnliche oder sogar gleiche rechtliche Maßnahmen in bezug auf einen Lebenssachverhalt bei aufgeteilter Gesetzgebungskompetenz denkbar sind. Dies gilt etwa für das Verhältnis von Straßenrecht und Straßenverkehrsrecht. So ist es sowohl aufgrund von Maßnahmen nach der StVO als auch aufgrund einer Widmungsbeschränkung möglich, gleichartige Beschränkungen des Straßenverkehrs herbeizuführen ${ }^{184}$. Ein Beispiel aus dem Baurecht ist das Institut der Teilungsgenehmigung. So gibt es neben den bundesrechtlichen $\S \S 19$ ff. BauGB auch Teilungsgenehmigungen nach den Landesbauordnungen ${ }^{185}$. Obwohl damit Bundes- und Landesgesetzgeber das gleiche rechtliche Instrument verwenden, indem sie die Teilung von Grundstücken einer Genehmigungspflicht unterziehen, bestehen hiergegen kompetenzrechtlich zumindest nach Auffassung des BVerfG keine Beden$\operatorname{ken}^{186}$. Der Versuch des BVerfG, mit der Unmittelbarkeitsformel die Wirkungsweise von Maßnahmen und damit die Bundeskompetenz zu umschreiben, ist auch nach der eigenen Rechtsprechung des Gerichts überholt. Die Unmittelbarkeitsformel ist somit nicht nur "farblos"187, sondern als Abgrenzungskriterium ungeeignet.

${ }^{182}$ Kritisch gegenüber dieser Differenzierung auch Steinberg, NJW 1981, S. 552. Zur Rettung der Ausführung des BVerwG meint J. Ziegler, DVBI. 1984, S. 380, daß das BVerwG hier der Unmittelbarkeitsformel einen anderen Sinn unterlege, indem es sich auf den Zweck der gesetzlichen Regelung beziehe und nicht auf den Gegenstand. Richtiger dürfte es dagegen sein zu sagen, daß das Abstellen auf die Unmittelbarkeitsformel in diesem Zusammenhang ersatzlos hätte weggelassen werden müssen und nur eine Phrasenreverenz an das BVerfG ist.

${ }^{183}$ BVerfGE 3, 424.

184 So für den Fall der Unterbindung des Schwerlastverkehrs BWVGH, Urteil vom 25.06.1981, DÖV 1982, S. 206 ff., mit Anmerkung Steiner, DÖV 1982, S. 554 f.

${ }^{185}$ Etwa Art. 11 BayBO.

${ }^{186}$ BVerfG, Beschluß vom 28.10.1975, E 40, $261 \mathrm{ff}$. Als Begründung führt das BVerfG an, $\mathrm{da} B$ es um Anforderungen im Interesse der öffentlichen Sicherheit und Ordnung gehe, siehe ebenda S. 267.

${ }^{187}$ So Schmidt-Aßmann, Stadtentwicklung, S. 119; Brohm, Verkehrsberuhigung, S. 62. 
c) Länderkompetenzen im Baurecht und materieller Polizeibegriff

Kompetenzkataloge werden vom Verfassungsgeber meist nach überkommenen Kategorien und Vorstellungen aufgestellt ${ }^{188}$. Die historische Auslegungsmethode spielt deshalb bei der näheren Bestimmung von Kompetenzvorschriften eine besondere Rolle. Dies war auch bei der Erstellung des Baurechtsgutachtens durch das BVerfG nicht anders. So bemüht das BVerfG die Parallele mit Art. 10 Nr. 4 WRV, um zu begründen, daß die Kompetenz "Bodenrecht" des Art. 74 Nr. 18 GG nicht als "Baurecht" oder "Bauwesen" zu verstehen ist ${ }^{189}$. Die Frage, ob das "Baupolizeirecht im bisher gebräuchlichen Sinne" zur Bundeskompetenz gehört, war somit zu verneinen. Das, was bis dahin unter "Baupolizeirecht" verstanden wurde, war dem Bund nur soweit zugewiesen, wie es sich um Planungsrecht oder um Anforderungen an Wohngebäude ${ }^{190}$ handelt. Anstatt nur diese schlichte aber richtige Begründung zu wählen, hat das BVerfG weiterhin ausgeführt, das Baupolizeirecht sei ein Teil des Polizeirechts und das Polizeirecht sei Sache der Landesgesetzgebung ${ }^{191}$. Das BVerfG hat also - obwohl dies vollkommen überflüssig war - versucht, auch die Landeskompetenz positiv zu umschreiben. Die Feststellung, daß das Baupolizeirecht verstanden als die Tätigkeit, die den Baupolizeibehörden oblag, Teil des (materiellen) Polizeirechts sei, war jedoch schon zur Zeit der Erstellung des Gutachtens unrichtig. So waren schon zur damaligen Zeit den Baupolizeibehörden in weitem Umfang wohlfahrtspflegerische Aufgaben zugewiesen ${ }^{192}$. Auch zur Zeit der Erstellung des Baurechtsgutachtens war aus dem Störungsverhinderungsstaat bereits ein Leistungsstaat geworden ${ }^{193}$. Als Beispiel für Aufgaben mit zumindest teilweise auch wohlfahrtspflegerischem Charakter werden etwa die Preußischen Verunstaltungsgesetze von 1902 und 1907 angeführt ${ }^{194}$. Mit ih-

\footnotetext{
${ }^{188}$ Pestalozza, DÖV 1972, S. 182.

${ }^{189}$ BVerfGE 3, 433.

${ }^{190}$ Durch die Kompetenz "Wohnungswesen" in Art. 74 Nr. 18 GG.

${ }^{191}$ BVerfGE 3, 433.

${ }^{192}$ B. Schulte, S. $68 \mathrm{ff}$.

193 Dittus, DVBl. 1956, S. 252.

194 Dittus, DVBI. 1956, S. 252; Büge / Zinkahn, S. 11; Oelker S. 158. So auch Watzke, Denkmalschutz- und Stadtplanungsrecht, S. 41, wonach die gestalterischen Anforderungen dem Schutz von Rechtsgütern, die zu den Werten des sozialen und kulturellen Lebens gehören, dienen. Dies habe mit Gefahrenabwehr nichts zu tun. Ebenso Martens, Gefahrenabwehr, S. 130 . Vgl. auch $\S 57$ Abs. $2 \mathrm{~S}$. 1 BauO NW, wodurch vor allem das Baugestaltungsrecht per Fiktion zum Gefahrenabwehrrecht wird. Siehe dazu Gubelt, NWVBI. 1988, S. 130.
} 
nen hatte der Gesetzgeber Teile des Baurechts, die das PrOVG in seinem "Kreuzberg"-Urteil aus der polizeilichen Generalklausel ausgeschieden hatte, den Baupolizeibehörden spezialgesetzlich wieder übertragen ${ }^{195}$.

Das BVerwG nimmt diesen Wandel in den Aufgaben der Baupolizeibehörden allerdings durchaus zur Kenntnis ${ }^{196}$. Insofern haben die Ausführungen zur positiven Begründung der Landeskompetenz über die Gleichung Baupolizeirecht $=$ Polizeirecht im materiellen Sinn $=$ Landeskompetenz nur erläuternden Charakter. Daher ist es unrichtig, wenn festgestellt wird, daß BVerfG habe nur das Baupolizeirecht im Sinne der Vergangenheit zugesprochen, nicht aber die Regelung der Anforderungen an Bauten im Rahmen einer nicht polizeilich geflaggten Fachverwaltung ${ }^{197}$. "Zugesprochen" wird eine Materie durch Art. 70 Abs. 1 GG grundsätzlich den Ländern, soweit eine Bundeskompetenz vom GG und im vorliegenden Fall durch Art. 74 Nr. 18 GG nicht begründet ist, gleichgültig, ob die Materie nun "verpolizeilicht" oder "entpolizeilicht" ist.

Die Richtigkeit der grundsätzlichen Kompetenzaufteilung im Baurecht läßt sich somit auch nicht mit dem Versuch in Frage stellen, den Nachweis zu führen, daß das Bauordnungsrecht heute weitgehend auch wohlfahrtspflegerischen Zielen dient ${ }^{198}$. Die Landeskompetenz erstreckt sich durch die Nichtausschöpfung der Kompetenz "Wohnungswesen" durch den Bund auf den gesamten Bereich des Baurechts mit Ausnahme der Materien, die der Bund aufgrund seiner Kompetenz für das Bodenrecht regeln kann und geregelt hat. Diese Bundeskompetenz definiert das BVerfG aber nicht als das gesamte baurechtliche Nichtpolizeirecht sondern vor allem als Planungsrecht ${ }^{199}$. Von verfassungswegen gibt es somit keine Beschränkung der landesgesetzgeberischen Kompetenzen auf den Bereich des materiellen Polizeibegriffs.

\footnotetext{
${ }^{195}$ Weyreuther, Eigentum, S. 26.

${ }^{196}$ BVerfGE 3, 431.

${ }^{197}$ So aber Dittus, DVBI. 1956, S. 285.

198 So aber B. Schulte, S. 70 ff. Zutreffend hingegen Bülow, S. 78. Zu den von den Bauordnungen wahrgenommenen wohlfahrtspflegerischen Aufgaben siehe auch Bauer, S. $57 \mathrm{ff}$.

${ }^{199}$ BVerfGE 3, 432. Siehe dazu unten A II $3 \mathrm{c}$ dd a. E..
} 


\section{Der städtebauliche Bezug als tatsächlich verwendeter Abgrenzungsmaßstab}

\section{a) Das Beispiel der Stadterhaltungssatzungen}

Bei aller Kritik am Baurechtsgutachten ist diesem in einem Punkt auf jeden Fall zuzustimmen: Eine Zweiteilung des Baurechts ist durch Art. $74 \mathrm{Nr}$. 18 GG vorgegeben ${ }^{200}$. Denn "Bodenrecht" läßt sich auch heute nicht mit "Baurecht" gleichsetzen. Eine umfassende Bundeszuständigkeit besteht daher nach wie vor nicht ${ }^{201}$. Da eine Abgrenzung des Bauplanungs- vom Bauordnungsrecht mittels der vom BVerfG aufgestellten Begriffe aber letztlich nicht möglich ist, haben sich Literatur und Rechtsprechung heute von dem Versuch, diese Abgrenzung über die Art der zu treffenden Maßnahmen vorzunehmen, zwar nicht unbedingt ausdrücklich, aber doch konkludent eindeutig verabschiedet. Ein gutes Beispiel hierfür ist die Diskussion um die Verfassungsmäßigkeit der Vorschriften über städtebauliche Erhaltungssatzungen. Die BBauG-Novelle von 1976 fügte in das BBauG den $\S 39 \mathrm{~h} \mathrm{ein}{ }^{202}$. Diese Vorschrift war Ausdruck eines Wandels städtebaulicher Leitvorstellungen. An die Stelle radikaler Flächensanierungen soll die Erhaltung und Fortentwicklung des vorhandenen baulichen Bestandes treten ${ }^{203}$. Die $\S \S 172$ ff. BauGB geben den Gemeinden die Möglichkeit, den Abbruch, die Änderung oder die Nutzungsänderung von baulichen Anlagen in erhaltungswürdigen Gebieten unter Genehmigungsvorbehalt zu stellen und auf diese Weise gegebenenfalls zu verhindern.

Die Gemeinden erhalten durch die $\S \S 172 \mathrm{ff}$. BauGB vom Bund die Kompetenz zugewiesen, Denkmalschutz zu betreiben ${ }^{204}$. Dies muß zunächst problematisch erscheinen. Schließlich wird das Denkmalschutzrecht allgemein als eine Materie angesehen, die in die Gesetzgebungskompetenz der Länder fällt ${ }^{205}$. Überlappungen mit dem Recht der Stadterhaltungssatzungen

${ }^{200}$ So im Grundsatz auch Redeker, in: Neues Städtebaurecht, S. 30, der zwar bezweifelt, ob die damaligen für das Gutachten geltenden Grundsätze auch heute noch gültig sind, jedoch im weiteren ebenfalls von einer grundsätzlichen Aufteilung ausgeht.

${ }^{201}$ BVerfG, Beschluß vom 28.10.1975, E 40, 261 (265); Rößler, in: Neues Städtebaurecht, S. 127.

${ }^{202}$ Entspricht weitgehend den $\S 172$ ff. BauGB.

${ }^{203}$ Breuer, Stadtentwicklung, S. 16.

${ }^{204}$ Henke, S. 39 ff.; Hönes, S. 40.

${ }^{205}$ Hönes, S. 43. Laut Bartlsperger, DVBI. 1981, S. 294, ist dies unstreitig. Siehe auch die Bedenken des Bundesrates in BT-Drs. 7/2496, S. 78. 
bestehen zumindest teilweise im Hinblick auf den Gegenstand, auf den sich die Regelungen beziehen. So kann auch ein sog. Ensemble Denkmal im Sinne der Landesdenkmalschutzgesetze sein. Andererseits kann die Denkmalwürdigkeit unter anderem auch durch "städtebauliche Bedeutung" erlangt werden ${ }^{206}$. Die Denkmalschutzgesetze erfüllen ihre Schutzfunktion auch mit demselben rechtlichen Mittel wie Stadterhaltungssatzungen, nämlich indem etwa die Änderung oder Beseitigung unter Genehmigungsvorbehalt gestellt wird ${ }^{207}$.

Wenn aber ein identischer Sachverhalt wie die Erhaltung von baulichen Anlagen mit wirkungsgleichen oder zumindest wirkungsähnlichen Instrumentarien einer rechtlichen Regelung unterzogen wird, ist dies kompetenzrechtlich nur dann zu rechtfertigen, wenn weder der Gegenstand der rechtlichen Regelung noch die Wirkweise für die kompetenzmäßige Zuordnung entscheidend ist, sondern es vielmehr auf ein drittes Merkmal ankommt, das die Zuordnung sowohl zur Bundes- als auch zur Länderkompetenz möglich macht. Allerdings ist versucht worden, die Problematik des Zusammentreffens von landesrechtlicher und bundesrechtlicher Regelung von einem Konflikt in einen Nichtkonflikt umzuinterpretieren. Als Argument dafür wird angeführt, es handele sich nicht um ein "Gegeneinander" der Regelung der gleichen Materie, sondern um ein Miteinander im Sinne des Schutzes von überkommener Bausubstanz ${ }^{208}$. Diese Argumentation überzeugt jedoch nicht ${ }^{209}$. Eine Kollision zwischen Bundes- und Landesrecht mit der Folge des Zurücktretens des Landesrechts nach Art. 31 GG liegt nicht schon dann vor, wenn etwa der eine Gesetzgeber "für" und der andere "gegen" die Erhaltung von überkommener Bausubstanz eine rechtliche Regelung erläßt. Eine Kollision ist bereits dann gegeben, wenn ein Gesetzgeber einen Bereich regelt, den der andere bereits geregelt hat. Mit einer Argumentation, die die gemeinsame Schutzrichtung in den Vordergrund stellt, läßt sich die Problematik des möglichen Nebeneinanders von Stadterhaltungssatzungen auf bundesrechtlicher Grundlage und Landesdenkmalschutzrecht nicht auflösen. Eine solche Sichtweise überbetont den Schutz eines bestimmten öffentlichen Belangs und vernachlässigt die Interessen des Eigentümers. Denn jedes

${ }^{206}$ Finkelnburg, Festschrift Juristische Gesellschaft Berlin, S. 138; Henke, S. 32 ff. m. w. N.

$207 \S 8$ Abs. 1 BW DSchG; Art. 6 BayDSchG; $\$ 10$ DSchG Bln; $\S 10$ BremDSchG; 99 HamDSchG; § 16 HessDSchG; 10 NdsDSchG; § 9 NWDSchG; 13 DSchPfG R.Pf.; $\$ 12$ SDschG; 99 DSchG SI.H.

${ }^{208}$ Henke, S. 46.

209 Siehe die Parallele bei der "gemeinsamen Verantwortung" zum Schutz des Ortsbildes, oben A II 1 a. 
"Mehr" an Schutz für die Bausubstanz ist gleichzeitig auch ein Mehr an Belastung für den Eigentümer. $\mathrm{Daß}$ insbesondere im Bereich des Art. 14 GG eine strikte Einhaltung der Kompetenzordnung nötig ist, wurde bereits ausgeführt $^{210}$.

Wenn sich aber das Stadterhaltungsrecht nach dem BauGB und das Denkmalschutzrecht der Länder weder vom geregelten Lebenssachverhalt noch im Hinblick auf die Wirkungsweise des rechtlichen Instrumentariums unterscheiden, bleibt - wenn nicht entweder das Landesrecht vom Bundesrecht nach Art. 31 GG verdrängt werden oder das Bundesrecht verfassungswidrig sein soll - nur noch die Zuordnung zu verschiedenen Kompetenzen dadurch, daß die bundesrechtlichen und landesrechtlichen Vorschriften ein unterschiedliches Regelungsziel verfolgen und damit eine unterschiedliche Funktion haben ${ }^{211}$. Dies ist auch der Ansatz des BVerfG, wenn es die Verfassungsmäßigkeit der Bestimmungen über Stadterhaltungssatzungen mit dem Argument rechtfertigt, es handele sich um "städtebaulichen Denkmalschutz"212. Die Fülle von Zitaten, die das BVerfG im Anschluß hieran aufzählt, sollte jedoch nicht darüber hinwegtäuschen, daß über das, was "städtebaulicher Denkmalschutz" bedeutet, keinesfalls Einigkeit besteht. So wird dieser Begriff etwa als Synonym für das Recht der Stadterhaltungssatzungen gebraucht ${ }^{213}$. Dies kann vom BVerfG kaum gemeint gewesen sein, denn dadurch, daß man den Vorschriften über Stadterhaltungssatzungen einen anderen Namen gibt, kann ihre Verfassungsmäßigkeit nicht begründet werden. Bartlsperger verwendet den Begriff des "städtebaulichen Denkmalschutzes" als Ausdruck dafür, daß bereits auf der Ebene des Stadtplanungsrechts rechtsatzmäßig über die Fragen des Denkmalschutzes entschieden wird. Die Folge wäre, daß dann, wenn etwa in einem Bebauungsplan die Belange des Denkmalschutzes mit abgewogen worden sind, die Anwendung der Landesdenkmalgesetze suspendiert würde ${ }^{214}$. Dafür, sich auf eine so weitgehende Aussage festzulegen, bestand für das BVerfG im

${ }^{210}$ Siehe oben A II $1 \mathrm{~b}$.

211 So auch Friauf / Wendt, S. 57. Für den Bereich der Werbeanlagen siehe Sendler, BBauBl. 1968, S. 15; Steinberg, NJW 1981, S. 552, ders., Baurecht, S. 267. Speziell für das Baurecht Wiechert, Baurecht, S. 281; Schlotterbeck, in: Schlotterbeck / von Arnim, § 3 Rn. 38. Diese Auffassung liegt auch der Auslegung der Bestimmungen des Art. 91 Abs. 1 Nr. 1 BayBO und weitgehend der Formulierung der Parallelbestimmungen in den anderen Landesbauordnungen zugrunde. Vgl. dazu oben A I 2 a und $b$.

${ }^{212}$ BVerfG, Beschluß vom 26.01.1987, NVwZ 1987, S. 879; ebenso Schlichter / Stich / Tittel, §39 h, Rn. 2.

${ }^{213}$ Und zwar von Watzke, ZfBR 1981, S. 10.

${ }^{214}$ Bartlsperger, DVBI. 1981, S. 293 und 295. 
vorliegenden Fall aber auch kein Anlaß, zumal damit die Verfassungsmäßigkeit von $\S 39 \mathrm{~h} \mathrm{BBauG}$ ebenfalls nicht begründet worden wäre. Das BVerfG dürfte daher mit der Verwendung des Begriffs "städtebaulicher Denkmalschutz" gemeint haben, da $\beta$ es um die Regelung von Fragen des Denkmalschutzes in ihrem städtebaulichen Zusammenhang geht ${ }^{215}$. Der Bund hat danach nicht die Befugnis, isoliert Fragen des Denkmalschutzes zu regeln, sondern er braucht hierfür einen städtebaulichen Ansatzpunkt. Ein solcher Ansatzpunkt liegt dann vor, wenn es final bzw. funktional ${ }^{216}$ um die Regelung der städtebaulichen Entwicklung des Gemeindegebietes geht ${ }^{217}$. Insofern besteht eine Parallele zum Recht der Werbeanlagen, die als solche auch weder nur dem Bauordnungs- noch dem Bauplanungsrecht zuzuordnen sind. Das Bundesrecht kann nach Auffassung des BVerwG vielmehr insoweit Bestimmungen treffen, als es um die Regelung eines baurechtlich relevanten Vorgangs unter planungsrechtlichen Gesichtspunkten geht ${ }^{218}$. Werbeanlagen dürfen danach also sowohl vom Bauplanungsrecht als auch vom Bauordnungsrecht entsprechend den dort verfolgten Zielen einer rechtlichen Regelung unterzogen werden. Eine weitere Parallele bietet das Verhältnis von Straßenrecht und Sraßenverkehrsrecht. Derselbe Sachverhalt kann aus der Sichtweise beider Materien beurteilt und mit Mitteln beider Bereiche darf auf ihn reagiert werden ${ }^{219}$.

Auf diese Weise wird die Funktion der Bauleitplanung nach Auffassung der Rechtsprechung zur kompetenzrechtlichen Rechtfertigung für Festsetzungsmöglichkeiten. Bei der Bauleitplanung geht es final um die Regelung der städtebaulichen Ordnung ( $\$ 1$ Abs. 3 BauGB). Während also das Regelungsziel des Denkmalschutzrechts darin besteht, etwa ein Gebäude oder ein Ensemble um seiner selbst willen, vor allem aufgrund seiner historischen Bedeutung zu erhalten, muß eine Stadterhaltungssatzung städtebaulich gerechtfertigt sein. Dies gibt sich auch aus der Vorschrift des § 172 BauGB. Dort ist in $\S 172$ Abs. 1 Nr. 1 von "städtebaulicher Eigenart" und "städtebaulicher Gestalt", in Nr. 3 von "städtebaulichen Umstrukturierungen" die Rede.

${ }^{215}$ So auch Bartlsperger, DVBI. 1981, S. 295.

${ }^{216}$ So Gaentzsch, Berliner Kommentar, $\S 1 \mathrm{Rn}$. 8. Eine inhaltliche Differenz dürfte in dieser anderen Terminolgie nicht zu sehen sein.

217 Wohl ähnlich Lemmel, Berliner Kommentar, § 172 Rn. 3: "Die Berücksichtigung des Denkmalschutzes ist jedoch, weil es sich insoweit um einen Teil der geordneten städtebaulichen Entwicklung handelt, in dem hier in Rede stehenden Umfang dem Bodenrecht zuzuordnen ..."

${ }^{218}$ BVerwG, Urteil vom 28.04.1972, E 40, 94 (96).

${ }^{219}$ So Steiner, Straßen- und Wegerecht, S. 606 Rn. 7. 
In § 172 Abs. 3 wird die "städtebauliche" als Oberbegriff für die geschichtliche und künstlerische Bedeutung verwendet. Der Wortlaut des $\S 172$ BauGB bringt somit zum Ausdruck, was sich auch aus der Rechtsprechung des BVerfG und der Berufung auf den Begriff des "städtebaulichen Denkmalschutzes" ergibt: Der Begriff "städtebaulich", also die Bezogenheit auf den Städtebau und somit das Ziel, die städtebauliche Entwicklung und Ordnung zu lenken und zu gestalten, ist der kompetenzrechtliche Schlüssel, mit dem Bundeskompetenzen auch in Rechtsmaterien begründet werden, für die kein spezieller Kompetenztitel für den Bund vorhanden ist. Eine Kollision zwischen Landesdenkmalrecht und Bundesrecht in Form der Bestimmungen über Stadterhaltungssatzungen besteht nach Auffassung des BVerfG deshalb nicht, weil sich die bundesrechtliche Regelung von einem anderen Regelungsziel her mit der Erhaltung von baulichen Anlagen beschäftigt. Eine Bundeskompetenz liege vor, weil es um die Verwirklichung von städtebaulichen Zielen geht ${ }^{220}$.

Eine solche finale Abgrenzung führt im übrigen auch das BVerfG in seiner Entscheidung zur Einführung einer landesrechtlichen Teilungsgenehmigung durch ${ }^{221}$. Landesrechtliche Teilungsgenehmigungen seien deshalb zulässig, weil es um Anforderungen im Interesse der öffentlichen Sicherheit und Ordnung gehe ${ }^{222}$, womit das BVerfG darauf abstellt, daß das Regelungsziel ein anderes ist als bei der Teilungsgenehmigung nach den $\S \S 19 \mathrm{ff}$. BauGB.

b) Schwierigkeiten bei der Bestimmung des städtebaulichen Bezugs am Beispiel der Stadtgestaltung

Die Besinnung auf das Merkmal des "städtebaulichen Bezugs" führt weg von den letztlich nichtssagenden Abgrenzungsformeln "Unmittelbarkeit" und "rechtliche Beziehungen des Menschen zu Grund und Boden", die häufig aus dem Baurechtsgutachten des BVerfG zitiert werden. Der Begriff "städtebaulicher Bezug" ist jedoch nicht so präzise, daß sich daraus von vornherein eine exakte und einleuchtende Grenzziehung zwischen Bauordnungs- und Bauplanungsrecht ergibt. Besonders deutlich wird dies in der Rechtspre-

${ }^{220}$ BVerwG, Urteil vom 03.07.1987, NVwZ 1988, S. 357 ff. Daß es beim Begriff des "städtebaulichen Denkmalschutzes" um eine finale Abgrenzung geht, übersieht die Kritik von Hönes, S. $39 \mathrm{ff}$.

${ }^{221}$ Beschluß vom 28.10.1975, E 40, $261 \mathrm{ff}$.

${ }^{222}$ BVerfGE 40, 266. 
A. Örtliche Bauvorschriften zwischen Bauplanungs- und Bauordnungsrecht

chung des OVG Lüneburg ${ }^{223}$, in der es um die Frage ging, inwieweit die optische Gestaltung eines bestimmten Gemeindegebietes einer städtebaulichen Regelung zugänglich ist.

Eine auch in optischer Hinsicht ansprechende Gebietsgestaltung läßt sich unter Ausklammerung des bauplanungsrechtlichen Instrumentariums nicht erzielen. $\mathrm{Da} B$ die Frage nach der optischen Gestaltung in wesentlichem Umfang auch vom Bauplanungsrecht beeinflußt wird, ist deshalb heute anerkannt ${ }^{224}$. Aus diesem Grund können bauplanerische Instrumente zumindest auch im Interesse der Stadtgestaltung eingesetzt werden, z. B. dazu, ein bestimmtes Erscheinungsbild einer Hauptgeschäftsstraße zu fördern ${ }^{225}$. Die Tatsache, daß § 1 Abs. 5 S. 2 BauGB nur von der Berücksichtigung der Gestaltung des Orts- und Landschaftsbildes spricht, steht dem nicht entgegen. Dies darf vor allem nicht dahin verstanden werden, da $\beta$ ein finaler Einsatz des bauplanungsrechtlichen Instrumentariums für Fragen der Stadtgestaltung nicht möglich wäre. Vielmehr konkretisieren die abwägungserheblichen Belange des $\S 1$ Abs. 5 S. 2 BauGB die allgemeinen Zielvorstellungen des $\S 1$ Abs. 5 S. 1 BauGB $^{226}$.

Das OVG hatte nun unter anderem über das Problem zu befinden, ob bauliche Veränderungen im Bereich einer Stadterhaltungssatzung von dem durch die Satzung statuierten Genehmigungsvorbehalt erfaßt würden, oder ob die Veränderung nur mittels einer örtlichen Bauvorschrift und zwar in Form einer Schutzvorschrift, also aufgrund Bauordnungsrechts verhindert werden konnte. Nach der Feststellung, daß gestalterische Belange im Grenzbereich von Bauordnungs- und Bauplanungsrecht liegen, kommt das Gericht zu dem Ergebnis, daß die streitige Anbringung einer Werbeanlage dem Bereich des Landesbauordnungsrecht zuzuordnen sei und daher durch eine Stadterhaltungssatzung nicht abgewehrt werden könne ${ }^{227}$. Als Begründung wird angeführt, daß es um Anforderungen an ein einzelnes Bauwerk ginge und nicht um die "globale Gestaltung" des Raumes ${ }^{228}$. Wenn es also

223 Urteil vom 25.04.1983, NJW 1984, S. 2905 ff. und Urteil vom 10.10.1982, DÖV 1983, S. $387 \mathrm{ff}$.

${ }^{224}$ Boeddinghaus, Stadterhaltung, S. 56; Heinz, S. 13 ff.; Mehlhorn, S. 12 und im einzelnen S. 95; Trieb / Schmidt / Paetow / Buch / Strobel, S. 83.

${ }^{225}$ Bezüglich der Möglichkeit des Ausschlusses von Spielhallen aus optischen Gründen zu Unrecht zweifelnd daher Erdmann, DVBI. 1988, S. 1097.

${ }^{226}$ Boeddinghaus, Stadterhaltung, S. 56. Ausführlich unten A II $2 \mathrm{c} \mathrm{cc}$ (1).

${ }^{227}$ DÖV 1983, S. 388.

228 (Fn. 227). 
um die "globale Gestaltung" geht, handelt es sich nach Auffassung des OVG Lüneburg um einen dem Städtebaurecht zugänglichen Sachverhalt, geht es dagegen um Anforderungen an ein Einzelbauwerk, so sei der Bereich des Bauordnungsrechts angesprochen. Konsequent beschränkt das OVG die Genehmigungspflicht nach $\S 172$ Abs. 1 Nr. 1 i. V. m. Abs. 3 BauGB auch nicht mehr auf Merkmale, die einer Festsetzung im Bebauungsplan zugänglich sind ${ }^{229}$. Auch wenn etwa Bestimmungen über Spitzgiebel nicht in Bebauungsplänen sondern nur in örtlichen Bauvorschriften zu treffen seien, so könne die Änderung eines solchen Spitzgiebels wegen der vielfältigen Wiederholung in städtebauliche Qualität "umschlagen" und damit das Ortsbild nach $\S 172$ Abs. 3 BauGB prägen ${ }^{230}$. Den gegen die Theorie von der "globalen Gestaltung" naheliegenden Einwand, gerade die in den Bauordnungen vorgesehene Möglichkeit des Erlasses von örtlichen Bauvorschriften zeige, $\mathrm{da} ß$ auch das Bauordnungsrecht Befugnisse zur Gebietsgestaltung enthalte, läßt das OVG nicht gelten: Das landesrechtliche Gestaltungsrecht befasse sich mit den ästhetischen Wirkungen der einzelnen baulichen Anlage und gelange erst über diesen individuellen Ansatzpunkt zu generellen Anforderungen in örtlichen Bauvorschriften ${ }^{231}$.

Mit dieser Auffassung steht das OVG nicht allein. In die gleiche Richtung gehen Formulierungen, wonach das Städtebaurecht den Raum aus globaler Sicht gestalte, das Bauordnungsrecht hingegen sich mit den von der einzelnen baulichen Anlage ausgehenden Störung befasse ${ }^{232}$ oder die noch allgemeinere Formel, wonach sich das Bauaufsichtsrecht nur mit den an die einzelne bauliche Anlage, das Bauwerk zu stellenden Anforderungen beschäftige $^{233}$. Dies beruht auf der Überlegung, daß Vorgänge, die zunächst nur bauordnungsrechtlich relevant sind, durch graduelle Steigerung auch qualitativ eine andere Dimension erreichen können. Weyreuther hat hierfür den Begriff vom "Umschlag in das Bodenrecht" geprägt ${ }^{24}$.

${ }^{229}$ Urteil vom 25.04.1983, NJW 1984, S. 2909. Anders noch im Urteil vom 10.10.1982, DÖV 1983, S. 388.

230 NJW 1984, S. 2909.

231 OVG Lüneburg, DÖV 1983, S. 388.

${ }^{232}$ Friauf / Wendt, S. 21; Schmidt-Aßmann, in: Ernst / Zinkahn / Bielenberg, § 1 Rn. 238 ff.; Grauvogel, in: Brügelmann, BBauG, § 1 Rn. 202 a. E.; Friauf / Wendt, S. 21; Trieb / Schmidt / Paetow / Buch / Strobel, S. 80; Engelmann, S. 94. Ähnlich auch Moench / Schmidt, S. 5: Bodenrechtlich relevant sei der städtebauliche Gesamteindruck einer Ortssilhouette.

${ }^{233}$ Schlez, Neues Bauordnungsrecht, S. 29; Battis, Öffentliches Baurecht, S. 15.

${ }^{234}$ BauR 1972, S. 4. 
Die Auffassung, das Städtebaurecht ermögliche Anforderungen nur insoweit, wie die "globale Gestaltung" also der optische Gebietscharakter betroffen ist, überzeugt jedoch nicht. Eine "globale Gestaltung" läßt sich nur dann verwirklichen, wenn man für mehrere einzelne Bauwerke entsprechende Anforderungen stellt. Nur dadurch, daß eine nennenswerte Zahl von Einzelgebäuden die an sie gestellten Anforderungen erfüllt, kommt es zu einem entsprechenden Gesamteindruck. Zwar kann es sein, da $B$ bei bereits bestehender Bebauung bauliche Veränderungen an einem einzelnen Gebäude nicht dazu führen, daß das Gebäude erheblich aus dem Rahmen fällt, so daß der Gesamteindruck dadurch nicht gestört wird. Daher dürfte das OVG den Begriff des "Prägens" in § 172 Abs. 3 BauGB richtig ausgelegt haben. Einfachrechtlich mag es so sein, da $\beta$ die Änderung einer baulichen Anlage nach $\S 172$ Abs. 3 BauGB nur dann versagt werden kann, wenn sie ein gewisses Gewicht hat, also eine "städtebauliche Dimension" erreicht ${ }^{235}$. Auch mag die Unterscheidung zwischen "additivem" und "divisivem" Fügen, also die Frage, ob sich die angestrebte Ganzheit aus der Summe der Teile oder die Anforderungen an die Teile aus der angestrebten Ganzheit ergibt, für die Planungstheorie von Bedeutung $\operatorname{sein}^{236}$. Ein prinzipieller Unterschied zwischen bauordnungsrechtlichen und bauplanungsrechtlichen Gestaltungszielen läßt sich hieraus aber nicht ableiten ${ }^{237}$. Wenn sich eine Gemeinde für die Gestaltung eines Neubaugebietes dahingehend entscheidet, $\mathrm{da} ß$ dort eine niedrige Bebauung mit für die Gegend charakteristischem weißen Außenanstrich erfolgen soll, so ist die Festsetzung eingeschossiger Bauweise im Bebauungsplan zur Erreichung dieses Gestaltungsziels genauso global wie die Festlegung des weißen Außenanstrichs in einer örtlichen Bauvorschrift. Der Gesamteindruck wird dadurch erreicht, daß bei den einzelnen Gebäuden diese Vorschriften durchgesetzt werden. Keinesfalls unterscheidet sich die Festsetzung des Außenanstrichs von der der eingeschossigen Bauweise dadurch, daß es beim Außenanstrich zunächst um das einzelne Gebäude geht und erst "die Summe zu einer umfasssenden flächendeckenden Regelung führt" ${ }^{\prime 238}$. Jedenfalls würde für die Festsetzung der Geschoßzahl das Gleiche gelten. Andernfalls käme es zu einer neuen und ebenfalls unfruchtbaren mittelbar-/unmittelbar-Unterscheidung. Ginge es "unmittelbar" um die Gestaltung eines Gebietes, so läge Bauplanungsrecht

\footnotetext{
235 So das OVG Lüneburg, DÖV 1983, S. 389

${ }^{236}$ Siehe Wienands, Grundlagen, S. $135 \mathrm{ff}$.

${ }^{237}$ Ebenso Fehrmann, BauR 1971, S. 145.

${ }^{238}$ So aber Friauf / Wendt, S. 21.
} 
vor, ginge es "unmittelbar" um das einzelne Bauwerk und nur "mittelbar" um den Gesamtraum, würde es sich um Bauordnungsrecht handeln. Die Zuordnung zum einen oder anderen Bereich wäre willkürlich. Geht man davon aus, daß es sich bei örtlichen Bauvorschriften um ein zu Recht im Bauordnungsrecht geregeltes Instrumentarium handelt, dann läßt sich somit eine Gleichung dergestalt, daß globale Gestaltung dem Städtebaurecht und nichtglobale dem Bauordnungsrecht zuzurechnen ist, nicht aufstellen.

\section{c) Das BauGB und der Begriff der geordneten städtebaulichen Entwicklung}

\section{aa) Kompetenzrechtliche Begrenzungsnormen im BauGB}

Die finale Bezogenheit auf die städtebauliche Entwicklung und Ordnung ist - wie dargestellt - die Rechtfertigung dafür, mit der nach heute überwiegender Auffassung das Bauplanungsrecht auf eigentlich den Ländern verbliebene Kompetenzbereiche zugreifen kann ${ }^{239}$. Will man über die Brauchbarkeit dieses Maßstabs entscheiden, so bedarf er einer Präzisierung. Hierfür bietet sich eine interpretatorische Anleihe bei den einfachgesetzlichen Normen des BauGB an. Denn die Bezogenheit auf die städtebauliche Entwicklung und Ordnung spielt auch in dessen Rahmen eine erhebliche Rolle. So taucht der Begriff der "geordneten städtebaulichen Entwicklung" an einer Vielzahl von Stellen im BauGB auf ${ }^{240}$. Er wird dabei jedoch nicht einheitlich verwendet, sondern ist aus dem jeweiligen Zusammenhang heraus zu verstehen ${ }^{241}$. So sind zwar die Begriffe "städtebauliche Entwicklung und Ordnung" in $\S 1$ Abs. 3 BauGB und "geordnete städtebauliche Entwicklung" in $\S 1$ Abs. 5 S. 1 BauGB bedeutungsgleich ${ }^{242}$. Jedoch verweist etwa $\S 20$ Abs. 1 Nr. 3 BauGB durch die Verwendung des Begriffs "geordnete städtebauliche Entwicklung" auf die Vorschriften des $\S 35$ Abs. 1 bis 3 BauGB $^{243}$. Daher kann es eine allgemein anerkannte und für alle Normen des BauGB geltende Definition des Begriffs "geordnete städtebauliche Entwicklung" nicht geben.

Vor allem bei $\S 1$ Abs. 3 und 5 BauGB kommt es aber zu einem Gleichlauf von einfachem Recht und verfassungsrechtlichem Abgrenzungsmaß-

\footnotetext{
${ }^{239}$ Siehe oben A II 3 a.

${ }^{240}$ Gaentzsch, Berliner Kommentar, § 1 Rn. 8, mit entsprechenden Nachweisen.

${ }^{241}$ Anders Gaentzsch (Fn. 240), wonach der Begriff jeweils denselben Inhalt habe.

242 Schmidt-Aßmann, BauR 1978, S. 100.

${ }^{243}$ Krautzberger, in: Battis / Krautzberger / Löhr, § 20 Rn. 16.
} 
stab. $\S 1$ Abs. 3 und 5 BauGB fordern für den Erlaß von Bauleitplänen als des zentralen Instituts im BauGB und damit des Städtebaurechts eine städtebauliche Rechtfertigung. Bauleitpläne dürfen nach einfachem Recht nur mit finalem Bezug auf die städtebauliche Entwicklung und Ordnung erlassen werden, was für die Bauleitplanung zu der vor allem im Fachplanungsrecht diskutierten, aber auch für die Bauleitplanung geforderten grundsätzlichen Planrechtfertigung führt ${ }^{244}$.

\section{bb) Konkretisierung des verfassungsrechtlichen Abgrenzungsmaßstabes durch 1 Abs. 3 BauGB}

Sucht man auf diese Weise eine Hilfe für die Auslegung des Art. $74 \mathrm{Nr}$. $18 \mathrm{GG}$, so führt dies im Fall des $\S 1$ Abs. 3 BauGB zu keinen neuen Erkenntnissen. Diese Vorschrift hat einen letztlich nur auf Extremfälle beschränkten Anwendungsbereich. Vor allem legen die bisherigen Interpretationsbemühungen den Schwerpunkt sehr auf das Merkmal "Erforderlichkeit" und weniger auf die Präzisierung des Begriffs "städtebauliche Entwicklung und Ordnung" 245 . Zudem wird der Gemeinde zur Erfüllung der Voraussetzungen des $\S 1$ Abs. 3 ein weitgehendes Ermessen eingeräumt. Zunächst forderte das BVerwG immerhin noch eine planerische Konzeption der Gemeinde. Fehlte es an einer erkennbaren Konzeption, sollte es an der Erforderlichkeit der Bauleitplanung mangeln ${ }^{246}$. Später wurde sogar diese ohnehin nicht weitreichende Forderung weiter relativiert. Erst dann, wenn kein öffentlicher Belang vorhanden sei, der "als bodenrechtlich relevant Element einer Ordnung der städtebaulichen Entwicklung" ist, mangele es an der Erforderlichkeit der Bauleitplanung ${ }^{247}$. Auf bestimmte Ordnungsvorstellungen der Gemeinde soll es nicht ankommen, vielmehr reiche ein rein objektiv funktioneller Zusammenhang ${ }^{248}$.

Dadurch hat der $\S 1$ Abs. 3 BauGB kaum noch eine praktische Bedeutung für die Plankontrolle und bietet wenig Handhabe zur Konkretisierung des auch verfassungsrechtlich relevanten Begriffs der städtebaulichen Entwicklung und Ordnung. Denn ein öffentlicher Belang, der grundsätzlich als

\footnotetext{
${ }^{244}$ BVerwG, Urteil vom 07.07.1978, DVBI. 1978, S. 845 (847), Urteil vom 14.02.1975, E 48, $56(60)$.

${ }^{245} \mathrm{Zu}$ Recht kritisch deshalb Weyreuther, DVBI. 1981, S. 370.

${ }^{246}$ BVerwG, Urteil vom 07.05.1971, DöV 1971, S. 633 ff.

${ }^{247}$ BVerwG, Urteil vom 05.07.1974, E 45, 309 ff. (312) ("Floatglas").

${ }^{248}$ BVerwG (Fn. 247).
} 
Element der Planrechtfertigung dienen kann, dürfte rein objektiv immer zu finden $\operatorname{sein}^{249}$. Ein Bauleitplan, der ohne daß der Abwägungsvorgang zu überprüfen wäre, quasi auf den ersten Blick keinerlei Bezug zu irgendeinem Belang hat, der durch Bauleitplanung verfolgt werden darf, ist schwer vorstellbar. Nur in Zusammenhang mit $\S 9$ Abs. 1 BauGB und dem Gebot der Erforderlichkeit einer getroffenen Festsetzung kommt dem § 1 Abs. 3 BauGB noch insofern eine Bedeutung zu, als es um den Fall des "Etikettenschwindels" geht, also die in einem Bebauungsplan getroffenen Festsetzungen eigentlich nicht gewollt sind, sondern die Zwecksetzung der Planung sich in den mit der Festsetzung getroffenen Nebenwirkungen erschöpft ${ }^{250}$.

\section{cc) Konkretisierung des verfassungsrechtlichen Abgrenzungsmaßstabes über $§ 1$ Abs. 5 BauGB}

\section{(1) Öffentliche Belange und Planrechtfertigung}

Dem $\S 1$ Abs. 3 BauGB läßt sich somit für die Konkretisierung des Art. 74 Nr. 18 GG nichts entnehmen. Anders sieht es dagegen mit $\S 1$ Abs. 5 S. 1 BauGB aus. Hierbei handelt es sich um den Hauptleitsatz für den Einsatz der Bauleitplanung schlechthin ${ }^{251}$. Der Begriff "geordnete städtebauliche Entwicklung" ist auch gegenüber den anderen in § 1 Abs. $5 \mathrm{~S}$. 1 BauGB genannten Zielen wie der "sozialgerechten Bodennutzung" und "menschenwürdigen Umwelt" der übergeordnete allgemeine Leitbegriff ${ }^{252}$. Vor allem wird $\S 1$ Abs. 5 S. 1 aber konkretisiert durch $\S 1$ Abs. 5 S. 2 BauGB. Dort sind in nicht abschließender Weise eine Reihe von Belangen genannt, die bei der Aufstellung von Bauleitplänen zu berücksichtigen sind. Diese Aufzählung verdeutlicht, welche Belange der Gesetzgeber unter anderem bei der Bauleitplanung berücksichtigt haben will, um von einer geordneten

${ }^{249}$ Siehe auch Fakler, S. 20, wonach der $§ 1$ Abs. 3 BauGB eine "nur sehr beschränkte Selektionsfunktion" habe.

${ }^{250}$ BVerwG, Urteil vom 14.07.1971, E 40, 258 (262). Die durch das BauGB vorgenommene Textänderung im Einleitungssatz des $\S 9$ Abs. 1, durch die u. a. die Worte "soweit es erforderlich ist" gestrichen wurden, verlagert die Problematik insoweit wieder mehr in den Bereich des $\$ 1$ Abs. 3 BauGB.

${ }^{251}$ BVerwG, Urteil vom 12.12.1969, E 34, 301 (307) zum alten $\S 1$ Abs. 1 BBauG. Schlichter / Stich / Tittel, BBauG, § 1 Rn. 16; Hoppe, DVBI. 1964, S. 169, spricht von "übergeordneter primärer Zielsetzung der Bauleitplanung", Gaentzsch, Berliner Kommentar, § 1 Rn. 43, vom obersten inhaltlichen Ziel der Bauleitplanung.

${ }^{252}$ Krautzberger, in: Battis / Krautzberger / Löhr, §1 Rn. 56; BT-Drs. 7/5059, S. 2. 
städtebaulichen Entwicklung sprechen zu können ${ }^{253}$. Liest man den Katalog des $\S 1$ Abs. 5 S. 2 BauGB negativ, so erhält man die Antwort darauf, wann eine geordnete städtebauliche Entwicklung nicht vorliegt, nämlich bei ungesunden Wohn- und Arbeitsverhältnissen (Nr. 1), einseitiger Bevölkerungsstruktur (Nr. 2), aber auch bei einer Verunstaltung des Orts- und Landschaftsbildes (Nr. 4). Die zu berücksichtigenden Belange sind Zweck- und Zielsetzung und damit möglicher rechtfertigender Grund für die Bauleitplanung ${ }^{254}$. Es ist nicht so, daß die in $\S 1$ Abs. 5 S. 2 BauGB genannten Belange nur im Rahmen der Verfolgung einer anderen Zielsetzung zu berücksichtigen wären. Die in $\S 1$ Abs. 5 S. 2 BauGB sind "gesetzlich formulierte Spezialzwecke"2ss.

Zwar wird im allgemeinen noch daran festgehalten, daß es sich bei § 1 Abs. 5 BauGB um gerichtlich voll überprüfbare unbestimmte Rechtsbegriffe handeln soll ${ }^{256}$. Da der $\S 1$ Abs. 5 BauGB relativ weitmaschig ist und die in $\S 1$ Abs. 5 S. 2 BauGB genannten "Spezialzwecke" sich teilweise überschneiden, teilweise aber auch in entgegengesetzte Richtungen weisen, kommt dem $\S 1$ Abs. 5 BauGB insoweit aber eine relativ geringe plandeterminierende und plankontrollierende $\mathrm{Kraft} \mathrm{zu}^{25}$. Mehr als gewisse Tendenzaussagen lassen sich dem $\S 1$ Abs. 5 BauGB nicht entnehmen ${ }^{258}$. Vielmehr ist es die Gemeinde selbst, die die konkret anzustrebenden Ziele setzt ${ }^{259}$.

Diese Freiheit der Gemeinden in der Zielsetzung führt jedoch zu einem gewissen Dilemma. Der Katalog des § 1 Abs. 5 S. 2 BauGB enthält nämlich eine Reihe von Berücksichtigungspflichten, deren spezialgesetzliche Wahrnehmung nach allgemeiner Auffassung nicht in die Zuständigkeit des Bundesgesetzgebers gehört, vor allem die Belange des Denkmalschutzes (Nr. 5), aber auch die Gestaltung des Orts- und Landschaftsbildes (Nr. 4). Dies hat zu dem Versuch geführt, die als Sachbereiche formulierten Belange "imma-

${ }^{253}$ Krautzberger, in: Battis / Krautzberger / Löhr, §1 Rn. 58.

${ }^{254}$ Gaentzsch, DSt. 1974, S. 487.

${ }^{255}$ Papier, NJW 1977, S. 1716; Boeddinghaus, Stadterhaltung, S. 56. Ausführlich unten A II $3 \operatorname{ccc}(1)$.

${ }^{256}$ Grundlegend ist die Entscheidung BVerwG, Urteil vom 12.12.1969, E 34, 301 (308) bezüglich $\S 1$ Abs. 4 S. 1, S. 3 und Abs. 5 BBauG a. F. Die Novelle von 1976, auf die die auch heute im BauGB geltende Fassung zurückgeht, stellt nur eine redaktionelle Klarstellung dar, so daB die Rechtsprechung des BVerwG weiterhin Geltung beansprucht. Siehe SchmidtAßmann, BauR 1978, S. 102: "Grundsatz struktureller Kontinuität".

257 Schmidt-Aßmann, BauR 1978, S. 102; Hoppe, DVBI. 1974, S. 645.

258

259

Gaentzsch, Berliner Kommentar, § 1 Rn. 43.

Gaentzsch (Fn. 258). 
nent" einzuschränken. Sie sollen nicht als solche "relevant" sein, sondern nur in ihren boden-, raum- und siedlungsstrukturellen Bezügen ${ }^{260}$. Die Gemeinde soll nicht über den Weg der Bauleitplanung versuchen dürfen, den Sachbereich selbst in den Griff zu bekommen ${ }^{261}$. Insoweit soll es sich sogar um einen allgemeinen Gedanken des Städtebaurechts handeln, der in $\S 15$ Abs. 3 BauNVO seinen positivrechtlichen Niederschlag gefunden habe ${ }^{262}$. Meist wird die Beschränkung damit erklärt, daß die Bauleitplanung "kein Instrument zentraler Gesellschaftsplanung" $\mathrm{se}^{263}$. Dazu wird häufig ergänzt, die Gemeinde dürfe auf dem Weg über die Bauleitplanung beispielsweise keine Wettbewerbspolitik oder Wirtschaftsplanung betreiben ${ }^{264}$. Nur im $\mathrm{Zu}$ sammenhang mit dem öffentlichen Interesse an der Vorbereitung und Leitung der Bodennutzung erhielten die genannten Belange eine städtebauliche Qualität ${ }^{265}$.

Die Richtigkeit dieser Thesen erscheint jedoch zweifelhaft. Es gibt einen zutreffenden Aussagekern, der sich aus konsequenter Anwendung des Abwägungsgebotes ergibt. Die Verallgemeinerung ist jedoch unzutreffend. Was etwa das Verbot der Wirtschaftsplanung oder Wirtschaftspolitik betrifft, so gibt es kein Verbot der Berücksichtigung wirtschaftlicher Belange im Städtebau schlechthin ${ }^{266}$. Es läßt sich auch kaum bestreiten, daß die Gemeinden in massiver Form über den Weg der Bauleitplanung versuchen, die Wirtschaftsentwicklung in ihrem Gemeindegebiet zu beeinflussen, z. B. durch die Ausweisung oder auch Nichtausweisung von in der BauNVO vorgesehenen gewerbebezogenen Baugebieten ${ }^{267}$. Ob man diesen tatsächlichen Befund nun dadurch rechtfertigt, daß man sagt, es sei nicht Aufgabe der Städtebauer, Gewerbepolitik zu betreiben, sondern nur, die Ziele und Festlegungen der

${ }^{260}$ Schmidt-Aßmann, in: Ernst / Zinkahn / Bielenberg, BBauG, $\$ 1$ Rn. 178, ders., BauR 1978, S. 102; Papier, NJW 1977, S. 1716; Grauvogel, in: Brügelmann, BBauG, § 1 Rn. 361; Moench / Schmidt, S. 5.

${ }^{261}$ Schmidt-Aßmann (Fn. 260), § 1 Rn. 171.

${ }^{262}$ Grauvogel, in: Brügelmann, BBauG, § 1 Rn. 7; BWVGH, Urteil vom 30.06.1982, DÖV 1983, S. $76(78)$.

263 Schmidt-Aßmann (Fn. 260), § 1 Rn. 171, ders., BauR 1978, S. 102. Ähnlich Ronellenfitsch, S. 57, wonach die Gemeinden keine "Gesellschaftspolitik" betreiben dürften.

${ }^{264}$ Schmidt-Aßmann (Fn. 260), §1 Rn. 178; Bielenberg, in: Ernst / Zinkahn / Bielenberg, BauNVO, $\S 15$ Rn. 18; Stober, WiVw 1984, S. 129 und 141; Krautzberger, in: Battis / Krautzberger / Löhr, § 1 Rn. 79; Schrödter, § 1 Rn. 9 c.

${ }^{265}$ Gaentzsch, Berliner Kommentar, $\$ 1$ Rn. 42.

${ }^{266}$ So auch Bielenberg, in: Ernst / Zinkahn / Bielenberg, BauNVO, § 15 Rn. 18.

${ }^{267}$ Stober, WiVerw. 1984, S. 129. 
Gewerbepolitik städtebaulich sinnvoll umzusetzen ${ }^{268}$, ist angesichts der den Gemeinden bei der Bauleitplanung zustehenden Gestaltungsfreiheit wohl mehr ein terminologischer als ein sachlicher Unterschied. Auch der Gesetzgeber greift über das Baurecht in das wirtschaftliche Geschehen ein. So hat er beispielsweise großflächige Einzelhandelsbetriebe unter anderem wegen der Auswirkungen auf Verkehr, Umwelt und Nahversorgung der Bevölkerung als strukturpolitisch bedenklich angesehen und durch $\S 11$ Abs. 3 BauNVO einem besonderen bebauungsrechtlichen Planverfahren unterzogen $^{269}$, dadurch aber auch den bodenpolitischen Vorstellungen der Gemeinden in gewissem Maße unterstellt.

Was den Gemeinden allerdings untersagt ist - und dies ist der zutreffende Gedanke an der Feststellung, die Gemeinden dürften keine "Wirtschaftspolitik" betreiben - ist das Herausplanen von bestimmten Gewerbebetrieben aus ihrem Gemeindegebiet, ohne daß dies die konkrete örtliche Situation rechtfertigt ${ }^{270}$. So ist es den Gemeinden nicht erlaubt, etwa Supermärkte oder Spielhallen deshalb nach § 1 Abs. 9 BauNVO auszuschließen, weil es sich um Spielhallen oder Supermärkte handelt ${ }^{271}$. Wenn die Gemeinden eine solche Festsetzung nach $\S 1$ Abs. 9 BauNVO treffen, müssen sie an die Sekundärwirkungen solcher Betriebe anknüpfen. Dazu gehören etwa Lärmbelästigungen für die Anwohner, die Gefährdung wohnnaher Versorgung oder die Verödung der Innenstädte ${ }^{272}$. Über die Anknüpfung hieran ${ }^{273}$ können die Gemeinden sich im Rahmen ihres Planungsermessens für oder gegen die Förderung der Ansiedlung von solchen Gewerbebetrieben entscheiden. Sie können die von diesen Betrieben ausgehenden Sekundärwirkungen zum Anlaß nehmen, etwas gegen die Betriebe zu unternehmen, sie

${ }^{268}$ So Hieber, S. 63.

${ }^{269}$ Hüttenbrink, DVBI. 1983, S. 533; Schwerdtner, BauR 1986, S. 253; Battis, DÖV 1978, S. 121.

270 Dolde / Schlarmann, BauR 1984, S. 131; Hauth, Bau R 1986, S. 652.

271 Siehe auch VG Münster, Urteil vom 24.07.86, GewArchiv 1987, S. 69 (70), wonach ein "soziales Unwerturteil" über Spielhallen bauplanungsrechtlich irrelevant sei.

272 BayVGH, Urteil vom 12.06.1986, GewArchiv 1987, S. 140; OVG NW, Urteil vom 01.07.1986, GewArchiv 1987, S. 158 (159); Marcks, in: Landmann / Rohmer, § 33 i Rn. 27; Bielenberg, in: Ernst / Zinkahn / Bielenberg, BauNVO, § 1 Rn. 33 u. Die verbrauchernahe Versorgung ist durch das BauGB sogar ausdrücklich in den Katalog des $\S 1$ Abs. 5 S. 2 BauGB aufgenommen worden, siehe Nr. 8. Zu den relevanten Gründen für den Ausschluß von Spielhallen siehe Erdmann, DVBI. 1988, S. 1096; Schlichter / Friedrich, S. 202 f. Für großflächige Einzelhandelsgeschäfte Hauth, BauR 1986, S. 652.

273 Jahn, BayVBI. 1988, S. 41, spricht von "Deckungsgleichheit wettbewerbspolitischer Vorstellungen und städtebaulicher Anliegen". 
können dies aber auch unterlassen. Dies folgt zwingend aus der Gestaltungsfreiheit, die $\S 1$ Abs. 3 und Abs. 6 BauGB den Gemeinden einräumt.

Die Gemeinden dürfen damit insoweit Wirtschafts- und Wettbewerbspolitik betreiben, wie sie die Anforderungen des Abwägungsgebotes einhalten. Die Entscheidung gegen bestimmte Betriebe ist solange zulässig, wie sie sich abwägungsfehlerfrei erreichen läßt. Erst dann, wenn sich nicht genügend negative Sekundärwirkungen auf dem Negativkonto der unerwünschten Betriebe verbuchen lassen und die Gemeinde den Ausschluß des Gewerbebetriebes letztlich auf ein Unwerturteil über die betreffende gewerbliche Tätigkeit an sich stützt, begeht sie einen Abwägungsfehler, indem sie die gewerbliche Betätigung als negativ in die Abwägung einstellt, während Art. 12 GG und $\S 1$ GewO eine negative Bewertung verbieten. Denn die Frage, ob und mit welchem Gewicht ein Belang in die Abwägung einfließt, untersteht nicht der Disposition der Gemeinde ${ }^{274}$.

Dementsprechend formuliert das BVerwG die Frage des Ausschlusses von Spielhallen dahingehend, daß es der Gemeinde verwehrt sei, eine von der Wertung des Bundesgesetzgebers abweichende "Spielhallenpolitik" zu betreiben $^{275}$. Die Gemeinden dürfen also wohl Spielhallenpolitik betreiben, aber eben nur, soweit sich dies mit den vom formellen Gesetzgeber vorgegebenen Wertungen vereinbaren läßt. Gleiches gilt für das Beispiel, wonach es den Gemeinden verwehrt sei, den Trägern der staatlichen vor den Trägern der freien Wohlfahrtspflege einen Vorrang zukommen zu $\operatorname{lassen}^{276}$. Soweit mit einer solchen Begründung ein Bauleitplan aufgestellt würde, verstieße die Abwägung gegen in den § 93 BSHG zum Ausdruck kommenden Vorrang freier Träger und wäre rechtswidrig. Daher ist nicht $\S 1$ Abs. 5 S. 1 und S. 2, sondern das Abwägungsgebot in $\S 1$ Abs. 6 BauGB der richtige Anknüpfungspunkt, um zu verhindern, daß die Gemeinden sich in Dinge einmischen, die sie "nichts angehen".

Der Versuch, die in $\S 1$ Abs. 5 S. 2 BauGB genannten Belange immanent einzuschränken, widerspricht weiterhin auch dem Charakter der Bauleitplanung als Nichtfachplanung. Denn die in $\S 1$ Abs. 5 S. 2 BauGB genannten Belange bilden vor allem das abwägungserhebliche Material für die Abwä-

${ }^{274}$ Krautzberger, in: Battis / Krautzberger / Löhr, § 1 Rn. 91 m. w. N.

275 BVerwG, Beschluß vom 22.05.1987, DVBI. 1987, S. 1001 (1002). Hervorhebung vom Verfasser.

${ }^{276}$ Schmidt-Aßmann, in: Ernst / Zinkahn / Bielenberg, BBauG, § 1 Rn. 171. 
A. Örtliche Bauvorschriften zwischen Bauplanungs- und Bauordnungsrecht

gung nach § 1 Abs. 6 BauGB $^{27}$. Das Abwägungsgebot des $\S 1$ Abs. 6 BauGB soll nach Auffassung des BVerwG sogar im Rechtsstaatsprinzip wurzeln ${ }^{278}$. Gerade bei der Bauleitplanung folgt die Notwendigkeit einer Abwägung daraus, daß eine Vielzahl von Interessen berührt wird, die deshalb zum Ausgleich gebracht werden müssen ${ }^{279}$. Bauleitplanung ist "planerische Gestaltung von Interessengeflechten" ${ }^{\prime 280}$. Dabei muß die planende Stelle alle einigermaßen erheblichen, schutzwürdigen und erkennbaren Interessen berücksichtigen ${ }^{281}$. Der Auftrag zum Interessenausgleich betrifft alle berührten öffentlichen und privaten Belange, ist also umfassend. Ein so verstandener umfassender Abwägungs- und Gestaltungsauftrag an die Gemeinden läuft aber letztlich jedem Versuch zuwider, zwischen den in $\S 1$ Abs. 5 BauGB genannten Zielen der Bauleitplanung und dem Abwägungsgebot im Hinblick auf die relevanten Belange einen Unterschied zu machen ${ }^{282}$. Wenn die Pflicht zur Abwägung umfassend ist, können die anzustrebenden Ziele nicht restriktiv verstanden werden. Denn wenn ein Belang in die Abwägung eingestellt werden muß und es sich um mehr handeln soll als einen reinen "Zählposten", dann muß man diesem Belang zugestehen, daß er die konkrete Planung bei entsprechendem Gewicht in seine Richtung lenken kann.

Den zwischen dem umfassenden Abwägungsgebot des § 1 Abs. 6 BauGB und dem angeblich restriktiv zu interpretierenden Gestaltungsauftrag des $\S 1 \mathrm{Abs} .5 \mathrm{BauGB}$ entstehenden Widerspruch kann man auch nicht dadurch auflösen, daß man zu unterscheiden versucht zwischen solchen Belangen, die "positiv" die Bauleitplanung rechtfertigen und solchen, die nur "negativ", also quasi auf der Passivseite zu berücksichtigen sind ${ }^{283}$. So ist es gesicherte Erkenntnis der Abwägungslehre, daß sich Belange bei entsprechendem $\mathrm{Ge}$ wicht auch im Abwägungsergebnis niederschlagen müssen ${ }^{284}$. Wenn sie aber

${ }^{277}$ Krautzberger, in: Battis / Krautzberger / Löhr, § 1 Rn. 58; Schmidt-Aßmann, BauR 1978, S. 105.

278 BVerwG, Beschluß vom 21.09.1971, Buchh. 406.11, § 173 BBauG Nr. 9, Urteil vom 14.03.1975, Buchh. 406.21, § 1 BaugestVO Nr. 1 S. 1 (5).

${ }^{279}$ Schmidt-Aßmann, Grundfragen, S. 65; Grauvogel, in: Brügelmann, BBauG, § 1 Rn. 151.

${ }^{280}$ Weyreuther, DÖV 1977, S. 420.

${ }^{281}$ BVerwG, Beschluß vom 09.11.1979, NJW 1980, S. 1061 ff. = E 59, 87 (97 f.).

${ }^{282}$ So aber vor allem Schmidt-Aßmann, in: Ernst / Zinkahn / Bielenberg, BBauG, § $1 \mathrm{Rn}$. 311. Weiterhin Grauvogel, in: Brügelmann, BBauG, § 1 Anm. 439; Krautzberger, in: Battis / Krautzberger / Löhr, \&1 Rn. 61. Eher wie hier Langer, VerwArchiv 80 (1989), S. 363, für das Verhältnis von örtlichen und überörtlichen Planungen.

283 So aber Schmidt-Aßmann, in: Ernst / Zinkahn / Bielenberg, BBauG, § 1 Rn. 311. Für das Preußische Fluchtliniengesetz schon Saran, S. 87.

${ }^{284}$ Grundlegend BVerwG, Urteil vom 05.07.1974, E 45, 309 (312 f.) ("Floatglas"). 
letztlich das Abwägungsergebnis "gestalten", dann wird man von einer Berücksichtigung rein auf der "Passivseite" nicht sprechen können.

$\mathrm{Da}$ die zu berücksichtigenden Belange somit gleichzeitig zulässige Ziele der Bauleitplanung sind, ist es durchaus denkbar, daß eine Gemeinde eine bestimmte Bauleitplanung, wie etwa die Beschränkung der Bebauung in einem Gebiet auf eingeschossige Bauweise, nur deshalb betreibt, um die Aussicht auf eine mittelalterliche Stadtsilhouette zu schützen ${ }^{285}$. Es kann dazu kommen, daß ein abwägungserheblicher Belang in einer solchen Weise dominiert, daß er die Bauleitplanung maßgeblich oder fast alleine bestimmt. Wenn aber bauplanerische Maßnahmen nötig sind, um etwa einem denkmalschutzrechtlichen Problem gerecht zu werden, kann die Zulässigkeit der Bauleitplanung nicht davon abhängen, ob der Gemeinde die Wahrnehmung von Aufgaben des Denkmalschutzes sonst obliegt oder nicht. Die Aussage, die Gemeinde dürfe nicht versuchen, den "Sachverhalt an sich" in den Griff zu bekommen, ist inhaltsleer. Soweit die Gemeinde die Anforderungen des Abwägungsgebotes einhält, darf sie die entsprechende Planung vornehmen. Im Bereich der Bauleitplanung sind insoweit die Pflichten und Rechte der Gemeinde notwendigerweise kongruent. Der Pflicht zur Berücksichtigung bestimmter Belange korrespondiert das Recht, die Bauleitplanung gegebenenfalls positiv für diesen Belang einzusetzen.

Die in $\S 1$ Abs. 5 S. 2 BauGB genannten Belange sind also zu ergänzen, sie sind nicht - auch nicht immanent - zu beschränken. Der Begriff der "geordneten städtebaulichen Entwicklung" wird also über § 1 Abs. 5 S. 2 und Abs. 6 BauGB konkretisiert durch eine nicht abgrenzbare Zahl von Belangen, die in die Abwägung einzustellen sind. Eine geordnete städtebauliche Entwicklung liegt dann vor, wenn die abwägungserheblichen Belange sich in einem ausgewogenen Verhältnis zueinander befinden. Der für die grundsätzliche Planrechtfertigung einer Bauleitplanung erforderliche städtebauliche Bezug liegt somit dann vor, wenn die Gemeinde durch die Planung eines der Ziele fördern kann, die nach $\S 1$ Abs. 5 und 6 BauGB zum notwendigen Abwägungsmaterial gehören. Dieser Bezug ist entsprechend der Rechtsprechung zu § 1 Abs. 3 BauGB objektiv zu sehen ${ }^{286}$. Ob die Festsetzung im übrigen einen zulässigen Inhalt hat, ist nach den Grundsätzen der Abwägungslehre zu entscheiden.

${ }^{285}$ Beispiele aus der Rechtsprechung bei Stich, Schutz und Erhaltung städtebaulicher Gesamtanlagen, S. 377 ff. Weiterhin etwa OVG Koblenz, Urteil vom 27.05.1987, NVwZ 1988, S. 371.

${ }^{286}$ Siehe oben A II $3 \mathrm{c} \mathrm{bb}$. 
(2) Private Belange und Planrechtfertigung

Die These, daß jeder abwägungserhebliche Belang eine Bauleitplanung rechtfertigen kann, läßt sich nicht damit in Frage stellen, daß dann die grundsätzliche Planrechtfertigung sich auch aus einem rein privaten Interesse ergeben könnte. Es ist bereits die Frage angesprochen worden, ob es möglich ist, die Festsetzung von Flachdächern in örtlichen Bauvorschriften auf Wunsch der betroffenen Eigentümer zu ändern ${ }^{287}$. Versteht man den Begriff der "städtebaulichen Absicht" in Art. 91 Abs. 1 Nr. 1 BayBO und $\S 56 \mathrm{NBauO}$ im gleichen Sinn wie in $\$ 1$ Abs. $5 \mathrm{BauGB}$, so ist die Frage nach der hier vertretenen Auffassung zu bejahen. Die These, rein private Belange reichten für die grundsätzliche Planrechtfertigung nicht aus ${ }^{288}$, führt nämlich ebenfalls zu einer nicht durchführbaren Trennung von $\S 1$ Abs. 5 und 6 BauGB.

Vielmehr sprechen für die Möglichkeit einer Planrechtfertigung durch private Belange eine Reihe von Gründen. Zunächst haben die öffentlichen Belange im Rahmen der Abwägung nach § 1 Abs. 6 BauGB nach allgemeiner Ansicht keine grundsätzlich höhere Wertigkeit als private Belange ${ }^{289}$. Öffentliche Interessen brauchen deshalb bei einer Bebauungsplanung zumindest in der Regel nicht "im Vordergrund" zu stehen ${ }^{200}$. Soweit dies auch mit den abwägungserheblichen öffentlichen Belangen vereinbar ist, spricht nichts dagegen, die Festsetzungen eines Bebauungsplans auch im privaten Interesse durchzuführen. Es wäre angesichts des Art. $14 \mathrm{GG}$ und der damit verbundenen Wertentscheidung zugunsten des privaten Eigentums kaum einsichtig, wenn ein Bebauungsplan, der Eigentümerbefugnisse einschränkt, deshalb nicht geändert werden darf, weil ein "öffentliches Interesse" dafür nicht zu finden ist, obwohl unter Umständen auch kein öffentliches Interesse mehr für die Beibehaltung der Beschränkung besteht. Für die Eignung privater Belange zur Planrechtfertigung spricht auch, daß die öffentlichen Be-

${ }^{287}$ Siehe oben A I 2 a aa.

${ }^{288}$ Vergleiche etwa Ronellenfitsch, S. 57; Gaentzsch, Berliner Kommentar, § 1 Rn. 8; Sendler, BauR 1970, S. 6; OVG Saarland, Urteil vom 17.10.1969, BRS 22, Nr. 5 S. 143. Vgl. auch BVerwG, BeschluB vom 06.11.1968, BRS Band 22, Nr. 1 S. 1. In dem vom OVG Lüneburg entschiedenen Fall bestand jedoch die Gefahr des Entstehens einer Splittersiedlung, so daß ohnehin ein Abwägungsfehler vorlag, siehe OVG Saarland, ebenda, S. 15.

${ }^{289}$ Schmidt-Aßmann, Abwägungselemente, S. 14; Reinhard, S. 46; Schulze-Fielitz, Sozialplanung, S. $30 \mathrm{ff}$.

${ }^{290}$ Anders allerdings Sendler, BauR 1970, S. 6. 
lange letztlich individuelle Bedürfnisse verallgemeinern ${ }^{291}$. Dadurch wird die Unterscheidung zwischen öffentlichen und privaten Belangen aber ohnehin unscharf $^{292}$. Zudem werden z. B. im Gefahrenabwehrrecht private Belange im öffentlichen Interesse geschützt ${ }^{293}$, was die Gleichung "öffentliches Interesse $=$ Interessen einer unbestimmten Zahl Privater" ohnehin zweifelhaft erscheinen läßt $\mathrm{t}^{24}$. Selbst wenn man der Verallgemeinerungsthese folgt, vermag niemand zu sagen, wieviel undicht gewordene Flachdächer in einer Gemeinde vorliegen müssen, bis aus dem privaten Belang der Vermeidung eines Wassereimereinsatzes der öffentliche des Schutzes der Gesundheit der Bevölkerung wird.

Weiterhin sieht die Gegenmeinung die Bauleitplanung zu einseitig als Eingriffsmaßnahme. Dies ist aufgrund der eigentumsausgestaltenden Funktion der Bauleitplanung überholt ${ }^{295}$, was vor allem die Diskussion um die Frage zeigt, ob und inwieweit der Art. 14 GG "Baufreiheit" garantiert. Eine direkt aus Art. 14 GG folgende Baufreiheit gibt es als Individualgrundrecht nicht ${ }^{296}$. "Baurechtliche" Baufreiheit besteht nur in dem Maße, wie sie aus den $\S \S 30 \mathrm{ff}$. BauGB folgt ${ }^{297}$. Damit ist die aufgrund der institutionellen Garantie des Eigentums mit dem Grundeigentum grundsätzlich verbundene verfassungsrechtliche Baufreiheit ${ }^{298}$ in erheblichem $\mathrm{Maße}$ von einem gemeindlichen Planungsakt abhängig. Zwar ist es zu weitgehend, im Sinne der Theorie von der öffentlichrechtlich vermittelten Bebauungsbefugnis davon auszugehen, daß das Recht zu Bauen überhaupt nur ein durch staatlichen Planungsakt verliehenes subjektiv-öffentliches Recht sei ${ }^{299}$. Hierbei werden

291 Schulze-Fielitz, Sozialplanung, S. 306. Vgl. auch W. Schmidt, VVDStRL 33 (1974), S. 198, zu Partikularinteressen als latent öffentliche Interessen. Ähnlich aus Leisner, DÖV 1970, S. 220: Die Verwaltung kann praktisch jedes private Interesse sich als öffentliches zu eigen machen.

292 So wohl auch Schmidt-Aßmann, BauR 1978, S. 106: Private und öffentliche Interessen sind in der konkreten Planungssituation häufig nicht zu trennen.

293 Leisner, DÖV 1970, S. 220.

294 Leisner, DÖV 1970, S. 222.

295 So auch Pfaff, Planungsrechtsprechung, S. 153.

${ }^{296}$ Hoppe, DVBI. 1964, S. 166; Erbguth, JuS 1988, S. 702; Ernst / Hoppe, Rn. 166.

${ }^{297}$ Battis, DÖV 1978, S. 118; Papier, BauR 1978, S. 301; Friauf / Wendt, S. 73; Knemeyer, Baurecht, S. 428; Friauf, S. 503.

${ }^{298}$ Dazu siehe Kimminich, Eigentum, Rn. 140.

${ }^{209}$ So aber etwa $H$. Schulte, Baufreiheit, S. 139: "Bauen ist ohne Bauleitplanung nicht möglich." Götz, S. 42; Breuer, DÖV 1978, S. 192, ders., Bodenrecht, S. 169 f., ders., Planung, S. 188: "Baufreiheit besteht nach dem BBauG nur im Rahmen der Planung." Weitere Nachweise zu dieser Auffassung bei $H$. Börger, S. 47. 
A. Örtliche Bauvorschriften zwischen Bauplanungs- und Bauordnungsrecht

die $\S \S 34,35$ BauGB zu Ausnahmevorschriften degradiert ${ }^{300}$, was ihrer praktischen Bedeutung nicht gerecht wird. Zudem verkürzt die Theorie von der öffentlichrechtlich vermittelten Bebauungsbefugnis den Eigentumsschutz erheblich. Beschränkungen der Baufreiheit, wie sie etwa in $\$ 334$ und 35 BauGB vorgesehen sind, bräuchten sich nicht mehr an Art. 14 GG und vor allem dem Übermaßverbot messen lassen ${ }^{301}$.

Die von der Theorie der Bebauungsbefugnis zu Unrecht verabsolutierte Tatsache der Planabhängigkeit der Grundstücksnutzung zeigt jedoch, daß Bauleitplanung zunächst vor allem dem Bereich der Leistungsverwaltung zuzuordnen ist. Zutreffende Erkenntnis dieser Theorie ist es, daß die Bauleitplanung das Eigentumsrecht aus Art. 14 GG ausgestaltet ${ }^{302}$. Sie hat "Zuteilungsfunktion" und gibt dem Eigentum unter Umständen eine neue Qualität ${ }^{303}$. Diese "neue Qualität" ist aber im Vergleich zum bisherigen $\mathrm{Zu}$ stand nicht notwendig von beschränkendem, sondern häufig von ermöglichendem Charakter.

Desweiteren ist die Art und Weise der Ableitung des Erfordernisses einer Planrechtfertigung in der Rechtsprechung des BVerwG ein Beleg für die hier vertretene Ansicht. Das BVerwG begründet die Notwendigkeit der Planrechtfertigung grundsätzlich mit den Eigentumsbeschränkungen, die von einer hoheitlichen Planung ausgehen ${ }^{304}$. Dann aber ist eine Rechtfertigung durch öffentliche Belange nicht erforderlich, wenn für die Planbetroffenen eine Belastung insoweit nicht eintritt, und sei es deshalb, weil sie selbst die Planung wünschen. Es kommt damit auf den konkreten Inhalt des Bebauungsplanes an, inwieweit ein "öffentlicher Belang" zur Planrechtfertigung vorliegen muß. Wird etwa eine öffentliche Verkehrsfläche durch Bebauungsplan festgesetzt, kann für das Erfordernis der Planrechtfertigung nichts anderes gelten als sonst im Straßenrecht auch. Soll hingegen beispielsweise für einige Grundstücke das zulässige $\mathrm{Ma} ß$ der baulichen Nutzung erhöht werden, läßt sich dies auch mit privaten Belangen rechtfertigen.

Nur dann, wenn man von der grundsätzlichen Möglichkeit ausgeht, daß eine Planung auch durch private Interessen gerechtfertigt werden kann, er-

\footnotetext{
${ }^{300}$ Vgl. etwa H. Schulte, Baufreiheit, S. 133 Rn. 6.

${ }^{301}$ Ernst / Hoppe, Rn. 166. Ablehnend zur Theorie der Bebauungsbefugnis aus geschichtlichen Überlegungen heraus auch $H$. Börger, S. 53 .

${ }^{302}$ Battis, DÖV 1978, S. 118.

${ }^{303}$ Battis, DÖV 1978, S. 119; Breuer, DÖV 1978, S. 191; BVerwG, Urteil vom 11.03.1988, BayVBI. 1988, S. 568 ff.; BVerfG, Beschluß vom 14.05.1985, E 70, 35 (53).
}

${ }^{304}$ BVerwG, Urteil vom 05.07.1974, E 45, 309 (313). 
klärt sich weiterhin der Ausschluß eines Anspruchs auf eine bestimmte Bauleitplanung durch $\S 2$ Abs. 3 BauGB. Die Versuche, trotzdem unter Umständen zu einem subjektiv-öffentlichen Recht auf eine bestimmte Bauleitplanung zu kommen ${ }^{305}$, lassen sich nur daraus erklären, daß eine Planung im privaten Interesse nicht per se gegen den in $\S 1$ Abs. 5 BauGB konstituierten Bezug zur geordneten städtebaulichen Entwicklung verstößt. Schließlich widerspricht ein Grundsatz des Inhalts, daß private Belange eine Bauleitplanung nicht rechtfertigen können, den rechtstatsächlichen Verhältnissen und hat schon deshalb keine Aussicht auf wirkliche Befolgung, weil wie schon die Diskussion um die Erforderlichkeit der Bauleitplanung nach $\S 1$ Abs. 3 BauGB ergeben hat ${ }^{306}$ - ein öffentlicher Belang sich notfalls immer (er-)finden läßt. Gefördert wird auf diese Weise lediglich die Unehrlichkeit im Planaufstellungsverfahren.

Das Merkmal der "Planrechtfertigung" hat somit für den Bereich der Bauleitplanung in der Regel keine eigentliche Relevanz. Von Bedeutung ist es vor allem im Bereich der Fachplanung. Dort ist eine Einschränkung der durch Art. 14 GG geschützten Rechte nur dann zulässig, wenn das jeweilige Vorhaben nach den Zielsetzungen des betreffenden Fachgesetzes vernünftigerweise geboten ist ${ }^{307}$. Bei einer Fachplanung geht es um die Verfolgung bereichsspezifischer Verwaltungszwecke ${ }^{308}$. Bei ihr wird im Interesse der fachplanerischen Zielsetzung dem Eigentümer etwas genommen, d. h. die Eigentumsposition wird - gegebenenfalls gegen Entschädigung - verkürzt. Bei der Bauleitplanung als Gesamtplanung ${ }^{309}$ oder gebietsbezogener Planung ist dies dagegen nicht grundsätzlich der Fall. Die belastenden Wirkungen, zu denen eine Bauleitplanung auch führt, geschehen im Unterschied zur Fachplanung häufig im Interesse einer gemeinsamen Begünstigung. So verbindet ein Bebauungsplan z. B. durch die Festsetzung eines allgemeinen Wohngebietes die betroffenen Grundstückseigentümer zu einer Gruppe, die nicht nur kollektiv belastet, sondern auch kollektiv berechtigt wird ${ }^{310}$. Es be-

${ }^{305}$ Zum Diskussionsstand ausführlich Westbomke, S. 93 ff.; weiterhin Fackler, vor allem S. $129 \mathrm{ff}$.

${ }^{306}$ Siehe oben A II $3 \mathrm{c}$ aa.

${ }^{307}$ Siehe für die fernstraßenrechtliche Planrechtfertigung Steiner, Straßen- und Wegerecht, Rn. 59 m. w. N.

${ }^{308}$ Hoppe, Kommunale Selbstverwaltung, S. 561; Erbguth, NVwZ 1989, S. 608: Planfeststellungen im Fachplanungsrecht sind monofinal ausgerichtet.

${ }^{309}$ Ossenbühl, DJT-Gutachten, S. 28.

${ }^{310}$ Timmermann, S. 69. 
steht eine Art Austauschverhältnis zwischen den Eigentümern ${ }^{311}$. Mit dem Gebietscharakter nicht vereinbare Nutzungen sind allen Eigentümern gegenüber verboten, ihr Verbotensein kommt aber auch allen Eigentümern zugute und vermittelt ihnen unter Umständen auch subjektive Klagerechte $^{312}$.

Dem Problem des "Gefälligkeitsbebauungsplans" läßt sich schließlich durch entsprechend strikte Anwendung der Abwägungsgrundsätze gerecht werden. Denn wenn zugunsten eines einzelnen unter nicht hinnehmbarer Zurückstellung öffentlicher oder anderer privater Interessen geplant wird, liegt immer auch ein Abwägungsmangel vor. Auch eine maßgebliche durch private Interessen veranlaßte Bauleitplanung ist somit grundsätzlich zulässig. Es kann daher daran festgehalten werden, daß jeder Belang, der in die Abwägung einzustellen ist, eine Bauleitplanung rechtfertigen und damit in seinem Sinne lenken kann.

\section{(3) Folgen für die finale Abgrenzung} zwischen Bauordnungs- und Bauplanungsrecht

Bauleitplanung dient von sich aus somit keinen bestimmten Interessen ${ }^{313}$, weder öffentlichen noch privaten. Daher gibt es auch keine Dichotomie bauordnungsrechtlicher und bauplanungsrechtlicher Regelungsziele ${ }^{314}$. Zulässige Regelungsziele des Bauordnungsrechts haben keine Sperrwirkung für das Bauplanungsrecht, genauso wie umgekehrt Fragen der öffentlichen Sicherheit und Ordnung auch im Bauplanungsrecht zu beachten sind ${ }^{315}$.

Dies hat für die hier zu lösenden Kompetenzfragen folgende Konsequenz: Wenn sich die Bundeskompetenz "Bodenrecht" dadurch kennzeichnen soll, daß das Ziel der gesetzgeberischen Maßnahme in der Ordnung der städtebaulichen Entwicklung besteht, lassen sich die mit diesem Begriff auch umfaßten spezialgesetzlich geregelten Belange wie etwa der Denkmalschutz hiervon nicht trennen. Der Begriff der geordneten städtebaulichen Entwicklung hat eine Weite, die letztlich alle Regelungsziele mit umfaßt, die mit der baulichen Nutzung von Grund in Zusammenhang stehen. Wenn also

\footnotetext{
${ }^{311}$ Sendler, BauR 1970, S. 6.

${ }^{312}$ Siehe dazu Schlichter, Berliner Kommentar, vor $\$ \$ 29-38$, Rn. 51 m. w. N.

313 J. Ziegler, ZfBR 1980, S. 275.

${ }^{314}$ Anders etwa Erdmann, DVB1. 1988, S. 1097.

${ }^{315}$ Schlichter, Berliner Kommentar, Einf., Rn. 76.
} 
ausgeführt wird, die Gemeinde dürfe für keine anderen als städtebauliche Zwecke den Plantyp Flächennutzungsplan oder Bebauungsplan verwen$\operatorname{den}^{316}$, so hat dies keinen großen Aussagewert. Deshalb, weil die Belange des $\S 1$ Abs. 5 S. 2 BauGB und die nach $\S 1$ Abs. 6 BauGB sonst in der Abwägung zu berücksichtigenden Belange in keinem Stufenverhältnis stehen ${ }^{317}$, fehlt es für die Bauleitplanung an einer Zweckprogrammierung ${ }^{318}$.

Dadurch gerät die Klärung der Kompetenzfrage im Baurecht zunächst in eine Sackgasse. Wenn es bei der Kompetenz "Bodenrecht" final darum geht, eine geordnete städtebauliche Entwicklung herbeizuführen, im Rahmen der städtebaulichen Entwicklung aber eine unbegrenzte Zahl von Belangen zu berücksichtigen ist, dann ist die Kompetenz "Bodenrecht" nicht eingrenzbar. Sie wäre letztlich das Einfallstor für den Bundesgesetzgeber, das die Normierung beliebiger Bereiche rechtfertigen würde. Eine allein finale Abgrenzung der Bundeskompetenz ist somit nicht möglich. Insofern hatte das im Rahmen dieser Untersuchung vielgeschmähte Baurechtsgutachten des BVerfG so Unrecht nicht, wenn es versucht hat, die Bodenrechtskompetenz über die Unmittelbarkeitsformel und das Herausstellen der Festsetzungen über die Art der baulichen Nutzung instrumental zu beschreiben.

\section{dd) Die geschichtliche Entwicklung des Bauplanungsrecht und die Kompetenz "Bodenrecht"}

Das BVerfG hat in seinem Baurechtsgutachten nicht nur die Unmittelbarkeitsformel als Abgrenzungsmaßstab genannt. Es hat auch darauf hingewiesen, daß das Bodenrecht vor allem Planungsrecht ist ${ }^{319}$. Zu Recht hat es betont, daß die Kompetenz des Art. 74 Nr. 18 GG in Anlehnung an Art. 10 Nr. 4 WRV formuliert und daher aus dem historischen Zusammenhang zu interpretieren ist ${ }^{320}$. Geht man der historischen Entwicklung vor allem des Bauplanungsrechts nach, so erhält man wichtige Hinweise darauf, wodurch sich diese Materie vom übrigen Baurecht unterscheidet. Dabei stellt man

${ }^{316}$ Krautzberger, in: Battis / Krautzberger / Löhr, §1 Rn. 56.

${ }^{317}$ Schmidt-Aßmann, Abwägungselemente, S. 11 und 13; Westermann, Bestimmung des Eigentumsinhalts, S. 103.

${ }^{318}$ Vergleiche Papier, NJW 1977, S. 1715.

319 Siehe BVerfGE 3, 432, wonach das Baupolizeirecht mit Ausnahme des Planungsrechts zur Kompetenz der Länder gehört. Dies bedeutet, daß das Planungsrecht selbst die Bundeskompetenz umschreibt.

${ }^{320}$ BVerfGE 3, 414. Siehe auch allgemein BVerfG, Beschluß vom 25.04.1972, E 33, 52 (61) m. w. N. 
fest, daß die Schaffung eines funktionsfähigen Planungsinstrumentariums historisch gesehen der eigentliche Ansatzpunkt für die Entwicklung des modernen Städtebaurechts und die Herauslösung aus dem Bereich des Polizeirechts ist.

Als erster wichtiger Vorläufer des heutigen gemeindlichen bodenrechtlichen Instrumentariums ist die Planung der Trennung von öffentlichen, also vor allem Straßenflächen, von den privaten Flächen durch Fluchtlinienfestsetzungen zu nennen ${ }^{321}$. Am bedeutendsten ist in diesem Zusammenhang das preußische Fluchtliniengesetz vom 2. Juli 1875, durch das die Befugnis zur Festsetzung von Fluchtlinien von den Polizeibehörden ${ }^{322}$ auf die Gemeinden übertragen wurde, sich also von einem polizeirechtlichen Instrument zum Vorläufer moderner gemeindlicher Bauleitplanung entwickelte ${ }^{323}$. Auch heute bildet die Planung von öffentlichen Verkehrsflächen eine wichtige Aufgabe der gemeindlichen Bauleitplanung ${ }^{324}$. Die Errichtung von Erschließungsanlagen setzt nach § 125 Abs. 1 BauGB sogar zwingend den Erlaß eines Bebauungsplans voraus. Wenn niemand mehr davon ausgeht, daß alleine mit der Festsetzung von Straßenflächen sich die bauliche Entwicklung im Gemeindegebiet angemessen lenken läßt, sondern neben anderen Planungsinstrumenten vor allem $\S 9$ Abs. 1 BauGB eine Fülle von anderen Festsetzungsmöglichkeiten vorsieht, so ist auch dies eine Erfahrung der aus einer reinen Straßenplanung resultierenden Fehlentwicklungen. Denn eine städtebauliche Planung, die sich auf die Festlegung von Verkehrsflächen und damit auf das Baureifmachen von Grundstücken beschränkt ${ }^{325}$, zeigte sich nicht in der Lage, die aus Überbetonung der Baufreiheit, fortschreitender Industrialisierung und zügellosen Stadterweiterungen folgenden städtebaulichen Mißstände wirksam zu bekämpfen ${ }^{326}$, etwa die Entstehung der Mietskasernen mit schlecht belichteten und schlecht belüfteten sowie zu engen Wohnungen, die unter anderem für den mangelhaften gesundheitlichen $\mathrm{Zu}$ -

${ }^{321}$ Baumeister, S. 75; Schmidt-Aßmann, Grundfragen, S. 24. Ausführlich zur historischen Entwicklung des Städtebaurechts ders., Grundfragen, S. 8 ff.

${ }^{322} \mathrm{Zu}$ Rechtsgrundlagen und Verfahren siehe Otto Meyer / Saß, S. 17.

${ }^{323}$ Kalusche, S. 143; Ernst, BBauBI. 1953, S. 210; Schrödter, DVBI. 1975, S. 850; Albers, S. 194; Ronellenfitsch, S. 29; Matzerath / Thienel, in: Die Verwaltung 10 (1977), S. 177.

${ }^{324}$ Siehe $\$ 9$ Abs. 1 Nr. 11 BauGB.

${ }^{325}$ Kabel, S. 166.

${ }^{326}$ Obwohl eine Pflicht zur Berücksichtigung einer Reihe sozialer Belange wie heute nach $\S 1$ Abs. 5 BauGB bestand, siehe $\S 3$ Abs. 2 und 3 des PreuBischen Baufluchtliniengesetzes i. d. F. des Wohnungsgesetzes, vgl. Saran, S. 85 f. Im übrigen siehe auch Püttner, HbKWP, Band 3, S. 317; Gaentzsch, HbKWP, Band 3, S. 365; Berg, in: Deutsche Verwaltungsgeschichte, Band IV, S. 432. 
stand der Bevölkerung verantwortlich gemacht wurden ${ }^{327}$. Ein weiterer sich ergebender Mißstand war das "willkürliche Durcheinander von Wohnhäusern und Fabriken", das nicht nur ebenfalls gesundheitliche Schäden bei den Anwohnern hervorrief, sondern auch die Gewerbebetriebe in ihrer weiteren Entwicklung behinderte ${ }^{328}$. Die willkürliche Zulassung von Mietskasernen förderte zudem auch die Bodenspekulation ${ }^{329}$.

Solche Mißstände forderten umfassendere planerische Maßnahmen als sie nach dem Instrumentarium der Fluchtliniengesetze möglich waren. Die weitere gesetzliche Entwicklung kennzeichnete sich daher dadurch, daß man versuchte, über die Veränderung und vor allem die Verfeinerung und Ergänzung der Planungsinstrumente die private Baufreiheit als Hauptursache der Mißstände einzuschränken und zu kanalisieren ${ }^{330}$. Als besonders notwendig erwies es sich, Art und Maß der baulichen Nutzung der Grundstücke zu lenken ${ }^{331}$. So schuf man zur Regelung der Art der baulichen Nutzung sog. Bauzonenpläne ${ }^{332}$, wie etwa die Verordnung der Stadt Frankfurt/Main "betreffend das Bauen in der Außenstadt" vom 17.10.1881, die zwischen "Wohnvierteln" ( 2 Nr. 2), "Fabrikvierteln" (§ 2 Nr. 3) und "gemischten Vierteln" (§ 2 Nr. 4) unterschied ${ }^{333}$. Dabei mußte man vor allem im preußischen Rechtsbereich als Rechtsgrundlage zunächst auf das Polizeirecht zurückgreifen, nämlich auf $\S 10$ II $17 \mathrm{ALR}^{334}$. Erst später wurden insoweit ausdrückliche gesetzliche Ermächtigungen erlassen ${ }^{335}$, da vor allem wegen der restriktiven Interpretation der polizeirechtlichen Generalklausel durch die Rechtsprechung des PrOVG ("Kreuzberg-Urteil") eine wirkliche städtebauliche Gestaltung nicht möglich war. Desgleichen wurde auch die Einschränkung des Maßes der baulichen Nutzung zunächst aufgrund der allgemeinen

${ }^{327}$ Siehe vor allem die Angaben bei Baumeister, S. 12 ff. Weiterhin Rodriguez-Lores, Stadthygiene, S. 41; Albers, Stadtplanung, S. 30.

${ }^{328}$ Kabel, S. 67.

${ }^{329}$ Baltz / Fischer, S. 233.

${ }^{330}$ Rodriguez-Lores / Fehl, S. 542.

${ }^{331}$ Kalusche, S. 158.

${ }^{332} \mathrm{Zu}$ gleichbedeutenden Begriffen siehe Kabel, S. 148.

${ }^{333}$ Die Verordnung ist abgedruckt bei Rodriguez-Lores / Fehl, S. $247 \mathrm{ff}$.

${ }^{334}$ Kabel, S. 148; Schmidt-Aßmann, Grundfragen, S. $28 \mathrm{ff}$.

${ }^{335}$ Vor allem zu nennen ist Art. 4 S. 1 Nr. 1 des Preußischen WohnungsG, PrGS Nr. 9 vom 28.03.1918, S. 23 f. Dabei handelte es sich jedoch nach wie vor um eine Aufgabe der Baupolizei. Die städtebaulichen Instrumente lagen also nicht einheitlich bei den Gemeinden. Siehe Schultze, S. 62. 
polizeilichen Generalklausel durchgeführt, bis auch hier spezialgesetzliche Ermächtigungen erlassen wurden ${ }^{336}$.

Eine wesentliche Erkenntnis aus der historischen Entwicklung ist es somit, da $\beta$ die Lenkung der baulichen Entwicklung die Möglichkeit voraussetzt, ungezügelte Baufreiheit zu verhindern und die Bautätigkeit aktiv zu lenken. Allein ein punktuelles Einschreiten gegen städtebauliche Mißstände konnte jedoch nicht zum Erfolg führen. Vielmehr setzte sich mehr und mehr die Erkenntnis durch, daß es sich bei der Lenkung der städtebaulichen Entwicklung um eine einheitliche Aufgabe handelt, daß nur die Behandlung der auftauchenden Probleme aus einer Gesamtschau heraus einen befriedigenden Ausgleich der vielseitigen Anforderungen verspricht, die eine geordnete städtebauliche Entwicklung fordert ${ }^{337}$. Daraus folgen im Grundsatz zwei Notwendigkeiten, und zwar zum einen eine Kodifizierung der verschiedenen städtebaulichen Instrumentarien wie Bauleitplanung, Umlegung und Enteignung $^{338}$, zum anderen überhaupt ein Planungsinstrumentarium zu schaffen, das im Sinne einer Gesamtschau die sich gegenseitig überlappenden und sich bedingenden Probleme einer Lösung zuführen kann. Ergebnis der Erkenntnis über die Notwendigkeit einer Gesamtbetrachtung ist etwa die Entwicklung einer zweiteiligen Planung, also einer Gesamtplanung ähnlich der Flächennutzungsplanung nach dem BauGB ("Generalbebauungsplan", "Flächenaufteilungsplan") und einer darauf aufbauenden Einzelplanung ${ }^{339}$.

Eine besonders bemerkenswerte gesetzgeberische Leistung ist in diesem Sinne das Allgemeine Baugesetz für das Königreich Sachsen vom 1. Juli 1900. In ihm kommt es sowohl zu einer Zusammenfassung des Rechtsstoffes als auch zur Entwicklung einer Bauleitplanung mit erstaunlich modernen $Z_{\text {Zügen }}{ }^{340}$. So werden nach $\S 16$ dieses Gesetzes Dinge durch Bebauungsplan geregelt, die auch heute zu den Essentialia der Bauleitplanung gehören, wie etwa die Festlegung der Straßen- und Bauflächen, der Gebäudehöhe, der

${ }^{336}$ Vor allem Art. $4 \S 1$ Nr. 2 PreuBisches WohnungsG. Siehe Kabel, S. 148; Kalusche, S. 164.

337 Zinkahn, in: Ernst / Zinkahn / Bielenberg, Einl., Rn. 11, spricht von der "Sicht der Einheit der städtebaulichen Aufgaben", Kabel, S. 165, von "Einheit des Städtebaus". Siehe auch Matzerath / Thienel, Die Verwaltung 10 (1977), S. 178.

${ }^{338}$ Die Zusammenfassung der rechtlichen Grundlagen des Städtebaus war auch einer der maßgeblichen Gründe für die Schaffung des BauGB. Siehe Schlichter, Berliner Kommentar, Einf., Rn. 33.

339 Albers, AfK 1967, S. 198. Einzelheiten bei Kabel, S. 128 ff.

${ }^{340}$ Breuer, Städtebaureform, S. 512 f.; Groschupf, DVBI. 1975, S. 874; Schlichter, Berliner Kommentar, Einf. Rn. 5, bescheinigt diesem Gesetz den für die damalige Zeit höchsten Entwicklungsstand. Ebenso Schmidt-Aßmann, Grundfragen, S. 30. 
Bauweise oder der Zulässigkeit von Gewerbeanlagen, also der Art der baulichen Nutzung ${ }^{341}$. Auch das Preußische WohnungsG von 1918 löste sich von der reinen Straßenplanung und schuf sowohl eine gewisse Zusammenfassung der städtebaulichen Instrumente als auch ein dem sächsischen Gesetz ähnliches Planungsinstrumentarium ${ }^{342}$.

Solche Gesetzeskodifikationen waren die Voraussetzung für die Schaffung von Plänen als Instrumente eines umfassenden Interessenausgleichs. Solange von einem Gesetz nur einzelne städtebauliche Mißstände bekämpft wurden, fehlte notwendigerweise eine Orientierung an einer Gesamtkonzeption. Daß gerade im Sächsischen Baugesetzbuch und im Preußischen Wohnungsgeset $z$ der heutigen Bauleitplanung vergleichbare Instrumente geschaffen wurden, hängt somit damit zusammen, daß durch diese Gesetze mehr als nur eine Teillösung städtebaulicher Probleme zumindest im Grundsatz angestrebt wurde. Ein weiterer wichtiger Vorläufer für das 1960 in kraft getretene BBauG ist schließlich die BauregelungsVO vom 15.Februar $1936^{343}$. Die dort getroffenen Regelungen ähneln in weitem Umfang den Bestimmungen der heutigen BauNVO und zum Teil dem heutigen BauGB $^{344}$.

Zusammenfassend läßt sich die geschichtliche Entwicklung des Bauplanungsrecht in dem hier interessierenden Zusammenhang beschreiben als eine Materie, die sich aus dem Polizeirecht heraus über städtebauliche Einzelregelungen entwickelt hat zu einem kodifizierten Planungsinstrumentarium zur umfassenden Lösung städtebaulicher Probleme $e^{345}$. Für die Auslegung der Kompetenz "Bodenrecht" des Art. 74 Nr. 18 GG hat dies folgende Konsequenz: Die entscheidende Passage im Baurechtsgutachten des BVerfG ist nicht die vielzitierte Unmittelbarkeitsformel, sondern die Tatsache, daß das Bodenrecht vor allem Planungsrecht ist ${ }^{346}$. Das Planungsrecht auf dem Gebiet des Baurechts kennzeichnet sich in seiner historischen

${ }^{341}$ Der Gesetzestext ist abgedruckt bei Rodriguez-Lores / Fehl, S. $258 \mathrm{ff}$.

342 Albers, AfK 1967, S. 195. Siehe Art. $4 \S 1$ PrWoG. Ausführlich Schmidt-Aßmann, Grundfragen, S. $34 \mathrm{ff}$.

${ }^{343}$ RGBI I, S. 104.

${ }^{344}$ So entspricht etwa $\S 1$ Abs. 1 und 2 mit der dort vorgesehenen Möglichkeit, bestimmte Baugebiete durch BaupolizeiVO als Wohn-, Kleinsiedlungs-, Geschäfts- oder Gewerbegebiete auszuweisen, in ihrer Grundidee den $\S 1$ Abs. 2, 2 ff. BauNVO. $§ 2$ Abs. 1 BauregelungsVO entspricht §§ 16, 17 BauNVO, § 3 BauregelungsVO dem § 35 BauGB.

345 Ähnlich auch Schmidt-Aßmann, Grundfragen, S. 60.

${ }^{346}$ BVerfGE 3, 432. In diese Richtung argumentiert auch Stich, in: Neues Städtebaurecht, S. 125 . 
Entwicklung dadurch, daß den Gemeinden Planungsinstrumente in die Hand gegeben werden müssen, die diese benötigen, um städtebauliche Mißstände zu verhindern oder - mit positivem Akzent formuliert - um die städtebauliche Entwicklung zu ordnen. Der Art. 74 Nr. 18 GG läßt sich nun nicht dahingehend verstehen, $\mathrm{da} B$ er den Bestand an Planungsinstrumenten festlegt, die sich bis dahin als notwendig erwiesen hatten. Zwar sind solche planerischen Festsetzungsmöglichkeiten auf jeden Fall von der Baurechtskompetenz umfaßt. Der Bundesgesetzgeber ist aber zu einer weiteren gesetzgeberischen Regelung auf dem Gebiet des Bauwesens befugt, als die Notwendigkeit reicht, den Planungsträgern die notwendigen Befugnisse einzuräumen. Die Frage, welche Instrumente den Gemeinden zur Verfügung stehen müssen, läßt sich dabei nicht ein für alle Mal festlegen. Es handelt sich vielmehr um einen dauernden Entwicklungsprozeß aufgrund ständig sich wandelnder Gegebenheiten und Verhältnisse ${ }^{347}$. Der Bundesgesetzgeber darf den Gemeinden solche Befugnisse an die Hand geben, die diese benötigen, um ihrer Gesamtverantwortung für die Ordnung der baulichen Entwicklung des Gemeindegebietes gerecht zu werden. Soweit gesetzgeberische Maßnahmen in diesem Sinne einen städtebaulichen Bezug haben, können sie auch in Bereiche eingreifen, die wie bei den Stadterhaltungssatzungen den Ländern obliegen. Die Kompetenz "Bodenrecht" umfaßt also das Planungsrecht, das erforderlich ist, um eine geordnete städtebauliche Entwicklung zu garantieren.

ee) Konkretisienung der aufgrund der Bodenrechtskompetenz zulässigen Festsetzungen

Wenn die Planungsinstrumentarien von der Bodenrechtskompetenz umfaßt sind, die der jeweilige Planungsträger benötigt, um der Gesamtverantwortung für die bauliche Entwicklung im Gemeindegebiet gerecht zu werden, dann ist diese Kompetenz nicht nur final mit Bezug auf die geordnete städtebauliche Entwicklung, sondern auch instrumental, also objektiv zu interpretieren. Diese Konzeption spiegelt sich auch im BauGB wider. Eine restriktive Interpretation der in $\S 1$ Abs. 5 BauGB genannten Belange und damit eine Einschränkung der potentiellen Ziele der Bauleitplanung ist wie gesehen - nicht möglich. Dementsprechend ist die Aufzählung der öffentlichen Belange in $\S 1$ Abs. 5 BauGB nicht abschließend. Abschließend

347 Siehe auch Oskar Schneider, S. 20: Geänderte gesellschaftliche Aufgabenstellungen erfordern von Zeit zu Zeit eine Überprüfung der gesetzlichen Grundlagen. 
ist - neben den anderen Bestimmungen des BauGB, die eine nach außen verbindliche Festlegung zulassen - aber der Katalog des § 9 Abs. 1 BauGB. Diese Vorschriften sind die eigentliche und wesentliche Schranke dafür, daß sich die Gemeinde nicht in Dinge "einmischt", in die sie sich nicht einmischen soll. Die Frage, zu welchen nach außen verbindlichen Festsetzungen der Bundesgesetzgeber die Gemeinden ermächtigen darf, ist damit doch der entscheidende Ansatz für die Auslegung der Bodenrechtskompetenz aus Art. 74 Nr. 18 GG.

Es fragt sich somit, wann davon auszugehen ist, daß die Gemeinden eine bestimmte Festsetzungsmöglichkeit "benötigen". Legt man hierbei die historische Entwicklung mit zugrunde, so lassen sich für ein "Benötigen" in diesem Sinne kumulativ erforderliche Kriterien nennen:

1. Die fragliche Festsetzung muß einen spezifischen Bezug zur Nutzung von Grund und Boden haben.

2. Der von der Festsetzung positiv oder negativ betroffene Belang muß in einem Spannungsverhältnis mit anderen Belangen stehen, die ebenfalls Anforderungen an eine bestimmte Nutzung von Grund und Boden stellen und deshalb einen planerischen Interessenausgleich verlangen.

Das erste Erfordernis ergibt sich teilweise bereits aus dem Wortlaut des Art. 74 Nr. 18 GG. "Bodenrecht" kann nur etwas sein, was Bezug zu Grund und Boden hat. Es muß also auf jeden Fall Raumbedeutsamkeit im Sinne der Inanspruchnahme von Grund und Boden vorliegen ${ }^{348}$. Ein solcher Bezug muß in dem Sinne spezifisch sein, daß entschieden wird, ob und in welcher Weise der Boden an einer bestimmten Stelle genutzt werden darf, nicht ob die Nutzung von Grund und Boden überhaupt, unabhängig von der örtlichen Situation zulässig ist oder nicht. Daher fallen unter die Bodenrechtskompetenz nur solche Festsetzungen, deren Notwendigkeit sich nach der Konzeption des Gesetzgebers typischerweise aus der besonderen örtlichen Situation ergeben sollen. Alle Bestimmungen in den Landesbauordnungen, die Anforderungen ohne Rücksicht auf den konkreten Einzelfall an alle Gebäude oder an alle Gebäude einer bestimmten Art oder in einem bestimmten Gebiet stellen, könnten aufgrund der Bodenrechtskompetenz nicht erlassen werden. Dies gilt solange, bis der Bundesgesetzgeber die Entscheidung trifft, $\mathrm{da}$ eine generelle Regelung nicht nötig ist. Entscheidend ist also der Bezug zu einer konkreten örtlichen Situation. Nur soweit örtliche Besonderheiten

${ }^{348}$ Vgl. $\$ 3$ Abs. 1 ROG. 
denkbar sind, die das genaue Maß der zu stellenden Anforderungen bestimmen, darf der Bundesgesetzgeber aufgrund der Baurechtskompetenz den Gemeinden eine entsprechende Festsetzungsmöglichkeit einräumen. Würde etwa der Gesetzgeber die Gemeinden ermächtigen, z. B. Spielhallen ohne konkreten örtlichen Anlaß aus dem Gemeindegebiet herauszuplanen, wäre dies von der Kompetenz "Bodenrecht" nicht gedeckt. Ein Bezug zur Nutzung von Grund und Boden liegt nicht schon dann vor, wenn für eine Tätigkeit überhaupt Grund und Boden benötigt wird, weil dann letztlich jede Tätigkeit erfaßt würde. Er ist nur dann gegeben, wenn es um die Tätigkeit deshalb geht, weil sie an einer bestimmten Stelle ausgeführt werden soll und sich hierfür spezifische Gründe nennen lassen.

Die in $\S 9$ Abs. 1 BauGB aufgeführten Festsetzungsmöglichkeiten erfüllen in der Regel dieses Kriterium. Auch die $\S \S 172 \mathrm{ff}$. BauGB haben in diesem Sinne einen Bezug zu Grund und Boden. "Nutzung" ist auch die Nutzung des Bodens durch das Gebäude, das gerade an der betreffenden Stelle steht. Unter dieses erste allgemeine Kriterium fallen aber auch alle die Festsetzungen, die üblicherweise in örtlichen Bauvorschriften getroffen werden. Auch die Frage, ob man ein geneigtes oder ein Flachdach errichten darf oder ob das Haus weiß oder gelb zu streichen ist, regelt das Wie der Nutzung von Grund und Boden.

Das zweite Erfordernis ergibt sich aus der Notwendigkeit einer gesamtheitlichen Sicht der städtebaulichen Entwicklung und der Abgrenzung zu Kompetenzen, die ebenfalls die Nutzung von Grund und Boden an einer bestimmten Stelle betreffen, aber trotzdem nicht unter das Bodenrecht fallen. Die Schaffung einer städtebaulichen Festsetzungsmöglichkeit setzt voraus, daß die fragliche Festsetzung Rückwirkung auf die Verfolgung anderer Belange hat, die mit einer bestimmten Bodennutzung an einer bestimmten Stelle zusammenhängen, daß also typischerweise eine Vernetzung mit anderen Belangen vorliegt, und zwar in der Weise, daß nicht - wie etwa bei einer Ermessensausübung - das pro und contra abgewogen und danach entschieden werden soll, sondern daß nach der Entscheidung für die Festsetzung in der Regel andere Festsetzungen erforderlich werden, um die $\mathrm{Zu}$ rückstellung der Belange zu kompensieren oder um die Festsetzung überhaupt wirksam werden zu lassen und somit planerisch abzusichern. Gerade für die Bauleitplanung trifft das zu, was teilweise als wesentliches Merkmal eines Plans überhaupt angesehen wird: Eine Reihe von Maßnahmen sind nötig, die zueinander in einem unlösbaren Verhältnis gegenseitiger Ergänzung und Abhängigkeit stehen; die verschiedenen Maßnahmen gewährleisten den gewünschten Erfolg nur durch ihr Zusammenwirken, sie sind der- 
art aufeinander angewiesen, daß die Änderung oder der Wegfall einer Maßnahme eine Kettenreaktion auslöst, die die gesamte Konzeption in Frage stellt ${ }^{349}$; eine Teilregelung der betreffenden Frage durch eine andere Stelle oder durch dieselbe Stelle in einem anderen Verfahren erscheint nicht sinnvoll.

Aus dem Erfordernis, dem zuständigen örtlichen Planungsträger ein angemessenes Instrumentarium zur Beplanung des Bodens aufgrund der spezifischen örtlichen Situation zu geben, rechtfertigen sich also bundesrechtliche Satzungs- und Festsetzungsermächtigungen an die Gemeinde. In ähnliche Richtung scheint auch das BVerwG zu tendieren. In bezug auf Stadterhaltungssatzungen geht es davon aus, daß das Bodenrecht insoweit "die zu erhaltenden baulichen Anlagen in ihrer Beziehung zur aktuellen Stadtstruktur und ihrer stadträumlichen Funktion für das gegenwärtige Zusammenleben der Menschen" in den Blick nähme ${ }^{350}$. Dies ist zwar eher eine Beschreibung des Instruments der Stadterhaltungssatzungen als eine Begründung ihrer Verfassungsmäßigkeit. Die Formulierung zeigt aber, daß nach Auffassung des BVerwG das kompetenzrechtlich wesentliche Merkmal darin zu sehen ist, daß aufgrund der vielseitigen Wirkungen auf die Gesamtsituation der städtebaulichen Entwicklung auch die Erhaltung von baulichen Anlagen unter die Bodenrechtskompetenz fällt. Denn oft kommt eine wirkliche Erhaltung nur dann zustande, wenn es durch eine Reihe von ergänzenden Maßnahmen, wie etwa der Zuweisung einer den heutigen wirtschaftlichen und sozialen Anforderungen entsprechenden Nutzung, zu einer Refunktionalisierung alter Stadtgebiete kommt ${ }^{351}$.

Greift man sich als Beispiel den $\S 172$ Abs. 3 BauGB heraus, so ist es kompetenzrechtlich folgerichtig und notwendig, die Versagung der Genehmigung von bestimmten Voraussetzungen abhängig zu machen, die es der Gemeinde verwehren, "Denkmalschutz an sich" zu betreiben ${ }^{352}$. Denn die Erhaltung einer im denkmalschutzrechtlichen Sinne erhaltungswürdigen

349 Obermayer, VVDStRL 18 (1960), S. 149, ders., Allgemeines Verwaltungsrecht, S. 195; Badura, Festschrift BayVerfGH, S. 179; BVerwG, Urteil vom 30.04.1969, Buchh. 407.4, § 17 FStrG, Nr. 12 S. $6(10)=$ NJW 1969, S. 1868 (1869). Damit soll nicht gesagt sein, daß diese Formel als allgemeine Plandefinition geeignet ist. Zu den Schwierigkeiten bei der begrifflichen Umschreibung von "Planung" siehe Hoppe, Festgabe für von Unruh, S. 557.

350 BVerwG, Urteil vom 03.07.1987, NVwZ 1988, S. 357 (359). Ähnlich auch Watzke, Denkmalschutz- und Stadtplanungsrecht, S. 104 f.; Gaentzsch, ZSSD 1974, S. 278.

${ }^{351}$ Hoppe, Gedächtnisschrift für Klein, S. 195; Watzke, Denkmalschutz- und Stadtplanungsrecht, S. 105.

352 BVerwG, NVwZ 1988, S. 359. 
baulichen Anlage festzusetzen, gehört nicht grundsätzlich zum rechtlichen Instrumentarium, das eine Gemeinde braucht, um der Gesamtverantwortung für die städtebauliche Entwicklung gerecht zu werden. Meist handelt es sich nur um einen Konflikt zwischen Eigentümerinteressen und den Belangen des Denkmalschutzes, die im Rahmen einer Ermessensausübung angemessen zum Ausgleich gebracht werden können. Planerische Entscheidungen zur "Abfederung" sind in der Regel nicht erforderlich. Eine "städtebauliche Dimension" wird bei der Frage der Erhaltung einer baulichen Anlage eben nicht immer erreicht. Demgemäß beschränkt § 172 Abs. 3 BauGB die Versagung der Genehmigung auf Fälle mit städtebaulichem Gesamtbezug.

Neben der Bereitstellung des eigentlichen Planungsinstrumentariums wird man es dem Bundesgesetzgeber im Rahmen seiner Planungsrechtskompetenz zubilligen können, wie in den $\S 29 \mathrm{ff}$. BauGB Planersatzmaßstäbe bis zur rechtsverbindlichen Aufstellung von Bebauungsplänen vorzusehen oder in $\S 14 \mathrm{ff}$. und $\S 19 \mathrm{ff}$. BauGB Sicherungsinstrumente für die Bauleitplanung einzuführen. Das, was an Planungsinstumentarien notwendig ist, gibt dabei den äußeren Rahmen für Hilfsinstrumente und Planersatzmaßstäbe. Wenn also etwa in $\S 34$ Abs. 1 S. 2 2. HS BauGB eine Nichtbeeinträchtigung des Ortsbildes verlangt wird, so folgt bereits aus der Akzessorietät zur Planungskompetenz eine Beschränkung auf solche Merkmale einer baulichen Anlage, die auch vom $\S 9$ Abs. 1 BauGB erfaßt werden ${ }^{353}$.

Sind die zulässigen Festsetzungen vom Bundesgesetzgeber normiert, hat schließlich auch die finale Abgrenzung zwischen Bundesrecht und Landesrecht wieder einen gewissen Sinn ${ }^{354}$. Zwar dient auch die Bauleitplanung den Interessen der öffentlichen Sicherheit und Ordnung. Trotzdem hat das BVerfG Recht, wenn es neben $\S 19$ ff. BáuGB landesrechtliche Teilungsgenehmigungen für zulässig hält ${ }^{355}$. Dies läßt sich zwar nicht damit begründen, daß das Bauordnungsrecht dem Schutz von Sicherheit und Ordnung dient, weil das beim Bauplanungsrecht auch der Fall ist. Bei dem Instrument der Teilungsgenehmigung handelt es sich aber um ein Sicherungsinstrument zur Verwirklichung der eigentlichen Festsetzungsmöglichkeiten oder der Anforderungen des betreffenden Gesetzes. Und dieses Regelungsziel ist bei Bauordnungs- und Bauplanungsrecht verschieden.

${ }^{353}$ So auch OVG Berlin, Urteil vom 03.07.1981, BRS Band 38, Nr. 71; Dyong, in: Ernst / Zinkahn / Bielenberg, § 34 BauGB, Rn. 77.

${ }^{354}$ Siehe oben A II 3 a.

${ }^{355}$ BVerfG, Beschluß vom 28.10.1975, E 40, 261 ff. 


\section{III. Übertragung des gefundenen Ergebnisses auf die Kollisionsprobleme bei örtlichen Bauvorschriften}

\section{Probleme bei den "baugestalterischen Vorschriften"}

a) Die Verfolgung "städtebaulicher" Absichten

Art. 91 Abs. 1 Nr. 1 BayBauO und $\S 56$ NBauO ermächtigen die Gemeinden zum Erlaß von Vorschriften zur Verwirklichung von "städtebaulichen" Absichten. Die kompetenzrechtlichen Bedenken gegen diese Begriffsbildung, die bis zu dem Versuch führten, den Begriff verfassungskonform im Sinne von "baugestalterischen" Absichten zu interpretieren ${ }^{356}$, sind unangebracht. Zwar verweist der Begriff "städtebaulich" auf den Begriff "Städtebaurecht" und damit auf die Kompetenz Bodenrecht des Art. $74 \mathrm{Nr}$. 18 GG. Die im "Städtebaurecht" verfolgten Belange sind jedoch deshalb, weil die abwägungserheblichen Belange auch mögliche Zielsetzungen der Bauleitplanung sind ${ }^{357}$, von einer derartigen Weite, daß ihnen keinerlei Exklusivwirkung zukommen kann. Ansonsten gäbe es fast überhaupt keine Belange mehr, die zulässigerweise in Landesgesetzen noch verfolgt werden könnten.

Die Interpretation des Merkmals "städtebauliche Absichten" wird also mit einem kompetenzrechtlichen Scheinproblem belastet. Die Auslegung kann erfolgen, ohne Rücksicht darauf zu nehmen, ob und inwieweit ähnliche Absichten auch im Bauplanungsrecht verfolgt werden können. Im Gegensatz zu einer verfassungskonformen Interpretation des Merkmals "städtebauliche Absichten" im Sinne von "baugestalterische Absichten" dürfte es vielmehr richtig sein, den Begriff der "baugestalterischen Absichten" im Sinne von "städtebauliche Absichten" zu verstehen ${ }^{338}$. Daß die unterschiedlichen Formulierungen etwas Unterschiedliches bedeuten sollen, ist ohnehin nicht erkennbar $^{399}$. Interpretiert man den Begriff der "baugestalterischen" Absicht im Sinne von "städtebauliche Absicht" und versteht man diesen Begriff wie im BauGB, so vermeidet man auch ein Ergebnis, wie es das OVG Lüneburg

\footnotetext{
${ }^{356}$ Siehe Koch / Molodovsky / Rahm, Art. 91 Anm. 2.2; Seybold, S. 35.

357 Siehe oben A II 3 c cc (1).

${ }^{358} \mathrm{Vgl}$. oben A I 2 a bb.

${ }^{359}$ Ebenda.
} 
in einer Flachdachentscheidung gewonnen hat ${ }^{360}, \mathrm{da}$ nämlich die Änderung einer örtlichen Bauvorschrift nichtig sein soll, wenn sie maßgeblich veranlaßt war durch die Tatsache, daß die vorgeschriebenen Flachdächer undicht waren, und nicht durch ein "gestalterisches" Anliegen. Es ist wenig überzeugend, wenn eine örtliche Bauvorschrift dann geändert werden kann, wenn die Mehrheit im Gemeinderat Spitzdächer "schöner" findet als Flachdächer, aber nicht dann, wenn die Flachdachkonstruktionen Gefahren für Eigentum und Gesundheit der Bewohner herbeiführen und die Änderung deshalb erfolgen soll.

Von der Planungspraxis wird Stadtplanung auch keinesfalls nur als künstlerische Aufgabe verstanden. Stadtästhetik soll keine schöne Zutat oder Umweltkosmetik sein, sondern aufgrund der psychischen Wirkungen der Stadtgestalt der Verfolgung essentieller menschlicher Interessen dienen $^{361}$. Auch hierzu würde sich ein merkwürdiger Kontrast ergeben, wenn man es für zulässig halten würde, eine örtliche Bauvorschrift zu ändern wegen oft wohl mehr vermuteten als erwiesenen psychischen Wirkungen ${ }^{362}$, nicht aber bei effektiv drohenden Gesundheits- oder Vermögensschäden. Eine solche Auffassung fördert zudem eine Tendenz zur Unehrlichkeit bei der Satzungsbegründung. Zum anderen trifft auch die Gemeinde vor allem aus Art. 2 Abs. 2 S. 1 GG, aber auch aus Art. 14 GG eine Schutzpflicht für grundrechtlich geschützte Rechtsgüter. Auch dieser Zusammenhang legt es nahe, den Begriff "baugestalterische Absichten" im Sinne von "städtebauliche Absichten", also entsprechend der Formulierung in der Bayerischen Bauordnung zu verstehen. Was schließlich die Begründung von Antennenverboten aus anderen als gestalterischen Anliegen betrifft ${ }^{363}$, so ist die $\mathrm{Be}$ schränkung des Grundrechts aus Art. 5 Abs. 1 S. 12 . HS GG (Informationsfreiheit) aus finanziellen oder medienpolitischen Gründen abwägungsfehlerhaft ${ }^{364}$ und zwingt ebenfalls nicht zur Beschränkung des Regelungsziels örtlicher Bauvorschriften auf rein optische Belange.

Die Zulässigkeit der Änderung einer Satzung über örtliche Bauvorschriften aus Gründen des Gesundheits- oder Eigentumsschutzes läßt sich

360 OVG Lüneburg, Beschluß vom 30.06.1987, BauR 1988, S. 309. Wie das OVG allerdings auch Moench / Schmidt, S. 35; Büge / Zinkahn, S. 34; Lerche, Beilage Nr. 6 DB 1969, S.9.

${ }^{361}$ Trieb, Stadtgestaltung, S. 38.

${ }^{362}$ Siehe Trieb, Stadtgestaltung, S. 47: Anwendung von im wesentlichen empirischen Theorien von nur relativem Wahrheitsgehalt.

${ }^{363}$ Vgl. Hermann, S. 38.

${ }^{364}$ Ausführlich dazu Hermann, S. 68 ff. 
schließlich auch nicht mit dem Argument in Frage stellen, angesichts der gesetzlichen Anforderungen an die Sicherheit von Bauwerken in den Landesbauordnungen sei nur die Berücksichtigung gestalterischer Ziele sinnvoll ${ }^{365}$. Das, was häufig als nur gestalterische Regelung verstanden wird, tangiert wie das Beispiel der Flachdachfestlegungen zeigt - oft ganz erheblich auch andere Belange, die dementsprechende Berücksichtigung verlangen. Soweit also die Gemeinden Festsetzungen in örtlichen Bauvorschriften ändern wollen, in denen Flachdächer vorgesehen sind, kann diese Änderung grundsätzlich auch damit begründet werden, die gängigen Flachdachkonstruktionen hätten sich als untauglich erwiesen und dies führe zu Gefahren für grundrechtlich geschützte Güter der Bewohner.

Nicht zu folgen ist dem OVG Lüneburg auch darin, daß die Gemeinden beim Erlaß von baugestalterischen Vorschriften daran gehindert seien, "global" auf den Gebietscharakter einzuwirken ${ }^{366}$. Diese Unterscheidung ist zum einen nicht durchführbar ${ }^{367}$. Der verfassungsrechtliche Grund, der das OVG zu dieser Unterscheidung geführt hat, existiert zudem nicht. Die "globale Gestaltung" ist keine domaine reservée des Städtebaurechts. Zwar darf die Gemeinde auch auf dem Weg der Bauleitplanung Festsetzungen treffen, die zu einer bestimmten Gestaltung des Gemeindegebietes führen. Dieses Recht zur Gestaltung findet aber seine Grenzen in den möglichen Festsetzungen, die der Bundesgesetzgeber den Gemeinden eingeräumt hat. Da zudem die auch im Städtebaurecht verfolgten Zwecke keine Ausschlußwirkung haben können, steht es kompetenzrechtlich somit dem Landesgesetzgeber frei, den Gemeinden Gestaltungsmöglichkeiten einzuräumen, die ihnen das Bundesrecht nicht ermöglicht.

\section{b) Überschneidungen von möglichen Festsetzungen}

Insbesondere die Festlegung der Firstrichtung hat sich als Einordnungsproblem insoweit erwiesen, als sowohl eine Festsetzung im Bebauungsplan aufgrund des $\S 9$ Abs. 1 Nr. 2 BauGB für möglich gehalten wird, als auch eine Festsetzung in örtlichen Bauvorschriften ${ }^{368}$. Während Überschneidungen der Regelungsziele grundsätzlich unproblematisch sind, sind den bau-

\footnotetext{
${ }^{365}$ In diese Richtung Lerche, Beilage DB Nr. 6 1969, S. 9.

${ }^{366}$ OVG Lüneburg, Urteil vom 10.10.1982, DÖV 1983, S. 387 (388).

${ }^{367}$ Siehe oben A II 3 b.

${ }^{368}$ Siehe oben A I 2 a cc.
} 
planungsrechtlichen Festsetzungsmöglichkeiten entsprechende Festsetzungen auf landesrechtlicher Grundlage unzulässig. Wenn der Bundesgesetzgeber sich für die Möglichkeit einer Festsetzung in einem städtebaulichen Plan entschieden hat, entfaltet dies Sperrwirkung. Die Bestimmung kann dann nur in einem Bebauungsplan getroffen werden, soweit nicht die Vorschrift des BauGB selbst einen Vorrang zugunsten anderer Regelungsmöglichkeiten enthält ${ }^{369}$, oder sonst zu erkennen gibt, daß sie einen Vorrang des Landesrechts anerkennt, wie z. B. die Einschränkung von Stellplätzen in $\S 12$ Abs. 6 BauNVO $^{370}$.

Der Bundesgesetzgeber darf allerdings eine Festsetzungsmöglichkeit nur dann vorsehen, wenn sie aufgrund einer planerischen Konzeption erfolgen soll. Entscheidet er sich für eine solche Notwendigkeit, müssen aber grundsätzlich auch die vorgesehenen Verfahrensvorschriften eingehalten werden, die einen entsprechenden Interessenausgleich gewährleisten ${ }^{371}$. Gerade die Notwendigkeit eines solchen Interessenausgleichs ist es, die den Bundesgesetzgeber zu der entsprechenden Festsetzung legitimiert. Die Festlegung der Firstrichtung in örtlichen Bauvorschriften scheidet also dann aus, wenn der Bundesgesetzgeber zulässigerweise eine Festsetzungsmöglichkeit nach $\S 9$ Abs. 1 BauGB vorgesehen hat.

$\mathrm{Da}$ eine Festlegung der Firstrichtung nach § 9 Abs. 1 Nr. 2 BauGB nach überwiegender Ansicht möglich sein soll, wurde bereits ausgeführt ${ }^{372}$. Nach dem hier entwickelten Abgrenzungsmaßstab sprechen gegen eine solche Interpretation keine Bedenken. Die Festlegung der Firstrichtung geschieht häufig in engem Zusammenhang etwa mit den Festsetzungen über Baulinien $^{373}$. Sie ist z. B. dann von Bedeutung, wenn neu zu errichtende Baukörper sich einem historischen Altstadtbild entsprechend einfügen sollen ${ }^{374}$. In gewissem Maße berührt ihre Festlegung zudem nachbarliche Belange, da dadurch auch die Besonnung von Nachbargrundstücken beeinflußt wird. Weiterhin haben auch bauplanerische Festsetzungen eine erhebliche Bedeutung für die angestrebte Stadtgestalt. Die anderen auch für die Stadtgestaltung wichtigen Vorgaben wie Baulinien, Baugrenzen, GFZ, GRZ etc.

\footnotetext{
${ }^{369}$ Ein Beispiel hierfür ist etwa $\$ 9$ Abs. 1 Nr. 16 BauGB.

${ }^{370}$ Dazu siehe oben A I $2 \mathrm{~d}$ bb.

${ }^{371}$ Battis, in: Battis / Krautzberger / Löhr, § 3 Rn. 5 m. w. N.

${ }^{372}$ Siehe oben A I 2 a cc.

${ }^{373}$ Vergleiche die Beispiele bei Heinz, S. 50 ff.

${ }^{374}$ Siehe Heinz, S. 53.
} 
bleiben ohne die Möglichkeit der Festlegung der Firstrichtung möglicherweise unvollständig, soweit mit ihnen - was zulässig ist - eine bestimmte Stadtgestalt durch eine bestimmte Baukörperdimensionierung erstrebt wird $^{375}$.

Es erscheint daher nicht sinnvoll, etwa Baulinien und Geschoßzahl im Bebauungsplan und die Firstrichtung in einem anderen rechtlichen Verfahren festzulegen. Die Festlegung der Firstrichtung ist eine ausgleichs- und ergänzungsbedürftige Maßnahme zu anderen, die bauliche Grundstücksnutzung betreffenden Festsetzungen. Daher kann man ihre Festlegung als ein notwendiges Planungsinstrument für die Bauleitplanung ansehen. Da § 9 Abs. 1 Nr. 2 BauGB sich auch durchaus so auslegen läßt, daß dort auch die Firstrichtung erfaßt ist ${ }^{376}$, ist davon auszugehen, daß die Festsetzung der Firstrichtung aufgrund von $\S 9$ Abs. $1 \mathrm{Nr} .2$ BauGB möglich ist und damit eine Festlegung in örtlichen Bauvorschriften ausscheidet.

Aus den gleichen Gründen ist auch die Festlegung der Gebäudehöhe nur im Bebauungsplan nach $\S 16$ Abs. 3 BauNVO und nicht in einer Satzung über örtliche Bauvorschriften möglich. Noch mehr als bei der Festlegung der Firstrichtung ist hier ein Ausgleich verschiedener Belange nötig, so daß der Bundesgesetzgeber zu Recht eine Festlegung im Wege des Bebauungsplans vorgesehen hat. $\$ 73$ Abs. 1 Nr. 7 LBO BW ist somit unwirksam. Gleiches gilt für die Festlegung der Gebäudetiefe nach $\S 73$ Abs. 1 Nr. 8 LBO BW. Auch hier besteht eine Möglichkeit zur eindeutigen Regelung durch Bebauungsplan $^{37}$.

\section{Probleme bei den denkmalschützenden Vorschriften}

Aufgrund des einfachen Rechts bietet es sich an, örtliche Bauvorschriften und Stadterhaltungssatzungen gegebenenfalls kumulativ einzusetzen, um etwa den optischen Charakter eines Altstadtbereiches zu bewahren ${ }^{378}$. Dieses praktisch sinnvolle Zusammenwirken ist von der Zielrichtung her auch

${ }^{375}$ Zur Bedeutung der Festlegung der Firstrichtung siehe Büge / Zinkahn, S. 38. Ferner RdErl. des Reichsarbeitsministers betr. VO über die Baugestaltung vom 17.12.1936, RArbBl. 1937, S. 4, abgedruckt bei Büge / Zinkahn, S. 142 f., zu $\S 2$ und 3, Abs. 3.

${ }^{376}$ Siehe oben A I 2 a cc.

${ }^{37}$ Vgl. Schlotterbeck, in: Schlotterbeck / von Arnim, $\$ 73$ Rn. 32 und oben A I 2 a cc. 378

Dazu siehe oben A I 2 b cc. 
kompetenzrechtlich möglich. Beide Instrumente können im Sinne einer "globalen" Gestaltung eingesetzt werden ${ }^{379}$.

Im instrumentalen Bereich ergibt sich folgendes Ergebnis: Die $\$ \S 172 \mathrm{ff}$. BauGB reservieren nicht das gesamte Denkmalschutzrecht als notwendiges Planungsinstrumentarium und damit auch als Planungsmasse für die Bauleitplanung. Sie geben der Gemeinde nur die Instrumente in die Hand, die sie im denkmalschutzrechtlichen Bereich benötigt, um ihrer städtebaulichen Gesamtverantwortung gerecht zu werden. Da die Länder eigentlich für den Sachbereich Denkmalschutzrecht zuständig sind, ist es ihnen nicht verwehrt, zur Förderung des öffentlichen Belanges Denkmalschutz weitere rechtliche Instrumentarien zu schaffen. Unproblematisch ist deshalb auch die Vorschrift des $\$ 73$ Abs. 1 Nr. 2 LBO BW, soweit es dort um die Erhaltung schützenswerter Teile einzelner baulicher Anlagen geht. Diese Vorschrift läßt sich verfassungskonform so auslegen, daß sie nur für solche Teile von baulichen Anlagen gilt, die nicht von einer Stadterhaltungssatzung ergriffen werden können. Die Interpretation der Vorschrift in diesem Sinne entspricht auch dem Willen des Gesetzgebers ${ }^{380}$. $\$ 73$ Abs. 1 Nr. 2 LBO BW kommt daher insoweit nur dann zur Anwendung, wenn sonst im Bereich des Schutzes von Teilen erhaltenswerter baulicher Anlagen eine Lücke besteht $^{381}$.

Sperrwirkung für den Landesgesetzgeber entfalten die bundesrechtlichen Vorschriften des Bauplanungsrechts jedoch dann, wenn die landesrechtlichen Bestimmungen in Regelungsgegenstand, Erlaßgründen und rechtlicher Wirkung den bundesrechtlichen Instrumenten entsprechen. Dann fordert vor allem auch die Eigentumsgarantie des Art. 14 GG, daß nur eine Behörde in einem Verfahren über die notwendige Sozialbindung des Eigentums entscheidet ${ }^{382}$. Daher dürfte etwa das Landesdenkmalrecht von $\S 172$ Abs. 3 BauGB insoweit verdrängt werden, als dort zur Erhaltung baulicher Anlagen wegen städtebaulicher Bedeutung Genehmigungsvorbehalte vorgesehen werden ${ }^{383}$. Im Verhältnis der denkmalschützenden örtlichen Bauvorschriften zu den Stadterhaltungssatzungen stellt sich dieses Problem jedoch

${ }^{379}$ Siehe dazu oben A III 1 a.

${ }^{380}$ BW LTDrs. 8/3410, S. 117. Unzutreffend in der Begründung ist nur die Annahme, Ausstattungsdetails fielen grundsätzlich nicht unter die $\S 172 \mathrm{ff}$. BauGB. Siehe dazu oben A I 2 b cc.

${ }^{381}$ So auch Schlotterbeck, in: Schlotterbeck / von Arnim, § 73 Rn. 11.

${ }^{382}$ Siehe oben A II 1 b.

${ }^{383}$ Im Ergebnis wie hier Bartlsperger, DVBl. 1981, S. 288; a. A. wohl Henke, S. 36. 
nicht. Unzulässig ist auch in Schutzvorschriften die Festlegung der Firstrichtung $^{384}$.

\section{Bauleitplanung und Abstandsflächen}

\section{a) Das Problem der Ersatzbauleitplanung}

Vor allem durch die Möglichkeit der Vergrößerung von Abstandsflächen erhalten die Gemeinden die Möglichkeit, in gewissem Umfang auch ohne förmliche Bauleitplanung städtebauliche Ergebnisse zu erzielen, die sonst den Erlaß eines Bebauungsplans voraussetzen ${ }^{385}$. Nach dem hier entwickelten Abgrenzungsmaßstab sind diese Ermächtigungen kompetenzrechtlich trotzdem unbedenklich. Das Abstandsflächenrecht gehört zum Bauordnungsrecht. Dies ergibt sich zwar nicht aus der Unmittelbarkeitsformel, aber daraus, daß es sich um Nichtplanungsrecht handelt. Die Abstandsflächenregelungen enthalten zwar Regelungen, die auf planungsrechtliche Festsetzungen reagieren, setzen jedoch für ihre grundsätzliche Geltung keinen Planungsakt voraus.

Man wird es daher den Landesgesetzgebern nicht verwehren können, die von ihm getroffenen allgemeinen Bestimmungen insoweit zur Disposition der Gemeinden zu stellen, daß diese befugt sind, sie zu vergrößern. Der Unterschied etwa zur Festlegung von Gebäudehöhen und -tiefen besteht darin, daß die Landesgesetzgeber nicht gehindert sind, in Bereichen, in denen sie zulässig allgemeine Anforderungen an bauliche Anlagen gestellt haben, hiervon die Möglichkeit der Abweichung zu gestatten. Daß dies den Gemeinden zusätzlich einen gewissen Planungsspielraum eröffnet, spielt keine Rolle. Nicht jede Art von Planung der Bodennutzung fält in die Kompetenz "Bodenrecht". Wenn es sich nicht um eine Planung handelt, besteht lediglich keine Bundeskompetenz. In bezug auf das Regelungsziel "Auflockerung der Bebauung" hat das Städtebaurecht ebenfalls keine Sperrwirkung ${ }^{386}$. Das Problem, daß die Gemeinden durch den Erlaß einer einfachen Satzung über die Änderung von Abstandsflächen das aufwendi-

384 Insoweit gelten die Ausführungen $\mathrm{zu}$ den baugestalterischen Vorschriften, oben A III $1 \mathrm{~b}$.

${ }^{385}$ Siehe oben A I 2 c cc.

386 Somit ist $\S 73$ Abs. $1 \mathrm{Nr}$. 6 LBO BW kompetenzrechtlich unproblematisch, der eine Modifizierung aus "städtebaulichen Gründen" vorsieht. 
gere Verfahren zur Aufstellung eines Bebauungsplans umgehen könnten, ist deshalb auf andere Weise zu lösen. Richtiger Ansatzpunkt hierfür ist die Erkenntnis, daß der Gemeinde für die Frage, ob sie eine einfache Satzung oder einen Bebauungsplan aufstellt, einen gewissen Ermessensspielraum hat. Sollte im Einzelfall die städtebauliche Lage wegen größerer Konfliktbewältigungsprobleme den Erlaß eines Bebauungsplans erfordern, stellt die Gemeinde aber trotzdem nur eine Satzung über die Vergrößerung von Abstandsvorschriften auf, so ist diese Satzung wegen Ermessensfehlers nich$\operatorname{tig}^{387}$.

\section{b) Zur Ermöglichungsfunktion von örtlichen Bauvorschriften}

Wesentlich schwieriger ist die Frage zu beantworten, ob die Gemeinde bei der Bauleitplanung an Abstandsflächenvorschriften in den Landesbauordnungen gebunden ist. Besteht eine solche Bindung, so haben örtliche Bauvorschriften eine "Ermöglichungsfunktion". Sie bilden dann eine Brücke für die Verwirklichung bauplanerischer Festsetzungen, die sonst an den Abstandsvorschriften scheitern würden.

Die ganz überwiegende Meinung bejaht eine grundsätzliche Bindung der Bauleitplanung an Abstandsflächenvorschriften ${ }^{388}$. Trotzdem dürfte das Gegenteil richtig sein. Es gibt kein materielles Abgrenzungskriterium für die Frage, ob eine Bestimmung zum Bauordnungs- oder Bauplanungsrecht gehört. Vor allem ist es nicht möglich, beide Rechtskreise über die Unmittelbarkeitsformel oder über den materiellen Polizeirechtsbegriff voneinander zu scheiden. Es ist somit dem Landesgesetzgeber nicht verwehrt, wie z. B. durch Abstandsflächenregelungen zu bestimmen, daß an bestimmten Stellen bauliche Anlagen nicht errichtet werden dürfen, weil Gebäude einen bestimmten Abstand zur Grundstücksgrenze einhalten müssen. Die Grenze für solche landesrechtlichen Regelungen besteht lediglich darin, daß es nach den bundesrechtlichen Vorschriften der $\S \S 29 \mathrm{ff}$. BauGB, und zwar vor allem durch § 34 BauGB, dem Landesrecht verwehrt wird, nach diesen Vorschriften grundsätzlich zulässige zu unzulässigen Vorhaben zu machen. Das BVerwG drückt dies dahingehend aus, daß es den Landesgesetzgebern nicht erlaubt sei, den $\S \S 30$ ff. BauGB bodenrechtliche Regelungen hinzuzufügen $^{389}$. Eine solche Aussage ist zwar insoweit mißverständlich, als es

\footnotetext{
${ }^{387}$ Siehe dazu ausführlicher unten E II 2 b.

388 Weyreuther, BauR 1972, S. 1 ff.; Knaup / Stange, § 23 I 3 b, S. 199 m. w. N.

${ }^{389}$ BVerwG, Urteil vom 24.02.1978, E 55, 272 (277).
} 
eben kein eigenständiges materielles Kriterium dafür gibt, wann eine Regelung eine solche bodenrechtlicher Art ist. Dies ist jedoch kein Hindernis für eine Sperrwirkung der Normen des BauGB zulasten landesgesetzgeberischer Regelungen. Nur die Fragestellung lautet nicht dahingehend, ob eine Regelung bodenrechtlich oder nicht bodenrechtlich ist, sondern schlichter, aber richtiger, ob und inwieweit die bundesgesetzgeberische Regelung abschließend sein will und inwieweit nicht ${ }^{390}$. Dies ist letztlich auch genau die Überlegung, die etwa das BVerwG zu dem Ergebnis geführt hat, daß "funktionaler" Außenbereichsschutz durch landesrechtliche Regelungen neben $\S 35$ BauGB nicht möglich ist, "optischer" Außenbereichsschutz aber wohl ${ }^{391}$.

Für das Verhältnis von $\S 34$ BauGB zu den Abstandsvorschriften ergibt sich daraus folgendes: $\S 34$ BauGB entscheidet grundsätzlich über die Bebaubarkeit eines Grundstücks. Das Merkmal "Einfügen" ist jedoch nicht immer frei von Anwendungszweifeln und gibt keine vollkommen exakte Vorgabe für die Situierung eines Gebäudes auf einem Grundstück. Man wird den $\S 34$ BauGB daher nicht dahingehend verstehen können, daß er die Feinsteuerung durch landesrechtliche Abstandsvorschriften verdrängen will $^{392}$. Von allzu großer Bedeutung ist diese Frage ohnehin nicht. § 34 BauGB ist eine planungsrechtliche Vorschrift im Sinne der Landesbauordnungen, der gegenüber den Abstandsflächenbestimmungen im Falle einer Kollision aufgrund einfachgesetzlicher Regelungen der Vorrang zukommt ${ }^{393}$.

Anders stellt sich dagegen die Lage für den Planbereich dar. Alle die Belange, die durch die Vorschriften über Abstandsvorschriften gefördert werden sollen wie ausreichende Belichtung, Belüftung und sonstige Belange des Grundstücksnachbarn sind notwendiges Abwägungsmaterial nach § 1 Abs. 6 BauGB. Wenn sich der Bebauungsplan bewußt und abwägungsfehlerfrei für eine Planung entscheidet, die nur dadurch zu verwirklichen ist, daß Abstandsvorschriften nicht eingehalten werden, dann ist dieser Bauleitplan entgegen der überwiegenden Auffassung gültig und auch vollziehbar. Dem wird zwar entgegengehalten, daß der Bebauungsplan als dem Landesrecht

${ }^{390}$ Den äußeren Rahmen bilden aufgrund des Planersatzcharakters der $\S 34,35$ BauGB die im Bebauungsplan möglichen Festsetzungen.

${ }^{391}$ BVerwGE 55, 275. Siehe dazu oben A II 3 b.

392 So im Ergebnis auch BVerwG, Beschluß vom 06.01.1970, DVBI. 1970, S. $830 \mathrm{ff}$.

393 Siehe oben A I 2 c bb; weiterhin OVG Münster, Urteil vom 23.11.1971, BRS Band 24, Nr. 101 S. 147 ff.; BWVGH, Urteil vom 11.05.1971, BRS Band 24, Nr. 102 S. 151 ff.; Urteil vom 24.06.1971, BRS Band 24, Nr. 103 S. 152 ff. und Urteil vom 16.07.1971, BRS Band 24, Nr. 104 S. 153 ff. 
zugehörige Satzung im Rang unter dem förmlichen Landesgesetz stände und insoweit die Gemeinde an die Bestimmungen in den Bauordnungen über Abstandsvorschriften gebunden sei $^{394}$. Diese Argumentation übersieht aber, daß es vorrangig um die Frage geht, ob das BauGB als Bundesgesetz die Gemeinden von der Bindung an die landesrechtlichen Bestimmungen befreien kann. Und diese Frage ist zu bejahen, da die Bauleitplanung die mit der Bodennutzung verbundenen Interessenkonflikte umfassender lösen kann. Die Abstandsbestimmungen in den Landesbauordnungen sind zwar extrem lang, kompliziert und gelegentlich sogar kaum verständlich ${ }^{395}$. Sie bleiben aber bei allem Bemühen um Differenzierung letztlich schematisch $^{396}$. Ob sie ihrem ursprünglichen Zweck, gesunde Wohnverhältnisse zu erreichen, überhaupt gerecht werden, wird man zudem bezweifeln können $^{397}$.

Hingegen kann die gemeindliche Bauleitplanung auf die spezifischen Besonderheiten eines jeden Grundstücks eingehen. Sie kann Verkürzungen der Nachbarinteressen durch Unterschreitung der Abstandsflächen auf andere Weise kompensieren ${ }^{398}$. Das Bauplanungsrecht und damit auch die Bauleitplanung selbst haben daher gegenüber dem Bauordnungsrecht eine institutionelle Vorrangstellung ${ }^{399}$. Diese Vorrangstellung gründet sich maßgeblich auf das Abwägungsgebot des $\S 1$ Abs. $6 \mathrm{BauGB}^{400}$. Wenn unter gerechter Abwägung auch der nachbarlichen Interessen die Gemeinde zu dem Ergebnis kommt, daß eine Unterschreitung der Abstandsflächen zur Verwirklichung der planerischen Konzeption möglich ist, besteht kein rechtfertigender Grund mehr dafür, trotzdem auf einer Geltung der Abstandsvorschriften zu beharren. Zwar sind Abstandsflächenbestimmungen eine mit dem Übermaßverbot vereinbare Sozialbindung des Grundeigentums. Dieser grundsätzlich zulässigen Sozialbindung mangelt es aber dann an einem rechtfertigenden Grund, wenn sich aus der von der gemeindlichen Bauleit-

\footnotetext{
${ }^{394}$ Schrödter, § 9 Rn. 9; Knaup / Stange, S. 199 m. w. N.
}

395 Besonders "eindrucksvoll" sind etwa die Bemühungen um die Auslegung des 16-m-Privilegs nach Art. 6 Abs. 5 BayBO; siehe dazu Simon, Art. 6 Rn. 43 ff.

${ }^{396} \mathrm{Vgl}$. Oeter, S. 30: Die Abstandsflächenbestimmungen sorgen für ein gleichmäßig langweiliges Erscheinungsbild aller neuen Wohngebiete.

397 Boeddinghaus, BauR 1989, S. 6, im Anschluß an Oeter, S. 30.

398 Vergleiche den Vorschlag von Oeter, S. 31.

399 So auch Bartlsperger, DVBI. 1981, S. 293 für das Verhältnis der Bauleitplanung zum Denkmalschutzrecht.

${ }^{400}$ Bartlsperger, DVBI. 1981, S. 294. 
planung konkret gestalteten Situation eine Notwendigkeit für die Einhaltung eines Grenzabstandes nicht mehr ergibt.

Daraus ist aber nicht der Schluß zu ziehen, daß die Abstandsflächenbestimmungen im Planbereich überhaupt keine Bedeutung mehr hätten. Die Bauleitplanung kann sich über die Abstandsvorschriften hinwegsetzen, wenn sie die betroffenen Belange mit in die Abwägung einbezieht, sie muß es aber nicht und sie tut es auch meistens nicht. In den wichtigsten Fällen, wie etwa der Festsetzung geschlossener Bauweise ( $\$ 22$ Abs. 3 BauNVO), ist eine Derogierung der Abstandsvorschriften schon deshalb nicht nötig, weil diese selbst keine Geltung beanspruchen. Im übrigen werden Bauleitplanungen ohne Rücksicht auf bestimmte Grundstücksgrenzen durchgeführt. Häufig werden Grundstücke erst nach der Beplanung geteilt und verkauft, so daß auch erst danach Grundstücksgrenzen entstehen. Solange sich vor allem aus der Begründung des Bebauungsplans oder direkt aus seinen Festsetzungen nicht ergibt, daß die Abstandsvorschriften nicht gelten sollen, kommen die bauplanerischen Festsetzungen neben den entsprechenden Abstandsbestimmungen der Landesbauordnungen zur Anwendung.

Für die Frage, welche Funktion die örtlichen Bauvorschriften haben, wenn es darum geht, die Abstandsflächen zu verringern, ergibt sich damit folgendes Ergebnis: Im Nichtplanbereich hat diese Möglichkeit eine gewisse Relevanz. Die Gemeinden können die Abstandsvorschriften, die grundsätzlich Geltung beanspruchen, modifizieren. Im Planbereich kommt ihr dagegen keine Bedeutung zu. Ein Bebauungsplan braucht die Krücke örtlicher Bauvorschriften über die Modifizierung von Abstandsflächen nicht, um sich über die entsprechenden landesbauordnungsrechtlichen Bestimmungen hinwegzusetzen. Vorschriften in den Landesbauordnungen, wonach bauplanerische Festsetzungen den Bestimmungen über Abstandsflächen vorgehen, haben daher nur deklaratorische Bedeutung ${ }^{401}$. Wenn der BayVGH die Abweichung von Abstandsflächen im Bebauungsplan zu einem restriktiv zu handhabenden Ausnahmefall machen möchte ${ }^{402}$, läßt sich dieses Ergebnis nur über entsprechende Anforderungen an die Abwägung nach $\S 1$ Abs. 6 BauGB erreichen, nicht über eine Interpretation des $\S 7$ Abs. 1 BayBO.

\footnotetext{
${ }^{401}$ Ausführliche Nachweise oben A I 2 c bb.

${ }^{402}$ BayVGH, Beschluß vom 20.11.1986, BayVBI. 1987, S. 337 (338).
} 


\section{Kompetenzrechtliche Qualifikation von örtlichen Bauvorschriften}

Die bisherige Untersuchung der Bestimmungen über örtliche Bauvorschriften führt zu dem Ergebnis, daß es im wesentlichen zwei große Bereiche gibt, die sowohl praktisch als auch theoretisch eine erhebliche Bedeutung haben. Dies sind die baugestalterischen und die Schutzvorschriften. Die Modifizierung von Abstandsflächen ist dagegen aufgrund der institutionellen Vorrangstellung der Bauleitplanung von geringer Bedeutung. Die weitere Untersuchung wird sich deshalb vor allem auf die baugestalterischen und die denkmalschützenden Vorschriften konzentrieren.

Nachdem ein Abgrenzungsmaßstab für die Kompetenz des Bundes aus Art. 74 Nr. 18 GG entwickelt wurde, läßt sich nun die Frage stellen, ob nicht ein Teil der Festsetzungen, die üblicherweise in örtlichen Bauvorschriften getroffen werden, in den Katalog des $\S 9$ Abs. 1 BauGB aufgenommen werden könnten. Ein spezifischer Bodenbezug ist bei den üblichen Festlegungen in örtlichen Bauvorschriften ohne weiteres gegeben ${ }^{403}$. Diese Frage entscheidet sich desweiteren danach, ob es sich insoweit um eine für die Planungstätigkeit der Gemeinde erforderliche Festsetzung handelt, da der verfolgte Belang in einem notwendig ausgleichsbedürftigen Verhältnis mit anderen spezifische Bodennutzungsprobleme aufwerfenden Belangen steht.

Kein allein entscheidendes Argument für eine Bundeszuständigkeit ist die Einheitlichkeit der Aufgabe Stadtgestaltung. Zwar erfolgt "Stadtgestaltung" heute sowohl mit Mitteln des Bauplanungs- als auch des Bauordnungsrechts ${ }^{404}$. Würde man aber dahingehend argumentieren, daß Stadtgestaltung eine einheitliche Aufgabe sei und deshalb den Gemeinden die entsprechenden Planungsmittel zur Verfügung stehen müssen, würde man wieder in den Fehler einer isoliert finalen Betrachtungsweise verfallen. Stadtgestaltung ist zwar unzweifelhaft ein Ziel der Bauleitplanung, es ist aber auch alles andere mögliche Zwecksetzung, was sich mit ihr abwägungsfehlerfrei erreichen läßt. Eine Bundeskompetenz kann sich daher nicht aus der Aufgabe ergeben, und sei sie noch so einheitlich.

${ }^{403}$ Siehe oben A II $3 \mathrm{c}$ ee.

${ }^{404}$ Gaentzsch, DSt. 1969, S. 375, ders., DSt. 1974, S. 488; Boeddinghaus, Stadterhaltung, Rn. 130 f.; Bay. Staatsministerium des Inneren, Stadtgestalt und Denkmalschutz im Städtebau, S. 9. Zur Gestaltrelevanz bauplanerischer Festsetzungen siehe vor allem Heinz, S. 18; Einsele, Stadtbauwelt 1974, S. 143 f.; speziell zum Fall von Baulinien und Baugrenzen als Mittel der Stadtgestaltung auch Kuhn, DVBI. 1968, S. 501, der jedoch zu Unrecht davon ausgeht, daß mit Mitteln des Bauplanungsrechts keine Baugestaltung betrieben werden dürfe. Es gibt ja - wie gesehen - keine speziellen dem Bauordnungsrecht vorbehaltenen Zwecke. So wohl auch Kuhn selbst, ebenda. 
Die Notwendigkeit eines Interessenausgleichs und damit eine Bundeskompetenz dürfte aber auf jeden Fall zu bejahen sein, wenn die entsprechenden Festsetzungen nachbarliche Belange berühren. Das, was auch den Nachbarn betrifft, bedarf einer Gesamtschau und unter Umständen eines Ausgleichs. Von den typischen Festlegungen in örtlichen Bauvorschriften betrifft dies vor allem die Dachgestaltung. Gerade die Festsetzung von Dachform und Neigungswinkel gehört in der Regel zu einem planerischen Gesamtkonzept für eine Bauleitplanung. Gleiches gilt für die Geschoß- und Traufhöhen. Vor allem die Gestaltung des Daches und die Dachneigung beeinflussen zusammen mit planungsrechtlichen Festsetzungen aufgrund des BauGB, wie etwa der Geschoßzahl und Geschoßflächenzahl ( $\$ 16 \mathrm{Abs} .2 \mathrm{Nr}$. 1 und 3 BauNVO), Belüftung, Belichtung und Besonnung der Nachbargrundstücke ${ }^{405}$. Die nachbarlichen Interessen lassen sich bei der Planaufstellung für einen Bebauungsplan nicht angemessen berücksichtigen, wenn die genannten Fragen ausgeklammert bleiben. Daher ist auch nur konsequent, wenn Festsetzungen in örtlichen Bauvorschriften insoweit genau wie solchen in Bebauungsplänen über die Geschoßzahl nachbarschützende Funktion zugesprochen wird ${ }^{406}$. Die konkret mögliche Dachgestaltung hängt auch einfachgesetzlich mit der Bestimmung des Maßes der baulichen Nutzung zusammen, und zwar über die Vorschrift des $\S 20$ Abs. 2 S. 2 BauNVO. Danach hat die nutzbare Fläche eines Dachgeschosses auch dann Rückwirkung auf die festgesetzte Geschoßfläche, wenn das Dachgeschoß selbst kein Vollgeschoß im Sinne des $\S 18$ BauNVO in Verbindung mit der jeweiligen Landesbauordnung ist ${ }^{407}$. Daher kann etwa die Frage der Nutzbarkeit oder Nichtnutzbarkeit des Daches entscheidend dafür sein, ob etwa ein- oder zweigeschossige Bauweise festgesetzt wird ${ }^{408}$. Bei der konkreten Baukörperdimensionierung handelt es sich daher um einen einheitlichen Abwägungs- und Gestaltungsvorgang. Er läßt sich nicht sinnvoll aufspalten in eine auf Bundesrecht beruhende Festsetzung über das Maß der baulichen Nutzung und eine bauordnungsrechtliche über die Dachgestaltung. Es wäre daher angebracht, dies in den Katalog des $\S 9$ Abs. 1 BauGB aufzunehmen. Dem läßt sich auch nicht entgegenhalten, es handele sich insoweit um den "Kern des landesrechtlichen Gestaltungsrechts", so daß eine Aufnahme in

\footnotetext{
${ }^{405}$ Bosch, ZfBR 1987, S. 185.

${ }^{406}$ Siehe die Nachweise bei Bosch, ZfBR 1987, S. 184.

${ }^{407}$ Hierzu und zu weiteren Beispielen siehe Bosch, ZfBR 1987, S. 185.

${ }^{408}$ Bosch (Fn. 406).
} 
den $\S 9$ Abs. 1 BauGB unzulässig sei ${ }^{409}$. Denn eine Materie, deren "Kern" bei den Ländern verbleiben müßte, kennen die Art. 70 ff. GG nicht.

Was die Festsetzungen betrifft, die mehr optische Bedeutung haben, wie Bestimmungen über den Außenanstrich, Dacheindeckung, Art der Fenster etc. lassen sich sowohl für als auch gegen die Notwendigkeit eines planerischen Interessenausgleichs entsprechende Argumente finden. Ein notwendiger Zusammenhang mit den üblicherweise im Bebauungsplan getroffenen Festsetzungen wie etwa Art und $\mathrm{Ma} B$ der baulichen Nutzung besteht auf den ersten Blick nicht unbedingt. So läßt sich die Festlegung von eingeschossiger Bauweise unabhängig davon treffen, welche Vorstellungen die Gemeinde im Hinblick auf Einfriedungen und Farbe des Außenanstrichs hat. Andererseits hängt etwa der Gebietscharakter, den die Gemeinde vor allem durch die Bauleitplanung mittels der Festsetzung der Art der baulichen Nutzung bestimmt, wesentlich auch von den optischen Anforderungen ab. Daraus resultiert etwa die Forderung, daß örtliche Bauvorschriften nicht im Sinne einer verselbständigten Stadtgestaltung als reine Stadtkosmetik eingesetzt werden sollen, sondern daß insoweit ein stadtplanerisches Gesamtkonzept nötig ist ${ }^{40}$. Die Belange, die auch für die nach $\S 9$ Abs. 1 BauGB möglichen Festsetzungen im Rahmen der Abwägung eine Rolle spielen, sind häufig auch für den Erlaß von baugestalterischen und denkmalschützenden Vorschriften von Bedeutung. Auch diese Festsetzungen stehen im Spannungsverhältnis unterschiedlicher Anforderungen an die Bodennutzung, wie Ortsbild- und Denkmalpflege, Interessen der Eigentümer auch gesundheitlicher $\mathrm{Art}^{411}$, Interessen der Wirtschaft vor allem bei Festsetzungen in Bezug auf Werbeanlagen, Interessen des Fremdenverkehrs etc ${ }^{412}$. Dies macht durchaus in gewissem Maße einen planerischen Interessenausgleich notwendig, wobei die abwägungserheblichen Belange zumindest teilidentisch sind mit denen, die auch bei der Aufstellung etwa eines Bebauungsplans zu berücksichtigen sind $d^{413}$. Wenn etwa in einer Stadt aufgrund von

409 So aber Schmaltz, VR 1983, S. 221. Ähnlich auch Kuhn, DVBI. 1968, S. 498 ff.

${ }^{410}$ Hörst, Städte- und Gemeinderat 1977, S. 187; Simon, Art. 91 Rn. 6. Siehe auch Trieb, in: Neues Städtebaurecht, S. 150, der sich für die Verpflichtung zu einer "Ortsbildplanung" ausspricht. 27.

${ }^{411}$ Wie etwa die Flachdachentscheidungen zeigen, siehe die Nachweise oben A I 2 a aa, Fn

412 Insoweit kann Stadtbildpflege auch erhebliche wirtschaftliche Bedeutung haben, siehe Debold-Kritter, Bauwelt 1977, S. 44.

${ }^{413}$ Siehe auch OVG Münster, Urteil vom 19.08.1983, NVwZ 1984, S. 595, wo aufgrund eines untrennbaren Regelungszusammenhangs zwischen Festsetzungen nach $\$ 9$ Abs. 1 BauGB und solchen, die nach $\S 9$ Abs. 4 BauGB in den Bebauungsplan aufgenommen werden, die 
Schutzvorschriften in erheblichem Maße Werbeanlagen eingeschränkt werden, mag dies zulasten der Gewerbebetriebe auch damit begründbar sein, $\mathrm{da} ß$ an anderer Stelle mit bauplanungsrechtlichen Mitteln etwas zur Erhöhung der Attraktivität etwa der Innenstadt getan wurde. Bestimmt die Gemeinde für ein Wohngebiet relativ detailliert eine weitgehend einheitliche äußere Gestaltung der Gebäude, um so ein "ruhiges Bild" zu erreichen, erhält der Eigentümer, dem die vorgeschriebene Gestaltung unter Umständen nicht gefällt, eine "Gegenleistung" durch die Beschränkung der Nutzung auf reine Wohnzwecke im eigentlichen Bebauungsplan, so daß von daher auch akustisch "Ruhe" herrscht. Insoweit wird man für die üblichen Festlegungen in örtlichen Bauvorschriften insgesamt davon ausgehen können, daß in vielen Fällen ein gewisser Interessenausgleich oder auch eine planerische Ergänzung naheliegt. Auch bei den Festlegungen in örtlichen Bauvorschriften, die nicht die Baukörperdimensionierung betreffen, handelt es sich damit um potentielles Bauplanungsrecht.

Es läßt sich somit feststellen, daß eine Übernahme der gängigerweise in örtlichen Bauvorschriften getroffenen Festsetzungen in den Katalog des § 9 Abs. 1 BauGB nicht nur möglich, sondern teilweise durchaus wünschenswert wäre. Zum einen würde dies diese Festsetzungen von dem Vorurteil befreien, es handele sich nur um ein Gestaltungsmittel, mit dem die Gemeinde optische Wirkungen erzielen darf, das aber sonst keinen weiteren Zwecken dient. Die Ziele, die die Gemeinde mit baugestalterischen und denkmalschützenden Vorschriften anstreben darf, sind durchaus vielfältig. Die Entscheidung etwa, welche Art von Einfriedungen eine Gemeinde zuläßt, hat nicht nur Auswirkung auf die optische Wirkung des Gemeindegebietes. Sie ist auch kommunikationsfördernd oder -hemmend, sie erleichtert oder erschwert möglicherweise terroristische Gewaltakte, was etwa in einem Villenviertel durchaus relevant werden kann. Desweiteren erschweren die uneinheitlichen, aber letztlich doch im großen und ganzen einheitlich auszulegenden landesrechtlichen Vorschriften die rechtsdogmatische Erfassung und Klärung ${ }^{414}$. So halten und entwickeln sich leichter Irrtümer, die deshalb weniger stark in das Bewußtsein der juristischen Öffentlichkeit treten, weil es sich "nur" um die Auslegung einer landesrechtlichen Norm handelt.

Andererseits ist für die Festlegungen, die nicht direkt Nachbarinteressen berühren, ein Verfahren zur Aufstellung eines Bebauungsplanes in vielen

Normenkontrollklage gegen örtliche Bauvorschriften nach $\S 47$ Abs. 1 Nr. 1 VwGO zulässig sei. Dazu ausführlich unten $\mathrm{E} I 1 \mathrm{c}$.

${ }^{414}$ Vgl. dazu auch Ortloff, NVwZ 1989, S. 615. 
Fällen recht aufwendig, wenn nicht ohnehin für das betreffende Gebiet nach $\S 1$ Abs. 3 BauGB ein Bebauungsplan aufzustellen ist. Besteht etwa im unbeplanten Innenbereich ( $\$ 34$ BauGB) nur ein Bedürfnis danach, den zulässigen Außenanstrich von Gebäuden rechtssatzmäßig festzulegen, so ist es ein Zuviel an Verfahren, deshalb einen Bebauungsplan zu erlassen. Es wäre - falls solche Festsetzungen de lege ferenda in den Katalog des $\$ 9$ Abs. 1 BauGB aufgenommen würden - aus diesem Grunde eine Regelung dergestalt zu empfehlen, daß Festlegungen durch einfache Satzungen über örtliche Bauvorschriften solange zulässig sind, bis für das betreffende Gebiet ein Bebauungsplan vorliegt. Dadurch ließe sich die Sperrwirkung, die $\S 9$ Abs. 1 BauGB sonst zulasten entsprechender landesrechtlicher Bestimmungen ausübt, vermeiden. 


\title{
B. Die Garantie der gemeindlichen Selbstverwaltung und Stadtgestaltung durch örtliche Bauvorschriften
}

\author{
I. Die Einordnung des Erlasses von \\ örtlichen Bauvorschriften in die Aufgabensysteme \\ nach den Kommunalgesetzen der Länder
}

\section{Dualistisches und monistisches Modell}

Die Feststellung, daß es sich bei den Bestimmungen über örtliche Bauvorschriften um potentielles Bauplanungsrecht handelt, leitet über zur Frage der Einordnung des Erlasses örtlicher Bauvorschriften in das gemeindliche Aufgabensystem. Der Erlaß von Bauleitplänen obliegt nach $\S 2$ Abs. 1 S. 1 BauGB den Gemeinden in eigener Verantwortung. Demgegenüber ist der Vollzug der Bauordnung in der Regel eine staatliche Aufgabe ${ }^{1}$, die nur teilweise unter gleichzeitiger Sicherung staatlicher Einflußmöglichkeiten an die Gemeinden übertragen ist.

Eine Diskussion der Frage, welchem Bereich der Erlaß örtlicher Bauvorschriften zuzuordnen ist, setzt jedoch eine gewisse terminologische Verständigung voraus. Denn in der Bundesrepublik unterscheidet man bezüglich der gemeindlichen Aufgabenerfüllung zwei Modelle. Es gibt zum einen das traditionelle dualistische, zum anderen entsprechend dem sog. Weinheimer Entwurf das monistische System ${ }^{2}$. Der grundsätzliche Unterschied soll vor allem darin liegen, daß beim dualistischen Modell getrennt wird zwischen Selbstverwaltungsaufgaben und Staatsaufgaben, während beim monistischen Modell von einem einheitlichen Begriff der öffentlichen Aufgaben ausgegangen wird, deren Erfüllung im Gemeindegebiet grundsätzlich allein und in eigener Verantwortung den Gemeinden obliegt ${ }^{3}$. Dabei werden die bayerischen, rheinland-pfälzischen und saarländischen Regelungen auf das duali-

\footnotetext{
${ }^{1}$ Siehe nur Art. 63 Abs. 1 BayBO.

${ }^{2}$ Schmidt-Eichstaedt, HbKWP, Band 3, S. 15; Seewald, Rn. 113 f.; Schmidt-Aßmann, Kommunalrecht, S. $126 \mathrm{ff}$.

${ }^{3}$ Schmidt-Aßmann, Kommunalrecht, S. 127.
} 
stische Modell zurückgeführt ${ }^{4}$, bei der niedersächsischen Regelung besteht eine gewisse Uneinigkeit ${ }^{5}$, die übrigen kommunalgesetzlichen Regelungen werden zum monistischen System gerechnet ${ }^{6}$.

Obwohl sich beide Modelle von der Idee her stark unterscheiden, führt die Ausgestaltung durch die Landesgesetzgeber vor allem im Bereich der Staatsaufsicht zu weitgehend angenäherten Ergebnissen. Es gibt in beiden Modellen Aufgaben, die die Gemeinden unabhängig von staatlichen Weisungen erfüllen ${ }^{7}$. Aber auch dann, wenn man entsprechend dem monistischen Modell von einem einheitlichen Begriff öffentlicher Aufgaben ausgeht, ist der Staat darauf angewiesen, bei gewissen Aufgabenbereichen über die reine Rechtsmäßigkeitskontrolle hinaus sich ein Weisungsrecht vorzubehalten. Dies führte in den Ländern, die dem Weinheimer Entwurf gefolgt sind, zur Schaffung von "Pflichtaufgaben nach Weisung"8. Obwohl im monistischen System von einem einheitlichen Aufgabenbegriff ausgegangen wird, haben die Landesgesetzgeber damit häufig etwas Ähnliches geschaffen wie den "übertragenen Wirkungskreis" im Sinne des herkömmlichen dualistischen Modells'. Da auch im Bereich der BayGO das Weisungsrecht der Fachaufsichtsbehörden durch Art. 109 Abs. 2 S. 2 BayGO stark eingeschränkt ist, unterscheiden sich monistisches und dualistisches System in ihrer tatsächlichen gesetzlichen Ausformung auch keinesfalls dadurch, daß im Bereich des monistischen Systems nur eine "mehr oder weniger eingeschränkte Fachaufsicht stattfindet" ${ }^{10}$. Vielmehr dürften sich beide Systeme sowohl in der gesetzlichen Ausformung als auch in der praktischen Handhabung weitgehend ähneln ${ }^{11}$.

${ }^{4}$ Vgl. Art. 7 und 8 BayGO; § 2 Abs. 2 Rh.Pf.GemO; § 6 Abs. 1 SaarlKSVG.

${ }^{5}$ Vgl. §§ 4, 5 NGO. Für die Zuordnung zum monistischen System wohl Seewald, Rn. 11 Fn. 111. Für die Zuordnung zum dualistischen System die ganz überwiegende Meinung, siehe Schmidt-Eichstaedt, HbKWP Band 3, S. 17; Schmidt-Aßmann, Kommunalrecht, S. 126; Korte, VerwArchiv 61 (1970), S. 6; Westbomke, S. 86; Ipsen, Kommunalrecht, S. 72.

${ }^{6} \S 2$ Abs. 1 GemO BW; § 2 HessGO; 22 GO NRW; § 2 GO SI.H.

${ }^{7}$ Schmidt-Aßmann, Kommunalrecht, S. 127.

${ }^{8}$ Schmidt-Aßmann, Kommunalrecht, S. 127; Seewald, Rn. 116 ff.; $\$ 2$ Abs. 2 und 3 GemO BW; § 4 HGO; § 3 GO NRW; § 3 GO Sl.H.

${ }^{9}$ Korte, VerwArchiv 61 (1970), S. 5; Wolf Weber, S. 111, der von einer "weitgehenden Identität ${ }^{n}$ zwischen Weisungsaufgaben und Aufgaben des übertragenen Wirkungskreises spricht. Eine alle Fälle umfassende allgemeine Qualifikation dürfte wohl nicht möglich sein, so Stober, in: Wolff / Bachof / Stober, Verwaltungsrecht II, § 86 X Rn. 191.

${ }^{10}$ So aber Seewald, Rn. 115.

${ }^{11}$ So auch Berg, Festschrift Bayerischer Gemeindetag, S. 156; Brohm, DÖV 1986, S. 398. 
Für die weitere Untersuchung des Erlasses örtlicher Bauvorschriften kann daher von folgendem Ergebnis ausgegangen werden: Sowohl in dualistischen als auch in monistischen Systemen obliegen den Gemeinden Aufgaben, bei deren Erfüllung keine Zweckmäßigkeitskontrolle stattfindet, die also unabhängig von staatlichen Weisungsmöglichkeiten erfüllt werden. Daneben gibt es andere Bereiche, in denen die Gemeinden in allerdings unterschiedlichem Maße staatlicher Ingerenz im Hinblick auf die Zweckmäßigkeit der Aufgabenerfüllung ausgesetzt $\operatorname{sind}^{12}$. Um die Terminologie zu vereinfachen, wird entsprechend dem dualistischen System von "eigenen" und zur Kennzeichnung des Bereichs, in dem die Möglichkeit staatlicher Zweckmäßigkeitskontrolle besteht, von "übertragenen Angelegenheiten" oder "übertragenem Wirkungskreis" gesprochen. Gegenüber der Verwendung des neutralen Begriffs "Fremdverwaltung" ${ }^{13}$ bringt dies deutlicher zum Ausdruck, daß es sich um in eigener Kompetenz zu erfüllende und keinesfalls um "fremde" Aufgaben der Gemeinde handelt ${ }^{14}$. Die Verwendung der eigentlich auf das dualistische Modell hinweisenden Begriffe ist im übrigen auch in Ländern mit monistischem System üblich ${ }^{15}$. Gute Gründe sprechen zudem für die Annahme, daß auch das Grundgesetz im Grundsatz vom dualistischen Modell ausgeht ${ }^{16}$. Weiterhin hat das dualistische Modell den Vorzug etwas größerer Klarheit, wie vor allem der Einordnungsstreit um die "Pflichtaufgaben nach Weisung" zeigt ${ }^{17}$. Schließlich wird das Problem um die Einordnung von örtlichen Bauvorschriften vor allem in Bayern kontrovers behandelt ${ }^{18}$, wo ein dualistisches Aufgabensystem besteht. Deshalb wird im Folgenden dieses Modell zugrunde gelegt.

${ }^{12}$ Schmidt-Aßmann, Kommunalrecht, S. 133.

${ }^{13}$ Diesen Begriff bevorzugen etwa Stober, in: Wolff / Bachof / Stober, Verwaltungsrecht II, § 86 X Rn. 198; Schmidt-Jortzig, Organisationshoheit, S. 188, ders., Kommunalrecht, Rn. 541 S. 184; Stern, Staatsrecht, Band 1, S. 412; Mengelkoch, S. 125 Rn. 16.

${ }^{14}$ Gönnew'ein, S. 102; Knemeyer, Festschrift Bayerischer Gemeindetag, S. 118, ders., DVBl. 1984, S. 29, ders., Gemeinden unter dem Einfluß der Fachbehörden, S. 11, vor allem unter Verweis auf Art. 6 BayGO, ders., DÖV 1988, S. 398 und 400, wo stattdessen der Begriff "Weisungsaufgaben" vorgeschlagen wird. Kritisch zum Begriff "Fremdverwaltung" auch von Unruh, DÖV 1977, S. 469. Da es sich um eine Aufgabe der Gemeinde handelt, überzeugt die von Burmeister, Neukonzeption, S. 124 f., angenommene Verfassungswidrigkeit des dualistischen Modells nicht recht. Zur Konzeption Burmeisters siehe ausführlicher unten B II 2.

${ }^{15}$ Vgl. BW LTDrs. 8/3410, S. 20.

${ }^{16}$ Siehe Schnidt-Eichstaedt, HbKWP, Band 3, S. 19, der etwa den Wortlaut des Art. 28 Abs. 2 GG und den Art. 85 Abs. 3 GG anführt.

${ }^{17}$ Siehe dazu Schmidt-Eichstaedt (Fn. 16), S. 20 ff.; Clemens, DSt. 1986, S. 265; Gönnewein, S. 107 ff.; Erichsen, Kommunalrecht, S. 127.

${ }^{18}$ Siehe den folgenden Abschnitt. 


\section{Die Regelungen in den Landesbauordnungen im Hinblick auf die Frage des Wirkungskreises}

Für die Einordnung von örtlichen Bauvorschriften in den eigenen oder übertragenen Wirkungskreis erscheinen auf den ersten Blick beide Lösungen möglich. Man kann etwa auf die Nähe zur Bauleitplanung und darauf hinweisen, daß die Rechtsform "Satzung" das klassische Instrument zur Regelung von Selbstverwaltungsangelegenheiten ist $^{19}$, und deshalb von einem Erla $B$ im eigenen Wirkungskreis ausgehen ${ }^{20}$. Andererseits spricht die Rechtsform Satzung nicht zwingend für den eigenen Wirkungskreis, es gibt durchaus Satzungen im übertragenen Wirkungskreis ${ }^{21}$. Zudem ist das Bauordnungsrecht in wesentlichen Teilen Gefahrenabwehrrecht, was in gewisser Weise ein Indiz dafür sein kann, daß der Erlaß von örtlichen Bauvorschriften wie der Vollzug der Bauordnung im übrigen für die Gemeinden eine Aufgabe des übertragenen Wirkungskreises ist ${ }^{22}$. Dementsprechend sieht die MBauO 1981 in $\S 82$ Abs. 3 den Erlaß von örtlichen Bauvorschriften durch Satzung im übertragenen Wirkungskreis vor. Schließlich spricht auch eine historische Überlegung für die Einordnung in den übertragenen Wirkungskreis. § 2 Abs. 1 der BaugestVO als Vorgänger der heutigen Regelungen über örtliche Bauvorschriften sah den Erlaß von örtlichen Vorschriften alternativ auf zwei Wegen vor. Sie waren entweder als Ortssatzungen von den Gemeinden oder als Baupolizeiverordnung von einer staatlichen Behörde zu erlassen. Das jeweilige Verfahren bestimmte nach $\S 3$ Abs. 3 BaugestVO die oberste Landesbaubehörde. Diese sollte die Entscheidung

\footnotetext{
${ }^{19}$ Schmidt-Aßmann, Festgabe für von Unruh, S. 607; Maurer, Allgemeines Verwaltungsrecht, § 4 Rn. 14, S. 48.

${ }^{20}$ So etwa Gaentzsch, DSt. 1969, S. 377; Moench / Schmidt, S. 32; Schlotterbeck, in: Schlotterbeck / von Arnim, § 73 Rn. 1; Orlloff, Öffentliches Baurecht, Band II, S. 32.

${ }^{21}$ Siehe etwa Art. 23 S. 2 BayGO; Masson / Samper, Art. 23 Rn. 6; Lerche, DB Beilage Nr. $6 / 69$, S. 6. Ausführlich unten B III 4.

22 In diesem Sinne etwa BayVGH, Urteil vom 29.10.1985, BayVBI. 1986, S. 213 und neuerdings auch Simon, Art. 91 Anm. 1, Bearbeitungsstand November 1988. Anders noch ders., ebenda, Bearbeitungsstand April 1983. Zur Einordnung in den übertragenen Wirkungskreis tendiert der BayVGH auch im Beschluß vom 19.11.1985, BayVBI. 1986, S. 370 f., 371. Hierfür auch Löhr, in: Battis / Krautzberger / Löhr, § 9 Rn. 111. Die Kommentierung von Löhr ist jedoch schon deshalb unrichtig, weil nicht nach der jeweiligen landesrechtlichen Rechtslage unterschieden wird. Eine einheitliche Aussage ist aber nicht möglich, siehe dazu die folgenden Ausführungen. Vergleiche im übrigen $\S 57$ Abs. 2 S. 2 BauO NW, der ausdrücklich klarstellt, $\mathrm{da} B$ der Erlaß von örtlichen Bauvorschriften nicht zum Bereich der Gefahrenabwehr zählt. Für die Zugehörigkeit des Erlasses örtlicher Bauvorschriften zu den Staatsaufgaben und damit zum übertragenen Wirkungskreis hingegen die Gesetzesbegründung zur LBO BW, siehe BW LTDrs. 8/3410, S. 120.
} 
landeseinheitlich danach treffen, welches Verfahren für die Abstufung der Bebauung vorgesehen war $^{23}$. Es handelte sich daher beim Erlaß von Vorschriften über die Baugestaltung um eine grundsätzlich staatliche Aufgabe, die entweder von einer staatlichen Behörde durch Rechtsverordnung oder von der Gemeinde durch Satzung erfüllt wurde. Die Rechtsform Satzung fand somit deshalb Eingang in das Recht örtlicher Bauvorschriften, weil und soweit diese von den Gemeinden erlassen wurden, nicht deshalb, weil es sich um eine Selbstverwaltungsangelegenheit handelte.

Da sich systematisch und historisch sowohl Argumente für eine Einordnung zu den Selbstverwaltungs- als auch zu den übertragenen Angelegenheiten finden, verwundert es nicht, daß die Landesgesetzgeber sich in diesem Punkt nicht einheitlich entschieden haben. Es lassen sich 3 Kategorien unterscheiden:

1. Zunächst gibt es den Fall der eindeutigen Zuordnung zum übertragenen Wirkungskreis durch $\S 56$ i. V. m. 97 Abs. 1 S. 1 NBauO.

2. Desweiteren findet sich der Fall der Inbezugnahme von $\S 11 \mathrm{~S} .2$ $\mathrm{BBauG}^{24}$ oder $\S 11$ Abs. $2 \mathrm{BauGB}^{25}$. $11 \mathrm{~S} .2 \mathrm{BBauG} /$ \& 11 Abs. 2 BauGB erklären für die Genehmigung von Bebauungsplänen den $\S 6$ Abs. 2 BBauG / BauGB für anwendbar. § 6 Abs. 2 BBauG / BauGB sieht für den Erlaß eines Flächennutzungsplans nur eine Rechtmäßigkeitskontrolle vor. Dies läßt bei entsprechender Anwendung auf örtliche Bauvorschriften auf einen Erlaß im eigenen Wirkungskreis schließen. Die Vorschriften in den Landesbauordnungen, die auf das BBauG / BauGB verweisen, gelten jedoch zunächst nur für den Fall, daß örtliche Bauvorschriften als Festsetzungen in den Bebauungsplan aufgenommen werden. Da jedoch der $\S 9$ Abs. 4 BauGB und die entsprechenden landesbauordnungsrechtlichen Bestimmungen, die eine Aufnahme ermöglichen, am materiell bauordnungsrechtlichen Charakter der Vorschriften nach überwiegender Meinung nichts ändern sollen ${ }^{26}$, läßt sich diesen Verweisungsvorschriften der Hinweis entnehmen, daß die örtlichen Bauvorschriften schlechthin, also auch dann,

23 RdErl. des Reichsarbeitsministers betr. Verordnung über die Baugestaltung vom 17.12.1936, RArbBI. 1937 I, S. 4, zu §§ 2 und 3, Abs. 10, abgedruckt bei Büge / Zinkahn, S. 142 ff. Es handelte sich insoweit um eine Zweckmäßigkeitsfrage, siehe Büge / Zinkahn, S. 33.

${ }^{24}$ Die Landesbauordnungen sind weitgehend noch nicht an das BauGB angepaßt. Siehe insoweit $\S 81$ Abs. 4 2. HS BauO NW; $§ 86$ Abs. 6 S. 2 LBauO Rh.Pf. Zu der Frage, ob es sich um eine statische oder dynamische Verweisung handelt, siehe unten E I 2 b.

${ }^{25} \S 83$ Abs. 4 LBO Saarl.

${ }^{26}$ Löhr, in: Battis / Krautzberger / Löhr, § 9 Rn. 107 und 111. 
wenn sie als selbständige Satzung erlassen werden, nur einer Rechtmäßigkeitskontrolle unterliegen und demgemäß dem Selbstverwaltungsbereich zuzuordnen $\operatorname{sind}^{27}$.

3. Schließlich gibt es noch Landesbauordnungen, bei denen ein Verweis auf $\S 11$ S. 2 BBauG / § 11 Abs. 2 BauGB nicht erfolgt ist und die auch sonst keine Klarstellung der Frage enthalten. Dies gilt für $\S 73 \mathrm{LBO}$ BW, Art. 91 BayBauO und $\S 118$ HBO. Im Bereich dieser Landesbauordnungen fällt eine Lösung der Einordnungsfrage schwer ${ }^{28}$. Vor allem für den Bereich der BayBO bietet sich das Argument an, da $\beta \S 11$ S. 2 BBauG gerade nicht, sondern nur $\S 11 \mathrm{~S}$. 1 in bezug genommen worden ist. Ganz zwingend ist dies aber nicht. Die Verweisung auf $\S 11 \mathrm{~S} .2$ BBauG erfolgt auch hier im Rahmen der Vorschriften, die gelten sollen, wenn die örtlichen Bauvorschriften in den Bebauungsplan aufgenommen werden ${ }^{20}$. Daraus könnte man bei ausdrücklicher Erwähnung des $\S 11 \mathrm{~S}$. 2 BBauG den vom Gesetzgeber möglicherweise nicht beabsichtigten Schluß ziehen, daß im Fall der Aufnahme in den Bebauungsplan ein anderer Prüfungsmaßstab gelten soll als bei einem schlichten Satzungserlaß, also insoweit keine Analogie, sondern einen Umkehrschluß vornehmen. Insofern hat die Nichterwähnung des $\S 11$ S. 2 BauGB unter Umständen einen guten Sinn, nämlich nichts zu regeln, was ohnehin schon gilt. Weiterhin ist die Umwandlung der Verordnungsermächtigung in eine Satzungsermächtigung durch die Novelle zur BayBO vom 02.07.1982 zumindest ein Indiz dafür, daß der Gesetzgeber mit der Rechtsform auch inhaltlich etwas ändern wollte ${ }^{30}$. Ansonsten wäre nicht erklärlich, was die Gesetzesänderung sollte ${ }^{31}$.

Angesichts der Tatsache, daß Satzungen, die im übertragenen Wirkungskreis erlassen werden, eher die Ausnahme bilden, sprechen für alle drei Bauordnungen insgesamt die besseren Gründe dafür, daß von einer reinen Rechtmäßigkeitskontrolle und somit von einem Erlaß im eigenen WirS. 92.

${ }^{27}$ Rößler, S. 484. So auch die Gesetzesbegründung zu $\$ 81$ BauO NW, LT-Drs. 9/2721,

${ }^{28}$ Für eigenen Wirkungskreis etwa Schlotterbeck, in: Schlotterbeck / von Arnim, § 73 Rn. 1; DVBayBO vom 02.07.1982, GVBI. S. 15. Für übertragenen Wirkungskreis Koch / Molodovsky / Rahm, Art. 91 Anm. 4.1.1.; Stadtler / Baumgartner / Wiebel, Art. 91 Anm. I; Sauter, § 111 Rn. 21; Simon, Art. 91 Anm. 1 (Stand November 1988, anders Stand April 1983).

${ }^{29}$ Anders allerdings $\$ 73$ Abs. 4 LBO BW.

30 Ähnlich für die Rechtslage in NRW auch OVG Münster, Urteil vom 30.06.1983, BRS Band 40, Nr. 152 S. 337; auch Gaentzsch, DSt. 1969, S. 377.

${ }^{31}$ So auch Keller, S. 23 f. Daß der künftige Erlaß im eigenen Wirkungskreis dem Willen des bayerischen Gesetzgebers entsprach, ergibt auch die Gesetzesbegründung. Siehe Bay.LTDrs. $8 / 7854$, S. $50 \mathrm{zu} \S 1$ Nr. 104 (Art. 107) a. 
kungskreis auszugehen ist. Zugegebenermaßen ist aber auch die entgegengesetzte Auffassung vertretbar.

\section{Der verfassungsrechtliche Spielraum bei der Einordnung von örtlichen Bauvorschriften}

\section{Problemstellung}

Die Analyse des einfachen Rechts hat ergeben, daß insgesamt die besseren Gründe dafür sprechen, daß örtliche Bauvorschriften im eigenen Wirkungskreis erlassen werden ${ }^{32}$, da $\beta$ aber die Annahme eines Erlasses im übertragenen Wirkungskreis ebenfalls vertretbar ist. Eine abschließende Entscheidung der Einordnungsfrage kann jedoch nicht erfolgen ohne eine Berücksichtigung der verfassungsrechtlichen Garantie der kommunalen Aufgabenerfüllung in Art. 28 Abs. 2 S. 1 GG. Dabei stellen sich zwei Hauptprobleme. Das eine ist die Frage, ob nicht die Zuordnung zum eigenen Wirkungskreis von Verfassungs wegen zwingend ist. Dies ergibt sich aus folgender Überlegung: Nach Auffassung des BVerfG und der ganz überwiegenden Meinung in der Literatur handelt es sich bei Art. 28 Abs. 2 GG um eine institutionelle Garantie der kommunalen Selbstverwaltung, die den Gemeinden die eigenverantwortliche Erfüllung bestimmter Aufgaben, nämlich solcher mit vor allem örtlichem Bezug garantiert ${ }^{33}$. Dieser grundsätzlich geschützte Bereich ist jedoch gesetzlichen Einwirkungen zugänglich, soweit sie den Kernbereich der kommunalen Selbstverwaltung unangetastet las$\operatorname{sen}^{34}$. So wird in der Literatur etwa die "Planungshoheit" und damit vor allem die Befugnis zur Bauleitplanung zu diesem Kernbereich gezählt ${ }^{35}$.

${ }^{32}$ Ausnahme: Die Rechtslage in Niedersachsen, siehe $\S 56,97$ NBauO.

${ }^{33}$ Dazu ausführlich Strüer, S. 83 ff.; weiterhin etwa Badura, DÖV 1963, S. 565; von Mutius, Deutsche Verwaltungsgeschichte, Band 5, S. 335; Bethge, Die Verwaltung 15 (1982), S. 205 ff., ders., Festgabe für von Unruh, S. 149 ff. Zwar bezeichnet Schmidt-Jortzig, Kommunalrecht, Rn. 513, die Annahme einer institutionellen Garantie als unstreitig. Es gibt jedoch auch einige Gegenstimmen. Siehe etwa Richter, Verfassungsprobleme, S. 86; weiterhin Knemeyer, Festgabe für von Unruh, S. 219 ff.; Knemeyer / Emmert, JZ 1982, S. 285.

${ }^{34}$ Siehe etwa BVerfG, Beschluß vom 17.01.1967, E 21, 117 (128); Beschluß vom 21.05.1968, E 23, 353 (364); Beschluß vom 24.06.1969, E 26, 228 (238); Urteil vom 10.12.1974, E 38, 258 (278) und neuerdings vor allem Beschluß vom 23.11.1988, DVBI. 1989, S. 300 (301), jeweils mit weiteren Nachweisen.

35 Siehe etwa Erichsen, Kommunalrecht, S. 194; Schultze, S. 77; Gaentzsch, HbKWP, Band 3, S. 371; Giegerich, JA 1988, S. 374; Funke / Schroer, ZG 1986, S. 262; Erbguth, Jura 1988, S. 566; Köstering, DÖV 1981, S. 691; Hoppe, in: Festgabe für von Unruh, S. 568, ders., 
Durch die Qualifizierung der üblichen Festlegungen in örtlichen Bauvorschriften als "potentielles Bauplanungsrecht" ${ }^{136}$ stellt sich daher die Frage, ob nicht auch der Erlaß von örtlichen Bauvorschriften zum Kernbereich gehört. Das würde dazu führen, daß gesetzgeberische Beschränkungen der von Art. 28 Abs. 2 S. 1 GG garantierten Eigenverantwortlichkeit unzulässig wären. Eine Einordnung in den eigenen Wirkungskreis wäre damit zwingend.

Selbst wenn sich eine Zugehörigkeit des Erlasses örtlicher Bauvorschriften zum Kernbereich der kommunalen Selbstverwaltung nicht nachweisen ließe, ergibt sich als weiteres Problem, ob der Gesetzesvorbehalt des Art. 28 Abs. 2 S. 1 GG ("im Rahmen der Gesetze") die Unterstellung des Erlasses von örtlichen Bauvorschriften unter die Fachaufsicht erlaubt. Denkbar ist auch, daß bei Zuordnung zum übertragenen Wirkungskreis ein Qualifikationfehler vorliegen würde, weil zu Unrecht von einer überörtlichen und nicht von einer örtlichen Angelegenheit ausgegangen wird ${ }^{37}$.

\section{Alternative Konzeptionen zur Auslegung des Art. 28 Abs. 2 GG}

Die oben genannten Fragen stellen sich nun von vornherein nicht, wenn man die Ansichten von BVerfG und herrschender Lehre zur Auslegung von Art. 28 Abs. 2 GG verwirft und stattdessen einer alternativen Auffassung folgt. Hierfür bietet sich vor allem das sog. funktionelle Selbstverwaltungsverständnis ${ }^{38}$ und die "Neukonzeption" Burmeisters ${ }^{39}$ an. Dem funktionellen Selbstverständnis liegt das Modell eines Leistungs- und Verwaltungsverbundes zwischen kreisangehörigen Gemeinden und Kreisen zugrunde ${ }^{40}$. Die Verteilung der Aufgaben zwischen beiden Verwaltungsträgern erfolgt da-

HbStR, Band III, S. 703 Rn. 106; Grave, BauR 1980, S. 206; Zöllner, BayVBI. 1987, S. 551; Schmidt-Aßmann, Kommunalrecht, S. 118, der jedoch offen läßt, ob dies für alle in § 9 Abs. 1 BauGB genannten Festsetzungen gilt. Ebenso ders., Festschrift für Fabricius, S. 257. Etwas unklar Ronellenfitsch, S. 34, wonach § 2 Abs. $1 \mathrm{~S} .1 \mathrm{BBauG}$ "faktisch" Verfassungsrang habe, es aber zu begrüßen sei, daß das BVerfG eine Festlegung vermieden habe. Weitere Nachweise bei Blümel, VerwArchiv 75 (1982), S. 341.

${ }^{36}$ Siehe oben A III 4.

${ }^{37}$ Dazu ausführlich unten B II 4.

${ }^{38}$ Siehe Roters, Kommunale Mitwirkung, etwa S. 210.

39 Verfassungstheoretische Neukonzeption der kommunalen Selbstverwaltungsgarantie, 1977.

${ }^{40}$ Vgl. Pappermann, DÖV 1973, S. 508, ders., VerwArchiv 65 (1974), S. 176, ders., DÖV 1975, S. 183. 
nach im Sinne einer höchstmöglichen Effizienz der Aufgabenerledigung ${ }^{41}$. Eine verfassungsrechtlich zwingende Zuordnung einer Aufgabe zu den Gemeinden soll es nicht geben ${ }^{42}$, so daß weder die Frage der Zuordnung zum Kernbereich noch die angedeuteten Qualifikationsprobleme viru-lent werden. Das funktionelle Selbstverständnis scheitert jedoch schon am Wortlaut der Verfassung ${ }^{43}$. Der Idee eines Leistungs- und Verwaltungsverbundes steht vor allem entgegen, daß die Garantie des Art. 28 Abs. 2 S. 1 GG für die Gemeinden auch gegenüber den Kreisen gilt ${ }^{44}$. Der Vorschlag, den Wortlaut des Art. 28 Abs. 2 S. 1 GG im Sinne des funktionellen Selbstverständnisses zu ändern ${ }^{45}$, bestätigt letztlich, daß de constitutione lata eine solche Interpretation der kommunalen Selbstverwaltungsgarantie des GG nicht möglich ist ${ }^{46}$.

Nach der Neukonzeption Burmeisters ist die gemeindliche Selbstverwaltungsgarantie ein staatsorganisatorisches Aufbauprinzip, wonach die $\mathrm{Ge}$ meinden grundsätzlich untere Vollzugsinstanz der staatlichen Verwaltungsaufgaben $\operatorname{sind}^{47}$. Den Gemeinden seien überall dort Wahrnehmungskompetenzen garantiert, wo die Erfüllung von Aufgaben mit unmittelbarer Bedeutung für die örtliche Gemeinschaft anstehe ${ }^{48}$. Folgt man der Konzeption Bumeisters, erledigt sich die Frage nach der Zugehörigkeit des Erlasses örtlicher Bauvorschriften zum Kernbereich der kommunalen Selbstverwaltung. Ein solcher Kernbereich unantastbarer gemeindlicher Wahrnehmungskompetenzen existiert nach dieser Auffassung nicht ${ }^{49}$. Auch die der herrschenden Meinung zugrunde liegende Unterscheidung von "örtlichen" und "überörtlichen" Aufgaben wird von Burmeister verworfen ${ }^{50}$. Daher würde sich auch das Qualifikationsproblem nicht stellen.

\footnotetext{
${ }^{41}$ Pappermann, VerwArchiv 65 (1974), S. 176.

${ }^{42}$ Pappermann (Fn. 41)..

${ }^{43}$ Blümel, VVDStRL 36 (1977), S. 247 ff.; von Mutius, Jura 1982, S. 31, ders., Festgabe für von Unruh, S. 236 und 249, ders., DJT-Gutachten, S. 18, 21, ders., BayVBI. 1988, S. 645; Stern, HbKWP, Band 1, S. 209.; Erbguth, Bauplanungsrecht, S. 5 Rn. 9.

${ }^{44}$ So jetzt vor allem BVerfG, Beschluß vom 23.11.1988, DVB1. 1989, S. 300 (303). Anders etwa Pappermann, DÖV 1975, S. 187.

${ }^{45}$ Pappermann, DÖV 1973, S. 508, ders., DÖV 1975, S. 187.

${ }^{46}$ Siehe auch die Kritik von Schmidt-Jortzig, Kommunalrecht, Rn. 499 und 500.

${ }^{47}$ Burmeister, Neukonzeption, S. 105.

${ }^{48}$ Burmeister, Neukonzeption, S. 74; zustimmend Oebbecke, DVBI. 1987, S. 870.

${ }^{49}$ Burmeister, Neukonzeption, S. 100.

${ }^{50}$ Burmeister, Neukonzeption, S. 70 ff.
} 
Im Rahmen dieser Arbeit ist - genausowenig wie im Hinblick auf das funktionelle Selbstverwaltungsverständnis - weder eine umfassende Darstellung der Neukonzeption noch eine umfassende Kritik möglich. Es erscheint jedoch mehr als zweifelhaft, ob man den Gemeinden den angestrebten guten Dienst erweist, wenn man - wie Burmeister in seiner Neukonzeption - völlig mit den traditionellen Vorstellungen bricht und durch einen radikalen Neuansatz versucht, zu einem effektiveren Schutz zu kommen ${ }^{51}$. So gibt es vor allem in neuerer Zeit einige Entwicklungen in Literatur und Rechtsprechung, die durchaus auf der Habenseite der Bemühungen um eine Stärkung der kommunalen Selbstverwaltung stehen, jedoch den Bruch mit der Tradition vermeiden und mit der Konzeption Burmeisters nicht recht in Einklang zu bringen sind. Ein Beispiel ist etwa die Diskussion um das sog. Selbstgestaltungsrecht der Gemeinden ${ }^{52}$. Das Recht einer Gemeinde, ihr Gepräge und ihre Struktur selbst zu bestimmen ${ }^{53}$, kann sich nur aus einer materialen Garantie der Erfüllung von spezifisch nur sie betreffenden Angelegenheiten ergeben ${ }^{54}$. Ein weiterer Habenposten der Gemeinden ist die in letzter Zeit verstärkte Betonung des Übermaßverbotes bei Eingriffen in die kommunale Selbstverwaltung ${ }^{55}$. Lehnt man ein Verständnis des Art. 28 Abs. 2 GG im Sinne einer materialen Garantie ab und macht man die Gemeinden so zu Untereinheiten der Staatsverwaltung, so wird die auch von Burmeister befürwortete Anwendung des Übermaßverbotes als Grenze für "staatliche" Tätigkeitskontrolle ${ }^{56}$ in besonderer Weise rechtfertigungsbedürftig. Dies hat seinen Grund darin, daß zumindest überwiegend das Übermaßverbot aus den Grundrechten abgeleitet wird ${ }^{57}$. Zwar geht das BVerfG auch von einer Fundierung des Übermaßverbotes im Rechtsstaats-

${ }^{51}$ In diese Richtung gehen auch die Bedenken von Erbel, Die Verwaltung 11 (1978), S. 505; Brohm, DVBI. 1984, S. 296; Hendler, Selbstverwaltung, S. 203.

52 Siehe dazu unten B I 3 a.

${ }^{53}$ So die Definition von Blümel, Festschrift Ule, S. 19.

${ }^{54}$ Zur Ablehnung eines materialen Substrats an Aufgaben siehe Burmeister, Neukonzeption, S. 71.

${ }^{55}$ BVerfG, Beschluß vom 07.10.1980, E 56, 298 (313 f.); BVerwG, Urteil vom 04.08.1983, E 67, 321 (323) - Rastede - ; Blümel, Festgabe für von Unruh, S. 299; Schink, Subsidiaritätsprinzip, S. 63, ders., DVBI. 1983, S. 1172; Widera, S. 58 f.; Hinkel, NVwZ 1985, S. 229; Hendler, Selbstverwaltung, S. 199; Hassel, VerwRundschau 1984, S. 147.

${ }^{56}$ Siehe Burmeister, Neukonzeption, S. 106 und $136 \mathrm{ff}$.

${ }^{57}$ Vgl. Alexy, Theorie der Grundrechte, S. 100 ff.; Dechsling, Verhältnismäßigkeitsgebot, S. 85 f. mit weiteren Nachweisen; Jakobs, Verhältnismäßigkeit, S. 44; Langheineken, S. 99 ff. Siehe auch Hassel, VerwRundschau 1984, S. 148: Nutzung der zu den Grundrechten entwickelten Regeln für Art. 28 Abs. 2 GG. 
prinzip aus ${ }^{58}$. Hierfür fehlt es jedoch an einer Begründung, was eine Argumentation auf der Grundlage dieser Rechtsprechung zu einem unsicheren Unterfangen macht ${ }^{59}$. Will man sich wie Burmeister im Bereich des Art. 28 Abs. 2 GG von grundrechtlich geprägten Sichtweisen generell lösen ${ }^{60}$, so muß man sich fragen lassen, warum damit nicht auch das Übermaßverbot verabschiedet wird. Damit droht der Verlust des nach dem gegenwärtigen Stand der Dogmatik wichtigsten Schutzinstrumentes.

Der zweite Einwand gegen eine völlige Neuorientierung im Sinne Burmeisters ist die Tatsache, daß seine Neukonzeption zwar in vielen, aber durchaus nicht in allen Punkten überzeugt. So will Burmeister den Gemeinden nur dort Wahrnehmungskompetenzen einräumen, wo es um die Erfüllung einer Aufgabe mit unmittelbarer Bedeutung für die örtliche Gemeinschaft geht ${ }^{61}$. Dies soll daraus folgen, daß Art. 28 Abs. 2 GG von "allen Angelegenheiten der örtlichen Gemeinschaft" und nicht von "allen örtlichen Angelegenheiten der Gemeinschaft" spreche, so daß die Beschränkung der Gemeinden auf örtliche Angelegenheiten verfehlt sei ${ }^{62}$. Grundsätzlich lassen sich für diese Kritik an der traditionellen Auffassung gute Gründe anfüh$\operatorname{ren}^{63}$. Was man sich jedoch unter "unmittelbarer" Bedeutung vorstellen soll, bleibt wegen fehlender Exemplifizierung weitgehend unklar ${ }^{64}$. Das vor allem angeführte Wortlautargument ist zudem angreifbar. Eine Textinterpretation des Art. 28 Abs. 2 S. 1 GG spricht keineswegs zwingend gegen die traditionelle Sichtweise, wonach Angelegenheiten mit primär überörtlichem Bezug nicht unter die Garantie der gemeindlichen Selbstverwaltung fallen ${ }^{65}$, denn das sind dann nach dieser Auffassung eben keine Angelegenheiten der örtlichen, sondern der überörtlichen Gemeinschaft.

Auch die Folgerungen, die Burmeister aus seiner Neukonzeption zieht, überzeugen nicht und führen so zu Bedenken gegen die Richtigkeit seiner

${ }^{58}$ Siehe etwa BVerfG, Beschluß vom 14.12.1965, E 19, 330 (348); Beschluß vom 05.03.1968, E 23, 127 (133) m. w. N.; Beschluß vom 31.07.1987, E 75, 1 (16); Beschluß vom 12.05.1987, E 76, 1 (50).

59 Zur Ablehnung einer Ableitung des Übermaßverbotes aus "dem" Rechtsstaatsprinzip siehe Dechsling, Verhältnismäßigkeitsgebot, S. 121; Langheinecken, S. 83.

${ }^{60}$ Burmeister, Neukonzeption, S. 88.

${ }^{61}$ Burmeister, Neukonzeption, S. 71.

${ }^{62}$ Burmeister, Neukonzeption, S. $70 \mathrm{ff}$.

${ }^{63}$ Siehe ausführlicher unten B II $4 \mathrm{~b}$.

${ }^{64}$ Kritisch deshalb auch Erbel, Die Verwaltung 11 (1978), S. 502.

65 Siehe BVerfG, Urteil vom 30.06.1958, E 8, 122 ff. (134). Weitere Nachweise bei Burmeister, Neukonzeption, S. 21 und unten im Text. 
Prämissen. Das gilt vor allem für die Annahme, das dualistische Aufgabensystem sei verfassungswidrig ${ }^{66}$. Auch die übertragenen Angelegenheiten nach dem dualistischen System sind kompetenzmäßig "eigene" und keine "fremden" Angelegenheiten der Gemeinden, ein gewisser Unterschied besteht höchstens im Maß der staatlichen Aufsicht, ohne daß hierzu eindeutige Aussagen möglich wären ${ }^{67}$. Zwar mag dem dualistischen System in Idee und Terminologie der Gedanke der Trennung von staatlichem und kommunalem Wirkungskreis zugrunde liegen; das monistische und das dualistische System sind aber praktisch weitgehend vergleichbar ${ }^{68}$.

Sowohl das funktionelle Selbstverständnis als auch die Neukonzeption Burmeisters sehen sich somit zu vielen Einwänden ausgesetzt, als daß sie pauschal an die Stelle der bisherigen Dogmatik zum Art. 28 Abs. 2 S. 1 GG treten könnten. Die oben dargestellten Einordnungsfragen müssen deshalb gelöst werden. Zeigen sich hierbei Ungereimtheiten und Widersprüche in der herrschenden Meinung, wird jedoch möglicherweise auf den einen oder anderen Aspekt vor allem der Neukonzeption Burmeisters zurückzukommen sein.

\title{
3. Örtliche Bauvorschriften und Kernbereich der kommunalen Selbstverwaltungsgarantie
}

\author{
a) Die Rechtsprechung des BVerfG zum Problem \\ des Kernbereichs der kommunalen Selbstverwaltung
}

Für die vorliegende Untersuchung soll grundsätzlich vom herrschenden Verständnis zur Auslegung des Art. 28 Abs. 2 GG ausgegangen werden. Es stellt sich somit das Problem, ob örtliche Bauvorschriften dem Kernbereich der kommunalen Selbstverwaltung zuzuordnen sind. Wenn dies der Fall wäre, könnten sie nur im eigenen Wirkungskreis erlassen werden.

Eine Äußerung des BVerfG speziell zu dieser Frage gibt es nicht. Aber auch wenn man die Rechtsprechung des Gerichts zum Problem des Kernbereichs im übrigen durchsieht, erhält man kein zumindest einigermaßen eindeutiges Kriterium dafür, wann eine Aufgabe zum absolut geschützten Bereich der kommunalen Selbstverwaltung gehört. Vielmehr bestätigt sich

\footnotetext{
${ }^{66}$ Burmeister, Neukonzeption, S. $116 \mathrm{ff}$.

${ }^{67}$ Siehe dazu oben B 11.

${ }^{68}$ Siehe oben B I 1.
} 
die Aussage, daß eine genaue Definition des Kernbereichs bisher in der Rechtsprechung noch nicht stattgefunden hat ${ }^{69}$. So bestimmt die vom BVerfG häufig abgestellte historische Betrachtungsweise in aller Regel nicht das positive Substrat der kommunalen Selbstverwaltung, sondern die Herkömmlichkeit der von den Gemeinden im Wege der Verfassungsbeschwerde gerügten Beeinträchtigungen ${ }^{70}$. Eine Umschreibung des Kernbereichs der kommunalen Selbstverwaltung erfolgt in der Rechtsprechung des BVerfG somit wenn überhaupt so nur relativ schemenhaft über die Skizzierung zulässiger Grenzen staatlicher Eingriffsrechte ${ }^{71}$.

Im sog. Memmingen-Beschlu $\beta^{72}$ dürfte deutlich geworden sein, daß Antworten auf Fragen nach der Zugehörigkeit sog. funktioneller Aufgaben - als funktionelle Angelegenheiten lassen sich solche Angelegenheiten bezeichnen, die die Gemeinden im Rahmen ihrer örtlichen Zuständigkeit zu einer bestimmten Zweckerreichung wahrnehmen, im Gegensatz zu den institutionellen, die sich auf die Erhaltung und Funktionsfähigkeit der Kommunen beziehen $^{\text {T3 }}$ - vom BVerfG in absehbarer Zeit nicht zu erwarten sind. Zwar gab das Gericht einer kommunalen Verfassungsbeschwerde statt, ließ aber offen, ob die "Planungshoheit", die in der Literatur besonders gerne zum Kernbereich der kommunalen Selbstverwaltung gezählt wird ${ }^{74}$, wirklich zum Kernbereich gehört ${ }^{75}$. Später hat das BVerfG sogar ausdrücklich ausgesprochen, daß zum Wesensgehalt der kommunalen Selbstverwaltung kein gegenständlich bestimmter oder nach feststehenden Merkmalen bestimmbarer

\footnotetext{
${ }^{99}$ Wolf Weber, S. 12.

${ }^{70}$ So auch von Mutius / Schoch, DVBI. 1981, S. 1080. Siehe etwa BVerfG, Beschluß vom 29.04.1958, E 7, 358 (364): "Art. 28 Abs. 2 GG schließt eine Regelung nicht aus, die auf Grund der geschichtlichen Entwicklung des Kommunalrechts als mit dem Wesen der kommunalen Selbstverwaltung vereinbar angesehen wird"; Beschluß vom 26.11.1963, E 17, 172 (182): "Gewisse Beeinträchtigungen der Personalhoheit der Gemeinden sind herkömmlich"; Beschluß vom 17.01.1967, E 21, 117 (130): "Gewisse Beschränkungen können auch abgesehen von ... Herkömmlichkeit zulässig sein"; Beschlüsse vom 21.05.1968 und 10.12.1974, E 23, 353 (367) und E 38, 258 (279): "Auch Änderungen, die in der Linie einer vernünftigen Fortentwicklung des Systems liegen, sind zulässig."

${ }^{71}$ Nicht ganz zutreffend somit Macher, S. 62.

72 BVerfG, Beschluß vom 07.10.80, E 56, $298 \mathrm{ff}$.

${ }^{73}$ Siehe Niemeier, Bund und Gemeinden, S. 135; Schmidt-Jortzig, Organisationshoheit, S. 127 ff.; von Mutius / Schoch, DVBl. 1981, S. 1078 m. w. N. Das Gleiche ist wohl gemeint, wenn zwischen Existenz- und Zweckaufgaben unterschieden wird. Siehe dazu Schmidt-Jortzig, Kommunalrecht, Rn. 505.

${ }^{74}$ Ausführliche Nachweise oben B II 1, Fn. 35.

75 Beschluß vom 07.10.1980, E 56, 298 (312). Dem folgend etwa BayVGH, Urteil vom 07.07.1983, DVBI. 1983, S. 1157 (1160). Die Frage wurde vom BVerfG noch einmal ausdrücklich offen gelassen im Beschluß vom 23.06.1987, E 76, 107 (119).
} 
Aufgabenkatalog gehöre ${ }^{76}$. Damit erübrigt sich praktisch die Diskussion, ob eine bestimmte Aufgabe in den Kernbereich fällt und damit zwingend zum eigenen Wirkungskreis gehört.

\section{b) Das Problem der Zuordnung der Bauleitplanung zum Kernbereich}

Bei der Frage der Zuordnung funktioneller Angelegenheiten in den Kernbereich der kommunalen Selbstverwaltung ist es für die vorliegende Untersuchung von besonderem Interesse, wie diese Frage für die Befugnis zur Bauleitplanung entschieden wird. Zumindest wenn die Antwort im Hinblick auf das für die gemeindliche Planungstätigkeit zentrale Institut der Bauleitplanung dahingehend lautet, da $B$ die Zugehörigkeit zum Kernbereich zu verneinen ist, kann für die Befugnis zum Erlaß örtlicher Bauvorschriften, die ja weitgehend nur zu ergänzenden Festlegungen ermächtigen, nichts anderes gelten.

Die Enthaltsamkeit der BVerfG vor allem im Memmingen-Beschlu $\beta^{\pi}$ in bezug auf die Entscheidung der Frage, ob die "Planungshoheit" zum Kernbereich des Art. 28 Abs. 2 S. 1 GG gehört, hat eine ausführliche Untersuchung dieser Frage veranla $\mathrm{Bt}^{78}$. Widera kommt dabei $\mathrm{zu}$ dem Ergebnis, sowohl die Flächennutzungsplanung als auch die Aufstellung von Bebauungsplänen fielen in den "Kernbereich" der kommunalen Selbstverwaltungsgarantie und seien gegen einen gesetzgeberischen Entzug absolut geschützt ${ }^{79}$.

Zuzustimmen ist Widera zunächst darin, daß die häufig anzutreffende These, wonach die "Planungshoheit" den Gemeinden durch Art. 28 Abs. 2 GG garantiert sei, zwar plakativ, aber letztlich wenig aussagekräftig ist. Der Begriff der "Planungshoheit" ist zu diffus, um einer unmittelbaren Subsumtion unter Art. 28 Abs. 2 GG fähig zu sein. Vielmehr muß die Frage nach dem Umfang der gemeindlichen Selbstverwaltungsgarantie und auch die nach der Zugehörigkeit zum Kernbereich anhand der einzelnen Sachfrage, z. B. der Flächennutzungsplanung oder der Bebauungsplanaufstellung geklärt werden ${ }^{80}$.

\footnotetext{
${ }^{76}$ BVerfG, Beschluß vom 23.11.1988, DVBI. 1989, S. 301.

$\pi$ BVerfG, Beschluß vom 07.10.80, E 56, $298 \mathrm{ff}$.

${ }^{78}$ Widera, Zur verfassungsrechtlichen Gewährleistung gemeindlicher Planungshoheit, 1985.

${ }^{79}$ Widera, S. 123, 127.

${ }^{80}$ Widera, S. 81, $106 \mathrm{ff}$.
} 
Es fällt jedoch schwer, überzeugende Argumente für die angenommene Zugehörigkeit der Flächennutzungsplanung oder des Erlasses von Bebauungsplänen zum Kernbereich der gemeindlichen Selbstverwaltungsgarantie zu finden. Zwar ist die Bauleitplanung und vor allem die Befugnis zum Erlaß von Bebauungsplänen derzeit unstreitig eines der wichtigsten Instrumente der Gemeinden zur Gestaltung der örtlichen Lebensverhältnisse. Zuzugeben ist auch, daß derzeit keine Gründe ersichtlich sind, die angesichts des die Kompetenzen der Gemeinde schützenden Übermaßverbotes einen Entzug der Bauleitplanung rechtfertigen könnten ${ }^{81}$. Dies allein reicht aber noch nicht aus, die Befugnis zur Bauleitplanung durch Einordnung in den Kernbereich der gemeindlichen Selbstverwaltungsgarantie von vornherein jedem Zugriff des einfachen Gesetzgebers zu entziehen. Denn die Frage, ob eine Aufgabe im funktionellen Sinn zum Kernbereich gehört, ist in dieser Form - so ist wohl auch die neuere Rechtsprechung des BVerfG zu verste$h^{82}$ - überhaupt nicht beantwortbar. Eine positive Definition des Kernbereichs in Form der Kennzeichnung, Beschreibung oder Nennung bestimmter Aufgaben ist in der Rechtsprechung des BVerfG zu Recht nicht erfolgt. Eine solche positive Definition wäre im günstigsten Fall überflüssig und im ungünstigsten Fall schädlich, und zwar aus einer Reihe von Gründen.

Zunächst sei klargestellt, daß die Prämisse eines dem Gesetzgeber verschlossenen Kernbereichs sich nur dann ergibt, wenn man davon ausgeht, daß Art. 28 Abs. 2 GG eine institutionelle Garantie enthält. Leugnet man das Vorliegen einer institutionellen Garantie, dann stellt sich das Problem des Kernbereichs von vornherein nicht ${ }^{83}$, und zwar auch nicht durch Art. 19 Abs. 2 GG. Diese Vorschrift hat schon als Eingriffsschranke im Grundrechtsbereich kaum Relevanz erlangt ${ }^{84}$, so daß kein Anlaß besteht, sie systemwidrig auf den Art. 28 Abs. 2 GG anzuwenden. Institutionelle Garantien wurden in der Weimarer Zeit entwickelt, um bestimmten verfassungsrechtlichen Regelungen einen Schutz auch gegen den einfachen Gesetzgeber zu vermitteln ${ }^{85}$. Aus Art. 127 WRV wurde deshalb eine solche Garantie ab-

${ }^{81}$ So auch Roters, Art. 28 Rn. 43.

${ }^{82}$ Siehe oben B II 3 a.

${ }^{83}$ So Richter, DVBI. 1978, S. 784; Knemeyer, Festgabe für von Unruh, S. 211 f. und 224. Etwas anders wohl ders., Gemeinden und Kreise, S. 22. Wiedergabe der Kritik an der Annahme einer institutionellen Garantie bei Hofmann, Gemeinden und Kreise, S. 34.

84 Siehe Jarass, Art. 19 Rn. 7; Hassel, VerwRundschau 1984, S. 149.

${ }^{85}$ Siehe Schmitt, Verfassungslehre, S. 170. 
geleitet, um eine Beseitigung der kommunalen Selbstverwaltung durch den einfachen Gesetzgeber zu verhindern. Die im Zweiten Hauptteil der WRV enthaltenen Grundrechte und vor allem auch der Art. 127 WRV wurden ursprünglich als formale Prinzipien angesehen, die letztlich nicht mehr besagten als der Grundsatz der Gesetzmäßigkeit der Verwaltung auch ${ }^{86}$. Die Annahme einer institutionellen Garantie hatte den Zweck, die extreme Möglichkeit der vollständigen oder weitgehenden Beseitigung der kommunalen Selbstverwaltung auszuschließen, und zwar durchaus unter Inkaufnahme der damit verbundenen Abgrenzungsschwierigkeiten ${ }^{87}$.

Die weitere Entwicklung der kommunalen Selbstverwaltung unter dem GG hat dann gezeigt, daß mit Hilfe der institutionellen Garantie und der damit verbundenen Vorstellung eines für den einfachen Gesetzgeber unantastbaren Kernbereichs aufgrund der Diffusität der Eingriffsgrenzen nicht mehr erreicht werden konnte, als diese Konstruktion ursprünglich leisten sollte. $\mathrm{Zu}$ einem Generalangriff des Gesetzgebers auf die kommunale Selbstverwaltung kam es nicht, und andere effektive Schutzfunktionen ließen sich aus ihr nicht entwickeln. Man kann sogar bezweifeln, ob der Lehre von den Einrichtungsgarantien auch dann eine so große Zustimmung sicher gewesen wäre, wenn es bereits in der damaligen Zeit eine Bindung auch des formellen Gesetzgebers an das Übermaßverbot gegeben hätte. Dieses Prinzip war zwar auch in der Weimarer Zeit als Rechtmäßigkeitsvoraussetzung vor allem für polizeiliche Maßnahmen bekannt ${ }^{88}$, wurde aber erst durch die Rechtsprechung des BVerfG zu einem auch den Gesetzgeber bindenden Gebot $^{2}$. Heute dürfte die Kernbereichslehre als Schutzinstrument gegen den Entzug funktioneller Aufgaben durch den Gesetzgeber vom Übermaßverbot sogar vollkommen ersetzt werden ${ }^{90}$. Zwar hat die angebliche Erosion der kommunalen Selbstverwaltung trotz dessen unbestrittener Geltung stattgefunden ${ }^{91}$. Das mag aber zum einen damit zusammenhängen, daß die

${ }^{86}$ Anschütz, Art. 127, Anm. 1 S. 582: "leerlaufender Grundrechtsartikel". Ausführlich Glum, AöR 56 (1929), S. 392 ff.

${ }^{87}$ Siehe Schmitt, Freiheitsrechte und institutionelle Garantien, S. 148. Auch Thoma, in: Nipperdey (Hrsg.), Band 1, S. 33 und 38.

${ }^{88}$ Zimmerli S. 9. Auch Schneider, Festgabe 25 Jahre BVerfG, Band II, S. 394, vor allem mit Hinweisen auf die ideengeschichtliche Entwicklung.

${ }^{89}$ Herzog, in: Maunz / Herzog / Dürig / Scholz, Art. 20, S. 288 Rn. 71. Ausführliche Nachweise bei Wendt, AöR 104 (1979), S. 415.

90 So auch Schink, Subsidiaritätsprinzip, S. 63, ders., DVBI. 1983, S. 1172; Hassel, VerwRundschau 1984, S. 148; von Mutius / Schoch, DVBI. 1981, S. 1080 m. w. N. Anders Widera, S. 56, mit ausführlicher Darstellung des Streitstandes.

${ }^{91}$ Vgl. Blümel, Festgabe für von Unruh, S. 282. 
bisherigen, die kommunale Selbstverwaltung beschränkenden Maßnahmen mit der Garantie des Art. 28 Abs. 2 GG vereinbar waren oder auch daran, daß das Übermaßverbot in der Vergangenheit nicht immer genügend beachtet wurde. Die Betonung dieses Grundsatzes wird aber wegen der damit verbundenen Beschränkung auf den zu entscheidenden Einzelfall immer einen effektiveren Schutz vermitteln als die Suche nach einer festen Eingriffsgrenze, vor deren Umschreibung die Gerichte schon wegen der damit verbundenen Festlegung für die Zukunft nach Möglichkeit absehen wer$\operatorname{den}^{92}$. Vor allem bietet das Übermaßverbot aber gegen jeden gesetzlichen Aufgabenentzug Schutz, nicht erst in Extremfällen wie die Kernbereichslehre. Der Schutz durch das Übermaßverbot ist auch gleichermaßen umfassend, denn die Aspekte, die zu einer Umschreibung des Kernbereichs verwendet werden, würden im Rahmen der Überprüfung eines Gesetzes, das den Gemeinden die Befugnis zur Bauleitplanung entzieht, auch in die Prüfung der Verhältnismäßigkeit im engeren Sinne einfließen. Dies gilt sowohl für die Argumentation mit der historischen als auch für die mit der effektivaktuellen Bedeutung einer Aufgabe ${ }^{93}$. Auch die teilweise zur Bestimmung des Kernbereichs herangezogene Formel, ob eine bestimmte Aufgabe für den Typus der kommunalen Selbstverwaltung prägend ist ${ }^{94}$, findet im Rahmen der Verhältnismäßigkeitsprüfung notwendigerweise Berücksichtigung. Schließlich ist auch im Sinne der sog. Substraktionstheorie eine Verhältnismäßigkeit der gesetzgeberischen Maßnahme umso eher zu verneinen, je weniger Aufgaben den Gemeinden zu einer eigenverantwortlichen und kraftvollen Betätigung noch verbleiben ${ }^{95}$. Bereits dieser Gesichtspunkt spricht dafür, die Suche nach dem Kernbereich der kommunalen Selbstverwaltung aufzugeben und bei fraglichen Maßnahmen umso sorgfältiger die Frage der Verhältnismäßigkeit zu klären.

Es dürfte damit letztlich gar kein Fall denkbar sein, in dem das Übermaßverbot von einer gesetzgeberischen Maßnahme nicht verletzt wird, die Kernbereichsgarantie aber wohl. In dem Moment, in dem der Kernbereich

\footnotetext{
${ }^{92}$ Eine positive Beurteilung des Übermaßverbotes trotz angenommener Wirkungslosigkeit in der Vergangenheit findet sich auch bei Blïmel, Festgabe für von Unruh, S. 283.

${ }^{93}$ Zur Bedeutung dieses Merkmals für die Bestimmung des Kernbereichs siehe Widera, S. 74 m. w. N.

94 Stern, Staatsrecht, Band 1, II 4 / 12, S. 416, ders., HbKWP, Band 1, S. 206; SchmidtJortzig, Einrichtungsgarantien, S. 42.

${ }^{95}$ Zur Substraktionstheorie siehe BVerwG, Urteil vom 22.11.1957, E 6, 19 (25). Die Substraktionstheorie vermittelt allerdings nur wenig Schutz, siehe die Kritik bei Schmidt-Jortzig, Einrichtungsgarantien, S. 40; Widera, S. 64; Blümel, VVDStRL 36 (1977), S. 213. Sie wird aber der historischen Wurzel institutioneller Garantien durchaus gerecht.
} 
berührt wäre, wäre die staatliche Maßnahme immer unverhältnismäßig im engeren Sinne. Damit löst sich jedoch noch nicht das Problem, wann der Kernbereich berührt ist. Nur ist es nicht hilfreich, sich hierzu die Frage zu stellen, ob eine einzelne funktionelle Angelegenheit zum Kernbereich gehört. Die institutionelle Garantie mag im Bereich der institutionellen Angelegenheiten gewisse, wenn auch beschränkte, so doch einigermaßen gesicherte, da zeitbeständige Antworten bereithalten, etwa die Befugnis zur Schaffung organisatorischer Voraussetzungen für das Tätigwerden der Organe oder die Vermögensverwaltung ${ }^{96}$. Im Bereich der funktionellen Angelegenheiten kann und soll sie dies nicht. Ein effektiver Schutz gemeindlicher Selbstverwaltung ist nur dann möglich, wenn die verfassungsrechtliche Garantie des Art. 28 Abs. 2 GG auf sich wandelnde Lebensverhältnisse eine den jeweiligen Umständen angemessene Antwort gibt. Jede nur durch Verfassungsänderung widerrufliche Zuordnung einer funktionellen Angelegenheit führt aber zur Gefahr von Erstarrung. Die Festschreibung irgendeines status-quo liegt gerade nicht im Interesse der Gemeinden und kann daher der Garantie des Art. 28 Abs. 2 GG auch nicht entnommen werden. Die Wanderungsprozesse, die sicherlich in der Erscheinungsform der Hochzonung von ursprünglich gemeindlichen Kompetenzen auf den Staat oder andere Entscheidungsträger zu einem Verlust an gemeindlicher Wahrnehmungszuständigkeit führten ${ }^{97}$, haben den Gemeinden gerade die Kompetenz eingebracht, die ihnen heute von Verfassungs wegen - für den einfachen Gesetzgeber also unantastbar - zugeordnet werden soll, nämlich die gemeindliche Bauleitplanung. Sie ist erst im Laufe dieses Jahrhunderts und maßgeblich erst nach 1945 von einer polizeilichen Aufgabe zu einer kommunalen Selbstverwaltungsaufgabe geworden ${ }^{98}$. Weiterhin wird in neuerer Zeit die Energieversorgung durch Fernwärme als Aufgabe der Gemeinden entdeckt $t^{99}$, was ein weiterer Fall für einen Wanderungsprozeß von "oben" nach "unten" wäre. Neue Entwicklungen der Technik werden auch in Zukunft

${ }^{96}$ Siehe Ipsen, Kommunalrecht, S. 54. Kritisch zu einer solchen Annahme auch mit weiteren Beispielen Schnidt-Jortzig, Kommunalrecht, Rn. 505 und 506. Siehe auch Forsthoff, Die öffentliche Körperschaft, S. 104: Selbstverwaltung als existentielle Absonderung vom Staat.

${ }^{97}$ Ein Beispiel ist etwa der Übergang der Energieversorgung auf überregional organisierte Versorgungsunternehmen, siehe Obernolte / Danner, Vorb. EnWG A I 1; Werner Weber, S. 51. Weitere Beispiele für Wanderungsprozesse wie Arbeitsverwaltung und Denkmalschutz bei Schmidt-Jorzig, Organisationshoheit, S. 61 Fn. 102; Scheuner, AfK 1973, S. 22.

${ }^{98}$ Ausführlich dazu Widera, S. 90 ff. Weiterhin siehe Zeitler, BayVBI. 1987, S. 682; Brohm, DöV 1986, S. 297.

99 Berg, Festschrift Bayerischer Gemeindetag, S. 156; Schmidt-Aßmann, Kommunalrecht, S. 115, ders., Festschrift für Fabricius, S. 258; Roters, Art. 28 GG Rn. 42 c. 
Herauf- oder Herabzonungen notwendig machen. Solche Prozesse sind nicht von vornherein günstig oder ungünstig für die gemeindliche Selbstverwaltung. Man kann sie nur in gewissem Rahmen verfassungsrechtlich akzeptieren oder nicht akzeptieren, sie aber nicht nur als Einbahnstraße stattfinden lassen wollen.

Die Frage, ob eine bestimmte Aufgabe wie die Bauleitplanung zum Kernbereich der kommunalen Selbstverwaltung gehört, ist schließlich auch deshalb nicht sinnvoll beantwortbar, weil immer der Gesamtbestand an gemeindlichen Aufgaben betrachtet werden muß. Geht man im Falle des Art. 28 Abs. 2 GG vom Vorliegen einer institutionellen Garantie aus, so ist diese Garantie nur dann, aber auch schon dann erfüllt, wenn den Gemeinden ein bestimmter Aufgabenbestand zu einer selbstverantwortlichen Aufgabenerfüllung zusteht ${ }^{100}$, was sich als Kernbereich- oder Wesensgehaltsgarantie verstehen 1 läßt ${ }^{101}$. Es geht dabei aber nur um einen gewissen Bestand, nicht um bestimmte Aufgaben ${ }^{102}$. Dies ergibt sich aus der Schutzfunktion einer institutionellen Garantie. Es sollen zwar bestimmte Einrichtungen auf Dauer in den wesentlichen Zügen gesichert werden, ohne aber eine sinnvolle Weiterentwicklung zu blockieren ${ }^{103}$. Daher darf man nicht nur eine oder einzelne Aufgaben in den Blick nehmen. So wandern Aufgaben nicht nur, sie wandeln sich auch. Sie können an Bedeutung gewinnen ${ }^{104}$ aber auch verlie$\operatorname{ren}^{105}$. Eine Aufgabe, die man heute als "typusbestimmend" ansehen mag, muß dies nicht für immer bleiben.

Aber selbst wenn man diese Wandlungsmöglichkeiten zugesteht und meint, immerhin ließen sich für den jeweiligen Zeitabschnitt Aussagen zur Zugehörigkeit zum Kernbereich machen, kommt eine Fixierung von Aufgaben im Kernbereich nicht in Betracht. So ist bei der Frage, ob der Kernbereich der gemeindlichen Selbstverwaltungsgarantie noch gewahrt ist, auch

${ }^{100}$ Macher, S. 61; Badura, DÖV 1963, S. 565.

${ }^{101}$ Es handelt sich insofern nicht um eine Anleihe aus dem Grundrechtsbereich, sondern um eine Folge aus der Annahme einer institutionellen Garantie. Siehe Blümel, Festgabe für von Unruh, S. 269, vor allem Fn. 18.

${ }^{102}$ So auch Brohm, DVBI. 1980, S. 657, ders., DVBI. 1984, S. 297: Art. 28 Abs. 2 schreibt keinen Bestand bestimmter Aufgaben der Gemeinden fest. Ebenso Loschelder, Dispositionsbefugnis, S. 51; Schmidt-Jortzig, Einrichtungsgarantien, S. 46; Niemeier, Bund und Gemeinden, S. 133.

${ }^{103}$ Loschelder, Dispositionsbefugnis, S. 51; Schmidt-Jortzig, Einrichtungsgarantien, S. 37; Blümel, Festgabe für von Unruh, S. 274.

${ }^{104}$ Wie etwa die Zuordnung der Bauleitplanung zum Kernbereich aufgrund der "effektiven aktuellen Bedeutung" durch Widera, S. 74 f., zeigt.

${ }^{105}$ Siehe die Überlegungen von Hinkel, NVwZ 1985, S. 227. 
zu berücksichtigen, ob der Gemeinde für eine etwa entzogene Aufgabe andere Aufgaben übertragen worden sind oder ihr zumindest Beteiligungsrechte an der höherstufigen Aufgabenerfüllung eingeräumt worden sind ${ }^{106}$. Denn auch die eigenverantwortliche Beteiligung an einem Willensbildungsproze $B$ ist eine Form von Aufgabenerfüllung. Solange sich die Befugnisse der Gemeinden nicht auf solche Beteiligungsrechte reduzieren, können sie bei der Frage nach der Erfüllung der institutionellen Garantie in gewissem Maße durchaus Berücksichtigung finden. Deshalb sollte man auch die Wahrnehmung von übertragenen Angelegenheiten durch die Gemeinden nicht grundsätzlich negativ, sondern vielmehr gerade positiv werten ${ }^{107}$. Die "Überschwemmung der Gemeinden mit Auftragsangelegenheiten" führt nicht zu einer Verkümmerung der gemeindlichen Selbstverwaltung ${ }^{108}$. Vielfach hängen eigene und übertragene Angelegenheiten so eng zusammen, $\mathrm{da} ß$ es für die Gemeinden bei der Erfüllung ihrer Selbstverwaltungsaufgaben durchaus förderlich ist, wenn sie auch für eine sachlich damit zusammenhängende staatliche Angelegenheit zuständig sind ${ }^{109}$. Ein gutes Beispiel hierfür ist der Baurechtsvollzug. Ist eine Gemeinde auch Baugenehmigungsbehörde, ist sie nicht darauf angewiesen, Baugenehmigungen, die ohne ihr Einvernehmen oder gegen Festsetzungen im Bebauungsplan erteilt wurden, mit Berufung auf ihre Planungshoheit anzufechten, sondern sie kann die Baugenehmigungsanträge ablehnen. Ein weiterer Fall einer den Gemeinden in der Regel höchst willkommenen übertragenen Angelegenheit ist der Vollzug des $\S 45 \mathrm{StVO}^{110}$. Zudem können die Gemeinden auch im übertragenen Wirkungskreis Sachnähe, Bürgernähe und Anpassungsfähigkeit in den Verwaltungsvollzug einbringen ${ }^{111}$.

Bildlich läßt sich der hier vertretene Standpunkt folgendermaßen beschreiben: Wenn man den Art. 28 Abs. 2 GG als institutionelle Garantie versteht, muß ein Kernbereich vorhanden sein, der sich gesetzgeberischem Zugriff entzieht. Dieser Kernbereich liegt auch fest, d. h. seine Grenzen ver-

${ }^{106}$ Sog. Kompensationsmodell. Siehe dazu Blümel, VVDStRL 36 (1977), S. 248 m. w. N.; Stern, Staatsrecht, Band 1, S. 425; Widera, S. 38. Ähnlich auch Schmidt-Jortzig, Einrichtungsgarantien, S. 36, allgemein für die Frage des "Angriffs" gegen die Substanz einer Einrichtungsgarantie.

107 In diese Richtung auch Brohm, DVBI. 1984, S. 298, ders., DÖV 1986, S. 399 ff.

${ }^{108}$ So aber Macher, S. 90 m. w. N.; Stüer, S. 217; Werner Weber, S. 66 f.; Petz, BayVBI. 1989, S. 357.

${ }^{109}$ So auch Brohm, DÖV 1986, S. 399; Hinkel, NVwZ 1985, S. 230.

${ }^{110}$ Siehe dazu ausführlich Steiner, DAR 1989, S. 404.

${ }^{111}$ Brohm, DÖV 1986, S. 399. Siehe auch unten B III 3. 
schieben sich nicht ${ }^{112}$. Nicht fest liegen hingegen die sog. funktionellen Angelegenheiten, die sich unter Umständen in diesem Kern befinden. Sie sind vielmehr ständig in der Lage, vom Kern- in den Garantiebereich oder vom Garantie- in den Kernbereich zu wandern. Entsprechende Zentrifugal- oder Zentripetalkräfte löst vor allem der Gesetzgeber aus, wenn er etwa eine $\mathrm{Zu}$ ständigkeitsverlagerung in Form einer Herauf- oder Herabzonung vornehmen will. Ob die von ihm verursachte Fliehkraft ausreicht, um eine Aufgabe vom Kernbereich zu trennen - unabhängig von der Frage, ob sich die Aufgabe im oder nur in der Nähe vom Kernbereich befindet - , hängt vor allem davon ab, wieviel andere Angelegenheiten diesen Kern noch ausfüllen, und inwieweit der Gesetzgeber ersatzweise Kompensationsbefugnisse vorsieht. Man kann dieses Bild noch weiter strapazieren: Ein besonders "schwerer" Bestandteil wie etwa die Befugnis zur Bauleitplanung wird sich nur dann vom Kern entfernen lassen und sich durch mehrere kleine Bestandteile aufwiegen lassen, wenn die Gründe hierfür auch entsprechend gewichtig sind. Damit gleicht aber der Schutz der gemeindlichen Selbstverwaltung durch die Annahme eines unantastbaren Kernbereichs endgültig der Wirkungsweise des Übermaßverbotes. Je mehr der Garantiebereich der gemeindlichen Selbstverwaltung sich verringert und nur noch der Kernbereich übrig bleibt, desto stärker müssen die Gründe für eine Beschränkung von gemeindlichen Wahrnehmungskompetenzen sein. Ist außer dem Kernbereich nichts mehr übrig, gibt es keine legitimierenden Gründe mehr für einen gesetzgeberischen Eingriff. Dies alles läßt sich aber nur entscheiden unter Berücksichtigung des Zustandes der gemeindlichen Selbstverwaltung in der konkreten Eingriffssituation und unter Beachtung der geltend gemachten Gründe und der vorgesehenen Kompensationsmaßnahmen.

Dem BVerfG ist somit zuzustimmen, wenn es davon ausgeht, daß zum Kernbereich der kommunalen Selbstverwaltung kein gegenständlich bestimmter oder nach feststehenden Merkmalen bestimmbarer Aufgabenkatalog gehört ${ }^{113}$. Damit ist auch die Bauleitplanung nicht unverrückbar dem Kernbereich der Garantie der kommunalen Selbstverwaltung zuzuordnen. $\mathrm{Da} ß$ der Erlaß örtlicher Bauvorschriften derzeit unbedingt im eigenen Wirkungskreis stattfinden muß, weil sonst der "Kern" nicht mehr genügend mit Aufgaben besetzt wäre, wird man ebenfalls nicht behaupten können. Daher gibt es auch für den Bereich der örtlichen Bauvorschriften unter dem Gesichtspunkt des Kernbereichs keine grundsätzliche Bindung des Landes-

\footnotetext{
112 Anders Schmidt-Jortzig, Einrichtungsgarantien, S. 45.

${ }^{113}$ Siehe etwa BVerfG, Beschluß vom 23.11.1988, DVBl. 1989, S. 301.
} 
gesetzgebers dahin, da $\beta$ der Erla $\beta$ solcher Vorschriften zwingend dem eigenen Wirkungskreis zuzuordnen ist.

\section{Die Bedeutung des Gesetzesvorbehaltes in Art. 28 Abs. 2 S. 1 GG}

\section{a) Problemstellung}

Mit dem Ergebnis, daß die von vielen befürwortete Annahme eines Kernbereichs der kommunalen Selbstverwaltungsgarantie trotz des potentiell bauplanungsrechtlichen Charakters örtlicher Bauvorschriften nicht zu einer zwingenden Zuordnung zum eigenen Wirkungskreis der Gemeinden führt, ist die Bedeutung der kommunalen Selbstverwaltungsgarantie für die Auslegung der landesrechtlichen Bestimmungen über örtliche Bauvorschriften allerdings noch nicht erschöpft. Vielmehr spielt auch das Verständnis des Gesetzesvorbehaltes in Art. 28 Abs. 2 S. 1 GG eine Rolle. Immerhin wählen die Landesgesetzgeber für ein zumindest rechtstatsächlich weitgehend identisch gehandhabtes Instrumentarium bei der Frage des möglichen staatlichen Einflusses unterschiedliche Lösungen. Damit stellt sich das Problem, ob die Landesgesetzgeber einen ihnen insoweit zustehenden Gestaltungsspielraum ausgeschöpft haben oder ob dem einen oder anderen Landesgesetzgeber ein Qualifikationsfehler unterlaufen ist.

Ausgangspunkt solcher Überlegungen ist die in der gemeindlichen Selbstverwaltungsgarantie des GG enthaltene Klausel "im Rahmen der Gesetze". Deren genaue Bedeutung ist noch nicht restlos geklärt. Überwunden ist aber immerhin die Auffassung, daß sich der Gesetzesvorbehalt nicht auf das Eigenverantwortlichkeitsprinzip beziehe, sondern nur eine Einschränkung des Aufgabenkreises erlaube ${ }^{114}$. Gegen ein solches Verständnis spricht vor allem, daß die Einführung eines Weisungsrechts der Aufsichtsbehörde gegenüber dem völligen Aufgabenentzug oft ein milderes Mittel darstellen wird $^{115}$, was die Verfassungsgarantie der kommunalen Selbstverwaltung kaum ausschließen will.

Es ist aber immer noch streitig, ob sich der Vorbehalt auch auf die Regelung des Umfangs gemeindlicher Aufgabenerfüllung oder nur auf die

\footnotetext{
${ }^{114}$ Siehe die Nachweise bei Hendler, Selbstverwaltung S. 197. Auch von Mutius hat seine gegenteilige Auffassung aus dem DJT-Gutachten wieder aufgegeben, siehe dieser, Jura 1982, S. 37 mit Anm. 79.

${ }^{115}$ Hendler, Selbstverwaltung, S. 197.
} 
Durchführung bezieht. Trotz einer anderslautenden herrschenden Meinung und Rechtsprechung ${ }^{116}$ findet sich immer noch die These, der Gesetzesvorbehalt des Art. 28 Abs. 2 S. 1 GG umfasse nur die Art und Weise der Aufgabenerfüllung. Den Gemeinden sei also von Art. 28 Abs. 2 S. 1 GG ein "Kompetenzblock" garantiert, der einen gesetzlichen Entzug verbiete ${ }^{117}$. Prämisse dieser Auffassung ist es, daß die den Gemeinden obliegenden Aufgaben exakt als örtlich oder überörtlich einzustufen sind. Zumindest ein "Schwerpunkt" im örtlichen oder überörtlichen Bereich muß sich danach feststellen lassen ${ }^{118}$. Fiele eine Aufgabe in den örtlichen Bereich, so wäre eine Kontrolle der Zweckmäßigkeit der Aufgabenerledigung durch staatliche Instanzen verfassungswidrig ${ }^{119}$. Die übergemeindliche / "staatliche" Betroffenheit kann dann nur durch zwingende gesetzliche Normierungen zur Geltung gebracht werden, also etwa wie bei den Pflichtaufgaben im eigenen Wirkungskreis, wo das "Ob" der Aufgabenerfüllung durch den Staat per Gesetz vorgegeben ist und den Kommunen das "Wie" überlassen bleibt $^{120}$.

Für die Auslegung der Bestimmungen über örtliche Bauvorschriften hätte dies folgende Konsequenz: Unterstellt man, daß die unterschiedlichen Regelungen verfassungsmäßig sind, so würden die Gemeinden unter ähnlichem

${ }^{116}$ Diese tritt für eine Erstreckung auf beide Elemente ein. Siehe Schmidt-Jortzig, Organisationshoheit, S. 82, ders., Kommunalrecht, S. 167; von Mutius, Deutsche Verwaltungsgeschichte, Band 4, S. 334; Frers, DVB1. 1989, S. 451; Erichen, Kommunalrecht, S. 192; Hendler, Selbstverwaltung, S. 196 m. w. N. Ebenso das BVerfG, siehe nur Beschluß vom 23.11.1988, DVB1. 1989, S. 300 (301).

117 So vor allem Richter, Verfassungsprobleme, S. 146, etwas abgeschwächt auch ders., DVB1. 1978, S. 785. Dieser Konzeption im wesentlichen folgend Knemeyer / Emmert, S. 285; Knemeyer, Festgabe für von Unruh, S. 224; wiederum Knemeyer zustimmend Koch / Hosch, S. 108. In diesem Sinne wohl auch von Mutius, BayVBI. 1988, S. 645: "Der Gesetzesvorbehalt des Art. 28 Abs. 2 S. 1 GG ermöglicht lediglich eine staatliche Einschränkung der Art und Weise der kommunalen Aufgabenerledigung; er vermag jedoch nicht eine Beschränkung, insbesondere einen Entzug gemeindlicher Zuständigkeiten selbst zu legitimieren". So auch Werner Weber, S. 50 mit Hinweisen auf ältere Stellungnahmen. Weiterhin Schultze, S. 72, möglicherweise auch Grawert, VVDStRL 36 (1977), S. 281: " ... bilden die Gemeindeaufgaben einen festen Block."

$118 \mathrm{Zu}$ diesem Merkmal Knemeyer, Festgabe für von Unruh, S. 222, ders., Festschrift Bayerischer Gemeindetag, S. 108 f., ders., DVB1. 1984, S. 25.

${ }^{119}$ Richter, Verfassungsprobleme, S. 149; wohl auch Faber, Art. 28 Rn. 40: Rechtlich könne es sich gegenüber der Eigenverantwortlichkeit nur um Rechtsaufsicht handeln. Gelegentlich wird auch die Unzulässigkeit einer Zweckmäßigkeitsüberprüfung z. B. für die gemeindliche Bauleitplanung angenommen, ohne daß insoweit auf den Kernbereich abgestellt wird und ohne daß recht klar wird, wie sich dies mit der herrschenden Meinung zur Erstreckung des Gesetzesvorbehaltes auch auf die Eigenverantwortlichkeit zusammenreimen soll. Siehe etwa Hoppe, Festgabe für von Unruh, S. 583.

${ }^{120}$ Knemeyer, Festgabe für von Unruh, S. 224 ff. 
Etikett beim Erlaß örtlicher Bauvorschriften verschiedene Arten von Aufgaben erfüllen. Eine potentielle Zweckmäßigkeitskontrolle durch den Staat würde ausscheiden, soweit eine Aufgabe zum "Kompetenzblock" der Gemeinden gehört, so daß es sich bei der Zuordnung zum übertragenen Wirkungskreis - will die Regelung verfassungsgemäß sein - eben nur um eine Aufgabe handeln kann, die nicht in diesen "Block" gehört. Vor allem im Bereich der NBauO wären damit "örtliche" Bauvorschriften ein Instrument zur Durchführung einer staatlichen Aufgabe, nämlich einer solchen mit "schwerpunktmäßig" überörtlichem Bezug, während es in den Bauordnungen, in denen eine Zuordnung zum eigenen Wirkungskreis vom jeweiligen Gesetzgeber eindeutig vorgenommen wurde oder nach dem Gesetzestext zumindest naheliegt, eine andere, nämlich die Erfüllung einer örtlichen Aufgabe der Gegenstand des Erlasses solcher Vorschriften wäre. Da dem Gesetzgeber nach der "Kompetenzblock-Theorie" insoweit kein Ermessen und kein Gestaltungsspielraum zusteht, er vielmehr nur dazu aufgerufen ist, deklaratorisch den Gemeinden die örtlichen Aufgaben zuzuweisen ${ }^{121}$, ist also entweder zumindest einem Landesgesetzgeber ein Qualifikationsfehler unterlaufen, oder es gibt kein einigermaßen einheitlich zu beurteilendes Rechtsinstitut "örtliche Bauvorschriften".

Weniger offensichtlich, aber letztlich genauso stellt sich das Qualifikationsproblem auch auf dem Boden der herrschenden Meinung. Diese geht ebenfalls davon aus, daß das Merkmal "Angelegenheiten der örtlichen Gemeinschaft" kompetenzbegrenzende Funktion hat ${ }^{122}$. So seien Angelegenheiten der örtlichen Gemeinschaft nur solche, die "in der örtlichen Gemeinschaft wurzeln", die "auf die örtliche Gemeinschaft einen spezifischen Bezug haben und von der örtlichen Gemeinschaft eigenverantwortlich und selbständig bewältigt werden können"123. Getragen ist diese Auffassung vor allem von der Sorge, die Gemeinden würden sich sonst zu allgemeinpolitischen, insbesondere verteidigungspolitischen Fragen äußern ${ }^{124}$. Daraus ergibt sich dann, daß bei solchen Angelegenheiten, die nicht oder nicht mehr im so verstandenen Sinne solche der örtlichen Gemeinschaft sind, der Art.

${ }^{121}$ Richter, Verfassungsprobleme, S. 135.

${ }^{122}$ Siehe Hendler, Selbstverwaltung, S. 195; Grawer, VVDStRL 36 (1977), S. 286.

${ }^{123}$ BVerfG, Urteil vom 30.07.1958, E 8, 122 (134); Beschluß vom 17.01.1979, E 50, 195 (201); Urteil vom 24.07.1979, E 52, 95 (120); BeschluB vom 23.11.1988, DVBI. 1989, S. 300 (302). Dem folgend etwa BayVGH, Urteil vom 24.02.1988, BayVBI. 1989, S. 14 (15).

124 Siehe die Entscheidung des BayVGH, BayVBI. 1989, S. 15 und des BVerfG, DVBI. 1989, S. 302. 
28 Abs. 2 GG den Gemeinden bei der Aufgabenerfüllung keinen Schutz bietet $^{125}$.

Auch auf der Grundlage der herrschenden Meinung stellt sich damit die Frage, ob unter dem Etikett "örtliche Bauvorschriften" eigentlich die gleichen Aufgaben erfüllt werden. Dies wäre dann der Fall, wenn es sich z. B. auch im Fall der NBauO um eine örtliche Angelegenheit handelt, die aus gesamtstaatlichen Interessen in Ausübung des Gesetzesvorbehaltes des Art. 28 Abs. 2 GG einer Fachaufsicht unterworfen ist. Es wäre dann nicht der Fall, wenn eine überörtliche Angelegenheit vorliegen würde, die aus Gründen der Bürgernähe, Verwaltungseffizienz oder sonstigen Erwägungen von den Gemeinden wahrgenommen wird. Insofern überzeugt es nicht, wenn bei übertragenen Angelegenheiten generell eine Berufung auf den Art. 28 Abs. 2 GG ausscheiden soll ${ }^{126}$. Man müßte vielmehr anläßlich jeder einzelnen Aufgabe im übertragenen Wirkungskreis die Frage stellen, ob die Fachaufsicht aufgrund des Gesetzesvorbehaltes eingeführt wurde, oder ob die Gemeinden von vornherein gar keinen Anspruch auf eigenverantwortliche Aufgabenerfüllung haben. Dies ist von der herrschenden Meinung wohl nicht gewollt und erscheint auch nicht als besonders sinnvoll, ergibt sich aber aus der kumulativen Annahme, daß das Örtlichkeitsmerkmal kompetenzbegrenzenden Charakter hat und daß zusätzlich auch gesetzliche Einschränkungen der Eigenverantwortlichkeit bei der Aufgabenerfüllung möglich sind.

b) Die Aufgabenqualifikation durch den formellen Gesetzgeber

Betrachtet man den Art. 28 Abs. 2 GG nicht abstrakt theoretisch, sondern anhand einer von den einzelnen Landesgesetzgebern konkret vorgenommenen unterschiedlichen Einordnung in das kommunale Aufgabensystem, so überzeugt weder die "Kompetenz-Block-Theorie" noch die herrschende Meinung. Beide Auffassungen sind darauf angewiesen, überörtliche von örtlichen Aufgaben abgrenzen zu können. Dies ist jedoch nicht mit annähernd ausreichender Präzision möglich ${ }^{127}$. Umschreibt man die gemeind-

${ }^{125}$ Vgl. nur Stern, Staatsrecht, Band 1, S. 412. Vergleiche auch Burmeister, Neukonzeption, S. 22: Metamorphose der Verwaltungsagenden bei wachsender Bedeutung einer Angelegenheit über den örtlichen Bereich hinaus.

${ }^{126}$ So aber die ganz h. M., siehe BVerfG, Urteil vom 21.06.1988, E 78, 331 (341); BVerwG, Urteil vom 27.11.1981, NVwZ 1982, S. 310; J. Ipsen, S. 271.

127 So auch Blümel, VVDStRL 36 (1977), S. 245, ders., Festgabe für von Unruh, S. 284; Gallwas, BayVBI. 1973, S. 396 ff.; Loschelder, Gebietsgestaltung, S. 197; Widera, S. 31; 
lichen Aufgaben etwa als solche, die "innerhalb der Grenzen der Gemeinde anfallen und nicht zugleich Aufgaben im Gesamtgebiet der größeren Organisationseinheit Gemeindeverband darstellen"128, so beantwortet man die Frage nicht, wonach sich dies entscheiden lassen soll. Auch eine Schwerpunktbetrachtung ${ }^{129}$ hilft nicht weiter, solange keine anerkannten und justiziablen Maßstäbe zur Bestimmung dieses Schwerpunktes vorliegen. Eine Definition wie die, wonach Angelegenheiten der örtlichen Gemeinschaft zu verstehen seien als "diejenigen Vorhaben, deren bestmögliche Verwirklichung durch die organisierten eigenen Handlungskräfte der Menschen in einem geschlossenen Siedlungsraum für ihre gemeinschaftlichen Lebensbedürfnisse von konkretem Interesse ist" ${ }^{130}$, unterstreicht nur den gebotenen Abschied von der Suche nach einem materialen Kriterium, mit dem die Alternative "örtlich oder überörtlich" von Verfassungs wegen abschließend entschieden werden könnte.

Das Örtlichkeitsmerkmal des Art. 28 Abs. 2 GG ist vielmehr ein durch eine politische Entscheidung des zuständigen Gesetzgebers konkretisierungsbedürftiger Begriff. Fast jede Aufgabe hat sowohl örtliche als auch überörtliche Bezüge. Damit sind keinesfalls alle Versuche zur Umschreibung von Angelegenheiten der örtlichen Gemeinschaft nutzlos. Ob der Gesetzgeber die ihm zustehenden Gestaltungsgrenzen eingehalten hat, dürfte zwar letztlich nur anhand des Übermaßverbotes zu überprüfen sein: Je stärker aber der "örtliche Bezug" ist, desto mehr ist der Gesetzgeber verpflichtet, für einen Zuständigkeitsentzug zulasten der Gemeinden entsprechend gewichtige Gründe anzuführen. Jede Auslegung des Art. 28 Abs. 2 GG, die auf eine exakte Abgrenzung angewiesen ist, zwingt hingegen letztlich die Gerichte in die ihnen nicht zustehende Rolle eines Ersatzgesetzgebers ${ }^{131}$. Die Gemeinden sind also tatsächlich grundsätzlich allzuständig, und zwar ohne Begrenzung auf "örtliche" Angelegenheiten. Ihnen ist es durch Art. 28 Abs. 2 S. 1 GG gestattet, jede beliebige öffentliche Angelegenheit wahrzu-

Burmeister, Neukonzeption, S. 24 m. w. N.; Maunz, Festschrift für Zeidler, S. 1160; Brohm, DVBI. 1980, S. 657; Pappermann, VerwArchiv 65 (1974), S. 173, ders., DÖV 1973, S. 507, ders., DÖV 1975, S. 182 und 186; Oebbecke, DVBI. 1987, S. 870. Anders wohl J. Ipsen, der eine normative ( = keine deskriptive) Betrachtungsweise empfiehlt. Für die Frage, welche Angelegenheiten von der Gemeinde erfüllt werden sollen, bedarf es jedoch auch eines Kriteriums.

${ }^{128}$ So Knemeyer, Festgabe für von Unruh, S. 222.

${ }^{129}$ Siehe dazu die Nachweise oben Fn. 118.

${ }^{130}$ Schmidt-Jortzig, DÖV 1989, S. 148.

${ }^{131}$ In diese Richtung auch Wagener, Gemeinden und Kreise, S. 29. 
nehmen, für die keine andere Zuständigkeit besteht ${ }^{132}$. Insofern braucht man die Zuständigkeit der Gemeinden auch nicht zu vermuten, wie dies häufig angenommen wird ${ }^{133}$. Art. 28 Abs. 2 GG ist eine originäre Aufgabenzuteilung an die Gemeinden ${ }^{134}$, den Gemeinden wird verfassungsunmittelbar ein Aufgabenbereich eingeräumt ${ }^{135}$, und zwar insoweit, als die Gemeinden befugt sind, auf allen vom Staat nicht geordneten Gebieten eigene Initiativen zu entfalten ${ }^{136}$. So kann eine Aufgabe nur dann zu einer Aufgabe der überörtlichen Gemeinschaft werden, wenn Verfassung oder Gesetz einen überörtlichen Verwaltungsträger mit der Aufgabenerfüllung betrauen. Schon die Aufgabenerfüllung durch die Kreise ist daher trotz verfassungsrechtlicher Funktionsgewährleistung von einer gesetzlichen Zuweisung abhängig ${ }^{137}$. Nichts anderes gilt im Verhältnis zu staatlichen Verwaltungsträgern. Etwaige Befürchtungen, bei einer Aufgabe des Örtlichkeitsmerkmals bestände die Gefahr, daß die Gemeinden sich in ihnen nicht zustehender Weise zu verteidigungspolitischen Fragen äußern, dürften unbegründet sein. Art. 73 Nr. 1, $87 \mathrm{a}$ und $\mathrm{b}$ und 24 GG geben genügend Aufschluß für eine von der Verfassung gewollte ausschließliche Bundeszuständigkeit, woraus sich die Unzuständigkeit der Gemeinden ergibt ${ }^{138}$.

Diese Auffassung dürfte im übrigen auch die Möglichkeit bieten, tatsächlich ohne größere Umbrüche zu einem größeren Schutz der gemeindlichen Selbstverwaltung zu kommen. Soweit eine Aufgabe auch nur einen gewissen örtlichen Bezug hat - und dies dürfte bei fast jeder Aufgabe irgendwie der Fall sein - muß sich eine vom einfachen Gesetzgeber vorgesehene Aufgabenerfüllung durch andere Stellen als die Gemeinde vor dem Übermaßverbot rechtfertigen lassen. Bei einem solchen Verständnis wäre es auch nicht so, daß bei wachsenden überörtlichen Bezügen sich ein qualitativer Um-

${ }^{132}$ Thiele, DVBI. 1980, S. 12. Siehe auch Art. 6 BayGO. Gegen die Annahme gemeindlicher Allzuständigkeit Maunz, Festgabe für von Unruh, S. 1163, der Art. 28 Abs. 2 S. 1 GG jede unmittelbar kompetenzbegründende Wirkung absprechen will.

${ }^{133}$ So etwa von Mutius, Festgabe für von Unruh, S. 244; auch Korte, VerwArchiv 61 (1970), S. 39, der die Zuständigkeitsvermutung aus dem Subsidiaritätsprinzip ableiten möchte. Vgl. weiterhin die ausführlichen Nachweise bei Blümel, VerwArchiv 77 (1984), S. 208.

${ }^{134}$ Blïmel, VerwArchiv 77 (1984), S. 209.

${ }^{135}$ Papier, DVBI. 1984, S. 455. Auch Püttner, HbKWP, Band 3, S. 6.

${ }^{136}$ Siehe Scheuner, AfK 1973, S. 21; Loschelder, Gebietsgestaltung, S. 43; Mengelkoch, Kommunalrecht, S. $129 \mathrm{Rn} .26$.

${ }^{137}$ Siehe die Rastede-Entscheidung des BVerwG, Urteil vom 04.08.1983, E 67, 321 (324); Blümel, VerwArchiv 77 (1984), S. 305; Knemeyer, Festgabe für von Unruh, S. 220; Loschelder, Gebietsgestaltung, S. 42 f.; Hartmut Krüger, NWVBI. 1987, S. 97.

${ }^{138}$ So wohl auch Erichsen, Kommunalrecht, S. 116. 
schlag vollzieht und der Art. 28 Abs. 2 GG auf einmal keine Schutzfunktion mehr bietet ${ }^{139}$. Auch bei wachsenden überörtlichen Verflechtungen kommt es nicht zu einem automatischen Kompetenzverlust, sondern nur zu verstärkten Möglichkeiten der Kompetenzbeschränkung durch gesetzgeberische Maßnahmen ${ }^{140}$. Jede Einflußnahme auf die gemeindliche Aufgabenerfüllung auch im Wege der Fachaufsicht ist ein grundsätzlich die gemeindliche Selbstverwaltungsgarantie berührender Vorgang ${ }^{141}$. Hierfür spräche im übrigen, daß die Unterstellung unter die Fachaufsicht keinesfalls immer eine für die Gemeinden einschneidendere Maßnahme ist als detaillierte gesetzliche Vorgaben, deren Einhaltung zwar nur im Wege der Rechtsaufsicht überprüfbar ist, die aber den Gemeinden kaum Anwendungsspielräume las$\operatorname{sen}^{142}$.

c) "Rahmen der Gesetze" nach Art. 28 Abs. 2 S. 1 GG und Gesetzesvorbehalt

In der bisherigen Diskussion wurde die Formel "im Rahmen der Gesetze" weitgehend als eine den grundrechtlichen Eingriffsvorbehalten vergleichbare Bestimmung behandelt. Ein solches Verständnis ist jedoch nur bedingt richtig. Es ist nicht nur die Aufgabe des Gesetzgebers, den Tätigkeitsbereich der Gemeinden durch das Zuständigmachen anderer Verwaltungsträger oder durch die Einführung von Weisungsrechten zu beschränken. Es obliegt ihm auch, den Gemeinden überhaupt das nötige rechtliche Handlungsinstrumentarium zur Verfügung zu stellen ${ }^{143}$. Die zumindest teilweise sicherlich zutreffende Kritik an der Einschränkung des gemeindlichen Spielraums durch eine immer mehr ins Detail gehende Gesetzgebung ${ }^{144}$ greift durchaus

${ }^{139}$ Siehe die insofern völlig berechtigte Kritik von Burmeister, Neukonzeption, S. 22, an der h. M.

${ }^{140}$ Insofern besteht eine gewisse Übereinstimmung mit Burmeister, Neukonzeption, S. 71 ff. Wie hier auch Widera, S. 41.

${ }^{141}$ So auch Burmeister, Neukonzeption, S. 137 und 179. Anders die ganz herrschende Meinung und Rechtsprechung, siehe etwa BVerfG, BeschluB vom 21.06.1988, E 78, 331 (341); BVerwG, Urteil vom 27.11.1981, NVwZ 1982, S. 310 (311); J. Ipsen, S. 271.

$142 \mathrm{Vgl}$. auch die Überlegungen von Widera, S. 68.

143 Steinberg, JuS 1982, S. 580. So auch Pfaff, VerwArchiv 72 (1979), S. 22, wonach die kommunale Selbstverwaltung deshalb in der Defensive sei, weil die Vergesetzlichung und Verplanung kritisiert werde, statt eine selbstverwaltungsgerechte Planung und Gesetzgebung zu fordem. Weiterhin Köttgen, Die Gemeinden und der Bundesgesetzgeber, S. 44 und S. 46 ff.

144 Stüer, S. 183 f.; von Mutius, DJT-Gutachten, S. 58 f., ders., Deutsche Verwaltungsgeschichte, Band S, S. 338; Pappermann, DVBI. 1981, S. 1040 f.; Knemeyer, NJW 1980, S. 1141. 
die Hauptzielrichtung einer institutionellen Garantie richtig auf, nämlich Schutz gegenüber dem einfachen Gesetzgeber zu gewähren ${ }^{145}$. Dabei gerät jedoch leicht in den Hintergrund, daß die Gemeinden etwa zur Bauleitplanung oder auch zum Erla $\beta$ von örtlichen Bauvorschriften eine gesetzliche Ermächtigung benötigen ${ }^{146}$. Dies ergibt sich zum einen aus dem sog. rechtsstaatlichen Gesetzesvorbehalt ${ }^{147}$. Denn sowohl der Erlaß von Bebauungsplänen als auch von örtlichen Bauvorschriften ist trotz aller begünstigenden Wirkungen, die vor allem Bebauungspläne haben können, unter Umständen auch ein Eingriff in das Eigentum ${ }^{148}$. Aber auch der sog. demokratische Gesetzesvorbehalt ${ }^{149}$ fordert eine Mitverantwortung des parlamentarischen $\mathrm{Ge}$ setzgebers für die gemeindliche Verwaltungstätigkeit. Dies gilt gerade wegen der begünstigenden Wirkungen etwa der Bauleitplanung. Denn der parlamentarische Gesetzgeber hat alle "wesentlichen Entscheidungen" selbst zu treffen, und "wesentlich" ist gerade das, was wesentlich für die Verwirklichung von Grundrechten ist ${ }^{150}$. Denkt man an die bereits angesprochene vielfältige Planabhängigkeit der Nutzung von Grundeigentum ${ }^{151}$, wird man eine Wesentlichkeit in diesem Sinne nicht verneinen können.

Allerdings wird die Auffassung vertreten, die Gemeinden seien auch ohne ausdrückliche gesetzliche Ermächtigung befugt, etwa inhalts- und schrankenbestimmende Regelungen des Eigentums vorzunehmen ${ }^{152}$. Damit wird sowohl die Geltung des demokratischen als auch des rechtsstaatlichen Gesetzesvorbehaltes gegenüber der gemeindlichen Rechtssetzung bestritten.

\footnotetext{
${ }^{145}$ Siehe Schmidt-Jortzig, Einrichtungsgarantien, S. 34.

146 Siehe Schmidt-Aßmann, Kommunale Rechtsetzung, S. 8; auch Knemeyer, NJW 1980, S. 1142, der die rechtsstaatlich gebotene (!) Ausformung der Befugnisse für einen Grund der Einschränkung kommunaler Handlungsräume hält.

${ }^{147}$ Zum Begriff siehe Ossenbühl, Vorbehalt des Gesetzes, S. 19. Der Begriff "Gesetzes-" Vorbehalt meint im folgenden den "Parlaments-", nicht nur den allgemeinen Rechtssatzvorbehalt. Zur Terminologie siehe Staupe, S. 29 f.; E.-W. Böckenförde, Gesetz und gesetzgebende Gewalt, S. 393.

148 Zur weiteren Geltung des rechtsstaatlichen Gesetzesvorbehaltes neben der sog. Wesentlichkeitstheorie siehe Pieroth / Schlink, Rn. 307; M. Börger, S. 11; Staupe, S. 116 ff. Zum Eingriffscharakter von Bebauungsplänen siehe BVerfG, Beschluß vom 14.05.1985, E 70, 35 (50).

${ }^{149}$ Zum Begriff siehe Ossenbiühl, Vorbehalt des Gesetzes, S. 20.

${ }^{150}$ Kisker, NJW 1977, S. 1318.

${ }^{151}$ Siehe dazu oben A II 3 c cc (2).

${ }^{152}$ Meyer, Finanzverfassung, S. 55 und 60; Meyn, Gesetzesvorbehalt und Rechtsetzungsbefugnis, S. 54; Jakob, DÖV 1970, S. 671; Faber, Art. 28 Rn. 41. Ähnlich wohl auch Gallwas, BayVBI. 1973, S. 400. Anders die ganz herrschende Meinung, siehe etwa Starck, NJW 1972, S. 1490; Papier, DVBI. 1975, S. 463 m. w. N.; Bethge, NVwZ 1983, S. 578 und die weiteren Nachweise im Text.
} 
Diese Auffassung findet eine gewisse Stütze im Wortlaut des Art. 28 Abs. 2 GG. Aufgrund der Verwendung des Wortes "regeln" in Art. 28 Abs. 2 Satz 1 im Gegensatz zu "-verwaltung" in Art. 28 Abs. 2 S. 2 geht man vielfach davon aus, $\mathrm{da} B$ den Gemeinden schon von Verfassungs wegen die Befugnis zuerkannt ist, Rechtssätze zu erlassen ${ }^{153}$. Maßgeblich ist weiterhin vor allem die Annahme, da $B$ angesichts der "vollgültigen demokratischen Legitimation der Gemeindeparlamente" der allgemeine Gesetzesvorbehalt kommunalen Rechtsetzungsakten gegenüber nicht gelten soll ${ }^{154}$.

Der Verweis auf den Wortlaut des Art. 28 Abs. 2 S. 1 GG trägt jedoch höchstens die Annahme, daß den Gemeinden gegenüber dem Staat die Befugnis garantiert ist, Rechtssätze zu erlassen. Hieraus folgt nicht, daß den Gemeinden dies auch ohne gesetzliche Ermächtigung gegenüber dem Bürger erlaubt sein muß. Insoweit handelt es sich nur um eine Garantie gegenüber dem Staat, den Gemeinden die entsprechenden Rechtsgrundlagen zum Normerlaß zur Verfügung zu stellen ${ }^{155}$. Es kommt also entscheidend darauf an, ob tatsächlich Gemeindeparlamente und staatliche Parlamente und die von ihnen beschlossenen Normen im Hinblick auf ihre Legitimation gleichgestellt werden können.

Dies ist aber eindeutig zu verneinen. So kann man beispielsweise für den Gemeinderat nach der BayGO nur eingeschränkt von einer Repräsentation des Teilvolkes Gemeindevolk ausgehen ${ }^{156}$. Aber auch aus anderen Gründen verbietet es sich, Parlament und Gemeinderat in bezug auf die Legitimation für eigentumsrelevante Regelungen gleichzustellen. Außer der demokratischen Wahl der Mitglieder gibt es noch eine Reihe von weiteren Gründen, die für eine besondere inhaltliche Güte ${ }^{157}$ des formellen Gesetzes sprechen. Genannt seien etwa die Bestimmungen über die Rechtsstellung der Mitglieder im Hinblick auf Immunität und Indemnität (etwa Art. 46 GG), oder die Vorschriften über die Beteiligung anderer Organe am Gesetzgebungsver-

${ }^{153}$ So Jakob, DÖV 1970, S. 669; Kunig, S. 330; Lohr, S. 153 ff.; W. Ziegler, S. 29; Meyn, Gesetzesvorbehalt und Rechtssetzungsbefugnis, S. 10 m. w. N. Kritisch etwa Köttgen, DVB1. 1955, S. 449.

${ }^{154}$ Meyer, Finanzverfassung, S. 55; Meyn, Gesetzesvorbehalt und Rechtssetzungsbefugnis, S. 46. Ähnlich auch Jakob, DOOV 1970, S. 670; beschränkt auf den allgemeinen rechtsstaatlichen Gesetzesvorbehalt auch Bleckmann, DVBI. 1987, S. 1086.

155 Schmidt-Aßmann, Festgabe für von Unruh, S. 608, ders., Kommunalrecht, S. 111; Bethge, NVwZ 1983, S. 579.

${ }^{156}$ Schröder, S. 359 f. Gründe hierfür sind einmal das Stimmrecht des Ersten Bürgermeisters im Gemeinderat und die Möglichkeit der Zuwahl berufsmäßiger Gemeinderatsmitglieder, siehe Schröder, ebenda.

157 Starck, Gesetzesbegriff, S. 169; von Amim, DVBI. 1987, S. 1243 f. 
fahren wie etwa die des Bundesrates (Art. 77 ff. GG) oder in Bayern des Senats (Art. 34 ff. BV).

Schließlich ist es auch unrichtig, daß angesichts der "Gemeinwohlverpflichtung" gemeindlicher Rechtsetzung die vom BVerfG im sog. FacharztBeschluß beschriebene Gefahr der einseitigen Durchsetzung von Sonderinteressen ${ }^{158}$ nicht besteht ${ }^{159}$. Genau wie bei der Rechtsetzung durch ärztliche Berufskammern ohne formellgesetzliche Normierung der vor allem grundrechtsrelevanten Fragen die Gefahr der Diskriminierung von Außenseitern oder Berufsanfängern besteht, können auch in den Gemeinden Tendenzen auftreten, "Zugezogene" oder andere Personengruppen zu benachteiligen. Ein Beispiel aus jüngerer Zeit ist etwa die Diskussion um die Zweitwohnungssteuer für Nichtgemeindeangehörige ${ }^{160}$.

Auch für die gemeindliche Rechtsetzung gilt somit sowohl der demokratische als auch der rechtsstaatliche Gesetzesvorbehalt ${ }^{161}$. Die Garantie kommunaler Rechtsetzung durch Art. 28 Abs. 2 GG ist nur eine Garantie gegenüber dem Staat, jedoch keine Grundlage einer Regelungsbefugnis gegenüber dem Bürger. Damit ist der formelle Gesetzgeber aber neben seiner Verpflichtung im Hinblick auf die Zurverfügungstellung gemeindlichen Handlungsinstrumentariums gleichzeitig aufgerufen, seiner aus den Grundrechten folgenden Schutzverpflichtung nachzukommen. Dann greift aber jedes Verständnis des Art. 28 Abs. 2 S. 1 GG zu kurz, das entscheidend auf einen Unterschied zwischen Überörtlichkeit und Örtlichkeit abhebt. In der konkreten Anwendung auf den Erlaß örtlicher Bauvorschriften bedeutet dies: Der Gesetzgeber hat nicht nur die Wahl, den Erlaß von örtlichen Bauvorschriften durch die Gemeinden entweder im eigenen oder im übertragenen Wirkungskreis vorzusehen. Eine weitere Möglichkeit besteht darin, auf solche Vorschriften zur Vermeidung weiterer Eigentumsbeeinträchtigungen ganz zu verzichten. Muß der Gesetzgeber aber beim Erlaß etwa von Bestimmungen über örtliche Bauvorschriften jedoch nicht nur die Effektivierung der kommunalen Selbstverwaltung im Auge haben, dann ist seine Entschei-

${ }^{158}$ BVerfG, Beschluß vom 09.05.1972, E 33, 125 (159).

159 So aber Meyn, Gesetzesvorbehalt und Rechtsetzungsbefugnis, S. 43. Zu optimistisch auch Bleckmann, DVBI. 1987, S. 1086. Anders dagegen Schmidt-Aßmann, Gedächtnisschrift für Martens, S. 256.

${ }^{160}$ BVerfG, Beschluß vom 06.12.1983, E 65, 325 ff. Wie hier auch Schneider, Gesetzgebung, S. 165: Ortsgebundenheit aufgrund der geringen Distanz der Beteiligten zum Gegenstand der Satzungsbeschlüsse sei förderlich, aber auch bedenklich.

${ }^{161}$ Schmidt-Aßmann, HbKWP, Band 3, S. 185, ders., Kommunale Rechtsetzung, S. 8, ders., Festgabe für von Unruh, S. 608; Ossenbühl, HbStR, Band III, S. 477 Rn. 29. 
dung, örtliche Bauvorschriften im übertragenen Wirkungskreis den Gemeinden als Handlungsinstrumentarium zur Verfügung zu stellen, nicht zwingend eine Entscheidung dafür, daß die überörtliche Betroffenheit überwiegt ${ }^{162}$. Die Verweisung in den übertragenen Wirkungskreis kann auch den Grund haben, daß der Gesetzgeber aus Gründen des Grundrechtsschutzes den Aufsichtsbehörden eine Eingriffsmöglichkeit vorbehalten wollte. Dies kann durchaus ein angemessener Weg zum Schutz von Grundrechten sein. Vor allem dann, wenn mögliche Fehlentwicklungen nicht sicher vorhersehbar wären, kann so eine Konkordanz zwischen gemeindlichen Gestaltungsinteressen und der staatlichen Pflicht zur Absicherung von Grundrechten gefunden werden. Wären die Aufsichtsbehörden von Verfassungs wegen auf die Rechtmäßigkeitskontrolle beschränkt, bliebe nur eine entsprechend detaillierte Gesetzgebung, mit der die gemeindliche Entscheidungsfreiheit unter Umständen erheblich eingeschränkt würde, ohne daß es zu einem besseren Grundrechtsschutz käme.

\section{d) Fazit}

Die Klausel "im Rahmen der Gesetze" hat somit - will man einen Vergleich mit den Grundrechten ziehen - eher Ähnlichkeit mit einer Grundrechtsschranke oder einem Begrenzungsvorbehalt als mit einem Eingriffsoder Gesetzesvorbehalt ${ }^{163}$. Der Gesetzgeber hat die Pflicht zur Ausgestaltung $^{164}$. Diese Pflicht muß aber mit einem gewissen Gestaltungsspielraum korrespondieren, ohne da $B$ damit gleich das Ergebnis verbunden ist, die Zuordnung zum örtlichen oder überörtlichen Bereich könne nach freiem Belieben des Gesetzgebers erfolgen ${ }^{165}$. Je größer der örtliche Bezug ist, desto mehr verlangt Art. 28 Abs. 2 GG eine verwaltungsmäßige Beteiligung der Gemeinden. Die örtliche Radizierung ist jedoch nicht der einzige zu beachtende Gesichtspunkt. Vielmehr hat der formelle Gesetzgeber auch seine Garantiefunktion für den Schutz der Grundrechte zu beachten. Für den dabei stattfindenden Interpretations-, Wertungs- und Konkretisierungsprozess dürfte es zwar eine Reihe von Entscheidungsdeterminanten ge-

162 Mit überörtlicher Betroffenheit sind hier gemeint die durch die Verflechtung der Lebensverhältnisse ausgelösten Auswirkungen auf den außergemeindlichen Bereich.

${ }^{163}$ So auch Roters, Art. 28 GG, Rn. 56; Schmidt-Jortzig, Kommunalrecht, S. 167.

164 Dies dürfte auch einer der wesentlichen Aussagen der Rastede-Entscheidung des BVerfG (DVBI. 1989, S. 300 ff.) sein; siehe dazu Schoch, VerwArchiv 81 (1990), S. 26.

${ }^{165}$ Dies befürchtet offenbar Stüer, S. 245. Ähnlich die Argumentation bei Hartmut Krüger, NWVBI. 1987, S. 100. 
ben $^{106}$. Es handelt sich aber auf jeden Fall um mehr als einen schlichten Subsumtionsvorgang.

Für den Bereich der örtlichen Bauvorschriften ergibt sich daraus folgendes: Die unterschiedlichen Entscheidungen der Landesgesetzgeber führen im Hinblick auf den Wirkungskreis - angenommen es liegt kein Qualifikationsfehler vor - nicht dazu, daß eine wesensmäßige Unterscheidung der Aufgaben etwa im Sinne von "primär kommunal" oder "primär staatlich" nötig ist. Es ist möglich, daß verschiedene Gesetzgeber hinsichtlich der gleichen Aufgabe zu unterschiedlichen Auffassungen bezüglich des erforderlichen Maßes staatlicher Einflußmöglichkeiten kommen. Eine Grenze bildet insofern im wesentlichen das Übermaßverbot. Es lassen sich für die Einordnung in den eigenen Wirkungskreis ebenso hinreichende Gründe anführen, wie für die Zuweisung in den übertragenen ${ }^{167}$. Auch gegen die niedersächsische Lösung bestehen daher keine Bedenken.

\section{Gemeindliche Gestaltungsbefugnisse und Wirkungskreiszuordnung}

\section{Das gemeindliche Selbstgestaltungsrecht}

Der Art. 28 Abs. 2 GG garantiert den Gemeinden die grundsätzliche Zuständigkeit zur Erfüllung öffentlicher Aufgaben auf ihrem Gemeindegebiet, soweit nicht Verfassung oder Gesetz einen anderen Verwaltungsträger für zuständig erklären. Es stellt sich nun die Frage, ob es Befugnisse gibt, die den Gemeinden - unabhängig von den bisherigen Überlegungen zu Kernbereich und Gesetzesvorbehalt im Rahmen des Art. 28 Abs. 2 S. 1 GG - nur im eigenen Wirkungskreis zustehen können. Gäbe es solche Aufgaben, könnte sich daraus für den Bereich der örtlichen Bauvorschriften die Konsequenz ableiten, daß aus den unterschiedlichen Entscheidungen der Landesgesetzgeber im Hinblick auf den Wirkungskreis materiellrechtliche Konsequenzen bei der Auslegung der Befugnisnormen resultieren. Möglicherweise sind bestimmte Begründungen für Anforderungen an die Baugestaltung nur im eigenen Wirkungskreis zulässig. Für eine solche Annahme würden Überlegungen sprechen, wonach die besondere Qualität von Befugnis-

\footnotetext{
${ }^{166}$ So von Mutius, Festgabe für von Unruh, S. 256.

${ }^{167}$ Siehe oben B I 2.
} 
sen im eigenen Wirkungskreis in der Möglichkeit der Berücksichtigung lokaler Besonderheiten besteht ${ }^{168}$. Teilweise wird auch mit dem Begriff der "politischen Entscheidung" argumentiert ${ }^{169}$. Gemeint sind damit solche Entscheidungen, in denen die Gemeinden ihr Wesen selbst bestimmen, in denen sie "Individualität" gewinnen und durchsetzen kann und die deshalb nur im eigenen Wirkungskreis möglich sein sollen ${ }^{170}$.

Näheren Aufschluß in dieser Hinsicht ergibt zunächst die Diskussion um das sog. gemeindliche Selbstgestaltungsrecht. $\mathrm{Da}$ die Gemeinden ein solches Selbstgestaltungsrecht haben, wird in letzter Zeit häufiger betont ${ }^{171}$. Hierunter sei zu verstehen, daß jede Gemeinde das Recht habe, Struktur und Gepräge ihres Ortes selbst zu bestimmen ${ }^{172}$. Aus einem so verstandenen Selbstgestaltungsrecht läßt sich die Befugnis der Gemeinden ableiten, ihren "Typus", ihr "Image"173, ihr "Bild" zu bewahren oder zu entwickeln, letztlich also eine Garantie ihrer "kommunalen Identität"174 oder "Individualität".

Die Ableitung eines Selbstgestaltungsrechts aus Art. 28 Abs. 2 S. 1 GG dürfte grundsätzlich zutreffend sein. Die Bedeutung der kommunalen Selbstverwaltungsgarantie erschöpft sich nicht in der Aussage, daß den Gemeinden Kompetenzen zur Verfügung stehen müssen. Gerade das Bemühen, den Kommunen Planungsbefugnisse zu sichern ${ }^{175}$, zeigt, daß es vor allem um solche Aufgaben und Befugnisse geht, die den Gemeinden substanzielle Gestaltungs- und Entwicklungsmöglichkeiten eröffnen ${ }^{176}$. Die Selbst-

${ }^{168}$ Etwa Starck, AöR 92 (1967), S. 451.

169 Schröder, S. 350; Jakob, DÖV 1970, S. 667; Starck, AöR 92 (1967), S. 451.

${ }^{170}$ So etwa schon Stier-Somlo, S. 196; Klüber, S. 12.

${ }^{171}$ Siehe vor allem Blümel, Festschrift für Ule, S. 19 ff.; BayVGH, Urteil vom 06.06.1989, BayVBI. 1990, S. 48 (50). Siehe auch die weiteren Nachweise im Text.

172 BayVGH, Beschluß vom 19.11.1985, BayVBI. 1986, S. 370 (372). Siehe auch BVerwG, Urteil vom 19.03.1976, BayVBI. 1976, S. 692 (693); Langer, VerwArchiv 80 (1989), S. 353; Brohm, DVBI. 1980, S. 357.

${ }^{173}$ Diesen Begriff verwenden etwa Trieb, Stadtgestaltung, S. 110; Wienands, Stadtgestaltungsgutachten Bochum, II S. 2 ff.; Faber, Art. 28 Rn. 31; Mehlhorn, S. 77; Blümel, Festschrift für Ule, S. 36, nennt dies allgemein "Funktionsbestimmung".

${ }^{174}$ Ziebill, AfK 1964, S. 36; Langer, VerwArchiv 80 (1989), S. 354. Zur kommunalrechtlichen Zulässigkeit der Erlangung kommunaler Identität durch Sportförderung siehe Steiner, DÖV 1983, S. 179, ders., DVerwPr. 1987, S. 173.

${ }^{175}$ Zur Diskussion um die Verankerung der Befugnisse in der Bauleitplanung im Kernbereich der kommunalen Selbstverwaltung siehe oben B II 3 b.

${ }^{176}$ Siehe BVerfG, Urteil vom 20.03.52, E 1, 167 (175): Die Gemeinden dürfen nicht die Gelegenheit zu kraftvoller Betätigung verlieren; Beschluß vom 12.07.60, E 11, 266 (270): Die örtliche Gemeinschaft soll nach dem Leitbild des Art. 28 GG ihr Schicksal selbst in die Hand nehmen und in eigener Verantwortung solidarisch gestalten; Beschluß vom 07.10.1980, E 56, 
verwaltungs- ist somit vor allem eine Selbstgestaltungsgarantie. In gewissem Gegensatz zu der getroffenen relativ weiten Definition des gemeindlichen "Selbstgestaltungsrechts" (umschrieben als Befugnis, Struktur und Gepräge zu bestimmen), steht allerdings dessen bisher sichtbar gemachter rechtlicher Anwendungsbereich. Deutlich wird dies an einer Feststellung von Blümel, wonach das gemeindliche Selbstgestaltungsrecht neben der Planungshoheit und den anderen Gemeindehoheiten ein weiterer Bestandteil des verfassungsrechtlich garantierten Selbstverwaltungsrechts $\operatorname{se}^{17}$. Die Bedeutung des gemeindlichen Selbstgestaltungsrechts liege vor allem darin, als Abwehrrecht gegen fremde Planungen und Maßnahmen dann zur Verfügung zu ste-hen, wenn eine Berufung auf die Planungshoheit nicht in Betracht komme $\mathrm{e}^{178}$.

Eine solche Einordnung bietet sich zunächst an, wenn man versucht, das gemeindliche Selbstgestaltungsrecht in seiner Entwicklung durch die bisherige Rechtsprechung zusammenzufassen. Diese verlangt für die Abwehr fremder Planungen mit Berufung auf die "Planungshoheit" in der Regel hinreichend konkretisierte gemeindliche Vorstellungen ${ }^{179}$. Wird aber die gemeindliche Entwicklung dadurch vereitelt, daß nicht bestimmte ins Auge gefaßte Projekte, sondern vielmehr Planungsmöglichkeiten beeinträchtigt werden, oder werden sonst "Struktur und Gepräge" beeinflußt, so bietet sich das gemeindliche Selbstgestaltungsrecht quasi als Auffangrecht an. Man wird aber schon wegen der betonten Auffangfunktion bezweifeln können, $\mathrm{da} ß$ das gemeindliche Selbstgestaltungsrecht wirklich neben anderen "Hoheiten" wie Planungshoheit, Finanzhoheit, Personalhoheit etc. anzusiedeln ist. Auch dürfte es nicht zutreffend sein, Planungshoheit und Selbstgestaltungsrecht weitgehend gleichzusetzen ${ }^{180}$. Vielmehr umschreiben Begriffe wie Planungshoheit, Finanzhoheit oder Satzungshoheit eher Instrumente zur Erlangung gemeindlicher Individualität ${ }^{181}$. So ist etwa gemeindliche Planung kein Selbstzweck. "Planungshoheit" hat die Gemeinde wegen des Produktes der Planung, nicht wegen des Vorgangs. Gleiches gilt für die

298 (312), wonach den Gemeinden ein "ausreichender Spielraum zur Ausübung kommunaler Selbstverwaltung" bleiben muß.

${ }^{17}$ Festgabe für von Unruh, S. 30 und 34. Hervorhebung nicht im Original.

${ }^{178}$ Blümel, Festgabe für von Unruh, S. 41 und 42.

179 Nachweise bei Blümel, Festgabe für von Unruh, S. 31; Würtenberger, BayVBI. 1982, S. 676 .

${ }^{180}$ So aber Lerche, Festschrift BayVGH, S. 234.

181 Für die gemeindliche Rechtsetzungsbefugnis siehe Schmidt-Aßmann, Kommunale Rechtsetzung, S. 1. 
Satzungshoheit ${ }^{182}$. Auch die anderen "Hoheiten" werden den Gemeinden zugesprochen, damit sie für sich in gewissem Maße das erreichen können, was sie erreichen wollen ${ }^{183}$. Akzeptiert man die Definition des gemeindlichen Selbstgestaltungsrecht, die lautet, daß es um das Recht geht, Struktur und Gepräge des Ortes zu bestimmen ${ }^{184}$, dann sind die bisher anerkannten "Hoheiten" eher spezielle Garantien zur Verwirklichung der allgemeinen Garantie "gemeindliche Selbstgestaltung". Sie finden ihren Grund und ihr Ziel in der Selbstgestaltungsgarantie. Das gemeindliche Selbstgestaltungsrecht ist eher "hinter" den anderen "Hoheiten", nicht "neben" ihnen anzusiedeln, es ist vor allem eine Verdeutlichung der Zielrichtung der Selbstverwaltungsgarantie in dem Sinne, daß Art. 28 Abs. 2 GG nicht nur gemeindlichen Verwaltungsvollzug, sondern Verwaltung zur Individualitätsbildung garantiert. Da es sich somit beim gemeindlichen Selbstgestaltungsrecht um eine Verdeutlichung der allgemeinen Garantie des Art. 28 Abs. 2 S. 1 GG handelt, unterliegt es konsequenterweise den gleichen Beschränkungen, wie die Garantie der kommunalen Selbstverwaltung auch ${ }^{185}$. Für die vorliegende Untersuchung ist aber vor allem wichtig, da $\beta$ sich aus der kommunalen Selbstverwaltungsgarantie ergibt, da $B$ den Gemeinden Möglichkeiten zur Individualitätsbildung offen stehen müssen.

\section{Genuin gemeindliche Aufgaben}

Die Gemeinden können nur dann ihr Selbstgestaltungsrecht wahrnehmen, wenn sie zum einen rechtliche Kompetenzen, und zwar vor allem Planungskompetenzen haben, und wenn sie zum anderen noch über zu verplanende Agenden verfügen ${ }^{186}$. Bei den Kompetenzen läßt sich aus dem Selbstgestaltungsrecht eine weitere Differenzierung ableiten. Die Gemeinden haben zunächst und vor allem Anspruch auf Befugnisse zur Erfüllung öffentlicher Aufgaben, die dann, wenn sie nicht von den Gemeinden erfüllt würden, von anderen Verwaltungsorganen wahrzunehmen wären, die also staatlichen

\footnotetext{
${ }^{182}$ Meyn, Gesetzesvorbehalt und Rechtsetzungsbefugnis, S. 24 Anm. 48.

${ }^{183} \mathrm{Vgl}$. auch die parallelen Überlegungen Burmeisters, Neukonzeption, S. 102, zur "Unsinnigkeit" der Zuordnung dieser Hoheiten als Tätigkeits- oder Aufgabengebiete.

${ }^{184}$ BayVGH, Beschluß vom 19.11.1985, BayVBI. 1986, S. 370 (372).

${ }^{185}$ BVerwG, Urteil vom 19.03.1976, BayVBI. 1976, S. 692 (693).

186 Relevant wird dies vor allem bei der Einschränkung der gemeindlichen Bauleitplanungsmöglichkeiten durch landesplanerische Ziele, siehe Gaentzsch, Berliner Kommentar, § 1 Rn. 31.
} 
Charakter haben ${ }^{187}$. Für die Erfüllung staatlicher Verwaltungsaufgaben auf dem Gemeindegebiet sind zunächst die Gemeinden zuständig und vom $\mathrm{Ge}$ setzgeber mit entsprechenden Handlungsinstrumentarien auszustatten. Gemeindliche Individualität entsteht mit dem Verwaltungsvollzug dadurch, daß jede Gemeinde unter den rechtlich möglichen Alternativen zur Aufgabenerfüllung diejenige auswählt, die ihr am ehesten ins Konzept paßt.

Es ist aber auch denkbar, daß die Gemeinden Befugnisse zur Erfüllung von solchen Aufgaben haben oder einsetzen, die vom Staat nicht wahrgenommen werden können, in denen sich vor allem ihre Individualitätsbildung unmittelbar vollzieht, ohne den "Umweg" über die Erfüllung einer staatlichen Aufgabe. Dies gilt auch dann, wenn man die Gemeinden zur "mittelbaren Staatsverwaltung" zählt ${ }^{188}$. Mit einer solchen Qualifizierung ist nicht zwingend die Konsequenz verbunden, daß nur solche Aufgaben erfüllt werden können, die von Bund oder Ländern quasi mit Rückholrecht übertragen worden sind ${ }^{189}$. Aufgaben, die in diesem Sinn nur von der Gemeinde selbst erfüllt werden können, lassen sich als "genuin gemeindlich" bezeichnen.

Besonders im Bereich der Baugestaltung wird die Feststellung, daß die Gemeinden unter Umständen nur genuin gemeindliche Gründe für den Verwaltungsvollzug anführen können, relevant ${ }^{190}$. Die Gemeinden nehmen beim Erlaß von örtlichen Bauvorschriften zum einen "staatliche" (im Sinne von "nicht genuin gemeindliche") Aufgaben wahr. Dies ist dann der Fall, wenn die Anforderungen an Gebäude mit Interessen gerechtfertigt werden,

${ }^{187}$ Zur Unterscheidung von öffentlichen und staatlichen Aufgaben siehe Martens, Öffentlich als Rechtsbegriff, S. 121; Schmidt-Aßmann, Gedächtnisschrift für Martens, S. 260; Isensee, HbStR, Band III, S. $63 \mathrm{Rn}$. 136. Hinweise speziell für den kommunalen Bereich finden sich etwa bei Langer, VerwArchiv 80 (1989), S. 369 f.; weiterhin bei Erbguth, DVBl. 1986, S. 1232, wenn dieser überlegt, ob die Grundsätze der planerischen Gestaltung bei Bauleitplanungen auf andere Aktionsfelder staatlicher Planung übertragbar seien, oder ob die Planungsfreiheit u. U. aus deren Selbstverwaltungsrecht folge. Weiterhin Faber, Art. 28 Rn. 31, der die Identitätsfindung als "Kernbereich" der kommunalen Selbstverwaltung versteht. Sehr grundsätzlich zur Spannungslage zwischen staatlichen und lokalen Gruppeninteressen Loschelder, Gebietsgestaltung, S. 106 ff.

188

So etwa Forsthoff, Lehrbuch, S. 478; Hassel, Verwaltungsrundschau 1984, S. 146; gegen eine Gleichsetzung von nittelbarer Staatsverwaltung und Selbstverwaltung etwa $E$. R. Huber, Selbstverwaltung, S. 146.

189 Zur parallelen Problematik bei den öffentlich-rechtlichen Rundfunkanstalten vgl. Emmerich / Steiner, S. 63. Bei der Frage, ob die Gemeinden zur mittelbaren Staatsverwaltung zu zählen sind, dürfte es sich vielfach um ein terminologisches Problem handeln, das auf einer unterschiedlichen Verwendung des Wortes "staatlich" beruht. Der Begriff "staatlich" kann entweder nur Bund und Länder, oder den im GG geordneten Gesamtorganismus unter Einschluß der Gemeinden umfassen, so Hendler, Selbstverwaltung, S. 296 f.; Loschelder, Gebietsgestaltung, S. 89; Meyer, Finanzverfassung, S. 58.

${ }^{190}$ Ausführlich unten C und D. 
die auch vom Staat ${ }^{191}$ selbst wahrgenommen werden könnten und unter Umständen auch wahrgenommen werden, wie etwa beim Erlaß von denkmalschützenden Vorschriften. Es gibt jedoch auch Fälle der Wahrnehmung von nur gemeindlichen Belangen. Ein solcher Fall würde im Bereich der Baugestaltung dann vorliegen, wenn die Gemeinde in einer Satzung über örtliche Bauvorschriften eine bestimmte Gestaltung vorschreibt, die sich nur dadurch begründen läßt, daß die Gemeinde ihren Willen geltend macht, auf diese Weise das eigene "Bild" zu beeinflussen, bei der also kein anderes auch staatliches Interesse, wie z. B. der Schutz eines Orts- oder Landschaftsbildes oder Gründe des Denkmalschutzes, eine Rolle spielt ${ }^{192}$.

Ist die Erfüllung einer solchen genuin gemeindlichen Aufgabe nur im eigenen Wirkungskreis möglich, so wäre der Umfang der Ermächtigungen in den Landesbauordnungen teilweise unterschiedlich. Der Inhalt der möglichen Anforderungen würde sich zwar nicht unterscheiden, wohl aber die Erlaßvoraussetzungen. Im übertragenen Wirkungskreis müßte es etwa um die Erhaltung der Eigenart eines schutzwürdigen Straßen- oder Ortsbildes gehen, im eigenen Wirkungskreis würde der Wunsch der Gemeinde nach einer bestimmten Gestaltung unter Umständen genügen ${ }^{193}$.

\section{Gemeindliche Individualität und kommunales Aufgabensystem}

Aus dem gemeindlichen Selbstgestaltungsrecht läßt sich die Befugnis der Gemeinden zur Individualitätserhaltung und -entwicklung ableiten ${ }^{194}$. Daraus folgt die Möglichkeit, daß die Gemeinden etwa Anforderungen an die Baugestaltung nur deshalb erlassen, um so ihr "Bild" zu pflegen ${ }^{195}$. Individualität läßt sich nun zwar nur in Eigen- und nicht in Fremdbestimmung erreichen. Für die Frage, welchen Einfluß das gemeindliche Recht der Selbstgestaltung auf die Zuweisung von Befugnissen in den eigenen bzw. übertragenen Wirkungskreis hat, ergibt sich trotzdem folgendes: Grundsätzlich unterliegt das gemeindliche Selbstgestaltungsrecht den gleichen Beschränkun-

\footnotetext{
${ }^{191}$ Also vor allem von den Ländern.

${ }^{192}$ Zur genauen Eingrenzung dieses Bereichs siehe unten D.

${ }^{193}$ Dies setzt allerdings die Vereinbarkeit mit der Eigentumsgarantie voraus, siehe unten

${ }^{194}$ Siehe oben B III 1.

195 Siehe oben B III 1.
} D II 1. 
gen wie das Selbstverwaltungsrecht auch ${ }^{196}$. Es läßt sich daher keinesfalls ein Schlu $ß$ dahingehend ziehen, da $\beta$ alles, was individualitätsbildend wirkt, den Gemeinden zur eigenen und unbeeinflußten Entscheidung zusteht. Viele Entscheidungen, die die gemeindliche Identität existentiell prägen, sind von den Gemeinden nicht einmal im übertragenen Wirkungskreis, sondern gar nicht zu treffen, weil sie staatlichen Behörden obliegen. Als Beispiel sei etwa die Namensgebung genannt. So ist etwa in Bayern schon die Frage, ob eine Gemeinde sich "Stadt" nennen darf, von einer staatlichen Verleihung abhängig $^{197}$, ganz abgesehen davon, daß die Identität einer Gemeinde ganz erheblich z. B. von überörtlichen Planungen bestimmt werden kann.

Die zwingende Einordnung in den eigenen Wirkungskreis kommt somit von vornherein nur dann in Betracht, wenn der Gesetzgeber überhaupt eine gemeindliche Kompetenz vorgesehen hat. Was die Erfüllung "staatlicher" Aufgaben betrifft, so können die Gemeinden aber auch bei Entscheidungen im übertragenen Wirkungskreis Individualität entwickeln. Die Geltendmachung kommunaler Präferenzen ist keine Besonderheit des eigenen Wirkungskreises ${ }^{198}$. Gerade die Ortsnähe wird sogar häufig der Grund sein, warum die Gemeinden in die Aufgabenerfüllung eingeschaltet werden ${ }^{199}$. Im übertragenen Wirkungskreis sind örtliche Besonderheiten berücksichtigungsfähig. Dies gilt zwar nur im Rahmen des vom staatlichen Gesetzgeber vorgegebenen Zweckprogramms, an das die Gemeinden gebunden sind ${ }^{200}$, aber auch damit können die Gemeinden ihre Individualität fördern und entwickeln. Sie haben die Möglichkeit - allerdings unter Vorbehalt einer Korrektur durch die Aufsichtsbehörden -, sich zwischen den vom staatlichen Zweckprogramm zugelassenen Gesichtspunkten für diejenigen zu entscheiden, die ihren Vorstellungen über die Entwicklung des Gemeindegebietes am ehesten entsprechen. Auch die Übertragung von Angelegenheiten entspricht damit der Forderung des Subsidiaritätsprinzips, daß der Staat keine Aufgaben wahrnehmen soll, die auch die "engere" Gemeinschaft nach eigenen Kräften erledigen kann. Der Gesetzgeber wird seiner aus Art. 28 Abs. 2 S. 1 GG und speziell dem Selbstgestaltungsrecht ableitbaren Pflicht, den

\footnotetext{
${ }^{196}$ Siehe oben B III 1.

${ }^{197}$ Siehe Art. 3 Abs. 2 BayGO. Zur Verfassungsmäßigkeit der Beschränkungen bei der Namensgebung mit Art. 28 Abs. 2 S. 1 GG siehe BVerfG, Beschluß vom 17.01.1979, E 50, 195 (201).

198 Schröder, S. 352 m. w. N.; Brohm, DÖV 1986, S. 402.

199 Brohm, DÖV 1986, S. 399; Korte, VerwArchiv (61) 1970, S. 26

${ }^{200}$ Siehe Hufen / Leiß, BayVBI. 1987, S. 299 ff.
} 
Gemeinden Entscheidungs- und vor allem Planungsbefugnisse zu übertragen, auch dann gerecht, wenn er eine Aufgabenerfüllung im übertragenen Wirkungskreis vorsieht.

Nicht einmal für den Fall unmittelbarer Individualitätsbildung wird man davon ausgehen können, daß eine Zuordnung zum eigenen Wirkungskreis zwingend ist. Die mit einer Zuweisung in den eigenen Wirkungskreis verbundene Möglichkeit des Eingreifens der Aufsichtsbehörden kann aus Gründen des Grundrechtsschutzes vom Gesetzgeber vorgesehen sein und sich auch aus einer richtigen Anwendung des Übermaßverbotes zugunsten der gemeindlichen Selbstverwaltung ergeben. Denn die Zuweisung einer Aufgabe in den übertragenen Wirkungskreis schränkt den gemeindlichen Entscheidungsfreiraum möglicherweise erheblich weniger ein als die Zuweisung in den eigenen, wenn dann der Gesetzgeber gezwungen wäre, zur Ermöglichung einer angemessenen Rechtmäßigkeitskontrolle detaillierte gesetzgeberische Bestimmungen zu erlassen ${ }^{201}$.

Die Aufwertung des übertragenen Wirkungskreises findet damit für die vorliegende Untersuchung ihren Abschluß. Auch sog. genuin gemeindliche Aufgaben können im übertragenen Wirkungskreis rechtlich umgesetzt werden. Für den Bereich der Baugestaltung folgt daraus, da $B$ die Ermächtigungen zum Erlaß von örtlichen Bauvorschriften in den einzelnen Landesbauordnungen nicht deshalb unterschiedlich auszulegen sind, weil die Landesgesetzgeber unterschiedliche Lösungen für die Einordnung in das kommuale Aufgabensystem getroffen haben. Beispielsweise können baugestalterische Anforderungen - soweit die landesrechtlichen Bestimmungen dies vorsehen $^{202}$ - sowohl zur Erfüllung von "staatlichen", als auch unmittelbar zur Individualitäts- oder Identitätsbildung eingesetzt werden.

\section{Satzung und Rechtsverordnung als Instrumente gemeindlicher Selbstgestaltung}
a) Die mögliche Relevanz der Unterscheidung
für den Bereich örtlicher Bauvorschriften

Die Untersuchung der Einordnung von örtlichen Bauvorschriften in das kommunale Aufgabensystem hat zu dem Ergebnis geführt, daß sowohl die

\footnotetext{
${ }^{201}$ Vergleiche die parallele Argumentation oben B II 4 b a. E.

${ }^{202}$ Dazu unten C und D.
} 
Zuweisung zum Erlaß im eigenen wie auch im übertragenen Wirkungskreis mit der Verfassungsgarantie des Art. 28 Abs. 2 S. 1 GG vereinbar ist. Die Wahl der einen oder anderen Lösung führt auch zu keinen Unterschieden in bezug auf die Möglichkeit der Erfüllung von genuin gemeindlichen Aufgaben.

An diese Feststellung knüpfen sich nun zwei Fragen an. Die erste lautet, ob die Entscheidung eines Landesgesetzgebers für den eigenen oder den übertragenen Wirkungskreis im Hinblick auf die Rechtsform für den Erlaß von örtlichen Bauvorschriften zwingende Folgen hat, oder ob der Landesgesetzgeber dafür, ob er eine Satzungs- oder Rechtsverordnungsermächtigung vorsieht, Wahlfreiheit hat. Geht man von einer solchen Wahlfreiheit aus, stellt sich die weitere Frage, ob sich aus einer getroffenen Wahl irgendwelche Folgen ergeben, etwa für die Erfüllung sog. genuin gemeindlicher Aufgaben.

Die Annahme, daß dem Erlaß von örtlichen Bauvorschriften im übertragenen Wirkungskreis nur die Rechtsform der Rechtsverordnung entspricht, ist durchaus verbreitet. So lautet die wohl am häufigsten genannte Definition für Satzungen dahingehend, daß es sich dabei um Rechtsetzungsakte selbständiger, dem Staat eingegliederter Verwaltungsträger zur Regelung ihrer eigenen Angelegenheiten handelt, wobei der "übertragene Wirkungskreis" nicht zu den eigenen Angelegenheiten im Sinne dieser Definition zählt ${ }^{203}$. Soweit der Erlaß örtlicher Bauvorschriften dem übertragenen Wirkungskreis zugerechnet wird, wird eine Rechtsverordnungsermächtigung als "rechtssystematisch sachgerechter"204, eine Satzungsermächtigung gar als "systemwidrig" angesehen ${ }^{205}$.

Die Gegenauffassung wird etwa vom BayVGH vertreten. Zwar werden seit 1982 örtliche Bauvorschriften nach der BayBO nicht mehr als Rechtsverordnung, sondern als Satzung erlassen ${ }^{206}$. Der BayVGH zieht hieraus aber nicht den Schluß, daß örtliche Bauvorschriften nach der Änderung im eigenen und nicht mehr im übertragenen Wirkungskreis erlassen werden; er

${ }^{203}$ Siehe etwa Schmidt-Aßmann, Kommunale Rechtsetzung, S. 4, ders., HbKWP, Band 3, S. 182; Stern, Staatsrecht, Band 1, § 20 IV 4 S. 820. Ähnlich auch Ossenbühl, in Erichsen / Martens, S. 108 und ders., HbStR, Band III, S. 466 Rn. 6, wonach sich im gemeindlichen Bereich Satzungen und Rechtsverordnungen nur vom Aufgabenbereich her - also Selbstverwaltungsaufgabe / Staatsaufgabe - abgrenzen lassen.

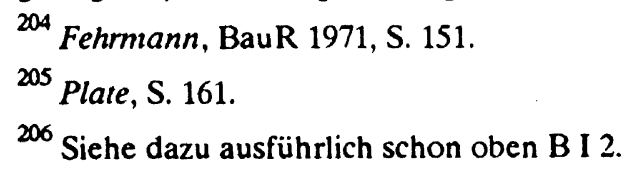


betont vielmehr die Möglichkeit des Satzungserlasses auch im übertragenen Wirkungskreis ${ }^{207}$.

b) Die Verwendung von Rechtsverordnungs- und Satzungsermächtigungen in der Rechtsordnung

Untersucht man die tatsächliche Verwendung von Satzungs- und Rechtsverordnungsermächtigungen bei der gemeindlichen Rechtsetzung, so ergibt sich insoweit ein Argument für die Rechtsprechung des BayVGH. Die Umwandlung der Rechtsverordnungs- in eine Satzungsermächtigung im Bereich der BayBO ist zwar ein starkes Indiz für den gesetzgeberischen Willen, daß örtliche Bauvorschriften nicht mehr im übertragenen, sondern im eigenen Wirkungskreis erlassen werden sollen ${ }^{208}$. Es besteht aber in der bundesdeutschen Gesetzgebungspraxis keine einheitliche Linie in dem Sinn, daß Rechtsverordnungsermächtigungen stets dem übertragenen und Satzungsermächtigungen immer dem eigenen Wirkungskreis zugeordnet werden.

Es finden sich allerdings Sachverhalte, bei denen sowohl eine Einordnung in den eigenen oder übertragenen Wirkungskreis in Betracht kommt, und in denen Satzung und Rechtsverordnung je nachdem vorgesehen werden, ob die Aufgabe im eigenen oder übertragenen Wirkungskreis erledigt werden soll. So wird der Zwang zum Anschluß an gemeindliche Wasserversorgungsunternehmen gegenwärtig durch gemeindliche Satzungen begründet ${ }^{209}$. Dies ist darauf zurückzuführen, daß man heute gegenüber dem Aspekt der Gefahrenabwehr mehr den der Daseinsvorsorge als typische Selbstverwaltungsaufgabe betont. Hingegen erfolgte etwa nach Preußischem Recht die Auferlegung eines Benutzungszwanges durch Rechtsverordnung ${ }^{210}$. Hier folgt also die gewählte Rechtsform der Entscheidung des Gesetzgebers im Hinblick auf den Wirkungskreis.

In den weitaus überwiegenden Fällen werden auch sonst im Bereich der gemeindlichen Rechtsetzung Satzungen im eigenen und Rechtsverordnungen im übertragenen Wirkungskreis erlassen. Ein allgemeiner Grundsatz läßt sich daraus aber trotzdem nicht ableiten. Denkbar ungeeignet zum Be-

${ }^{207}$ BayVGH, Urteil vom 29.10.1985, BayVBI. 1986, S. 213 und Beschluß vom 19.11.1985, BayVBI. 1986, S. 370 f.

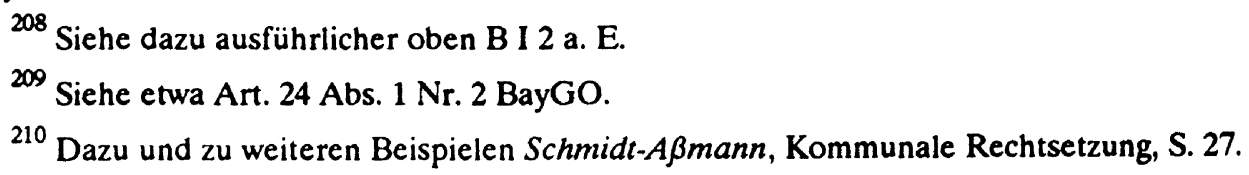


leg dieser Behauptung ist allerdings das gelegentlich angeführte Beispiel der statuarischen Bestimmungen nach $\S 119$ a Abs. 2 GewO. Wenn dies tatsächlich der Hauptanwendungsfall einer Satzung im übertragenen Wirkungskreis wäre ${ }^{211}$, könnte man der Figur der Satzung im übertragenen Wirkungskreis wirklich jede systembildende Kraft absprechen. Denn der im Jahre 1891 erlassene $\S 119$ a Abs. $2 \mathrm{GewO}^{212}$ ist heute vollkommen bedeutungslos ${ }^{213}$. Insoweit läßt sich in der Tat von einem "Residuum aus einer weitgehend überholten Phase des Gemeinderechts" sprechen ${ }^{214}$.

Wesentlich bessere Beispiele bietet die Rechtsentwicklung in BadenWürttemberg. Dort kommt es in jüngerer Zeit zu einer Art Wiederentdeckung der Satzung in übertragenen Angelegenheiten ${ }^{215}$. Ausgangspunkt hierfür sind Bestrebungen zur Stärkung der kommunalen Selbstverwaltung durch die Umwandlung von Rechtsverordnungs- in Satzungsermächtigungen $^{216}$. Nach $\S 4$ Abs. 1 S. 2 GemO BW sind auch in Weisungsangelegenheiten Satzungsermächtigungen möglich. Durch eine solche Umwandlung von Rechtsverordnungs- in Satzungsermächtigungen verringern sich die Einflußmöglichkeiten der Aufsichtsbehörden ${ }^{217}$. Ein Ergebnis der Bemühungen, auf diese Weise die Stellung der Kommunen zu stärken, ist etwa die Änderung von $\S 47$ StrG BW vom 26.09.1987 $7^{218}$. Danach erfolgt die Auferlegung der Straßenunterhaltung auf die Eigentümer angrenzender Grundstücke nicht mehr durch Rechtsverordnung, sondern durch Satzung in übertragenen Angelegenheiten.

Es ist daher zumindest nicht mehr zutreffend, daß die Satzung im übertragenen Wirkungskreis "praktisch keine Rolle" spiele ${ }^{219}$. Zwar sind Satzungen im eigenen Wirkungskreis durchaus der Regelfall, Satzungen im übertragenen Wirkungskreis aber keinesfalls so selten, daß man vom "faktischen

\footnotetext{
${ }^{211}$ So für die BayGO Masson / Samper, Art. 23 GO Rn. 6.

212 Ströhsel, § 119 a.

${ }^{213}$ Bäck / Hoffinann / Janssen / Volmer, §119 a IV S. 455; Westbomke, S. 90.

214 So Badura, DÖV 1963, S. 567 mit Anm. 58.

${ }^{215}$ Bisher gab es etwa das Beispiel des Satzungserlasses nach dem Bad.-Würt. Feuerwehrgesetz. Siehe dazu Westbomke, S. 89 mit Anm. 124.

${ }^{216}$ Siehe Bad.-Würt. LT-Drs. Nr. 8/2896 und 8/3115.

${ }^{217}$ Siehe Bad.-Würt. LT-Drs. Nr. 8/2896, S. 12: statt Selbsteintrittsrecht nach $§ 14$ PolG nur noch Rechtsaufsicht.

218 GBI. S. $477 \mathrm{ff}$.

${ }^{219}$ So aber Badura (Fn. 214).
} 
Reflex ihrer rechtlich gegebenen Irregularität" sprechen könnte ${ }^{220}$. Unzutreffend war auch die Prognose, daß mit dem Verschwinden des dualistischen Aufgabensystems sich die konstruktiven Schwierigkeiten mit der Satzung im übertragenen Wirkungskreis erledigen ${ }^{221}$. Zum einen besteht das duale Aufgabensystem weiter, zum anderen zeigt gerade das Beispiel von Baden-Württemberg, daß auch in eigentlich monistischen Systemen diese Erscheinung eine Rolle spielt.

Es gibt jedoch nicht nur Satzungen im übertragenen Wirkungskreis, die man ignorieren müßte, wenn man gemeindliche Satzungen und Rechtsverordnungen nach dem Kriterium eigener / übertragener Wirkungskreis trennen will. Es existieren nämlich auch noch Rechtsverordnungen im eigenen Wirkungskreis, die nicht in dieses Schema passen wollen, und zwar die nichtbewehrten Polizeiverordnungen nach dem BayLStVG ${ }^{222}$. Die Rechtsverordnung als typisches Mittel zur Abwehr abstrakter Gefahren steht hier den Gemeinden auch dann zur Verfügung, wenn - was von Art. 83 Abs. 1 $\mathrm{BV}$ in gewissem Maße vorgegeben ist ${ }^{23}$ - materielle Polizeitätigkeit im eigenen Wirkungskreis ausgeübt wird.

\section{c) Zur Frage der verfassungsrechrlichen Zulässigkeit der festgestellten landesrechtlichen Regelungen}

Verfassungsrechtliche Bedenken gegen die Tatsache, daß sich die Landesgesetzgeber in gewissem Maße eine Wahlfreiheit zugestehen, wenn es um die Entscheidung zwischen Rechtsverordnung und Satzung und deren Zuordnung zum eigenen oder übertragenen Wirkungskreis der Gemeinden geht, könnten vor allem aus Art. 80 Abs. 1 S. 2 GG hergeleitet werden. Die rechtsstaatlichen und demokratischen Grundsätze des Art. 80 Abs. 1 GG sind nach der Rechtsprechung des BVerfG auch für die Landesgesetzgebung verbindlich ${ }^{224}$. Die Landesverfassungen enthalten vielfach wortidentische Bestimmungen ${ }^{225}$. Im Fall der BV erfolgt eine Interpretation des

${ }^{220}$ So aber Badura (Fn. 214), für den damaligen Stand: Die geringe Bedeutung der Satzung im übertragenen Wirkungskreis in Bayern sei der faktische Reflex ihrer Irregularität.

${ }^{221}$ In diese Richtung aber Badura (Fn. 214).

${ }^{222}$ Berner / Böhmer. Art. 42 Rn. 6.

223 Siehe Emmerig, BayVBI. 1975, S. 286.

${ }^{224}$ BVerfG, BeschluB vom 20.10.1981, JZ 1982, S. 755 (758).

${ }^{225}$ Art. 61 Abs. 1 S. 2 Verf. BW; Art. 53 Abs. 1 S. 2 Verf. HH; Art. 34 Abs. 1 S. 2 Vorl. Nieders.Verf.; Art. 70 Abs. 1 S. 2 Verf. NRW; Art. 110 S. 2 Verf. Rh.Pf.; Art. 104 Abs. 1 S. 2 Verf. Saarl.; Art. 33 Abs. 1 S. 2 Verf. SI.H. 
Art. 55 Nr. 2 S. 3 entsprechend der Rechtsprechung des BVerfG zur bundesverfassungsrechtlichen Bestimmung des Art. 80 Abs. 1 S. $2 G^{226}$.

Vor allem dann, wenn ein Gesetzgeber statt einer Rechtsverordnungseine Satzungsermächtigung im übertragenen Wirkungskreis vorsieht, könnte man eine mögliche Umgehung des Art. 80 Abs. 1 S. 2 GG bzw. der entsprechenden landesverfassungsrechtlichen Bestimmungen befürchten. Denn auf die "autonome" Satzungsgewalt wendet das BVerfG in ständiger Rechtsprechung die Maßstäbe des Art. 80 Abs. 1 S. 2 GG zumindest grundsätzlich nicht $a^{227}$. Diese Rechtsprechung des BVerfG bezieht sich jedoch eben nur auf "autonome" Rechtsetzung, worunter nach der Diktion des Gerichts der Satzungserlaß im eigenen Wirkungskreis zu verstehen ist. Daher können bei Satzungen im übertragenen Wirkungskreis die Grundsätze des Art. 80 Abs. 1 S. 2 GG ohne weiteres analog angewendet werden ${ }^{228}$. Gegen Ermächtigungen zum Erlaß von Satzungen im übertragenen Wirkungskreis lassen sich daher aus Art. 80 Abs. 1 S. 2 GG und den landesverfassungsrechtlichen Parallelbestimmungen keine Bedenken herleiten.

Auch gegen die zweite etwas von der Regel abweichende Konstruktion, nämlich Rechtsverordnungsermächtigungen im eigenen Wirkungskreis, lassen sich verfassungsrechtliche Einwände nicht erheben. Wendet man den Art. 80 Abs. 1 S. 2 GG auf solche Rechtsverordnungen nicht an, so ergeben sich aus dieser Bestimmung auch keine Bedenken. Wendet man ihn an, führt dies ebenfalls zu keinen Schwierigkeiten. Nach dem Gesetzesvorbehalt des Art. 28 Abs. 2 S. 1 GG sind Einschränkungen der gemeindlichen Eigenverantwortlichkeit möglich.

Insgesamt läßt sich damit folgendes Fazit ziehen: Satzung und Rechtsverordnung werden, zumindest was die Zuordnung zum eigenen oder übertragenen Wirkungskreis betrifft, im geltenden Recht wenigstens teilweise austauschbar eingesetzt ${ }^{229}$. Verfassungsrechtliche Bedenken gegen einen solchen Formentausch bestehen keine ${ }^{230}$.

\footnotetext{
${ }^{226}$ Siehe die Rechtsprechungsnachweise bei Meder, Art. 55 Rn. 12.

${ }^{227}$ BVerfG, Beschluß vom 09.05.1972, E 32, 125 (157) m. w. N.

${ }^{228}$ So auch Lerche, DB Beilage Nr. 6/69, S. 5.

229 Anders Badura, DÖV 1963, S. 567.

${ }^{230}$ So wohl auch Badura (Fn. 229).
} 
Eine zwingende Zuordnung von Satzungen zum eigenen und Rechtsverordnungen zum übertragenen Wirkungskreis gibt es somit nicht. Es existieren aber noch eine Reihe weiterer Abgrenzungsvorschläge für das Verhältnis zwischen beiden Rechtsformen, die Rückschlüsse auf die Frage erlauben könnten, ob es etwa für die Auslegung des Art. 91 BayBO n. F. einen Unterschied macht, wenn für den Erlaß von örtlichen Bauvorschriften statt einer Rechtsverordnungs- eine Satzungsermächtigung vorgesehen ist.

Überwunden ist heute immerhin der Versuch, Satzungen und Rechtsverordnungen nach ihrem Geltungsgrund $\mathrm{zu}$ unterscheiden, indem man Rechtsverordnungen als "abgeleitetes" und Satzungen als "originäres" Recht versteht $^{231}$. Diese Auffassung widerspricht zum einen dem heute anerkannten Grundsatz der Einheit der Staatsgewalt und läßt sich mit dem auch für Gemeindesatzungen geltenden Vorbehalt des Gesetzes, der zumindest im grundrechtsrelevanten Bereich gilt ${ }^{232}$, nicht vereinbaren ${ }^{233}$. Auch die Satzungsgewalt wird - gegebenenfalls durch Art. 28 Abs. 2 S. 1 GG - "verliehen", auch Satzungen sind insoweit "abgeleitetes" Recht ${ }^{234}$.

Auch die Auffassung, wonach Rechtsverordnungen von staatlichen und Satzungen von nichtstaatlichen Stellen erlassen werden ${ }^{235}$, ist für die gemeindliche Rechtsetzung nicht zutreffend. Rechtsverordnungen werden nicht vom Bürgermeister in Organleihe für den Staat, sondern von den Gemeinden im eigenen Namen erlassen ${ }^{236}$. Der Erlaß durch nicht-staatliche

${ }^{231}$ Etwa Niemeyer, Bund und Gemeinden, S. 147. Ausführliche Nachweise und Darstellung weiterhin bei Kiess, S. $40 \mathrm{ff}$.

232 Siehe dazu oben B II $4 \mathrm{c}$.

${ }^{233}$ Westbomke, S. 69 f.; Kiess, S. 42 f.

${ }^{234}$ Haug, S. 39 m. w. N. So auch Meyer, Finanzverfassung, S. 59: "Ausübung von Satzungsgewalt ist also Betätigung einer von der Verfassung verliehenen oder anerkannten Rechtsposition."

235 Für die Weimarer Zeit siehe Jacobi, HbDStR, Band II, S. 238; Jellinek, Verwaltungsrecht, S. 131; Peters, HbDStR, Band II, S. 264. Siehe aus der Zeit der Geltung des GG von Danwitz, S. 24; Hermes, S. 97, die Satzungen dem Prinzip der Dezentralisation und Rechtsverordnungen dem der Dekonzentration zuordnen. Weiterhin BVerfG, Urteil vom 14.07.1959, E 10, 20 (50). An diese Rechtsprechung anknüpfend $P$. Kirchhof, Festgabe BVerfG, Band II, S. 83: "Rechtsverordnungen sind Rechtsätze, die von einer staatlichen Stelle ausgehen, ohne Gesetz zu sein." Schneider, Festschrift für Möhring, S. 525, ders., Gesetzgebung, S. 160; Wilke, AöR 98 (1973), S. 207, ebenfalls in Anlehnung an das BVerfG. Ähnlich aus Kiess, S. 78, der meint, die Gemeinde erhalte dann die Stellung eines Staatsorgans, wenn sie beim NormerlaB staatlichen Weisungen unterliegt.

${ }^{236}$ So zutreffend Hamann, S. 52; Badura, DÖV 1963, S. 563; ausführlich W. Ziegler, S. 421; Bedenken insoweit auch bei Wilke, AöR 98 (1973), S. 208. 
Stellen kennzeichnet zwar den Satzungs-, unterscheidet ihn aber nicht vom Verordnungserla $\beta^{237}$.

An der Eigenschaft der Gemeinden als Gebietskörperschaften scheitert auch die zweite Gruppe von Ansichten, die versucht, anhand irgendeiner Nähebeziehung zwischen Normgeber und Normadressat den Unterschied zwischen Satzung und Rechtsverordnung zu erklären, etwa dergestalt, daß unter die Satzungsbefugnis nur Angehörige des jeweiligen Verbandes fal$\operatorname{len}^{238}$. Gerade die hier besonders interessierenden gemeindlichen Satzungen können auch für Nichtgemeindeangehörige gelten. $\mathrm{Daß}$ es sich hierbei nicht um ein geeignetes Gegenbeispiel handeln soll ${ }^{239}$, ist nicht recht einsehbar. Abgrenzungstheorien, die gerade den wichtigen Fall der gemeindlichen Rechtsetzung nicht erklären können, haben zumindest für die vorliegende Untersuchung keinen relevanten Erkenntniswert ${ }^{240}$.

Eine subtile Abwandlung der Theorie, wonach Rechtsverordnung und Satzung nach dem Adressatenkreis zu unterscheiden sind, liegt vor, wenn behauptet wird, Satzungen seien solche Vorschriften, die Beziehungen zwischen der Gemeinde und ihren Angehörigen sowie Personen regeln, die auf andere Weise mit der Gemeinde "in Beziehung treten ${ }^{\text {"241 }}$. Diese Auffassung hat jedoch zu sehr das Beispiel kommunaler Einrichtungen im Auge. Es werden aber beispielsweise auch Bebauungspläne als Satzungen erlassen ( 10 BauGB). Es ist aber nicht recht ersichtlich, warum ein Bauwilliger zur Gemeinde in "Beziehung" tritt, jemand, der entgegen einer sicherheitsrechtlichen Verordnung ein Grundstück betreten will aber nicht.

Nicht als Unterscheidungskriterium zu Rechtsverordnungsermächtigungen eignen sich auch Beschreibungen des Wesens der Satzungsautonomie als "Instrument zur Verringerung des Abstandes zwischen Normgeber und Normadressat"242, als "Mittel zur Anregung von Eigeninitiative und Eigenverantwortung" ${ }^{243}$, als Instrument zur "Abschirmung eines Sachbereichs ge-

${ }^{237}$ So auch Haug, S. 89.

${ }^{238}$ Aus der Weimarer Zeit siehe Peters, HbDStR, Band II, S. 266. Unter der Geltung des GG siehe Schneider, Festschrift für Möhring, S. 530.

239 So Schneider, Festschrift für Möhring, S. 530.

${ }^{240}$ Gegen diese Auffassung auch Kiess, S. 61; Haug, S. 88.

${ }^{241}$ So die Auffassung von Kreßel, BayVBI. 1967, S. 414.

${ }^{242}$ P. Kirchhof, Festgabe 25 Jahre BVerfG, Band II, S. 85; Dölker, S. 95; Morlok, S. 116.

${ }^{243}$ Starck, AöR 92 (1967), S. 452. 
gen unbeschränkte staatliche Einwirkung"244 oder zur Berücksichtigung örtlicher und sachlicher Verschiedenheiten ${ }^{245}$. Auch eine vom kommunalen Vertretungsorgan erlassene Rechtsverordnung verringert den "Abstand" zwischen Normgeber und Adressat in gleichem Maße, wie dies auch bei Satzungen geschieht. Auch Rechtsverordnungsermächtigungen können in gewissem Maße Eigeninitiative und Eigenverantwortung stärken, auch bei Rechtsverordnungsermächtigungen kann der staatliche Einfluß beschränkt werden, und zur Berücksichtigung von örtlichen und sachlichen Verschiedenheiten reicht ohnehin die Dekonzentration ${ }^{246}$.

Auch sonst lassen sich Satzungen und Rechtsverordnungen nach keiner klaren Formel scheiden. Es gibt in den einzelnen Bundesländern Unterschiede im Detail, aber keine im Grundsatz. So werden zwar Satzungen durchweg vom Gemeinderat also der kommunalen Vertretungskörperschaft erlassen. Zum Teil ist dies aber auch bei Rechtsverordnungen der Fall ${ }^{247}$. Auch das Maß des Einflusses der Aufsichtsbehörden läßt sich nicht eindeutig definieren. Zwar sind tendenziell die Ingerenzmöglichkeiten der Aufsichtsbehörden stärker, wenn es sich um eine Verordnungsermächtigung handelt. Aber auch dies gilt nicht generell ${ }^{248}$. Auch im Bereich Genehmigung und Veröffentlichung lassen sich allgemein formulierbare Unterschiede nicht ausmachen ${ }^{249}$.

\section{e) Von Art. 80 GG ausgehende Abgrenzungsversuche}

Versuche, eine Unterscheidung zwischen Rechtsverordnungen und Satzungen zu erreichen, müssen daher bei den Bestimmungen ansetzen, die insoweit vor allem die Landesgesetzgeber speziell für den Erlaß von Rechtsverordnungsermächtigungen in die Pflicht nehmen, nämlich bei Art. 80

${ }^{244}$ P. Kirchhof, Festgabe 25 Jahre BVerfG, Band II, S. 85.

${ }^{245}$ P. Kirchhof, Festgabe 25 Jahre BVerfG, Band II, S. 85; Starck, AöR 92 (1967), S. 458, ders., Gesetzesbegriff, S. 46; Peters, HbDStR, Band II, S. 270; Dölker, S. 95.

${ }^{246}$ Siehe dazu oben B III 3 und Maunz, Art. 80 Rn. 48: "Die Berücksichtigung von örtlichen und sachlichen Verschiedenheiten bildet gelegentlich auch den Anlaß für Rechtsverordnungsermächtigungen."

${ }^{247}$ Siehe nur Art. 42 Abs. 1 BayLStVG. Ausführliche Nachweise auf das insoweit uneinheitliche Landesrecht bei Vogel, Gefahrenabwehr, S. $500 \mathrm{ff}$.

${ }^{248}$ Siehe die Nachweise bei Schmidt-Aßmann, Kommunale Rechtsetzung, S. 29.

${ }^{249}$ Siehe etwa Art. 25, 26 BayGO und Art. 47, 51 BayLStVG, die sich weitgehend ähneln. Weiterhin Hamann, S. 45 und die ausführliche Auflistung bei W. Ziegler, S. 68 ff. 
Abs. 1 S. 2 GG und den Parallelbestimmungen in den Landesverfassungen $^{250}$. Insoweit läßt sich die Frage stellen, ob unter Rückgriff auf das Maß der notwendigen formellgesetzlichen Vordeterminierung im Rückschluß Hinweise auf möglicherweise unterschiedliche Anwendungsbereiche gewonnen werden können.

Die Hoffnung, Rechtsverordnungen und Satzungen auf diese Weise zu unterscheiden und so zu unterschiedlichen Einsatzfeldern zu kommen, wird aber auf den ersten Blick enttäuscht. Zwar gelten die "Programmiermaßstäbe"251 des Art. 80 Abs. 1 S. 2 GG nach ständiger Rechtsprechung des BVerfG $^{252}$ mit weitgehender Billigung des Schrifttums ${ }^{253}$ nur für Rechtsverordnungen und weder unmittelbar noch analog für die Einräumung von Satzungsautonomie. Für letztere verlangt das BVerfG aber, daß der Gesetzgeber die "wesentlichen", d. h. vor allem die grundrechtsrelevanten Fragen selbst regelt ${ }^{254}$.

Trotzdem ist damit noch nicht entschieden, daß die Anforderungen an den Erlaß einer Satzungs- und einer Rechtsverordnungsermächtigung sich entsprechen. Das BVerfG hat seine Wesentlichkeitstheorie zunächst im Bereich der Satzungsautonomie entwickelt und später auch auf Gebiete übertragen, in denen eher ein Abstellen auf Art. 80 Abs. 1 S. 2 GG zu erwarten gewesen wäre ${ }^{255}$. Mittlerweile hat es aber eine Verknüpfung insoweit hergestellt, als es den Art. 80 Abs. 1 S. 2 GG als eine Art Ausprägung der Wesentlichkeitstheorie bezeichnet. Das Erfordernis "hinreichender" Bestimmtheit, das das Gericht aus dieser Vorschrift ableitet, stelle die notwendige Ergänzung und Konkretisierung des aus dem Demokratie- und Rechtsstaatsprinzip folgenden Grundsatzes des Vorbehaltes des Gesetzes dar ${ }^{256}$.

${ }^{250}$ Siehe die Nachweise oben B III 4 c, Fn. 225.

${ }^{251}$ So Schmidt-Aßmann, Kommunale Rechtsetzung, S. 7

${ }^{252} \mathrm{Vgl}$. etwa BVerfG, Beschluß vom 02.05.1961, E 12, 319 (325); Urteil vom 14.12.1965, E 19, 253 (267); Beschluß vom 21.12.1966, E 21, 54 (62); Beschluß vom 23.02.1972, E 32, 346 (360 f.).

253 Siehe etwa Schmidt-Aßmann, Kommunale Rechtsetzung, S. 8; Bryde, Art. 80 Rn. 10. Differenzierend allerdings Westbomke, S. 74 f. Weitere Nachweise bei Dölker, S. $60 \mathrm{ff}$.

${ }^{254}$ Sog. Facharzt-Beschluß des BVerfG vom 09.05.1972, E 33, 125 (158).

${ }^{255}$ Roellecke, NJW 1978, S. 1777 mit Nachweisen.

${ }^{256}$ BVerfG, Beschluß vom 20.12.1984, JZ 1982, S. 755 (758) = E 58, 257 ff. und auch schon BVerfG, BeschluB vom 08.08.1978, E 49, 89 (127) - Kalkar-Entscheidung - . Zustimmend Erichsen, Festschrift Jur. Gesellschaft Berlin, S. 122; wohl auch Schulze-Fielitz, Parlamentarische Gesetzgebung, S. 172. 
Damit wird aber nicht recht deutlich, wie sich das BVerfG das Verhältnis zwischen den Anforderungen des Art. 80 Abs. 1 S. 2 GG und der Wesentlichkeitstheorie letztlich vorstellt ${ }^{257}$. Gegen die vorgenommene Verknüpfung von Art. 80 Abs. $1 \mathrm{~S} .2$ GG mit der Wesentlichkeitstheorie ist daher nicht ganz zu Unrecht der Vorwurf der Undurchsichtigkeit erhoben worden ${ }^{258}$. Es entspräche bisheriger Tradition in der Rechtsprechung des BVerfG, nicht der ungeschriebenen Wesentlichkeitstheorie, sondern den Bestimmtheitsanforderungen des Art. 80 Abs. 1 S. 2 GG die Antwort auf die Frage zu entnehmen, welche Probleme im formellen Gesetz geregelt werden müssen und welche dem Verordnungsgeber überlassen werden können; demgegenüber verwende das BVerfG nun die Wesentlichkeitstheorie zur Abgrenzung des Bereiches von formellem Gesetz und Verordnungsermächtigung ${ }^{299}$.

Es gibt somit zwei grundsätzliche Deutungen des Verhältnisses zwischen Wesentlichkeitstheorie und Art. 80 Abs. 1 S. 2 GG. Zum einen eine Art "Integrationstheorie" ${ }^{\mu 200}$, die davon ausgeht, daß die Anforderungen der Wesentlichkeitstheorie auch durch entsprechende Interpretation der Bestimmtheitsanforderungen des Art. 80 Abs. 1 S. 2 GG erfüllt werden können $^{261}$. Das notwendige Maß parlamentarischer Selbstentscheidung würde die genauen Anforderungen an die Bestimmtheit der gesetzlichen Ermächtigung im Hinblick auf die Maßstäbe des Art. 80 Abs. 1 S. 2 GG beeinflussen. Die wesentlichen Entscheidungen könnten vom Parlament auch dadurch erfüllt werden, daß Inhalt, Ausmaß und Zweck hinreichend bestimmt werden. Folgt man einem solchen Verständnis, so kommt man zwanglos dazu, daß sich die Anforderungen des Parlamentsvorbehaltes an Satzungen und Rechtsverordnungen entsprechen. Hierfür ließe sich auch anführen, $\mathrm{da} ß$ es für einen betroffenen Bürger weitgehend gleichgültig ist, ob eine ihn belastende Maßnahme als Verordnung oder Satzung ergeht ${ }^{262}$.

${ }^{257}$ So auch Kloepfer, JZ. 1984, S. 692. Allgemein auch Staupe, S. 130.

${ }^{258}$ Vor allem von Wilke, JZ 1982, S. 759. Kritisch auch Kloepfer, JZ 1984, S. 692 f.; von Danwitz, S. 50, der die Unklarheit aber auch bei den Stellungnahmen des Schrifttums sieht. Vergleiche dieser, S. 86.

${ }^{259}$ Wilke, JZ 1982, S. 759, 760.

${ }^{260}$ Von Danwitz, S. 89, spricht von "Identitätsthese".

${ }^{261}$ So wohl Wilke, JZ 1982, S. 759, 760. Auch Pietzcker, JuS 1979, S. 712 mit Anm. 27; deutlich von Danwitz, S. 93; Niehues, 51. DJT Teil M, S. 46; Ossenbühl, Festschrift für Bosch, S. 756; Kloepfer, JZ 1984, S. 693 und 695; Bryde, Art. 80 Rn. 4, hält diesen Weg für theoretisch möglich, jedoch nicht mit der Rechtsprechung des BVerfG in Einklang stehend.

${ }^{262}$ Kunig, S. 331; Dölker, S. 111 ff. 
Überwiegend favorisiert wird aber die andere Deutungsmöglichkeit, eine Art "Kumulierungstheorie". Danach setzt der Art. 80 Abs. 1 S. 2 GG die Zulässigkeit einer Delegation voraus. Die Frage nach ihrer Zulässigkeit beantwortet nicht der Art. 80 Abs. 1 S. 2 GG, sondern die Wesentlichkeitstheorie ${ }^{263}$. Nur im "abgeschwächt wesentlichen Bereich", also dort, wo zwar eine rechtssatzmäßige, aber keine formellgesetzliche Regelung geboten ist, würde dann die Wesentlichkeitstheorie das Maß der Bestimmtheit nach Art. 80 Abs. 1 S. 2 GG bestimmen ${ }^{264}$. Für den Vergleich von Rechtsverordnungen und Satzungen ergäbe sich daraus folgendes: Die Wesentlichkeitstheorie führt zu einem partiellen Delegationsverbot, das sowohl für Rechtsverordnungen als auch für Satzungen gilt. Zusätzlich müßten bei Rechtsverordnungsermächtigungen auch noch die Anforderungen des Art. 80 Abs. 1 S. 2 GG erfüllt sein ${ }^{265}$. Somit ergäbe sich ein Mehr an formell-gesetzlicher Determinierung einer Rechtsverordnungsermächtigung gegenüber einer Satzungsermächtigung ${ }^{266}$. Klargestellt sei, daß dies mit der im Anschluß an die Rechtsprechung des BVerfG häufig vorgenommenen Unterscheidung zwischen ausschließlichen und übertragbaren Parlamentsentscheidungen und originären Exekutiventscheidungen ${ }^{267}$ unmittelbar nichts zu tun hat. Damit ist nur ausgesagt, daß das Parlament gewisse Entscheidungen treffen muß, andere treffen kann und dritte nicht treffen darf. Hier geht es jedoch darum, auf welchem Wege das Parlament selbst entscheidet.

Die "Kumulierungstheorie" vermag nicht recht zu überzeugen. Störend ist schon die Vorstellung, daß zur Kategorie des Wesentlichen, in der der Gesetzgeber selbst die Regelungen treffen muß, und der des Unwesentlichen, in der er nicht entscheiden muß, noch die des minder- oder abgeschwächt Wesentlichen käme ${ }^{268}$, in der er die Maßstäbe des Art. 80 Abs. 1 S. 2 GG einzuhalten hätte. Eine solche Zwischenkategorie zwischen Wesentlichem und Unwesentlichem kann es nicht geben. Das ergibt sich schon aus allgemeinen rechtsstaatlichen Bestimmtheitsüberlegungen. Eine Norm ist nur dann bestimmt, wenn sich ihr entnehmen läßt, was sie aussagen will. Auch

${ }^{263}$ So ausführlich Staupe, S. 146 ff. Weiterhin Hennecke, DÖV 1982, S. 696; Papier, Vorbehalt des Gesetzes, S. 57; Falkenberg, BayVBI. 1978, S. 168; Eberle, DÖV 1984, S. 487; wohl auch Heussner, Festschrift für Erwin Stein, S.119 und 120; Umbach, Festschrift für Faller, S. 128; Hermes, S. 130.

${ }^{264}$ So tendenziell Heussner, Festschrift für Erwin Stein, S. 122.

${ }^{265}$ So eindeutig Staupe, S. 146. Siehe auch Lerche, DVBI. 1958, S. 530.

${ }^{266}$ So deutlich Hermes, S. 98.

${ }^{267}$ Krebs, Jura 1979, S. 311; Rengeling, NJW 1978, S. 2219; Staupe, S. 36.

${ }^{268}$ Vgl. Kloepfer, JZ 1984, S. 692. 
bei einer Verordnungsermächtigung oder auch einer Ermessensnorm ist das nicht anders. Diese sind zwar nicht "self-executing". Es besteht also für die eigentliche Anwendung noch ein Konkretisierungsspielraum. Solange die Norm aber nicht dahingehend lautet, daß die Verwaltung machen kann was sie will, ergeben sich aus ihr Grenzen für die Entscheidung der Verwaltungsbehörde ${ }^{269}$. Die parlamentarische Entscheidung liegt dann in der Konstituierung dieser Grenzen. Diese können eng oder weit gesteckt sein, sie können aber nur gesteckt oder nicht gesteckt, nicht aber unter Beachtung des Art. 80 Abs. 1 S. 2 GG teilweise gesteckt sein. Die parlamentarische Eigenentscheidung kann also der Verwaltung einen engen oder weiten Spielraum lassen, aber eben immer nur einen Spielraum oder keinen Spielraum, weil sich sonst die Grenzen der gesetzlichen Ermächtigung nicht ziehen lassen.

Selbstverständlich ist es denkbar, daß eine Regelungsmaterie so wesentlich ist, daß alle Entscheidungen abschließend vom Parlament selbst getroffen werden müssen. Der Regelfall ist dies aber nicht. So gibt es auf den meisten Gebieten wesentliche und unwesentliche Entscheidungen. Ob der Gesetzgeber nun einige Fragen abschließend selbst regelt und für die anderen Fragen unter Beachtung der von der Wesentlichkeitstheorie vorgegebenen Entscheidungsgrenzen eine Verordnungsermächtigung erteilt, oder ob er insgesamt eine Verordnungsermächtigung erteilt und dabei die wesentlichen Entscheidungen so vorbestimmt, $\mathrm{da} \beta$ für den Verordnungsgeber kein Regelungsspielraum im Bereich des Wesentlichen mehr bleibt, ist aber eine Frage der zweckmäßigen Gesetzestechnik. So zeugen die Entscheidungen des BVerfG zur mittelbaren Entscheidungserheblichkeit des formellen Gesetzes in Fällen, in denen die Verwaltungsentscheidung auf eine gleichlautende Verordnung gestützt war ${ }^{270}$, auch davon, daß es vielfach im Sinne der Normklarheit wünschenswert ist, daß eine Verordnung alle normativen Entscheidungen enthält, und zwar sowohl diejenigen, die schon vom Parlament definitiv vorgegeben waren, als auch diejenigen, die von der Exekutive hinzugefügt wurden. Der Einwand, im Fall einer Verordnungsermächtigung sei eine Sachentscheidung letztlich deshalb noch nicht getroffen, weil nur gesagt wird "so könnte es sein", und nicht "so hat es zu sein"271, ist nicht schlüssig.

${ }^{269} \mathrm{Vgl}$. auch Umbach, Festschrift für Faller, S. 128: Jeder Vorbehalt des Gesetzes schließt einen Kern ausschließlicher Parlamentskompetenzen ein.

270 Etwa BVerfG, Beschluß vom 24.06.1971, E 30, 227 (240); Beschluß vom 25.01.1972, E 32, 260 (266).

${ }^{271}$ So Lerche, DVBI. 1958, S. 530 mit Anm. 62. 
Dem Parlament steht es frei, die Exekutive zum Erlaß einer Verordnung zu verpflichten ${ }^{272}$. Dabei kann es das formelle Recht so ausgestalten, daß auch dann, wenn der Verordnungsgeber seinem Regelungsauftrag nicht nachkommt, keine Anwendungssperre eintritt ${ }^{273}$.

Damit entfällt auch der Einwand gegen die "Integrationstheorie", daß Fälle denkbar seien, in denen zwar der Gesetzgeber alles Wesentliche regelt, aber eine Verordnungsermächtigung beispielsweise deshalb unwirksam sei, weil sie die Anforderungen des Art. 80 Abs. 1 S. 2 GG etwa bezüglich des Ausmaßes der Ermächtigung nicht erfüllt ${ }^{274}$. Zum einen fehlt dann eine wesentliche Entscheidung, zum anderen dürfte sich in der bisherigen Rechtsprechung des BVerfG zu Art. 80 Abs. 1 S. 2 GG hinreichend gezeigt haben, daß ohne Rückgriff auf die Regelungsmaterie die Erfüllung der Anforderungen des Art. 80 Abs. 1 S. 2 GG nicht zu überprüfen ist ${ }^{275}$. Zweck, Inhalt und Ausma $B$ der Ermächtigung haben sich als rein formelle Begriffe erwiesen, die immer mehr oder weniger eng oder weit ausgelegt werden können. Insoweit sind die Kriterien, die zur Umschreibung des "Wesentlichen" dienen, auch im Art. 80 Abs. 1 S. 2 GG zur Klärung der hinreichenden Bestimmtheit herangezogen worden. Der Art. 80 Abs. 1 S. 2 GG bedarf einer materiellen Substantiierung, die die Wesentlichkeitstheorie leisten $\operatorname{kann}^{276}$. So entspricht es einer Anwendung der vom BVerfG entwickelten Wesentlichkeitstheorie, wenn das Maß der erforderlichen Konkretheit einer gesetzlichen Regelung danach bestimmt wird, von welcher Eigenart der jeweilige Regelungsbereich vor allem im Hinblick auf die betroffenen Grundrechtspositionen ist ${ }^{2 m}$. Dadurch, daß die jeweiligen Regelungsberei-

272 Von Danwitz S. 180; BVerwG Urteil vom 17.01.1985, E 71, 1 (6); BVerfG, Beschluß vom 31.11.88, BayVBI. 1989, S. 461 (463) zu § 43 BImSchG.

${ }^{273}$ Vgl. BVerfG (Fn. 272).

${ }^{274}$ So aber Staupe, S. 146.

275 Geitmann, S. 133 ff.; Dölker, S. 110. Vgl. auch Rengeling, NJW 1978, S. 2221. Anders Hermes, S. 130, der den Art. 80 Abs. 1 S. 2 GG auf seine Bedeutung als formelle Organisationsnorm beschränken will, jedoch den Nachweis der Konturierbarkeit, die daraus folgen soll, schuldig bleibt.

${ }^{276}$ So auch Börger, S. 34; Pestalozza, NJW 1981, S. 2082: "Vor allem im Bereich des "Wesentlichen" müssen die Anforderungen an die Verordnungsermächtigung gesteigert werden. Konkreter, detaillierter, genauer wird der Gesetzgeber hier Inhalt, Zweck und Ausmaß der Ermächtigung angeben müssen." Von Danwitz, S. 91: "Frappierende terminologische Übereinstimmung".

27 Siehe vor allem BVerfG, Beschluß vom 20.10.1981, E 58, 257 (278); Beschluß vom 14.07.1981, E 58, 137 (146); Spanner, BayVBI. 1986, S. 225 f.; Lepa, AöR 105 (1980), S. 344; Starck, Gesetzesbegriff, S. 293. 
che und die betroffenen Grundrechte stark heterogen sind, ist die Rechtsprechung des BVerfG zu Art. 80 Abs. 1 S. 2 GG über die reichhaltige Kasuistik hinaus genausowenig zu einer klaren Linie gelangt ${ }^{278}$ wie sich bisher aus der Wesentlichkeitstheorie mehr als allgemeine Formeln ableiten lies$\operatorname{sen}^{229}$. Daß etwa die Anforderungen des Art. 80 Abs. 1 S. 2 GG bei belastenden Regelungen möglicherweise strenger sind als bei begünstigenden ${ }^{280}$, dürfte sich auch durch Abstellen auf die "Wesentlichkeit" ergeben. Daß bei vielgestaltigen oder sich schnell wandelnden Verhältnissen, also entsprechender "Sachstruktur der jeweiligen Materie" ${ }^{\text {281 }}$ die Anforderungen an eine formell-gesetzgeberische Entscheidung tendenziell geringer sind, gilt nicht nur für die Anforderungen des Art. 80 Abs. 1 S. 2 GG, sondern genauso auch für die Wesentlichkeitstheorie ${ }^{282}$.

Zur endgültigen Beanwortung der Frage, ob der "Integrationstheorie" zu folgen ist und für an Gemeinden erteilte Rechtsverordnungs- und Satzungsermächtigungen hinsichtlich der formell-gesetzlichen Bestimmtheit nach Art. 80 Abs. 1 S. 2 GG und unmittelbarer Anwendung der Wesentlichkeitstheorie wirklich die gleichen Voraussetzungen gelten sollen, fehlt jedoch bisher in der Rechtsprechung des BVerfG zu Art. 80 Abs. 1 S. 2 GG zum einen eine Unterscheidung nach der Art des Delegators. Nicht entschieden ist die Frage, ob sich Abstriche an Ausmaß, Zweck und Inhalt einer Rechtsverordnungsermächtigung machen lassen, wenn der Delegator durch ein demokratisch zumindest einigermaßen legitimiertes Beschlußorgan entscheidet. Schwerfallen dürfte ein solcher Schritt dem BVerfG gegebenenfalls jedoch nicht. Immerhin hat das BVerfG die Nichtanwendung des Art. 80 Abs. 1 S. 2 GG auf Satzungsermächtigungen an die Gemeinden damit begründet, da $\beta$ insoweit der Gewaltenteilungsgrundsatz nicht durchbrochen werde, da die Rechtssetzungsbefugnis innerhalb der Legislative nur auf an-

${ }^{278}$ Siehe vor allem die Darstellung bei Hasskarl, AöR 94 (1969), S. 99 m. w. N. Weiterhin Ossenbühl, HbStR, Band III, S. 395. Vergleiche auch den Bericht der Enquete-Kommission Verfassungsreform, BT-Drs. 7/5924, S. 89: "Sichere Maßstäbe für die Abgrenzung des Delegationsspielraums haben sich aus Art. 80 Abs. 1 S. 2 GG nicht entwickeln lassen." Klein, DÖV 1975, S. 523 f.; Rengeling, NJW 1978, S. 2221.

${ }^{279}$ Vgl. die Kritik von Kloepfer, JZ 1984, S. 692; weiterhin Staupe, S. 112; Krebs, Jura 1979, S. 308; Kisker, DVBI. 1982, S. 887; Ossenbühl, Vorbehalt des Gesetzes, S. 27; Umbach, Festschrift für Faller, S. $121 \mathrm{ff}$.

${ }^{280}$ So BVerfG, Beschluß vom 30.01.1968, E 23, 62 (73); Beschluß vom 19.04.1978, E 48, 210 (222).

\footnotetext{
${ }^{281}$ Lerche, Bayerisches Schulrecht, S. 38.

${ }^{282}$ Börger, S. 42; Lerche, Bayerisches Schulrecht, S. 38.
} 
dere demokratische Gremien und nicht auf die Exekutive verlagert wird ${ }^{283}$. Dieses Argument ist zwar anfechtbar, weil zum einen der Gemeinderat nach allgemeiner Auffassung ein Verwaltungsorgan ist und nicht zur "Legislative" gehört, zum anderen seine "demokratische Legitimation" keinesfalls mit derjenigen des Parlaments auf eine Stufe gestellt werden kann ${ }^{284}$. Das BVerfG zeigt damit aber, daß es durchaus bereit ist, die Art der ermächtigten Stelle bei der Frage nach der notwendigen Bestimmtheit einer Ermächtigung zu berücksichtigen ${ }^{285}$. Dann spricht aber nichts dagegen, für das Maß der Bestimmtheit heranzuziehen, was für die Frage der Anwendbarkeit des Art. 80 Abs. 1 S. 2 GG das maßgebliche Argument ist ${ }^{286}$.

Ebenfalls noch nicht ausdrücklich geäußert hat sich das BVerfG dazu, ob das $\mathrm{Maß}$ an formell-gesetzlicher Steuerung des späteren Normerlasses danach differenziert werden darf, daß etwa durch die Erteilung von Verordnungsermächtigungen an die Gemeinden in höherem Maße örtliche Verschiedenheiten berücksichtigt werden können, was als Argument für die behauptete tendenziell geringere Gesetzesakzessorietät und Gesetzeslenkung bei Satzungsermächtigungen angeführt wird ${ }^{287}$. Auch die Berücksichtigung dieses Kriteriums würde aber auf der Linie der bisherigen Rechtsprechung des BVerfG liegen. Wenn etwa das BVerfG aufgrund der Besonderheiten von Wirtschafts- und Preislenkungsmaßnahmen eine eher weite Auslegung des Art. 80 Abs. 1 S. 2 GG rechtfertigt ${ }^{288}$, spricht nichts dagegen, dies auf die Notwendigkeit der verstärkten Berücksichtigung örtlicher Verschiedenheiten zu übertragen.

Auch aus der primär staatsorganisatorischen Bedeutung des Art. 80 Abs. 1 S. 2 GG lassen sich Bedenken gegen die hier entwickelte Auffassung, wonach sich das Maß der parlamentarischen Mitverantwortung bei Rechtsverordnungen und Satzungen entspricht, nicht ableiten. Zwar hat die Forderung nach Bestimmtheit einer gesetzlichen Verordnungsermächtigung aus den Erfahrungen der Weimarer Zeit heraus zunächst das Verhältnis von

${ }^{283}$ Beschluß vom 21.12.1966, E 21, 54 (62 f.); Beschluß vom 02.05.1961, E 12, 319 (325); Beschluß vom 09.05.1972, E 33, 125 (157 f.).

${ }^{284}$ Siehe dazu auch oben B II $4 \mathrm{c}$.

${ }^{285}$ Insofern kann einem Punkt der Kritik von Kloepfer, JZ 1984, S. 692, an der Wesentlichkeitstheorie Rechnung getragen werden.

286 Ähnlich argumentiert auch Westbomke, S. 79 ff., der die Maßstäbe des Art. 80 Abs. 1 S. 2 GG bei fehlender demokratischer Legitimation des Satzungsgebers auch auf Satzungen anwenden will.

${ }^{287}$ Siehe Conrad, BayVBI. 1967, S. 388.

${ }^{288}$ Vgl. BVerfG, Beschluß vom 12.11.1958, E 8, 274 (300 f.). 
Parlament und Exekutive im Auge ${ }^{289}$. Eine erneute Selbstentmachtung des Parlaments soll verhindert werden ${ }^{200}$. Die weite Interpretation von Art. 2 Abs. 1 GG im Sinne einer allgemeinen Handlungsfreiheit führt jedoch im Staat-Bürger-Verhältnis zu einer Relevanz auch zunächst scheinbar rein staatsorganisatorischer Regelungen. Die Anforderungen, die sich an die Bestimmtheit einer gesetzlichen Regelung aus der Sicht Legislative - Exekutive zu stellen sind, sind daher auch für das Verhältnis Staat - Bürger von Bedeutung. Dann ist es aber konsequent, ebenfalls die zunächst staatsorganisatorische Regelung des Art. 80 Abs. 1 S. 2 GG entsprechend den sich aus der Staat-Bürger-Beziehung ergebenden Forderungen zu interpretieren.

Insgesamt kann man somit feststellen, daß die Anforderungen, die Art. 80 Abs. 1 S. 2 GG an die Bestimmtheit einer Rechtsverordnungsermächtigung stellt, und die Anforderungen an die Bestimmtheit einer Satzungsermächtigung aufgrund direkter Anwendung der Wesentlichkeitstheorie sich entsprechen $^{291}$. Art. 80 Abs. 1 S. 2 GG und die Bemühungen um eine Ausweitung des Vorbehaltes des Gesetzes stehen so gesehen auch in keinem Spannungsverhältnis ${ }^{202}$. Die unter Zugrundelegung des Wesentlichkeitskriteriums angestellten Überlegungen lassen sich in einigen Teilen schon in der Rechtsprechung zu Art. 80 Abs. 1 S. 2 GG nachweisen, sie sind andererseits auch in der Lage, weitere Hinweise für die Auslegung des Art. 80 Abs. 1 S. 2 GG zu geben. Der Gesetzgeber kann daher mit einer Wahl für eine Satzungs- oder Rechtsverordnungsermächtigung auch kein aufgrund unterschiedlicher Bestimmtheitsanforderungen aus der Verfassung ableitbares Formenverbot unterlaufen ${ }^{293}$. Von den rechtlichen Voraussetzungen an die Bestimmtheit einer gesetzlichen Ermächtigung läßt sich daher zunächst nicht auf den möglichen unterschiedlichen Anwendungsbereich schließen.

${ }^{289}$ Zoller, S. 75; Ossenbühl, HbStR, Band III, S. 395 und ders., HbStR, Band III, S. 482, ders., Festschrift für Huber, S. 284 mit Anm. 6, wo die Verordnungsgewalt in der Weimarer Zeit und unter dem nationalsozialistischen Regime als Trauma der deutschen Verfassungsentwicklung bezeichnet wird. Siehe dazu ausführlich, Staupe, S. $63 \mathrm{ff}$.

${ }^{290}$ Bryde, Art. 80 Rn. 1; JöR n. F., Band 1 (1951), S. 588 ff.

291 Ähnlich auch Schmidt-Aßmann, Kommunale Rechtsetzung, S. 8, wonach die Anforderungen an Satzungsermächtigungen "nicht allzu weit" unter denen des Art. 80 Abs. 1 S. 2 GG liegen dürfen. Unklar dagegen Meyn, DVBI. 1977, S. 600, der meint, daß sich eine Tendenz ankündigen würde, nach der autonome Satzungsgeber strengeren Anforderungen unterworfen werden sollten als die staatliche Exekutive. Zumindest für den gemeindlichen Bereich läßt sich eine solche Tendenz nicht belegen. Unnötig kompliziert, im Ergebnis aber wohl wie hier auch Zöllner, BayVB1. 1987, S. 551, der "Satzungen" gegebenenfalls als "Rechtsverordnungen" behandelt wissen will.

292 So aber Umbach, Festschrift für Faller, S. 128.

293 Anders Zöllner, BayVBl. 1987, S. 551. 
Vielmehr muß gelten, daß der Anwendungsbereich die an die Bestimmtheit zu stellenden Anforderungen determiniert. Somit hat der Gesetzgeber im Bereich der örtlichen Bauvorschriften grundsätzlich die Wahl zwischen einer Rechtsverordnungs- und einer Satzungsermächtigung. Die Anforderungen an eine formell-gesetzliche Selbstentscheidung entsprechen sich.

$\mathrm{Zu}$ beantworten bleibt daher noch die zweite hiermit zusammenhängende Frage, ob es einen Anwendungsbereich für Satzungsermächtigungen gibt, der einer Rechtsverordnungsermächtigung verschlossen ist, etwa unter dem Aspekt "genuin gemeindliche Aufgaben". Ein der Rechtsverordnungsermächtigung verschlossener Bereich wäre deshalb denkbar, weil der Gesetzesvorbehalt des Art. 80 Abs. 1 S. 2 GG und auch der der entsprechenden Bestimmungen in den Landesverfassungen ein rein formenbezogener ist ${ }^{294}$. Dies ergibt sich daraus, daß das GG in Art. 80 keinen eigenständigen Begriff der Rechtsverordnung definiert, sondern den aus der Weimarer Zeit bekannten Begriff übernimmt und die Landesverfassungen sich wiederum an das GG anschließen. Dort war aber die Rechtsverordnung das typische Instrument zur Wahrnehmung von Rechtsetzungsaufgaben durch die staatliche Exekutive ${ }^{295}$. Aus diesem Grund fordert Art. 80 Abs. 1 S. 2 GG vom Gesetzgeber eine Einhaltung der dort genannten Programmiermaßstäbe.

Die Rechtsverordnung ist daher das von der Verfassung vorgesehene typische Instrument, mit dem sich der parlamentarische Gesetzgeber von eigenen Normierungen entlastet, aus Selbstschutzgründen aber von Verfassungs wegen verpflichtet wird, die dann folgende Normsetzung hinreichend vorherzubestimmen. Die Anforderungen, die der Art. 80 Abs. 1 S. 2 GG an Rechtsverordnungsermächtigungen stellt, sind deshalb - unabhängig davon, ob man sie je nach Regelungsbereich eng oder weit zieht - eigentlich nicht einhaltbar, wenn zu einer Rechtsetzung ermächtigt werden soll, die vom formellen Gesetzgeber selbst überhaupt nicht vorgenommen werden kann, weil sie keine staatliche Aufgabe betrifft ${ }^{206}$. Anders als bei der Wesentlichkeitstheorie müssen im Rahmen des Art. 80 Abs. 1 S. 2 GG zumindest Bedenken im Hinblick auf die Einhaltung der Programmiermaßstäbe auftauchen. Der formelle Schutzmechanismus des Art. 80 Abs. 1 S. 2 GG und der entsprechenden Vorschriften in den Landesverfassungen spricht daher gegen den Einsatz von Rechtsverordnungsermächtigungen, wenn formelle

\footnotetext{
294 Schmidt-Aßmann, Festgabe für von Unruh, S. 610.

205 Siehe Jellinek, Verwaltungsrecht, S. 131; Jacobi, HbDStR, Band II, S. 238; Peters, HbDStR, Band II, S. 264.

${ }^{296}$ So im Ansatz auch Zöllner, BayVBI. 1987, S. 551.
} 
Gesetze nicht in Betracht kommen. Da es aber vor allem im gemeindlichen Bereich und vor allem bei Fragen der Baugestaltung Aufgaben gibt, die wegen der Individualitätsgarantie des Art. 28 Abs. 2 S. 1 GG zwar öffentlicher nicht aber staatlicher Natur sind ${ }^{297}$, ist insofern eine Satzungsermächtigung zumindest sachgerechter, soweit die Erfüllung genuin gemeindlicher Aufgaben von der jeweiligen Befugnisnorm umfaßt sein soll.

${ }^{297}$ Siehe dazu oben B III 2. 


\section{C. Örtliche Bauvorschriften und baugestalterische Generalklauseln}

\section{Allgemeines zu baugestalterischen Anforderungen}

\section{Bestandsaufnahme der baugestalterischen Anforderungen in den Landesbauordnungen}

a) Übersicht über die gesetzlichen Regelungen

Örtliche Bauvorschriften in Form von Schutzvorschriften und baugestalterischen Vorschriften ermächtigen die Gemeinden zum Erlaß von Anforderungen an die äußere Gestaltung baulicher Anlagen. Solche Anforderungen stellen aber nicht nur die von den Gemeinden zu erlassenden Satzungen, sondern auch die allgemeinen baurechtlichen Generalklauseln und die gestaltungsrechtlichen Generalklauseln in den Landesbauordnungen. Die genaue Funktion von örtlichen Bauvorschriften ist nun nur dann zu verstehen, wenn Umfang und Bedeutung der allgemeinen gesetzlichen Anforderungen aufgezeigt worden sind. Dies folgt bei einigen Landesbauordnungen schon daraus, daß der Erlaß von örtlichen Bauvorschriften auf den "Rahmen" der jeweiligen Bauordnung beschränkt wird ${ }^{1}$. Der Erlaß von örtlichen Bauvorschriften ist damit nur zur Verwirklichung solcher Ziele zulässig, die von den übrigen Vorschriften der Landesbauordnungen vorgegeben werden. Gelegentlich wird dies auch für die Bauordnungen, in denen eine ausdrückliche Beschränkung nicht erfolgt ist, als allgemein geltender Grundsatz angesehen ${ }^{2}$. Ohne Einigkeit über den Umfang der allgemeinen Gestaltungsanforderungen in den Landesbauordnungen besteht somit notwendig Unklarheit über den Umfang der Ermächtigung zum Erlaß von örtlichen Bauvorschriften.

${ }^{1} \S 73$ LBO BW: "im Rahmen dieses Gesetzes"; § 81 HBauO: "zur Verwirklichung der in $\S 3$ bezeichneten allgemeinen Anforderungen". Anders hingegen $\S 56 \mathrm{NBauO}$ : "auch über die Anforderungen der $\$ \$ 14,49,53$ hinausgehend".

${ }^{2}$ Plate, S. 164; Lerche, Beilage DB Nr. 6 1969, S. 9; Watzke, Denkmalschutz- und Stadtplanungsrecht, S. 51 m. w. N. Dem folgend Friauf / Wendt, S. 33 und 37; Stadtler / Baugartner /Wiebel, Komm. BayBO 21/10a Art. 3 Anm. 1. 
Der Wortlaut der generalklauselartigen Anforderungen an die Baugestaltung in den Landesbauordnungen ist nicht ganz einheitlich. So findet sich zum Teil die Forderung, bauliche Anlagen dürften nicht "verunstaltet" sein bzw. wirken ${ }^{3}$ oder sie müßten "einwandfrei gestaltet" $\operatorname{sein}^{4}$. Hierbei handelt es sich um eine Grundforderung an die bauliche Anlage an sich, die Anforderungen sind umgebungsunabhängig ${ }^{5}$. Nicht in diesen Zusammenhang gehört dagegen die in den Generalklauseln ebenfalls aufgestellte Forderung nach "werkgerechter Durchbildung" und "Beachtung der anerkannten Regeln der Baukunst". Die Einhaltung solcher Regeln kann zwar auch Auswirkungen auf die äußere Gestaltung eines Gebäudes haben. Es handelt sich hierbei jedoch um Anforderungen der Bautechnik, es geht der Intention nach nicht um eine bestimmte Gestaltung, sondern um die Einhaltung des technischen Standards ${ }^{6}$. So spricht heute $\S 3$ Abs. 1 S. 2 BauO NW nicht mehr von den "anerkannten Regeln der Baukunst" sondern von den "anerkannten Regeln der Technik", ohne daß damit eine inhaltliche Änderung bezweckt gewesen wäre ${ }^{7}$. Die Frage der Einhaltung des technischen Standards ist aber der Frage nach dem Wie der Gestaltung untergeordnet.

Neben den umgebungsunabhängigen stellen die Landesbauordnungen auch umgebungsabhängige Anforderungen auf. Dazu gehören die Bestimmungen, die verlangen, daß bauliche Anlagen die Umgebung, also vor allem das bestehende Straßen-, Orts- und Landschaftsbild nicht "verunstalten"8, daß sie sich in Umwelt, Natur und Landschaft "einfügen" müssen" oder daß

$3 \S 3$ Abs. 1 S. 2, 13 Abs. 1 LBO BW; Art. 12 Abs. 1 BayBO; 3 Abs. 1 S. 2 BauO Bln; $\S 14$ Abs. 1 BremLBauO; $\S 12$ Abs. 1 HBauO; $\S 3$ Abs. 1 S. 3, 14 Abs. 1 HBO; $\S \S 1$ Abs. 3,53 NBauO; $\S 12$ Abs. 1 BauO NW; $\$ 5$ Abs. 1 S. 2 LBauO Rh.Pf.; $\$ 4$ Abs. 1 LBO Saarl.; $\$ 12$ Abs. 1 LBO Sl.H.

${ }^{4}$ Art. 3 Abs. 1 S. 2 BayBO.

${ }^{5}$ Burger / Gutschow / Krause, S. 119, sprechen insoweit von "absoluten" im Gegensatz zu "relativen" (umgebungsabhängigen) Anforderungen. Diese Begriffsbildung erscheint jedoch sprachlich weniger eindeutig als der Gegensatz umgebungsabhängig und umgebungsunabhängig und soll daher hier nicht verwendet werden.

${ }^{6}$ Watzke, Baupolizei, S. 37, ders., Denkmalschutz- und Stadtplanungsrecht, S. 44; Rasch / Schaetzell, \& 3, Erl. zu Abs. 1, S. 94 ; Engelmann, S. 51; Ortloff, GE 1987, S. 26 ff., ders., Öffentliches Baurecht, Band II, S. 14 f.; Oelker, S. 165; Domning / Fuß, LBO, Erl. § 3 Anm. 5.

${ }^{7}$ Bork / Köster, Erl. § 3 BauO NW Rn. 7.

${ }^{8} \S \S 3$ Abs. 1 S. 2,13 Abs. 2 S. 1 BauO BW; Art. 3 Abs. 1 S. 2, 12 Abs. 2 BayBauO; $\$ 10$ Abs. 2 BauO Bln; $\S 14$ Abs. 2 BremLBauO; $\S 12$ Abs. 2 HBauO; $\S 14$ Abs. $2 \mathrm{HBO}$; $\S 1$ Abs. 3, 53 NBauO; $\S 12$ Abs. 2 S. 1 BauO NW; $\S 5$ Abs. 2 S. 1 LBauO Rh.Pf.; $\S 4$ Abs. 1 S. 2 LBO Saarl.; § 12 Abs. 2 S. 2 LBO Sl.H.

9 \& Abs. 1 S. 2 1. HS BauO BIn. 
sie das Gesamtbild der Umgebung nicht stören dürfen ${ }^{10}$. Die gleichen Anforderungen werden dann meist auch für die "beabsichtigte" Gestaltung gestellt $^{11}$. Besonderheiten liefern schließlich Art. 12 Abs. 3 BayBO, wonach sich bauliche Anlagen in die Bebauung der näheren Umgebung "einfügen" müssen, soweit kein Bebauungsplan und keine örtliche Bauvorschrift über die Gestaltung besteht, sowie $\S 4$ Abs. 2 S. 2 LBO Saarl., der Anforderungen an Gebäude stellt, die an vorhandene Gebäude angebaut werden; die Baumassen und Bauteile müssen danach in ein ausgewogenes, das Straßenbild nicht störendes Verhältnis zueinander gebracht werden. Eine Art spezielle Rückkoppelung für die sog. Schutzvorschriften im Rahmen von örtlichen Bauvorschriften findet sich schließlich in den meisten Landesbauordnungen in der Forderung, daß Rücksicht zu nehmen sei auf Bau-, Kultur- und Naturdenkmale ${ }^{12}$.

b) Der Einfluß der Rechtsprechung des BVerwG zu § 1 BaugestVO auf die Ausformung der gesetzlichen Gestaltungsanforderungen

Aus den vorgestellten Anforderungen in den Generalklauseln lassen sich zwei Tendenzen ablesen. Es zeigt sich in ihnen einerseits das Bemühen und andererseits das Zögern der Landesgesetzgeber, auf dem Gebiet der Baugestaltung über den Bereich der Verunstaltungsabwehr hinauszugehen. Zurückzuführen ist beides auf die Rechtsprechung des BVerwG. Dieses hatte in einer Grundsatzentscheidung zu $\S 1$ der BaugestaltungsVO von $1936^{13}$, in dem unter anderem die Forderung nach "anständiger Baugesinnung", "werkgerechter Durchbildung" und einwandfreiem Einfügen in die Umgebung enthalten war, in nach Auffassung des BVerwG in Betracht kommender verfassungskonformer Auslegung mit Rücksicht auf den Bestimmtheitsgrundsatz ausgesprochen restriktiv interpretiert ${ }^{14}$. Das BVerwG entschied sich zwar für die grundsätzliche Weitergeltung der BaugestVO und damit gegen die Auffassung, die BaugestVO sei deshalb unwirksam, weil sie natio-

${ }^{10} \$ 3$ Abs. 1 S. 2 2. HS BauO Bln.

${ }^{11} \S \S 3$ Abs. 1 S. 2, 13 Abs. 2 S. 1 BauO BW; Art. 12 Abs. 2 BayBO; $\S 10$ Abs. 2 BauO Bln; $\S 12$ Abs. 2 S. 1 HBauO; $\S 12$ Abs. 2 S. 1 HBO; $\S 53$ NBauO; $\S 12$ Abs. 2 S. 2 BauO NW; 55 Abs. 2 S. 1 LBauO Rh.Pf.; $\$ 4$ Abs. 2 S. 2 BauO Saarl.; $\$ 12$ Abs. 2 S. 1 LBO Sl.H.

${ }^{12} \S 13$ Abs. 2 S. 2 LBO BW; $\S 14$ Abs. 2 S. 2 BremLBauO; § 12 Abs. 2 S. 2 HBauO; 14 Abs. 2 S. 2 HBO; $\$ 5$ Abs. 2 S. 2 LBauO Rh.Pf.; $\$ 4$ Abs. 2 S. 1 BauO Saarl.; $\S 12$ Abs. 2 S. 2 LBO Sl.H.

${ }^{13}$ RGBI. I 1936, S. 938.

${ }^{14}$ BVerwG, Urteil vom 28.06.1955, E 2, 172 ff. 
nalsozialistisches Gedankengut enthalte ${ }^{15}$. Die Forderung nach "anständiger Baugesinnung" sei aber nur dann hinreichend bestimmt, wenn damit nicht schon eine bloße Unschönheit, sondern nur eine Verunstaltung verhindert werden solle ${ }^{16}$. Eine Verunstaltung liegt aber nach Auffassung des BVerwG erst dann vor, wenn ein "häßlicher, das ästhetische Empfinden nicht bloß beeinträchtigender, sondern verletzender Zustand" gegeben sei $^{17}$. Auch die Forderung nach einwandfreiem Einfügen in die Umgebung sei nur dann hinreichend bestimmt, wenn dies so zu verstehen sei, daß die bauliche Anlage das Gesamtbild der Umgebung nicht stören, der Gegensatz zwischen ihr und der Umgebung vom Betrachter nicht als belastend oder Unlust erregend empfunden werden dürfe ${ }^{18}$. Als Maßstab hierfür käme es auf die Beurteilung eines sog. gebildeten Durchschnittsbetrachters $\mathrm{an}^{19}$.

Diese Entscheidung hat Zustimmung ${ }^{20}$ aber auch vielfältige Kritik erfahren. Angezweifelt wurde, ob - soweit den inhaltlichen Ausführungen des BVerwG zuzustimmen wäre - wirklich noch eine verfassungskonforme Auslegung in Betracht kam ${ }^{21}$. Denn die Beschränkung auf die reine Verunstaltungsabwehr - auch die Reduzierung des Einfügungsgebotes wurde in diesem Sinne verstanden - widersprach den in der BaugestVO zum Ausdruck kommenden Bestrebungen im Hinblick auf eine optisch ansprechende Gestaltung und Erhaltung des Orts- und Landschaftsbildes ${ }^{22}$. Kritisiert wurde auch die Heranziehung des "gebildeten Durchschnittsbetrachters". So seien Fragen der Baukunst besser von Experten als von gebildeten Durchschnittsmenschen zu entscheiden ${ }^{23}$.

15 Diese Bedenken gingen vor allem zurück auf eine Entscheidung des PrOVG, siehe Urteil vom 23.02.1939, E 104, 228 (231). Vergleiche zum damaligen Meinungsstand die Nachweise bei Zinkahn, DVBI. 1951, S. 370 und DÖV 1953, S. 161 ff.

${ }^{16}$ BVerwGE 2, 176.

${ }^{17}$ BVerwGE 2, 177. Diese Formel hat gewisse Ähnlichkeit mit einer Formulierung in der "Anweisung zur Ausführung des «Gesetzes gegen die Verunstaltung von Ortschaften und landschaftlich hervorragenden Gegenden vom 15. Juli 1907"" vom 04. August 1907, MinBliV, S. 281, abgedruckt bei Heine, S. 86 (87): "Im allgemeinen wird jede Schaffung eines positiv häßlichen und daher jedes für ästhetische Gestaltung offene Auge verletzenden Zustandes als grobe Verunstaltung anzusehen sein." Eben diese Formulierung verwendet auch das PrOVG im "Kreuzberg-Urteil" vom 14.06.1882, E 9, 353 (382).

${ }^{18}$ BVerwGE 2, 177.

${ }^{19}$ BVerwGE 2, 177.

${ }^{20}$ Etwa von Maué, BBauBl. 1957, S. 470 f.; J. Wolff, BBauBl. 1957, S. 341 ff.

${ }^{21}$ Schweiger, DVBI. 1968, S. 488; Looks, S. 45.

22 Schmidt-Tophoff, BBauBl. 1957, S. 233.

${ }^{23}$ Schmidt-Tophoff, BBauBl. 1957, S. 233; Kretschmer, DVBI. 1970, S. 56. 
Das Urteil des BVerwG hatte aber für die weitere gesetzgeberische Entwicklung des Baugestaltungsrechts einen wichtigen verfassungsrechtlichen Orientierungspunkt gesetzt. Die zu erlassenden Landesbauordnungen mußten sich mit dem vom BVerwG vorgegeben Argument auseinandersetzen, wonach über das "ästhetisch Befriedigende" ein Konsens nicht bestehe ${ }^{24}$ und demgemäß generalklauselartige gesetzgeberische Anforderungen nur im Rahmen eines relativen ästhetischen Minimums, also dort, wo ein gewisser Grundkonsens noch ersichtlich ist, möglich seien. Denn die Ausführungen des BVerwG zu den Begriffen "Verunstaltung" und "gebildeter Durchschnittsbetrachter" bezweckten letztlich nichts anderes, als zu versuchen, den Bereich zu bestimmen, in dem aufgrund einigermaßen noch übereinstimmender Anschauungen eine berechenbare Entscheidung möglich ist.

So ist es erklärbar, daß die meisten der in der Folgezeit erlassenen Landesbauordnungen sich auf die vom BVerwG vorgegebenen Maßstäbe beschränkten ${ }^{25}$. Sie folgten damit weitgehend nicht den weitergehenden Vorschlägen der MBauO 1960. Diese verlangte in $\S 3$ Abs. 1 S. 2 und 14 Abs. 1 ein "einwandfreies Gestalten" von baulichen Anlagen, ferner ein "in Einklang bringen" mit der Umgebung dergestalt, daß das Straßen-, Orts- und Landschaftsbild "nicht gestört" wird ( $\S 3$ Abs. 1 S. 2 und 14 Abs. 2 $\mathrm{MBauO}$ ). Damit sollte es über die Abwehr verunstaltender Anlagen hinaus Aufgabe der Bauaufsicht sein, die Baukultur zu wahren und zu fördern ${ }^{26}$. Versuche, sich von den restriktiven Annahmen des BVerwG im Sinne der MBauO $1960 \mathrm{zu}$ lösen, ist die Forderung nach "einwandfreier Gestaltung", ebenso wie die in Anlehnung an $\S 14$ Abs. $3 \mathrm{MBauO}$ erfolgte Ersetzung des Maßstabes des Empfindens des gebildeten Durchschnittsbetrachters durch den des Empfindens eines "sachkundigen und erfahrenen Betrachters"27, obwohl das BVerwG einen empfindsameren Personenkreis als den der "gebildeten Durchschnittsbetrachter" als nicht zuverlässig auswählbar bezeichnet hatte ${ }^{28}$. Als weiterer gesetzgeberischer Anlauf in Richtung auf ein "Mehr" als Verunstaltungsabwehr wird schließlich der Art. 12 Abs. 3 BayBO mit seiner dem $\S 34$ Abs. $1 \mathrm{BBauG}$ entlehnten Forderung nach Einfügen ei-

\footnotetext{
${ }^{24}$ Siehe BVerwGE 2, 176.

${ }^{25}$ Zur Rechtslage in Hamburg siehe Koch, Landesplanung und Städtebau, S. 284.

${ }^{26}$ Einf. in die MBauO des Bundesministers für Wohnungsbau, S. 122.

${ }^{27}$ Etwa in $\S 14$ Abs. 3 BremLBauO. Siehe auch $\S 72$ Abs. 4 HBauO a. F.: "erfahrener und verständiger Betrachter"; dies ist seit der Novelle vom 01.06.1986, GVBl. 1986, S. 183 ff., entfallen.

${ }^{28}$ BVerwGE 2, 177.
} 
ner baulichen Anlage in die nähere Umgebung verstanden ${ }^{29}$. Auch $\S 4$ Abs. 1 S. 2 LBO Saarl. wird man hier einzuordnen haben.

Insgesamt lassen sich die in den Landesbauordnungen enthaltenen Anforderungen an die Baugestaltung folgendermaßen zusammenfassen: Die meisten Landesbauordnungen halten sich schon terminologisch bei ihren in den Generalklauseln enthaltenen Anforderungen im Rahmen der vom BVerwG vorgegebenen Bahn der Beschränkung auf die Verunstaltungsabwehr. Trotz der vielfach verlauteten Kritik an der Rechtsprechung des BVerwG zeigen sich nur vereinzelt gesetzgeberische Formulierungen, die als Ansätze im Hinblick auf weitergehende Anforderungen an die Baugestaltung verstanden werden könnten. Der Wunsch nach weitergehendem Schutz scheint vorhanden zu sein, das Vertrauen darauf, daß dieser angesichts des verfassungsrechtlichen Bestimmtheitsgrundsatzes durch Generalklauseln erreichbar ist, jedoch weitgehend nicht.

\section{Das Problem des fehlenden Konsenses in ästhetischen Fragen}

Die seit dem Grundsatzurteil des BVerwG zu § 1 BaugestVO vergangene Zeit läßt es angebracht erscheinen, die Richtigkeit der dort vorgenommenen Beschränkung der Anforderungen an die Baugestaltung auf die Frage des Verunstaltungsschutzes noch einmal zu überprüfen. Die Entscheidung des BVerwG stammt aus einer Zeit, in der dem Wiederaufbau der kriegszerstörten deutschen Städte noch eindeutig Vorrang gegenüber anderen Forderungen wie solchen nach Schaffung einer ansprechenden Stadtgestalt gegeben wurde ${ }^{30}$. Heute dagegen soll sich das ästhetische Empfinden wieder mehr an den Geboten der Stadtbildpflege und den Gesetzen der architektonischen Harmonie ausrichten ${ }^{31}$. Durch die zunehmende Befriedigung der "Primärbedürfnisse" gewinne die Qualität der urbanen Umwelt größere Bedeutung ${ }^{32}$. Auch die zum Teil in den Landesbauordnungen vorgenommene Loslösung von den Grundsätzen des BVerwG verlangen nach einer Über-

\footnotetext{
${ }^{29}$ So von Hüffer, BayVBI. 1984, S. 12 ff. Ausführlich dazu unten C III 2 c.

${ }^{30}$ Vergleiche etwa die Kritik von Zinkahn, DVBI. 1951, S. 368 und DÖV 1953, S. 161 anı damaligen Ausmaß der Außenwerbung.

31 So etwa OVG Berlin, Beschluß vom 13.01.1984, BauR 1984, S. 624. Ebenso Simon, Art. 12 Rn. 36 S. 52. Ähnlich auch Engel, AfK 1975, S. 214: "veränderte optische Bedürfnisse"; weiterhin Ortloff, Öffentliches Baurecht, Band II, S. 31: "verstärktes bauliches Umweltbewußtsein".

${ }^{32}$ Trieb, Stadtgestaltung, S. 19; Trieb / Schmidt / Paetow / Buch / Strobel, S. 14.
} 
prüfung der Aussagen im Urteil zur BaugestVO von 1936. Die landesrechtlichen Regelungen wären - unterstellt, die Aussagen des BVerwG hätten auch heute noch Gültigkeit - möglicherweise verfassungswidrig.

Das BVerwG beschränkte die Anforderungen an die Baugestaltung wegen der sonst fehlenden Bestimmtheit des von der BaugestVO verwendeten Begriffs "anständige Baugesinnung" auf die Verunstaltungsabwehr. Immerhin nennen die heutigen gestaltungsrechtlichen Generalklauseln die Elemente des optischen Eindrucks einer baulichen Anlage, die zu einer Verunstaltung führen können, also vor allem Form, Maßstab, Verhältnis der Baumassen und Bauteile sowie Werkstoff und Farbe ${ }^{33}$. Damit zählen die Landesbauordnungen jedoch nur die Merkmale auf, die den optischen Eindruck einer baulichen Anlage im wesentlichen prägen. Sie geben aber genauso wenig wie der Begriff "anständige Baugesinnung" eine Antwort darauf, welche Farben, Formen etc. verunstaltend wirken ${ }^{34}$.

Entscheidend ist damit nach wie vor die Frage nach dem Maß der Übereinstimmung in ästhetischen Fragen. Der Ausgangspunkt des BVerwG, daß es keine allgemeinen Anschauungen darüber gibt, was "ästhetisch befriedigend" ist, dürfte dabei heute sogar noch eher zutreffen als in den fünfziger Jahren, und zwar gerade für den Bereich der Baugestaltung ${ }^{35}$. Bereits die allgemeinen Wertvorstellungen sind weitgehend heterogenisier ${ }^{36}$. Gerade ästhetische Maßstäbe sind zudem nicht nur heterogen, sie unterliegen auch einem relativ schnellen Wande ${ }^{37}$. Ein Hinweis hierauf ist der Vorschlag, Gestaltungssatzungen nur mit begrenzter Gültigkeitsdauer, etwa für 3 - 5 Jahre zu erlassen, da die Urteile über visuelle Sachverhalte einem entsprechend starken Wechsel unterlägen ${ }^{38}$.

\footnotetext{
${ }^{33}$ Siehe etwa Art. 12 Abs. 1 BayBO.
}

34 Eine gewisse Ausnahme bildet $\$ 12$ Abs. 4 HBO, wonach Dachaufbauten und Dacheinschnitte höchstens der Hälfte der Länge ihrer zugehörigen Gebäudeseite entsprechen dürfen, siehe dazu auch unten Fn. 107.

${ }^{35}$ So auch Vollmer, ArchPF 1980, S. 102; Engelmann, S. 36 ff.; Ortlieb, S. 16; Heinz, S. 13: "Ein Gestaltkonsens ist nicht mehr verhanden." Daß dies auch schon im letzten Jahrhundert so war, zeigen die Ausführungen von Baumeister, S. 265. Vergleiche auch die Kontroverse um die Aufstellung von Gartenzwergen im gemeinschaftlichen Eigentum einer Wohnanlage, OVG Hamburg, Beschluß vom 20.04.1988, NJW 1988, S. 2052. Sehr vorsichtig auch Albers, Planungsrecht, S. 222 f.: "Relativität gestalterischer Regeln".

36 Allgemein hierzu Erichsen, VVDStRL 35 (1976), S. 175. Ähnlich auch Martens, DÖV 1982, S. 91: rapider Verlust an allgemein als verbindlich anerkannten Wertvorstellungen. Siehe weiterhin auch $R$. Schmidt, BayVBI. 1988, S. 1.

${ }^{37}$ Eberl, BayVBI. 1987, S. 353.

${ }^{38}$ Burger / Gutschow / Krause, S. 153; Jaeger, ZSSD 1979, S. 304. 
Ein Blick auf die Bemühungen der wissenschaftlichen Ästhetik bestätigt diesen Befund. So sind für das Problem der juristischen Kunstdefinition von dort schon keine Hilfen zu erwarten ${ }^{39}$. Dies gilt noch mehr für die Frage, was künstlerisch oder ästhetisch "richtig" oder "wertvoll" ist. So machen moderne Kunsttheorien vielfach nicht die Seinsbestimmung von Kunst sondern die Funktionen der Kunst zum Gegenstand ihrer Überlegungen ${ }^{40}$. Das BVerwG mit seinen stark emotional geprägten Formeln wie "Verletzung des ästhetischen Empfindens" dürfte sich zum Teil einer beißenden Kritik ausgesetzt sehen, legt man insoweit Maßstäbe aus der wissenschaftlichen Kunsttheorie an. So bezeichnet etwa Goodman, einer der einflußreichsten Vertreter der amerikanischen analytischen Philosophie, ein Verständnis von ästhetischer Erfahrung im Sinne einer Art "emotionales Bad" oder "Orgie" als "blödsinnig"41. Vielmehr hätten Emotionen in der ästhetischen Erfahrung eine kognitive Funktion, ein Kunstwerk werde sowohl durch Sinne als auch durch Gefühle aufgefaßt ${ }^{42}$. Somit kann etwas, was im Sinne des BVerwG "Unlust" erregt, für die Erkenntnis eines Kunstwerkes durchaus wesentlich sein. Dies mag bereits genügen, um zu belegen, daß auch diejenigen, die sich quasi hauptamtlich mit Fragen von Kunst und Ästhetik befassen, es nicht mehr als ihre Aufgabe ansehen, zu definieren, wann etwas "schön" ist und wann nicht.

Untersucht man schließlich die gängigen Kommentierungen und die Rechtsprechung zu den Verunstaltungsbestimmungen, so beseitigt dies vollends Zweifel an der These, daß auch heute eigentlich kein Konsens über Fragen der Baugestaltung herrscht. Man findet entweder überhaupt keine klaren Stellungnahmen zu der Frage, wann eine Verunstaltung vorliegen soll, oder die vertretenen Auffassungen sind mehr als zweifelhaft. Als Beispiel seien hier nur Stellungnahmen zum Thema Dachgestaltung genannt. Trifft man etwa auf den Satz, daß bei Dachauf- und -ausbauten auf das rechte Verhältnis zu den übrigen Bauteilen des Gebäudes zu achten ist ${ }^{43}$, so ist das eher ein Appell an den Bauherrn als eine Umschreibung von Voraussetzungen, die bei fehlender Beachtung ein Eingreifen der Bauaufsichtsbehörden rechtfertigen. Gleiches gilt für die Feststellung, wonach Dachaufund -ausbauten möglichst vermieden, bei steilen Dächern Dachaufbauten

\footnotetext{
${ }^{39}$ Knies, S. 142.

${ }^{40}$ Iser, S. 34.

${ }^{41}$ Goodman, S. 573.

${ }^{42}$ Goodman, S. 575.

${ }^{43}$ Simon, Art. 12 Rn. 15.
} 
einen bescheidenen unauffälligen Umfang haben sollen und daß sog. positive den negativen Dachgauben (also Dacheinschnitten) vorzuziehen seien ${ }^{44}$. Andere sind dagegen für den Geltungsbereich der gleichen Bauordnung der Auffassung, daß negative Dachgauben meistens verunstaltend wirken ${ }^{45}$. Dies ist jedoch wohl eher die Verabsolutierung einer persönlichen Geschmacksrichtung ${ }^{46}$. So fordert ganz im Gegensatz zur Ablehnung von Dachgauben in der bayerischen Kommentarliteratur eine textliche Festsetzung für ein Baugebiet in Grunewald die Ausbildung von Dächern in plastischer Form durch Dachgauben ${ }^{47}$. Historisch wertvolle Dachlandschaften können zudem gerade in Bayern in hohem Maße durch Dachgauben geprägt sein ${ }^{48}$. Bereits dieses Teilproblem macht somit deutlich, wie schwierig es ist, einigermaßen präzise und gleichzeitig in konsensfähiger Weise allgemeine Anforderungen an die Gestaltung baulicher Anlagen zu umschreiben. Insofern ist die Auffassung des BVerwG nach wie vor richtig, daß Feststellungen darüber, was "ästhetisch befriedigend" ist, kaum möglich sind.

\section{Der maßgebliche grundrechtliche Prüfungsmaßstab}

Ein Hauseigentümer ist grundsätzlich frei in der Entscheidung, welches Aussehen er seinem Gebäude geben will. Das ist eine Konsequenz aus der Privatnützigkeit des Eigentums. Privatnützigkeit bedeutet, daß der Eigentumsgegenstand einem Rechtsträger zugeordnet ist, in dessen Hand er als Grundlage privater Initiative und im eigenverantwortlichen privaten Interesse von Nutzen sein soll ${ }^{49}$. Dieser "Nutzen" ist nicht nur als ökonomischer Nutzen zu verstehen. Art. 14 GG zeichnet sich gegenüber seinen historischen Vorläufern gerade dadurch aus, daß er primär eine Bestandsgarantie enthält ${ }^{50}$. Freiheit im vermögensrechtlichen Bereich bedeutet nicht nur, vermögenswerte Gegenstände wegen ihres Vermögenswertes haben und

${ }^{44}$ Simon, Art. 12 Rn. 15. Kritisch zu diesen Ausführungen von Simon auch Moench / Schmidt, S. 15.

${ }^{45}$ Koch / Molodovsky / Rahm, Art. 12 Anm. 4.3.

${ }^{46}$ So auch Vollmer, ArchivPF 1980, S. 107; OVG Lüneburg, Urteil vom 28.02.1977, BRS Band 32, Nr. 114: "Dachgauben wirken nicht generell verunstaltend."

${ }^{47}$ Nachweis bei Rave, S. 48.

${ }^{48}$ Beispielsweise Bamberg. Siehe dazu "Alte Städte - alte Dörfer", S. 119.

${ }^{49}$ Soell, NVwZ 1984, S. 186, ders., DVB1. 1983, S. 242.

${ }^{50}$ Ausführlich dazu Boehmer, NJW 1988, S. 2563 ff. 
behalten zu dürfen. Sie kann auch darin bestehen, gerade die konkreten Vermögensgegenstände zu behalten und mit ihnen nach eigenem Belieben zu verfahren. Art. 14 Abs. $1 \mathrm{~S} .1 \mathrm{GG}$ ist insoweit eine spezialgesetzliche Verbürgung des Persönlichkeitsrechts ${ }^{51}$. Dies ist auch als "menschliche" Seite des privaten Eigentums bezeichnet worden, im Gegensatz zum "sachlichen", dem Eigentum als Vermögenswert ${ }^{52}$. Ob dies eine geglückte Begriffsbildung ist, mag dahingestellt bleiben. Der zugrunde liegende Gedanke ist jedenfalls richtig. Somit umfaßt die Eigentumsgarantie des Grundgesetzes auch das Recht des Eigentümers, den eigenen Gegenständen ein dem eigenen Geschmack entsprechendes Aussehen zu geben ${ }^{53}$. Sowohl bei umgebungsabhängigen als auch umgebungsunabhängigen Anforderungen und beim Erlaß von örtlichen Bauvorschriften stellt sich damit die Frage, ob und inwieweit mittels baugestalterischer Vorschriften diese Freiheit des Eigentümers beschränkt werden darf. Vor allem einschlägiger grundrechtlicher Prüfungsmaßstab ist somit Art. 14 Abs. 1 und 2 GG.

Allerdings werden auch andere Grundrechte insoweit für relevant gehalten. Was den Art. 12 GG unter dem Gesichtspunkt der Berufsfreiheit der Architekten betrifft ${ }^{54}$, dürfte jedoch wohl schon der Schutzbereich nicht berührt sein. Baugestalterische Anforderungen haben keine berufsregelnde Tenden $z^{55}$. Weiterhin wird vielfach die Auffassung vertreten, neben Art. 14 GG sei auch oder sogar vor allem Art. 5 Abs. 3 GG, also die Kunstfreiheitsgarantie, Maßstab für die Zulässigkeit von Anforderungen an die Baugestaltung ${ }^{56}$. Während das BVerwG die Ausübung von Kunstfreiheit durch Gestaltung von Bauwerken schlicht in die nach Art. 14 Abs. 1 S. 2 und Abs. 2 GG zulässigerweise gezogenen Schranken verweist ${ }^{57}$, widmen sich Autoren mit literarischer Vorliebe für Art. 5 Abs. 3 GG im Anschluß an die Feststellung, die Errichtung von Gebäuden sei zumindest häufig auch "Kunst" im Sinne des Art. 5 Abs. 3 GG $^{58}$, dem Problem der Schrankenkon-

\footnotetext{
${ }^{51}$ Henschel, NJW 1989, S. 938.

${ }^{52}$ Boehmer, NJW 1988, S. 2562. Vergleiche zu dieser Begriffsbildung auch Ekcy, S. 227.

53 So auch Hoppe, Gedächtnisschrift Klein, S. 220.

54 Dazu ausführlich Kromik, S. 101 ff. Weiterhin auch Moench / Schmidt, S. 2.

55 So auch VGH Kassel, Beschluß vom 27.07.1988, NVwZ-RR 1989, S. 360 (361).

56 Ausführlich in diesem Sinne Seybold, S. 95 ff. Weiterhin Erbel, Kunstfreiheitsgarantie, S. 165; Looks, S. 85; Moench / Schmidt, S. 52 ff.

${ }^{57}$ BVerwG, Beschluß vom 10.12.1979, BRS Band 35, Nr. 133 S. 254 f. So auch Zinkahn, DÖV 1953, S. 165.

${ }^{58}$ Erbel, Kunstfreiheitsgarantie, S. 165; Seybold, S. 95; Looks, S. 85.
} 
kurrenz beim Zusammentreffen von Grundrechtsausübung nach Art. 5 Abs. 3 und Art. 14 GG. Das weitgehend einhellige Ergebnis besteht dann darin, daß - im Gegensatz zur Rechtsprechung des BVerwG - insoweit der nicht unter Gesetzesvorbehalt stehenden Garantie des Art. 5 Abs. 3 GG der Vorrang gebühre ${ }^{59}$. Nachdem auf diese Weise die Entscheidung über den Außenanstrich, die Dachneigung und die Frage der Kleinteiligkeit der Fenster unter den Schutz eines Grundrechts ohne Gesetzesvorbehalt gestellt worden ist, werden die wahren Befugnisse des Künstlers Hauseigentümer und eines eventuellen Befugnishelfers Architekt dann aber oft - wenn auch mit erheblichem Begründungsaufwand - wieder auf das Maß zurückgestutzt, das sich auch ergeben hätte, wenn man die Problematik von vornherein auf eine Prüfung des Art. 14 GG beschränkt hätte ${ }^{60}$. Gegebenenfalls werden zur Erreichung dieses Ergebnisses "sachimmanente ästhetische Elementarschranken" entwickelt ${ }^{61}$, oder man greift auf das Sozialstaatsprinzip zurück und beschränkt die Kunstfreiheit aufgrund einer angenommenen Verpflichtung des Staates zu einer Garantie des architektonisch-landschaftlichen Gesamtbildes wegen sozialpsychischer Funktion der Architektur ${ }^{62}$.

Im Rahmen der vorliegenden Arbeit soll darauf verzichtet werden, diesen Begründungen noch eine weitere Variante hinzuzufügen. Rechtfertigen läßt sich dies damit, daß die durch örtliche Bauvorschriften getroffenen Bestimmungen in der Regel keine Kunstausübung im Sinne von Art. 5 Abs. 3 GG beschränken. Errichtet jemand ein Gebäude und verwendet er als Dachmaterial unterschiedliche Ziegel, die er aus Kostengründen aus Restbeständen zusammengekauft hat, dann fehlt es in den meisten Fällen schon am Willen, überhaupt "Kunst" auszuüben ${ }^{63}$. So mag es auf Heimatverbundenheit beruhen, wenn jemand, weil er aus Norddeutschland stammt, sein Gebäude in der neuen Wohngegend in Süddeutschland mit roten Klinkersteinen verkleiden will, obwohl dort nur weiß verputzte Häuser üblich und aufgrund der Witterungsverhältnisse auch vollkommen ausreichend sind. Auch die Frage, ob man lieber mit oder ohne Dachgauben baut, ist meistens kein Ausdruck "freier schöpferischer Gestaltung", sondern dient gegebenenfalls der Belichtung des Dachgeschosses durch stehende Fenster.

\footnotetext{
${ }^{\$ 9}$ Erbel, Kunstfreiheitsgarantie, S. 169; Seybold, S. 129; Looks, S. 84.

${ }^{60}$ Siehe etwa die Ausführungen von Seybold, S. 142 ff.

${ }^{61}$ Und zwar von Erbel, Kunstfreiheitsgarantie, S. 170.

${ }^{62}$ So Looks, S. 142.

${ }^{63}$ Dazu, daß insoweit zunächst von der subjektiven Behauptung auszugehen ist, siehe von Münch, Art. 5 GG Rn. 60.
} 
Zwar ist es unzutreffend, daß "Kunst" im Sinne von Art. 5 Abs. 3 GG nur dann vorliegt, wenn gemäß der allgemeinen baugestalterischen Vorschriften in den Landesbauordnungen eine einwandfreie ästhetische Gestaltung gegeben ist ${ }^{64}$. Es kann somit durchaus vorkommen, daß baugestalterische Anforderungen mit der Grundrechtsverbürgung des Art. 5 Abs. 3 GG in Konflikt geraten. Der Regelfall ist dies aber sicherlich nicht ${ }^{65}$. Da es sich bei Problemen mit baugestalterischen Anforderungen häufig ohnehin um Quisquilien dreht, erscheint es nicht angebracht, die grundrechtliche Problematik vorrangig im Bereich des Art. 5 Abs. 3 GG anzusiedeln. Falls Architekten versuchen wollen, künstlerisch wertvolle Gebäude zu erstellen, werden sie ohnehin bei den Planungsämtern und Baugenehmigungsbehörden häufig auf offene Türen treffen. Gegebenenfalls können Hindernisse, die sich aus erlassenen örtlichen Bauvorschriften ergeben, im Wege des Dispenses beseitigt werden. Bei der Entscheidung über eine solche Befreiung wäre dann die grundrechtliche Wertentscheidung des Art. 5 Abs. 3 GG entsprechend zu berücksichtigen ${ }^{66}$. Mit "sensiblen Entwerfer-Architekten" gibt es insoweit aber in der Regel auch gar keine Auseinandersetzungen ${ }^{67}$. Eine Beschränkung auf die eigentumsrechtlichen Fragen erscheint somit aufgrund der praktisch eingeschränkten Relevanz des Problems des Eingriffs in Art. 5 Abs. 3 GG vertretbar.

\section{Die umgebungsunabhängigen Anforderungen an die Baugestaltung}

\section{Umgebungsunabhängige Anforderungen und Sozialbindung des Eigentums}

Auch wenn im Rahmen dieser Untersuchung die grundrechtliche Problematik nur anhand der im Vergleich mit der Kunstfreiheitsgarantie in sehr

\footnotetext{
${ }^{64}$ So aber Scheerbarth, S. 186. Zutreffend hiergegen Erbel, Kunstfreiheitsgarantie, S. 166.

${ }^{65}$ Anders Erbel, Kunstfreiheitsgarantie, S. 165, wonach der Bau fast jeden Gebäudes den ein oder anderen künstlerischen Aspekt habe. Selbst wenn dies so wäre, wäre damit nicht gesagt, daß deshalb in der Regel auch ein Konflikt dieses künstlerischen Elements mit örtlichen Bauvorschriften vorliegt. Zu Recht skeptisch gegenüber einer generellen Relevanz des Art. 5 Abs. 3 GG daher Moench / Schmidt, S. 53 f.

${ }^{66}$ Moench / Schmidt, S. 57, gehen sogar davon aus, daß ein Anspruch auf Erteilung einer Befreiung besteht, wenn ein Bauwerk den Schutz des Art. 5 Abs. 3 GG genieBt.

${ }^{67}$ Gutschow, S. 92.
} 
viel weiterem Umfang gesetzgeberischen Bestimmungen zugänglichen Eigentumsgarantie untersucht werden soll, so ist die Frage, ob umgebungsunabhängige Anforderungen an die Baugestaltung grundrechtswidrig sind, nicht ganz einfach zu beantworten. Ausgangspunkt der Überlegungen muß sein, daß der Gesetzgeber nur dann in die dem Eigentümer zustehende Befugnis, den eigenen Gegenständen ein ihm gefallendes Aussehen zu geben, eingreifen darf, wenn der Eigentumsgegenstand in einem sozialen Spannungsverhältnis steht, also soziale Bezüge oder eine soziale Funktion als Begründung für die Eigentumsbindung angeführt werden können. So hat das BVerfG im Mitbestimmungsurteil ausgeführt ${ }^{68}$, daß die Befugnis des Gesetzgebers zur Inhalts- und Schrankenbestimmung umso weiter gehe, je mehr das Eigentumsobjekt in einem sozialen Bezug und einer sozialen Funktion stehe ${ }^{6}$. Diese Aussage wird man noch erweitern müssen: Ohne sozialen Bezug oder soziale Funktion des konkreten Eigentumsgegenstandes ist jede Eigentumsbindung unzulässig ${ }^{70}$. Grundlage und Rechtfertigung jeder Sozialbindung ist es, daß die Menschen in einer Gemeinschaft leben ${ }^{71}$. Solange nun kein sozialer Bezug oder keine soziale Funktion eines Eigentumsgegenstandes besteht, gibt es auch kein öffentliches Interesse für eine Eigentumsbindung. Das Vorhandensein eines sozialen Spannungsverhältnisses ist damit die Grundvoraussetzung für die Definition eines öffentlichen Interesses an einer Eigentumsbindung durch den Staat.

Letztlich wird man aber - da kaum jemand wie Robinson auf einer einsamen Insel lebt ${ }^{72}$ - sich bei fast jedem Gegenstand eine soziale Funktion oder einen sozialen Bezug vorstellen können. Auch die Krawatten, die jemand trägt ${ }^{73}$, stehen dann, wenn sie von jemandem erblickt werden können, in einem "sozialen Bezug". Die Marmelade, die man morgens zum Frühstück ißt, kann etwa aufgrund des möglicherweise entstehenden Verpackungsabfalls zu einem sozialen Spannungsverhältnis führen. Damit teilen sozialer Bezug und soziale Funktion das Schicksal, das auch den Begriff des öffentlichen Interesses ereilt hat. Er ist nicht von der Verfassung vorgegeben, sondern wird vom Staat und vor allem vom parlamentarischen Gesetzgeber definiert. Da der Staat im Grundsatz selbst über die von ihm zu erle-

\footnotetext{
${ }^{68}$ Urteil vom 01.03.1979, E 50, 290 ff.

${ }^{69}$ BVerfGE 50, 340.

${ }^{70}$ So wohl auch Böhmer, AgrarR 1984, Beilage I/1984 zu Heft 4, S. 17.

${ }^{71}$ Böhmer, NJW 1988, S. 2568.

${ }^{72}$ Beispiel in Anlehnung an Böhmer (Fn 71).

${ }^{73}$ Beispiel in Anlehnung an Böhmer (Fn 71).
} 
digenden Staatsaufgaben bestimmt ${ }^{74}$, entscheidet der Gesetzgeber darüber, aus welchen sozialen Bezügen sich ein öffentliches Interesse als Rechtfertigung zu Eingriffen in Grundrechte und damit auch zur Inhalts- und Schrankenbestimmung des Eigentums herleiten läßt. Es gibt auch insoweit kein vorgegebenes Gemeinwohl ${ }^{75}$.

Die Befugnis des Gesetzgebers zur Definition des öffentlichen Interesses besteht aber eben nur "in den Grenzen der Verfassung" ${ }^{\text {76 }}$. Zwar wird die Förderung von Ästhetik als eine legitime Staatsaufgabe angesehen ${ }^{n}$. Der Begriff des "öffentlichen Interesses" ist jedoch aus dem jeweiligen Funktionszusammenhang heraus zu verstehen, $d . h$. er hat keinen feststehenden Inhalt, sondern divergiert nach dem jeweiligen Normzusammenhang ${ }^{78}$. In diesem Sinne führt der Funktionszusammenhang des öffentlichen Interesses "Förderung von Ästhetik" mit der Eigentumsgarantie dazu, daß die Förderung von Ästhetik allein kein öffentlicher Belang ist, der ein öffentliches Interesse an einer Eigentumsbindung begründen könnte. Dies ergibt sich aus folgenden Überlegungen: Wenn die Förderung von Ästhetik ein öffentlicher Belang wäre, der eine Eigentumsbeschränkung rechtfertigt, dann ist kein Grund dafür ersichtlich, warum nicht alle Gegenstände, die mit unterschiedlichem Aussehen geschaffen werden können, einer entsprechenden Eigentumsbeschränkung unterworfen werden. So könnte der Gesetzgeber auch Vorschriften darüber erlassen, wie Wohnzimmer zu gestalten sind, welche Farben für Autos "schön" sind, welche Krawatten ästhetischen Maßstäben am ehesten gerecht werden etc. Dies wird niemand ernsthaft vertreten wollen. Die Beispiele zeigen, daß das Fehlen von Ästhetik nicht notwendigerweise einen hinreichenden sozialen Bezug hat, der den Gesetzgeber zum Eingreifen berechtigen würde. Niemand wird gezwungen, sich anzusehen, wie andere ihr Wohnzimmer einrichten. Scheußliche Krawatten und verbeulte oder uneinheitlich lackierte Autos erscheinen hinnehmbar. Wenn man nun ausgerechnet für die Grabgestaltung ${ }^{\text {T9 }}$ und für die äußere Gestaltung von Anlagen, die den Bauordnungen unterliegen, eine Ausnahme

${ }^{74}$ Steiner, Öffentliche Verwaltung durch Private, S. 52; ähnlich auch Isensee, HbStR, Band III, Rn. 88 S. 39 und Rn. 156 S. 71.

${ }^{75}$ Häberle, DVBl. 1972, S. 911.

${ }^{76}$ Steiner, Öffentliche Verwaltung durch Private, S. 52.

${ }^{n}$ Siehe Bull, Staatsaufgaben, S. 343; kritisch für baugestalterische Vorschriften hingegen schon Baumeister, S. 265: "Denn was heißt Schönheit im vulgären Sinn? Sie heißt: Das Bauen kostet mehr Geld."

${ }^{78}$ Rupp, Wohl der Allgemeinheit, S. 124.

79 Dazu grundsätzlich Bachof, AöR 78 (1952/53), S. 82 ff. 
macht, so wird man dies daher nicht mit der Förderung von Ästhetik oder der Verhinderung der Beeinträchtigung von Ästhetik begründen können. Rechtfertigender Grund ist vielmehr die besonders qualifizierte Wirkung auf die überwiegende Zahl der Betrachter, die Tatsache, daß sie durch den Anblick des Gebäudes tatsächlich in ihrem ästhetischen Empfinden im Sinne der Rechtsprechung des BVerwG "verletzt" werden, daß in ihnen ein Gefühl des Mißfallens erweckt und Kritik und der Wunsch nach Abhilfe herausgefordert werden ${ }^{80}$. Solche Wirkungen, also die durch die innere Reaktion der Betrachter bei diesen verursachte verringerte Lebensqualität ${ }^{81}$, darf der Gesetzgeber als hinreichend gewichtiger sozialer Bezug definieren und ein öffentliches Interesse für eine Eigentumsbindung annehmen. Daß nun gerade für den Bauordnungen unterliegende Anlagen Gestaltungsanforderungen gestellt werden, findet seine Begründung darin, daß etwa Gebäude in besonderer Weise den optischen Eindruck des Lebensumfeldes der meisten Menschen prägen, anders als zum Beispiel Autos, die ohnehin häufig an verschiedenen Stellen auftauchen und nach gewisser Zeit aus dem Sraßenbild wieder verschwinden.

Es ist also nicht die Schaffung von "ästhetisch Wertvollem" oder auch nur "Wertvollerem", was Eigentumsbindungen durch Gestaltanforderungen an Gebäude rechtfertigt, sondern die besonders qualifizierte Wirkung des als häßlich Empfundenen auf die Betrachter. Damit erscheint die Beschränkung von umgebungsunabhängigen Anforderungen auf die Verunstaltungsabwehr in einem anderen Licht. Denn zumindest bei den umgebungsunabhängigen Maßstäben ist es nicht vor allem der Bestimmtheitsgrundsatz, der gesetzgeberischen Anforderungen eine Grenze setzt. Die eigentliche Grenze für bauästhetische (umgebungsunabhängige) Anforderungen zieht vor allem die Eigentumsgarantie. Eine im engeren Sinne verhältnismäßige Eigentumsbeschränkung liegt nur dann vor, wenn wirklich die ganz überwiegende Zahl der Betrachter eine bauliche Anlage aus ästhetischen Gründen für nicht hinnehmbar hält. Nur dann hat der Gesetzgeber das Recht, durch Anforderungen an die optische Gestaltung von Gegenständen die grundsätzliche Freiheit des Eigentümers im Hinblick auf das Aussehen "seiner" Gegenstände einzuschränken. Sind nur einzelne, etwa besonders empfindliche und geschulte Betrachter der Meinung, daß eine Anlage optisch anders

\footnotetext{
${ }^{80}$ BWVGH, Urteil vom 12.10.1983, insoweit abgedruckt bei Bork / Köster, Erl. § 12 Rn. 1. Ähnlich auch die Diskussion im "Gartenzwerg"-Fall, siehe OLG Hamburg, Beschluß vom 20.04.1988, NJW 1988, S. 2052 (2053).
}

${ }^{81} \mathrm{Vgl}$. Einsele, Stadtbauwelt 1974, S. 142. 
gestaltet sein müsse, dann reicht dies für eine Eigentumsbindung nicht. Denn der Eigentümer braucht sich nicht nach der Meinung einzelner anderer richten, mag sein eigener Geschmack oder seine Betonung von wirtschaftlichen vor ästhetischen Interessen auch noch so fragwürdig sein.

\section{Kulturgestaltungsmacht des Staates und Förderung der Bauästhetik}

Die Feststellung, daß der Staat bauästhetische umgebungsunabhängige Anforderungen nur als Reflex auf die Anschauungen der Mehrheit der Betrachter stellen kann, steht im Widerspruch zu Versuchen, bauästhetische Anforderungen allgemein und damit auch die umgebungsunabhängigen dadurch zu legitimieren, daß dem Staat eine "Kulturgestaltungsmacht" zuerkannt wird ${ }^{82}$. Gegen die Annahme, der Staat dürfe aufgrund seiner "Kulturgestaltungsmacht" weitergehende eigentumsbeschränkende Regelungen erlassen, sprechen jedoch erhebliche Bedenken. Sie bestätigen im Gegenteil den Befund, daß der Staat mit dem allgemeinen Ziel "Förderung der Ästhetik" keine Grundrechtsbindungen begründen darf.

Zwar mag man darüber diskutieren können, ob man aus Art. 5 Abs. 3 GG eine allgemeine Kulturstaatsbestimmung herauslesen kann ${ }^{83}$. Diskutabel ist es auch, Art. 5 Abs. 3 GG nicht als Garanten einer absoluten Staatsfreiheit der Kunst verstehen zu wollen ${ }^{84}$. Daraus wird man jedoch nicht die Befugnis für den Staat ableiten können, Kultur schlechthin und auf jedem Weg, also auch durch Grundrechtseingriffe zu "fördern". Aufgabe des Staates ist es nur, für den Schutz und die Förderung der Freiheit der Kunst zu sorgen ${ }^{85}$. Art. 5 Abs. 3 GG verpflichtet geradezu den Staat auf die Anerkennung einer sich autonom entfaltenden Sach- und Wesensgesetzlichkeit der Kunst ${ }^{86}$, staatlicher Kulturauftrag und damit auch staatliches Kulturgestaltungsrecht ist die Ermöglichung und nicht die Einschränkung von Freiheit ${ }^{87}$.

\footnotetext{
${ }^{82}$ So vor allem Seybold, S. 74 ff; grundsätzlich zum Begriff "Kulturgestaltungsmacht" siehe Ernst-Rudolf Huber, Kulturstaat, S. 12 ff.

${ }^{83}$ So etwa Scholz, Art. 5 Rn. 8. Hiergegen wohl zu Recht kritisch Steiner, VVDStRL 42 (1984), S. 13; Mihatsch, S. 61 ff.; speziell im Hinblick auf die Förderung von Baukultur auch Moench / Schmidt, S. 56.

${ }^{84}$ So etwa Knies, Freiheit der Kunst und Kulturstaat, S. 248.

${ }^{85}$ Badura, Staatsrecht, C 76, S. 134.

${ }^{86}$ Steiner, VVDStRL 42 (1984), S. 15 m. w. N.

${ }^{87}$ Grimm, VVDStRL 42 (1984), S. 67.
} 
Die Tatsache, daß der Staat bei der Kunst- und Kulturförderung auf Vorbereitung und Hilfestellung beschränkt ist ${ }^{88}$, ergibt sich auch daraus, daß der Staat selbst gar nicht Künstler oder Kulturschaffender sein kann. Bei aller Schwierigkeit oder gar Unmöglichkeit, "Kunst" im Verfassungssinne zu definieren $^{89}$, besteht doch weitgehend Einigkeit dahingehend, daß sich "Kunst" gerade durch Eigengesetzlichkeit auszeichnet ${ }^{90}$. Überhaupt leidet die Formel "Kunstfreiheit nach Art. 5 Abs. 3 GG = Kulturförderungspflicht = Förderung höherer Ästhetik"191 daran, daß Kunst im verfassungsrechtlichen Sinne und Ästhetik sich keinesfalls zwangsläufig bedingen. Vor allem wird Kunst nicht dadurch zur Kunst, daß sie bestimmten ästhetischen Maßstäben genügt ${ }^{92}$. Man mag die Spezifika künstlerischer Handlungsabläufe und die Vorstellung des jeweiligen Grundrechtsinhabers, künstlerisch tätig zu $\operatorname{sein}^{93}$ oder eine bestimmte Qualität eigenschöpferischer Formgebung ${ }^{94}$ als entscheidendes Merkmal von "Kunst" ansehen, auf jeden Fall ist es nicht das Merkmal der "Schönheit""s5.

Auch daraus, daß bei baugestalterischen Anforderungen vor allem die Eigentumsgarantie für die verfassungsrechtliche Zulässigkeit maßgeblich ist, führt nicht zur Zulässigkeit einer staatlichen Definition dessen, was "ästhetisch", "schön" oder "künstlerisch wertvoll" ist. Zwar ist die Anerkennung der sich autonom entfaltenden Sach- und Wesensgesetzlichkeit der Kunst, die etwa im Verbot des staatlichen Kunstrichtertums zum Ausdruck kommt, vor allem eine Anerkennung zum Schutz der Kunstfreiheit. Leitet man aber aus Art. 5 Abs. 3 GG eine Kulturstaatszielbestimmung und damit die Kulturgestaltungsmacht $a b$, dann erhält deshalb der Staat gegenüber anderen Grundrechten nicht die Befugnis, die ihm der Art. 5 Abs. 3 GG im Hinblick auf die Kunstfreiheit gerade verwehren will und die der Art. 5 Abs. 3 GG auch den Künstlern selbst nicht einräumt, nämlich Kunst zu betreiben zulasten von

${ }^{88}$ So Herber Krüger, S. 808; Steiner, VVDStRL 42 (1984), S. 29; Häberle, AöR 110 (1985), S. 611: "Der Verfassungsstaat schafft Kunst und Kultur nicht, er rezipiert oder fördert sie - er ist insofern nur "vernittelt produktiv»."

${ }^{89}$ Siehe etwa von Münch, Art. 5 Rn. 60.

${ }^{90}$ Hufen, Freiheit der Kunst, S. 180.

${ }^{91}$ Wie sie vor allem den Ausführungen von Seybold, S. 62 ff., zugrunde liegen.

92 Siehe Hufen, Freiheit der Kunst, S. 118.

${ }^{93}$ So Hufcn, Freiheit der Kunst, S. 118.

${ }^{94}$ So Badura, Staatsrecht, C 76, S. 134.

${ }^{95}$ Badura, Staatsrecht, C 76, S. 134. 
grundrechtlich geschützten Positionen Dritter ${ }^{96}$. Denn diese schränken auch das ohne Gesetzesvorbehalt gewährte Grundrecht aus Art. 5 Abs. 3 GG ein.

Art. 5 Abs. 3 GG, der weitergehende "bauästhetische" Anforderungen legitimieren soll, ist höchstens ein Argument gegen ein solches staatliches Tätigwerden. Gerade die Kunstfreiheitsgarantie fordert ein staatliches Identifikationsverbot ${ }^{97}$. Grundidee dafür ist es, daß nur ein sich nicht identifizierender Staat die Möglichkeit eröffne, daß Menschen trotz aller Verschiedenheiten in einem Staate zusammenleben können, ohne um ihre Eigenart fürchten zu müssen ${ }^{98}$. Der moderne Staat soll sich mit keiner "Besonderheit" identifizieren dürfen". Speziell für den Bereich des Art. 5 Abs. 3 GG komme es so zu einem Verbot einer vom Staat gesetzten verbindlichen materialen Kunstidee ${ }^{100}$. Ein Fall der "Identifizierung" wäre aber auch die verbindliche Konstituierung ästhetischer Maßstäbe durch baugestalterische Vorschriften. Damit mag insgesamt für den Bereich der Kunst- und Kulturförderung noch nicht viel gewonnen $\operatorname{sein}^{101}$. Trotzdem ist die Aussage, daß das Identifikationsverbot Eingriffe in den status negativus des Art. 5 Abs. 3 GG verhindert, eine anerkannte Erkenntnis. Gestattet man es nun dem Staat, gegenüber der Eigentumsgarantie verbindlich ästhetische Maßstäbe zu konstituieren, so mag man dies - soweit man das Identifikationsverbot überhaupt anerkennt - noch nicht für einen Anwendungsfall halten. Denn die Verschiedenheit von Menschen, deren Zusammenleben das Identifikationsverbot ermöglichen soll, kommt nicht unbedingt in dem Aussehen ihrer Häuser zum Ausdruck. Man wird aber nicht dem Staat unter Berufung auf Art. 5 Abs. 3 GG Befugnisse zuerkennen können, die ihm der Art. 5 Abs. 3 GG für seinen Bereich gerade verbietet.

Diese Überlegungen bestätigen somit letztlich das Ergebnis, welches auch anhand der Eigentumsgarantie entwickelt wurde. "Förderung der Ästhetik" ist kein Belang, der eine eigentumseinschränkende Regelung rechtfertigen

${ }^{96}$ Siehe BVerfG (VPA), Beschluß vom 19.03.1984, NJW 1984, S. 1293 (1294) ("Sprayer von Zürich"); Starck, Art. 5 Abs. 3 Rn. 213.

${ }^{97}$ So auch Watzke, Denkmalschutz- und Stadtplanungsrecht, S. 45.

${ }^{98}$ Herbert Krïger, S. 181.

99 Herbert Krïger, S. 181; Schlaich, Neutralität, S. 237; siehe auch Zippelius, Allgemeine Staatslehre, § 26 II S. 220. Inwieweit die Auffassung von Krïger differenziert gesehen werden muß, kann im vorliegenden Fall nicht erörtert werden. Siehe dazu vor allem Schlaich, S. 237 ff.

\footnotetext{
${ }^{100}$ Steiner, HdDStR, Band III, S. 1242 Rn. 9.

${ }^{101}$ So Jung, S. 69.
} 
kann, weil zumindest im Rahmen des status negativus der Staat nicht verbindlich entscheiden darf, was ästhetisch ist und was nicht.

\section{Der Maßstab für die Beurteilung einer Verunstaltung}
a) Zutreffendes an der Argumentation mit dem Topos
"gebildeter Durchschnittsbetrachter"

Das BVerwG hat vor allem in seiner Entscheidung zu § 1 BaugestVO den sog. gebildeten Durchschnittsbetrachter für die Beurteilung der Frage herangezogen, ob die von der BaugestVO aufgestellten Forderungen erfüllt sind. Seitdem drehen sich wissenschaftliche Erörterungen zum Thema Baugestaltung meistens schwerpunktmäßig um die Frage des Bestimmtheitsgrundsatzes $^{102}$. Auch das BVerwG hat nach dem Urteil zur BaugestVO immer wieder in der Bestimmtheitsfrage das eigentliche Problem von baugestalterischen Anforderungen gesehen und versucht, es mit der Figur des gebildeten Durchschnittsbetrachters zu lösen. Deutlich wird dies etwa in den Entscheidungen des BVerwG, in denen das Gericht Versuchen des OVG Münster entgegentritt, das "ästhetische Urteil" des Betrachters durch ein zugrunde liegendes "moralisches" Urteil zu erklären ${ }^{103}$. Wohl zu Recht erscheinen dem BVerwG Spekulationen darüber, welche moralische Einstellung ein Durchschnittsbetrachter zu einer bestimmten Werbeanlage hat, als nicht genügend sicher voraussehbar, oder besser ausgedrückt, als noch weniger voraussehbar als eine Entscheidung auf Grundlage der eigenen Formeln.

Die Heranziehung der Figur des "gebildeten Durchschnittsbetrachters" hat lebhafte Kritik erfahren, insbesondere in der Hinsicht, daß dann, wenn statt auf das Urteil des gebildeten Durchschnittsbetrachters auf das eines geschulten Betrachters abgestellt würde, nicht weniger sondern sogar mehr Bestimmtheit in der Rechtsanwendung $\mathrm{zu}$ erwarten sei $^{104}$. Jedoch dürfte auch dann, wenn man sich überhaupt auf eine solche Diskussion einlassen will, eher dem BVerwG Recht zu geben sein. Der Kreis der besonders emp-

\footnotetext{
Text. ${ }^{103}$ BVerwG, Urteil vom 27.01.1959, DÖV 1959, S. 792 ff.; Urteil vom 19.12.1963, E 17, 322 ff.

${ }^{104}$ Etwa von Kretschmer, DVBl. 1970, S. 56; Schweiger, DVBI. 1968, S. 488; Engelmann, S. $143 \mathrm{ff}$.
}

${ }^{102}$ Vergleiche die Monographien von Looks und Michel, sowie die weiteren Nachweise im 
findsamen und geschulten Betrachter ist noch weniger sicher eingrenzbar als der der gebildeten Durchschnittsbetrachter ${ }^{105}$. Angesichts des weitgehenden Fehlens anerkannter Maßstäbe für die Beurteilung dessen, was ästhetisch ist und was nicht, dürfte sich letztlich für jedes gewünschte Ergebnis ein "Sachverständiger" finden lassen.

Geht man jedoch davon aus, daß der Staat vor allem aus eigentumsrechtlichen Gründen gehindert ist, strengere ästhetische Maßstäbe anzulegen, als es das BVerwG in seiner Entscheidung zu $\S 1$ BaugestVO getan hat, dann ist jede Kritik am BVerwG mit dem Ziel der Erreichung eines "Mehr" an Förderung der Bauästhetik im Ergebnis unberechtigt. Die Rechtsprechung des BVerwG beschäftigt sich zwar primär mit dem Bestimmtheitsgrundsatz. Sie schöpft jedoch ihre eigentliche Berechtigung aus dem bereits dargestellten eigentumsrechtlichen Kern. Es ist nämlich vordergründig, im Bestimmtheitsgrundsatz das Kardinalproblem bauästhetischer Anforderungen schlechthin sehen zu wollen. Die Argumentation mit dem Bestimmtheitsgrundsatz mag im Fall der Entscheidung des BVerwG zur Frage der Verfassungsmäßigkeit des $\S 1$ BaugestVO angebracht gewesen sein. Insgesamt erschöpft sie die Problematik von gestalterischen Anforderungen an der Bauordnung unterliegende Anlagen nicht. Dem Bestimmtheitsgrundsatz kann der formelle Gesetzgeber gerecht werden. Er könnte etwa, statt eine Generalklausel zu verwenden, detailliert vorschreiben, wie z. B. ein Einfamilienwohnhaus zu gestalten wäre ${ }^{106}$. Der Bestimmtheitsgrundsatz untersagt es dem Gesetzgeber, in die Bauordnungen eine Bestimmung aufzunehmen wie "Wohnzwecken dienende Häuser sind schön anzustreichen". Er verbietet es dem Gesetzgeber nicht, unter Zugrundelegung einer bestimmten Farbskala ein oder zwei Farben vorzuschreiben. Hält man dies zu Recht trotzdem für unzulässig, dann braucht man hierfür einen anderen verfassungsrechtlichen Ansatzpunkt, und zwar die Eigentumsgarantie ${ }^{107}$.

Somit ist das Maß bauästhetischer Vorschriften, welches das BVerwG aufgrund des Bestimmtheitsgrundsatzes anhand der Entscheidung zu $\S 1$ BaugestVO für zulässig gehalten hat, und das, was aus eigentumsrechtlichen Gründen überhaupt zulässig ist, wenn auch eher zufällig, identisch. Denn die

\footnotetext{
${ }^{105}$ BVerwG, Urteil vom 28.06.1955, E 2, 172 (177).

${ }^{106}$ Vergleiche die Regelung des $\S 12$ Abs. 4 HBO (Dachgauben nur zur Hälfte der Länge der Gebäudeseite).

${ }^{107} \S 12$ Abs. 4 HBO dürfte sich im Rahmen des bisher anerkannten Verunstaltungsmaßstabes halten. Er enthält zudem in S. 2 eine Ausnahmemöglichkeit. Insgesamt ist von seiner Verfassungsmäßigkeit auszugehen.
} 
allgemein akzeptierten Maßstäbe, die das BVerwG durch die Figur des gebildeten Durchschnittsbetrachters und die verwendeten subjektiven Formeln zu bestimmen versucht, bilden auch den Rahmen, in dem der Grundeigentümer in seiner gestaltungsrechtlichen Freiheit beschränkt werden darf. Der gebildete Durchschnittsbetrachter ist nicht mehr als der Repräsentant einer hinreichend breiten Masse potentieller Betrachter, die durch den Anblick eines verunstaltet wirkenden Gebäudes in hinreichend qualifiziertem Maße betroffen, also "verletzt" werden, oder in denen "Unlust" erregt wird. Käme es zu solchen Wirkungen nur bei wenigen "geschulten" Betrachtern, würde dies für eine eigentumsbeschränkende Regelung nicht ausreichen.

b) Versuche einer Konkretisierung des "gebildeten Durchschnittsbetrachters"

Stimmt man dem Ausgangspunkt zu, daß letztlich die Eigentumsgarantie umgebungsunabhängige Anforderungen auf die Abwehr von Verunstaltungen im Sinne der Rechtsprechung des BVerwG beschränkt, ist die Diskussion darüber, ob nun der Kreis der geschulten und empfindsamen Betrachter genauer möglich ist als die Bestimmung des gebildeten Durchschnittsbetrachters, erledigt. Ein "Mehr" an umgebungsunabhängigen Anforderungen ist von Verfassungs wegen ohnehin ausgeschlossen. Es spricht aber viel dafür, den gebildeten Durchschnittsbetrachter trotzdem aus dem Recht der Baugestaltung zu verabschieden. Die Diskussionen um ihn bringen entweder keinen Gewinn oder wirken zum Teil sogar geradezu grotesk. Häufig wird etwa bei Erklärungs- und Konkretisierungsversuchen nur die eine Leerformel durch eine andere ersetzt, wenn etwa das Empfinden des gebildeten Durchschnittsbetrachters dann verletzt sein soll, wenn "individualistische Rücksichtslosigkeit triumphiert" ${ }^{\text {"108 }}$. Vor allem aber führt die fiktive Testfigur "gebildeter Durchschnittsbetrachter" zu der ständigen Versuchung, doch irgendwie konkreter zu bestimmen, wann denn "jemand" ein gebildeter Durchschnittsmensch ist und wann nicht, oder wie man sich denn einen solchen quasi mit Haut und Haaren vorzustellen habe. Harmlos wirkt dabei noch die Ansicht, der gebildete Durchschnittsmensch sei ein Mensch der Mitte und kein Repräsentant der Masse ${ }^{109}$, und er brauche auch nicht Einwohner der Gemeinde zu sein, in der sich die fragliche bauliche Anlage befindet ${ }^{110}$. Daß die Diskussion auf diese Weise in die falschen Bahnen gerät,

\footnotetext{
${ }^{108}$ Siehe Engelmann, S. 123 m. w. N.

${ }^{109}$ Engelmann, S. 128.

${ }^{110}$ Engelmann, S. 126.
} 
zeigt sich aber dann, wenn man etwa in der Begründung zu $\S 72$ Abs. 4 HBauO a. F. auf den Satz trifft, der "erfahrene und verständige Betrachter" sei deshalb zum Maßstab der Beurteilung gemacht worden, damit das Urteil nicht auf zufälligen Tagesgesichtspunkten, sondern auf verständiger länger geübter Betrachtung beruhen soll ${ }^{11}$. Unerklärlich bleibt, woher der hamburgische Gesetzgeber die Erkenntnis nimmt, daß ein gebildeter Durchschnittsbetrachter sein Urteil nach zufälligen Tagesgesichtspunkten fällt ${ }^{112}$. Weiterhin finden sich Feststellungen wie die, daß der gebildete Durchschnittsbetrachter sich nicht nur für die Form neuer Automobile, sondern auch für die Gestaltung von Bauwerken interessieren müsse und daß er einige der berühmtesten Baumeister seiner Umgebung kennen sollte ${ }^{113}$.

Solche Diskussionen verlassen irgendwann das Terrain ernsthaft betriebener Rechtsauslegung. Man kann durchaus davon sprechen, daß zum Teil versucht wird, sich in ein Geistermännchen hineinzuversetzen ${ }^{114}$. Der gebildete Durchschnittsbetrachter ist jedoch nur eine Denkhilfe, die deshalb für notwendig gehalten wurde, weil angesichts der vielfältigen Fallgestaltungen eine andere allgemeine Umschreibung von "Verunstaltung" nicht möglich erschien. Ist aber diese Denkhilfe weniger eine Hilfe als vielmehr ein Nährboden für Konflikte, ist es angebracht, nach einem anderen Weg zu suchen. Viel wäre schon dadurch gewonnen, daß man sich weniger an dem Problem der Bestimmtheit und mehr an der Eigentumsgarantie orientiert und deshalb den imaginären gebildeten Durchschnittsbetrachter durch die reellen potentiellen Betrachter ersetzt. Als Ertrag aus der Diskussion um die Figur des gebildeten Durchschnittsbetrachters kann dabei durchaus die Erkenntnis mitgenommen werden, daß es nur auf solche Betrachter ankommen kann, die ästhetischen Eindrücken gegenüber überhaupt aufgeschlossen sind $^{115}$. Auch über die Einhaltung der guten Sitten ( $\$ 138$ BGB) kann niemand entscheiden, der keine sittlichen Normen als verbindlich anerkennt. Verunstaltung wäre dann das, was von der überwiegenden Mehrzahl der potentiellen Betrachter, die offen sind für ästhetische Eindrücke, als das ästhetische Empfinden verletzend und damit als nicht mehr hinnehmbar an-

\footnotetext{
${ }^{111}$ Drs. der Hamburgischen Bürgerschaft vom 09.04.1968, Nr. 1258 S. 64.

112 Ähnlich auch Plate, S. 121, der davon ausgeht, daß insoweit nur das konkretisiert würde, was auf der Grundlage der Rechtsprechung des BVerwG ohnehin gilt.

${ }^{113}$ So die Überlegungen von Maier, BayVBI. 1980, S. 10.

${ }^{114}$ So Engelmann, S. 141.

${ }^{115} \mathrm{Vgl}$. BVerwGE 2, 177.
} 
gesehen wird. Dabei soll es sich nach wie vor um eine Rechtsfrage handeln, die nicht etwa durch Meinungsumfragen oder Sachverständige zu entscheiden wäre.

Somit ist eine inhaltliche Differenz zu den vom BVerwG vorgegebenen Maßstäben nicht gewollt. Es soll - was auch Ziel der Figur des gebildeten Durchschnittsbetrachters war $^{116}$ - eine zumindest einigermaßen nachprüfbare und rationale Entscheidung ermöglicht werden, die nicht auf die Meinung eines Amtswalters abstellt, bei der die Diskussion aber auch nicht ins Abstruse gerät. Die Definition hätte zudem den Vorteil, daß sie weniger den Blick für die eigentliche Wertung verstellt, die nur eine beschränkte Verunstaltungsabwehr zuläßt. Sie hätte mit der Formel vom gebildeten Durchschnittsbetrachter aber auch gemeinsam, daß sie nicht gerade durch Präzision besticht. Dies liegt aber wohl an der Natur der Sache.

\section{Relevanz der umgebungsunabhängigen gestaltungsrechtlichen} Generalklauseln für das Institut der örtlichen Bauvorschriften

Aus einer eigentumsrechtlichen Begründung der Beschränkung der umgebungsunabhängigen Maßstäbe auf die Verunstaltungsabwehr ergeben sich Konsequenzen für die Auslegung der baugestalterischen Anforderungen in den Generalklauseln der Landesbauordnungen. Auch wenn "einwandfreie Gestaltung" ${ }^{117}$ gefordert wird, kann nicht mehr verlangt werden als "Nichtverunstaltung"118. Vorschriften, bei denen aufgrund entgegenstehenden Willens der Landesgesetzgeber eine verfassungskonforme Auslegung nicht in Betracht kommt ${ }^{119}$, sind die betreffenden Vorschriften wegen Verstoßes gegen Art. 14 GG verfassungswidrig. Das nach dem erfolgten Wiederaufbau der deutschen Städte angeblich gestiegene ästhetische Empfinden ${ }^{120}$ steht dem nicht entgegen. Das Verunstaltungsverbot läßt Spielraum für eine strengere Handhabung. Es müßte allerdings der Nachweis geführt werden,

\footnotetext{
${ }^{116}$ Plate, S. 124; BVerwG, Urteil vom 19.12.1963, E 17, 322 (328).

${ }^{117}$ Nachweise oben C I 1 a.

${ }^{118}$ Dies nimmt auch das OVG Hamburg für die Vorschrift des $\$ 72 \mathrm{HBauO}$ a. F. an, siehe Urteil vom 22.12.1983, BRS Band 42, Nr. 134 S. 306 (307).

${ }^{119}$ Wie dies Kretschmer, DVBl. 1970, S. 55, für die damalige Rechtslage im Saarland annahm.

${ }^{120}$ So das OVG Berlin, Beschluß vom 13.01.1984, BauR 1984, S. 624; Simon, Art. 12 Rn. 36 S. 52.
} 
daß das ästhetische Durchschnittsempfinden auf einer "höheren" Ebene anzusiedeln wäre als bisher angenommen.

Die genaue Definition des umgebungsunabhängigen Maßstabes hat aber für die vorliegende Untersuchung keine entscheidende Bedeutung, und zwar aus zwei Gesichtspunkten heraus. Zum einen ist die praktische Relevanz der umgebungsunabhängigen Generalklauseln eingeschränkt. Dies ergibt unschwer eine Analyse der publizierten Rechtsprechung zur Verunstaltungsabwehr. Die ganz überwiegende Zahl der veröffentlichten Entscheidungen, die sich mit dem Problem der Verunstaltung im weiteren Sinne, also aus umgebungsunabhängiger und aus umgebungsabhängiger Sicht beschäftigen, legen vor allem den umgebungsabhängigen Maßstab zugrunde ${ }^{121}$. Wird tatsächlich einmal der umgebungsunabhängige Maßstab angesprochen, so leistet der Umgebungsmaßstab gute Dienste als weiteres und weniger angreifbares Argument ${ }^{122}$. Trifft man dann tatsächlich auf eine Entscheidung, die in ihrer Begründung alleine auf den umgebungsunabhängigen Maßstab abstellt, so wirkt sie sofort zweifelhaft. Als Beispiel hierfür mag ein Urteil des VGH Mannheim dienen ${ }^{123}$. Dort ging es um die einer Jugendstilfassade nicht entsprechende Vergrößerung von Dachgauben. Hier kam der VGH zu dem Ergebnis, daß eine Verunstaltung vorliege, da eine breite Fensterfront im Dachgeschoß dem Gesamtgebäude unangemessen und daher stilwidrig

${ }^{121}$ Vgl. aus der jüngeren Zeit: BVerwG, Beschluß vom 19.01.1978, BRS Band 33, Nr. 71 im Zusammenhang mit $\S 35$ BBauG; BayVGH, Urteil vom 30.07.1979, BRS Band 35, Nr. 135 S. $256 \mathrm{ff}$., zum Ersetzen von Sprossenfenstern durch Einscheibenfenstern in einer in bezug auf die Fassadengliederung anspruchsvollen Umgebung; BWVGH, Urteil vom 11.12.1984, BRS Band 44, Nr. 117 S. 284 f., zur Verunstaltung eines Baugebietes durch eine Anschlagtafel; Urteil vom 25.11.1982, BRS Band 39, Nr. 144 S. 311 ff., zur Verunstaltung des Straßenbildes durch Sichtschutzanlage; Urteil vom 26.06.1981, BRS Band 38, Nr. 107 S. 235 ff., zur Verunstaltung des Landschaftsbildes durch Maschendrahtzaun; OVG Berlin, Urteil vom 07.12.1984, BRS Band 42, Nr. 44 S. 113 ff., zur Störung eines Ortsbildes durch einen Antennengittermast; Urteil vom 03.07.1981, BRS Band 38, Nr. 71 S. 160 ff., zu Einfriedungen; Urteil vom 12.09.1980, BRS Band 36, Nr. 145 S. 311, zu einem Jägerzaun in einer Umgebung mit Bohleneinfriedungen; OVG Bremen, Urteil vom 26.08.1986, BRS Band 46, Nr. 119 S. 279 f., zur Verunstaltung anderer baulicher Anlagen durch eine Werbeanlage; HessVGH, Urteil vom 19.05.1978, BRS Band 33, Nr. 123 S. 245 ff., zur Beeinträchtigung eines historischen Marktplatzes durch ein Werbetransparent; OVG Lüneburg, Urteil vom 03.07.1987, BRS Band 47, Nr. 118 S. 312 f., zur Verunstaltung des Ortsbildes durch Flachgaragen; Urteil vom 29.03.1979, BRS Band 35, Nr. 131 S. 249 f., zu einem Flachdach in einer Reihe von Satteldächern; Urteil vom 25.01.1978, BRS Band 33, Nr. 53 S. 116 ff., zur Beeinträchtigung des Ortsbildes durch einen Treppenhausanbau; OVG Münster, Urteil vom 07.02.1979, BRS Band 35, Nr. 130 S. 248 f., ebenfalls zum Zusammentreffen von Flachdach mit Satteldächern; OVG Saarlouis, Beschluß vom 26.06.1985, BRS Band 44, Nr. 162 S. 391 ff., zur Störung des Straßenbildes durch Dachform.

${ }^{122}$ So etwa dem OVG Hamburg, Urteil vom 22.12.1983, BRS Band 42, Nr. 134 S. 306 ff.

${ }^{123}$ Urteil vom 31.10.1979, BRS Band 35, Nr. 134 S. 255 f. 
$\operatorname{sei}^{124}$. Die Bedenken gegen das Ergebnis des VGH ergeben sich aus der Überlegung, ob hier nicht das Verunstaltungsverbot der Auffüllung einer denkmalschutzrechtlichen Lücke diente. Denn wenn die Fassade nicht denkmalrechtlich geschützt war, dann wäre der Eigentümer - stellt man nur auf den umgebungsunabhängigen Maßstab ab - berechtigt gewesen, die ganze Fassade und nicht nur die Dachgauben zu ändern. Das Ergebnis wäre gewesen, daß statt nur im Bereich der Dachgauben insgesamt die Jugendstilfassade verschwunden wäre. Auch in diesem Fall wäre ein Abstellen etwa auf das Verbot der Verunstaltung des Straßenbildes, also auf einen umgebungsabhängigen Maßstab, überzeugender gewesen und hätte den hier vorgebrachten Einwand nicht zugelassen. $\mathrm{Da}$ die Möglichkeit hierzu bestand, deutet der VGH selbst an, indem er bei der Begründung, warum die Dachgauben eine optisch untergeordnete Rolle spielen müssen, auf die Nachbarhäuser verweist ${ }^{125}$.

Die umgebungsunabhängigen Maßstäbe haben zudem für das Institut der örtlichen Bauvorschriften keine unmittelbare Bedeutung. Beides hat nur insoweit etwas miteinander zu tun, als es um Baugestaltung geht und sich in den Argumentationsmustern gewisse Parallelen zeigen. Soweit aber etwa eine Fundierung örtlicher Bauvorschriften in der Generalklausel vom Gesetz vorgesehen ist oder allgemein für erforderlich gehalten wird ${ }^{126}$, kann sie in den umgebungsunabhängigen Anforderungen in den Generalklauseln nicht gefunden werden. Durch örtliche Bauvorschriften ist eine Konkretisierung des umgebungsunabhängigen Maßstabes nicht möglich. Dies ergibt sich vor allem daraus, daß es beim umgebungsunabhängigen Maßstab gerade nicht auf örtliche Besonderheiten ankommen kann. Es würde daher jeder einleuchtende Grund dafür fehlen, warum in der Gemeinde X ein andere Konkretisierung gelten sollte als in der Gemeinde Y. Die Unsicherheiten, die bei Auslegung und Anwendung des umgebungsunabhängigen Maßstabes vorhanden sind, können durch örtliche Bauvorschriften nicht behoben werden.

\footnotetext{
${ }^{124}$ BRS Band 35, S. 256.

${ }^{125}$ BRS Band 35, S. 255.

${ }^{126}$ Siehe etwa Watzke, Denkmalschutz- und Stadtplanungsrecht, S. 51; Plate, S. 164; Lerche, DB Beilage 6/69, S. 9; Friauf / Wendt, S. 33 und 37.
} 


\section{Formellgesetzliche umgebungsabhängige Anforderungen an die Baugestaltung und ihre Relevanz für den Bereich der örtlichen Bauvorschriften}

\section{Umgebungsabhängige Gestaltungsanforderungen und Eigentumsgarantie}

a) Umgebungsabhängige Forderungen und Bauästhetik

Die umgebungsunabhängigen Anforderungen in den Landesbauordnungen spielen - wie gesehen - für das Institut der örtlichen Bauvorschriften unmittelbar keine Rolle. Für die Klärung des Verhältnisses zwischen örtlichen Bauvorschriften und den allgemeinen gestaltungsrechtlichen Anforderungen der Bauordnungen ist daher das Hauptaugenmerk auf die umgebungsabhängigen Maßstäbe zu legen. Für die Auslegung der umgebungsabhängigen Maßstäbe in den Generalklauseln ergeben sich im Vergleich zu den umgebungsunabhängigen Anforderungen einige grundlegende Unterschiede. Dies gilt vor allem für den im vorhergehenden Abschnitt gewonnenen Befund, wonach die Förderung der Bauästhetik über das Mittel des Erlasses von eigentumsbeschränkenden Regelungen nur im Rahmen der Verunstaltungsabwehr möglich ist. Hieraus darf nicht der Schluß gezogen werden, da $\beta$ baugestalterische Anforderungen überhaupt von Verfassungs wegen ausgeschlossen sind, soweit sie über den engen, vom BVerwG in der Entscheidung zu § 1 BaugestVO gezogenen Rahmen hinausgehen. Vielmehr sind auch weitergehende Anforderungen durchaus möglich, soweit ein entsprechend gewichtiger öffentlicher Belang für eine Beschränkung der Eigentümerbefugnisse spricht. Solche Belange sind etwa Erfordernisse zum Schutz des Straßen-, Orts- und Landschaftsbildes.

Dieser Schutz von Orts-, Straßen- und Landschaftsbild ist die hauptsächliche historische Wurzel für die heutigen baugestalterischen Anforderun$\operatorname{gen}^{127}$. So waren vor allem Beeinträchtigungen des Rheintales durch Reklametafeln der Anlaß für den Erlaß des Preußischen Gesetzes gegen die Verunstaltung landschaftlich hervorragender Gegenden vom 2. Juni $1902^{128}$. Auch beim Gesetz vom 15. Juli $1907^{129}$ war Schutzgut das Orts- oder

\footnotetext{
${ }^{127}$ Siehe Lerche, Werbung und Verfassung, S. 132.

128 PrGS, S. 159.

${ }^{129}$ PrGS, S. 260.
} 
Straßenbild ${ }^{130}$ bzw. Aspekte des Denkmalschutzes ${ }^{131}$. Daß solche Belange auch Eigentumsbindungen über den Rahmen des Verunstaltungsschutzes hinaus rechtfertigen, wird auch in der Rechtsprechung des BVerwG deutlich. Das Gericht war einige Jahre nach dem Grundsatzurteil zu Baugestaltung und Bestimmtheitsgrundsatz mit der Frage befaßt, ob die einschränkende Auslegung auch aus eigentumsrechtlichen Gründen notwendig sei, und zwar im Zusammenhang mit einem in Hamburg erlassenen Werbeverbot an Brücken ${ }^{132}$. So findet sich im betreffenden Urteil zum hamburgischen Werbeverbot an Brücken die allgemeine Feststellung, daß auch die Verhinderung von bloßen Unschönheiten oder Störungen der architektonischen Harmonie ein legitimes öffentliches Anliegen sei, welches eine Eigentumsbindung rechtfertige ${ }^{133}$. Auf den ersten Blick könnte man sogar einen Gegensatz zu den hier getroffenen Aussagen über die eigentumsrechtliche $\mathrm{Zu}$ lässigkeit von umgebungsunabhängigen Anforderungen vermuten. Die Ausführungen des BVerwG sind aber im Zusammenhang damit zu lesen, $\mathrm{da} ß$ das Ziel des Brückenwerbungsgesetzes - wie das BVerwG auch selbst feststellt ${ }^{134}$ - darin bestand, unerwünschte Erscheinungen aus dem Straßenund Landschaftsbild fernzuhalten. Damit wird aber ein umgebungsabhängiger Maßstab angelegt. Das BVerwG verläßt also den eng gezogenen Kreis des Urteils zu $\S 1$ BaugestVO bei der Frage einer baugestalterischen Vorschrift aus Gründen des Umgebungsschutzes. Die Formel des BVerwG zum Problem der eigentumsrechtlichen Zulässigkeit von baugestalterischen Anforderungen lautet seitdem, es entspreche der ständigen Rechtsprechung des Gerichts, daß die Verhinderung der Beeinträchtigung des Charakters eines vorhandenen Baugebietes als beachtenswertes öffentliches Anliegen, das Eigentumsbindungen rechtfertigen könne, anzusehen $\operatorname{sei}^{135}$.

Bei den umgebungsunabhängigen Anforderungen war ausgeführt worden, daß das allgemeine Interesse "Förderung der Ästhetik" keine eigentumseinschränkende Regelung rechtfertigen könne. Immerhin war der Begriff "Ästhetik" noch insoweit relevant, als das verletzte ästhetische Empfinden der

\footnotetext{
${ }^{130}$ Siehe $\S 1$ und $\S 2$ Abs. 1 S. 1 des Gesetzes.

${ }^{131} \S 2$ Abs. 1 S. 2 des Gesetzes.

${ }^{132}$ BVerwG, Urteil vom 29.08.1961, DÖV 1962, S. 142 f.

${ }^{133}$ BVerwG (Fn 132), S. 143.

${ }^{134}$ BVerwG (Fn 132), S. 143.
}

${ }^{135}$ BVerwG, Urteil vom 22.02.1980, DÖV 1980, S. 521; Urteil vom 28.04.1972, E 40, 94 (99); Beschluß vom 29.12.1964, DVBI. 1965, S. 203. 
potentiellen Betrachter die Eigentumsbeschränkungen legitimierte. Im vorliegenden Zusammenhang der umgebungsabhängigen Anforderungen wird zwar auch von Eigentumsbeschränkungen aus ästhetischen Gründen gesprochen ${ }^{136}$. Gewonnen ist mit dieser Aussage jedoch nichts. Mit guten Gründen kann man auch die Auffassung vertreten, daß der Belang "Schutz von Straßen-, Orts- und Landschaftsbild" ästhetisch indifferent sei, da Harmonie im Sinne von Einfügen in die bestehende, vor allem bauliche Ordnung keinen ästhetischen Wert darstelle ${ }^{137}$. Dies ist etwa dahingehend formuliert worden, daß sowohl das "ästhetisch Werthafte" als auch das "Unwerthafte" wohlgeordnet sein könne ${ }^{138}$. Einfacher ausgedrückt: Auch ein "ruhiges Bild" ist nicht in jedem Fall "schön".

Letztlich ist damit eine Diskussion über die Frage, ob etwa der Schutz charakteristischer Arbeitersiedlungen im Ruhrgebiet durch örtliche Bauvorschriften ein ästhetisches Anliegen ist ${ }^{139}$ - unabhängig wie die Antwort lautet - ohne rechtliche Konsequenz. Wenn es etwa den Gemeinden beim Erlaß von entsprechenden Ortssatzungen um die Förderung von Ästhetik ginge, ließen sich die getroffenen Eigentumsbeschränkungen damit allein nicht rechtfertigen. Genau wie bei den umgebungsunabhängigen Anforderungen sind weder der Staat noch die Gemeinden definitionsbefugt. Die Gemeinden brauchen dies auch gar nicht zu sein, denn sie können häufig ein anderes legitimes öffentliches Interesse für die Beschränkung anführen wie etwa die Bewahrung historischer oder regionaler Identität, den Schutz des Orts- oder Straßenbildes etc. Dies reicht grundsätzlich für die Rechtfertigung von eigentumsbeschränkenden Regelungen aus. Ist jemand Eigentümer eines Wohnhauses in einer charakteristischen Arbeitersiedlung, so wird er nicht eigentlich in ästhetischen Fragen bevormundet, wenn ihm Vorschriften über die Gestaltung seines Hauses gemacht werden. Dadurch schwingen sich die Gemeinden nicht zum ästhetischen Vormund des Eigentümers auf. Es werden lediglich die Konsequenzen gezogen aus der spezifischen Belegenheit des Gebäudes in einem bestimmten Gebiet. Solche Regelungen werden nicht dadurch unzulässig, daß man ebenfalls wohl unwiderlegbar meinen kann, es handele sich letztlich doch um eine ästhetische Frage. Daraus, daß allein aus ästhetischen Gründen eigentumsbeschränkende Regelungen nicht

\footnotetext{
${ }^{136}$ So Lerche, Werbung und Verfassung, S. 132.

${ }^{137}$ Michel, S. 131.

${ }^{138}$ Michel, S. 135.

${ }^{139}$ Nachweise zu Versuchen in diese Richtung bei Friauf/Wendt, S. $11 \mathrm{ff}$.
} 
zulässig sind, folgt nicht, daß solche Beschränkungen auch aus Gründen unzulässig sind, die man mit vertretbarer Begründung als ästhetische Fragen ansehen kann.

Als Ergebnis bleibt somit festzuhalten: Das bei den umgebungsunabhängigen Gestaltungsanforderungen gefundene Ergebnis, wonach baugestalterische Anforderungen aus eigentumsrechtlichen Gründen nur zum Schutz eines allgemein akzeptierten ästhetischen Minimums möglich sind, gilt für den Bereich der umgebungsabhängigen Anforderungen nicht. Hier gibt es öffentliche Belange nicht notwendigerweise ästhetischer und nicht nur ästhetischer Art, die weitergehende Anforderungen rechtfertigen. Insofern ist es auch richtig, den Bereich von baugestalterischen und denkmalschützenden Vorschriften nicht als "Bauästhetisches Ortsrecht" zu bezeichnen ${ }^{140}$. Örtliche Bauvorschriften sind nicht primär ein Instrument zur Förderung der Bauästhetik ${ }^{141}$. Sie können dazu nur dadurch werden, daß man die eigentumsbeschränkende Regelungen rechtfertigenden Interessen zu untergeordneten ästhetischen Belangen macht und dadurch indirekt zu einer Förderung von Bauästhetik kommt. Ein solches Verfahren verstellt aber den Blick für die eigentlichen Gründe, die baugestalterische Einschränkungen der Eigentümerbefugnisse rechtfertigen.

b) Versuche der Absicherung ungebungsabhängiger Anforderungen an die Baugestaltung aufgrund verfassungsrechtlicher Determinierung

Eigentlich reicht die Feststellung, der Schutz des vorhandenen Straßen-, Orts- und Landschaftsbildes sei ein legitimes öffentliches Interesse, aus, um zumindest grundsätzlich eigentumsbeschränkende Regelungen zu rechtfertigen. Auch im Rahmen der Einschränkung der Eigentümerbefugnisse gilt, daß es keinen allgemeinen Verfassungsvorbehalt für staatliche Aufgaben gibt $^{142}$. Trotzdem soll an dieser Stelle auf Versuche eingegangen werden, bestimmte Anforderungen an die Stadtgestalt verfassungsrechtlich "positiv" abzusichern. Ihnen liegt insgesamt ein Verständnis von Stadtgestaltung als "bewußte Arbeit an der psychischen Qualität unserer Städte" zugrunde ${ }^{143}$.

${ }^{140}$ So aber der Titel der Monographie von Seybold. Siehe dazu oben A I 2 a aa.

${ }^{141}$ Anders Seybold, S. 17, der davon ausgeht, daß die im Rahmen von örtlichen Bauvorschriften möglichen Gestaltungen "meist bauästhetisch wertvoll" seien.

142 Steiner, VVDStRL 42 (1984), S. 17; so auch Böhmer im Sondervotum BVerfGE 56, 266 (277): Der Kreis der dem Staat obliegenden Aufgaben ist in den Grenzen der Verfassung offen.

${ }^{143}$ Trieb, Stadtgestaltung, S. 15. 
Ergeben sich aus den darzustellenden Auffassungen, die hierauf aufbauen, objektive oder gar subjektive Grundrechtsverbürgungen für eine ansprechende Stadtgestalt, so ist dies in zweifacher Hinsicht von erheblicher Bedeutung. Zum einen wären dann die Gründe, die für eigentumsbeschränkende Regelungen sprechen, von erheblich höherem Gewicht, als wenn der Gesetzgeber sich nur auf einen von ihm definierten öffentlichen Belang berufen könnte. Stadtgestaltung erfolgt zwar nicht nur, aber auch durch örtliche Bauvorschriften ${ }^{144}$. Solche Vorschriften ließen sich vor allem angesichts des primär über eine zulässige Eigentumsbindung entscheidenden Übermaßverbotes umso eher rechtfertigen, je mehr von einer grundrechtlichen Determinierung auszugehen wäre. Weiterhin wäre der formelle oder auch der Ortsgesetzgeber nicht nur berechtigt, sondern unter Umständen sogar verpflichtet, für entsprechend weitgehende Einschränkungen der Eigentümerbefugnisse zu sorgen ${ }^{145}$.

Ein besonders weitgehender Versuch, zu einer grundrechtlichen Absicherung umgebungsabhängiger Anforderungen an bauliche Anlagen zu kommen, besteht darin, aus Art. 1 und Art. 2 Abs. 1 GG ein "Grundrecht auf Stadtgestaltung" zu entnehmen ${ }^{146}$, und zwar wohl im Sinne einer subjektiven Rechtsposition. Ausgangspunkt dieser Überlegungen ist es, daß die jeweilige Stadtgestalt Auswirkungen auf die Psyche des Menschen, seine Kommunikationsfähigkeit, sein körperliches Wohlbefinden, letztlich auf seine gesamte kulturelle, soziale und wirtschaftliche Existenz hat ${ }^{147}$. Durch eine negative Stadtgestalt werde ihm ein "Teil seiner Selbstbestimmung" genommen, er gerate in eine "Objektsituation"148. Kombiniert man dies mit einem Grundrechtsverständnis, das die Grundrechte als sozialstaatliche Teilhaberechte versteht ${ }^{149}$, so scheint der Weg zur Annahme eines subjektiv-öffentlichen Rechts auf Stadtgestaltung geebnet ${ }^{150}$.

\footnotetext{
${ }^{144}$ Trieb, Stadtgestaltung, S. 102.

145 So etwa Namgalies, S. 229, der über die Verunstaltungsabwehr hinausgehende Anforderungen grundrechtlich für geboten hält.

${ }^{146}$ So Namgalies, Das Grundrecht auf Stadtgestaltung. Dem folgend Mehlhorn, Stadterhaltung, S. 9.

147 Schulze-Fielitz, Sozialplanung, S. 184; Namgalies, S. 232, Schlußthese Nr. 3; Trieb, in: Neues Städtebaurecht, S. 150, ders., Stadtgestaltung, S. 19 ff.

${ }^{148}$ Namgalies, S. 147 und 153.

149 Siehe Schulze-Fielitz, Sozialplanung, S. 56 mit ausführlichen Nachweisen.

${ }^{150}$ Vgl. Namgalies, S. 232, These Nr. 3.
} 
Ohne daß an dieser Stelle eine ausführliche Auseinandersetzung mit dem Grundrechtsverständnis im Sinne sozialer Teilhaberechte möglich ist ${ }^{151}$, zeigt dieses Beispiel, wie leicht man durch ein solches Verständnis in die Nähe eines nicht einmal durch präzise Forderungen umschreibbares Wunschdenken gerät. So ist es vorstellbar, wie ein Anspruch des Bürgers gegen den Staat etwa auf Zuweisung eines Studienplatzes aussehen könnte ${ }^{152}$. Bei einem Anspruch auf "Stadtgestaltung" gilt dies jedoch nicht. Die "Stadtgestalt" kann nicht einem Bürger als subjektives Recht zugeordnet werden, auch nicht als Teilhaberecht. Der angestellte Vergleich mit einem "Grundrecht auf Umweltschutz"153 stützt eine solche Annahme nicht. Zwar gibt es nach der Verfassungsordnung des Grundgesetzes Schutzpflichten zugunsten grundrechtlich geschützter Individualgüter. Es gibt jedoch kein "Grundrecht auf Umweltschutz" ${ }^{\text {"154 }}$. Selbst wenn man aber den Vergleich mit einem "Grundrecht auf Umweltschutz" ziehen wollte, ließe sich dies nicht als Beleg für die Annahme eines "Grundrechts auf Stadtgestaltung" heranziehen. Denn beim Umweltschutz besteht wenigstens eine eingeschränkte Gleichgerichtetheit der Interessen. So kommt der Schutz der natürlichen Lebensgrundlagen der körperlichen Integrität eines jeden Bürgers irgendwie zugute. Hingegen gibt es ein solches zumindest eingeschränkt gleichgerichtetes Interesse in bezug auf die Stadtgestaltung nicht. So mag ein Bürger an dem Café XY in seinem Heimatort hängen, weil er dort sein erstes Rendezvous hatte ${ }^{155}$. Ein anderer hingegen wünscht wegen entsprechend negativer Erinnerungen den baldigen Abriß des Gebäudes. Ansprüche an die Stadtgestalt sind beliebig und häufig entgegengesetzt. Ein "Grundrecht auf Stadtgestaltung" scheitert somit - abgesehen von allen anderen Bedenken gegen das Verständnis von Grundrechten als Leistungsrechten - vor allem daran, daß ein individualisierbarer Inhalt praktisch nicht denkbar ist.

Eine subjektiv-rechtliche Verbürgung einer bestimmten Stadtgestalt gibt es somit nicht. Aber auch objektiv-rechtlich, etwa aufgrund einer "Konkordanz von Grundrechten und Staatszielbestimmungen", wobei insbesondere

${ }^{151}$ Siehe etwa aus neuerer Zeit die kurze Kritik von Karpen, NJW 1988, S. 2518; weiterhin Stern, Staatsrecht, Band III/1, §67, vor allem S. 694 ff.

152 Vgl. die "numerus-clausus"-Entscheidung des BVerfG, Urteil vom 18.07.1972, E 33, 313 (331 f.)

\footnotetext{
${ }^{153}$ So Namgalies, S. 168.

154 Ausführlich dazu Soell, NuR 1985, S. 206 ff.

${ }^{155}$ Beispiel von Schulze-Fielitz, Sozialplanung, S. 184.
} 
das Sozialstaatsprinzip angesprochen $\operatorname{se}^{156}$, besteht keine Pflicht des Staates zu Eingriffen in das Eigentum in Form von baugestalterischen oder denkmalschützenden Vorschriften. Im Bereich des Denkmalschutzes durch Stadterhaltungssatzungen wird zwar eine solche Verpflichtung angenommen ${ }^{157}$. Unabhängig von der Frage, ob dieser Auffassung für den Bereich der Stadterhaltungssatzungen zuzustimmen ist, kommt eine Übertragung auf den Bereich der Baugestaltung nicht in Betracht. Zumindest sprechen die sozialwissenschaftlichen Forschungsergebnisse, die eine verfassungsrechtliche Pflicht zur Erhaltung alter Städte begründen sollen, eher gegen als für die Normierung vor allem von baugestalterischen Anforderungen. So soll etwa ein "erlebnisreiches Stadtbild" die Auseinandersetzung des Betrachters "herausfordern", den "Wahrnehmungsproze $B$ verlängern" und damit die intellektuelle Neugier des Betrachters befriedigen ${ }^{158}$. Baugestalterische und denkmalschützende Vorschriften mögen nun zum Teil durchaus ein "erlebnisreiches Stadtbild" erhalten, indem etwa in Altstadtbereichen durch die baugestalterische Generalklausel oder durch eine örtliche Bauvorschrift einheitliche und eintönige Fassaden, z. B. von gewerblichen Unternehmen, unterbunden werden. In der Regel wirken aber gestalterische Anforderungen sowohl in formellgesetzlichen Generalklauseln als auch in örtlichen Bauvorschriften eher optisch nivellierend. Teilweise führen sich die örtlichen Bauvorschriften einiger Gemeinden so selbst ad absurdum, indem für den Erlaß der Satzung als maßgeblicher Grund herausgestellt wird, daß das abwechselungsreiche Straßenbild erhalten werden soll und dann haarklein eine bestimmte einheitliche Gestaltung vorgeschrieben wird ${ }^{199}$. So sehen es Stadtplaner durchaus als ihre Aufgabe an, über den Erlaß von baugestalterischen Vorschriften die Grundstückseigentümer in einem "krampfhaften Drang nach Originalität" zu bremsen ${ }^{160}$. Das so definierte Planungsziel geht weniger in Richtung auf Erlebnisreichtum, sondern eher zur optischen Einpassung. Abwechselung soll "innerhalb einer gegebenen Bandbreite" erreicht werden ${ }^{161}$.

\footnotetext{
${ }^{156}$ Henke, S. 78.

${ }^{157}$ Henke, S. 79.

${ }^{158}$ So Henke, S. 71; Namgalies, S. 37.
}

${ }^{159}$ Siehe das bei Hoek, S. 52, erwähnte Beispiel der Satzung über die Gestaltung der Altstadt von Lüneburg vom 18.07.1980.

${ }^{160}$ Siehe etwa Heinz, S. 13.

${ }^{161}$ Trieb, Stadtgestaltung, S. 176. 
Insgesamt dürfte sich daher eine verfassungsrechtliche Determinierung eines bestimmten Maßes an baugestalterischen Anforderungen nicht ergeben. Aufgrund des Sozialstaatsprinzips sind sowohl der Staat als auch die Kommunen gehalten, für eine auch baulich menschengerechte Umwelt zu sorgen. Dafür sind sozialwissenschaftliche Forschungsergebnisse möglicherweise eine Hilfestellung. Eine gesicherte Verdichtung solcher Ergebnisse dahingehend, daß eine verfassungsrechtliche Pflicht anzunehmen ist, im Bereich von baugestalterischen Generalklauseln oder von örtlichen Bauvorschriften das eine tun oder das andere lassen zu müssen, ist aber wohl noch nicht ersichtlich.

\section{Die Reichweite der umgebungsabhängigen Anforderungen an die Baugestaltung}

a) Schutz des bestehenden Straßen-, Orts- und Landschaftsbildes

aa) Die Regelungen in den Landesbauordnungen

In bezug auf den Umgebungsschutz konstituieren die meisten Landesbauordnungen in den Generalklauseln ein Verunstaltungsverbot ${ }^{162}$. Nur die BauO Bln entspricht heute noch dem Vorschlag der MBauO 1960, wonach das Straßen-, Orts- und Landschaftsbild nicht gestört werden dürfe ${ }^{163}$. Die Musterbauordnung selbst verfolgte mit dem Vorschlag der Formulierung "nicht stören" durchaus die Absicht, zu den höheren und vom BVerwG mit Berufung auf den Bestimmtheitsgrundsatz heruntergeschraubten Anforderungen der BaugestVO zurückzukehren ${ }^{164}$. Gleichwohl werden heute die Unterschiede in den Formulierungen in den Landesbauordnungen als solche rein terminologischer Art angesehen. Ein sachlicher Unterschied sei nicht gewollt ${ }^{165}$. Diese Auffassung läßt sich durchaus begründen. Vermutlich war auch hier das Urteil des BVerwG zu § 1 BaugestVO mit seiner verfassungsrechtlich begründeten restriktiven Interpretation richtungsweisend ${ }^{166}$. 1

\footnotetext{
${ }^{162}$ Siehe die Nachweise oben C I 1 a.

${ }^{163} \S \S 3$ Abs. 1 S. 2 und 14 MBauO 1960; siehe § 3 Abs. 1 S. 2 2. HS BauO Bln.

${ }^{164}$ Vollmer, ArchivPF 1980, S. 101.

${ }^{165}$ Für die BauO Bln siehe OVG Berlin, Urteil vom 11.02.1966, BRS Band 17, S. 171 (172). Allgemein Watzke, Baupolizei, S. 42; Plate, S. 117.

${ }^{166}$ BVerwG, Urteil vom 28.06.1955, E 2, $172 \mathrm{ff}$.
} 
BaugestVO enthielt die Forderung, daß sich eine bauliche Anlage in die Umgebung einwandfrei einfügen müsse. Diese Bestimmung wurde vom BVerwG dahingehend ausgelegt, daß die bauliche Anlage "das Gesamtbild der Umgebung nicht stören, der Gegensatz zwischen ihr und der Umgebung von dem Betrachter nicht als belastend oder Unlust erregend empfunden werden dürfe ${ }^{167}$. Da eine Gesetzesbestimmung, die den subjektiven Schlußteil des Satzes übernommen hätte, wohl unüblich gewesen wäre, blieben für die Gesetzesformulierung noch zwei Möglichkeiten. Entweder man verwendete den ebenfalls vom BVerwG verwendeten objektiven Ausdruck "nicht stören", oder man unternahm einen Rückgriff auf den Begriff "Verunstaltung", der vom BVerwG jedoch nur für den umgebungsunabhängigen Maßstab verwendet wurde. Somit läßt sich durchaus davon ausgehen, daß ein sachlicher Unterschied nicht gewollt war.

Auch bei den Rücksichtnahmeklauseln ${ }^{168}$ gilt nichts anderes. Es handelt sich lediglich um eine Erläuterung zu den allgemeinen umgebungsabhängigen Anforderungen. Die Forderung nach Rücksichtnahme bringt nur zum Ausdruck, was auch ohne ausdrückliche gesetzliche Normierung, wie etwa in Bayern, gilt: Eine Störung oder Verunstaltung der Umgebung ist umso eher anzunehmen, je schutzwürdiger die Umgebung ist. Eine eigenständige Bedeutung kommt diesen Bestimmungen daher nicht $\mathrm{zu}^{169}$.

bb) Unterschiede und Gemeinsamkeiten bei der Auslegung im Vergleich zum umgebungsunabliängigen Maßstab

Die Übernahme des Verunstaltungsmaßstabes aus dem Bereich der umgebungsunabhängigen in den der umgebungsabhängigen Anforderungen ist jedoch nicht unproblematisch. So sind die Schutzgüter von umgebungsabhängigen und umgebungsunabhängigen Anforderungen - wie ausgeführt nicht identisch. Während es bei den umgebungsunabhängigen Maßstäben wenn auch in stark subjektivierter Weise - um den Schutz von "Ästhetik" geht, ist dies bei den umgebungsabhängigen Anforderungen nicht der Fall.

${ }^{167}$ BVerwE 2, 177.

${ }^{168}$ Nachweise oben CI 1 a, Fn. 12.

${ }^{169}$ Bork / Köster, Erl. § 13 BauO NW Rn. 8; Schlotterbeck, in: Schlotterbeck / von Arnim, $\S 13$ Rn. 14; Watzke, Denkmalschutz- und Stadtplanungsrecht, S. 48; siehe auch HessVGH, Urteil vom 19.05.1978, BRS Band 33, Nr. 123 S. 248: Das Rücksichtnahmegebot betone den gestalterischen Widerspruch zwischen dem vorhandenen und der neu hinzutretenden Anlage. 
Bei ihnen verhindert ein von ästhetischen Vorstellungen geprägtes Verständnis eine sachgerechte Befassung.

Dieser Unterschied wird zumindest ansatzweise auch vom BVerwG selbst berücksichtigt, indem bei der Frage, wann ein einwandfreies Einfügen in die Umgebung nach § 1 BaugestVO vorliegt, gerade anders als bei der "anständigen Baugesinnung" nicht auf das ästhetische Empfinden abgestellt wird, sondern eine deutlich abweichende Formulierung verwendet wird, daß nämlich "der Gegensatz zwischen baulicher Anlage und Umgebung nicht als belastend oder Unlust erregend" empfunden werden dürfe ${ }^{170}$. Diese sehr berechtigte unterschiedliche Terminologie scheint das BVerwG aber sofort dadurch wieder zurückzunehmen, daß zur Beurteilung der definierten Merkmale auf das Empfinden eines für ästhetische Eindrücke offenen Betrachters abgestellt wird ${ }^{171}$. Dies kann jedoch eigentlich nicht für alle Merkmale des $\S 1$ BaugestVO auch so gemeint gewesen sein. Denn dann würde der gebildete Durchschnittsbetrachter auch nach seinem ästhetischen Empfinden darüber zu entscheiden haben, ob eine Anlage "werkgerecht durchgebildet" ist. Werkgerechte Durchbildung bedeutet aber nach Auffassung des BVerwG, daß die allgemeinen handwerklichen Regeln eingehalten worden $\operatorname{sind}^{172}$. Eine solche Frage kann jedoch sinnvollerweise nur von einem Sachverständigen beurteilt werden ${ }^{173}$.

Eine gewisse parallele Argumentation zu den umgebungsunabhängigen Anforderungen ist gleichwohl angebracht. Die umgebungsabhängigen Maßstäbe betreffen allerdings nicht eigentlich das "ästhetische Minimum", sondern ein Minimum dessen, was angesichts einer schutzwürdigen Umgebung an Einschränkung der baugestalterischen Freiheit von der überwiegenden Anzahl der Betrachter verlangt wird, also eine Beeinträchtigung des Harmonieempfindens. Obwohl beim Schutz etwa des Ortsbildes die rechtfertigende Wirkung eigentumsbeschränkender Maßnahmen nicht notwendig in der Wirkung auf die Betrachter besteht, ist trotzdem ein Maßstab heranzuziehen, der auf allgemein akzeptierte Anschauungen abhebt. Dies ergibt sich nicht aus dem Schutzgut, sondern daraus, daß eine gewisse Denkhilfe benötigt wird, um die umgebungsunabhängigen Anforderungen justiziabel zu machen. Es läßt sich ansonsten ohne rechtssatzmäßige Normierung in örtli-

\footnotetext{
${ }^{170}$ BVerwGE 2, 177.

${ }^{171}$ BVerwGE 2, 177.

${ }^{172}$ BVerwGE 2, 177. Anders wohl nur Michel, S. 128; hiergegen zutreffend Plate, S. 115.

${ }^{173}$ So zutreffend Maier, BayVB1. 1980, S. 7; Engelmann, S. 51.
} 
chen Bauvorschriften angesichts der Vielzahl der möglichen Fallgestaltungen kaum ein Maßstab entwickeln, nach dem das $\mathrm{Maß}$ der Zulässigkeit von baugestalterischen Abweichungen beurteilt werden könnte. Das Verbot der Verunstaltung der Umgebung ist daher so auszulegen, daß damit eine Unterschreitung dessen untersagt wird, was nach allgemein akzeptierten Maßstäben von den insoweit aufgeschlossenen Betrachtern als Rücksicht auf die Umgebung verlangt wird.

\section{cc) Konkretisienungsmöglichkeiten durch örtliche Bauvorschriften}

Unabhängig davon, ob man die hier bevorzugte Formel der Garantie des harmonischen Minimums, oder die Formeln des BVerwG über "Unlust erregen" und "als Belastung empfinden" bevorzugt und hierfür den gebildeten Durchschnittsbetrachter heranzieht ${ }^{174}$, stellt sich auch auf dieser relativ niedrigen Ebene das Problem der rechtsstaatlichen Bestimmtheit. Zwar nähert man sich dem Bestimmtheitsgrundsatz überhaupt nur dadurch, daß man die Anforderungen möglichst weit herunterschraubt. Aber auch dann lassen sich die auftauchenden Probleme nicht immer sicher lösen. Akzeptierte Auffassungen sind ähnlich schwer zu finden wie bei umgebungsunabhängigen Fra$\operatorname{gen}^{175}$. Bei den Umgebungsmaßstäben gibt es zwar durch die vorgegebene Umgebung einen gewissen objektiven Anhaltspunkt. Angesichts der nicht überschaubaren Fülle unterschiedlicher Sachverhaltsgestaltungen fehlen aber objektive Kriterien dafür, wann ein Abweichen noch hinnehmbar ist und wann nicht. Man ist deshalb auf die angeführten Umschreibungen angewiesen, die jedoch notwendigerweise in weiten Bereichen unscharf sind.

Daher bleibt auch den Gerichten bei der Entscheidung von Zweifelsfragen nichts anderes übrig, als eine Ortsbesichtigung durchzuführen, zu beschreiben, inwieweit ein Widerspruch zwischen der baulichen Anlage und der Umgebung besteht und sich dann für oder gegen die Annahme einer Verunstaltung zu entscheiden, ohne daß dies noch intersubjektiv erklärbar ist. So finden sich dann in Begründungen zu Entscheidungen von Oberverwaltungsgerichten typischerweise folgende Ausführungen:

(1) Auch ein aufgeschlossener Betrachter empfinde eine Flachdachgarage in einer Umgebung, wo sich sonst nur Satteldächer befinden, als unschön,

${ }^{174}$ Siehe BVerwGE 2, 177.

${ }^{175} \mathrm{Vgl}$. dazu z. B. die bei Rave, S. 41 ff., beschriebene Kontroverse über den Schutz der "Onkel-Tom-Siedlung" in Berlin. 
aber nicht als häßlich ${ }^{176}$. Wenn das OVG zur entgegengesetzten Aussage gekommen wäre, hätte das auch niemand widerlegen können.

(2) Asymmetrische Baukörper könnten als verunstaltend nur dann angesehen werden, wenn das Ungleichmäßige nicht nur stört, sondern verletzt. Dies sei im gegebenen Fall nicht zu erwarten ${ }^{177}$.

Diese Beispiele ließen sich fortsetzen. Letztlich läuft jede Entscheidung entweder auf eine Behauptung hinaus, die vielleicht umschrieben und erläutert, aber nicht wirklich begründet werden kann, oder die Gerichte werden gezwungen, ihren Entscheidungen allgemeine Grundsätze zugrunde zu legen, die angesichts der Vielzahl von möglichen Fällen in regional sehr unterschiedlichen Gebieten immer Zweifel an ihrer Gültigkeit aufkommen lassen. Eine solche Rechtslage ist rechtsstaatlich unbefriedigend. Auch wenn man den Umgebungsschutz auf ein Minimum herabsetzt, haben viele Entscheidungen zu diesem Komplex zumindest einen Hauch von Willkür. Im Bereich der Konkretisierung umgebungsabhängiger Anforderungen an die Baugestaltung besteht somit ein möglicher und rechtsstaatlich sinnvoller Anwendungsbereich für den Erlaß von örtlichen Bauvorschriften ${ }^{178}$. Da umgebungsabhängige Anforderungen schon begriffsmäßig von örtlichen Besonderheiten abhängen, ist eine Einschaltung der Gemeinden durch die Einräumung der Rechtssetzungsbefugnis sinnvoll.

Eine andere Frage ist jedoch die, ob der Einsatz örtlicher Bauvorschriften zur Konkretisierung der in den Generalklauseln enthaltenen Anforderungen mit den Formulierungen der Ermächtigungen zum Satzungserlaß vereinbar ist. Bedenken werden daraus hergeleitet, daß die Landesbauordnungen für den Erlaß von denkmalschützenden Vorschriften und teilweise auch für baugestalterische Vorschriften ${ }^{179}$ das Stellen von "besonderen Anforderungen" verlangen ${ }^{180}$. Zwingend ist dieser Einwand aber nicht. Als "besondere Anforderungen" können auch solche Bestimmungen angesehen werden, die zwar inhaltlich nicht über den von den Generalklauseln vorgegebenen Rahmen hinausgehen, sich aber ausdrücklich aus ihnen nicht ergeben, sondern

${ }^{176}$ OVG Lüneburg, Urteil vom 03.07.1987, BRS Band 47, Nr. 118 S. 312 (313).

${ }^{177}$ OVG Lüneburg, Urteil vom 28.02.1977, BRS Band 32, Nr. 114 S. 212 (213).

${ }^{178}$ Anders wohl das OVG Lüneburg, Urteil vom 12.02.1982, BRS Band 33, Nr. 12 S. 280 (281), sowie Seybold, S. 16, die davon ausgehen, nur der Bereich der "positiven Gestaltungspflege" eröffne insoweit einen sinnvollen Anwendungsbereich.

${ }^{179}$ Vgl. z. B. Art. 91 Abs. 1 Nr. 1 Nr. 2 BayBO; $\$ 73$ Abs. 1 Nr. 2 LBO BW.

${ }^{180}$ So Büge / Zinkahn, S. 34: Es sollen keine Anforderungen gestellt werden, die bereits allgemein gültig sind. 
nur belastet mit der allgemeinen Unsicherheit, die mit der Anwendung dieser Bestimmungen verbunden ist. Für dieses Ergebnis spricht, daß etwa $\S 56$ NBauO "besondere Anforderungen" verlangt, jedoch mit der ausdrücklichen Feststellung, da $B$ auch Anforderungen möglich sind, die inhaltlich über die Generalklauseln hinausgehen. Damit gibt sie jedoch gleichzeitig zu erkennen, daß auch "nur" Anforderungen zur Konkretisierung der allgemeinen Maßstäbe möglich sind.

b) Der Schutz der beabsichtigten Gestaltung des Straßen-, Orts- und Landschaftsbildes

aa) Die formulienıngsmäßigen Differenzen

Neben dem bereits bestehenden Straßen-, Orts- und Landschaftsbild verlangen die gestaltungsrechtlichen Generalklauseln auch eine Berücksichtigung der beabsichtigten Gestaltung ${ }^{181}$. Dieser Teil der gestaltungsrechtlichen Generalklauseln in den Landesbauordnungen führt zu einer Reihe recht diffiziler Probleme. Zunächst schwankt die Terminologie zwischen "nicht verunstalten", "nicht beeinträchtigen" und "nicht stören"182. Auch hier besteht jedoch kein sachlicher Unterschied ${ }^{123}$. Der Schutz, der so dem beabsichtigten Straßen-, Orts- und Landschaftsbild zukommen kann, ist nicht weitergehend als derjenige für das bestehende. Daher gelten grundsätzlich die Kriterien, die auch dort für die Frage entscheidend sind, ob eine Verunstaltung vorliegt ${ }^{184}$. Die Gegenauffassung ${ }^{185}$ folgert zu Unrecht aus dem teilweise unterschiedlichen Wortlaut auf eine inhaltliche Differenz. Die Formulierung, die etwa die BayBO in Art. 12 Abs. 2 verwendet, daß nämlich die beabsichtigte Gestaltung nicht verunstaltet werden darf, ist zwar insofern zutreffend, als da $\beta$ aus dem Bestimmtheitsgrundsatz folgt, daß nur das "harmonische Minimum" geschützt werden darf. Sie ist aber auch problematisch. Von einer Beeinträchtigung des harmonischen Empfindens kann kaum gesprochen werden, wenn eine Harmonie noch nicht besteht, sondern erst geschaffen werden soll. Insofern ist die Abweichung in den Formulie-

\footnotetext{
${ }^{181}$ Nachweise dazu siehe oben CI 1 a, Fn. 11.

${ }^{182}$ Nachweise siehe oben C I 1 a.

${ }^{183}$ Zum Schutz des bestehenden Straßen-, Orts- und Landschaftsbildes, siehe oben C III 2 a aa.

${ }^{184}$ So zutreffend Bork / Köster, BauO NW Erl. § 12 Rn. 6; Gädike / Böckenförde / Temme, $\S 12$ Rn. 17; HessVGH, Urteil vom 23.01.1981, BRS Band 38, Nr. 146 S. 333.

${ }^{185}$ Stich / Gabelmann, 2.3. § 5 Rn. 4.
} 
rungen der anderen Landesbauordnungen, wenn sie wie etwa $\S 13$ Abs. 2 S. 1 LBO BW von "nicht beeinträchtigen" oder wie $\S 12$ Abs. 2 S. $1 \mathrm{HBauO}$ von "nicht stören" sprechen, berechtigt und auch erklärlich.

Allerdings hat der hessische Gesetzgeber mit der Wahl der Formulierung "nicht beeinträchtigen" in $\S 14$ Abs. 2 S. $1 \mathrm{HBO}$ anstelle von "nicht verunstalten" die Absicht verfolgt, nicht mehr auf die Verletzung des Empfindens eines gebildeten Durchschnittsbetrachters abzustellen, sondern bereits die Störung des Empfindens eines solchen Betrachters ausreichen zu lassen ${ }^{186}$. Ziel dieser Bestimmung ist es jedoch nicht, allein durch die Generalklausel zu verschärften Anforderungen zu kommen. Es sollte vielmehr Rücksicht genommen werden auf "positive Gestaltungsregeln" in örtlichen Bauvorschriften ${ }^{187}$.

\section{bb) Das Problem der rechtssatzmäßigen Konkretisienung}

Die Begründung im Gesetzentwurf zur HBO, daß die Generalklausel Rücksicht nehmen soll auf "positive Gestaltungsregeln" in örtlichen Bauvorschriften, führt unmittelbar zur eigentlichen Problematik des Schutzes des "beabsichtigten" Orts-, Straßen- und Landschaftsbildes. Es ist schwer erkennbar, welche Bedeutung dieser Teil der gestaltungsrechtlichen Generalklauseln eigentlich haben soll. Fordert man nämlich für seine Anwendung den Erlaß einer örtlichen Bauvorschrift ${ }^{188}$, dann hat er keinen eigenständigen Anwendungsbereich. Liegt etwa eine örtliche Bauvorschrift vor, mit der eine Gemeinde die von ihr gewünschte Gestaltung festlegt, dann führt ein Verstoß hiergegen zur Rechtswidrigkeit. Auf die Generalklausel kommt es nicht $a^{189}$. Nichts anderes gilt, wenn eine örtliche Bauvorschrift nach $\S 9$ Abs. 4 BauGB in den Bebauungsplan aufgenommen worden ist. Dies ändert nichts an ihrer materiellen Grundlage und Wirkung. Fordert man also das Vorliegen einer örtlichen Bauvorschrift, dann hat eine gestaltungsrechtliche

\footnotetext{
${ }^{186}$ Hess. LT-Drs. 8/55, S. 77.

${ }^{187}$ Hess. LT-Drs. 8/55, S. 77; HessVGH, BRS Band 38, Nr. 146 S. 333.

${ }^{188}$ Für die Notwendigkeit einer rechtssatzmäßigen Fixierung sprechen sich etwa aus: HessVGH, Urteil vom 23.01.1981, BRS Band 38, Nr. 146 S. 333 und Urteil vom 19.05.1978, BRS Band 33, Nr. 123 S. 245 (246); Boeddinghaus / Hahn, Art. 12 Rn. 23; Bork / Köster, BauO NW Erl. § 12 Rn. 7; Engelmann, S. 45; Gaentzsch, Die Bauverwaltung 1973, S. 411 m. w. N.; Koch / Molodovsky / Rahm, Art. 12 Anm. 5.2.; Rößler, § 12 Anm. 3 S. 68; Schlez, Neues Bauordnungsrecht, S. 56; Temme, in: Gädtke / Böckenförde / Temme, § 12 Rn. 17; Oelker, S. 165; Krebs, Baurecht, S. 396.
}

${ }^{189}$ So auch Sauter, § 111 Rn. 2 S. 5. 
Generalklausel, die das "Stören" der beabsichtigten Gestaltung verbietet, keine eigenständige Schutzfunktion.

Verlangt man also für die Anwendung der Klausel über den Schutz der beabsichtigten Gestaltung eine "rechtssatzmäßige Konkretisierung" und liegt dazu eine örtliche Bauvorschrift vor, dann benötigt man die Generalklausel nicht, um entsprechende Verbotswirkungen auszulösen. Es läßt sich nun die Frage stellen, ob dies bei anderen rechtssatzmäßigen oder rechtssatzähnlichen "Konkretisierungshilfen" anders ist. So wird die Auffassung vertreten, die erforderliche Konkretisierung ließe sich auch aus Bebauungs- oder Flächennutzungsplänen entnehmen ${ }^{190}$. Hiergegen werden jedoch zunächst Bedenken rechtsstaatlicher Art geltend gemacht. Mit dem Gebot der Normenklarheit sei es kaum vereinbar, die beabsichtigte Gestaltung relativ unzusammenhängend in verschiedene Verfahren zu zerstreuen ${ }^{191}$. Im Grundsatz mag die Aussage zutreffend sein, daß eine Zerstreuung von Bestimmungen, die für einen Sachbereich relevant sind, gegen das Rechtsstaatsprinzip verstößt. Gerade im vorliegenden Fall dürfte ein solcher Verstoß jedoch nicht vorliegen. Bei der Suche nach geplanten Gestaltungen im Hinblick auf die bauliche Nutzung auf Flächennutzungspläne und Bebauungspläne zurückzugreifen, ist naheliegend.

$\mathrm{Da} ß$ Flächennutzungsplan und Bebauungsplan trotzdem keine hinreichende Konkretisierungshilfe sind, ergibt sich aus anderen Gründen. So enthält der Flächennutzungsplan nur in relativ weitmaschiger Form Darstellungen etwa über die Art der baulichen Nutzung im Gemeindegebiet ( $\$ 5$ Abs. 2 BauGB, $\S 1$ Abs. 2 BauNVO). Aus ihm läßt sich für die dem Bauordnungsrecht unterliegenden Fragen der Außengestaltung in der Regel nichts entnehmen. Mehr als eine vage Vermutungsgrundlage können Darstellungen im Flächennutzungsplan nicht abgeben.

Ähnliches gilt auch für den Bebauungsplan, in den keine örtlichen Bauvorschriften als Festsetzungen nach $\S 9$ Abs. 4 BauGB aufgenommen worden sind. Zunächst enthält der Bebauungsplan nur Aussagen darüber, inwieweit die in $\S 9$ Abs. 1 BauGB abschließend aufgeführten Festsetzungsmöglichkeiten von der Gemeinde für ein bestimmtes Baugebiet vorgesehen sind. Gestaltungen, die insoweit vom Bebauungsplan "beabsichtigt" sind, unterliegen jedoch aus kompetenzrechtlichen Gründen nicht den bauordnungsrechtlichen Generalklauseln. Allerdings kann der Bebauungsplan auf-

\footnotetext{
${ }^{190}$ Vergleiche etwa Scheerbarth, S. 187; Engelmann, S. 45.

${ }^{191}$ Lerche, DB Beilage Nr. 6/69, S. 10.
} 
grund seiner Rechtsnormqualität nach der Rechtsprechung des BVerwG auch bauland- und baugebietswidrige Nutzungsarten ausschließen ${ }^{192}$. Er wirkt dann etwa für Werbeanlagen ähnlich wie eine örtliche Bauvorschrift, denn Werbeanlagen können in diesem Sinne baugebietswidrig sein ${ }^{193}$. Sie werden daher auch von den $\S \S 14,15$ BauNVO erfaßt, unabhängig davon, $o b$ es sich um bauliche Anlagen handelt oder nicht ${ }^{194}$. Wenn man nun allerdings entgegen dieser Rechtsprechung annimmt, der Bebauungsplan hätte keine eigene Verbotswirkung ${ }^{195}$, käme man zu einer Anwendungsmöglichkeit für den Schutz der "beabsichtigten" Gestaltung. Denn für diese Fälle würde der Bebauungsplan zwar eine konkrete Aussage treffen, jedoch einer Geltungsvermittlung durch eine formell-gesetzliche Vorschrift bedürfen. Vor allem durch die klarstellende Aufnahme des $\S 30$ Abs. 2 in das BauGB $^{196}$ dürfte der Gesetzgeber jedoch hinreichend zu erkennen gegeben haben, daß er die Auffassung des BVerwG über die eigenständige Verbotswirkung des Bebauungsplanes teilt. Es wäre zudem ein eigenartiger Widerspruch, den nach $\S 9$ Abs. 4 BauGB in den Bebauungsplan aufgenommenen örtlichen Bauvorschriften eine eigenständige Verbotswirkung zuzugestehen, den übrigen Festsetzungen aber nicht ${ }^{197}$, zumal der Planungsvorgang ein einheitlicher ist und nach der hier vertretenen Auffassung auch eine enge kompetenzrechtliche Verwandtschaft besteht.

Teilweise wird allerdings auch die Ansicht vertreten, dafür, daß auch die von einer Gemeinde für ein bestimmtes Gebiet beabsichtigte Gestaltung geschützt sei, sei eine rechtssatzmäßige Konkretisierung nicht erforderlich. Vielmehr reiche eine hinreichende Konkretisierung durch Planentwürfe, Aktenvermerke, Einzelentscheidungen oder Skizzen ${ }^{198}$. Absichten, die sich im wesentlichen nur aus informellen Vorgängen in der Verwaltung ergeben, sind jedoch nichts anderes als "Schubladenpläne". Soweit kein entsprechen-

192 BVerwG, Urteil vom 04.11.1966, DVBl. 1967, S. 283 f. = BRS Band 17, Nr. 1; Urteil vom 16.02.1968, BRS Band 20, Nr. 123 S. 186 (187); Urteil vom 02.03.1973, BRS Band 27, Nr. 4 S. $5(6)=$ DVBl. 1973, S. 636 f.; Urteil vom 28.04.1978, BRS Band 33, Nr. 31 S. 73 (75). Siehe auch Sendler, BBauBI. 1968, S. 15.

${ }^{193}$ BVerwG, Urteil vom 16.02.68, BRS Band 20, Nr. 123 S. 186 (187).

194 Sendler, BBauBl. 1968, S. 15.

195 So ausführlich Osthof, S. 49 ff.; weiterhin Evers, DVB1. 1968, S. 1 ff.

196 Schlichter, in: Berliner Kommentar zum BauGB, § 30 Rn. 13.

${ }^{197}$ So aber Osthof, S. 78.

${ }^{198}$ Büge / Zinkahn, S. 33; Koch / Molodovsky / Rahm, Art. 12 Anm. 5.2.; Simon, Art. 12 Rn. 21; Stadtler / Baumgartner / Wiebel, Kommentierung BayBO 21/10a, Art. 12 Anm. 4; Trieb / Schmidt / Paetow / Buch / Strobel, S. 94. 
des Rechtssetzungsverfahren durchlaufen worden ist, sind sie nicht verbindlich. Will man Entwürfen rechtliche Vorwirkungen zubilligen, ist dies - wie nach § 33 BauGB - in rechtsstaatlich unbedenklicher Weise nur mit begünstigender, nicht aber mit belastender Wirkung für das Grundeigentum möglich. Ansonsten wäre der Verwaltungswillkür Tür und Tor geöffnet, so daß zu verlangen ist, daß das Verfahren zur Aufstellung einer Satzung einzuhalten ist, das dem Bürger die Möglichkeit gibt, seine Rechte geltend zu machen. Im übrigen fehlt für betroffene Eigentümer jeder zuverlässige Weg, von nicht in Satzungen über örtliche Bauvorschriften enthaltenen Plänen und Absichten der Verwaltung Kenntnis zu erlangen. Würde man "Schubladenplänen" über die Generalklausel rechtliche Verbindlichkeit zubilligen, wäre den betroffenen Grunstückseigentümern auch die Möglichkeit genommen, sich gegen die Gestaltungsabsichten der Gemeinde im Wege der Normenkontrollklage nach $\S 47 \mathrm{VwGO}$ zu wehren. Solange also eine örtliche Bauvorschrift nicht rechtswirksam erlassen worden ist, können dem Bürger keine Pläne der Gemeinden im Hinblick auf diese oder jene angestrebte Gestaltung des Gemeindegebiets entgegengehalten werden.

Somit gilt auch für die derzeit geltenden Landesbauordnungen, was das BVerwG in seiner Grundsatzentscheidung zu $\S 1$ BaugestVO und zwar im besonderen zu $\S 1 \mathrm{~S} .2$ BaugestVO ausgeführt hat ${ }^{199}$ : Wenn die Gemeinden von § 2 BaugestVO oder heute von den Vorschriften in den Landesbauordnungen über den Erlaß von örtlichen Bauvorschriften auf den Weg der Rechtssetzung verwiesen werden, so ergibt sich daraus, daß daneben eine Möglichkeit, die Baugestaltung quasi nach ihrer freien Entschließung zu lenken, nicht gegeben sein kann. Es wäre ein gesetzgeberischer Widerspruch, die Gemeinden zum einen auf den erschwerten Weg der Rechtssetzung zu verweisen, ihnen aber gleichzeitig die Möglichkeit einzuräumen, ihre Vorstellungen auch ohne Einhaltung eines Rechtssetzungsverfahrens durchzusetzen ${ }^{200}$.

Zwar beschränken sich Ortssatzungen der Gemeinden gelegentlich auf ausgesprochen allgemeine Umschreibungen ihrer Gestaltungsabsichten, so etwa, wenn festgesetzt wird, daß "alle baulichen Anlagen ... äußerlich so zu gestalten sind, daß mit dem historischen Gebäudebestand ein bruchloser Zusammenhang besteht" ${ }^{201}$. Aber auch bei einer solchen allgemeinen For-

\footnotetext{
${ }^{199}$ BVerwGE 2, 176.

${ }^{200}$ BVerwGE 2, 176.

201 \$ 2 der Ortssatzung von Tübingen von 1975, zitiert nach Burger / Gutschow / Krause,
} S. 172. 
mulierung gilt nur das, was sich daraus als bestimmte Aussage herauslesen läßt. Läßt sich Klarheit über das, was eigentlich gewollt ist, nicht gewinnen, ist auch keine konkretisierte Absicht vorhanden, der über die Generalklausel Geltung zukommen könnte. Läßt sich eine konkrete Forderung bestimmen, gilt diese, ohne daß es auf die Generalklausel ankäme.

Ist somit für die Konkretisierung der Gestaltungsabsichten eine rechtssatzmäßige Festlegung zu fordern, so ergibt sich daraus auch, daß die maßgeblichen Absichten die Vorstellungen der kommunalen Körperschaft sind, die den Rechtssatz zu erlassen hat. Auf die Absichten der Baugenehmigungsbehörde kann es schon deshalb nicht ankommen, weil es nicht deren Aufgabe ist, das Gemeindegebiet in bestimmter Weise gestalten zu wol$\operatorname{len}^{202}$.

\section{cc) Weitere mögliche Anwendungsbereiche}

Ein möglicher Anwendungsbereich für die Klauseln über den Schutz der "beabsichtigten Gestaltung" wird weiterhin darin gesehen, Vorhaben zu unterbinden, die gegen eine in der bisherigen Bebauung bereits erkennbar gewordene Gestaltungsidee verstoßen ${ }^{203}$. Falls wirklich in der vorhandenen Bebauung eine Gestaltungsidee erkennbar wird, wird dieser Fall jedoch schon von den allgemeinen umgebungsabhängigen Anforderungen erfaßt, da dann bereits ein bestimmter Rahmen gegeben ist, der eine Forderung nach Harmonie begründen kann. Sind aber noch nicht genügend Gebäude vorhanden, dürfte ohne rechtssatzmäßige Fixierung nicht sicher zu entscheiden sein, wann eine bestimmte Gestaltungsidee der Gemeinde vorliegt, und wann aus Zufall, Ideenlosigkeit oder sachlichen Notwendigkeiten in einer bestimmten Art und Weise gebaut worden ist.

Ein relevanter Anwendungsbereich für den Schutz der beabsichtigten Gestaltung ließ sich nach den bisherigen Überlegungen nicht sichtbar machen. Deshalb könnte man auf den Gedanken verfallen, in den gestaltungsrechtlichen Generalklauseln insoweit keine Gestaltungsvorschriften fördernde sondern abschwächende Vorschriften zu sehen. Man könnte die Bestimmungen so verstehen, daß sie Anforderungen in örtlichen Bauvorschriften insoweit einschränken, als ein Verstoß gegen die getroffene Festsetzung nur

\footnotetext{
${ }^{202}$ Es überzeugt daher nicht, wenn Schlotterbeck, in: Schlotterbeck / von Arnim, § 3 Rn. 46, auf die Absichten der Baugenehmigungsbehörde abstellen will.

203

So Büge / Zinkahn, S. 32.
} 
insoweit unzulässig ist, wie eine Verunstaltung oder Störung, also ein Verstoß von einem gewissen Gewicht eintritt, nicht jedoch bei jeder Abweichung. Zwar ist es grundsätzlich denkbar, daß in diesem Sinne eine aufgrund von Landesbaurecht erlassene untergesetzliche Norm vom Landesbaurecht in seiner Geltung wieder eingeschränkt wird, genau wie im Bundesbaurecht $\S 38$ BauGB von der Beachtung der aufgrund von Bundesrecht erlassenen Bebauungspläne suspendiert. Dafür, daß dies von einem Landesgesetzgeber gewollt war, ist aber ein sicherer Beleg nicht zu finden ${ }^{204}$.

Damit ergibt sich das Ergebnis, daß für die Entscheidung über ein konkretes Baugesuch der Teil der baugestalterischen Generalklausel, der den Schutz der beabsichtigten Gestaltung des Orts-, Straßen- und Landschaftsbildes vorsieht, keine oder - verbindlicher formuliert - nur eine deklaratorische Bedeutung hat ${ }^{205}$. Die beabsichtigte Gestaltung steht einer Bauausführung nur dann entgegen, wenn eine örtliche Bauvorschrift vorliegt. Läßt aber eine örtliche Bauvorschrift eine bestimmte Gestaltung nicht $\mathrm{zu}$, ist schon deshalb ein Vorhaben rechtswidrig, ohne daß es auf die Generalklausel ankäme.

\section{dd) Beabsichtigte Gestaltung und "positive Gestaltungspflege"}

Die in der baugestalterischen Generalklausel enthaltene Anforderung an bauliche Anlagen auf Nichtverunstaltung oder Nichtstörung ${ }^{206}$ der beabsichtigten Gestaltung ist jedoch in anderer Hinsicht von Bedeutung. Der Erlaß von örtlichen Bauvorschriften ist nach einigen Landesbauordnungen ausdrücklich auf den Rahmen der jeweiligen Bauordnungen beschränkt ${ }^{207}$. Die Befugnis zum Erlaß von örtlichen Bauvorschriften wird nun von den Oberverwaltungsgerichten der Länder weitgehend übereinstimmend dahingehend verstanden, daß mit ihnen über die Verunstaltungsabwehr hinaus eine sog. positive Gestaltungspflege betrieben werden $\mathrm{kann}^{208}$. Dies wird in der Regel

${ }^{204}$ Unklar insoweit allerdings Wenzel / Bündgen, § 14 Rn. 1 und Hess. LT-Drs. 8/55, S. 77. Wie hier aber HessVGH, Urteil vom 19.05.1978, BRS Band 33, Nr. 123 S. 246, wonach $\S 14$ Abs. 2 S. 1 HBO nur deklaratorische Bedeutung zukäme, da konkrete Festsetzungen bereits für sich gelten würden.

${ }^{205}$ So auch HessVGH, Urteil vom 23.01.1981, BRS Band 38, Nr. 146 S. 333.

${ }^{206}$ Die Terminologie ist uneinheitlich, siehe oben C III 2 b aa.

${ }^{207}$ Siehe die Nachweise oben C I 1 a, Fn. 1.

${ }^{208}$ Aus der Rechtsprechung siehe BWVGH, Beschluß vom 26.08.1982, BRS Band 39, Nr. 133 S. 283 (284); HessVGH, Urteil vom 23.01.1981, BRS Band 38, Nr. 146 S. 33 und Urteil vom 30.06.1987, BRS Band 47, Nr. 121 S. 317 (319); OVG Lüneburg, Urteil vom 04.05.1979, 
etwas unscharf definiert als ein Hinausgehen über den Bereich der Verunstaltungsabwehr im Sinne des Setzens strengerer ästhetischer Maßstäbe ${ }^{209}$. Zumindest hinsichtlich der Bindung an die baugestaltungsrechtlichen Generalklauseln bestehen hiergegen keine Bedenken und zwar weder für die Landesbauordnungen, die eine solche Bindung ausdrücklich vorschreiben, noch wenn man insoweit von einem allgemein geltenden Grundsatz ausgeht $^{210}$. Denn aus der Forderung der gestaltungsrechtlichen Generalklausel nach Schutz der beabsichtigten Gestaltung ergibt sich, daß es den Gemeinden grundsätzlich erlaubt sein soll, die bauliche Gestaltung in Bezug auf dem Bauordnungsrecht unterliegende Sachbereiche aktiv zu beeinflussen, d. h. zumindest mehr zu tun, als sich auf tendenziell passive Verunstaltungsabwehr zu beschränken. Daher hat etwa der baden-württembergische Gesetzgeber die ursprüngliche Beschränkung örtlicher Bauvorschriften auf den Rahmen der allgemeinen Generalklausel vor allem im Hinblick auf die ebenfalls in der LBO BW enthaltene Forderung nach Einklang mit der beabsichtigten Gestaltung aufgehoben und durch eine Beschränkung auf den Rahmen der gesamten Bauordnung ersetzt ${ }^{211}$. "Gestaltung" bedeutet, daß die Gemeinden nicht darauf beschränkt sind, gegebenenfalls durch Einschaltung der Bauaufsichtsbehörden nur das zu bekämpfen, was ihnen von Grundeigentümern als Verunstaltung zugemutet wird, sondern daß sie selbst bestimmte Vorstellungen entwickeln und durchsetzen, daß sie ihr Orts- und Straßenbild nach ihren Absichten prägen ${ }^{212}$.

Daher ist es auch nicht nötig, den Begriff der "öffentlichen Sicherheit und Ordnung", den die bauordnungsrechtlichen Generalklauseln verwenden, und dabei vor allem den Begriff der "öffentlichen Ordnung" soweit ausufern zu lassen, da $\beta$ darunter auch wohlfahrtspflegerische Belange und damit die "positive Gestaltungspflege" fällt. Dies gelegentlich vor allem aus Sorge um eine sonst fehlende Landeskompetenz angenommen ${ }^{213}$. Eine solche Erweite-

BRS Band 35, Nr. 132 S. 251 (253); Urteil vom 11.02.1982, BRS Band 39, Nr. 132 S. 280 (281); Urteil vom 11.03.1983, BauR 1983, S. 563 f. = BRS Band 40, Nr. 151; Urteil vom 20.04.1986, BRS Band 46, Nr. 120 S. 280 (281); Urteil vom 09.01.1987, BRS Band 47, Nr. 122S. 321 (322); OVG Münster, Urteil vom 30.06.1978, BRS Band 33, Nr. 115 S. 238 (240); Urteil vom 30.06.1981, BRS Band 38, Nr. 138 S. 322 (323); Urteil vom 30.06.1983, BRS Band 40, Nr. 152 S. $335 \mathrm{ff}$.

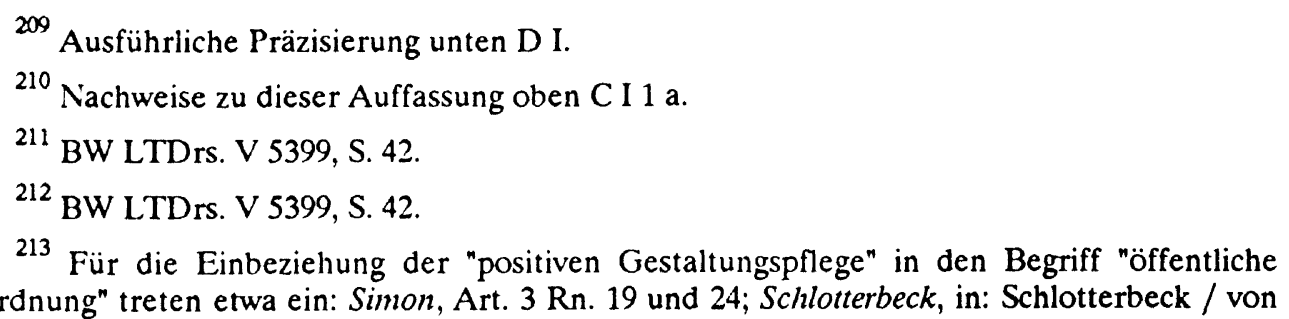


rung des Begriffs "öffentliche Ordnung" ist aber nicht nur überflüssig, sie ist zudem ausgesprochen unhistorisch. So erklärt sich der Erlaß der Preußischen Verunstaltungsgesetze von 1902 und 1907 gerade dadurch, daß das PrOVG im "Kreuzberg-Urteil"124 die Verfolgung solcher Belange aus der polizeilichen Generalklausel verbannt hatte ${ }^{215}$. Die Befürchtung, daß mit restriktiver Interpretation des Begriffes der öffentlichen Ordnung die Landeskompetenz entfiele, beruht außerdem auf einer mißverständlichen Interpretation des Baurechtsgutachtens des $\mathrm{BVerfG}^{216}$. Es gibt keine Beschränkung des Bauordnungsrechts auf den Bereich der Gefahrenabwehr. Zwar mag es richtig sein, daß die Unterscheidung zwischen Gefahrenabwehr und Wohlfahrtspflege zunehmend schwierig wenn nicht sogar fragwürdig wird ${ }^{217}$. Trotzdem würde der Begriff der "öffentlichen Ordnung" wohl endgültig jegliche Konturen verlieren, wollte man die Quisquilien, die häufig in örtlichen Bauvorschriften vorgeschrieben werden, als erforderlich zur Bekämpfung von Gefahren für die öffentliche Ordnung verstehen wollen.

Insgesamt läßt sich somit folgendes Fazit ziehen: Das in den gestaltungsrechtlichen Generalklauseln enthaltene Verbot der Störung der beabsichtigten Gestaltung des Orts-, Straßen- und Landschaftsbildes hat keinen eigenständigen Anwendungsbereich. Von Bedeutung sind diese Bestimmungen nur insofern, als die Bauordnungen darin zu erkennen geben, daß der Rahmen der Generalklauseln die Gebietsgestaltung durch örtliche Bauvorschriften nicht auf den Bereich der Verunstaltungsabwehr beschränkt.

\section{c) Eine bayerische Besonderheit: Art. 12 Abs. 3 BayBO}

Die bisher vorgestellten Bestimmungen in den Landesbauordnungen halten sich im Rahmen der vom BVerwG in seiner Grundsatzentscheidung zur BaugestVO gesteckten Grenzen. Bei den umgebungsunabhängigen Anforderungen ist dies vor allem auf die Eigentumsgarantie, bei den umgebungsabhängigen auf den Bestimmtheitsgrundsatz zurückzuführen. Untersucht werden soll deshalb noch die Vorschrift des Art. 12 Abs. 3

Arnim, Art. $3 \mathrm{Rn}$. 19, wonach "anständige Baugesinnung" zur öffentlichen Ordnung gehört; Stadtler / Baumgartner / Wiebel, Einf. in die BayBO 21/10a, S. 9: "Die sozialen Erfordirnisse müssen in den Bereich der öffentlichen Ordnung einbezogen werden." Ebenso Einf. in die MBauO, S. 122; Koch / Molodovsky / Rahm, Art. 3 Anm. 2.1.1.1.

${ }^{214}$ Urteil vom 14.06.1882, PrOVGE 9, 353 ff.

${ }^{215}$ Weyreuther, Eigentum, S. 14 ff.; von der Groeben, S. 438 ff.; Rott, NVwZ 1982, S. 364.

${ }^{216}$ Dazu oben A II 2 c.

${ }^{217}$ So Erichsen, VVDStRL 35 (1976), S. 177 ff. 
BayBO. Die Ansicht, daß der bayerische Gesetzgeber hier über die bisherigen engen Grenzen hinausgegangen sei, ist zumindest diskutabel ${ }^{218}$. In Art. 12 Abs. 3 BayBO wird für den Fall, daß keine örtliche Bauvorschrift über die Gestaltung und kein Bebauungsplan besteht, die Forderung nach Einfügen in die nähere Umgebung erhoben. Bei dem Einfügungserfordernis handelt es sich um eine Anleihe bei der Bestimmung des $\S 34 \mathrm{Abs} .1 \mathrm{BBauG}$ $1977^{219}$.

Der grundsätzliche Ansatz dieser Neuregelung ist zunächst zutreffend, daß nämlich § 34 Abs. 1 BBauG / BauGB nicht alle Gestaltungsmerkmale baulicher Anlagen erfaßt ${ }^{220}$. Dies ergibt sich in der Tat aus kompetenzrechtlichen Gesichtspunkten, und zwar aus dem grundsätzlich notwendigen Planersatzcharakter des $\$ 34 \mathrm{BBauG} / \mathrm{BauGB}^{221}$. Da die Bodenrechtskompetenz nach Art. $74 \mathrm{Nr}$. $18 \mathrm{GG}$ vor allem eine Bodenplanungsrechtskompetenz ist, kann die Plancrsatzvorschrift des $\S 34 \mathrm{BBauG} / \mathrm{BauGB}$ nur solche Merkmale beeinflussen, die aufgrund von Festsetzungen nach $\S 9$ Abs. 1 BauGB auch Gegenstand des maßgeblichen Planungsinstrumentes, nämlich des Bebauungsplanes, sind ${ }^{222}$. Die Tatsache, daß aufgrund des $\S 9$ Abs. 4 BauGB auch örtliche Bauvorschriften als Festsetzungen in den Bebauungsplan aufgenommen werden können, vermag hieran nichts zu ändern ${ }^{223}$. Der § 34 BBauG / BauGB wird kaum unterschiedlich ausgelegt werden können, je nachdem, ob die Landesgesetzgeber von der Möglichkeit des $\S 9$ Abs. 4 BauGB Gebrauch gemacht haben oder nicht.

Gegen die Auffassung, daß dem Art. 12 Abs. 3 BayBO eine über die Verunstaltungsabwehr hinausgehende Bedeutung zukäme, beruft sich der BayVGH auf den Bestimmtheitsgrundsatz ${ }^{22+}$. Weiterhin wird von Jäde ein etwas überraschender Einwand erhoben: Die vom Gesetzgeber gewollte und auch im Gesetzestext zum Ausdruck gekommene Anlehnung an § 34

${ }^{218}$ Für ein Verständnis in diesem Sinne etwa Hüffer. BayVBI. 1984, S. 12; Engelmann, S. 40 und S. 97 f. Anders hingegen BayVGH, Urteil vom 14.10.1982, BRS Band 39, Nr. 130 S. 279 f. und dem folgend Moench / Schmidt, S. 25.

${ }^{219}$ Bay. LT-Drs. 9/7854, S. 31.

${ }^{220}$ Siehe Bay. LT-Drs. 9/7854, S. 31.

${ }^{221} \mathrm{Zu}$ Bundeskompetenz im Baurecht ausführlich vor allem oben A II $3 \mathrm{c}$ dd.

222 So im Ergebnis auch BayVGH, Urteil vom 12.11.1987, BayVB1. 1989, S. 403: "§ 34 Abs. 1 BauGB erfaßt nur solche Beeinträchtigungen des Ortsbildes, die sich daraus ergeben, daß bei einem Vorhaben planungsrechtlich relevante Maßstäbe nicht berücksichtigt sind."

${ }^{223}$ So im Ergebnis auch OVG Berlin, BRS Band 38, Nr. 71 S. 160 (162). Dies gilt auch für den Außenbereich, siehe Weyreuther, Bauen im Außenbereich, S. 489.

${ }^{224}$ BayVGH, Urteil vom 14.10.1982, BRS Band 39, Nr. 130 S. 279. 
BBauG 1977 führe deshalb nicht zu einem "Mehr" als Verunstaltungsabwehr, weil das Merkmal des "Einfügens" in § 34 BBauG / BauGB durch das BVerwG vom Bauordnungsrecht her interpretiert werde; was mit der Folge des Nichteinfügens störend oder belastend auf die städtebauliche Situation wirke, sei identisch mit demjenigen Grade des Widerspruchs zur Umgebung, der bauordnungsrechtlich als Verunstaltung bezeichnet werde ${ }^{225}$.

Diesem Einwand ist aber zunächst entgegenzuhalten, daß die Einfügung des Art. 12 Abs. 3 in die BayBO nur dann einen Sinn gibt, wenn der Gesetzgeber über das hinausgehen wollte, was die übrigen Bestimmungen der Bauordnung an Anforderungen im Hinblick auf bauliche Anlagen bereits stellten. Ansonsten hätte kein Bedarf für eine Neuregelung bestanden. Zudem enthält die maßgebliche Entscheidung des BVerwG zum Einfügungsgebot des $\S 34 \mathrm{BBauG}$ zwar einen Hinweis auf die Entscheidung zu $\S 1$ Baugest $\mathrm{VO}^{226}$. Dies dahingehend zu verstehen, daß das BVerwG das Einfügungserfordernis in Anlehnung an den Verunstaltungsbegriff gedeutet habe ${ }^{227}$, dürfte diesen Bezug jedoch eindeutig überbewerten. Vielmehr definiert die Rechtsprechung des BVerwG den Begriff des "Einfügens" in $\S 34$ BBauG aus einem bauplanungsrechtlichen Gesamtzusammenhang heraus. Es bezieht sich dabei auch auf den Aspekt des Planungsbedürfnisses ${ }^{228}$. Wenn ein Vorhaben - so das BVerwG - bewältigungsbedürftige Spannungen begründe oder erhöhe, die quasi durch die Baulcitplanung "aufgefangen" werden müßten, so liege ein Einfügen im Sinne von $\S 34$ BBauG nicht vor ${ }^{229}$. In diesem Sinne müsse das Vorhaben harmonisch $\operatorname{sein}^{230}$.

Ist aber ein so verstandenes Planungsbedürfnis das entscheidende Indiz für die Frage, ob sich ein Vorhaben einfügt, so kann die Übertragung des Einfügungsmaßstabes in das Bauordnungsrecht nur in solchen Bereichen über den Verunstaltungsschutz hinausgehen, in denen ebenfalls ein solches Planungsbedürfnis entstehen kann. Dies ist sicherlich nicht bei allen Merk-

225 So Jäde, BayVB1. 1984, S. 11.

${ }^{226}$ BVerwG, Urteil vom 26.05.1978, BayVBI. 1979, S. 152 (155).

227 So Jäde, BayVBI. 1984, S. 11.

${ }^{228}$ BVerwG, BayVBI. 1979, S. 155.

${ }^{229}$ BVerwG, BayVBl. 1979, S. 155. Ein abstraktes Planungsbedürfnis allein ist jedoch kein Belang, der einem ansonsten zulässigen Vorhaben im Innenbereich entgegensteht, siehe BVerwG, Urteil vom 24.10.1980, BauR 1981, S. 48 (50); Schmidt-Aßmann, Das bebauungsrechtliche Planungserfordernis, S. 23 ff. Ein eventuelles Planungserfordernis ist ein Element bei der Auslegung des Merkmals "Einfügen", siehe Schmidt-Aßmann, ebenda, S. 46; Fackler, S. 45 .

${ }^{230}$ BVerwG, Urteil vom 22.05.1987, GewArchiv 1988, S. 38. 
malen der Fall, die den bauordnungsrechtlichen Gestaltungsregeln unterliegen. So mag ein vom Eigentümer gewählter Außenanstrich in die Umgebung passen oder nicht: Ein Planungsbedürfnis im Sinne der Rechtsprechung des BVerwG ergibt sich daraus nicht. Insofern stellt daher auch Art. 12 Abs. 3 BayBO keine weitergehenden Anforderungen als die anderen umgebungsabhängigen Maßstäbe. Bewältigungsbedürftige Spannungen können jedoch dann entstehen, wenn es um solche Merkmale geht, die nachbarliche Belange berühren, wie vor allem die Fragen der Dachgestaltung ${ }^{231}$. Dies wäre beispielsweise dann der Fall, wenn statt in der betreffenden Gegend üblicher Flachdächer ein geneigtes Dach errichtet werden soll. Hier braucht das "harmonische Minimum" etwa angesichts bereits vorhandener ähnlicher Dachkonstruktionen noch nicht in jedem Fall gestört zu sein. Trotzdem ist es denkbar, daß das Vorhaben gegen die Pflicht zur Rücksichtnahme auf dic Grenznachbarn verstößt und sich daher nicht "einfügt". Mit einer solchen Interpretation läßt sich daher dem Art. 12 Abs. 3 BayBO cin über den Verunstaltungsschutz hinausgehender Regelungszweck eröffnen. Im Ergebnis stellt also Art. 12 Abs. 3 BayBO zwar nicht im Hinblick auf alle, aber doch in bezug auf einige Gestaltungsmerkmale Anforderungen, die sich nicht bereits aus dem Verunstaltungsverbot ergeben.

\footnotetext{
${ }^{231}$ Siehe dazu ausführlich oben A III 4.
} 


\section{Erweiterter Umgebungsschutz und positive Gestaltungspflege durch örtliche Bauvorschriften}

\section{Der Begriff der "positiven Gestaltungspflege"}

\section{Positive Gestaltungspflege durch baugestalterische Vorschriften}

Die von den Landesbauordnungen den Gemeinden eingeräumten $\mathrm{Er}$ mächtigungen zum Erla $\beta$ von baugestalterischen Vorschriften werden von den Oberverwaltungsgerichten relativ einhellig als Befugnis aufgefaßt, eine sog. positive Gestaltungspflege zu betreiben'. Dieser Begriff hat trotz häufiger Verwendung jedoch keine klaren Konturen ${ }^{2}$. Ursprünglich dürfte die Verwendung des Adjektivs "positiv" auf die BaugestVO vom 10.11.1936 zurückzuführen sein ${ }^{3}$. Dort wurden statt der bisher gebräuchlichen "negativen" Begriffe wie "Verunstaltung", "Beeinträchtigung" oder "Störung" rechtsverbindlich "positive" Anforderungen gestellt, etwa dergestalt, daß die baulichen Anlagen "Ausdruck anständiger Baugesinnung" sein müssen und sich der Umgebung "einwandfrei einzufügen" hätten ( $\$ 1$ BaugestVO). Ob die gesetzlichen Bestimmungen in diesem Sinne "positiv" oder "negativ" formuliert sind, kann jedoch kaum entscheidend sein, wenn der Begriff der "positiven Gestaltungspflege" auf einen inhaltlichen Unterschied etwa zur reinen Verunstaltungsabwehr hindeuten soll ${ }^{4}$. "Negativ" formulierte Anforderungen sind nicht notwendigerweise weniger weitgehend als "positiv" formulierte, auch wenn dies im Verhältnis der BaugestVO zu den bis dahin geltenden Vorschriften so war ${ }^{5}$. Es ist zudem durchaus üblich, vom Gesetzgeber positiv

\footnotetext{
${ }^{1}$ Nachweise siehe C III 2 b dd, Fn. 208.

${ }^{2}$ So auch Seybold, S. 15: Für die positive Gestaltungspflege fehle es an einer allgemein anerkannten Definition.

${ }^{3}$ RGBI. I, S. 938. Vgl. etwa die Ausführungen von Engelmann, S. 22 ff.

${ }^{4}$ Anders wohl Looks, S. 8 f, Burger / Gutschow / Krause, S. 117, Weyreuther, Bauen in Außenbereich, S. 491, die das Wesen positiver Baupflege in positiven Formulierungen zu sehen scheinen.

${ }^{5}$ So wohl auch Büge / Zinkahn, S. 20; auch Zinkahn, DÖV 1953, S. 166, der der Ansicht ist, daß die Frage, ob Anforderungen positiv oder negativ formuliert seien, eine nur theoretische Bedeutung habe.
} 
formulierte Anforderungen negativ zu erklären, wie etwa die oben erwähnte Rechtsprechung des BVerwG zu § 34 BBauG zeigt, wonach ein Einfügen dann gegeben ist, wenn keine bewältigungsbedürftigen Spannungen entstehen ${ }^{6}$.

Man wird daher dem Begriff der "positiven Gestaltungspflege" nur dann gerecht werden können, wenn man auf ein inhaltliches Kriterium abstellt. Dies geschieht etwa, wenn die "positive Gestaltungspflege" folgendermaßen definiert wird: Sie ermögliche ein "Mehr" als reiner Verunstaltungsschutz', sie könne über die bloße Verunstaltungsabwehr hinausgehen ${ }^{8}$, es sei insoweit möglich, strengere ästhetische Maßstäbe zu setzen' ${ }^{9}$. Auch wenn man diesen Aussagen von der Grundtendenz her zustimmt, bleiben nach wie vor zwei unterschiedliche Deutungsmöglichkeiten. Zunächst läßt sich die Auffassung vertreten, daß "positive Gestaltungspflege" durch ein "Mehr" an Schutz gekennzeichnet sei. Bei einer solchen Begriffsdeutung ist gemeint, daß zum Schutz des Straßen-, Landschafts- und Ortsbildes nicht mehr nur das verboten wird, was gegen das oben definierte "harmonische Minimum" verstö $\mathrm{At}^{10}$, sondern auch geringere $A b w e i c h u n g e n$ unterbunden werden. Daß sich für einen so verstandenen Einsatz örtlicher Bauvorschriften ein durchaus relevanter Anwendungsbereich ergibt, wurde bereits ausgeführt ${ }^{11}$. Dieses Verständnis von "positiver Gestaltungspflege" dürfte gemeint sein, wenn angeführt wird, der Ortsgesetzgeber sei befugt, strengere ästhetische Maßstäbe anzulegen als es die allgemeinen gestalterischen Anforderungen zulas$\operatorname{sen}^{12}$, oder es darum gehe, ästhetisch unerwünschte Erscheinungen oder Beeinträchtigungen der architektonischen Harmonie vom Orts- und Landschaftsbild fernzuhalten ${ }^{13}$.

\footnotetext{
${ }^{6}$ Siehe C III 2 c.

${ }^{7}$ Seybold, S. 18.
}

${ }^{8}$ VGH Mannheim, Beschluß vom 26.08.1982, BRS Band 39, Nr. 133 S. 283 (284); OVG Münster, Urteil vom 30.06.1983, BRS Band 40, Nr. 152 S. 335 ff.; BayVGH, Urteil vom 12.09.1988, BayVBI. 1989, S. 212; Gaentzsch, Die Bauverwaltung 1973, S. 411; Simon, Art. 91 Rn. 5; Wiechert, Baurecht, S. 305; Battis, Öffentliches Baurecht, S. 231; König, Bayerisches Baurecht, S. 37.

${ }^{9}$ Rasch / Schaetzell, § 118 Erl. zu Abs. 1 und 2; HessVGH, Urteil vom 30.06.1987, BRS Band 47, Nr. $121=$ HessStuGZ 1988, S. 408.

${ }^{10}$ Siehe dazu oben C III 2 a bb.

${ }^{11}$ Siehe oben C III 2 a cc.

${ }^{12}$ So OVG Münster, Urteil vom 30.06.1978, BRS Band 33, Nr. 115 S. 238 (240); HessVGH, Urteil vom 30.06.1987, BRS Band 47, Nr. 121 = HessStuGZ 1988, S. 408 f.

${ }^{13}$ OVG Koblenz vom 01.06.1978, abgedruckt bei Stich / Sayn / Gabelmann, LBauO $\$ 123$ E 2 . 
Möchte man dies zum Ausdruck bringen, ist jedoch der Begriff der "positiven Gestaltungspflege" unangebracht. Geht es um den Schutz des status quo, also um die Verhinderung von negativen Erscheinungen, die nicht den Grad einer Störung im Sinne der allgemeinen und gestaltungsrechtlichen Generalklauseln erreichen, läßt sich eine so verstandene Pflege der Baukultur im Verhältnis zum Verunstaltungsschutz nicht durch das Begriffspaar "negativ" und "positiv" kennzeichnen. Der Unterschied zur Verunstaltungsabwehr ist insoweit ein quantitativer, kein qualitativer. Ist dieser Anwendungsbereich örtlicher Bauvorschriften gemeint, soll daher im folgenden nicht von "positiver Gestaltungspflege", sondern von "erweitertem Umgebungsschutz" oder "erweiterter Gebietspflege" gesprochen werden. Hingegen soll der Begriff der "positiven Gestaltungspflege" nur dann verwendet werden, wenn die Gemeinden beim Erlaß von örtlichen Bauvorschriften sich nicht auf das Nachvollziehen einer vom Gesetzgeber vorgegebenen Wertung beschränken, sie vielmehr über die Verhinderung von Verunstaltung oder auch nur von Unschönheiten hinaus eigene Gestaltungsmaßstäbe setzen ${ }^{14}$. "Positive Gestaltungspflege" soll also das umfassen, was der HessVGH als Voraussetzung für den Erlaß von baugestalterischen Vorschriften ansieht, daß nämlich mehr bezweckt wird, als die Erhaltung eines vorhandenen Straßen- und Ortsbildes ${ }^{15}$.

\section{Positive Gestaltungspflege durch Schutzvorschriften}

Versteht man den Begriff der positiven Gestaltungspflege als das Stellen von Voraussetzungen, die über eine Erhaltung des optischen status quo hinausgehen, dann kann es im Rahmen der sog. Schutzvorschriften eine positive Gestaltungspflege im hier definierten Sinne nicht geben. Zwar trifft man in der Rechtsprechung gelegentlich auf die Ansicht, auch im Rahmen der denkmalschützenden Vorschriften sei eine positive Gestaltungspflege möglich $^{16}$. Dies liegt aber daran, daß in der Rechtsprechung nicht zwischen positiver Gestaltungspflege und erweiterter Gebietspflege unterschieden wird.

\footnotetext{
${ }^{14} \mathrm{Vgl}$. OVG Lüneburg, Urteil vom 11.03.1983, BauR 1983, S. 563 f. = BRS Band 40, Nr. 151; OVG Lüneburg, Urteil vom 29.04.1986, BRS Band 46, Nr. 120 S. 280 (281).

${ }^{15}$ HessVGH, Urteil vom 23.01.1981, BRS Band 38, Nr. 146 S. 333 (334); Urteil vom 30.06.1987, BRS Band 47, Nr. 121 S. 317 (319).

${ }^{16}$ Als obiter dictum etwa in BWVGH, Beschluß vom 26.08.1982, BRS Band 39, Nr. 133 S. 283 (285); HessVGH, Urteil vom 23.01.1981, BRS Band 38, Nr. 146 S. 333; OVG Lüneburg, Urteil vom 09.01.1987, BRS Band 47, Nr. 122 S. 321 (322).
} 
Mehr als eine erweiterte Gebietspflege lassen die Landesbauordnungen aber für Schutzvorschriften schon vom Gesetzeswortlaut her nicht zu. Dort ist die Rede von besonderen Anforderungen, soweit dies zum Schutz von Straßen, Bauten, Plätzen etc. von bestimmter denkmalmäßiger Bedeutung erforderlich ist. Damit erhält zwar der Ortsgesetzgeber einen gewissen Gestaltungsspielraum ${ }^{17}$, so daß er auch Schutzvorschriften bewußt zur Gestaltung des Ortsbildes einsetzen kann. Der status quo bildet jedoch den Rahmen für den Einsatz von Schutzvorschriften. Beim Erlaß von Schutzvorschriften handelt es sich daher schon vom Wortlaut der gesetzlichen Ermächtigung her um eine Konkretisierung des Einfügungs- bzw. Rücksichtnahmegebotes der allgemeinen gestaltungsrechtlichen Generalklausel.

\section{Zur verfassungsrechtlichen Zulässigkeit einer positiven Gestaltungspflege}

\section{Die eigentumsrechtliche Zulässigkeit positiver Gestaltungspflege}

Erweiterter Umgebungsschutz stellt - wie bereits ausgeführt wurde - eine zulässige Inhaltsbeschränkung des Eigentums dar. Dies ist in ständiger Rechtsprechung der Verwaltungsgerichte anerkannt und unterliegt keinen Bedenken ${ }^{18}$. Wesentlich schwieriger ist dagegen die Frage zu beantworten, ob auch die positive Gestaltungspflege im hier definierten Sinne mit der Eigentumsgarantie vereinbar ist. Zwar findet sich in der Rechtsprechung des BVerwG, wie z. B in einem Beschluß vom 29.12.1964, die relativ stereotype Formel, daß gemäß ständiger Rechtsprechung das baugestalterische Ziel, eine Beeinträchtigung des vorhandenen oder durch Planung erstrebten Charakters eines Baugebietes zu verhindern, ein begründetes öffentliches Anliegen sei, das entsprechende Eigentumsbeschränkungen rechtfertigen könne ${ }^{19}$. Geht man dieser ständigen Rechtsprechung nach, so findet man jedoch in den zitierten Entscheidungen hinsichtlich des "durch Planung erstrebten Charakters eines Baugebietes" keinen Beleg. So läßt sich die in diesem Beschluß zitierte Entscheidung zum Hamb. Gesetz über die Außenwerbung an Brücken ${ }^{20}$ nur in den Bereich des erweiterten Gebiets- bzw. Landschafts-

\footnotetext{
${ }^{17}$ So auch OVG Münster, Urteil vom 30.06.1978, BRS Band 33, Nr. 115 S. 238 (239).

${ }^{18}$ Siehe dazu oben C III 1 a.

${ }^{19}$ BVerwG, Beschluß vom 29.12.1964, DÖV 1965, S. 343.

${ }^{20}$ BVerwG, Urteil vom 29.08.1961, DÖV 1962, S. 142.
} 
schutzes einordnen, denn das Gesetz verfolgte die Absicht, das bestehende Landschaftsbild zu schützen und nicht die, ein spezifisches Landschaftsbild ohne Werbung an Brücken zu schaffen. Auch die weiterhin in bezug genommene Entscheidung zur BaugestVO ${ }^{21}$ äußert sich zur Zulässigkeit positiver Gestaltungspflege nicht. Sie stellt insoweit nur klar, daß insbesondere die Vorschriften über Verunstaltung und die Einordnung baulicher Anlagen in die Umgebung zum überkommenen Eigentumsbegriff dazugehören und eine zulässige Eigentumsbeschränkung darstellen ${ }^{22}$.

In der Rechtsprechung nach dem Beschluß vom 29.12.1964 ${ }^{23}$ findet sich zwar weiterhin die Formel, daß der Schutz des durch Planung erstrebten Gebietscharakters ein begründetes öffentliches Anliegen sei. Es wird jedoch ein wichtiger Zusatz gemacht: Beachtenswertes öffentliches Anliegen sei die Verhinderung der Beeinträchtigung des durch Planung erstrebten Charakters durch funktionswidrige Anlagen ${ }^{24}$. Allerdings bezog sich der Beschluß von 1964 auch auf eine Werbeanlage. Gegenüber der dort zunächst allgemein gemachten Aussage über die Zulässigkeit des Schutzes der beabsichtigten Planung ist dies aber eine gewichtige Einschränkung. Denn daß der Rechtsprechung in dieser eingeschränkten Bedeutung zuzustimmen ist, ist wiederum relativ unproblematisch. Bestimmte Formen vor allem der Außenwerbung können den Gebietscharakter in Frage stellen. Sie stören etwa die Wohnruhe, auch ohne im akustischen Sinne "Krach zu machen"25. Wenn es aber keinen Bedenken unterliegt, daß die Gemeinden bestimmten Gebieten einen bestimmten Charakter verleihen können, lassen sich auch keine Bedenken dagegen erheben, diesen Gebietscharakter dann auch optisch zu wahren. Die Gründe, die für die Funktionstrennung durch Ausweisung bestimmter Baugebietsarten nach der BauNVO sprechen, rechtfertigen daher auch den gebietskonformen Ausschluß bzw. die entsprechende Beschränkung von Werbeanlagen. Man kann sogar daran zweifeln, ob ein solcher Einsatz örtlicher Bauvorschriften unter den hier definierten Begriff der positiven Gestaltungspflege paßt. Denn wenn etwa Werbeanlagen in Neubaugebieten eingeschränkt werden, dann wird, wenn sich die Gemeinde auf gebietswidrige Nutzungen beschränkt, nur das unterbunden, was ohnehin

${ }^{21}$ BVerwG, Urteil vom 28.06.1955, E 2, 172 ff.

22 BVerwGE 2, 179.

${ }^{23}$ DÖV 1965, S. 343.

${ }^{24}$ BVerwG, Urteil vom 28.04.1972, E 40, 94 (99); Urteil vom 22.02.1980, 4 C 44.76, DÖV 1980, S. 521 (Hervorhebung vom Verfasser).

${ }^{25}$ Weyreuther, BauR 1972, S. 4, spricht davon, sie seien "gebietswidrig laut". 
nicht in das Gebiet hineinpaßt und so ein antezipierter Gebietsschutz betrieben, den man auch in die Nähe der erweiterten Gebietspflege rücken kann.

Aus keiner der erwähnten Entscheidungen des BVerwG lassen sich daher für die eigentlichen eigentumsrechtlichen Probleme einer positiven Gestaltungspflege Schlüsse ziehen. Wenn die Gemeinden etwa Vorschriften über die Dachform und den Außenanstrich oder die Art von Einfriedungen erlassen, hat dies mit dem Verhindern funktionswidriger Anlagen nichts zu tun. Es besteht zwar oft ein Planungszusammenhang mit Festsetzungen nach § 9 Abs. $1 \mathrm{BauGB}^{26}$. Flachdächer sind in einem Wohngebiet aber grundsätzlich genauso wenig funktionswidrig wie geneigte Dächer auch. Der Gesamtzusammenhang der Planung mag ein gewisses Spektrum von möglichen Außenanstrichen oder Fenstergestaltungen ausschließen. Daß aber aus den in Frage kommenden Varianten eine vorgeschrieben wird, läßt sich nur dadurch erklären, daß die Gemeinde eine bestimmte Gestaltung will. Schreibt die Gemeinde in örtlichen Bauvorschriften als Einfriedungen Jägerzäune vor, kann sie nach gängiger Praxis diesen Willen durchsetzen, auch wenn Eigentümer lieber gleich hohe Hecken pflanzen würden.

Dies mit der Eigentumsgarantie zu vereinbaren fällt schwer. Den öffentlichen Belang, der insofern die Beschränkung der Eigentümerbefugnisse rechtfertigt, kann man nur in dem bereits erwähnten, in Art. 28 Abs. 2 GG fußenden gemeindlichen Selbstgestaltungsrecht sehen ${ }^{27}$. Versteht man dieses Selbstgestaltungsrecht in dem Sinne, daß die Gemeinden grundsätzlich das Recht haben sollen, Gepräge und Struktur des Ortes selbst zu bestimmen $^{28}$, dann wird man dem Gesetzgeber die Befugnis zugestehen können, den Gemeinden rechtliche Instrumentarien auch zur Grundrechtseinschränkung zur Verfügung zu stellen, damit diese ihr "Bild" bestimmen können ${ }^{29}$. In diesen Kontext läßt sich auch die Befugnis der Gemeinden zur positiven Gestaltungspflege einordnen. Es handelt sich dabei um eine genuin gemeindliche Entscheidung, für die allein die Satzungs- (d. h. nicht die Rechtsverordnungs-)form sachgerecht ist ${ }^{30}$.

\footnotetext{
${ }^{26} \mathrm{Vgl}$. die Ausführungen zur kompetenzrechtlichen Qualifikation von örtlichen Bauvorschriften, oben A III 4.

${ }^{27}$ Siehe oben B III 1.

${ }^{28}$ So BayVGH, Beschluß vom 19.11.1985, BayVBl. 1986, S. 370 (372). Weitere Nachweise oben B III 1.

${ }^{29}$ Ausführlich dazu oben B III 1 und 2.

${ }^{30}$ Siehe oben B III 4 e a. E.
} 
Dabei ist der Gesetzgeber selbstverständlich nicht frei in der Zurverfügungstellung eines solchen "Selbstverwirklichungsinstrumentariums". Er ist wie auch sonst im Bereich der Konstituierung von Inhalts- und Schrankenbestimmung des Eigentums - vor allem an das Übermaßverbot gebunden. Besonders die Frage, ob solche satzungsmäßigen Beschränkungen der Eigentümerbefugnisse verhältnismäßig im engeren Sinne sind, wird man jedoch zu bejahen haben. Die äußere Gestaltung baulicher Anlagen ist für das "Bild" einer Gemeinde von ganz entscheidender Bedeutung. Vor allem die in einer Gemeinde vorhandenen baulichen Anlagen prägen ihren "Charakter". Insbesondere dadurch, da $B$ heute Baumaterialien jeder Art überall verfügbar sind, bestehen keine von der geographischen Lage vorgegebenen und deshalb typischen Baustile mehr ${ }^{31}$. Den Gemeinden drohen dadurch Einheitsgesichter, wenn sie nicht die äußere Gestaltung baulicher Anlagen in gewissem Maße bestimmen können. Die für den Eigentümer sich ergebenden Beschränkungen mögen gelegentlich ärgerlich sein, besonders schwerwiegend sind sie in der Regel nicht. Dies gilt zumindest dann, wenn dem Eigentümer ein gewisser Gestaltungsspielraum verbleibt, die Gemeinde also das Aussehen des Gebäudes nicht bis in alle Einzelheiten vorschreibt, sondern sich auf das beschränkt, was für die Schaffung des angestrebten Ortsbildes wirklich unerläßlich ist ${ }^{32}$.

\section{Positive Gestaltungspflege und Identifikationsverbot}

Bedenken gegen die Zulässigkeit einer so verstandenen "positiven Gestaltungspflege" werden auch unter dem Gesichtspunkt des sog. Identifikationsverbotes erhoben. Eine "positive Gestaltungspflege" erfordere die Stellungnahme des Staates zu den im Kunstbereich geltenden und vielfach einander widersprechenden Theorien ${ }^{33}$. Verstände man die "positive Gestaltungspflege" tatsächlich als die Schaffung "höherer Ästhetik"34, so wäre dieser Einwand begründet. Nach den hier vertretenen Auffassungen ist er je-

\footnotetext{
${ }^{31}$ Trommer, Bauwelt 1977, S. 585; Roseneck / Mindak, Der Landkreis 1978, S. 181; Alte Städte - alte Dörfer, S. 7.

32 Siehe auch den Entwurf des Niedersächsischen Sozialministers vom 01.10.1975, wonach sich gestalterische Anforderungen immer auf eine Rahmensetzung beschränken muB; zitiert nach Burger / Krause / Gutschow, S. 137.

${ }^{33}$ So Watzke, Denkmalschutz- und Stadtplanungsrecht, S. 54; Friauf / Wendt, S. 37.

${ }^{34}$ Nachweise hierzu C III 1 a.
} 
doch selbst dann nicht schlüssig, wenn man - was in der vorliegenden Untersuchung nicht geschehen ist - baugestalterische Anforderungen vor allem unter dem Blickwinkel des Art. 5 Abs. 3 GG begutachtet. Zwar können auch die Gemeinden - genausowenig wie der Staat selbst auch - Kunstschaffende sein. Sie sollen dies durch den Erlaß von baugestalterischen Anforderungen aber auch nicht werden. Die Befugnis zum Erlaß solcher Anforderungen besteht nicht, um "Kunst", "ästhetisch Höherwertiges" oder ähnliches zu schaffen bzw. die Bautätigkeit in eine solche Richtung zu lenken, sondern um der Gemeinde die Möglichkeit zu geben, sich ihr eigenes Gepräge zu geben. $\mathrm{Ob}$ die Gemeinde meint, daß das, was sie schafft bzw. das, was aufgrund des von ihr vorgegebenen Rahmens geschaffen wird, künstlerisch wertvoll oder ästhetisch ist, ist irrelevant. Durch ein "unrichtiges" Selbstverständnis wird das, was den Gemeinden grundsätzlich erlaubt ist, nicht unzulässig.

Zudem streben die Gemeinden dann, wenn sie in einem bestimmten Gebiet eine bestimmte optische Gestaltung erreichen wollen, subjektiv auch gar keine Identifizierung mit einer bestimmten Kunstrichtung an. Dies ergibt sich oft schon daraus, daß die Gemeinden innerhalb ihres Gebietes an verschiedenen Stellen ganz verschiedene Gestaltungen vorschreiben ${ }^{35}$. Sie sind nur darauf angewiesen, daß in dem bestimmten Gebiet, in dem eine bestimmte Gestaltung angestrebt wird, auch alle Grundstückseigentümer "mitmachen".

Die mögliche Kollision mit dem Identifikationsverbot wird von vielen Bauordnungen $^{36}$ auch dadurch gemindert, daß der Erlaß von baugestalterischen Anforderungen auf "bestimmte, genau abgrenzbare Teile des $\mathrm{Ge}$ meindegebietes" beschränkt ist. Es wird den Gemeinden also versagt, ein einheitliches Gestaltungskonzept für das gesamte Gemeindegebiet vorzusehen $^{37}$. Es soll nicht einmal zulässig sein, für bestimmte Baugebietsarten einheitliche Bestimmungen zu erlassen ${ }^{38}$. Dadurch wird verhindert, daß die Gemeinden quasi freischwebend irgendetwas festsetzen. Vielmehr müssen sie bei ihren Gestaltungsanforderungen an die Besonderheiten des jeweili-

\footnotetext{
${ }^{35}$ Siehe etwa das bei Wiedenroth, S. 29, wiedergegebene Beispiel, wo zur Erhaltung und Neuinterpretation des "Bremer Hauses" im Ostertorviertel keine einheitliche sondern differenzierte Satzungen mit unterschiedlichen Gestaltungsmerkmalen erlassen wurden.

${ }^{36}$ Siehe etwa $\S 81$ Abs. 1 Nr. 1 BauO NW; $\S 83$ Abs. 1 Nr. 1 a LBO Saarl.

${ }^{37}$ Grosse-Suchsdorf / Schmaltz / Wiechert, \$56 Rn. 8; deutlich auch OVG Koblenz, Urteil vom 22.09.1988, BauR 1989, S. 68 (69), wonach stets eine "gebietsspezifische Gestaltungsabsicht" vorliegen muB.

${ }^{38}$ Rößler, BauO NW, S. 486.
} 
gen Gebietes anknüpfen ${ }^{39}$. Dies lenkt zwar die gemeindlichen Gestaltungsabsichten noch nicht wie bei den Schutzvorschriften in eine bestimmte Richtung. Die Gemeinden müssen aber den jeweiligen speziellen Gegebenheiten gerecht werden. Auf die Frage, "warum hier und nicht woanders?" muß es eine plausible Erklärung geben. Dies dürfte im übrigen zumindest für den Fall der "positiven Gestaltungspflege" auch für die BayBO gelten, die die genannte Beschränkung auf bestimmte, genau abgrenzbare Teile des Gemeindegebietes nicht enthält ${ }^{40}$. Insgesamt wird man daher aus dem möglicherweise einschlägigen Identifikationsverbot keine Bedenken gegen eine positive Gestaltungspflege herleiten können.

\section{Positive Gestaltungspflege und Bestimmtheitsgrundsatz}

a) Bestimmtheit der Satzungsbestimmungen

Bedenken gegen die Zulässigkeit einer positiven Gestaltungspflege im Hinblick auf den Bestimmtheitsgrundsatz lassen sich in zweierlei Weise erheben. Zum einen stellt sich die Frage nach der Bestimmtheit der jeweiligen Satzungsbestimmungen, desweiteren die nach der Bestimmtheit der Vorschriften in den Landesbauordnungen, die als Ermächtigungen zum Erlaß von positiven Gestaltungsvorschriften verstanden werden ${ }^{41}$. Die Frage der hinreichenden Bestimmtheit der jeweiligen Satzungsbestimmungen ist geradezu ein klassischer Dauerkonflikt zwischen den auf eine flexible "Verhandlungsposition" im Baugenehmigungsverfahren bedachten Stadtplanern und den auf rechtsstaatliche Bestimmtheit beharrenden Juristen ${ }^{42}$. Angesichts der Tatsache, daß genaue satzungsmäßige Gestaltungsanforderungen von Stadtbildplanern häufig als zu starr und für die Erreichung einer positiven Stadtgestalt nicht förderlich empfunden werden ${ }^{43}$, gibt es eine Reihe von Satzungsbestimmungen, die von dem Versuch zeugen, zu mehr Beweglich-

39 Böckenförde, in: Gädtke / Böckenförde / Temme, § 81 Rn. 11; OVG Koblenz, Urteil vom 22.09.1988, BauR 1989, S. 69.

${ }^{40}$ Anders Koch / Molodovsky / Rahm, Art. 91 Anm. 2.2.2.

${ }^{41}$ Siehe dazu den nächsten Abschnitt.

${ }^{42}$ Vergleiche etwa das bei Burger / Gutschow / Krause, S. 131, wiedergegebene Protokoll einer Stadtratssitzung in Celle.

${ }^{43}$ Siehe Matthaei, S. 9; Schlüter, Stadtbauwelt 1975, S. 260; Trieb / Schmidt / Paetow / Buch / Strobel, S. 109. Sehr pointiert Hackelsberger, S. 88: Der Erlaß einer Gestaltungssatzung sei ein Verfahren, dessen Absurdität auf Dauer jede Produktivität, ja Bewegung ausschließe. 
keit zu kommen, dabei aber fast unweigerlich in Konflikt mit dem Bestimmtheitsgrundsatz und damit in die Gefahr der Unwirksamkeit geraten.

Dafür lassen sich einige Beispiele nennen. Juristisch betrachtet relativ harmlos ist etwa eine Formulierung wie die, wonach die bauliche Anlage sich in das vorhandene Orts- und Straßenbild einfügen müsse ${ }^{44}$. Mehr als das, was eine formellgesetzliche Bestimmung mit einer solchen Formulierung erreichen kann, läßt sich, da der Bestimmtheitsgrundsatz für Satzungen nicht weniger gilt als für formelle Gesetze, so nicht erreichen. Gleiches gilt für Satzungsbestimmungen, die den Beurteilungsmaßstab verfeinern wollen, also in Anlehnung an Bestimmungen in einigen Landesbauordnungen für die Beurteilung der Gestaltung einen "sachkundigen und erfahrenen Betrachter" heranzuziehen ${ }^{45}$. Erhofft man sich mehr als das, was auch durch baugestalterische Generalklauseln möglich ist, wie etwa Gestaltung gemäß der fachlichen Beratung durch die zuständigen Ämter und Gremien ${ }^{46}$, dann läßt sich dies mit dem Erlaß einer solchen Satzung zumindest nicht erzwingen. Der vom Bestimmtheitsgrundsatz gezogene Rahmen ist der gleiche wie bei formellen Gesetzen auch. Eher als Motto und nicht im Sinne einer juristisch verbindlichen Normierung dürften auch Bestimmungen gedacht sein wie die, daß auf die Gestaltung der Häuserzeile in einer bestimmten Straße "besondere Sorgfalt" zu verwenden ${ }^{47}$, oder daß großer Wert auf die Gestaltung der Rückfassaden zu legen $\operatorname{sei}^{48}$. Bedenklich sind dagegen Bestimmungen, wie die, daß die Firstrichtung eines Gebäudes im Einvernehmen mit dem Bauamt und dem Landeskonservator erfolgen soll ${ }^{49}$, oder der Farbanstrich im Einvernehmen mit dem Stadtbauamt festzulegen sei $^{\text {is }}$. Dies verstößt auf jeden Fall gegen die Eigentumsgarantie. Den zuständigen Behörden wird so ein Ermessen im Hinblick auf Inhalts- und Schrankenbestimmung des Eigentums eingeräumt, was weder mit der gesetzlichen Konzeption der Baugenehmigung als gebundener Verwaltungsakt noch mit der

${ }^{44}$ So die Satzung der Stadt Aachen vom 27.06.1979, zitiert nach Matthaei ,S. 12. Weiterhin $\S 2$ der BaugestaltungsVO der Stadt Weißenburg, abgedruckt bei Zwanzig, Der Landkreis 1975, S. 281 f.

${ }^{45}$ So $\S 4$ der Ortssatzung der Stadt Celle vom 15.07.1971, zitiert nach Burger / Gutschow / Krause, S. 127.

${ }^{46}$ Siehe Matthaei, S. 9.

${ }^{47}$ Satzung der Stadt Detmold, zitiert nach Burger / Gutschow / Krause, S. 96.

${ }^{48}$ Zitiert nach Burger / Gutschow / Krause, S. 33.

${ }^{49}$ Satzung der Stadt Lemgo, zitiert nach Burger / Gutschow / Krause, S. 92.

${ }^{50} \S 4$ Abs. 3 S. 2 der BaugestVO der Stadt Weißenburg, abgedruckt bei Zwanzig, Der Landkreis 1975, S. $281 \mathrm{f}$. 
durch Art. 14 GG grundsätzlich geschützten Baufreiheit vereinbar ist. Gleiches gilt für jeden anderen Versuch, satzungsmäßige Rechtsverbindlichkeit mit dem Wunsch nach Flexibilität dergestalt zu verbinden, daß im Einzelfall öffentlichen Stellen ein Mitspracherecht an der konkreten Gestaltung zusteht.

Die notwendige Bestimmtheit der Satzungsbestimmungen ist trotz allem kein Argument gegen die grundsätzliche Zulässigkeit positiver Gestaltungspflege. Der Bestimmtheitsgrundsatz beschränkt nur in gewissem Maße den gemeindlichen Wunsch nach "Offenheit". Soweit dagegen die Gemeinden ihre Gestaltungsabsichten auch durch rechtsstaatlich unbedenkliche Formulierungen, z. B. durch die eindeutige Festlegung des zulässigen Dachneigungswinkels, die genaue Festlegung der zulässigen Größe der Fenster etc., durchsetzen können, ergeben sich insoweit keine Bedenken. Die Frage, ob dem rechtsstaatlichen Bestimmtheitsgrundsatz genügt werden kann, hängt damit von den konkreten Absichten ab. Ein grundsätzlicher Einwand gegen die Zulässigkeit positiver Gestaltungspflege ergibt sich daraus nicht.

b) Bestinıntheit der Ermächtigungsgrundlagen

Wird eine positive Gestaltungspflege aufgrund des Bestimmtheitsgrundsatzes für unzulässig gehalten, so beziehen sich diese Bedenken daher in erster Linie auf die Ermächtigungsnormen in den Landesbauordnungen. Dem Erfordernis der Bestimmtheit der jeweiligen Satzungsvorschriften läßt sich durch entsprechende Formulierungen in der Praxis nachkommen. Hingegen seien - so wird argumentiert - die Ermächtigungsvorschriften dann nicht mehr hinreichend konkret, wenn man in ihnen die Befugnis zur "positiven Gestaltungspflege" sehen wollte, weil ihnen dann nicht mehr entnommen werden könnte, "in welchem Rahmen die Gemeinden eigene gestalterische Absichten verwirklichen können" ${ }^{\text {"11. }}$.

Das Maß der notwendigen Bestimmtheit einer Satzungsermächtigung ergibt sich vor allem aus der sog. Wesentlichkeitstheorie. Da die positive Gestaltungspflege als genuin gemeindliche Aufgabe zu verstehen ist, deren staatliche Wahrnehmung nicht in Betracht kommt ${ }^{52}$, läßt sich aus einem Punkt die behauptete Unbestimmtheit der Ermächtigungen zum Erlaß von positiven Gestaltungsregeln nicht herleiten, nämlich daraus, daß der Ge-

\footnotetext{
${ }^{51}$ Friauf / Wendt, S. 36.

${ }^{52}$ Siehe oben B III 2.
} 
setzgeber den Gemeinden nicht vorgibt, welche Absichten sie verfolgen sollen. Der parlamentarische Gesetzgeber wird vielmehr seiner Verantwortung gerecht, wenn er den Gemeinden den Rahmen absteckt, in dem sie zulasten des privaten Grundeigentums vor allem ihr optisches Bild finden dürfen. Dieser Rahmen läßt sich nun für die Gemeinden im Wege der Auslegung der entsprechenden Ermächtigungsvorschriften in hinreichend konkretem Maße bestimmen. Zunächst können die Gemeinden nur solche Elemente der baulichen Anlage einer Regelung unterziehen, die überhaupt von außen sichtbar sind. Die Ermächtigungen sind auch noch nicht anders verstanden worden. Desweiteren sind die meisten auch optisch relevanten Entscheidungen für die Gestaltung eines Gebäudes ohnehin über $\S 9$ Abs. 1 BauGB zu treffen. Der Restbereich, der für baugestalterische Vorschriften noch übrig bleibt, besteht vor allem aus der Farbwahl, der Gestaltung von Dächern, Fenstern und Einfriedungen ${ }^{53}$. Damit läßt sich aus der Formel "Sichtbarkeit von außen minus Festsetzungen nach $\S 9$ Abs. 1 BauGB" der Betätigungsrahmen der Gemeinden eindeutig festlegen. Aus dem Bestimmtheitsgebot bestehen somit keine Bedenken dagegen, die landesrechtlichen Vorschriften über den Erlaß von örtlichen Bauvorschriften im Sinne einer positiven Baugestaltung zu interpretieren.

\footnotetext{
${ }^{53}$ Vergleiche die Aufzählung bei Kromik, S. 97.
} 


\section{E. Das Normenerlaßverfahren bei örtlichen Bauvorschriften - materiellrechtliche und verfahrensrechtliche Probleme}

\section{Die Aufnahme von örtlichen Bauvorschriften in den Bebauungsplan}

\section{Die Bedeutung des $§ 9$ Abs. 4 BauGB}

a) Formelle oder materielle Deutung des $\$ 9$ Abs. 41 . HS BauGB

Die Vorschrift des $\S 9$ Abs. 4 BauGB, wonach die Länder durch Rechtsvorschriften bestimmen können, daß auf Landesrecht beruhende Regelungen als Festsetzungen in den Bebauungsplan aufgenommen werden können, scheint auf den ersten Blick keine größeren Interpretationsprobleme aufzuwerfen. Die Vorgängervorschrift des $\S 9$ Abs. 2 BBauG 1960 hatte Anwendungsschwierigkeiten noch dadurch hervorgerufen, daß die Landesregierungen durch Rechtsverordnung über die Möglichkeit der Aufnahme in den Bebauungsplan entscheiden sollten ${ }^{1}$. Demgegenüber spricht $\S 9$ Abs. 4 BBauG n. F. / BauGB ${ }^{2}$ neutral von "Rechtsvorschriften" und respektiert damit das jeweilige Landesorganisationsrecht.

Das bisher am meisten diskutierte Problem im Hinblick auf die Aufnahme von Regelungen mit landesrechtlicher Grundlage ist damit erledigt. Die Möglichkeit des $\$ 9$ Abs. 4 BBauG / BauGB ist von den Landesgesetzgebern auch angenommen worden. Die Landesbauordnungen sehen weitgehend vor, da $\beta$ örtliche Bauvorschriften auch als Festsetzungen des Bebauungsplans erlassen werden können ${ }^{3}$.

\footnotetext{
${ }^{1} \mathrm{Zu}$ den damit zusammenhängenden Problemen siehe Fehrmann, BauR 1971, S. 148 ff.

${ }^{2}$ Die Vorschrift des $\$ 9$ Abs. 4 hat durch den Erlaß des Baugesetzbuchs keine Änderung erfahren, so daß die folgenden Feststellungen sowohl für $\S 9$ Abs. 4 BauGB als auch für $\S 9$ Abs. 4 BBauG gelten.

3 \$ 73 Abs. 6 LBO BW; Art. 91 Abs. 3 BayBO; $\$ 7$ AGBauGB BIn, GVBI. vom 19.12.1987, S. 2731; $\$ 110$ Abs. 4 BremLBauO; $\S 118$ Abs. 4 HBO i. V. m. $\S 1$ VO vom 28.01.1979, GVBI. I, S. $102 ; \S 98$ NBauO; $\$ 81$ Abs. 4 BauO NW; $\S 86$ Abs. 6 LBO Rh.Pf.; $\S 83$ Abs. 4 LBO Saarl.; $\$ 82$ Abs. 4 LBO SI.H.
} 
Die Bedeutung des $\S 9$ Abs. 4 BauGB wird relativ einhellig dahingehend verstanden, daß damit das bundesrechtliche Rechtsinstitut "Bebauungsplan" für Regelungen geöffnet wird, die auf Landesrecht beruhen, $d$. h. formal zur Verfügung gestellt wird, so daß die Sperrwirkung überwunden wird, die sich aus dem als abschließend konzipierten $\S 9$ Abs. 1 BauGB ergibt ${ }^{4}$. 9 Abs. 4 BauGB kommt danach eine rein formelle Bedeutung $\mathrm{zu}^{5}$. Einigkeit herrscht auch dahingehend, daß die aufgenommenen Regelungen ihren landesrechtlichen, d. h. für den Bereich der örtlichen Bauvorschriften ihren bauordnungsrechtlichen Charakter nicht verlieren. Bauordnungsrechtliche und bauplanungsrechtliche Regelungen würden lediglich in einem Planwerk zusammengefaßt ${ }^{6}$. Die Bedeutung des $\S 9 \mathrm{Abs} .4 \mathrm{BauGB}$ erschöpfe sich darin, den Ortsgesetzgeber von dem "Instrumentarium" des Bebauungsplans Gebrauch machen zu lassen?

Eine solche rein formale Deutung des $\S 9$ Abs. 4 BauGB vermag jedoch nicht recht zu überzeugen. Denn bei einer solchen Sicht wäre $\S 9$ Abs. 4 1. HS BauGB bedeutungslos, da seine Aussage vollkommen banal wäre. So ist es in der Rechtswissenschaft nichts Ungewöhnliches, einen auf den ersten Blick als Einheit erscheinenden Vorgang rechtlich zu trennen und insbesondere Maßnahmen von Behörden nach verschiedenen Rechtsgrundlagen aufzuschlüsseln. Die Tatsache, daß immer wieder betont wird, die in den Bebauungsplan aufgenommenen Vorschriften verlören nicht ihren landesrechtlichen Charakter, zeigt dies deutlich: Obwohl die einzelnen Festsetzungen sich äußerlich in einem Planwerk befinden, werden sie nach ihrer rechtlichen Herkunft unterschiedlich qualifiziert. Hätte § 9 Abs. 4 1. HS BauGB tatsächlich nur eine formale Bedeutung, so wäre seine Aussage letztlich die, da $ß$ auf ein- und demselben Blatt Papier eine Regelung aufgrund des BauGB und aufgrund Landesrechts enthalten sein dürfte. Das Rechtsinstitut Bebauungsplan würde aber kaum in seiner Funktionsfähigkeit gefährdet, würde man die rein äußerliche Verbindung auch ohne § 9 Abs. 4 BauGB und eine weitere landesrechtliche Regelung für zulässig halten. Denkt man sich etwa § 9 Abs. 4 BauGB in der Weise weg, daß es ihn oder eine ähnliche

\footnotetext{
${ }^{4}$ Gaentzsch, Berliner Kommentar, $\$ 9$ Rn. 67; Grauvogel, in: Kohlhammer Kommentar BBauG, § 9 III 2; Koch / Molodovsky / Rahm, Art. 91 Anm. 4.3.2.; OVG Lüneburg, Urteil vom 19.12.1979, DÖV 1980, S. 837 (838).

${ }^{5}$ Gelzer, Rn. 200; Bielenberg, in: Ernst / Zinkahn / Bielenberg, § 9 BBauG Rn. 86; BT-Drs. 7/2496, S. 41. Rn. 67.

${ }^{6}$ Löhr, in: Battis / Krautzberger / Löhr, § 9 Rn. 107; Gaentzsch, Berliner Kommentar $\$ 9$

${ }^{7}$ So das OVG Saarlouis, Urteil vom 04.12.1981, BRS Band 38, Nr. 48 S. 111.
} 
Vorschrift nie gegeben hätte, dann würde man kaum zur Rechtswidrigkeit einer oder beider Satzungen kommen, wenn eine Gemeinde einen Bebauungsplan mit Festsetzungen nach $\S 9$ Abs. 1 BauGB und etwa örtliche Bauvorschriften parallel aufstellen und beschließen und zusammengefaßt veröffentlichen würde. Vielmehr würden dann, wenn die entsprechenden formellen und materiellen Voraussetzungen vorliegen, beide Satzungen für wirksam erlassen gehalten werden. Als einzige mögliche Einschränkung wäre denkbar, daß das Gebot der Planklarheit verletzt wäre. Der Planklarheit ist aber eher gedient, wenn sachlich zusammenhängende Regelungen auch zusammenhängend veröffentlicht werden.

Auch die Tatsache, daß $\S 9$ Abs. 4 BauGB eine Aufnahme in den Bebauungsplan "als Festsetzung" vorsieht, führt nicht zu einem Argument für die formale Betrachtungsweise. Der Begriff "Festsetzung" dient im BauGB als Umschreibung für die Rechtsverbindlichkeit der Regelungen eines Bebauungsplans im Gegensatz vor allem zu den "Darstellungen" des Flächennutzungsplans ${ }^{8}$. Normcharakter und damit Rechtsverbindlichkeit der aufzunehmenden Regelung setzt jedoch der $\S 9$ Abs. 4 BauGB voraus ${ }^{9}$. Werden solche landesrechtlichen Regelungen in den Bebauungsplan aufgenommen, so ändert sich auch insoweit an deren rechtlicher Qualität nichts. Die landesrechtlichen Regelungen wären ohne Aufnahme in den Bebauungsplan rechtsverbindlich und sie bleiben es bei einer Aufnahme. Schließlich bedeutet die landesrechtliche Aufnahme in den Bebauungsplan "als Festsetzung" auch nicht, daß die landesrechtlichen Bestimmungen damit in jeder Hinsicht wie eine Festsetzung des Bebauungsplanes zu behandeln wären. Dies zeigt deutlich der zweite Halbsatz des $\S 9$ Abs. 4 BauGB, der es gerade dem Landesgesetzgeber überläßt festzulegen, welche Regelungen des BauGB anzuwenden sind ${ }^{10}$.

Soll der 1. Halbsatz des $\S 9$ Abs. 4 BauGB somit eine Bedeutung haben, dann muß dort mehr geregelt werden als eine rein formelle Frage. Eine materielle Deutung des $\S 9$ Abs. 4 BauGB läßt sich auch ohne weiteres begründen. Der Gesetzgeber hat $\S 9$ Abs. 41 . HS BauGB vor allem für solche Regelungen geschaffen, die eine sachliche Nähe oder Verwandtschaft zu den nach $\S 9$ Abs. 1 BauGB möglichen Inhalten des Bebauungsplans ha-

\footnotetext{
${ }^{8}$ Vgl. §§ 5 Abs. 1 S. 1 und 8 Abs. 1 S. 1 BauGB.

${ }^{9}$ Gaentzsch, Berliner Kommentar, § 9 Rn. 67.

${ }^{10}$ Zur genauen Bedeutung dieser Bestimmung siehe den nächsten Abschnitt.
} 
ben $^{11}$. Auch wenn dies im Gesetzestext nicht ausdrücklich geregelt wird, handelt es sich insoweit um eine Voraussetzung dafür, daß die Länder von der Ermächtigung des $\S 9$ Abs. 4 1. HS BauGB Gebrauch machen dürfen ${ }^{12}$. Ermöglicht aber $\S 9$ Abs. 4 BauGB die Aufnahme von sachlich mit den Festsetzungen nach $\S 9$ Abs. 1 BauGB zusammenhängenden Regelungen in den Bebauungsplan, dann zieht er damit die Konsequenzen daraus, daß diese aufzunehmenden Normierungen die Festsetzungen nach $\S 9$ Abs. 1 BauGB inhaltlich ergänzen. Er ermöglicht die Schaffung eines materiellen Planungs- und Planzusammenhangs zur Regelung von Gegenständen, die sachlich zusammengehören, aber vom Bundesgesetzgeber aus angenommenen oder tatsächlich vorhandenen kompetenzrechtlichen Schranken nicht insgesamt normiert worden sind.

Hiergegen mag man einwenden, daß es der Gemeinde auch sonst nicht verwehrt ist, etwa ein Bebauungsplanaufstellungsverfahren und ein Verfahren zum Erlaß einer örtlichen Bauvorschrift gleichzeitig zu betreiben und inhaltlich aufeinander zu beziehen. Um noch einmal das Beispiel der Dachgestaltung aufzugreifen: Will die Gemeinde zweigeschossige Bauweise festsetzen, so kann sie das damit begründen, daß geplant sei, im gleichzeitig betriebenen Verfahren zum Erlaß einer örtlichen Bauvorschrift Flachdächer vorzuschreiben und daß deshalb eine mit nachbarlichen Belangen vereinbare Höhenentwicklung der Gebäude garantiert sei. Trotzdem besteht zwischen einem solchen inhaltlich "In-Bezug-Stehen" zweier selbständiger Satzungen und einem materiellen Planungszusammenhang ein Unterschied. Denn letztlich bleibt es ein für das Bebauungsplanverfahren mit Unsicherheiten befrachtete Prognose, ob die angestrebte örtliche Bauvorschrift wirklich zustande kommt. Diese Unsicherheit ergibt sich eben daraus, daß nicht ein, sondern zwei Verfahren durchlaufen werden müssen. Durch unterschiedliche Verfahrensgestaltungen bei der Aufstellung, unterschiedliche staatliche Einflußnahme durch unterschiedliche Kontrollverfahren und Kontrollmaßstäbe kann es zu Verzögerungen oder Änderungen beim Erlaß einer der Satzungen kommen. Weiterhin ist es denkbar, daß etwa ein fehlerhafter Bebauungsplan wegen den $\S \S 214 \mathrm{ff}$. BauGB bestandskräftig ist, die an einem entsprechenden Mangel leidende örtliche Bauvorschrift aber nichtig ist. Durchlaufen also örtliche Bauvorschriften und der dazugehörige

\footnotetext{
${ }^{11}$ Gaentzsch, Berliner Kommentar, §9 Rn. 67.

${ }^{12}$ So wohl auch Bielenberg, in: Ernst / Zinkahn / Bielenberg, $\$ 9$ BBauG Rn. 85 b; Löhr, in: Battis / Krautzberger / Löhr, § 9 Rn. 109.
} 
Bebauungsplan unterschiedliche Verfahren, dann besteht die Gefahr, daß der materielle Zusammenhang zerrissen wird.

Rückwirkungen hat der $\S 9$ Abs. 4 BauGB so vor allem auf die Beschlußfassung im Gemeinderat. Instruktiv hierzu ist eine Entscheidung des OVG Münster ${ }^{13}$. Hierbei ging es um eine gemeinsame Abstimmung über einen Bebauungsplan und andere Beschlußgegenstände. Dem OVG Münster ist sicherlich zuzustimmen, wenn es ausführt, daß eine en-bloc-Beschlußfassung über einen Bebauungsplan, die Öffnungszeiten des kommunalen Freibades, eine Personalfrage etc. zu einem Abwägungsfehler bezüglich des Bebauungsplanes führt ${ }^{14}$. Die einzelnen Gegenstände haben untereinander keinen Zusammenhang. Wird ein solcher Zusammenhang sachwidrig hergestellt, müssen von den Gemeinderatsmitgliedern bei der Entscheidung über den Bebauungsplan Gesichtspunkte berücksichtigt werden, die in eine ordnungsgemäße Abwägung nicht hineingehören. Wo nun die genauen Grenzen einer solchen Verbindung verschiedener Beschlußgegenstände liegt, läßt das OVG Münster ausdrücklich offen, auch bezüglich der Frage, ob es etwa möglich ist, zwei unter Umständen zusammenhängende Bebauungspläne en-bloc abzustimmen ${ }^{15}$. Hingegen läßt sich die Frage für einen Bebauungsplan und die für dasselbe Gebiet zu erlassenen und in den Bebauungsplan aufzunehmenden örtlichen Bauvorschriften klar beantworten: Wegen der Vorschrift des $\S 9$ Abs. 4 BauGB ist gegen eine gemeinsame Beschlußfassung nicht nur nichts einzuwenden, sie ist deshalb, weil es sich um einen einheitlichen Plan handelt, sogar geboten ${ }^{16}$. Käme es nicht zu einer Aufnahme nach $\S 9$ Abs. 4 BauGB, würde zumindest der Grundsatz planerischer Vorsicht es gebieten, über den Bebauungsplan und die zugehörigen örtlichen Bauvorschriften getrennt abzustimmen.

Zusammenfassend läßt sich die Bedeutung des $\S 9$ Abs. 4 1. HS BauGB somit zunächst folgendermaßen beschreiben: Er ermöglicht einen einheitlichen Planungsakt bei Regelungen, die inhaltlich aufeinander bezogen sind, ohne daß aus dem Abwägungsgebot hiergegen Bedenken erhoben werden können.

\footnotetext{
${ }^{13}$ OVG Münster, Urteil vom 17.03.1987, NVwZ 1988, S. 1138 ff.

${ }^{14}$ OVG Münster (Fn. 13), S. 1139.

${ }^{15}$ OVG Münster (Fn. 13), S. 1140.

${ }^{16}$ Anders wohl HessVGH, Urteil vom 19.07.1988, BauR 1989, S. 178 (179).
} 
b) Die Anforderungen bei der Aufnahme von örtlichen Bauvorschriften in den Bebauungsplan

aa) Die Auslegung des $\$ 9$ Abs. 4 2. HS BauGB

Hat $\S 9$ Abs. 4 1. HS BauGB eine Aussage in der Hinsicht, daß er die Herstellung eines materiellen Planungs- und Planzusammenhanges ermöglicht, ergeben sich daraus Konsequenzen für die Auslegung des § 9 Abs. 4 2. HS BauGB. Diese Vorschrift darf nicht in einem Sinne verstanden werden, die dem von § 9 Abs. 4 BauGB geforderten Zusammenhang nicht entspricht. Die Aussage, die $\S 9$ Abs. 4 2. HS BauGB macht, besteht dann darin, daß er im Grundsatz nur für die Frage, welche Folgen an eine Festsetzung zu knüpfen sind, es den Landesgesetzgebern überläßt, hierfür die Anwendbarkeit von Vorschriften des BauGB vorzuschreiben oder auch nicht vorzuschreiben, also etwa für Ausnahmen und Befreiungen. Dagegen ist bis zur Schaffung einer solchen auf landesrechtlicher Grundlage beruhenden Festsetzung dasselbe, d. h. ein einheitliches Verfahren mit den Festsetzungen nach $\S 9$ Abs. 1 BauGB unter Beachtung der hierfür auch materiell geltenden Voraussetzungen zu durchlaufen ${ }^{17}$. Dies würde zwar den Erlaß einer örtlichen Bauvorschrift im Vergleich zum Erlaß einer einfachen Satzung gegebenenfalls verkomplizieren ${ }^{18}$. Die Pflicht zur Einhaltung umfangreicherer formeller und materieller Pflichten würde jedoch der weitgehenderen Möglichkeit des Zusammenspiels mit bauplanungsrechtlichen Festsetzungen entsprechen. § 9 Abs. 4 BauGB würde insgesamt die Aussage enthalten, daß bei Aufnahme von auf Landesrecht beruhenden Festsetzungen in den Bebauungsplan ein Plan in einem Verfahren zu erstellen wäre. Bei einer solchen Sichtweise würde sich auch die Streitfrage beantworten, ob bei Aufnahme von örtlichen Bauvorschriften in den Bebauungsplan die Einhaltung des Satzungsverfahrens in dem Sinne nachweisbar sein muß, daß die Gemeindevertretung sich darüber im klaren gewesen sein muß, neben dem eigentlichen Bebauungsplan eine weitere Satzung beschlossen zu haben ${ }^{19}$. Denn wenn es sich um ein Verfahren handelt und handeln muß, dann gibt

${ }^{17}$ So Gaentzsch, Berliner Kommentar, $\S 9$ Rn. 70; Löhr, in Battis / Krautzberger / Löhr, § 9 Rn. 108.

${ }^{18}$ So auch Hörst, Städte- und Gemeinderat 1977, S. 187.

${ }^{19}$ So vom Standpunkt eines formellen Verständnisses des $\S 9$ Abs. 41 . HS aus konsequent Gelzer, Rn. 202; ebenso HessVGH, Urteil vom 19.07.1988, BauR 1989, S. 178 (179), für den $\$ 9$ Abs. 2 BBauG a. F.; anders insoweit nicht konsequent Bielenberg, in: Ernst / Zinkahn / Bielenberg, BBauG, §9 Rn. 87 a; ablehnend auch J. Ziegler, ZfBR 1980, S. 280. 
es nur einen Plan, ein Verfahren und auch nur eine Satzung, die zu beschließen ist.

Versteht man dagegen $\S 9$ Abs. 4 2. HS BauGB dahingehend, daß dieser auch die Frage, inwieweit für die Planaufstellung die Normen des BauGB Anwendung finden, dem Ermessen des Landesgesetzgebers überlä $\mathrm{B}^{20}$, so führt man den $\S 9$ Abs. 42 . HS dahin, wo bei rein formeller Betrachtung auch der $\S 9$ Abs. 4 1. HS "landet", nämlich in die vollkommene Bedeutungslosigkeit. Denn stände es tatsächlich im Belieben des Landesgesetzgebers, ob und inwieweit auf das Verfahren für die in den Bebauungsplan aufgenommenen, auf landesrechtlicher Grundlage beruhenden Festsetzungen die Vorschriften des BauGB Anwendung finden, dann würde der Bundesgesetzgeber den Ländern etwas erlauben, was er ihnen gar nicht verbieten kann. Wenn die Länder verfahrensrechtlich nicht gebunden wären, stände es ihnen frei, bei der Ausgestaltung dieses Verfahrens auf die Vorschriften eines anderen Gesetzgebers zu verweisen. Zumindest könnte der Bundesgesetzgeber nicht verhindern, daß "seine" Normen von einem anderen Gesetzgeber in bezug genommen werden. Auch unter Geltung des $\S 9$ Abs. 2 BBauG 1960, der eine Klausel wie den $\S 9$ Abs. 4 2. HS BauGB / BBauG nicht enthielt, gab es landesrechtliche Vorschriften, die bei Aufnahme in den Bebauungsplan die Anwendung von bundesrechtlichen Verfahrensvorschriften vorsahen, ohne daß hiergegen rechtliche Bedenken erhoben werden konnten ${ }^{21}$. Will man dem Gesetzgeber nicht unterstellen, daß er im $\S 9$ Abs. 4 2. HS BauGB nur Sinnloses regelt, ist ein solches Verständnis nicht angebracht.

\section{bb) Die Anforderungen im einzelnen}

Das vom Wortlaut des $\S 9$ Abs. 4 BauGB nahegelegte und auch sinnvolle Ergebnis besteht somit darin, daß der Landesgesetzgeber grundsätzlich nur für die Rechtsfolgen aus Festsetzungen ein Ermessen hat, ob er das BauGB für anwendbar erklärt. Für die Schaffung von in den Bebauungsplan aufzunehmende Regelungen auf landesrechtlicher Grundlage müssen hingegen die vom BauGB vorgesehenen verfahrensmäßigen und materiellrechtlichen Voraussetzungen eingehalten werden. Diese Auffassung wird jedoch zumin-

${ }^{20}$ In diese Richtung etwa Bielenberg, in: Ernst / Zinkahn / Bielenberg, BBauG, \& 9 Rn. 87 a; Grauvogel, in: Kohlhammer Kommentar BBauG, \& 9 III 4.

${ }^{21}$ Bielenberg, in: Ernst / Zinkahn / Bielenberg, BBauG, § 9 Rn. 87 a, mit Hinweisen auf die damalige Rechtslage in den Ländern. 
dest auf den ersten Blick von den Landesgesetzgebern nicht geteilt. Die Landesbauordnungen erklären in der Regel einige, nicht aber alle Vorschriften für die Aufstellung von Bebauungsplänen für anwendbar ${ }^{22}$. So beschränken sich etwa $\S 82$ Abs. 4 LBO Sl.H. und auch das hessische Landesrecht $^{23}$ darauf, den $\S 12 \mathrm{BBauG}$, also die Vorschrift über das Inkrafttreten, für entsprechend anwendbar zu erklären ${ }^{24}$. Unter den Bauordnungen, die ausdrücklich nur einige Vorschriften des BBauG in bezug nehmen, nennt nur die BayBO die für die Bauleitplanaufstellung zentralen Bestimmungen des $\S 1$ Abs 5 - 7 BBauG und damit das Abwägungsgebot. Die ebenfalls wichtige Begründungspflicht des $\S 9$ Abs. $8 \mathrm{BBauG}$ wird dagegen in Art. 91 Abs. 3 S. 3 BayBO ausdrücklich von einer entsprechenden Anwendung ausgenommen.

Daraus, daß die nach $\S 9$ Abs. 4 BauGB in den Bebauungsplan aufgenommenen, auf Landesrecht beruhenden Bestimmungen materiell mit den eigentlichen bauplanungsrechtlichen Festsetzungen zu einer Einheit zusammengefaßt werden dürfen und deshalb verfahrens- und materiellrechtlich eine Einheit bilden müssen, läßt sich nun jedoch nicht der Schluß ziehen, daß deshalb jede Vorschrift für das Verfahren zur Aufstellung von Bebauungsplänen automatisch auch auf Regelungen aufgrund von Landesrecht Anwendung finden müßte ${ }^{25}$. Vielmehr gibt es eine Reihe von Vorschriften in den §§ 1 - 13 BauGB / BBauG, die für die Gegenstände, die in örtlichen Bauvorschriften geregelt werden können, selbst angesichts des Ziels, eine verfahrensmäßige und inhaltliche Einheit herzustellen, nicht zwingend auch dort Anwendung verlangen. So gibt es etwa für das (materiellrechtliche) Entwicklungsgebot des $\S 8$ Abs. 2 BauGB / BBauG keinen sinnvollen Anwendungsbereich. Andere Bestimmungen würden angesichts der vielfach geringeren Bedeutung der in örtlichen Bauvorschriften geregelten Sachverhalte als ein Zuviel an Voraussetzungen erscheinen und die in gewissen Stationen notwendige Konzentration auf das Wesentliche nur erschweren, wie etwa die Einhaltung des Abstimmungsgebotes des § 2 Abs. 4 BBauG / § 2

22 Anders $\S 73$ Abs. 6 LBO BW, $\S 110$ Abs. 4 BremLBauO und $\S 83$ Abs. 4 S. 2 LBO Saarl., die das Verfahren nach dem BBauG / BauGB für anwendbar erklären. Keine Abweichung gegenüber dem aufgrund der Ermächtigung des § 246 BauGB modifizierten Verfahrens zum Erlaß eigentlicher Bauleitpläne ergibt sich auch nach der Rechtslage in Berlin, siehe $\$ 7$ AGBauGB vom 19.12.1987, GVBI. S. $2731 \mathrm{f}$.

${ }^{23} \S 118$ Abs. 4 HBO i. V. m. § 1 VO vom 28.01.1977, GVBI. I, S. 102.

24 Vergleiche auch $\S 5$ Hamb. Gesetz über die Feststellung von Bauleitplänen vom 04.04.1978, GVBI. S. 89 f., der die Anwendung von Vorschriften des BBauG ganz ausschließt.

${ }^{25}$ So auch Gaentzsch, Berliner Kommentar, $\$ 9$ Rn. 71. 
Abs. 2 BauGB oder die frühzeitige Bürgerbeteiligung nach $\S 2$ a Abs. 1 - 5 BBauG / § 3 Abs. 1 BauGB.

$\mathrm{Da}$ der Landesgesetzgeber letztlich über die Art der Regelungen entscheidet, die in den Bebauungsplan aufgenommen werden sollen, wird man ihm ein gewisses Ermessen einräumen müssen. So spielt bei örtlichen Bauvorschriften die bei der Verfahrensbeteiligung für die Aufstellung eines Bebauungsplanes wichtige Rechtsschutzfunktion für die Betroffenen ${ }^{26}$ eine nur geringe Rolle. Verfahrensvorschriften und dabei vor allem Beteiligungsrechte sollen strukturelle Defizite des verwaltungsgerichtlichen Rechtsschutzes ausgleichen, der vor allem aufgrund des Zeitmomentes häufig zu spät kommt ${ }^{27}$. Örtliche Bauvorschriften sorgen jedoch - anders als Planfeststellungsbeschlüsse oder die eigentliche Bauleitplanung - seltener für vollendete Tatsachen, die hinterher nicht mehr rückgängig gemacht werden können. Vor allem beim erstmaligen Erlaß von örtlichen Bauvorschriften verliert ein Eigentümer in der Regel nichts dadurch, daß sich seine Nachbarn an die einschränkenden Bestimmungen halten. Dies kann etwa bei Änderungen von örtlichen Bauvorschriften wie in den Flachdachfällen auch einmal anders sein. Insgesamt hat die Rechtsschutzfunktion der Verfahrensgestaltung aber bei örtlichen Bauvorschriften eine im Vergleich zu den eigentlichen bauplanungsrechtlichen Festsetzungen untergeordnete Bedeutung.

Es steht daher dem Landesgesetzgeber frei, auch dann, wenn er eine materielle Planeinheit in Ausschöpfung der Ermächtigung des $\$ 9$ Abs. 4 BauGB erreichen will, einige Vorschriften des BBauG / BauGB von der entsprechenden Anwendung, die der $\S 9$ Abs. 4 BauGB grundsätzlich fordert, auszunehmen. $\mathrm{Da} \beta$ die Bestimmungen des BauGB gelten, folgt daraus, $\mathrm{da} \beta$ die Aufnahme von landesrechtlichen Vorschriften nach $\S 9$ Abs. 4 BauGB ermöglicht werden soll ${ }^{28}$. Da aber letztlich der Landesgesetzgeber über die Art der aufzunehmenden Vorschriften entscheidet, wird man ihm ein Ermessen dahingehend einräumen müssen, welche Vorschriften zur Ermöglichung eines Planzusammenhangs nötig sind und welche im Hinblick auf den Gegenstand der aufzunehmenden Vorschriften nicht passen. Die Bestimmungen der Landesbauordnungen, die die Anwendung bestimmter

\footnotetext{
${ }^{26}$ Vgl. dazu Blümel, Grundrechtsschutz durch Verfahrensgestaltung, S. 25 f.; Bethge, NJW 1982, S. 7; Ossenbühl, DÖV 1981, S. 6, ders., NVwZ 1982, S. 466; Kimminich, Fünftes Deutsches Atomrechtssymposium, S. 266; Wallraven-Lindl, S. 81; Fackler, S. 112

${ }^{27}$ Battis, DÖV 1981, S. 433; Pietzcker, VVDStRL 41 (1983), S. 201.

${ }^{28}$ So auch Gaentzsch, Berliner Kommentar, $\$ 9$ Rn. 71.
} 
Vorschriften vorsehen, sind deshalb - quasi in einer Art bundesrechtskonformer Auslegung - nicht so zu lesen, daß diese Vorschriften bei der Aufnahme gelten sollen, sondern in dem Sinne, daß die nicht genannten Vorschriften nicht gelten sollen.

Die Frage, welches "Pflichtprogramm" die Landesgesetzgeber vorschreiben müssen, damit eine Aufnahme im Sinne von $\S 9$ Abs. 4 BauGB möglich ist, läßt sich somit nur anhand der jeweiligen aufzunehmenden Regelungen und nicht generell für alle Möglichkeiten zur Ausschöpfung des § 9 Abs. 4 beantworten. Untersucht man diese Frage speziell für örtliche Bauvorschriften, so wird man zunächst feststellen müssen, daß die Geltung des Abwägungsgebotes zumindest im Grundsatz auch für örtliche Bauvorschriften unabdingbar ist. Der enge Zusammenhang zwischen Festsetzungen nach § 9 Abs. 1 BauGB und Regelungen aufgrund örtlicher Bauvorschriften besteht gerade in dem teilweise identischen Abwägungsmaterial und der gegenseitigen Ergänzung oder Kompensation ${ }^{29}$.

Die zweite Vorschrift, die für die Herstellung einer verfahrensmäßigen Einheit unerläßlich ist, ist $\S 2$ a Abs. 6 BBauG oder $\S 3$ Abs. 2 BauGB. Wenn die auf Landesrecht beruhenden Regelungen und die Festsetzungen aufgrund $\S 9$ Abs. 1 BauGB zu einer Einheit verschmolzen werden, dann können Bedenken und Anregungen sinnvollerweise nur dann erhoben werden, wenn auch die örtlichen Bauvorschriften ausgelegt und erläutert werden. Daraus ergibt sich, daß örtliche Bauvorschriften auch der Begründungspflicht des $\S 9$ Abs. 8 BauGB / BBauG unterliegen. Es wäre kein sinnvolles Ergebnis, eine Entwurfsbegründung nach $\S 3$ Abs. 2 BauGB zu verlangen, auf eine Begründung des beschlossenen Planes aber zu verzichten.

Entgegen $\S 97,98 \mathrm{NBauO}$ ist es auch nicht möglich, den Wirkungskreis anders zu bestimmen, als dies in $\S 2$ Abs. $1 \mathrm{~S}$. 1 BauGB vorgesehen ist. Wenn der Erlaß von örtlichen Bauvorschriften und von eigentlichen Bebauungsplänen ein einheitlicher Abwägungs- und Gestaltungsvorgang ist, dann kann die Entscheidungsfreiheit der planenden Gemeinde nicht einer unterschiedlichen staatlichen Aufsicht unterliegen. Denn die intendierte Zweckmäßigkeitskontrolle alleine für den Bereich der auf Landesrecht beruhenden Regelungen ist aufgrund des unter Umständen untrennbaren Regelungszusammenhangs mit den Festsetzungen aufgrund des $\S 9$ Abs. 1 BauGB nicht möglich. Dies gilt vor allem für Festsetzungen, die nachbarli-

\footnotetext{
${ }^{29}$ Siehe ausführlich oben A III 4.
} 
che Belange berühren ${ }^{30}$. Entscheidet sich eine Gemeinde etwa für die Zulassung einer zweigeschossigen Bauweise, beschränkt sie aber durch eine nach $\S 9$ Abs. 4 BauGB aufgenommene örtliche Bauvorschrift die Höhenentwicklung der Gebäude dadurch, daß sie nur Flachdächer oder Dächer mit geringem Neigungswinkel zuläßt, dann gehören diese beiden Festsetzungen zusammen. Sie lassen sich nicht in der Weise aufspalten, daß die Frage der Zweigeschossigkeit einer Rechtmäßigkeits- und die der Dachneigung einer Zweckmäßigkeitskontrolle unterworfen wird. Würde die Aufsichtsbehörde aus Zweckmäßigkeitsgründen für die Zulassung von Dächern mit größerem Neigungswinkel eintreten, dann greift sie damit in Festsetzungen der Gemeinde bezüglich solcher Fragen der Gebäudedimensionierung ein, bei der "eigentlich" nur eine Rechtmäßigkeitskontrolle möglich wäre. Die Einführung einer Zweckmäßigkeitskontrolle für inhaltlich mit Festsetzungen nach $\S 9$ Abs. 1 BauGB zusammenhängenden Bestimmungen in nach $\S 9$ Abs. 4 BauGB aufgenommenen örtlichen Bauvorschriften verstößt damit gegen die Garantie der Eigenverantwortlichkeit nach $\S 2$ Abs. 1 S. 1 BauGB. Ein solcher Zusammenhang zwischen Festlegungen auf landesrechtlicher Grundlage und solchen aufgrund des $\S 9$ Abs. 1 BauGB braucht zwar nicht in jedem Fall vorzuliegen. Er läßt sich aber auch bei keiner der üblichen Festlegungen gänzlich ausschließen ${ }^{31}$.

Weiterhin zwingend erforderlich zur Erlangung einer verfahrensmäßigen Einheit sind schließlich noch der Beschluß als einheitliche Satzung (§ 10 BauGB), ein einheitliches Kontrollverfahren ( $\$ 11 \mathrm{BauGB}$ ) und gleiche Regelungen für das Inkrafttreten ( $\$ 12 \mathrm{BauGB})$.

\section{c) Das Normenkontrollverfahren gegen örtliche Bauvorschriften als Bestandteile von Bebauungsplänen}

In der Rechtsprechung der Oberverwaltungsgerichte wird die Frage, ob die Statthaftigkeit eines Normenkontrollverfahrens gegen eine in den Bebauungsplan aufgenommene örtliche Bauvorschrift sich nach $\S 47$ Abs. 1 Nr. 1 oder Nr. 2 VwGO richtet, unterschiedlich beurteilt ${ }^{32}$. Ihre Beantwor-

\footnotetext{
${ }^{30}$ Vergleiche die ausführliche Parallelargumentation bei der Frage der kompetenzrechtlichen Qualifizierung der üblichen Festlegungen in örtlichen Bauvorschriften, oben A III 4.

${ }^{31}$ Siehe die Argumentation oben A III 4.

${ }^{32}$ Für Nr. 1: OVG Münster, Urteil vom 19.08.1983, NVwZ 1984, S. 595; BayVGH, Urteil vom 12.09.1988, BayVBl. 1989, S. 210 (211); zustimmend Ortloff, Öffentliches Baurecht, Band II, S. 35; für Nr. 2: OVG Saarlouis, Urteil vom 04.12.1981, BRS Band 38. Nr. 48 S. $110 \mathrm{ff}$.
} 
tung richtet sich danach, ob man - wie das OVG Saarlouis - den $\S 9$ Abs. 4 BauGB im formalen Sinne versteht, oder ob man eine materielle Sichtweise bevorzugt. Da nach der hier vertretenen Auffassung der $\S 9$ Abs. 4 BauGB eine materielle Bedeutung dergestalt hat, daß damit eine inhaltliche Verschmelzung von bauplanungsrechtlichen und bauordnungsrechtlichen Materien ermöglicht wird, ist eine Statthaftigkeit des Normenkontrollverfahrens nach $\S 47$ Abs. 1 Nr. 1 VwGO die sachgerechte prozessuale Konsequenz. Denn ist in einem Bundesland nur das Normenkontrollverfahren nach $\S 47$ Abs. $1 \mathrm{Nr} .1 \mathrm{VwGO}$ statthaft, dann ist häufig eine isolierte Überprüfung nur der auf $\S 9$ Abs. 1 BauGB beruhenden Festsetzungen nicht möglich. Das gemeinsame Abwägungsmaterial und der einheitliche Gestaltungsvorgang führen zu einem Regelungszusammenhang, so daß Festsetzungen nach $\S 9$ Abs. 1 und Abs. 4 nicht in jedem Fall isoliert beurteilt werden können ${ }^{33}$.

$\mathrm{Da}$ sich somit das Normenkontrollverfahren insgesamt nach $\S 47 \mathrm{Abs} .1$ Nr. 1 VwGO richtet, ist auch mit dem Wortlaut des $\S 47$ Abs. 1 Nr. 1 VwGO vereinbar. Örtliche Bauvorschriften, die nach $\S 9$ Abs. 4 BauGB in den Bebauungsplan aufgenommen worden sind, sind nach den Vorschriften des BauGB erlassen, und zwar nicht nur aufgrund des $\S 9$ Abs. 4 BauGB, sondern auch aufgrund weiterer anzuwendender Vorschriften.

\section{Die Verweisungen in den Landesbauordnungen auf das BauGB / BBauG}

a) Das Maß der Ausschöpfung der Ermächtigung des $\S 9$ Abs. 4 BauGB durch die Landesbauordnungen

aa) Abweichungen bei verfahrensrechtlichen Fragen

Zur Erreichung des von $\S 9$ Abs. 4 BauGB intendierten Planungs- und Planzusammenhangs unterliegen die Landesgesetzgeber einem gewissen Pflichtprogramm an formellen und materiellen Voraussetzungen, die für örtliche Bauvorschriften gelten müssen, wenn diese als Festsetzungen in den Bebauungsplan aufgenommen werden sollen. Untersucht man nun die Frage, inwieweit die Landesgesetzgeber die so verstandene Ermächtigung des $\S 9$ Abs. 4 BauGB wirksam ausgeschöpft haben, ergibt sich einmal das

${ }^{33}$ So auch das OVG Münster (Fn 32), S. 595. 
Problem, daß die meisten Landesbauordnungen ${ }^{34}$ noch das BBauG in Bezug nehmen ${ }^{35}$.

Wenn man deshalb zunächst von der Rechtslage unter dem BBauG ausgeht, haben es nicht alle Landesbauordnungen geschafft, in Ausschöpfung der Ermächtigung des $\S 9$ Abs. 4 einen materiellen Planzusammenhang mit den Festsetzungen nach $\S 9$ Abs. 1 BBauG herzustellen. Teilweise bestehen ausdrückliche Abweichungen von den für eine Aufnahme notwendigen Anforderungen, die keine "bundesrechtskonforme" Auslegung zulassen, so daß die von $\S 9$ Abs. 4 BBauG geforderte verfahrensmäßige und inhaltliche Einheit nicht ermöglicht wird. Dies ist in der Hauptsache dadurch zu erklären, daß die meisten Landesgesetzgeber von einem - hier nicht geteilten - formellen Verständnis des $\S 9$ Abs. 4 BBauG ausgingen, und sich deshalb frei in der Entscheidung wähnten, welche Vorschriften des BBauG sie für anwendbar erklärten. In vielen Fällen läßt der Gesetzeswortlaut jedoch eine bundesrechtskonforme Auslegung zu, die es ermöglicht, trotzdem von einer wirksamen Wahrnehmung der Ermächtigung des $\S 9$ Abs. 4 BBauG auszugehen.

Eindeutig nicht ausgeschöpft ist die Ermächtigung durch die NBauO und deren $\S \S 97$ und 98, die einen Erlaß der örtlichen Bauvorschriften auch dann im übertragenen Wirkungskreis vorsehen, wenn diese in den Bebauungsplan aufgenommen werden. Eine örtliche Bauvorschrift muß in "eigener Verantwortung" gemäß § 2 Abs. 1 S. 1 BBauG / BauGB und damit im eigenen Wirkungskreis erlassen werden.

Zweifelhaft ist auch die Rechtslage in Hessen und Schleswig-Holstein. Dort ist lediglich geregelt, da $\beta$ örtliche Bauvorschriften in den Bebauungsplan aufgenommen werden können und daß für das Inkrafttreten $\S 12$ $\mathrm{BBauG}$ gilt $^{36}$. Zwar sind die Verweisungen grundsätzlich nicht so $z u$ lesen, daß die Anwendbarkeit bestimmt wird, da dies der von $\S 9$ Abs. 4 BauGB vorausgesetzte Regelfall ist. Sie sind vielmehr in dem Sinne zu verstehen, $\mathrm{da} ß$ die nicht genannten Vorschriften von der Anwendung ausgeschlossen werden sollen ${ }^{37}$. Soweit aber nur $\S 12 \mathrm{BBauG}$ für anwendbar erklärt wird, kann man dies auch dahingehend auslegen, daß damit nicht die übrigen

\footnotetext{
34 Ausnahme: $\$ 83$ Abs. 4 LBO Saarl.

35 Siehe dazu den folgenden Abschnitt.

$36 \$ 82$ Abs. 4 LBO Sl.H.; $\$ 118$ Abs. 3 HBO i. V. m. $\$ 1$ VO vom 28.01.1979 GVBI. I,

${ }^{37}$ Siehe dazu oben D I 1 b.
} S. 102. 
Verfahrensvorschriften des BauGB von der Anwendung ausgeschlossen werden sollen, sondern daß die Landesgesetzgeber nur die Anwendbarkeit des gelegentlich unter rechtsstaatlichen Gesichtspunkten als problematisch empfundenen $\S 12 \mathrm{BBauG}^{38}$ ausdrücklich anordnen.

In der BayBO ist der einzig problematische Punkt der Art. 91 Abs. 3 S. 3 BayBO, welcher eine Begründungspflicht auch bei Aufnahme von örtlichen Bauvorschriften in den Bebauungsplan ausdrücklich ausschließt. Damit die Befugnis nach $\S 9$ Abs. 4 BauGB auch in Bayern ausgeschöpft werden kann, wird man die Vorschrift - entgegen der gesetzgeberischen Intention ${ }^{39}$ - restriktiv zu interpretieren haben. Sie kann eine Begründungspflicht nur insoweit ausschließen, als sie von $\S 9$ Abs. 8 BauGB im Zusammenhang des Gesamtkontextes des Bebauungsplanes auch nicht gefordert wird. Denn $\S 9$ Abs. 8 BauGB konstituiert keine generelle Begründungspflicht für schlechthin jede Festsetzung des Bebauungsplans. Gefordert werden nur Darlegungen zu den "zentralen Punkten"40. Wirklich grundlegende Aussagen enthalten in den Bebauungsplan aufgenommene örtliche Bauvorschriften aber häufig nicht. Insoweit kann die BayBO die allerdings ohnehin geltende Aussage treffen, daß eine Begründung nicht erforderlich ist.

\section{bb) Zum Problem der Abwägung}

Ein weiteres Problem im Hinblick auf die wirksame Ausschöpfung des $\S 9$ Abs. 4 BauGB ergibt sich daraus, daß die meisten Landesbauordnungen das Abwägungsgebot des $\S 1$ Abs. 6 BauGB nicht mit in die Liste der anzuwendenden Vorschriften aufgenommen haben. Hieraus läßt sich jedoch nicht der Schluß ziehen, daß damit beim Erlaß einer örtlichen Bauvorschrift keine Abwägung notwendig wäre. Vielmehr ist das Abwägungsgebot bereits Bestandteil der Befugnisnormen zum Erlaß von örtlichen Bauvorschriften, unabhängig davon, ob eine Aufnahme in den Bebauungsplan nach $₫ 9$ Abs. 4 BauGB stattfindet oder nicht. Die Pflicht zur Abwägung folgt schon daraus, $\mathrm{da} ß$ den Gemeinden für die Frage, ob eine örtliche Bauvorschrift zu erlas-

${ }^{38}$ Vgl. VGH Kassel, Vorlagebeschluß vom 10.06.1981, BauR 1981, S. 450 f. Die Verfassungsmäßigkeit der Vorschrift wird jedoch vom BVerfG bejaht, siehe Beschluß vom 22.11.1983, NVwZ 1984, S. 430.

39 Siehe dazu Simon, Art. $91 \mathrm{Rn} .32$.

40 BVerwG, Urteil vom 07.05.1971, DÖV 1971, S. 633 (635); BayVGH, Beschluß vom 10.03.1976, BRS Band 30, Nr. 9; Mainczyk, § 9 Rn. 51; Löhr, in: Battis / Krautzberger / Löhr, § Rn. 126: "tragende Gründe"; Gaentzsch, Berliner Kommentar, § 9 Rn. 84; Schlichter, in: Schlichter / Stich / Tittel, BBauG, §9 Rn. 37. 
sen ist, ein Ermessen ("kann") eingeräumt ist. Es besteht ein Entscheidungsspielraum der Gemeinde bezüglich des Erlasses als auch des Inhalts einer örtlichen Bauvorschrift. Dem entspricht die Pflicht zur Berücksichtigung aller berührten Interessen, d. h. vor allem der betroffenen Grundrechte. Von einer solchen Berücksichtigungspflicht wird bereits für jede Ermessensentscheidung der Verwaltung bei Erla $\beta$ eines Verwaltungsaktes ausgegangen ${ }^{41}$. Es besteht kein Anlaß anzunehmen, daß dies für den Erlaß einer Satzung über örtliche Bauvorschriften, die in weitaus breiterem Umfang grundrechtliche Betroffenheiten auslöst, nicht gelten soll. Die Annahme der Notwendigkeit einer Abwägung entspricht auch der weitgehend einhelligen Rechtsprechung der Oberverwaltungsgerichte ${ }^{42}$.

Die Ableitung der Abwägungspflicht unmittelbar aus der Befugnisnorm zum Erlaß örtlicher Bauvorschriften bietet die Möglichkeit, die Anforderungen des Abwägungsgebotes entsprechend dem jeweiligen Inhalt einer örtlichen Bauvorschrift sachgerecht zu interpretieren. So können sich im Hinblick auf das Maß der Entscheidungsfreiheit des Satzungsgebers durchaus Unterschiede ergeben zwischen der planerischen Abwägung nach § 1 Abs. 6 BauGB und dem Abwägungsgebot bei örtlichen Bauvorschriften. Dies gilt selbst dann, wenn es zu einer Aufnahme von örtlichen Bauvorschriften in den Bebauungsplan kommt. Auch sonst ist anerkannt, daß "Abwägungsgebot" nicht gleich "Abwägungsgebot" ist. Man unterscheidet etwa zwischen planerisch-gestaltender und nachvollziehender Abwägung ${ }^{43}$. Ein Fall der nachvollziehenden Abwägung liegt etwa bei § 35 BauGB, also bei der Entscheidung über die Zulässigkeit eines Vorhabens im Außenbereich vor $^{44}$. Eine ähnliche Unterscheidung dürfte auch bei örtlichen Bauvorschriften angebracht sein. Wird eine solche Satzung zur Konkretisierung des in den baugestalterischen Generalklauseln enthaltenen Verunstaltungsmaßstabes erlassen $^{45}$, dürfte ein Fall der nachvollziehenden Abwägung vorliegen.

${ }^{41}$ Vgl. nur Obermayer, Allgemeines Verwaltungsrecht, S. 163.

${ }^{42}$ BWVGH, Beschluß vom 26.08.1982, BRS Band 39, Nr. 133 S. 282 (284); HessVGH, Urteil vom 30.06.1987, BRS Band 47, Nr. 121 S. 317 (319) = HessStuGZ 1988, S. 408; OVG Lüneburg, Urteil vom 04.05.1979, BRS Band 34, Nr. 132 S. 251 (253); Urteil vom 12.02.1982, BRS Band 39, Nr. 132 S. 280 (281); OVG Münster, Urteil vom 30.06.1981, BRS Band 38, Nr. 138 S. 322 (323); Urteil vom 30.06.1983, BRS Band 40, Nr. 152 S. 335 (337).

${ }^{43}$ Siehe Weyreuther, BauR 1977, S. 297; Krautzberger, in: Battis / Krautzberger / Löhr, § 35 Rn. 6.

44 Vgl. BVerwG, Urteil vom 25.10.1967, E 28, 148 (151); Urteil vom 24.08.1979, S. 905 (907); Urteil vom 22.05.1987, NVwZ 1988, S. 54 (56).

${ }^{45}$ Dazu, daß es hierfür einen sinnvollen und von den Befugnisnormen zugelassenen Anwendungsbereich gibt, siehe oben C III 2 a cc. 
Der Satzungsgeber versucht in einem solchen Fall nur, den Inhalt einer Eigentumsbeschränkung "nachzuzeichnen", der bereits vom formellen Gesetzgeber vorgegeben ist. Auch hierfür hat er die relevanten Umstände, also etwa die Schutzwürdigkeit des Gebietes und die vorherrschenden Baustile zu ermitteln und in die Entscheidung einfließen zu lassen. Hierbei kann es zu einem Abwägungsfehler kommen, wenn beispielsweise der Satzungsgeber die Denkmaleigenschaft und damit die auch von der Generalklausel schon normierte besondere Schutzbedürftigkeit eines Gebäudes nicht erkennt. Es gibt aber nur eine rechtsrichtige Entscheidung und keine planerische Gestaltungsfreiheit, auch nicht bei Aufnahme in den Bebauungsplan.

Je mehr der Satzungsgeber den Bereich der Konkretisierung des Verunstaltungsmaßstabes verläßt und sich in Richtung einer erweiterten Gebietspflege oder sogar positiven Gestaltungspflege bewegt, desto eher ähneln die Anforderungen an die Abwägung der planerischen Abwägung nach $\S 1$ Abs. 6 BauGB. Der Satzungsgeber erhält einen erweiterten Gestaltungsspielraum. Je größer die Entscheidungsfreiheit der Gemeinde wird, desto stärker werden teils gleichgerichtete, teils unterschiedliche Interessen berührt und verlangen gegebenenfalls einen "Ausgleich". Beachtung fordern vor allem die Belange der Eigentümer, deren Befugnisse durch solche Satzungen konstitutiv beschnitten werden. Das Abwägungsgebot für örtliche Bauvorschriften dürfte dem Typus einer "gestaltenden Abwägung" wie im Bauplanungsrecht schließlich dann entsprechen, wenn es um Festsetzungen geht, die in einem untrennbaren Zusammenhang mit Festsetzungen im Bebauungsplan nach $\S 9$ Abs. 1 BauGB stehen, wenn etwa ein bestimmter Neigungswinkel des Daches vorgeschrieben wird, zum einen im Interesse des Nachbarn, zum anderen wegen der Rückwirkungen etwaiger Festsetzungen bezüglich des Maßes der baulichen Nutzung ${ }^{46}$, oder auch, wenn die Gemeinde ein stadtgestalterisches Gesamtkonzept durch Festsetzungen nach $\S 9$ Abs. 1 BBauG / BauGB und örtliche Bauvorschriften verwirklichen will und die Festlegungen deshalb aufeinander bezogen sind.

Teilweise wird in der Rechtsprechung der Oberverwaltungsgerichte als Rechtmäßigkeitsmaßstab für Satzungen über örtliche Bauvorschriften allerdings das Übermaßverbot verwendet ${ }^{47}$. Daraus ist jedoch nicht der Schluß zu ziehen, daß daneben die dargestellte Pflicht zur Abwägung nicht be-

\footnotetext{
${ }^{46}$ Siehe dazu schon die Überlegungen oben A III 4.
}

${ }^{47}$ BayVGH, Beschluß vom 09.03.1976, BRS Band 30, Nr. 109 S. 216 (217); OVG Münster, Urteil vom 30.06.1978, BRS Band 33, Nr. 115 S. 238 (240); OVG Lüneburg, Urteil vom 04.05.1979, BRS Band 34, Nr. 132 S. 251 (253). 
steht $^{48}$. Zwar ist im Rahmen der Prüfung der Verhältnismäßigkeit im engeren Sinne eine Proportionalitätsprüfung und damit auch eine Art Güterabwägung vorzunehmen ${ }^{49}$. Dies ist jedoch mehr eine Stimmigkeitskontrolle. Eine Beschränkung der Überprüfung örtlicher Bauvorschriften auf das Übermaßverbot würde damit dazu führen, daß die Anforderungen an den Erlaß einer Satzung über örtliche Bauvorschriften hinter denen einer normalen Ermessensentscheidung zurückblieben. Man kann deshalb das Übermaßverbot als Prüfungsmaßstab verwenden und damit abschließend zur Rechtswidrigkeit einer Satzung kommen. Weiterhin unterliegen die Gemeinden jedoch auch der Pflicht zur Berücksichtigung aller relevanten Umstände.

In der Rechtsprechung der Oberverwaltungsgerichte gibt es neben der Begründung der Abwägungspflicht aus dem einfachen Gesetzesrecht noch eine weitere Argumentationslinie, die dazu führen soll, daß der Erlaß einer Satzung über örtliche Bauvorschriften eine Abwägung voraussetzt. Dabei wird an eine Rechtsprechung des BVerwG vor allem zum Bauplanungsrecht und Planfeststellungsrecht angeknüpft. Das BVerwG vertritt in ständiger Rechtsprechung die Auffassung, daß das Abwägungsgebot dem Wesen rechtsstaatlicher Planung immanent sei; es wurzele im Bundesverfassungsrecht und trete gegebenenfalls ergänzend neben das einfache Bundes- oder Landesrecht, dessen Regelungen die Reichweite des rechtsstaatlichen Abwägungsgebotes nicht ausschöpfen ${ }^{\text {so }}$. Soweit daher das Abwägungsgebot sich nicht bereits dem einfachen Recht entnehmen lasse, trete es als Bundesrecht zu den Befugnisnormen über örtliche Bauvorschriften hinzu, da es sich hierbei um eine "Planung" im Sinne der Rechtsprechung des BVerwG handele ${ }^{51}$.

Die Frage, ob der Erlaß einer örtlichen Bauvorschrift im Sinne der bundesverwaltungsgerichtlichen Rechtsprechung eine "Planung" ist, dürfte sich aber kaum für alle Satzungen über örtliche Bauvorschriften einheitlich beantworten lassen. So kennzeichnet sich eine Planung vor allem durch die Notwendigkeit des umfassenden Ausgleichs unterschiedlicher Interessen ${ }^{52}$.

${ }^{48}$ Vgl. das OVG Lüneburg, BRS Band 34, S. 253.

${ }^{49}$ Pieroth / Schlink, Rn. 332; Dechsling, S. 8 ff.; Zimmerli, S.16.

${ }^{\text {so }}$ BVerwG, Urteil vom 20.10.1972, E 41, 67 (68); Urteil vom 14.02.1975, E 48, 56 (63); Urteil vom 07.07.1978, DVBl. 1978, S. 845 (848); Urteil vom 23.01.1981, E 61, 295 (301); Urteil vom 11.12.1981, E 64, 270 (272).

${ }^{51}$ So vor allem OVG Münster, Urteil vom 30.06.1983, BRS Band 40, Nr. 152 S. 337.

52 Gaentzsch, Verkehrsberuhigung, S. 31; Badura, Festschrift BayVerfGH, S. 173; Steiner, DAR 1989, S. 405 ff. Für örtliche Bauvorschriften BayVGH, Urteil vom 12.09.1988, BayVBI. 1989, S. 212. 
Dies ist - wie die Überlegungen zur kompetenzrechtlichen Qualifikation ${ }^{53}$ und zur Bedeutung des $\S 9 \mathrm{Abs} .4 \mathrm{BauGB}^{54}$ zeigen - für örtliche Bauvorschriften in einer Reihe von durchaus relevanten Fällen anzunehmen. Es gibt aber auch Satzungen, bei denen man von der Notwendigkeit eines umfassenden Ausgleichs verschiedener Interessen nicht wird sprechen können, etwa dann, wenn sich örtliche Bauvorschriften auf die Konkretisierung des Verunstaltungsmaßstabes beschränken, oder wenn bei einer örtlichen Bauvorschrift für ein Wohngebiet sich die Interessenkollision auf den Gegensatz zwischen den Gestaltungswünschen des Eigentümers und denen der Gemeinde beschränkt, ohne daß andere Belange wie Denkmalschutz, Interessen von Gewerbebetrieben, des Fremdenverkehrs etc. eine Rolle spielen.

Man wird somit davon auszugehen haben, daß das Abwägungsgebot maßgeblich vor allem in den Befugnisnormen zum Erlaß örtlicher Bauvorschriften als Rechtmäßigkeitsvoraussetzung enthalten ist. Das Gebot der Abwägung ist dann bundesverfassungsrechtlich "unterlegt", wenn eine "Planung" im Sinne der Rechtsprechung des BVerwG vorliegt ${ }^{55}$. Auf jeden Fall sehen aber die Landesbauordnungen eine Pflicht zur "Abwägung" vor. Hieraus resultieren - sofern es zu einer dem Bauplanungsrecht vergleichbaren "Gestaltung von Interessengeflechten" ${ }^{156}$ kommt - , die gleichen Pflichten wie nach $\S 1$ Abs. 6 BBauG / $§ 1$ Abs. 5 BauGB. Insofern ergeben sich keine Bedenken gegen eine wirksame Ausschöpfung der Ermächtigung des § 9 Abs. 4 BauGB / BBauG.

cc) Folgen aus einer Nichterfüllung des "Pflichtprogramms"

Bei den meisten Landesbauordnungen lassen sich die Inbezugnahmen des BBauG also so interpretieren, daß das von $\S 9$ Abs. 4 BBauG geforderte "Pflichtprogramm" erfüllt ist. Vor allem durch die NBauO ist aber die Ermächtigung des $\S 9$ Abs. 4 BBauG nicht wirksam in Anspruch genommen worden. Die Folgen, die sich für die planenden Gemeinden aus dieser Auffassung ergeben, halten sich jedoch in Grenzen. Die wichtigste praktische

${ }^{53}$ Oben A III 4.

54 Oben EI 1.

${ }^{55}$ Desweiteren ist eine verfassungsrechtliche Absicherung dadurch gegeben, da $\mathrm{B}$ eine $\mathrm{Ab}$ wägung deshalb erforderlich ist, soweit Grundrechte betroffen sind. Siehe dazu die Ausführungen unten $\mathrm{E}$ II 2 a aa.

${ }^{56}$ Vgl. Weyreuther, DÖV 1977, S. 420. 
Konsequenz ist die, daß sich die Statthaftigkeit eines Normenkontrollverfahrens nach $\S 47$ Abs. 1 Nr. 2 VwGO richtet, da eine "Aufnahme" in den Bebauungsplan nur zu einer formellen Übernahme führt. Im Bereich der eigentlichen Planung dürfen die Gemeinden alles das machen, was ihnen der Bundesgesetzgeber auch ohne wirksame Ausschöpfung der Ermächtigung des $\S 9$ Abs. 4 BauGB nicht verbieten kann. Sie können Verfahren zur Aufstellung eines Bebauungsplans und zum Satzungserla $ß$ gemeinsam betreiben und die Regelungen inhaltlich insoweit aufeinander beziehen, wie dies mit den Anforderungen des Abwägungsgebotes vereinbar ist. Die Abstimmung im Gemeinderat ist - zumindest nach den Grundsätzen der planerischen Vorsicht - über beide Satzungen jedoch getrennt vorzunehmen. Die "Koppelungsmöglichkeiten" sind dadurch tendenziell geringer. Die Gemeinden müssen vor allem bei den notwendigen Abwägungsprozessen die Möglichkeit beachten, da $\beta$ die eine Satzung rechtswirksam wird und die andere nicht. Dies muß gegebenenfalls bei der Planung berücksichtigt werden. Abwägungsfehler sind dann denkbar, wenn Anhaltspunkte dafür bestehen, da $B$ etwa die örtliche Bauvorschrift auf Vorbehalte bei den Aufsichtsbehörden trifft und dies beim Beschluß über den Bebauungsplan nicht entsprechend berücksichtigt wird. Zudem müssen die beiden Verfahren nachweisbar eingehalten werden und die Gemeindevertretungen sich darüber im klaren sein, daß es sich um zwei Satzungen handelt, die im Hinblick auf Inkrafttreten, Bestandskraft und gerichtliche Kontrolle verschiedene Wege gehen können. Insgesamt dürften sich aber in der Praxis keine zu gravierenden Unterschiede ergeben, zumal das BVerwG in einer jüngeren Entscheidung der Frage, inwieweit sich die Gemeinde bei der Aufstellung eines Bebauungsplans über Entscheidungen in anderen Verfahren Gedanken machen muß, keine große Bedeutung beigemessen hat ${ }^{57}$.

b) Die Inbezugnahme des BBauG durch die Landesbauordnungen als "Verweisungsproblem"

aa) Die grundsätzliche Problemstellung

In den meisten Vorschriften der Landesbauordnungen zur Ausschöpfung des $\S 9$ Abs. 4 werden ausdrücklich Vorschriften des BBauG in bezug ge-

57 BVerwG Beschluß vom 07.09.1988, BayVBI. 1989, S. 87 f., bezüglich der Kostenerstattung für Anlagen nach $\$ 9$ Abs. 1 Nr. 24 BauGB; siehe dazu die Kritik von Geiger, BayVBI. 1989, S. 90. 
nommen ${ }^{58}$. Hierunter findet sich unter anderem auch der $\S 11 \mathrm{BBauG}$, wonach Bebauungspläne der Genehmigung der höheren Verwaltungsbehörde bedürfen ${ }^{59}$. Gerade der $\S 11 \mathrm{BBauG}$ ist aber durch das neue BauGB wesentlich geändert worden. Bebauungspläne sind nach $\S 11$ Abs. 1 BauGB nur noch in Ausnahmefällen genehmigungspflichtig. In der Regel wird ein Anzeigeverfahren durchgeführt.

Es stellt sich damit die Frage, welches Kontrollverfahren nach Erlaß des BauGB für die in Bebauungspläne aufzunehmenden örtlichen Bauvorschriften gilt. Entweder kann man die Vorschriften der Landesbauordnungen als sog. statische Verweisungen verstehen, als Verweisungen also, die das BBauG in dem Zeitpunkt, wie es im Moment des Erlasses der jeweiligen Landesbauordnung galt, " übernimmt". Dies hätte zur Folge, daß örtliche Bauvorschriften, die gemäß $\S 9$ Abs. 4 BauGB Bestandteil des Bebauungsplanes werden, nach wie vor einer Genehmigungspflicht unterliegen ${ }^{60}$. Die andere Möglichkeit bestände darin, von einer sog. dynamischen Verweisung auszugehen ${ }^{61}$. Dann würden örtliche Bauvorschriften als Bestandteile des Bebauungsplanes in der Regel dem Anzeigeverfahren unterliegen ${ }^{62}$.

Während der Geltungsdauer des BBauG wurde die Frage, ob die Inbezugnahmen des BBauG dynamische oder statische Verweisungen sind, soweit erkennbar nicht problematisiert. Allgemein ging man wohl davon aus, daß "statische Verweisungen" vorliegen. Ein gewisses Indiz hierfür ist die Gesetzgebungspraxis in Bayern. Bei Novellen zum BBauG wurde eine konstitutive Anpassung der Vorschriften der Landesbauordnung für erforderlich gehalten ${ }^{63}$. Die Schaffung statischer Verweisungen dürfte auch dem Willen der Landesgesetzgeber entsprochen haben. Das folgt zum einen aus der Tatsache, daß die unzutreffende Meinung, wonach es den Landesgesetzgebern freistände, welche Verfahrensnormen des BBauG sie für aufzu-

\footnotetext{
58 Eine Ausnahme bildet die nach Erlaß des BauGB neugefaßte LBO Saarl., siehe $\S 83$ Abs. 4.

59 Teilweise wird der gesamte $\S 11$, zum Teil nur der $\S 11 \mathrm{~S} .1$ und S. 2 BBauG genannt. Nachweise dazu und zur damit verbundenen Problematik bezüglich des Wirkungskreises oben B I 1 b.

${ }^{60}$ So Koch / Molodovsky / Rahm, Art. 91 Anm. 4.3.4.

${ }^{61}$ Der Begriff stammt soweit ersichtlich von Ossenbühl, DVBI. 1967, S. 403.

${ }^{62}$ Es wäre jeweils das Verfahren durchzuführen, welches auch für den betreffenden eigentlichen Bebauungsplan zu durchlaufen ist.

${ }^{63}$ Siehe etwa das 4. Gesetz zur Änderung der BayBO vom 21.06.1982, GVBl. S. 313 ff., wo "§ 155 a des Bundesbaugesetzes" in Art. 107 Abs. 3 S. 2 BayBO a. F. ersetzt wurde durch "§§ $155 \mathrm{a}-155 \mathrm{c}$ des Bundesbaugesetzes sinngemäß", nachdem die $\S \S 155 \mathrm{~b}$ und $\mathrm{c}$ in das BBauG eingefügt worden waren.
} 
nehmende örtliche Bauvorschriften vorsahen, bis vor kurzem kaum bezweifelt wurde ${ }^{64}$. Zum anderen vermitteln die Vorschriften, in denen detailliert einzelne Bestimmungen des BBauG genannt werden, bei unbefangener Lektüre eher den Eindruck, als wollten die Landesgesetzgeber nur ganz bestimmte verfahrensrechtliche Anleihen vornehmen, was eher eine statische Verweisung vermuten läßt. Seit Inkrafttreten des BauGB herrscht nun eine gewisse Unsicherheit über die Auslegung der entsprechenden Bestimmungen der Landesbauordnungen ${ }^{65}$.

\section{bb) Terminologische Vorfragen}

Die bereits angestellten Überlegungen zur Auslegung des $\S 9$ Abs. 4 BBauG / BauGB lassen es zweifelhaft erscheinen, ob ein Verständnis der Inbezugnahmen des BBauG durch die Landesbauordnungen im Sinne einer "statischen Verweisung" richtig ist. Vielmehr erscheint die Annahme einer dynamischen Verweisung sachgerechter ${ }^{66}$, die Annahme einer statischen Verweisung führt hingegen zu reichlich abstrusen Ergebnissen. Werden nämlich örtliche Bauvorschriften als einfache Satzungen erlassen, so unterliegen sie als Folge des Abbaus von Genehmigungsvorbehalten im Zuge der Stärkung der kommunalen Selbstverwaltung z. B. in Bayern ${ }^{67}$ oder in Nordrhein-Westfalen keiner Genehmigungspflicht. Wären die Inbezugnahmen des $\S 11$ BBauG durch $\S 81$ Abs. 4 BauO NW und Art. 91 Abs. 3 S. 2 BayBO statische Verweisungen, so käme es zum einen zu dem kaum einsichtigen Resultat, daß die "wichtigen", d. h. für die städtebauliche Entwicklung und Ordnung der Gemeinde grundlegenden und die Planbetroffenen besonders berührenden Entscheidungen in Form von Festsetzungen nach $\S 9$ Abs. 1 BauGB keiner Genehmigungspflicht unterliegen, wohl hingegen die Quisquilien, die in örtlichen Bauvorschriften als Ergänzung dazu erlassen werden sollen, und das obwohl im Fall des Erlasses einer einfachen Satzung ebenfalls keine Genehmigungspflicht bestände. Weiterhin wäre dann, wenn es sich bei den Vorschriften der Landesbauordnungen um statische Verwei-

\footnotetext{
${ }^{64}$ Siehe die Nachweise oben E I 1 b aa.

${ }^{65}$ Vgl. die Kommentierung von Schlotterbeck, in: Schlotterbeck / von Arnim, $\$ 73$ Rn. 65 f., der zwar statt des BBauG das BauGB anwendet, wohl wegen der ausdrücklichen Regelung des $\$ 73$ Abs. 5 S. 2 LBO BW aber weiterhin von einer Genehmigungspflicht ausgeht.

${ }^{66}$ In diese Richtung auch Gaentzsch, Berliner Kommentar, §9 Rn. 71.

67 Siehe zu diesem Aspekt des Wegfalls von Genehmigungspflichten Dirk von der Heide, S. 27.
} 
sungen handeln würde, die Ermächtigung des $\S 9$ Abs. 4 BauGB derzeit nicht ausgeschöpft, da insoweit die verfahrensmäßige Einheit, die der $\S 9$ Abs. 4 BauGB für die Aufnahme fordert, vom Landesgesetzgeber durch ein generelles Genehmigungsverfahren verhindert würde.

Gegen die Zulässigkeit "dynamischer" Verweisungen werden aber eine Reihe von vor allem rechtsstaatlichen Bedenken vorgebrach ${ }^{68}$. Bevor nun auf diese Argumente eingegangen werden kann, muß noch eine terminologische Vorfrage geklärt werden. Denn die Alternative "dynamische oder statische Verweisung" kann nur dann diskutiert werden, wenn es sich bei der Inbezugnahme des BBauG durch die Landesbauordnungen überhaupt um eine "Verweisung" handelt, was nicht ganz zweifelsfrei erscheint, wenn man die einschlägige Literatur zur Verweisungsproblematik untersucht.

So unterscheidet vor allem Karpen die "unechte" oder "Verweisung im weiteren Sinne" von der "echten" oder "Verweisung im engeren Sinne" ${ }^{\prime \prime 9}$. Beispielsweise sei die früher in $\S 547 \mathrm{Abs} .1 \mathrm{ZPO}$ enthaltene Bezugnahme auf $\S 48$ EheG ("... bei einer auf $\S 48$ EheG gestützten Klage...") eine Verweisung im weiteren, unechten Sinne, da dies nur eine austauschbare Bezeichnung für den Klagegrund sei. Genauso könne es heißen "... bei einer Ehescheidungsklage wegen Aufhebung der häuslichen Gemeinschaft ...." ${ }^{70}$. Andererseits bezeichnet Karpen die Verweisung als ein der Wiederholung gleichwertiges und jederzeit austauschbares Hilfsmittel zur Ergänzung unvollständiger Rechtssätze ${ }^{71}$.

Die Diskussion, ob es sich bei den landesrechtlichen Bestimmungen, die das BBauG in bezug nehmen, in diesem Sinne um eine Verweisung im engeren oder weiteren Sinne handelt, braucht jedoch nicht geführt zu werden. Der Sinn dieser Unterscheidung ist unklar und ihre Praktikabilität zweifelhaft. Denn auch die erwähnte Bezugnahme der ZPO auf $\S 48$ EheG ist nichts anderes als die Vermeidung einer Textwiederholung. Würde der $\S 48$ EheG geändert, etwa indem auch andere Klagegründe aufgenommen würden, so stellten sich die klassischen Verweisungsprobleme, vor allem die Frage, ob die entsprechende Vorschrift der ZPO nur auf die ursprüngliche Fassung des $\S 48$ EheG oder auf die neue bezug nimmt. Die Tatsache, daß man meint zu wissen, nur die erste Alternative könne richtig sein, gibt für

\footnotetext{
${ }^{68}$ Ausführlich dazu unten E I $2 \mathrm{c}$.

${ }^{69}$ Siehe vor allem Karpen, in: Rödig (Hrsg.), S. 224.

${ }^{70}$ Karpen, in: Rödig (Hrsg.), S. 223.

${ }^{71}$ Karpen, Die Verweisung, S. 30; ebenso Brugger, VerwArchiv 78 (1987), S. 4.
} 
die Einführung der Unterscheidung von Verweisungen im "engeren", "weiteren", "echten" oder "unechten" Sinne keinen Anlaß.

Auch die Rechtsprechung des BVerfG spricht dafür, als "Verweisung" allgemein jede gesetzliche Formulierung einer Norm anzusehen, in der der Gesetzgeber den Tatbestand $\mathrm{d}^{72}$ nicht textlich vollständig ausformuliert ${ }^{3 /}$. So diskutiert das BVerfG die Vorschrift des Art. IV EGÄndGKO mit dem Wortlaut "... über das Vermögen der in $\S 15 \mathrm{Nr}$. 3 des Einführungsgesetzes zur Civilprozeßordnung bezeichneten juristischen Personen ..." genauso nach der Alternative "statische" oder "dynamische" Verweisung ${ }^{74}$, wie eine Bestimmung der Kostenordnung, die schlicht auf "landesrechtliche Vorschriften, die Gebührenfreiheit gewähren" verweist ${ }^{75}$. Folgt man einem solchen weiten Verständnis des Begriffes der "Verweisung", so kommt man auch keinesfalls vom "hundertsten ins tausendste" die Diskussion mit einer letztlich nicht sinnvollen Unterscheidung, wenn man versucht zu erklären, warum die genannten Beispiele aus der Rechtsprechung des BVerfG "Verweisungen" sein sollen, die genannte Inbezugnahme des EheG durch die ZPO oder auch die zivilrechtlicher Normen durch das Strafrecht jedoch nicht ${ }^{n}$.

Ein weiteres terminologisches Problem scheint weiterhin darin zu liegen, daß einige Landesbauordnungen nur in der Weise auf das BBauG verweisen, daß sie eine "entsprechende" ( $\$ 73$ Abs. 5 S. 1 und Abs. 6 LBO BW; $\S 98 \mathrm{NBauO}$ ) oder "sinngemäße" (Art. 91 Abs. 3 S. 2 BayBO) Anwendung von Vorschriften des BBauG vorschreiben. Solche gesetzgeberischen Anordnungen werden etwa von Clemens ${ }^{78}$ aus dem Begriff der "Verweisung" und damit aus der Diskussion um dynamische und statische Verweisungen ausgeklammert und im Anschluß an Karpen als "Verweisungsanalogien" zu einer insoweit anscheinend nicht problematischen Sondergattung erklärt ${ }^{79}$. Verweisung wäre in einem solchen Verständnis nur das, was etwa dahinge-

72 Gemeint ist der Tatbestand im weiteren Sinne, also sowohl die Voraussetzungen als auch die Rechtsfolgen.

${ }^{73}$ So wohl auch das Verständnis des BVerfG im Beschluß vom 15.07.1969, E 26, 339 (366).

${ }^{74}$ BVerfG, Beschluß vom 23.03.1982, E 60, 135 (155).

${ }^{75}$ BVerfG, Beschluß vom 01.03.1978, E 47, 285 (311).

${ }^{76}$ So aber Schneider, Gesetzgebung, S. 380 Rn. 32.

${ }^{n}$ So aber Schneider (Fn. 76).

${ }^{78}$ Siehe etwa Clemens, AöR 111 (1986), S. 78

${ }^{79}$ Vgl. Karpen, Die Verweisung, S. 78 und 164, ders., in: Rödig (Hrsg.), S. 230. 
hend beschrieben wird, daß die Vorschrift, auf die verwiesen wird, "photographiert" und so in vollem Umfang Teil der verweisenden Norm würde ${ }^{80}$.

Die Ausführungen Karpens, auf die sich Clemens bezieht, sind jedoch nicht recht eindeutig. So führt Karpen zwar den Begriff der "Verweisungsanalogie" ein ${ }^{81}$, nennt aber andererseits auch Gesetze, die eine "entsprechende" Anwendung von Vorschriften anderer Gesetze vorsehen, als Beispiel für "Verweisungen" ${ }^{82}$. Daß die Unterscheidung zwischen Verweisungsanalogien und Verweisungen vollkommen fruchtlos sein kann, zeigt das vorliegende Beispiel. Ob die einen Landesbauordnungen von "entsprechender" oder "sinngemäßer" Anwendung sprechen, die anderen dagegen schlicht von "sind anzuwenden" 83 , ändert für die Probleme, die sich daraus ergeben, daß statt des BBauG seit dem 01.07.1987 das BauGB gilt, nichts. Es gibt auch keinen Anhaltspunkt dafür, daß mit der unterschiedlichen Formulierung eine unterschiedliche Konzeption oder Aussage verbunden ist. Der terminologische Unterschied dürfte eher auf Zufälligkeiten in der Gesetzesformulierung beruhen. Auch die grundsätzliche Problematik unterscheidet sich nicht. Ob der Landesgesetzgeber dann, wenn er auf die jeweils geltende Fassung eines Bundesgesetzes verweist, die direkte oder die entsprechende Anwendung vorschreibt, führt beide Male zu der Frage, ob er insoweit seiner Pflicht, selbst einen hinreichend konkretisierten Normbefehl zu erlassen, nachgekommen ist.

Eine letzte Unterscheidung, die für die vorliegende Problematik nicht durchgeführt werden soll, ist die zwischen "dynamischer Verweisung" und "dynamischer Anknüpfung" ${ }^{44}$. Die dynamische Anknüpfung soll sich dadurch von der dynamischen Verweisung unterscheiden, daß das in bezug genommene Recht nicht inkorporiert wird, ihm kein zusätzlicher "Wirkbereich" erschlossen werde, sondern das Landesrecht lediglich eine eigene Regelung an die bundesrechtlichen Bestimmungen anschließe ${ }^{85}$. Auch bei der "echten Verweisung" knüpft jedoch das Land eine eigene Regelung an eine bundesrechtliche Bestimmung, nämlich die Inkorporation. Auch bei einer "Anknüpfung" entstehen die typischen Verweisungsprobleme bei Änderungen

\footnotetext{
${ }^{80}$ So Staats, in: Rödig (Hrsg.), S. 254.

${ }^{81}$ Karpen, Die Verweisung, S. 78 und 164, ders., in Rödig (Hrsg.), S. 230.

${ }^{82}$ Und zwar als Verweisungen im "engeren" oder "echten" Sinne, siehe Karpen, Die Verweisung, S. 67.

${ }^{83} \S 81$ Abs. 4 BauO NW; $\S 86$ Abs. 6 S. 2 LBauO Rh.Pf.

${ }^{84}$ Vgl. dazu den Versuch von Veh, BayVB1. 1987, S. 227.

${ }^{85}$ Veh, BayVBI. 1987, S. 227.
} 
der Norm, an die "angeknüpft" wird, auch bei der Anknüpfung wird eine an sich "unvollständige Norm ergänzt" also "extern aufgefüllt"86.

Es handelt sich bei der Inbezugnahme von Normen des BBauG durch die Landesbauordnungen somit um ein Verweisungsproblem. Die Annahme einer dynamischen Verweisung ist vom Ergebnis her sachgerechter. Ob gegen eine solche Interpretation verfassungsrechtliche Bedenken bestehen, ist im Folgenden zu untersuchen.

c) Bedenken gegen die Annahme einer dynamischen Verweisung durch die Landesbauordnungen auf Bundesbaurecht

Gegen die Zulässigkeit dynamischer "Fremdverweisungen", also von Verweisungen auf das Recht eines anderen Normgebers, werden erhebliche Bedenken erhoben. Zwar kommen solche Verweisungen in der deutschen Rechtsordnung häufig vor. Weiterhin hat das BVerfG dynamische Verweisungen als "grundsätzlich zulässig" bezeichnet ${ }^{87}$. Es hat sich dabei jedoch noch nicht abschließend festgelegt ${ }^{88}$.

Bedenken werden zunächst unter dem Gesichtspunkt der Gesetzesbestimmtheit vorgebracht. Bei der dynamischen Verweisung sei der Normadressat gehalten nachzuforschen, welches die jeweils geltende Fassung des Verweisungsobjektes sei; dies sei jedoch vor allem dem juristischen Laien nicht zumutbar ${ }^{89}$. Recht überzeugend ist dieses Argument jedoch nicht. Gerade für den "juristischen Laien" ist es vielfach sogar leichter, die aktuelle Fassung eines bestimmten Gesetzes herauszufinden als die Gesetzeslage zu irgendeinem in der Vergangenheit liegenden Zeitpunkt. Wenn der juristische Laie den Gesetzgeber soweit verstanden hat, daß dieser auf ein bestimmtes Gesetz in der jeweils gültigen Fassung verweisen will, ist dem Bestimmtheitsgrundsatz genügt. Die Frage, ob vom Normadressaten die Kenntnis des Gesetzes verlangt werden kann, auf das verwiesen wird, ist vielmehr ein Problem der Verkündung. Gerade unter diesem Gesichtspunkt lassen sich aber keine Bedenken erheben, die sich nicht auch gegen statische

${ }^{86}$ Vgl. Karpen, in: Rödig (Hrsg.), S. 226. So geht auch das BayObLG, Beschluß vom 03.06.1986, BayVBI. 1987, S. 27 (28), von einer Verweisung aus, wo Veh eine Anknüpfung sehen möchte.

${ }^{87}$ BVerfG, Beschluß vom 23.03.1982, E 60, 135 (155).

${ }^{88}$ Vergleiche BVerfG, Beschluß vom 01.03.1978, E 47, 285 (312). Bedenken gegen die Zulässigkeit einer dynamischen Verweisung werden angedeutet auch vom BVerwG, Beschluß vom 15.03.1989, NVwZ-RR 1989, S. 377 (378).

${ }^{89}$ Karpen, Die Verweisung, S. 161. 
Verweisungen erheben lassen. Auch gegen statische Verweisungen werden aber unter diesem Gesichtspunkt keine Bedenken geltend gemacht, weil für den Fall der Verweisung von Landes- auf Bundesrecht auch das Bundesgesetzblatt für den Landesbürger "zuständig" sei $^{90}$. Dem Bürger könnten Kenntnis und Zugriff auf die Verkündungsblätter des Bundes und seines Landes aufgrund seiner "dualen Bürgerstellung" zugemutet werden ${ }^{91}$. Entscheidend ist aber vor allem, daß die Verkündungsvorschriften in den Landesverfassunge ${ }^{92}$ nicht dahingehend auszulegen sind, daß damit die auch zur Zeit des Erlasses dieser Verfassungen übliche Verweisung von Landesauf Bundesrecht unterbunden werden sollte ${ }^{93}$.

Auch ein zweites Bestimmtheitsargument überzeugt nicht recht. Es lautet dahingehend, daß der Adressat im Zeitpunkt des Inkrafttretens einer Norm den sachlichen, persönlichen und zeitlichen Geltungsbereich der Norm nicht hinreichend deutlich und leicht überschauen kann, da beim Inkrafttreten ungewiß sei, wann und wie das Verweisungsobjekt in Zukunft geändert wird $^{94}$. Daraus, daß später Änderungen vorgenommen werden, läßt sich Unbestimmtheit speziell der Verweisungstechnik aber nicht herleiten. Auch bei nichtverweisenden Normen ist beim Inkrafttreten ungewiß, welche Änderungen in Zukunft vorgenommen werden.

Bedenken gegen die Zulässigkeit dynamischer Verweisungen lassen sich nur aus der Tatsache herleiten, daß bundesrechtliche Normen als Landesrecht gelten, ohne daß der Landesgesetzgeber die Geltung ausdrücklich beschlossen hat. Ein diskutabler Einwand ergibt sich daher zum einen aus dem Demokratieprinzip. Nach einer Formel des BVerfG verlangt dieses, daß die Ordnung eines nach dem Grundgesetz staatlicher Regelung offenstehenden Lebensbereichs durch Sätze des objektiven Rechts auf eine Willensentschließung der vom Volke bestellten Gesetzgebungsorgane zurückgeführt werden muß $\beta^{95}$. Demgemäß wird argumentiert, das Landesparlament verletze

${ }^{90}$ Karpen, Die Verweisung, S. 143, ders., in Rödig (Hrsg.), S. 240; Staats, S. 257; Brugger, VerwArchiv 78 (1987), S. 16; BayVerfGH, Entscheidung vom 31.01.1989, BayVBl. 1989, S. 267 (269). Anders lediglich Arndt, JuS 1979, S. 788, allerdings ohne klare Begründung.

${ }^{91}$ So Brugger, VerwArchiv 78 (1987), S. 1.

${ }^{92}$ Art. 63 Verf. BW; Art. 76 BV; Art. 46 Abs. 2 Verf. Bln; Art. 73 Verf. Bremen; Art. 52 Verf. HH; Art. 120 Verf. Hessen; Art. 36 Vorl. Nds. Verf.; Art. 71 Verf. NW; Art. 113 Verf. Rh.Pf.; Art. 102 Verf. Saarl.; Art. 34 Verf. Sl.H.

${ }^{93}$ Staats, S. 257.

${ }^{94}$ So Karpen, Die Verweisung, S. 162.

95 So BVerfG, Beschluß vom 14.06.1983, E 64, 208 (214), im Zusammenhang mit der gesetzlichen Verweisung auf tarifvertragliche Regelungen. 
mit der erstrebten "Arbeitserleichterung" seine demokratische Pflicht zur Gesetzesdeliberation ${ }^{96}$, mit der dynamischen Bezugnahme gebe der Gesetzgeber seine Gesetzgebungsbefugnisse preis ${ }^{97}$. Der Gesetzgeber begebe sich der Pflicht zur eigenverantwortlichen Prüfung und Entscheidung über die künftige Ausgestaltung des von ihm gesetzten Rechts ${ }^{98}$. Dadurch, daß das Landesvolk vom Bund mitregiert werde, sei die dem Demokratiebegriff eigene Identität zwischen Regierenden und Regierten verletzt ${ }^{99}$. Mit diesen Bedenken aus dem Demokratieprinzip gehen dann solche aus dem Bundesstaatsprinzip konsequent einher. Die Verfassungsentscheidung für den Bundesstaat statuiere die Pflicht der Länder zur Wahrung der Eigenstaatlichkeit und Erhaltung vor allem der Gesetzgebungsbefugnisse ${ }^{100}$. Die dynamische Fremdverweisung käme aber einer Teilentlassung der Gesetzgebungskompetenz des verweisenden Gesetzgebers zugunsten der Kompetenz des Gesetzgebers des Verweisungsobjektes gleich ${ }^{101}$. Sie sei deshalb nur dann zulässig, wenn sie sich als zulässige Ermächtigung zur Rechtssetzung nach Art. 80 Abs. 1 S. 2, 71 GG deuten lasse ${ }^{102}$.

Solche Einwände lassen sich mit dem Hinweis auf die unbestreitbaren praktischen Vorteile dynamischer Fremdverweisungen ${ }^{103}$ alleine nicht beiseite schieben. Zwar ist eine gewisse Rechtseinheit zwischen Bund und Ländern in vielen Fällen wünschenswert und nicht per se bundesstaatswidrig ${ }^{104}$. Bei Unzulässigkeit dynamischer Fremdverweisungen würde jedoch lediglich ein Zwang zur Parallelgesetzgebung entstehen. Eine solche Parallelgesetzgebung wäre nicht notwendigerweise "sinnentleert"105. Ihr Sinn bestände gerade darin, daß der Landesgesetzgeber sich bei jeder Änderung des Verweisungsobjektes darüber Gedanken machen müßte, ob er die Änderung übernimmt. Er muß sich für die Übernahme entscheiden. Zwar mag dann im

\footnotetext{
${ }^{96}$ Karpen, Die Verweisung, S. 180, ders., in: Rödig (Hrsg.), S. 238.

${ }^{97}$ Ossenbühl, DVB1. 1967, S. 404.

${ }^{98}$ BVerwG, Beschluß vom 15.03.1989, NVwZ-RR 1989, S. 378.

99 Ossenbühl, DVBI. 1967, S. 404. Dem folgend etwa Arndt, JuS 1979, S. 785; ähnlich Fuß, Festschrift für Paulick, S. 298.

${ }^{100}$ Ossenbühl, DVB1. 1967, S. 405.

${ }^{101}$ Karpen, in: Rödig (Hrsg.), S. 239.

102 Sachs, NJW 1981, S. 1652.

${ }^{103}$ Siehe dazu Göbel, S. 65 ff.; Fuß, Festschrift für Paulick, S. 294. Dynamische Verweisungen sind dementsprechend weit verbreitet. Beispiele aus dem Bereich des bayerischen Landesrechts in BayVerfGH, Entscheidung vom 31.01.1989, BayVBI. 1989, S. 267 (268).

${ }^{104}$ Schneider, Gesetzgebung, Rn. 398.

${ }^{105}$ So aber Baden, NJW 1979, S. 625.
} 
Ergebnis das Gleiche gelten wie bei Zulässigkeit einer dynamischen Verweisung auch. Entscheidend ist aber, daß die Bundesvorschrift in geänderter Form auch in dem betreffenden Bundesland gilt, weil es ausdrücklich beschlossen worden ist.

Die zutreffende Feststellung, daß der Landesgesetzgeber eine "Abkoppelung" vornehmen könne, wenn er zunächst dynamisch auf Bundesrecht verwiesen hätte ${ }^{106}$, vermag die erhobenen Bedenken ebenfalls nicht zu entkräften. Denn die "automatisch" erfolgten Änderungen gelten auf jeden Fall erst einmal bis zu dem Zeitpunkt, in dem das Verweisungsgesetz geändert wird, ganz abgesehen von der Frage, ob die möglicherweise eingetretenen Wirkungen überhaupt wieder rückgängig gemacht werden können ${ }^{107}$.

Auch der Vergleich mit dem Internationalen Privatrecht ist kein schlüssiges Argument für die Zulässigkeit dynamischer Verweisungen ${ }^{108}$. Zwar beruht dort der Anwendungsbefehl zugunsten des ausländischen Rechts auf einer inländischen Rechtsnorm ${ }^{109}$. Es geht aber grundsätzlich darum, die unterschiedlichen Geltungsansprüche verschiedener nationaler Rechtsordnungen gegebenenfalls zulasten der Anwendbarkeit des eigenen Rechts einzuschränken ${ }^{110}$. Hierbei können unter Umständen auch - im Rahmen des ordre public - Rechtsordnungen ohne demokratische Legitimation oder Recht, das mit den deutschen Grundrechten nicht vereinbar wäre, zur Anwendung kommen. Im Gegensatz dazu wollen bei einer dynamischen Verweisung nicht verschiedene Rechtsordnungen gelten ${ }^{111}$, es geht nur darum, daß sich eine Rechtsordnung an die Regelungen einer anderen "anhängt".

Wenn man dynamische Fremdverweisungen für zulässig halten will, dann kann man dies nur damit begründen, daß man die Grundannahme für die vor allem aus dem Demokratieprinzip abgeleiteten Bedenken bezweifelt. Der Ausgangspunkt, von dem aus die Bedenken gegen die Zulässigkeit sol-

\footnotetext{
${ }^{106}$ Schneider, Gesetzgebung, Rn. 398.

${ }^{107}$ So zutreffend Fuß, Festschrift für Paulick, S. 287; Arndt, JuS 1979, S. 785; Ehlers, DVBl. 1977, S. 694.

${ }^{108}$ Anders Schröcker, NJW 1967, S. 2290.

${ }^{109}$ So zutreffend Schröcker, NJW 1967, S. 2290.

${ }^{110}$ Schenke, NJW 1980, S. 749. Dementsprechend geht man davon aus, daß das ausländische Recht nicht in das deutsche "inkorporiert" wird, siehe Brugger, VerwArchiv 78 (1987), S. 6. Dieses Argument führt jedoch insoweit nicht recht weiter, als auch bei Nichtinkorporation der Geltungsbefehl auf dem deutschen Recht beruht. Siehe die ebenfalls nicht ergiebige Unterscheidung zwischen Anknüpfung und Verweisung oben E I $2 \mathrm{~b}$ bb.
}

${ }^{111}$ Vgl. auch Schenke, NJW 1980, S. 749, ders., Festschrift für Fröhler, S. 124. 
cher Verweisungen entwickelt werden, ist in der Tat nicht schlüssig. Er lautet dahingehend, daß der Inhalt des Landesrechts im Fall der dynamischen Fremdverweisung durch den Landesgesetzgeber auf Bundesrecht vom Bundesgesetzgeber (mit-)bestimmt wird. Dies kommt in Formulierungen zum Ausdruck, wonach die das Verweisungsgesetz erlassene Legislative den Schöpfer des Verweisungsobjektes in der Weise an der Gesetzgebung "beteilige", daß dieser durch die Veränderung des Verweisungsobjektes die Möglichkeit eingeräumt bekomme, auf den Inhalt der verweisenden Norm Einfluß zu nehmen ${ }^{112}$. Die dynamische Fremdverweisung sei deshalb eine versteckte Form der Übertragung ${ }^{113}$ oder Preisgabe ${ }^{114}$ der Gesetzgebungsbefugnis.

Dieser Ansatz wird jedoch schon von den eigenen Vertretern zum Teil nicht durchgehalten. So geht etwa Schenke davon aus, daß die gesetzliche Ermächtigung eines Organs oder Rechtssubjekts zur Rechtssetzung in beliebigem Umfang mit der dynamischen Verweisung austauschbar $\operatorname{sei}^{115}$. Dem Gesetzgeber könne aber nicht das, was ihm von Art. 80 GG verboten sei, über den Weg dynamischer Verweisungen erlaubt $\operatorname{sein}^{116}$. Dann muß man aber konsequent zur Unzulässigkeit jeder Form dynamischer Verweisungen kommen $^{117}$, denn die dem Art. 80 GG entsprechenden Vorschriften der Landesverfassungen sehen eine Verordnungsermächtigung an den Bund nicht vor und schließen sie aufgrund ihres abschließend konzipierten Adressatenkreises damit aus. Wenn es aber einem Land untersagt ist, den Bund zum Erlaß von Rechtsverordnungen für das Land zu ermächtigen, kann für formelle Gesetze kaum etwas anderes gelten. Die Delegation von Gesetzgebungsbefugnissen ist insoweit abschließend geregelt ${ }^{118}$. Folgt man somit der Theorie, daß Verweisungen eine Form der Übertragung von Gesetzgebungsbefugnissen darstellen und kommt man trotzdem unter Umständen

\footnotetext{
${ }^{112}$ Gamber, VBIBW 1983, S. 197; Schenke, NJW 1980, S. 744.

${ }^{113}$ So Schenke, NJW 1980, S. 748, ders., Festschrift für Fröhler, S. 92, 100, 113; Arndt, JuS
} 1979, S. 785. Anders zu Recht BayVerfGH, Entscheidung vom 31.01.1989, BayVB1. 1989, S. 267 (268): Dynamische Verweisungen übertragen keine Normsetzungsbefugnisse.

${ }^{114}$ So Ossenbühl, DVBl. 1967, S. 404.

${ }^{115}$ Schenke, NJW 1980, S. 745, ders., Festschrift für Fröhler, S. 114.

${ }^{116}$ Schenke, NJW 1980, S. 745, ders., Festschrift für Fröhler, S. 102.

117 So von einem solchen Verständnis her vollkommen folgerichtig Sachs, NJW 1981, S. 1652; Staats, S. 251.

118 Ossenbühl, DVBI. 1967, S. 402; Arndt, JuS 1979, S. 786. Anders Clemens, AöR 111 (1986), S. 82. 
zur Zulässigkeit solcher Verweisungen ${ }^{119}$, verläßt man letztlich die eigene Ausgangsthese.

Die Annahme einer Übertragung von Gesetzgebungsbefugnissen ist auch deshalb nicht schlüssig, weil damit dynamischen Fremdverweisungen eine Aussage unterstellt wird, die sie nicht oder zumindest nicht notwendigerweise haben. Ist die dynamische Verweisung nichts anderes als die unbedingte Übernahme des jeweiligen Inhalts einer anderen Norm in das eigene Recht ${ }^{120}$, also ein der Wiederholung gleichwertiges und gegen sie austauschbares Mittel, dann wären die Bedenken in der Tat berechtigt. Nur wird man dynamischen landesrechtlichen Verweisungen auf Bundesrecht nicht in jedem Fall eine solche Aussage unterschieben können. Um auf den Fall der Inbezugnahme des BBauG durch die Landesbauordnungen zurückzukommen: Wenn $\S 73$ Abs. 5 LBO BW bestimmt, daß der $\S 12$ BBauG beim Erla $ß$ von örtlichen Bauvorschriften entsprechend angewendet werden soll, dann wäre es blanke Wortklauberei, dem Landesgesetzgeber zu unterstellen, damit solle - egal was der Bundesgesetzgeber auch immer in $\S 12$ BBauG hineinschreibt - auch für örtliche Bauvorschriften gelten, und zwar selbst dann, wenn dort etwas geregelt würde, was nicht mehr im geringsten etwas mit dem Inkrafttreten von Satzungen zu tun hat. Die Aussage, die die Inbezugnahme des $B B a u G$ hat, ist doch vielmehr die, daß die Regeln für das Inkrafttreten von Bebauungsplänen auch gelten sollen für das Inkrafttreten von örtlichen Bauvorschriften.

Die Bezugnahme auf eine andere Norm in dynamischer Form ist somit kein blindes Abschreiben eines wie auch immer gearteten Inhalts dieser Norm, sondern ein auslegungsfähiger und auslegungsbedürftiger Anwendungsbefehl. Damit ist es aber nicht ausgeschlossen, daß bei einer dynamischen Verweisung genau wie sonst bei einer rechtlichen Regelung sich bestimmte Tatbestandsmerkmale ergeben, bei deren Vorliegen sich die Rechtsfolge, nämlich die entsprechende Anwendung der Norm auch im Landesrecht, ergibt. Der Unterschied zu einer "normalen" gesetzlichen Regelung besteht lediglich darin, daß dort tatsächliche Gegebenheiten zum Gegenstand einer rechtlichen Regelung gemacht werden. Dann stellt sich ganz analog bei Änderung der tatsächlichen Verhältnisse die Frage, ob die Norm auch auf diese Verhältnisse anwendbar ist. Bei einer Verweisung geht

${ }^{119}$ So Schenke, NJW 1980, S. 748, für den Bereich der konkurrierenden Gesetzgebungszuständigkeiten.

${ }^{120}$ So Brugger, VerwArchiv 78 (1987), S. 4; Clemens, AöR 111 (1986), S. 65. 
es im Unterschied dazu nur darum, inwieweit eine geänderte rechtliche Lage den Tatbestand der verweisenden Norm mit der Folge erfüllt, daß der Anwendungsbefehl gilt ${ }^{121}$. Von einem "parlamentslosen Parlamentsgesetz ${ }^{122}$ oder einer "Deliberation der Gesetzgebungsbefugnisse" läßt sich somit dann nicht sprechen, wenn der verweisende Gesetzgeber den möglichen und von ihm akzeptierten Inhalt der Verweisung vorzeichnet.

Zum entscheidenden Problem wird somit doch die Bestimmtheitsfrage ${ }^{123}$. Nur ergibt es sich nicht aus den Schwierigkeiten des juristischen Laien bei der Auffindung der jeweils geltenden Gesetzesfassung oder aus den Möglichkeiten späterer Änderungen, sondern daraus, daß die verweisende Norm hinreichend konkrete Aussagen dahingehend treffen muß, mit welchem möglichen Inhalt sie die Norm, auf die verwiesen wird, übernehmen will ${ }^{124}$. Dies ist aber weder für dynamische noch für Fremdverweisungen spezifisch. Als Beispiel mag etwa $\S 1192$ Abs. 1 BGB dienen. Wenn dort angeordnet wird, daß für Grundschulden die Regelungen des Hypothekenrechts gelten, soweit diese nicht eine Forderung voraussetzen, werden keine Bestimmtheitsbedenken geltend gemacht, auch wenn der Normadressat nur quasi mittelbar zum eigentlichen Normbefehl geführt wird, indem von ihm verlangt wird, die Normen des Hypothekenrechts dann anzuwenden, wenn diese keine Forderung voraussetzen. Soweit sich also bei einer dynamischen Fremdverweisung ein "Tatbestand" in dem Sinne ermitteln läßt, daß sich feststellen läßt, unter welchen Bedingungen andere Normen angewendet werden sollen, ist dem Bestimmtheitsgrundsatz genügt.

Gegen eine dynamische Verweisung ist somit dann weder unter demokratischen noch unter rechtsstaatlichen Bedingungen etwas einzuwenden, wenn sich der verweisenden Norm mit hinreichender Bestimmtheit entnehmen läßt, welche potentiellen Änderungen des Verweisungsobjektes von der Verweisung mit umfaßt sein sollen und welche nicht. Nötig ist nur, daß in der verweisenden Norm eine hinreichend konkrete Sachentscheidung ge-

\footnotetext{
${ }^{121}$ In diese Richtung argumentiert auch Schröcker, NJW 1967, S. 2289.

122 Die Verwendung dieses Begriffes im Zusammenhang mit Verweisungen geht im Anschluß an die Monographie von Quaritsch vor allem auf Ossenbühl, DVBl. 1967, S. 402, zurück.

${ }^{123}$ In diese Richtung tendiert auch Scholz, Festschrift für Müller, S. 524.

${ }^{124}$ Dem Bestimmtheitsgrundsatz wird man somit auch nicht alleine dadurch gerecht, daß die Verweisungsnorm nur erkennen läßt, welche Vorschriften sie in bezug nimmt, zumindest dann nicht, wenn man damit nur den Paragraphen eines bestimmten Gesetzes meint, vgl. Clemens, AöR 111 (1986), S. 85.
} 
troffen wird, unabhängig davon, ob dynamisch oder statisch, auf fremde oder auf eigene Normen verwiesen wird ${ }^{125}$. In eine ähnliche Richtung weisen Äußerungen, wonach dann, wenn ein "strukturiertes Regelungsfeld" vorliegt, auf das verwiesen wird, von einer ausreichenden formell-gesetzlichen Eigenentscheidung des verweisenden Gesetzgebers ausgegangen wird, hingegen nicht, wenn dem "bezogenen Normautor eine Regelungskompetenz im Sinne von "was immer dieser beschließen mag» eingeräumt wird" ${ }^{\text {"26 }}$. In ähnlicher Weise stellt das BVerfG darauf ab, ob die Regelungen, auf die verwiesen wird, im wesentlichen feststehen ${ }^{127}$.

Dies wird man jedoch dann, wenn es richtig sein soll, nicht dahingehend verstehen dürfen, daß der Spielraum für den "ausfüllenden Normgeber" begrenzt sein müsse ${ }^{128}$. Der für das Verweisungsobjekt zuständige Gesetzgeber ist nicht ermächtigt und unterliegt daher auch keinen Schranken. Wenn etwa der Bundesgesetzgeber auf die Idee käme, in § 12 BBauG / BauGB in Zukunft Fragen des Zugewinnausgleichs im Zusammenhang mit Eigentumswohnungen zu regeln, wäre er durch keine landesrechtliche Verweisung auf $\S 12$ BBauG daran gehindert.

Die Frage, ob das Regelungsfeld, auf das verwiesen wird, strukturiert ist und im wesentlichen feststeht oder nicht, ist nur, aber immerhin insoweit von Bedeutung, als sich daraus entnehmen läßt, ob und welche Vorstellungen der verweisende Gesetzgeber vom Inhalt der Verweisung hatte. War ein Normbereich "strukturiert", so geben diese Strukturen auch den Hinweis auf den Geltungsbereich der Verweisung.

Damit bleibt als Ergebnis folgendes festzuhalten: Dynamische Verweisungen führen nicht zu einer Übertragung von Gesetzgebungsbefugnissen. Sie sind daher auch nicht in jedem Fall unzulässig. Entscheidend ist vielmehr, ob sie in dem Sinne hinreichend bestimmt sind, daß sich aus ihnen ergibt, ob und inwieweit auch künftige Änderungen Gegenstand der rechtlichen Normierung werden sollen.

${ }^{125}$ Vgl. auch BVerfG, Schlußurteil vom 05.11.1975, E 40, 296 (316).

${ }^{126}$ Brugger, VerwArchiv 78 (1987), S. 25.

${ }^{127}$ BVerfG, Beschluß vom 15.07.1969, E 26, 338 (366 f.); Beschluß vom 14.06.1983, E 64, 208 (215); dem folgend auch BayVerfGH, Entscheidung vom 31.01.1989, BayVBl. 1989, S. 268 (269).

${ }^{128}$ So aber Clemens, AöR 111 (1986), S. 107. 
d) Inhalt und Bestimmtheit der Verweisungen in den Landesbauordnungen auf das BBauG

Der Grad an Bestimmtheit, den dynamische Verweisungen haben müssen, damit sie als zulässig angesehen werden können, läßt sich letztlich nur nach der sog. Wesentlichkeitstheorie ermitteln. In gewissen Zusammenhängen wird man verlangen müssen, daß der Inhalt des Tatbestandes, auf den verwiesen wird, bereits aufgrund der verweisenden Norm bzw. ihres unvollständigen Tatbestandes bestimmbar ist ${ }^{129}$. In anderen Bereichen, vor allem dann, wenn die Grundrechtsrelevanz gering ist, kann man es auch als ausreichend ansehen, daß sich erst anhand einer konkreten Änderung des Verweisungsobjektes sagen läßt, ob diese Änderung von der Verweisung umfaßt ist ${ }^{130}$. Auch spielt es eine Rolle, inwieweit für einen Bereich bereits verfassungsrechtliche Vorgaben bestehen, die den Spielraum für Änderungen ohnehin begrenzen ${ }^{131}$.

Untersucht man unter diesem Blickwinkel die Verweisungen der Landesbauordnungen auf das BBauG, so läßt sich deren Inhalt klar umschreiben: Die Landesgesetzgeber beziehen sich konkludent oder ausdrücklich auf die Regelung des $\S 9$ Abs. 4 BBauG / BauGB und wollen von der dort enthaltenen Ermächtigung Gebrauch machen. Sie konstituieren zu diesem Zweck weitgehend mit Erfolg ${ }^{132}$ eine verfahrens- und materiellrechtliche Einheit zwischen der Schaffung von Festsetzungen nach $\S 9$ Abs. 1 BBauG und von Bestimmungen in örtlichen Bauvorschriften. Was den etwa für Bayern und Nordrhein-Westfalen problematischen Fall der Genehmigungspflicht betrifft, sehen sie auch für die aufgenommenen Festsetzungen die im BBauG für Bebauungspläne normierte Genehmigungspflicht vor, obwohl bei isoliertem Erlaß eine solche Genehmigungspflicht nicht bestehen würde. Ersetzt nun wie geschehen der Bundesgesetzgeber die Genehmigungspflicht weitgehend durch ein Anzeigeverfahren, so läßt sich angesichts dieses durch Auslegung ermittelten Willens des Landesgesetzgebers hinreichend bestimmen, was für diesen Fall gewollt ist. Da die Genehmigungspflicht nur zur Herstellung einer verfahrensmäßigen Einheit mit dem Bebauungsplan auch auf örtliche Bauvorschriften erstreckt wurde, fehlt für eine weitere Genehmigungspflicht jeder weitere Grund. Als mögliche Auslegungsalternati-

\footnotetext{
${ }^{129}$ So Scholz, Festschrift für Müller, S. 524 ff.

${ }^{130}$ So wohl auch Scholz, Festschrift für Müller, S. 526.

${ }^{131}$ Clemens, AöR 111 (1986), S. 111, für das Verfahrensrecht.

${ }^{132}$ Siehe oben E I 2 a.
} 
ven bleiben die Annahme einer Genehmigungsfreiheit von örtlichen Bauvorschriften auch dann, wenn sie in den Bebauungsplan aufgenommen worden sind, oder die Erstreckung des Anzeigeverfahrens auf diese. Da der $\S 9$ Abs. 4 BBauG / BauGB eine auch verfahrensmäßige Einheit fordert, kommt es zur Ausfüllung dieser Ermächtigung nur durch die letztere Alternative. Versteht man die landesrechtlichen Verweise daher so, daß sie in der Regel für örtliche Bauvorschriften in Bebauungsplänen ein Anzeigeverfahren vorsehen ${ }^{133}$, ist dies auch kein "octroi". Das Anzeigeverfahren mag zwar rechtsdogmatische Besonderheiten aufweisen: In seiner Wirkung auf die Planungshoheit der Gemeinden ist es ein Minus gegenüber einer Genehmigungspflicht. Das Anzeigeverfahren ist also von den Verweisungen der Landesbauordnungen auf das $\mathrm{BBauG}$, das jetzt lediglich BauGB genannt wird $^{134}$, umfaßt.

Dieses Ergebnis läßt sich im übrigen auf die übrigen Vorschriften des BBauG, die in den Landesbauordnungen in Bezug genommen werden, übertragen. Insoweit sind die Bestimmungen von BBauG und BauGB jedoch inhaltlich identisch, so daß sich das Problem derzeit nicht in gleicher Schärfe stellt.

\section{Der Erlaß von örtlichen Bauvorschriften als einfache Satzungen}

\section{Verfahrensrechtliche Anforderungen an den Erlaß einer Satzung über örtliche Bauvorschriften}

\section{a) Allgemeines}

Im Grundsatz ist eine Satzung über örtliche Bauvorschriften eine gemeindliche Satzung wie jede andere gemeindliche Satzung auch. Strukturelle Eigenarten finden sich nur wenige. Weder bei Fragen der Erlaßzuständigkeit noch für den Geschäftsgang im Gemeinderat zeigen sich Besonderheiten ${ }^{135}$. Gewisse Ausnahmen ergeben sich allerdings aus gleichen Gründen wie im Bauplanungsrecht im Hinblick auf Darstellung und Bekanntgabe. Die Anforderungen lassen sich oft am besten zeichnerisch darstellen, eine

\footnotetext{
${ }^{133}$ So auch Gaentzsch, Berliner Kommentar, $\$ 9$ Rn. 71.

${ }^{134}$ Gaentzsch, Berliner Kommentar, $\$ 9$ Rn. 71.

${ }^{135}$ Siehe etwa die Ausführungen von Keller, S. 43 ff., für die Rechtslage in Bayern.
} 
Veröffentlichung von solchen Plänen wäre jedoch sehr aufwendig. Daher sehen etwa $\S 73$ Abs. 5 LBO BW und $\S 97$ NBauO weitgehend vor, daß örtliche Bauvorschriften entsprechend den Vorschriften für Bebauungspläne zu erlassen sind. Andere Landesbauordnungen bestimmen zumindest, daß zeichnerische Darstellungen möglich sind und eine Bekanntgabe insofern entsprechend den Regeln des $\S 12$ BBauG erfolgt ${ }^{136}$.

Ein Problem, das spezifisch den Erlaß von örtlichen Bauvorschriften betrifft, ist aber die Frage, ob die Festlegungen begründet werden müssen. Die Landesbauordnungen sehen eine Begründungspflicht in der Regel nicht vor $^{137}$. Art. 91 Abs. 3 S. 3 BayBO schließt eine Begründungspflicht sogar für solche örtlichen Bauvorschriften aus, die in den Bebauungsplan aufgenommen werden, woraus sich der klare Wille des Landesgesetzgebers ergibt, $\mathrm{da} ß$ auch einfache Satzungen einer Begründung nicht bedürfen sollen. Auch die anderen Landesbauordnungen verweisen im Rahmen der Bezugnahmen des BBauG / BauGB nicht auf § 9 Abs. 8. Auch hieraus läßt sich der Schluß ziehen, daß eine Begründungspflicht für einfache Satzungen ebenfalls nicht gewollt ist.

Die fehlende einfachgesetzliche Begründungspflicht hat sich jedoch für die gerichtliche Überprüfung von örtlichen Bauvorschriften als problematisch erwiesen. Vor allem wird die Kontrolle der für notwendig gehaltenen Abwägung ohne Begründungspflicht erschwert ${ }^{138}$. Die Entscheidung der Gesetzgeber, daß eine Begründung nicht erforderlich ist, wird deshalb in der Rechtsprechung der Oberverwaltungsgerichte auch nicht vorbehaltlos akzeptiert. So verlangt das OVG Münster, daß die vom Satzungsgeber angestellten Überlegungen in den Satzungsunterlagen zum Ausdruck kommen müssen $^{139}$. Zumindest bestände eine Obliegenheit der Gemeinden, ihre planerische Abwägung - mangels gesetzlicher Formerfordernisse: egal in welcher Weise - nachzuweisen. Falls das Gericht eine Abwägung der relevanten Belange nicht positiv feststellen könne, sei die Satzung für ungültig zu erklä$\operatorname{ren}^{140}$.

${ }^{136} \S 118 \mathrm{HBO} ; \S 81 \mathrm{Abs} .3 \mathrm{BauO} \mathrm{NW} ; \S 86$ Abs. 2 LBauO Rh.Pf.

${ }^{137}$ Eine Ausnahme bildet $\S 97 \mathrm{NBauO}$, siehe dazu Stich, Festschrift für Ule, S. 389. $\$ 73$ Abs. 5 LBO BW verweist hingegen ausdrücklich nicht auf $\S 9$ Abs. 8 BBauG.

${ }^{138}$ Vgl. OVG Münster, Urteil vom 30.06.1981, BRS Band 38, Nr. 138 S. 322 ff.; Urteil vom 30.06.1983, BRS Band 40, Nr. 152 S. 335 ff.; OVG Lüneburg, Urteil vom 12.02.1982, BRS Band 39, Nr. 132 S. 80 ff.

139 Urteil vom 30.06.1981, BRS Band 38, S. 322 ff.; zustimmend Koch / Molodovsky / Rahm, Art. 91 Anm. 4.2.4.

${ }^{140}$ Urteil vom 30.06.1983, BRS Band 38, S. 338. 
Die Gegenposition vertreten das OVG Lüneburg und der VGH Kassel. Während das OVG Münster die Entscheidung der Landesgesetzgeber, keine Begründung zu verlangen, durch eine nicht formgebundene Dokumentationsobliegenheit in gewisser Weise wieder überspielt, ziehen die beiden anderen Gerichte aus der von den Gesetzgebern nicht vorgesehenen Begründungspflicht materielle Konsequenzen. Mangels einer Begründungspflicht konzentriere sich die Abwägungskontrolle im wesentlichen auf das Abwägungsergebnis ${ }^{141}$.

$\mathrm{Da}$ auch in der Literatur vielfach Stellungnahmen dahingehend anzutreffen sind, daß staatliche Maßnahmen allgemein und untergesetzliche Rechtsnormen im speziellen generell zu begründen seien ${ }^{142}$, soll die Frage der Begründungspflicht hier schwerpunktmäßig untersucht werden. Terminologisch sei noch klargestellt, daß der Begriff "Begründung" im folgenden im Sinne von $\S 9$ Abs. 8 BauGB verstanden wird. Gemeint ist somit eine Erklärung zu Zielen, Gründen und maßgeblichen Erwägungen des Satzungserlasses, die bei der Abstimmung über die Satzung mitbeschlossen und dieser beigefügt wird. Geht es nur darum, daß hinterher entsprechende Erklärungen abgegeben werden, so wird der Begriff "Erläuterung" verwendet.

b) Versuche zur Ableitung einer Begründungspflicht für örtliche Bauvorschriften

aa) Begründungspflicht und Abwägungsgebot

Die Rechtsprechung der Oberverwaltungsgerichte ist sich darüber einig, daß einfache Satzungen über örtliche Bauvorschriften einer Begründung nicht bedürfen. Das OVG Münster kommt aber in seiner Entscheidung vom 30.06.1983 $3^{143} \mathrm{zu}$ dem Ergebnis, daß aus dem Abwägungsgebot und der daraus resultierenden Notwendigkeit einer gerichtlichen Kontrolle eine Pflicht der Gemeinden resultiere, ihre planerische Abwägung in irgendeiner Form nachzuweisen. Es läßt sich nun die Frage aufwerfen, ob man nicht doch einen Schritt über diese Rechtsprechung hinausgehen und aus dem Abwägungsgebot eine Begründungspflicht als notwendige verfahrensrechtliche

${ }^{141}$ OVG Lüneburg, Urteil vom 12.02.1982, BRS Band 39, Nr. 132 S. 280 (282); HessVGH, Urteil vom 30.06.1987; HessStuGZ 1988, S. 408; zustimmend Ortloff, Öffentliches Baurecht, Band II, S. 34.

${ }^{142}$ Siehe die Nachweise im weiteren Text.

${ }^{143}$ BRS Band 40, Nr. 152 S. 335 ff. 
Ergänzung ableiten sollte. So wird gelegentlich von einem "engen Zusammenhang" zwischen Abwägungsgebot und Begründungspflicht gesprochen ${ }^{144}$. Teilweise wird hieraus sogar der Schluß gezogen, daß das Fehlen einer vorgeschriebenen Begründung gleichzeitig einen materiellen Mangel darstelle $^{145}$.

Das OVG Münster übt demgegenüber jedoch zu Recht Zurückhaltung. Es geht nur davon aus, daß es der Gemeinde obliege, auf irgendeine Art und Weise ihre Abwägung nachzuweisen ${ }^{146}$. Es befindet sich dabei in Übereinstimmung mit der Rechtsprechung des BVerwG zum Verhältnis zwischen Begründungspflicht und Abwägungsgebot im Bauplanungsrecht. Diese Rechtsprechung läßt sich dahingehend zusammenfassen, daß eine Begründungspflicht trotz ihres engen Bezuges zum Abwägungsgebot nicht ihren verfahrensmäßigen Charakter verliere ${ }^{147}$. So kann der Nachweis einer ordnungsgemäßen Abwägung von der planenden Stelle auch durch Unterlagen wie Ratsprotokolle, Aktenauszüge und dergleichen geführt werden ${ }^{148}$. Auch so ließe sich das Ziel erreichen, daß nicht im nachhinein einer Satzung Erwägungen zugrunde gelegt werden, die nur angeblich die Entscheidung beeinflußt haben ${ }^{149}$. Dementsprechend kann eine Abwägung trotz fehlerhafter oder unvollständiger Begründung rechtmäßig sein; umgekehrt schließt auch eine korrekte Begründung einen Abwägungsfehler nicht letztlich aus ${ }^{150}$. Daß einem gegen eine Satzung über örtliche Bauvorschriften Rechtsschutz suchenden Bürger so möglicherweise Unterlagen entgegengehalten werden, die er nicht einsehen konnte ${ }^{151}$ - die Landesbauordnungen enthalten kein dem $\S 214$ Abs. 1 BauGB entsprechendes Einsichtsrecht - ist kein zwingendes Gegenargument gegen die Anwendung dieser Rechtsprechung auch im Bereich von Satzungen über örtliche Bauvorschriften. Das

${ }^{144}$ BVerwG, Beschluß vom 21.02.1986, NJW 1986, S. 2720; Meyer, in: Kohlhammer Kommentar BBauG, § 155 b Rn. 25.

${ }^{145}$ Lemmel, DVBI. 1981, S. 32O. Dem wohl folgend Ryu, S. $165 \mathrm{ff}$.

146 OVG Münster, BRS Band 40, Nr. 152 S. 335 (338).

${ }^{147}$ So auch Battis, in: Battis / Krautzberger / Löhr, § 214 Rn. 6; Keßler, S. 242.

148 BVerwG, Urteil vom 07.05.1971, DÖV 1971, S. 633 (635); Beschluß vom 21.02.1986, NJW 1986, S. 2720.

${ }^{149}$ BVerwG, jeweils ebenda; Grave, BauR 1980, S. 203.

${ }^{150}$ Kühling, S. 80 Rn. 181. In diese Richtung auch BVerwG, Urteil vom 05.12.1986, E 75, 215 (247). Unklar allerdings die Ausführung auf S. 251, wo die Begriffe Begründungsfehler und Abwägungsfehler wohl synonym gebraucht werden.

${ }^{151}$ So die Erwägung des OLG Düsseldorf, Urteil vom 18.10.1979, BauR 1980, S. 143, für das Bauplanungsrecht. 
Prozeßrisiko kann schon dadurch gemindert werden, daß man ein "Verschulden" der Gemeinde nach $\S 155$ Abs. 5 VwGO annimmt, wenn sie im verwaltungsgerichtlichen Verfahren Unterlagen nachschiebt, deren Kenntnisnahme sie vorher dem Bürger verweigert hatte.

Insgesamt kann man also der Rechtsprechung der Oberverwaltungsgerichte zustimmen, wonach aus dem Abwägungsgebot keine dem $\S 9$ Abs. 8 BauGB entsprechende Begründungspflicht folgt.

bb) Begründungspflicht aus Art. 20 Abs. 3 GG

Ein weiterer Versuch, zu einer allgemeinen und damit auch den Erlaß örtlicher Bauvorschriften erfassenden Begründungspflicht zu kommen, wurzelt in Art. 20 Abs. 3 GG $^{152}$ oder allgemeiner im Rechtsstaatsprinzip ${ }^{153}$. Ausgangspunkt einer solchen Annahme sind einmal Überlegungen zur Selbstkontrollfunktion eines Begründungszwanges; ohne vorgeschriebene Begründungspflicht bestehe die Gefahr, daß die staatlichen Organe sich den Bindungen, denen sie unterliegen, nicht bewußt werden und so die Voraussetzungen für ihr Handeln vorschnell annehmen ${ }^{154}$.

Zur Annahme einer Begründungspflicht für Satzungen über örtliche Bauvorschriften führt dieser Ansatz jedoch angeblich nicht. Die aus Art. 20 Abs. 3 GG folgende "Begründungspflicht" soll nur staatsinterne Bedeutung haben ${ }^{155}$. Dieser Pflicht wäre somit dann entsprochen, wenn die Gemeinde zwar durch Erstellung einer Begründung sich ihrer rechtlichen Bindungen bewußt wird und die so erstellte Begründung anschließend in den Papierkorb wirft. Problematisch ist im vorliegenden Zusammenhang aber die Frage nach der Notwendigkeit einer "externen" Begründung, also danach, ob der Satzung entsprechend der Bestimmung des $\S 9$ Abs. 8 BauGB eine Begründung beizufügen ist.

Zwar dürfte dem Ergebnis - nämlich keine Begründungspflicht aus Art. 20 Abs. 3 GG - zuzustimmen sein. Dies ergibt sich aber nicht aus der

152 So vor allem Lücke, S. $40 \mathrm{ff}$.

${ }^{153}$ Laubinger, VerwArchiv 75 (1982), S. 83 ff.; Scheffler, DÖV 1977, S. 768 ff. Auch das BVerfG, Urteil vom 16.01.1957, E 6, 32 (44), spricht von einem rechtsstaatlichen Grundsatz, daß der Staatsbürger, in dessen Rechte eingegriffen wird, die Gründe dafür erfährt. Ebenso BVerfG, BeschluB vom 29.10.1975, E 40, 276 (286); Kopp, Verfassungsrecht und Verwaltungsverfahrensrecht, S. $90 \mathrm{ff}$.

${ }^{154}$ Lücke, S. 40; ähnlich auch Scheffler, DÖV 1977, S. 768.

${ }^{155}$ Lücke, S. 45. 
Differenzierung zwischen "internen" und "externen" Begründungspflichten. Denn die Annahme einer reinen Staatsgerichtetheit des Art. 20 Abs. 3 GG, aus der diese Unterscheidung folgen soll ${ }^{156}$, erscheint fragwürdig. Immerhin wird der Art. 20 Abs. 3 GG als eine der verfassungsrechtlichen Ausformungen des Rechtsstaatsprinzips verstanden ${ }^{157}$. Damit bedarf die Behauptung, Art.20 Abs. 3 GG sei eine Verfassungsnorm, der keine "externen Funktionen wesenseigen sind"158, zumindest einer ausführlichen Argumentation ${ }^{159}$.

Die Verneinung einer aus Art. 20 Abs. 3 GG folgenden "externen" Begründungspflicht ist aber deshalb zutreffend, weil sich aus Art. 20 Abs. 3 GG überhaupt keine Begründungspflicht ableiten läßt, zumindest dann nicht, wenn man vor allem die Selbstkontrollfunktion in den Mittelpunkt der Überlegungen stellt. So keimt der Verdacht der Unrichtigkeit der These einer aus Art. 20 Abs. 3 GG ableitbaren Begründungspflicht bereits dann auf, wenn für sachlich und rechtlich einfach gelagerte Entscheidungen ein Begründungszwang nicht angenommen wird ${ }^{160}$. Was sachlich und rechtlich einfach ist, dürfte vor allem der Gesetzgeber zu entscheiden haben. Gleiches gilt, wenn eine Ausnahme von der Begründungspflicht vorliegen soll, weil übergeordnete Interessen des Allgemeinwohls oder sonstige schwerwiegende Belange vorliegen, die ein Absehen von der grundsätzlichen Begründungspflicht geboten erscheinen lassen ${ }^{161}$. Desweiteren gibt es eine Reihe von Maßnahmen, die ergänzend zu, aber auch statt einer Begründungspflicht der Verwaltung eine wirksame Selbstkontrolle ermöglichen ${ }^{162}$. Genannt seien etwa das sog. 4-Augen-Prinzip oder das Zusammenwirken mehrerer Entscheidungsträger. Ist aber die Begründungspflicht weder die in jedem Fall notwendige noch die einzige Möglichkeit, die Verwaltung zu einer wirksamen Selbstkontrolle zu veranlassen, ist die Annahme, daß sich aus Art. 20 Abs. 3 GG generell eine Begründungspflicht ergebe, wohl hinfällig.

${ }^{156}$ Siehe Lücke, S. 46.

157 Jarass, Art. 20 Anm. 21.

${ }^{158}$ Lücke, S. 44.

159 Durchaus mit "externen Funktionen" des Rechtsstaatsprinzips argumentiert z. B. Laubinger, VerwArchiv 75 (1982), S. 84.

${ }^{160}$ So Lücke S. 44. Zu weiteren Ausnahmen siehe auch Kopp, Verfassungsrecht und Verwaltungsverfahrensrecht, S. $49 \mathrm{ff}$.

${ }^{161} \mathrm{Zu}$ diesen Ausnahmen siehe Kopp, Verfassungsrecht und Verwaltungsverfahrensrecht, S. 49.

${ }^{162}$ Anders Lücke, S. 40 und auch Kopp, Verfassungsrecht und Verwaltungsverfahrensrecht, S. 47. 
Auch aus der Überlegung, daß das Rechtsstaatsprinzip dem Staat die Verpflichtung auferlege, den Bürgern alle Mittel an die Hand zu geben, um ihre materiellen Rechte wirksam durchsetzen und verteidigen zu können ${ }^{163}$, rechtfertigt sich die generelle Annahme bestimmter Verfahrenspflichten nicht. $\mathrm{Zu}$ unterschiedlich sind dafür die "materiellen Rechte" und die von daher erforderlichen verfahrensrechtlichen Sicherungen ${ }^{164}$. Es gibt also keinen aus Art. 20 Abs. 3 GG folgenden allgemeinen und damit auch Satzungen über örtliche Bauvorschriften erfassenden Begründungszwang.

\section{cc) Begründungspflicht aus Art. 19 Abs. 4 GG}

Ein weiterer Versuch, zu einer aus der Verfassung ableitbaren, auch Satzungen erfassenden Begründungspflicht zu kommen, gründet sich auf Art. 19 Abs. 4 S. 1 GG $^{165}$. Ausgangspunkt ist die Überlegung, daß bei einer nicht (extern) begründeten Entscheidung die Betroffenen in der Regel nicht wissen, weshalb sie ergangen ist; sie würden deshalb davon abgehalten, gerichtlichen Rechtsschutz in Anspruch zu nehmen. Jedenfalls wären sie aber gezwungen, den Rechtsschutz lediglich gestützt auf Mutmaßungen über die Motive der Maßnahme zu betreiben. Dies verstoße gegen die von Art. 19 Abs. 4 GG vermittelte Garantie des effektiven Rechtsschutzes ${ }^{166}$.

Auch diese Ableitung kommt jedoch nicht ohne Ausnahme aus. So soll der Begründungszwang dann nicht gelten, wenn dem Betroffenen die Gründe der Entscheidung bekanntgeworden oder wenn sie ohne weiteres zweifelsfrei erkennbar sind ${ }^{167}$. Die Ableitung einer Begründungspflicht aus der Garantie des effektiven Rechtsschutzes erlaubt zudem nur die Annahme einer Erläuterungspflicht. Die Chancen eines Rechtsstreites verläßlich abschätzen kann auch derjenige, dem auf Anfrage die Motive der Maßnahme

${ }^{163}$ Laubinger, VerwArchiv 75 (1982), S. 84.

${ }^{164}$ So auch Fackler, S. 93 f.; Laubinger, VerwArchiv 75 (1982), S. 84, verwickelt sich in einen kaum lösbaren Widerspruch zu seinen Ausführungen auf S. 76, wo er bei der Ableitung aus den Grundrechten ausdrücklich für eine differenzierte Betrachtungsweise eintritt. Ist aber eine generelle Aussage über notwendige verfahrensmäßige Sicherungen bei der grundrechtlichen Ableitung von Verfahrenspflichten falsch, kann sie bei einer Ableitung aus dem allgemeinen Rechtsstaatsprinzip kaum richtig sein.

${ }^{165}$ Siehe Schenke, BK Art. 19 Abs. 4 GG, Anm. 427, insbesondere für untergesetzliche Normen; Laubinger, VerwArchiv 1982, S. 82; Lücke, S. 57; Kopp, Verfassungsrecht und Verwaltungsverfahrensrecht, S. $159 \mathrm{ff}$.

${ }^{166}$ Lücke, S. 53.

${ }^{167}$ Lücke, S. 54. 
erläutert werden ${ }^{168}$. Das Prozeßrisiko bei unverschuldet unsicherer Tatsachenkenntnis läßt sich zudem auch durch entsprechende Auslegung der Kostenvorschriften beheben ${ }^{169}$.

Der Garantie des effektiven Rechtsschutzes kann somit auch auf anderem Wege, etwa auch durch eine nachträgliche Erläuterungspflicht entsprochen werden. Eine Begründungspflicht für örtliche Bauvorschriften im Sinne von $\S 9$ Abs. 8 BauGB ist aus Art. 19 Abs. 4 GG daher nicht ableitbar.

\section{dd) Grundrechtliche Ableitung einer Begründungspflicht}

\section{(1) Allgemeines zur Ableitung von Verfahrensanforderungen aus den Grundrechten}

Eine Begründungspflicht für örtliche Bauvorschriften in dem Sinn, daß bei Satzungserlaß entsprechend der Regelung des $\S 9$ Abs. 8 BauGB eine Begründung beizufügen ist, läßt sich somit letztlich höchstens aus den Grundrechten ableiten. Daß der Staat aus den Grundrechten verpflichtet ist, diesen auch verwaltungsverfahrensmäßig Geltung zu verschaffen, gehört heute zu den gesicherten Erkenntnissen in der Rechtsprechung des BVerfG und der Literatur ${ }^{170}$.

Obwohl seit der Mülheim-Kärlich-Entscheidung das Problem des Grundrechtsschutzes und der Grundrechtsverwirklichung durch Verfahrensgestaltung zu einem literarischen Dauerthema geworden ist ${ }^{171}$, wird die Frage nach einer grundrechtlich gebotenen Begründungspflicht eher am Rande behandelt. Dies dürfte daran liegen, daß die Mülheim-Kärlich-Entscheidung sich letztlich nur zur Frage der Ableitung der Verfassungsbeschwerdebefugnis bei der Verletzung von Vorschriften über die Beteiligung klagebefugter

\footnotetext{
${ }^{168}$ So auch Schenke, BK, Art. 19 Abs. 4, Rn. 427.

169 Siehe die Ausführungen zum Abwägungsgebot unten E II 2 a dd.

${ }^{170}$ Vor allem BVerfG, Beschluß vom 13.11.1979, E 52, 380 ff.; Beschluß vom 20.10.1979, NJW 1980, S. 759 ff. (Mülheim-Kärlich-Entscheidung); Beschluß vom 25.02.1981, NJW 1981, S. 1436. Aus dem Schrifttum etwa von Mutius, NJW 1982, S. 2154 ff.; Ossenbühl, DÖV 1981, S. 5; Dolde, NVwZ 1982, S. 65 ff.; Pietzcker, VVDStRL 41 (1983), S. 220 (Anspruch auf angemessenes Verfahren); Schmitt-Glaeser, in: Verfahren als staats- und verwaltungsrechtliche Kategorie, S. 51; P. M. Huber, S. 41 ff.; Staupe, S. 206; Erichsen, Festschrift Jur. Gesellschaft Berlin, S. 120.

171 Siehe neben den Nachweisen in der vorhergehenden Fußnote etwa Blümel, Grundrechtsschutz durch Verfahrensgestaltung, S. 29 ff.; Battis, DÖV 1981, S. 431 ff.; Hufen, NJW 1982, S. 2160 ff.; Redeker, NJW 1980, S. 1593 ff.; Wahl, VVDStRL 41 (1983), S. 167 ff.; Wallraven-Lindl, S. 86 ff.; Fackler, S. 90 ff., jeweils mit weiteren Nachweisen.
} 
Dritter geäußert hat ${ }^{172}$, nicht aber dazu, welche Verfahrensregelungen letztlich verfassungsrechtlich geboten $\operatorname{sind}^{173}$.

Immerhin findet sich aber bei Hufen die Auffassung, daß eine die grundrechtsrelevanten Rechts- und Tatsachenaspekte umfassende Begründung grundrechtsverbürgt $\operatorname{sei}^{174}$. Diese allgemein gehaltene Formulierung steht jedoch erkennbar vor dem Hintergrund der Auslegung der §§ 45, 46 VwVfG und ist daher wohl vor allem im Hinblick auf Verwaltungsakte gemeint ${ }^{175}$. Aus den weiteren Ausführungen, wonach die Kenntnis der Gründe grundrechtsrelevanten staatlichen Handelns ein persönliches Schutzrecht des Betroffenen sei, ohne daß der Grundrechtsschutz als solcher leerliefe ${ }^{176}$, zeigt sich, da $\beta$ auch hier die bereits aus anderen Ableitungszusammenhängen bekannten Ausnahmen gelten ${ }^{17}$, wenn die rechtlichen und tatsächlichen Gründe klar zutage liegen oder auch eine (nachträgliche) Erläuterung ausreichend ist.

Gerade dann, wenn Verfahrensnotwendigkeiten aus den Grundrechten abgeleitet werden, ist zudem die unterschiedliche Verfahrensabhängigkeit der verschiedenen Grundrechte zu berücksichtigen ${ }^{178}$; desweiteren kommt es nicht nur auf das jeweils betroffene Grundrecht, sondern ebenfalls auf die konkrete Eingriffssituation an $^{179}$. Angesichts des Komplementärcharakters der verfahrensrechtlichen Sicherungen für den materialen Grundrechtsschut ${ }^{180}$ ist dabei auch auf die Funktion zu achten, die die verfahrensrechtliche Sicherung in diesem Sinne haben kann. Eine für alle Grundrechte allgemein geltende Aussage bezüglich des $\mathrm{Ob}$ und Wie der Notwendigkeit einer Begründung läßt sich daher nicht machen.

\footnotetext{
${ }^{172}$ BVerfG, NJW 1980, S. 763; Ossenbühl, NJW 1981, S. 376.

${ }^{173}$ Ossenbühl, NVwZ 1982, S. 468.

${ }^{174}$ Hufen, NJW 1982, S. 2163, auch ders., Fehler im Verwaltungsverfahren, S. 208.

${ }^{175} \mathrm{Vgl}$. Hufen, NJW 1982, S. $2165 \mathrm{f}$.

${ }^{176}$ Hufen, NJW 1982, S. 2163.

17 Siehe die Ausführungen zu Art. 20 Abs. 3 und Art. 19 Abs. 4 GG in den vorhergehenden Abschnitten.

${ }^{178}$ Laubinger, VerwArchiv 75 (1982), S. 76; Ossenbühl, DÖV 1981, S. 5.

179 Im Sinne beider Aspekte von Mutius, NJW 1982, S. 2156; Pietzcker, VVDStRL 41 (1983), S. 209; Bethge, NJW 1982, S. 2; Kunig, S. 375. Zur Notwendigkeit einer differenzierten Betrachtungsweise im Konfliktfeld zwischen Verwaltungseffizienz und Rechtswahrung auch Wahl, VVDStRL 41 (1983), S. 171 und 186.

${ }^{180}$ Dazu, daß das BVerfG die verfahrensrechtlichen Sicherungen in diesem Sinne versteht, siehe von Mutius, NJW 1982, S. 2156.
} 
Schließlich ist zu betonen, daß die Konstituierung von Verfahrenspflichten zunächst Sache des Gesetzgebers ist ${ }^{181}$. Zwar wird man grundsätzlich die Verwaltung für verpflichtet halten können, fehlende verfahrensrechtliche Sicherungen unter unmittelbarem Rückgriff auf die Grundrechte auszufüllen ${ }^{182}$. Bei der Gestaltung des Verwaltungsverfahrens geht es aber nicht nur um Grundrechtsgestaltung und -verwirklichung, sondern auch um die effiziente Erfüllung von öffentlichen Aufgaben ${ }^{183}$. Daher dürfte es nur ganz ausnahmsweise möglich sein, ohne entsprechende gesetzgeberische Entscheidung unmittelbar aus den Grundrechten etwa eine Begründungspflicht anzunehmen ${ }^{184}$. Nur dann, wenn es sich um eine "elementare Verfahrensanforderung" ${ }^{\prime 185}$ handelt, wenn die fehlende verfahrensmäßige Sicherung einen unmittelbaren und nicht wieder kompensierbaren Eingriff in die materiale Grundrechtsgewährleistung deshalb darstellen würde, weil auch ein gerichtlicher Rechtsschutz zu spät käme ${ }^{186}$, kommt die unmittelbare Ableitung eines bestimmten Verfahrensrechts aus dem betroffenen Grundrecht in Betracht.

Eine verfassungsrechtlich gebotene Begründungspflicht ergibt sich somit wenn überhaupt - nur aus dem im speziellen Fall einschlägigen Grundrecht. Dabei allerdings auf Art. 1 Abs. 1 GG abzustellen und anzunehmen, der Einzelne würde zu einem "Objekt" gemacht, wenn belastende Entscheidungen nicht begründet werden ${ }^{187}$, dürfte indes nicht überzeugen ${ }^{188}$. Zumindest läßt sich dieser vor allem für Einzelmaßnahmen formulierte Gedanke nicht auf Normen und damit auch nicht auf Satzungen über örtliche Bauvorschriften übertragen. Angesichts der Vielzahl von gesetzlichen Bestimmungen, die den einzelnen betreffen, würde die Annahme übertrieben erscheinen, daß ohne Begründung jeder einzelnen "belastenden" Norm der Ein-

181 Ossenbühl, DÖV 1981, S. 9, ders., NVwZ 1982, S. 470; Pietzcker, VVDStRL 41 (1983), S. 209; Pitschas, S. 49.

${ }^{182}$ Laubinger, VerwArchiv 75 (1982), S. 77.

${ }^{183}$ Ossenbühl, NVwZ 1982, S. 466 ff.; Wahl, VVDStRL 41 (1983), S. 157.

${ }^{184}$ Allgemein Wahl, VVDStRL 41 (1983), S. 168: Das Gebotensein einer bestimmten Gestaltung im Verfahrensrecht sei äußerst voraussetzungsvoll.

${ }^{185}$ So Dolde, NVwZ 1982, S. 70; auch Wallraven-Lindl, S. 97 ff., die eine Parallele zur durch Art. 28 Abs. 2 GG gebotenen Anhörung von Gemeinden bei überörtlichen Planungen zieht.

${ }^{186} \mathrm{Zu}$ diesem Aspekt siehe vor allem Hesse, EuGRZ 1978, S. 436.

${ }^{187}$ So Lücke, S. 74 f.; Kopp, Verfassungsrecht und Verwaltungsverfahrensrecht, S. 47, ders., VwVfG, \& 39 Rn. 1.

${ }^{188}$ Kritisch zu einem solchen Ansatz auch Dolzer, DÖV 1985, S. 12; Laubinger, VerwArchiv 75 (1982), S. 80; Degenhart, DVBI. 1982, S. 878 Anm. 62. 
zelne in seinem Subjektsein betroffen sei. Den meisten dürfte es schon kaum möglich sein, die Vielzahl der sie betreffenden gesetzlichen Regelungen überhaupt auch nur annähernd zur Kenntnis zu nehmen. Zudem würde auch ein solcher Ansatz nicht zur Begründungspflicht im hier gesuchten Sinne, sondern ebenfalls höchstens zu einer Erläuterungspflicht führen.

\section{(2) Art. 14 GG und Begründungspflicht bei örtlichen Bauvorschriften}

Im vorliegenden Fall kann es also nur darum gehen, ob die Eigentumsgarantie des Art. 14 GG eine Gestaltung des Verfahrens zum Erlaß einer örtlichen Bauvorschrift dahingehend fordert, daß mit der Satzung auch eine entsprechende Begründung beschlossen werden muß. Betrachtet man hierzu die typische "Eingriffssituation", so läßt sich eine grundrechtlich gebotene Notwendigkeit des Eingehens auf die Belange eines jeden einzelnen Grundstückseigentümers nicht annehmen. Die Betroffenheiten ähneln sich weitgehend, untypische Fälle können durch Befreiungen gelöst werden. Was als Gegenstand einer möglichen Begründung verbleibt, sind einmal die mit der Satzung verfolgten Absichten, desweiteren Erklärungen dazu, warum die einzelnen Festsetzungen zur Erreichung dieser Absichten notwendig sind und eventuell Berechnungen zu den Mehrkosten, die durch die vorgeschriebene Gestaltung möglicherweise entstehen ${ }^{189}$.

Die Absichten, die mit örtlichen Bauvorschriften verfolgt werden, ergeben sich besonders bei Schutzvorschriften jedoch häufig bereits aus der Satzung selbst. Ihnen werden häufig Präambeln vorangestellt, die sowohl Erklärung als auch rechtsverbindliche Regelungen sind ${ }^{190}$. Was Art und Umfang der getroffenen Festsetzungen betrifft, so ist eine detaillierte Erklärung dann sehr aufwendig, wenn die Mitteilung der Ergebnisse einer durchgeführten Stadtbildanalyse für erforderlich gehalten wird ${ }^{191}$. Sieht man dies zurecht als zu aufwendig an, dann reichen relativ kurz gefaßte allgemeine Formulierungen. Hat eine Stadt ein anerkanntermaßen schützenswertes

${ }^{189}$ Siehe dazu Institut für Bauforschung, BBauBl. 1987, S. 278 ff.

190 Siehe die Vorschläge für Präambeln in der Schrift "Alte Städte - alte Dörfer", S. 16; weiterhin z. B. die Verordnung der Stadt Berching / Oberpfalz vom 28.01.1975: "Im Bewußtsein ihrer Verpflichtung zur Erhaltung des historischen Stadtbildes und der Denkmäler alter Städtebaukunst erläßt die Stadt Berching folgende ...."

${ }^{191}$ Zur grundsätzlichen Notwendigkeit einer solchen Analyse siehe "Alte Städte - alte Dörfer", S. 10 f.; Büchs, Der Landkreis, S. 411; Mehlhorn, S. 16 f. 
Stadtbild, so erklären sich die getroffenen Festsetzungen weitgehend von selbst.

Etwas anders liegt das Problem bei baugestalterischen Vorschriften. Unproblematisch ist auch hier der Fall, daß der von der Umgebung vorgegebene bauliche Rahmen konkretisiert wird, indem entweder der Verunstaltungsbegriff rechtssatzmäßig genau gefaßt oder eine erweiterte Gebietspflege betrieben wird ${ }^{192}$. Hier reicht ebenfalls ein einleitender Hinweis in der Präambel. Problematisch ist hingegen die positive Gestaltungspflege. Bereits die genaue Abgrenzung des Gebietes bedarf deshalb, weil eben nicht unbedingt an den Schutz eines bestehenden Straßen- oder Ortsbildes angeknüpft werden muß, der Erläuterung. Noch mehr gilt dies für die im einzelnen getroffenen Festsetzungen. Die Frage, warum unbedingt eine bestimmte Dachneigung, ein bestimmter Außenanstrich oder eine bestimmte Gestaltung der Einfriedungen vorgeschrieben wurde, versteht sich häufig nicht von selbst. Angesichts der Detailbesessenheit vieler Satzungen provozieren solche Festlegungen im Gegenteil eher Widerspruch. Ohne eine Stellungnahme dahingehend, warum eine bestimmte Festsetzung gewählt wurde, fehlen einem Eigentümer, der eine von der Satzung abweichende Gestaltung anstrebt, Anhaltspunkte dafür, ob seine Absichten mit den Gestaltungszielen der Gemeinde vereinbar sind. Dies kann trotz Widerspruchs zur Satzung deshalb der Fall sein, weil die Gemeinden aus dem Bestimmtheitsgrundsatz gezwungen sind, die Festlegungen möglichst detailliert zu treffen $^{193}$. Es kann deshalb leicht vorkommen, daß zwar dem Wortlaut nach ein Widerspruch zur Satzung vorliegt, dem Sinn nach aber nicht, etwa weil die vom Eigentümer angestrebte Gestaltung dem von der Gemeinde angestrebten Gesamteindruck nicht widerspricht. Insofern besteht für eine positive Gestaltungspflege zumindest ein Erklärungsbedarf.

De lege ferenda wäre eine Begründungspflicht wie in $\S 9$ Abs. 8 BauGB daher durchaus sinnvoll. Vor allem wäre der Eigentümer dadurch davor geschützt, daß die Gemeinde im nachhinein in ihre satzungsmäßigen Festlegungen irgendwelche Absichten hineinliest, die sie vorher gar nicht gehabt hat. Grundrechtlich zwingend gefordert ist eine Begründungspflicht jedoch auch bei einem solchen Ableitungsversuch nicht. Treffen Festlegungen in örtlichen Bauvorschriften auf Unverständnis bei den Betroffenen, läßt sich

\footnotetext{
${ }^{192} \mathrm{Zu}$ diesen Unterscheidungen siehe oben $\mathrm{D}$.

${ }^{193} \mathrm{Zu}$ dieser Grundschwierigkeit beim Erstellen von örtlichen Bauvorschriften siehe oben D II 3 a.
} 
dem auch durch nachträgliche Erklärungen entgegenwirken ${ }^{194}$. Die Pflicht zur Berücksichtigung der Belange der Eigentümer im Hinblick auf gesteigerte Baukosten, die durch gestalterische Vorschriften entstehen können, kann auch ohne Begründungspflicht zumindest in Extremfällen durch Anwendung des Übermaßverbotes gerichtlich kontrolliert werden. Der Aspekt des nachträglichen Nennens von Absichten, die bei Satzungserlaß gar keine Rolle gespielt haben, ist ebenfalls nicht so schwerwiegend, als daß eine unmittelbar grundrechtlich gebotene Begründungspflicht als zwingend notwendig erscheint ${ }^{195}$. Als Ergebnis bleibt somit festzuhalten, daß örtliche Bauvorschriften nach den Bestimmungen der meisten Landesbauordnungen nicht begründet zu werden brauchen. Auch aus verfassungsrechtlichen Bestimmungen läßt sich eine solche Pflicht nicht ableiten.

\section{Materiellrechtliche Anforderungen an den Erlaß örtlicher Bauvorschriften}

a) Das Abwägungsgebot bei örtlichen Bauvorschriften

aa) Die Konzeptionen der Oberverwaltungsgerichte

Die Frage nach der gerechten Abwägung zwischen den Gestaltungszielen der Gemeinden und den Interessen der Grundstückseigentümer ist wohl das zentrale Problem der Rechtmäßigkeit von örtlichen Bauvorschriften. Bereits bei der Erörterung der Frage, ob Satzungen über örtliche Bauvorschriften eine Begründung beizufügen ist, wurde darauf hingewiesen, daß es in der Rechtsprechung der Oberverwaltungsgerichte zwei verschiedene Konzepte zum Problem der Abwägungskontrolle gibt. In ihrem Ausgangspunkt sind sich die Gerichte - wie die hier angestellten Überlegungen gezeigt haben: zu Recht - einig: Es gibt für örtliche Bauvorschriften keine dem $\S 9$ Abs. 8 BauGB entsprechende Begründungspflicht. Unterschiedlich sind lediglich die Konsequenzen für die Abwägungskontrolle, die hieraus gezogen werden. Das OVG Münster entnimmt letztlich der verfahrensrechtlichen Entscheidung des nordrhein-westfälischen Gesetzgebers keine Folgerungen für die Überprüfung der Abwägung. Abwägungsvorgang und -ergebnis unterlägen der gerichtlichen Kontrolle. Die Gemeinden hätten daher die Obliegenheit,

\footnotetext{
194 So auch Laubinger, VerwArchiv 75 (1982), S. 76.

${ }^{195}$ Siehe dazu die ausführlicheren Erörterungen zum Abwägungsgebot unten E II 2 a dd.
} 
ihre planerische Abwägung in irgendeiner Form nachzuweisen; eine Satzung sei für ungültig zu erklären, wenn sich die Abwägung der relevanten Belange nicht positiv feststellen lasse ${ }^{196}$. Hingegen hat nach Auffassung des OVG Lüneburg und des VGH Kassel die nicht vorgesehene Begründungspficht eine materielle Konsequenz: Die Kontrolle der Abwägung konzentriere sich im wesentlichen auf das Abwägungsergebnis ${ }^{197}$.

Das OVG Lüneburg sieht sich im Hinblick auf die These der Beschränkung der Abwägungskontrolle auf das Abwägungsergebnis zunächst in einem gewissen Gegensatz zur Rechtsprechung des BVerwG zum Abwägungsgebot im Planungsrecht, da dort Anforderungen an Vorgang und Ergebnis gestellt würden. Es verneint aber deshalb einen Widerspruch hierzu, weil der "Ermessensspielraum" des Ortsgesetzgebers bei einer Gestaltungssatzung es nicht rechtfertige, von einer "Planung" auszugehen. Weiterhin habe eine örtliche Bauvorschrift nicht im entferntesten die eigentumsrechtliche Bedeutung etwa eines Bebauungsplanes ${ }^{198}$.

Nach den bereits angestellten Überlegungen zum Abwägungsgebot bei örtlichen Bauvorschriften ${ }^{199}$ kann man dem nicht uneingeschränkt zustimmen. Zwar liegt beim Erlaß einer örtlichen Bauvorschrift nicht in jedem Fall der Typus von "Planung" vor, von dem die Rechtsprechung des BVerwG ausgeht. Es läßt sich aber genausowenig davon sprechen, daß der Erlaß von örtlichen Bauvorschriften generell keine "Planung" sei. Insoweit ist das vor allem aus dem einfachen Gesetzesrecht ableitbare Abwägungsgebot verfassungsrechtlich teilweise "unterlegt"200. Es erscheint im übrigen zweifelhaft, ob man zur Begründung einer verfassungsrechtlichen Abwägungspflicht den "Umweg" über den Planungsbegriff gehen muß. Werden Grundrechte betroffen, so folgt schon daraus eine Pflicht zur Berücksichtigung der grundrechtlich geschützten Interessen. Dies führt dann, wenn der Verwaltung eine Entscheidungsfreiheit eingeräumt ist, zur "Abwägungspflicht", unabhängig davon, ob man insoweit schon von einer "Planung" zu sprechen bereit ist oder nicht. Zunächst soll deshalb untersucht werden, ob die Konzeption des OVG Lüneburg und des VGH Kassel bezüglich der Überprüfung der Abwägung bei örtlichen Bauvorschriften schon daran scheitert, daß eine ge-

\footnotetext{
196 OVG Münster, Urteil vom 30.06.1983, BRS Band 40, Nr. 152 S. 335 (338).

197 OVG Lüneburg, Urteil vom 12.02.1982, BRS Band 39, Nr. 132 S. 280 (282); HessVGH, Urteil vom 30.06.1987, HessStuGZ 1988, S. 408.

198 OVG Lüneburg, BRS Band 39, S. 282.

${ }^{199}$ Siehe oben E I 2 a bb.

${ }^{200}$ Siehe oben E 12 a bb.
} 
richtliche Kontrolle des Abwägungsvorgangs weitgehend nicht stattfinden soll, eine solche Überprüfung aber verfassungsrechtlich geboten ist.

\section{bb) Die Rechtsprechung des BVerwG zur Vorgangs- und Ergebniskontrolle bei Abwägungsprozessen}

Die Tatsache, daß das OVG Lüneburg sich in einem gewissen Gegensatz zur Rechtsprechung des BVerwG sieht und diesen Gegensatz nur dadurch meint auflösen zu können, daß es den Planungscharakter des Erlasses von Satzungen über örtliche Bauvorschriften verneint, überrascht etwas. Denn es gibt in der Rechtsprechung des BVerwG durchaus einen Hinweis, der eine Beschränkung im Sinne des OVG Lüneburg zuzulassen scheint. Allerdings geht das BVerwG - insofern hat das OVG Lüneburg Recht - grundsätzlich davon aus, daß sich das rechtsstaatliche Abwägungsgebot sowohl auf den Vorgang als auch auf das Ergebnis bezieht ${ }^{201}$. Es gestattet aber in der sog. Floatglas-Entscheidung dem Gesetzgeber, in dem ein oder anderen $\mathrm{Zu}$ sammenhang lediglich das Ergebnis eines Planvorgangs einer bestimmten Bindung zu unterwerfen, so daß es insoweit auf Erwägungen, Absichten, Motive etc. nicht ankäme ${ }^{202}$.

Das OVG Lüneburg hat an diese in der Rechtsprechung des BVerwG angelegte Differenzierungsmöglichkeit zwar terminologisch angeknüpft, ohne sich aber insoweit auf das BVerwG zu berufen. Dies ist im Ergebnis aus zwei Gründen durchaus richtig gewesen ${ }^{203}$. Zum einen war das BVerwG zum damaligen Zeitpunkt von der genannten Passage in der Floatglas-Entscheidung im Hinblick auf die mögliche Abwertung der Bedeutung des Abwägungsvorgangs wieder abgerückt. Deutlich wird dies vor allem in der Entscheidung zur verfassungskonformen Auslegung des $\S 155$ b Abs. 2 S. 2 $\mathrm{BBauG}^{204}$. Für die Interpretation dieser Bestimmung, wonach Mängel im Abwägungsvorgang nur dann erheblich sind, wenn sie offensichtlich und auf das Abwägungsergebnis von Einfluß gewesen sind, hätte sich eine Anknüpfung an die Passage im Floatglas-Urteil angeboten. Es wäre dann möglicherweise zu einer ähnlichen Aussage gekommen, wie das OVG Lüneburg

${ }^{201}$ Siehe nur BVerwG, Urteil vom 20.10.1972, E 41, 67 (71).

${ }^{202}$ BVerwG, Urteil vom 05.07.1974, E 45, 309 (313). Kritisch dazu etwa Bettermann, Festschrift für Huber, S. 49.

${ }^{203}$ Dem Urteil läßt sich nicht entnehmen, daß das OVG diese Überlegungen angestellt hätte.

${ }^{204}$ BVerwG, Urteil vom 21.08.1981, BauR 1981, S. 535 ff. 
in seiner Entscheidung zur Abwägungskontrolle bei örtlichen Bauvorschriften, daß nämlich die Kontrolle der Abwägung angesichts der vom Wortlaut des $\S 155$ Abs. 2 S. 2 BBauG nahegelegten Abwertung von Fehlern im Abwägungsvorgang im wesentlichen auf das Abwägungsergebnis zu konzentrieren sei. Das BVerwG ist diesen Weg jedoch nicht gegangen. Es hat den $\S 155$ Abs. 2 S. 2 BBauG in verfassungskonformer Weise ausgesprochen restriktiv interpretiert und kommt im Anschluß an die bekannte Feststellung, $\mathrm{da} ß$ sich das im Verfassungsrecht wurzelnde Abwägungsgebot sowohl auf den Abwägungsvorgang wie auch auf das Ergebnis beziehe, zur Verfassungsmäßigkeit des $\S 155$ b Abs. $2 \mathrm{~S}$. BBauG mit folgender Begründung: Das Abwägungsgebot sei wegen dessen verfassungsrechtlicher Absicherung nicht einzuschränken. Das Gebot an den Planungsträger, wonach der Abwägungsvorgang "gerecht" sein müsse, bleibe deshalb unberührt. Es gehe lediglich um die Folgen einer Nichtbeachtung des fortbestehenden Gebots gerechter Abwägung ${ }^{205}$. Desweiteren werde nicht allen Fehlern die Beachtlichkeit abgesprochen, sondern in verfassungskonformer Weise nur solchen des "inneren" Abwägungsvorgangs, also nur in dem Bereich, der sich nicht durch Akten, Pläne und Protokolle "sichtbar" machen läßt ${ }^{206}$. Der Senat zitiert zwar dann als Beleg die eigene Floatglas-Entscheidung ${ }^{207}$, verschleiert aber mit dem Hinweis auf einen dort durchgeführten "anderen Ansatz", daß nach der Aussage in jener Entscheidung nicht nur die Rechtsfolgen, sondern auch das Abwägungsgebot selbst in bezug auf den Abwägungsvorgang ("kommt insoweit auf alle Erwägungen, Abwägungen, Motive u.s.w. nicht an") und auch nicht nur hinsichtlich der inneren Seite sondern überhaupt einer gesetzgeberischen Beschränkung zugänglich sein sollte ${ }^{208}$. Das BVerwG hatte somit in der Entscheidung zur verfassungskonformen Auslegung des $\S 155 \mathrm{~b}$ Abs. 2 S. 2 BBauG deutlich zu erkennen gegeben, daß es sehr wohl eine weitgehende Überprüfung des Abwägungsvorganges aus rechtsstaatlichen Gründen für geboten hält.

Der zweite Grund, warum sich das OVG Lüneburg zu Recht in einem gewissen Gegensatz und nicht in zumindest partieller Übereinstimmung mit der Rechtsprechung des BVerwG gesehen hat, ergibt sich aus Folgendem: Die Anforderungen des BVerwG an die Abwägung waren - auch wenn die

\footnotetext{
${ }^{205}$ BVerwG (Fn. 204), S. 536.

${ }^{206}$ BVerwG (Fn. 204), S. 537.

${ }^{207}$ BVerwG (Fn. 204), S. 537.

${ }^{208}$ Siehe BVerwGE 45, 313.
} 
Rechtsprechung des BVerwG in sich teilweise widersprüchlich ist und dies nicht ganz klar zum Ausdruck kommt - ursprünglich im Sinne einer echten Doppelprüfung formuliert. Die Notwendigkeit sollte auch nicht nur daraus folgen, daß zwischen der Beschlußfassung über einen Plan und der Bekanntmachung Änderungen der Sach- und Rechtslage eintreten können ${ }^{209}$. Eine Doppelprüfung mag in einem solchen Fall besonders relevant werden, aufgestellt sind die Anforderungen vom BVerwG ursprünglich unabhängig hiervon. Dies zeigt sich vor allem daran, daß das BVerwG in der FloatglasEntscheidung davon ausging, die Anforderungen an die Abwägung richteten sich mit Ausnahme der Notwendigkeit einer Abwägung überhaupt sowohl an den Vorgang als auch an das Ergebnis ${ }^{210}$. Daraus wurde konsequent gefolgert, daß die spiegelbildlich zu den positiven Anforderungen formulierten Abwägungsfehler des Abwägungsdefizits, der Abwägungsfehlgewichtung und der Abwägungsdisproportionalität sowohl im Hinblick auf den Vorgang als auch im Hinblick auf das Ergebnis zu überprüfen seien ${ }^{211}$. Das OVG Lüneburg versteht aber unter dem Begriff "Kontrolle des Abwägungsergebnisses" wohl etwas anderes. Abwägungsergebniskontrolle ist nach Auffassung des OVG Lüneburg nur die Überprüfung der Unangemessenheit einer Norm $^{212}$, was vor allem dem Fehler der Abwägungsdisproportionalität entsprechen dürfte. Nicht kontrolliert werden soll hingegen, ob überhaupt eine Abwägung stattgefunden und ob die Interessen der betroffenen Grundstückseigentümer berücksichtigt worden $\operatorname{sind}^{213}$. Zumindest letzteres hätte nach der Floatglas-Entscheidung bei der Kontrolle des Abwägungsergebnisses aber überprüft werden müssen. Daher hat das OVG Lüneburg ein anderes Verständnis von Abwägungsergebniskontrolle, als es der FloatglasEntscheidung und damit dem Hinweis zugrunde liegt, daß in dem ein oder anderen Fall auch nur das Ergebnis einer rechtlichen Prüfung unterzogen werden darf.

Man wird der Rechtsprechung des OVG Lüneburg durchaus zustimmen können, wenn es von einem anderen Verständnis von "Abwägungsergebniskontrolle" ausgeht, als es im Floatglas-Urteil zum Ausdruck kommt. Die

${ }^{209}$ Mit diesem Argument wird die Notwendigkeit einer Doppelprüfung gerechtfertigt von Koch, DVBI. 1983, S. 1128, jedoch beschränkt auf den Fall der Rechtsänderung. Weiterhin siehe Erbguth, DVBI. 1986, S. 1233; Funke, DVBI. 1987, S. 513.

${ }^{210}$ BVerwGE 45, 315.

${ }^{211}$ So etwa Breuer, NVwZ 1982, S. 274
${ }^{212}$ OVG Lüneburg, BRS Band 38, S. 282.
${ }^{213}$ So wohl OVG Lüneburg (Fn. 212). 
Argumentation des BVerwG ist schon in sich unstimmig. So findet sich in der Floatglas-Entscheidung die Formulierung, die Notwendigkeit, daß eine Abwägung überhaupt stattgefunden hat, könne nur im Hinblick auf den Abwägungsvorgang "praktisch werden"214. Soll es sich aber beim Abwägungsgebot tatsächlich um rechtliche Anforderungen sowohl an Vorgang wie an Ergebnis handeln, dann muß das Gebot, daß überhaupt eine Abwägung stattzufinden hat, sich auch an das Ergebnis richten. Denn die anderen Anforderungen, da $\beta$ etwa die betroffenen Belange in die Abwägung eingestellt werden müssen, lassen sich nur dann erfüllen, wenn überhaupt eine Abwägung stattgefunden hat.

Das Hauptargument des BVerwG für die Theorie der Doppelkontrolle, daß es "offensichtlich sachwidrig" sei, wenn es allein darauf ankommen solle, was von der planenden Gemeinde bedacht worden sei, nicht jedoch darauf, was bei der Planung herauskomme ${ }^{215}$, überzeugt ebenfalls nicht. Wenn Planen nach der Auffassung des BVerwG die Befugnis beinhaltet, daß sich der Planungsträger für die Bevorzugung des einen und damit für die Zurückstellung eines anderen Belanges entscheiden $\mathbf{k a n n}^{216}$, dann ist es möglich, daß sich ein korrekt ermittelter und bewerteter Belang im Ergebnis letztlich nicht niederschlägt, weil es im Rahmen der planerischen Gestaltungsfreiheit lag, sich für seine Zurückstellung zu entscheiden und als Zurückstellung auch nur eine ergebnismäßige Nichtberücksichtigung in Betracht kam. Das Abwägungsgebot gehört zwar grundsätzlich dem materiellen und nicht dem Verfahrensrecht an, denn es entscheidet mit über die inhaltliche Richtigkeit des Ergebnisses ${ }^{217}$. Es hat jedoch gerade aufgrund der eingeräumten planerischen Gestaltungsfreiheit auch eine verfahrensartige Komponente ${ }^{218}$. Ähnlich wie bei Ermessens- ist auch bei Planungsentscheidungen eine Ergebniskontrolle nur in eingeschränktem Umfang möglich. Als Kompensation hierfür dient die aus dem Abwägungsgebot folgende Verpflichtung zur Einstellung aller berührten Belange in die Abwägung ${ }^{219}$. Recht hat das BVerwG, wenn es formuliert, daß es sachwidrig ist, wenn es allein darauf ankäme, was

${ }^{214}$ BVerwGE 45, 315. Kritisch Steinberg, Nachbarrecht, III Rn. 154 ff.

${ }^{215}$ BVerwGE 45, 315.

${ }^{216}$ BVerwGE 45, 315.

${ }^{217}$ Vgl. Funke, DVBl. 1987, S. 514; Rubel, S. 158; Bettermann, Festschrift für Huber, S. 48;

Schmidt-Aßmann, Art. 19 Abs. 4 GG, Rn. 214; Koch, DVBI. 1989, S. 400.

${ }^{218}$ So auch Keßler, S. 208; Steinberg, Nachbarrecht, III Rn. 162.

${ }^{219}$ Vgl. auch F. Kirchhof, NJW 1981, S. 2386; Schwerdtfeger, JuS 1983, S. 271. 
der Planungsträger bedacht hätte, nicht aber darauf, was im Ergebnis bei der Planung herauskommt ${ }^{220}$. Unrichtig ist es jedoch, hieraus den Schluß zu ziehen, daß damit sich die Anforderungen des Abwägungsgebotes auch an das Ergebnis richten. Es ist zwar nicht ohne Bedeutung, was bei der Planung herauskommt. Planen ist aber auch nicht die Herstellung einer Mixtur aus allen von dem Vorhaben berührten Belangen. Dies wird vom BVerwG selbst zum Teil auch deutlich so gesehen ${ }^{221}$.

Mittlerweile ist die Theorie der Doppelprüfung vom BVerwG wohl auch stillschweigend wieder aufgegeben worden. Ein Indiz hierfür ist die Entscheidung zum Flughafen München-II. Dort wiederholt das BVerwG zwar erneut seine stereotype Formel von der gerichtlichen Kontrolle, die sowohl Abwägungsvorgang als auch Abwägungsergebnis betrifft ${ }^{222}$, relativiert aber die Bedeutung des Abwägungsvorgangs dadurch, daß Fehler im Vorgang nur dann zur Rechtswidrigkeit eines Planes führen sollen, wenn sie sich auf das Abwägungsergebnis auch ausgewirkt haben ${ }^{223}$. Weiterhin findet sich in dem Urteil die Formulierung, daß auch hinsichtlich des Abwägungsergebnisses kein Bundesrecht verletzt sei, da die Abwägung nicht disproportional $\mathrm{sei}^{224}$. Der Fehler der Disproportionalität wird insoweit nicht beim Vorgang, sondern - genau wie vom OVG Lüneburg - nur beim Ergebnis geprüft $\mathrm{f}^{25}$.

Das nicht ganz einfache Verhältnis der Konzeption des OVG Lüneburg und auch des VGH Kassel im Hinblick auf die Abwägungskontrolle bei örtlichen Bauvorschriften im Verhältnis zur "Abwägungs"-Rechtsprechung des BVerwG läßt sich damit folgendermaßen beschreiben: Das BVerwG verlangt aus rechtsstaatlichen Gründen im Grundsatz eine Kontrolle sowohl des Vorgangs als auch des Ergebnisses. Mit der Passage in der FloatglasEntscheidung, die unter Umständen etwas zu erlauben scheint, läßt sich die Beschränkung der Abwägungskontrolle auf das Ergebnis im Sinne der Rechtsprechung des OVG Lüneburg zum einen deshalb nicht rechtfertigen, weil dieser Äußerung ein anderes Verständnis von Abwägungsergebniskon-

${ }^{220}$ BVerwGE 45, 315

${ }^{221}$ Vgl. nur BVerwG, Urteil vom 25.02.1988, NVwZ 1989, S. 152.

${ }^{222}$ BVerwG, Urteil vom 05.12.1986, E 75, 215 (244).

${ }^{223}$ BVerwGE 75, 251. Zu weiteren Urteilen Steinberg, Nachbarrecht, III Rn. $160 \mathrm{ff}$.

224 BVerwGE 75, 253. Ähnlich auch das OVG Koblenz, Urteil vom 27.05.1987, NVwZ 1988, S. 371, wo nur das Abwägungsergebnis für rechtswidrig gehalten wird, wenn Disproportionalität vorliegt.

${ }^{225}$ Auch Kühling, S. 79 Rn. 179, hält den Fehler der Disproportionalität nur im Hinblick auf das Ergebnis für relevant. 
trolle zugrunde liegt ${ }^{226}$. Zum anderen ist diese Rechtsprechung vom BVerwG konkludent weitgehend wieder aufgegeben worden.

\section{cc) Abwägungsvorgangs- und Abwägungsergebniskontrolle in der wissenschaftlichen Diskussion}

Die Rechtsprechung des BVerwG hat die rechtsdogmatische Diskussion um das Abwägungsgebot entscheidend geprägt, aber auch immer wieder Kritik des Schrifttums herausgefordert ${ }^{22}$. In jüngerer Zeit beschäftigt sich die Literatur verstärkt mit der Frage der oben schon erörterten und maßgeblich auf das BVerwG zurückgehenden Unterscheidung von Abwägungsvorgang und $\mathrm{Abwägungsergebni{ } ^ { 2 2 8 }}{ }^{20}$. Die Diskussion der Rechtsprechung des OVG Lüneburg hat gezeigt, daß diese Frage für die Kontrolle von örtlichen Bauvorschriften von besonderem Interesse ist. Da der Erlaß von örtlichen Bauvorschriften unter Umständen eine "Planung" sein kann, steht die Auffassung des OVG im Gegensatz zur Rechtsprechung des BVerwG, das grundsätzlich sowohl eine Vorgangs- als auch eine Ergebniskontrolle fordert.

Angesichts der nicht ganz klaren Rechtsprechung zu diesem Komplex sind die Stellungnahmen in der Literatur von besonderem Interesse. Denn richten sich die Anforderungen des Abwägungsgebotes grundsätzlich in den wesentlichen Ausprägungen auch an das Ergebnis, dann erscheint eine Beschränkung der gerichtlichen Abwägungskontrolle hierauf unter rechtsstaatlichen Gesichtspunkten vorstellbar. Verteilen sich dagegen die Anforderungen des Abwägungsgebotes und damit die Abwägungsfehler nach welchem Schlüssel auch immer auf Vorgang und Ergebnis, dann stellt das Abwägungsgebot Anforderungen an den Abwägungsproze $B$ als solchen. Die Beschränkung der Kontrolle im Sinne der Rechtsprechung des OVG Lüneburg nur auf das Abwägungsergebnis als Folge der fehlenden Begründungspflicht wird umso problematischer, je mehr dadurch die Prüfungsmaßstäbe beschränkt und Fehler sanktionslos gestellt werden. Nur dann, wenn bei einer

${ }^{226}$ Das OVG führt die Rechtsprechung auch nicht als Beleg für die eigenen Auffassungen an.

${ }^{227}$ Zunächst stand dabei vor allem die Frage der gerichtlichen Kontrolldichte im Vordergrund. Siehe etwa Hoppe, Festgabe 25 Jahre BVerwG, S. 295 ff., ders., DVBl. 1977, S. 143; Papier, DVB1. 1975, S. 462.

${ }^{228}$ Koch, DVBl. 1983, S. 1125 ff., ders., DVBl. 1989, S. 399 ff.; Heinze, NVwZ 1986, S. 87 ff.; Erbguth, DVBI. 1986, S. 1230 ff.; Ibler, DVBI. 1988, S. 469 ff.; Blumenberg, DVBI. 1989, S. 86 ff. 
solchen Beschränkung zumindest in gewissem Rahmen noch eine Überprüfung der wesentlichen Abwägungsfehler möglich ist, könnte man der Auffassung des OVG Lüneburg mit rechtsstaatlich gutem Gewissen zustimmen.

Bei den Stellungnahmen der Literatur zu diesem Problem lassen sich zwei Gruppen unterscheiden. Zum einen gibt es Extrempositionen, die nur eine Kontrolle des Ergebnisses oder nur eine Kontrolle des Vorgangs für notwendig halten. Zweitens gibt es "Verteilungstheorien", die ähnlich dem Vorgehen des BVerwG in der München-II-Entscheidung bestimmte Fehler dem Vorgang und andere dem Ergebnis zuordnen wollen. Im einzelnen lassen sich die Meinungen wie folgt skizzieren:

(1) Nur die Kontrolle des Abwägungsvorgangs ist verfassungsrechtlich geboten, die Kontrolle des Abwägungsergebnisses hingegen nicht, da es sich nur um eine Begründbarkeitskontrolle handeln kann, die aber nur dann sinnvoll ist, wenn sie "entscheidungskonservierend" eingesetzt werden kann. Dies komme wohl bei Ermessens-, nicht aber bei Planentscheidungen in Betracht ${ }^{229}$.

(2) Nur die Kontrolle des Abwägungsergebnisses ist verfassungsrechtlich geboten; dem Abwägungsgebot ist auch dann genügt, wenn die Entscheidung von einer nachträglich vollzogenen vorschriftsmäßigen Abwägung inhaltlich gedeckt ist ${ }^{230}$.

(3) Die Abwägungsfehler des Abwägungsausfalls, des Abwägungsdefizits und der Abwägungsfehlgewichtung sind dem Vorgang, der der Abwägungsdisproportionalität aber dem Ergebnis zuzurechnen ${ }^{231}$. Zu unterscheiden sei zwischen prozeßhaften und statischen Elementen; vor allem der angemessene Interessenausgleich sei statisch und daher ausschließlich ergebnisbezo$\operatorname{gen}^{232}$.

(4) Es geht um die Aufdeckung von Abwägungsfehlern aufgrund von verschiedenen Kontrollgegenständen; gewisse Fehler können schon am Plan als

${ }^{229}$ Koch, DVBl. 1983, S. 1128, ders., NVwZ 1989, S. 121; Koch / Hosch, S. 156.

${ }^{230}$ Heinze, NVwZ 1986, S. 87 (89), ders., NVwZ 1989, S. 121.

${ }^{231}$ Erbguth, DVB1. 1986, S. 1233, ders., Bauplanungsrecht, S. 75 Rn. 191; Keßler, S. 211; Blumenberg, DVBl. 1989, S. 90; -wohl auch Kühling, S. 79 Rn. 179. Ohne weitere Stellungnahme im Ergebnis auch Moench / Schmidt, S. 52.

${ }^{232}$ Erbguth und Blumenberg, jeweils ebenda. Etwas neutraler, aber in der Grundtendenz ähnlich Pietzcker, NVwZ 1989, S. 603: Das Abwägungsgebot besteht aus vorgangs- und ergebnisbezogenen Elementen. 
Produkt nachgewiesen werden, hingegen sei allein am Ergebnis der Planung nicht nachweisbar, ob überhaupt eine Abwägung stattgefunden habe ${ }^{233}$.

Die Auffassungen (1) bis (3) kämpfen, obwohl sie zum Teil zu völlig konträren Aussagen kommen, mit der gleichen Grundschwierigkeit. Sie beruhen alle drei auf einer letztlich beliebigen Festlegung des Trennungszeitpunktes zwischen Abwägungsvorgang und Abwägungsergebnis. Besonders deutlich wird dies bei der Position (3). Daß die Anforderungen an einen ordnungsgemäßen Interessenausgleich ausschließlich ergebnisbezogen seien, da es sich um ein "statisches Element" handele ${ }^{234}$, ist nicht hinreichend begründet und auch nicht einleuchtend. Schon die Formulierung des Fehlers der Abwägungsdisproportionalität durch die Rechtsprechung des BVerwG dahingehend, daß die "Vornahme des Ausgleichs zwischen verschiedenen Belangen nicht in einer Weise vorgenommen werden darf, der zur objektiven Gewichtigkeit einzelner Belange außer Verhältnis steht"235 läßt eher einen "prozeßhaften Charakter" als ein "statisches Element" ${ }^{236}$ vermuten. $\mathrm{Zu}$ behaupten, die Herstellung eines angemessenen Ausgleichs sei mehr oder weniger prozeßhaft als die angemessene Ermittlung und Gewichtung der Belange ist letztlich willkürlich ${ }^{237}$. Auch ein Hinweis auf die "Wesensverschiedenheit" von Abwägungsvorgang und Abwägungsergebnis ${ }^{238}$ wirkt dem argumentativen Defizit der Aufteilungstheorie nicht entgegen, denn diese Behauptung beruht wiederum auf der nicht genügend belegten Unterscheidung zwischen "prozeßhaft" und "statisch". Schließlich spricht gegen die Aufteilung der Fehlerfolgen auf Vorgang und Ergebnis auch, daß die genaue Unterscheidung der einzelnen Fehlerarten nicht in einem Maße möglich ist, wie es für eine stringente Aufteilung nötig wäre ${ }^{239}$.

Genausowenig überzeugen auch die beiden Extrempositionen. Es läßt sich zwar kaum bestreiten, daß eine Ergebniskontrolle, die nur eine $\mathrm{Be}$ -

233 Ibler, DVB1. 1988, S. 472, ders., Schranken planerischer Gestaltungsfreiheit, S. 272. Möglicherweise schwebt Kühling, S. 79 Rn. 179, etwas ähnliches vor, wenn er davon ausgeht, $\mathrm{da}$ gewisse Fehler erst bei Betrachtung des Gesamtergebnisses erkennbar werden. Eigentlich ist Kühling aber wohl als ein Vertreter der Auffassung (3) anzusehen.

234 So Erbguth, DVBI. 1986, S. 1233; Blumenberg, DVBI. 1989, S. 90.

${ }^{235}$ Siehe etwa BVerwG, Urteil vom 14.02.1975, E 48, 56 (64) und E 75, 253.

${ }^{236} \mathrm{Zu}$ diesen Begriffen siehe Erbguth, DVBl. 1986, S. 1233.

${ }^{237}$ So im Ergebnis auch Ibler, DVB1. 1988, S. 471, ders., Schranken planerischer Gestaltungsfreiheit, S. 270. Kritisch zu Recht auch Koch, DVB1. 1989, S. 401. Im Sinne einer Zuordnung der Abwägungsdisproportionalität auch zum Vorgang Papier, DVBI. 1975, S. 461.

${ }^{238}$ Blumenberg, DVBI. 1989, S. 90.

${ }^{239}$ Siehe insofern die Kritik von Rubel, S. 158, an der herrschenden Fehlerlehre. 
gründbarkeitskontrolle ist, bei Planentscheidungen überflüssig.ist ${ }^{240}$. Trennt man das Ergebnis auf diese Weise vom Vorgang ab, daß es praktisch nackt dasteht und ohne Rücksicht auf die konkreten Gegebenheiten des Plangebietes, die planerischen Absichten und Motive überprüft werden soll, dann ist es in der Tat schwierig, dem eine eigene Bedeutung beimessen zu wollen. Denn betrachtet man nur das Planergebnis, ist es fast immer möglich, sich irgendwelche Gründe zu denken, die ein solches Ergebnis rechtfertigen könnten. Dementsprechend kann man sich dann, wenn man den Abwägungsvorgang als "Planbegründung im materiellen Sinne" versteht, auf eine so definierte Vorgangskontrolle beschränken ${ }^{241}$. Bloß wird man sich dann fragen lassen müssen, wie man sich die Kontrolle einer Planbegründung vorstellt, ohne auf das Ergebnis zu achten. Ohne Ergebnis läßt sich eine Begründung nicht kontrollieren. Letztlich bezieht man auf diese Weise das Planergebnis in die Vorgangskontrolle ein.

Der goldene Schnitt zwischen Vorgangs- und Ergebniskontrolle läßt sich weiterhin nicht dahingehend machen, daß man unter Ergebniskontrolle das "rechtsrichtige Ergebnis" versteht ${ }^{242}$. Denn das "rechtsrichtige" Ergebnis ergibt sich letztlich aus den Anforderungen, die das Abwägungsgebot für Ermittlung, Gewichtung und Ausgleich der Belange stellt. Bei Planentscheidungen gibt es nicht ein, sondern typischerweise mehrere rechtsrichtige Ergebnisse, so daß man bei einer so verstandenen Ergebniskontrolle Elemente dessen, was andere zur Vorgangskontrolle zählen, der Ergebniskontrolle hinzurechnen muß. Bei wenig determinierten Entscheidungen bedeutet eben Sachrichtigkeit vor allem Verfahrensrichtigkeit ${ }^{243}$ oder besser ausgedrückt "Vorgangsrichtigkeit"244.

Richtiger erscheint es deshalb, den Abwägungsprozeß - unabhängig davon, ob es um ein verfassungsrechtliches oder einfachgesetzliches Abwägungsgebot geht - einheitlich zu sehen und zu verstehen ${ }^{245}$. Das Abwägungsergebnis ist der letzte Punkt, aber damit auch Bestandteil des Abwägungsvorgangs. Der Abwägungsvorgang ist solange nicht beendet, wie kein Abwä-

${ }^{240}$ So Koch, DVBl. 1983, S. 1128.

${ }^{241}$ So Koch, DVBI. 1989, S. 400.

${ }^{242}$ So Heinze, NVwZ 1986, S. 90.

243 Ossenbühl, NVwZ 1982, S. 466; auch Degenhart, DVBI. 1982, S. 877.

${ }^{244}$ Alexy, JZ 1986, S. 706.

${ }^{245}$ In diese Richtung wohl auch Keßler, S. 207: "Abwägung als Vorgang vollzieht sich in einem ... Grenzbereich zwischen formalem, d. h. normativ geregeltem Verfahren und dem fertigen Plan als Ergebnis dieser Vorgänge."; weiterhin Steinberg, Nachbarrecht, III Rn. 162. 
gungsergebnis vorliegt. Abwägungskontrolle heißt, daß die Emanationen des Abwägungsprozesses daraufhin untersucht werden müssen, ob sie Fehler hinsichtlich der Einhaltung der rechtlichen Anforderungen des Abwägungsgebotes erkennen lassen. Solche Emanationen sind das Planergebnis, aber auch die Begründung, die Korrespondenz, Aktenauszüge, Protokolle etc., die den Weg zur Findung dieses Ergebnisses dokumentieren. Zuzustimmen ist daher am ehesten der Auffassung (4). Es geht tatsächlich um verschiedene Prüfungsgegenstände. Nur ist es ungenau zu formulieren, daß sowohl Vorgang als auch Ergebnis darauf untersucht werden müssen, ob ein Abwägungsfehler vorliegt ${ }^{246}$. Was untersucht wird, sind nicht Vorgang und Ergebnis, sondern das Planergebnis und das, was ansonsten Hinweise auf die richtige Abwägung geben kann. Somit ist es zutreffend, daß die Anforderungen des Abwägungsgebotes nur einmal gestellt werden. Begründen läßt sich dies aber nur damit, daß man von der Unterscheidung zwischen Abwägungsvorgang und -ergebnis absieht, die insofern nicht weiterführt.

\section{dd) Abwägung und Abwägungskontrolle bei örtlichen Bauvorschriften}

Nach der hier entwickelten Konzeption ist somit immer der gesamte Abwägungsproze $B$ Gegenstand der gerichtlichen Kontrolle. Hinweise auf die Erfüllung oder Nichterfüllung des Abwägungsgebotes können sich dabei sowohl aus dem Planergebnis als auch aus dem ergeben, was den Abwägungs"vorgang" dokumentiert. Unterschiedliche rechtliche Anforderungen an Vorgang und Ergebnis oder auch eine Aufteilung der typischen Fehler sind nicht denkbar.

Damit ist nun immer noch nicht entschieden, ob für die Kontrolle der Abwägung der Auffassung des OVG Münster, das von einer Nachweisobliegenheit der Gemeinden für die Erfüllung der Abwägungspflicht ausgeht ${ }^{247}$, oder der des OVG Lüneburg und des VGH Kassel zu folgen ist. Die letztgenannte Auffassung verwendet zwar die mißverständlichen Begriffe "Kontrolle des Abwägungsvorganges" und "Kontrolle des Abwägungsergebnisses". Sie läßt sich jedoch terminologisch bereinigen. Richtigerweise ist vor allem die Auffassung des OVG Lüneburg dahingehend zu verstehen, daß die Abwägungskontrolle weitgehend nur anhand des Planergebnisses stattfindet. Dadurch, daß das OVG davon spricht, daß die Überprüfung des "Abwä-

\footnotetext{
246 So Ibler, DVBl. 1988, S. 472.

247 OVG Münster, BRS Band 40, S. 338.
} 
gungsvorganges weitgehend ausgeschlossen" $\operatorname{sei}^{248}$, bringt es mittelbar zum Ausdruck, daß es - soweit sich anhand anderer Umstände ein Abwägungsfehler nachweisen läßt - durchaus auch diesen berücksichtigen will. Der entscheidende Unterschied zwischen beiden Auffassungen besteht also in der Frage der Beweislast. Das OVG Münster verlangt von der Gemeinde den Nachweis, daß die einzelnen Anforderungen des Abwägungsgebotes eingehalten wurden. Das OVG Lüneburg geht hiervon bis zum Nachweis des Gegenteils aus und beschränkt sich auf eine Art Stimmigkeitskontrolle im Hinblick auf das Planergebnis.

Die Antwort auf die Frage, welcher Auffassung zu folgen ist, setzt Klarheit über drei Problemkreise voraus. Das OVG Münster kann zunächst nur dann Recht haben, wenn es die Beweislast für Abwägungsentscheidungen im allgemeinen richtig verteilt. Desweiteren muß die vom OVG Münster angenommene Beweislastverteilung entweder einer gesetzgeberischen Modifizierung nicht zugänglich sein, oder die Entscheidung der Landesgesetzgeber, für örtliche Bauvorschriften keine Begründungspflicht vorzusehen, darf nicht als eine solche Modifizierung verstanden werden.

Was die grundsätzliche Verteilung der Beweislast bei Abwägungsentscheidungen betrifft, so gibt es hierüber noch keine völlig gesicherten Erkenntnisse. Es nicht ganz einfach, mit der auch im Verwaltungsprozeß noch immer angewendeten Normbegünstigungstheorie eine Antwort zu finden ${ }^{249}$. Denn das Abwägungsgebot ist weder in seiner verfassungsrechtlichen Variante noch in der hier vor allem interessierenden einfachgesetzlichen Version letztverbindlich als Norm formuliert. Auch der mit erheblichem Begründungsaufwand gemachte Vorschlag, die Beweislast im verwaltungsgerichtlichen Verfahren demjenigen aufzuerlegen, bei dem ein eventuelles Fehlurteil den geringeren Schaden anrichtet ${ }^{250}$, führt nicht recht weiter. Vor allem bei einer im vorliegenden Zusammenhang interessierenden Normenkontrollklage bliebe offen, ob die Interessen aller Planbetroffenen oder nur die des Antragstellers "abzuwägen" wären und was zu geschehen hätte, wenn mögli-

248 OVG Lüneburg, BRS Band 39, S. 282.

${ }^{249}$ Zur grundsätzlichen Geltung der Normbegünstigungstheorie im Verwaltungsprozeß siehe etwa BVerwG, Beschluß vom 03.08.1988, BayVBI. 1989, S. 24. Weiterhin SchmittGlaeser, Verwaltungsprozeßrecht, Rn. 750 S. 294; Ule § 50 S. 274 ff.; Redeker / von Oertzen, $\S 108$ Anm. 12. Kritisch etwa Berg, Die verwaltungsrechtliche Entscheidung, S. 182 ff., ders., Festschrift für Menger, S. 551; Nierhaus, BayVBl. 1978, S. 752.

${ }^{250}$ So Berg, Die verwaltungsrechtliche Entscheidung, S. 223 f., ders., Festschrift für Menger, S. $549 \mathrm{f}$. 
cherweise andere Planbetroffene durch den Plan begünstigt werden. Käme es wirklich auf den möglichen Schaden eines Fehlurteils an, müßte das Gericht bei jeder non-liquet-Situation das gesamte Pro und Contra der Auswirkungen eines nichtigen und eines gültigen Planes abwägen, um so zu entscheiden, wem die Beweislast aufzuerlegen ist. Ein solches Verfahren wäre nicht nur völlig unpraktikabel, es würde auch nicht der Aufgabenstellung der Gerichte entsprechen.

Man wird die Beweislast daher problemangemessen typisiert verteilen müssen, vor allem nach Verantwortungs- und Verfügungssphären ${ }^{251}$. Bei Abwägungsprozessen dürfte es - insofern ist dem OVG Münster zuzustimmen - richtig sein, daß die planende Stelle die Einhaltung der grundsätzlichen Anforderungen an die Abwägung zu beweisen hat. Der Planungsträger hat die Unterlagen für die Darlegung, ob und wann was abgewogen worden ist $^{252}$. Nur der Beweis einer Behauptung wie der, daß die Behörde entgegen ihren Behauptungen von unsachlichen Motiven ausgegangen sei, würde dann dem Normbetroffenen obliegen.

Damit stellt sich desweiteren die Frage, ob die vom OVG Münster grundsätzlich richtig erkannte Beweislastverteilung vom einfachen Gesetzgeber modifiziert werden kann. Für den Erlaß örtlicher Bauvorschriften obliegt den Gemeinden eine in den Bauordnungen vorgesehene einfachgesetzliche Abwägungspflicht, die jedoch teilweise bundesverfassungsrechtlich unterlegt ist ${ }^{253}$. Die Abwägungspflicht aufgrund des einfachen Rechts obliegt der Dispositon des Landesgesetzgebers. Was das im Bundesverfassungsrecht wurzelnde Abwägungsgebot betrifft, das gegebenfalls neben einfaches Bundes- oder Landesrecht tritt $^{254}$, so dürfte auch dort eine Modifizierung der Beweislast durch den einfachen Gesetzgeber möglich sein. Ableiten läßt sich dies aus der bereits erwähnten Rechtsprechung des BVerwG zur verfas-

\footnotetext{
${ }^{251}$ Peschau, S. $58 \mathrm{ff}$.

${ }^{252}$ Anders wohl Peschau, S. 129, der dem Bürger den Nachweis der tatsächlichen Voraussetzungen von Abwägungsfehlern aufbürden will. Dies paßt aber zum einen nicht zu den von Peschau angestellten Überlegungen zur Verteilung der Beweislast nach Verantwortungs- und Verfügungssphären - siehe dieser, S. 58 ff. - , zum anderen ist nicht ganz klar, was Peschau unter "tatsächlichen" Voraussetzungen versteht. Nicht recht deutlich wird, ob damit auch der Fall gemeint ist, daß Unklarheit herrscht, ob ein bestimmter Belang in die Abwägung eingeflossen ist. Kritisch zur Konzeption von Peschau auch Steiner, Beschränkung von Luftverunreinigungen, S. 53. Grundsätzlich zustimmend zum Kriterium der Beweisnähe für die Beweislastverteilung Sonntag, S. 23.
}

${ }^{253}$ Ausführlich dazu oben E II 2 a aa a. E.

${ }^{254}$ Siehe dazu die Nachweise E II 2 a aa a. E.. 
sungskonformen Auslegung des $\S 155$ b Abs. 2 S. 2 BBauG $^{255}$. Das BVerwG gesteht in dieser Entscheidung dem Gesetzgeber die Möglichkeit zu, die Rechtsfolgen, die sich aus der Nichtbeachtung des Gebotes gerechter Abwägung ergeben, zu modifizieren ${ }^{256}$. Es legt den $\S 155$ b Abs. 2 S. 2 BBauG, der bei Abwägungsfehlern nur dann eine Nichtigkeit des Planes vorsieht, wenn die Mängel "offensichtlich und auf das Abwägungsergebnis von Einfluß gewesen sind", im Hinblick auf das Merkmal "offensichtlich" dahingehend aus, daß damit nur die sog. innere Seite des Abwägungsvorganges einer gerichtlichen Überprüfung entzogen ist. Hierzu zählen vor allem die Vorstellungen der Ratsmitglieder, also das, was sich nicht durch Protokolle, Aktenauszüge etc. sichtbar machen läßt ${ }^{257}$. Wenn damit das BVerwG das selbst entwickelte bundesverfassungsrechtliche Abwägungsgebot insoweit zurücknimmt, daß der Gesetzgeber die dem Planbetroffenen zur Verfügung stehenden Beweismittel einschränken kann, um einen Abwägungsfehler nachzuweisen, wird man auch davon ausgehen können, daß hinsichtlich der Beweislast der einfache Gesetzgeber einen gewissen Dispositionsspielraum hat.

Als dritter noch offener Punkt zur Widerlegung der Annahme des OVG Münster, wonach es der Gemeinde obliege, ihre Abwägung beim Satzungserlaß über örtliche Bauvorschriften in irgendeiner Art nachzuweisen, bleibt somit die Frage, ob davon auszugehen ist, daß die Landesgesetzgeber die Beweislast modifizieren wollten. Der Wille der meisten Landesgesetzgeber $^{258}$ dahingehend, daß Satzungen über örtliche Bauvorschriften nicht im Sinne von $\S 9$ Abs. 8 BauGB begründet werden sollen, kommt in den Landesbauordnungen klar zum Ausdruck ${ }^{259}$. Es wäre nun ein widersprüchlich anmutendes Ergebnis, wollte man den Gemeinden angesichts der klaren Entscheidung der Landesgesetzgeber gegen eine Begründungspflicht eine zumindest ähnliche Pflicht über das Abwägungsgebot wieder auferlegen. Die Art des Nachweises wäre zwar in das Belieben der Gemeinden gestellt. Die sinnvollste Möglichkeit zur Erfüllung einer solchen Obliegenheit ist aber die Anfertigung einer Begründung entsprechend § 9 Abs. 8 BauGB. Sieht ein Gesetzgeber eine Begründungspflicht ausdrücklich vor, ist dies als

\footnotetext{
${ }^{255}$ BVerwG, Urteil vom 21.08.1981, BauR 1981, S. 535 ff.

${ }^{256}$ BVerwG (Fn. 255), S. 536.

${ }^{257}$ BVerwG (Fn. 255), S. 537.

${ }^{258}$ Ausnahme: Niedersachsen, siehe oben E II 1 a.

${ }^{259}$ Siehe oben E II 1 a.
} 
deutlicher Hinweis darauf zu werten, daß eine entsprechende Beweispflicht der Behörde besteht ${ }^{260}$. Zumindest im vorliegenden Fall muß dies umgekehrt aber auch gelten. Man wird davon auszugehen haben, daß die Landesgesetzgeber mit ihrer Entscheidung über den Verzicht auf das formelle Erfordernis einer Begründung auch die materiellrechtliche Konsequenz gewollt haben, daß insofern der planenden Gemeinde die Beweislast für die Einhaltung der Anforderungen des Abwägungsgebotes nicht obliegt.

Eine solche Entscheidung der Landesgesetzgeber ist zumindest nicht unvertretbar. Es geht bei der vorliegenden Problematik nur um die Begründung von einfachen Satzungen über örtliche Bauvorschriften. Bei der Aufnahme in den Bebauungsplan sind die wesentlichen, $d$. $h$. vor allem die mit den bauplanungsrechtlichen Festsetzungen nach $\S 9$ Abs. 1 BauGB zusammenhängenden Bestimmungen schon deshalb zu begründen, weil sonst die Begründungspflicht nach § 9 Abs. 8 BauGB nur unvollständig erfüllt werden könnte ${ }^{261}$. Es können daher ähnliche Überlegungen angestellt werden wie bei der Frage, ob sich unmittelbar aus Art. 14 GG eine Begründungspflicht ableiten läßt $\mathrm{t}^{262}$. Eine solche Pflicht wäre de lege ferenda wünschenswert, ist aber grundrechtlich nicht zwingend geboten. Vergleichbares gilt für die Frage der Beweislast hinsichtlich der Abwägung. Die sich an die fehlende Begründungspflicht anschließende Beweislastumkehr ist aus grundrechtlicher Sicht keine optimale, aber eine vertretbare Lösung. Bei einfachen Satzungen über örtliche Bauvorschriften lassen sich die Abwägungsfragen dagegen weitgehend auch im nachhinein rekonstruieren ${ }^{263}$. Entscheidend ist meistens die Frage, ob das gemeindliche Stadtgestaltungskonzept die fraglichen Festlegungen erfordert. Die Abwägung zulasten der Eigentümerinteressen kann dabei nur dann rechtswirksam erfolgen, wenn die Gemeinde ein solches Gestaltungskonzept hat und die einzelnen die Eigentümer belastenden Regelungen zu dessen Verwirklichung auch erforderlich sind. Trifft die Gemeinde Festlegungen, die von ihren gestalterischen Plänen nicht gefordert sind oder hat sie überhaupt kein solches Konzept, so läßt sich eine entsprechende, die getroffenen Festlegungen legitimierende Gestaltungsidee hinterher schlecht erfinden, zumal die satzungsmäßigen Festlegungen meist selbst kundtun, welchem Zweck sie dienen sollen. Selbst wenn die Ge-

${ }^{260}$ Peschau, S. 58.

${ }^{261}$ Siehe dazu oben E 12 a a. E.

${ }^{262}$ Siehe oben E II 1 b dd (2).

${ }^{263}$ Dies zeigt auch die Entscheidung des HessVGH, Urteil vom 30.06.1987, HessStuGZ 1988 , S. $408 \mathrm{f}$. 
meinde sich erst im Verwaltungsproze $ß$ ein Konzept ausdenkt, das die Festlegungen rechtfertigen soll und das nach den in der Satzung gewählten Formulierungen denkbar wäre, so wird ein solches Konzept meist am Übermaßverbot scheitern. Setzt etwa eine örtliche Bauvorschrift aus optischen Gründen ein relativ teures Material für die Dachdeckung fest, und beruft sich die planende Gemeinde im Prozeß darauf, es käme ihr darauf an, $\mathrm{da} ß$ durch die Veränderungen des Materials im Laufe der Zeit ein auch farblich abwechslungsreiches Bild der Dachlandschaft ergäbe, dann kann ein solches Konzept zur Belebung der Dachlandschaft nur dann rechtmäßig sein, wenn die Gemeinde hierzu auch andere, den Eigentümer unter Umständen weniger belastende Mittel genutzt hat. Setzt sie dagegen für ein Baugebiet, bei dem insgesamt wenig Gewicht auf die Dachgestaltung gelegt wird, ein solches Material fest, dann verstößt dies gegen das Übermaßverbot $^{264}$. Deshalb läßt sich die Frage einer gerechten Abwägung bei reinen Gestaltungskonflikten leichter als bei anderen wesentlich komplexeren Entscheidungen auch anhand des Planergebnisses angemessen nachprüfen. Eine Stimmigkeitskontrolle bietet insoweit durchaus Möglichkeiten zur Aufhebung von Satzungen über örtliche Bauvorschriften.

Insgesamt läßt sich folgendes Fazit ziehen: Es ist nicht nach der aus grundrechtlicher Sicht optimalen, sondern nach der von den Gesetzgebern gewollten Lösung zu suchen. Hierbei wird man von einer Konkordanz zwischen Begründungspflicht und Beweislast für die Erfüllung der Anforderungen an die Abwägung auszugehen haben. Insofern ist nicht der Rechtsprechung des OVG Münster, sondern der des OVG Lüneburg und des VGH Kassel zu folgen: Die Überprüfung der Abwägung bei örtlichen Bauvorschriften beschränkt sich im wesentlichen auf eine Überprüfung des Planergebnisses. Es gibt keine Obliegenheit der Gemeinden, die Anforderungen des Abwägungsgebotes im übrigen nachzuweisen.

b) Die Wahl zwischen der Aufnahme örtlicher Bauvorschriften in den Bebauungsplan und dem Erlaß einer einfachen Satzung

Die Frage, ob örtliche Bauvorschriften als einfache Satzungen erlassen oder in den Bebauungsplan aufgenommen werden, wird allgemein als eine reine Zweckmäßigkeitsfrage angesehen ${ }^{265}$. Dem kann man nach den bisher

\footnotetext{
${ }^{264}$ Vergleiche die Entscheidung BayVGH, Urteil vom 12.09.1988, BayVBI. 1989, S. 212.

265 Simon, BayBO Art. 91 Anm. 3 a und 30; Böckenförde, in: Gädtke / Böckenförde / Temme, § 81 Anm. 31 .
} 
gewonnenen Ergebnissen nur bedingt zustimmen. Das Ermessen der Gemeinde, welchen Weg sie für den Erlaß von örtlichen Bauvorschriften wählt, ist rechtlich gebunden. Diese Bindung ergibt sich im Rückschluß aus den unterschiedlichen verfahrensrechtlichen Anforderungen und dem unterschiedlichen Maße einer gerichtlichen Kontrolle. So kann die Nichtaufnahme in den Bebauungsplan dazu führen, daß ein Normenkontrollverfahren gegen örtliche Bauvorschriften nicht statthaft ist ${ }^{266}$. Die fehlende Begründungspflicht führt anders als bei der Aufnahme in den Bebauungsplan zu einer nur eingeschränkten gerichtlichen Kontrolle ${ }^{267}$. Auch die Überprüfung durch staatliche Instanzen ist unterschiedlich. So gibt es nur bei Aufnahme in den Bebauungsplan ein Anzeigeverfahren, einfache Satzungen werden hingegen weitgehend ohne staatlichen Mitwirkungsakt in Kraft gesetzt $^{268}$. Diese strengeren Anforderungen beim Erlaß von örtlichen Bauvorschriften als Bestandteil des Bebauungsplans kann die Gemeinde aber nicht nach Belieben umgehen. Sie wird sich vielmehr bei der Entscheidung, ob sie eine einfache Satzung erläßt oder nach $\S 9$ Abs. 4 BauGB vorgeht, von folgenden Erwägungen leiten lassen müssen:

(1) Unproblematisch ist der Erlaß einer einfachen Satzung, wenn für das betreffende Gebiet kein Bebauungsplan vorliegt und nach zutreffender Einschätzung der Gemeinde nach § 1 Abs. 3 BauGB auch nicht erforderlich ist. Gegen den Erlaß einer einfachen Satzung läßt sich dann nichts einwenden.

(2) Für den Fall, daß auch ein Bebauungsplan für das betreffende Gebiet aufgestellt werden soll, ist in der Regel - soweit das Landesrecht diese Möglichkeit eröffnet - nur die Aufnahme der örtlichen Bauvorschriften in den Bebauungsplan nach § 9 Abs. 4 BauGB ermessensfehlerfrei. Dies ergibt sich daraus, daß das Abwägungsmaterial teilweise identisch ist, die Regelungen häufig aufeinander bezogen sind und deshalb eine Bewältigung der zum Teil gemeinsamen Probleme in einem Planwerk erforderlich ist ${ }^{269}$.

(3) Besteht für einen Planbereich ein Bebauungsplan ohne Festsetzungen, die nach $\S 9$ Abs. 4 BauGB aufgenommen worden sind, und sollen nun beispielsweise baugestalterische Vorschriften erlassen werden, so wird es auf den jeweiligen Inhalt der örtlichen Bauvorschrift ankommen, ob eine einfa-

\footnotetext{
${ }^{266}$ Siehe oben E I $1 \mathrm{c}$.

${ }^{267}$ Siehe oben E II 2 a dd.

${ }^{268}$ Siehe oben E I 2 b.

${ }^{269}$ Siehe die Erwägungen zur kompetenzrechtlichen Einordnung örtlicher Bauvorschriften, oben A III 4.
} 
che Satzung erlassen werden kann. Läßt sich davon ausgehen, daß bei ursprünglich gemeinsamer Planung die bestehenden Festsetzungen des Bebauungsplanes genauso getroffen worden wären, ist der Erlaß einer einfachen Satzung möglich. Kann man eine solche nachträgliche Prognose nicht zuverlässig treffen, ist grundsätzlich ein Verfahren zur Änderung des Bebauungsplanes mit dem Ziel durchzuführen, Festsetzungen nach § 9 Abs. 4 BauGB aufzunehmen. Dies ist etwa dann anzunehmen, wenn etwa nachträglich Bestimmungen über die Dachgestaltung oder sonstige die Gebäudedimensionierung betreffende Fragen erlassen werden sollen. Dies läßt sich im Abwägungsprozeß nicht trennen etwa von der Festsetzung des Maßes der baulichen Nutzung ${ }^{270}$. In einem solchen Bebauungsplanänderungsverfahren steht dann der gesamte Planinhalt erneut zur Disposition. Es sind deshalb alle Anforderungen verfahrens- und materiellrechtlicher Art an die Änderung eines Bebauungsplanes einzuhalten, nicht nur das "Pflichtprogramm", welches für die aufzunehmenden örtlichen Bauvorschriften gilt ${ }^{271}$.

(4) Besteht für einen Planbereich ein Bebauungsplan mit Festsetzungen nach $\S 9$ Abs. 4 BauGB, ist eine Änderung der aufgenommenen Festsetzungen ebenfalls nur im Wege eines Verfahrens auf Änderung des Bebauungsplanes möglich $^{272}$. Es ist davon auszugehen, daß für Festsetzungen nach $\S 9$ Abs. 1 und Abs. 4 BauGB ein einheitlicher Abwägungs- und Gestaltungsprozeß stattgefunden hat. Hieraus lassen sich nicht im nachhinein einzelne Fragen isolieren. Besonders die in letzter Zeit verstärkt auftretenden Änderungen von Flachdachfestsetzungen ${ }^{273}$ sind daher - soweit die ursprünglichen Festsetzungen nach $\S 9$ Abs. 4 BauGB erfolgt sind - nur im Verfahren einer Änderung des Bebauungsplanes möglich.

Festzuhalten ist auf jeden Fall, daß ein möglicher Nichtigkeitsgrund bei einfachen Satzungen auch darin bestehen kann, daß die Gemeinde es unterlassen hat, eine Aufnahme in den Bebauungsplan durchzuführen.

${ }^{270}$ Vergleiche die Überlegungen zur kompetenzrechtlichen Einordnung örtlicher Bauvorschriften, oben A III 4.

271 Gegebenenfalls ist selbstverständlich auch ein vereinfachtes Verfahren nach $\S 13$ BauGB zulässig.

272 So auch Bosch, ZfBR 1987, S. 185.

${ }^{273}$ Siehe die Nachweise oben A III 1 a. 


\section{Satzungen über Ortsgestaltung ohne rechtsverbindliche Festlegungen}

\section{a) Zusammenfassung der Schwierigkeiten bei einer Ortsgestaltung durch rechtsverbindliche Festlegungen}

Das Instrumentarium örtliche Bauvorschriften erhält - unabhängig vom Erlaßmodus als einfache Satzung oder als Bestandteil des Bebauungsplans aus der Planungspraxis bezüglich der Eignung zur Durchführung von Ortsgestaltung keinesfalls nur positive Kritiken ${ }^{274}$. Die Crux liegt insoweit im Bestimmtheitsgrundsatz. Gewünscht wird Flexibilität. Rechtlich notwendig ist Normbestimmtheit. Diese führt entweder dazu, daß der gesteckte Rahmen zu eng wird, so daß letztlich die Gebäude ideenlos gleich wirken, oder der Rahmen ist nicht eng genug, so daß Spielraum für Gestaltungen bleibt, die nicht im Sinne der Planer liegen.

Auch die genauen rechtlichen Anforderungen, denen örtliche Bauvorschriften unterzogen werden, sind aus der insoweit vor allem maßgeblichen Rechtsprechung der Oberverwaltungsgerichte nicht immer mit letzter Klarheit zu entnehmen. Eine Unterscheidung von positiver Gestaltungspflege und erweiterter Gebietspflege wird meist nicht durchgeführt ${ }^{275}$. Anforderungen, die an die Abwägung gestellt werden, sind nicht selten unklar und nicht immer widerspruchslos ${ }^{276}$. Die Gefahr, daß eine Satzung für unwirksam gehalten wird und deshalb der Spielraum der Eigentümer sich bis zur Grenze der baugestalterischen Generalklauseln erweitert, ist daher nicht unerheblich.

Desweiteren ist es für die Gemeinden nicht immer ganz einfach, wegen Verstößen gegen ihre örtlichen Bauvorschriften einzuschreiten. So sind kreisangehörige Gemeinden meist nicht für den Baurechtsvollzug zuständig. In der Regel werden sich die Eigentümer zudem auf das Übermaßverbot berufen, wenn sie den Winkel des Daches oder die Farbgestaltung für die Außenwände nicht ganz der gemeindlichen Satzung angepaßt haben und

${ }^{274}$ Siehe die Nachweise oben D II 3 a.

275 Vergleiche BayVGH, Urteil vom 12.09.1988, BayVBI. 1989, S. 210 (212), wo vor allem auf den schützenswerten Bestand oder auf eine schützenswerte Umgebung abgestellt wird, obwohl von "positiver Baupflege" die Rede ist.

${ }^{276}$ Als Beispiel mag wiederum die Entscheidung BayVGH, BayVBI. 1989, S. 210 ff. (212), gelten. So soll die dort angegriffene Planung zwar "niveauvoll" aber "nicht außergewöhnlich" sein. Vergleiche weiterhin auch die Frage der Kontrolle von Abwägungsergebnis und Abwägungsvorgang, oben E I! 2 a. 
deshalb mit einer Baubeseitigungsverfügung gegen sie vorgegangen wird. Auch wenn die Gemeinden bei einer wirksamen Gestaltungssatzung letztlich ihre Vorstellungen werden durchsetzen können, ist der notwendige Verwaltungsaufwand häufig erheblich.

b) Privatrechtliche Durchsetzung von Gestaltungsabsichten und Schutz der Eigentümerinteressen

Aufgrund dieser Schwierigkeiten mit örtlichen Bauvorschriften und ihrer Durchsetzung ist es ein bei Gemeinden nicht unbeliebtes Mittel, für solche Bereiche, in denen die Gemeinden unmittelbar Grundstückseigentümer oder über Beteiligungsgesellschaften verfügungsbefugt sind, auf den Erlaß einer Satzung zu verzichten und stattdessen die gewünschte Gestaltung den bauwilligen Interessenten bei der Veräußerung der Grundstücke in den privatrechtlichen Verträgen vorzuschreiben ${ }^{27}$.

Ein solches Verfahren ist nicht ohne weiteres bedenkenfrei. $\mathrm{Zu}$ Recht wird die Gefahr gesehen, daß die Gemeinde Anforderungen an die Baugestaltung, die sie satzungsmäßig nicht festlegen könnte, auf einem solchen Umweg doch durchsetzt ${ }^{278}$. Bedenken wird man gegen eine solche Umgehung des öffentlichen Baurechts vor allem dann haben müssen, wenn sich die Gemeinde Maßnahmen ersparen will, die auch zur Koordination gegenläufiger öffentlicher Interessen notwendig sind, wie etwa die eigentliche Bauleitplanung. Bei der Durchsetzung einer bestimmten optischen Gestaltung von Bauwerken treffen aber vor allem die Eigentümerinteressen und die gemeindlichen Gestaltungsabsichten aufeinander. Dieser Konflikt wird dadurch, daß die Gemeinde anfangs selbst Eigentümer ist, etwas abgemildert. Allerdings müßte die Gemeinde dann, wenn sie für die zunächst ihr gehörenden Grundstücke eine Satzung erlassen würde, die Interessen der potentiellen späteren Grundstückseigentümer in die Abwägung einstellen. Die Gemeinde plant in aller Regel den späteren Verkauf der Grundstücke. $\mathrm{Da}$ die Satzung damit - wie andere örtliche Bauvorschriften auch - die späteren Grundstückseigentümer in ihrer Baufreiheit einschränkt, ist für die Gemeinde erkennbar. Die Interessen der noch nicht namentlich bekannten

277 Dies wurde im übrigen auch schon im letzten Jahrhundert so praktiziert, siehe Baumeister, S. 267. Zur heutigen Situation allgemein Schuegraf, NJW 1964, S. 2088; Trieb / Schmidt / Paetow / Buch / Strobel, S. 89 ff.; Herb, S. 70 ff.; Birk, S. 78 ff.; Nick, S. 88 ff.; vergleiche auch Jaeger, ZSSD 1979, S. 302, zum "Gaggenauer Modell".

${ }^{278}$ Schuegraf, NJW 1964, S. 2091. 
späteren Eigentümer wären auch schutzwürdig und nicht unerheblich ${ }^{279}$. Dies muß nach der neueren Rechtsprechung des BVerwG schon deshalb gelten, weil auch den späteren Planbetroffenen die Befugnis zur Normenkontrollklage zugestanden wird ${ }^{280}$. Auch der BGH nimmt drittbezogene Amtspflichten zugunsten der späteren Erwerber von Grundstücken zur Wohnbebauung vor allem hinsichtlich der Vermeidung von Gesundheitsschäden $a^{281}$. Die Gemeinde muß also zumindest dann, wenn eine erstmalige spätere Wohnbebauung ins Auge gefaßt ist, die Interessen der späteren Eigentümer berücksichtigen, was man nicht allein auf den Schutz der körperlichen Unversehrtheit wird beschränken können. Der Gedanke ist auf den Schutz des Eigentums und damit auf spätere Gestaltungsinteressen übertragbar.

Wenn die Gemeinde somit bei einem Satzungserlaß nicht von der Berücksichtigung der Belange der späteren Eigentümerinteressen im Hinblick auf eine selbstbestimmte Gestaltung ihrer Gebäude befreit wäre, kann man sie von der Pflicht hierzu auch bei Erfüllung der öffentlichen Aufgabe Ortsgestaltung auf privatrechtlichem Wege nicht freistellen. Der Konflikt tritt aber trotzdem nur in abgemildeter Form auf. Anders als beim Überplanen fremder Grundstücke werden die Eigentümer nicht quasi von oben herab auf dem Satzungswege mit den Beschränkungen konfrontiert. Ihnen steht es frei, in den Vertragsverhandlungen auf Änderungen zu drängen oder auch von einem Kauf abzusehen. Die gestalterischen Auflagen sind Teil des "Zuschnitts", in der die Gemeinden die Grundstücke anbieten.

\section{c) Notwendige verfahrensmäßige Sicherungen}

Da die Gemeinden auch beim Abschluß privatrechtlicher Verträge bezüglich der darin enthaltenen Klauseln zur äußeren Gebäudegestaltung nicht davon entbunden sind, die späteren Eigentümerinteressen in Rechnung zu stellen, sind gewisse verfahrensmäßige Sicherungen für die Erfül-

${ }^{279} \mathrm{Zu}$ dieser Formel für die Berücksichtigung von privaten Interessen bei der Abwägung siehe BVerwG, Beschluß vom 09.11.1978, E 59, 87 (102 f.); zur Antragsbefugnis späterer Eigentümer siehe auch Dürr, Antragsbefugnis, S. $94 \mathrm{ff}$.

${ }^{280}$ BVerwG, Beschluß vom 11.11.1988, DVBI. 1989, S. 359 (360) = BayVB1. 1989, S. 315 ff. und Anmerkung von Dürr, DVBl. 1989, S. 360: Normenkontrollklagebefugnis auch des Mieters, der nach Erlaß des Bebauungsplans ins Plangebiet zieht. Die Gemeinde wird daher die Betroffenheit durch die Planung auch unabhängig von den bei Planerlaß vorhandenen Planbetroffenen zu beachten haben.

${ }^{281}$ BGH, Urteil vom 26.01.1989, NJW 1989, S. 976 ff. 
lung dieser Pflicht unumgänglich. Diese ergeben sich aus dem geltenden Kommunal- und Baurecht. Es ist nämlich zu verlangen, daß die geplante Gestaltung vom Gemeinderat beschlossen wird, und zwar in satzungsmäßiger Form. Hierbei handelt es sich um eine Parallele zum demokratischen Gesetzesvorbehalt ("Wesentlichkeitstheorie") im staatlichen Bereich ${ }^{282}$. Auch im kommunalen Bereich dürfte grundsätzlich der Gemeinderat dazu berufen sein, die grundlegenden Entscheidungen, also das, was nicht Angelegenheit der laufenden Verwaltung ist, selbst zu entscheiden ${ }^{283}$. Daß insoweit nicht nur ein Ratsvorbehalt, sondern auch ein "Vorbehalt der Satzung" anzunehmen ist ${ }^{284}$, ergibt sich aber auf jeden Fall aus einer sachgerechten Interpretation der Bauordnungen. Dort werden die Gemeinden auf die Satzungsform festgelegt, wenn sie örtliche Gestaltungsabsichten durchsetzen wollen. $\mathrm{Da}$ sie aus Gründen der besseren Praktikabilität auf auch im Außenverhältnis rechtsverbindliche Festlegungen verzichten wollen, stellt sie vom grundsätzlichen Satzungserfordernis nicht frei. Der Satzungserlaß sorgt für Publizität der gemeindlichen Vorstellungen, er sichert die Zuständigkeit des Rates und liefert einen rechtlichen Gegenstand für eine Normenkontrollklage bei Nichterfüllung der Abwägungspflichten ${ }^{285}$.

Die Bestimmtheitsanforderungen an einen solchen Satzungserlaß - und dies wahrt die Interessen der Planungspraxis - sind jedoch weniger weitgehend als bei einer nach außen wirksamen örtlichen Bauvorschrift. Die Gemeindevertretung braucht nur die grundsätzlichen Ziele und Anforderungen satzungsmäßig festzulegen. Die Einzelheiten können der Verwaltung überlassen bleiben. Diese erhält dadurch in den Kaufverhandlungen den gewünschten Verhandlungs- und Gestaltungsspielraum. Ein solches Verfahren erscheint der Gestaltung von Gebieten, in denen die Gemeinde die Grundstücke veräußert, insgesamt praktikabler als der Erlaß einer örtlichen Bauvorschrift im eigentlichen Sinne. Die Gemeinde bewegt sich bei einem solchen Vorgehen allerdings nicht im kommunal- und baurechtsfreien Raum. Nur unter Beachtung der genannten verfahrensrechtlichen und materiellrechtlichen Anforderungen lassen sich rechtliche Bedenken nicht erheben.

\footnotetext{
${ }^{282}$ Schmidt-Jortzig, ZG 1987, S. 200. Siehe auch Bethge, NVwZ 1983, S. 580.

${ }^{283}$ Siehe etwa Art. 29 und 37 BayGO.

${ }^{284}$ Schmidt-Jortzig, Kommunalrecht, Rn. 623, ders., ZG 1987, S. 201.

${ }^{285}$ Was allerdings voraussetzt, daß das Land die Befugnis nach $\S 47$ Abs. 1 Nr. 2 VwGO ausgeschöpft hat.
} 


\section{F. Zusammenfassung der wichtigsten Ergebnisse}

\section{Zu A:}

1. Im Bereich der örtlichen Bauvorschriften sind drei Hauptanwendungsfelder zu unterscheiden, und zwar die baugestalterischen Vorschriften, die denkmalschützenden und die Vorschriften zur Bestimmung von Abstandsflächen.

2. Bei allen drei Komplexen zeigen sich diverse Wechselwirkungen und Überschneidungen mit dem Städtebaurecht. Beispielsweise erscheint es fraglich, wie die gemeindliche Praxis erklärt werden kann, im Bebauungsplan und in örtlichen Bauvorschriften die gleichen Festlegungen (z. B. über die Firstrichtung) zu treffen und ob es möglich ist, durch Bebauungsplan und örtliche Bauvorschrift gleiche Ziele zu verfolgen.

3. Die auftretenden Abgrenzungsschwierigkeiten lassen sich mit den seit dem Baurechtsgutachten des BVerfG eingebürgerten Abgrenzungsformeln zur Definition der Kompetenz "Bodenrecht" des Art. 74 Nr. 18 GG nicht angemessen lösen.

4. Die Rechtsprechung vor allem des BVerfG hat sich mittlerweile konkludent von den nicht brauchbaren Formeln aus dem Baurechtsgutachten gelöst. Deutlich wird dies in der Diskussion um die verfassungsrechtliche Zulässigkeit eines städtebaulichen Denkmalschutzes in den $\S \S 172 \mathrm{ff}$. BauGB. Kompetenzrechtlicher Schlüssel zur Begründung einer Bundeskompetenz ist nach Auffassung der Rechtsprechung das Merkmal des städtebaulichen Bezugs, d. h. die finale Bezogenheit einer Maßnahme auf die städtebauliche Entwicklung und Ordnung. Dadurch kommt es zu einem Gleichklang zwischen verfassungsrechtlichem Abgrenzungsmaßstab und der grundsätzlichen Planrechtfertigung bei Bebauungsplänen vor allem nach § 1 Abs. 5 S. 1 BauGB.

5. Eine Analyse des $\S 1$ Abs. 5 S. 1 BauGB ergibt jedoch, daß jeder Belang, der im Rahmen der Bauleitplanung abwägungserheblich ist, grundsätzlich geeignet ist, als Planrechtfertigung für die Bauleitplanung zu dienen. Das Bauplanungsrecht ist auf keine bestimmten Zwecksetzungen festgelegt. Damit sind alle Ziele des Bauordnungsrechts ebenfalls solche des Baupla- 
nungsrechts. Auch dürfen die Gemeinden mit dem Instrument des Bebauungsplanes Denkmalschutz betreiben. Es kommt insofern stets nur darauf an, daß die konkrete Bauleitplanung abwägungsfehlerfrei erfolgt. Eine häufig vertretene "immanente" Einschränkung der in $\S 1$ Abs. 5 S. 2 BauGB genannten Belange ist nicht möglich.

6. Eine rein finale Abgrenzung des Bauplanungsrechts von anderen Materien scheidet somit ebenfalls aus. Ansonsten bestände die Gefahr des $\mathrm{Zu}$ griffs des Bundesgesetzgebers über die Kompetenz "Bodenrecht" auf praktisch jede zu erfüllende öffentliche Aufgabe.

7. Eine Bauleitplanung in privatem Interesse ist nicht von vornherein ausgeschlossen. Es kommt wiederum nur darauf an, daß die Gemeinde die Anforderungen des Abwägungsgebotes einhält. Die ganz überwiegende $\mathrm{Ge}$ genauffassung, die einen öffentlichen Belang für den Erlaß eines Bebauungsplanes fordert, sieht die Bauleitplanung zu einseitig als Eingriffsmaßnahme.

8. Bei der Suche nach einem praktikablen Abgrenzungsmaßstab gibt die historische Entwicklung des Städtebaurechts eine wichtige Auslegungshilfe. Das moderne städtebauliche Instrumentarium erklärt sich durch den $\mathrm{Ge}$ danken einer gesamtheitlichen Sicht der städtebaulichen Entwicklung und Ordnung. Bodenrecht ist daher Planungsrecht. Die Bodenrechtskompetenz umfaßt die Normierung solcher Festsetzungen, die der Planungsträger zur Lösung spezifischer Bodenrechtsprobleme in planmäßiger Art und Weise benötigt. Entscheidend ist, ob der mit einer Festsetzung vor allem verfolgte Belang in einem ausgleichs- und / oder ergänzungsbedürftigen Verhältnis mit anderen ebenfalls spezifischen Bodennutzungsbelangen dienenden Festsetzungen steht.

9. Aus einem solchen Verständnis ergibt sich eine institutionelle Vorrangstellung des Bebauungsplans gegenüber dem Bauordnungsrecht. Daraus folgt für die abstandsmodifizierenden örtlichen Bauvorschriften, daß diese keine "Ermöglichungsfunktion" für die Verwirklichung bauplanerischer Festsetzungen haben. Ein Bebauungsplan kann sich - soweit er abwägungsfehlerfrei erlassen wird - über die landesrechtlichen Abstandsvorschriften hinwegsetzen, und zwar unabhängig davon, ob und inwieweit ihm das Landesrecht Vorrang einräumt. Der Bebauungsplan benötigt insoweit keine Verwirklichungshilfe durch eine örtliche Bauvorschrift.

10. Örtliche Bauvorschriften sind weitgehend potentielles Bauplanungsrecht. Vor allem für die üblicherweise in örtlichen Bauvorschriften vorgesehenen Festlegungen der Dachgestaltung ist de lege ferenda eine Regelung 
im Rahmen des $\S 9$ Abs. 1 BauGB geboten. Auch die übrigen, in Satzungen über örtliche Bauvorschriften üblichen Festlegungen könnten in den $\S 9$ Abs. 1 BauGB aufgenommen werden. Dies ergibt sich daraus, daß die mit örtlichen Bauvorschriften verfolgten Belange häufig in einem ausgleichsund ergänzungsbedürftigen Verhältnis zu solchen Interessen stehen, die mit Festsetzungen nach $\S 9$ Abs. 1 BauGB verfolgt werden.

11. Örtliche Bauvorschriften mit baugestalterischen Vorschriften können auch für andere als rein gestalterische Ziele eingesetzt werden. Sachgerecht ist es, wie in Art. 91 Abs. 1 Nr. 1 BayBO von der Verfolgung von "städtebaulichen Zielen" auszugehen. Damit kann aber alles das Regelungsziel von örtlichen Bauvorschriften sein, was auch durch Bebauungsplan verfolgt werden könnte. Für die "Flachdach"-Fälle folgt daraus, daß solche Festsetzungen auch auf Wunsch der Eigentümer, also in privatem Interesse geändert werden können.

\section{Zu B:}

12. Die Frage, ob der Erlaß von örtlichen Bauvorschriften dem eigenen oder übertragenen Wirkungskreis zuzuordnen ist, läßt sich nicht für alle Bauordnungen mit letzter Gewißheit beantworten. Bei einer Auslegung des einfachen Rechts sprechen jedoch - abgesehen vom Fall der NBauO - die besseren Gründe für einen Erlaß im eigenen Wirkungskreis.

13. Die enge Verwandtschaft zwischen Städtebaurecht und örtlichen Bauvorschriften führt unter dem Aspekt des Kernbereichs der kommunalen Selbstverwaltung nicht dazu, daß der Erlaß von örtlichen Bauvorschriften zwingend dem eigenen Wirkungskreis zuzuordnen ist. Eine solche Annahme ist selbst für die im gegenwärtigen Zeitpunkt im BauGB geregelten Planungsinstrumente nicht angebracht. Die Frage, ob eine bestimmte Aufgabe im sog. funktionellen Sinn dem Kernbereich zuzuordnen ist, ist ohne Rücksicht auf mögliche Gründe für einen Aufgabenentzug gar nicht sinnvoll zu beantworten.

14. Der Gesetzesvorbehalt des Art. 28 Abs. 2 S. 1 GG berechtigt den Gesetzgeber dazu, sowohl den Umfang als auch die Eigenverantwortlichkeit gemeindlicher Aufgabenerfüllung zu verändern.

15. Es gibt kein brauchbares materiales Kriterium, mit dem eine primär örtliche von einer überörtlichen Aufgabe unterschieden werden kann. Überörtliche Verflechtungen einer Aufgabe führen deshalb unter dem Aspekt des Art. 28 Abs. 2 S. 1 GG zu keinem Kompetenzverlust der Gemeinden. Auch bei der Aufgabenerfüllung im übertragenen Wirkungskreis 
können sich die Gemeinden auf die Garantie des Art. 28 Abs. 2 S. 1 GG berufen. Die Gemeinden sind allzuständig, soweit nicht Gesetz oder Verfassung eine überörtliche Aufgabenerfüllung vorsehen.

16. Es ist nicht zu beanstanden, wenn vor allem der niedersächsische Landesgesetzgeber den Erlaß von örtlichen Bauvorschriften im übertragenen Wirkungskreis bestimmt. Die Landesgesetzgeber können für ein gleiches Instrumentarium insofern zu unterschiedlichen Ergebnissen kommen. Es kann keinem Landesgesetzgeber ein Qualifikationsfehler unterstellt werden. Auch ein Verstoß gegen das Übermaßverbot liegt nicht vor.

17. Es obliegt dem parlamentarischen Gesetzgeber, den Gemeinden ein ausreichendes rechtliches Handlungsinstrumentarium zur Verfügung zu stellen. Vor allem sind die Gemeinden nicht befugt, ohne ausdrückliche gesetzliche Ermächtigung örtliche Bauvorschriften oder Bebauungspläne zu erlassen. Dies ergibt sowohl der sog. demokratische als auch der sog. rechtsstaatliche Gesetzesvorbehalt.

18. Die gemeindliche Selbstverwaltungsgarantie des Art. 28 Abs. 2 GG enthält eine Selbstgestaltungsgarantie. Die Gemeinden haben danach das Recht, Struktur und Gepräge ihres Ortes zu prägen (Individualitäts- oder Identitätsgarantie). Dies zeigt sich vor allem in dem Bemühen, unter Berufung auf Art. 28 Abs. 2 GG den Gemeinden in substanzieller Weise Planungsbefugnisse und Planungsmöglichkeiten zu sichern.

19. Die gemeindliche Individualitätsbildung vollzieht sich vor allem durch die Erfüllung der "staatlichen" Verwaltungsaufgaben. Sie kann sowohl im eigenen wie auch im übertragenen Wirkungskreis erfolgen.

20. Daneben gibt es aber auch gemeindliche Befugnisse, die nicht als "staatliche" im engeren Sinne denkbar sind, sondern sich nur aus dem gemeindlichen Willen und Recht zur Individualitätsbildung erklären und rechtfertigen (sog. genuin gemeindliche Aufgaben und Befugnisse). Dies ist im Bereich der Baugestaltung etwa dann der Fall, wenn die Gemeinde eine örtliche Bauvorschrift maßgeblich deshalb erläßt, um ein bestimmtes "Bild" zu erzeugen und so einen gewünschten "Typus" oder "Charakter" zu erreichen. Auch solche genuin gemeindliche Befugnisse sind nicht zwingend dem eigenen Wirkungskreis zuzuordnen.

21. Örtliche Bauvorschriften werden heute überwiegend als Satzungen erlassen. Diese Entscheidung der Landesgesetzgeber ist unter keinem Gesichtspunkt zu beanstanden. Vor allem können auch Satzungen im übertragenen Wirkungskreis erlassen werden. 
22. Die Anforderungen, die Art. 80 Abs. 1 S. 2 GG an die formell-gesetzliche Vordeterminierung von Rechtsverordnungen stellt, entspricht dem $\mathrm{Ma} ß$ der parlamentarischen Mitverantwortung, welches für Satzungen über die sog. Wesentlichkeitstheorie verlangt wird.

23. Der im Zusammenhang mit örtlichen Bauvorschriften einzige relevante Unterschied zwischen Rechtsverordnungen und Satzungen ist der, daß für die Ausübung der genuin gemeindlichen Befugnisse im Bereich der Baugestaltung nur die Satzung die sachgerechte Rechtsform ist. Ansonsten sind Rechtsverordnungs- und Satzungsermächtigungen austauschbar.

\section{Zu C und D:}

24. Die allgemeinen und gestaltungsrechtlichen Generalklauseln in den Landesbauordnungen halten weitgehend an dem vom BVerwG in der Entscheidung zur BaugestVO vorgegebenen Rahmen fest. Nur vereinzelt zeigen sich Ansätze zu einem "Mehr" an Anforderungen an die Baugestaltung.

25. Nach wie vor stimmt der Ausgangspunkt der Entscheidung des BVerwG zu $§ 1$ BaugestVO, daß es kaum Übereinstimmung in ästhetischen Fragen gibt.

26. Maßgeblicher grundrechtlicher Prüfungsmaßstab für Anforderungen an die Baugestaltung ist vor allem die Eigentumsgarantie. Eingriffe in die Kunstfreiheitsgarantie bilden in der Praxis kein relevantes Problem und lassen sich durch sachgerechte Anwendung von Dispensvorschriften lösen. Der Schutzbereich des Art. 12 Abs. 1 GG wird durch Anforderungen an die Baugestaltung nicht berührt.

27. Die umgebungsunabhängigen Anforderungen an die Baugestaltung sind weniger aus Gründen der Bestimmtheit, als vor allem aus Gründen des Eigentumsschutzes auf die Verunstaltungsabwehr begrenzt. Nur die Vermeidung dessen, was von der überwiegenden Anzahl von insoweit aufgeschlossenen Betrachtern als verletzend empfunden wird, rechtfertigt eine Eigentumsbindung.

28. Weder der Staat noch die Gemeinden haben eine "Kulturgestaltungsmacht" in dem Sinne, daß ihnen die Befugnis zustände, durch Eingriffe in die Baufreiheit Baukunst zu fördern.

29. Der sog. gebildete Durchschnittsbetrachter, dessen verletztes ästhetisches Empfinden nach Auffassung der Rechtsprechung über das Vorliegen einer Verunstaltung entscheidet, sollte aus dem Recht der Baugestaltung verabschiedet werden. Eine Verunstaltung liegt vielmehr dann vor, wenn 
eine bauliche Anlage von der Mehrzahl der potentiellen Betrachter, die ästhetischen Eindrücken gegenüber offen ist, als nicht hinnehmbar empfunden wird und bei ihnen den Wunsch nach Abhilfe auslöst.

30. Die umgebungsunabhängigen Anforderungen haben in der Praxis kaum Bedeutung. Sie haben mit örtlichen Bauvorschriften nur insoweit etwas zu tun, als es um die äußere Gestaltung von baulichen Anlagen geht. Vor allem kommt Satzungen über örtliche Bauvorschriften keine Konkretisierungsfunktion für den umgebungsunabhängigen Gestaltungsmaßstab zu.

31. Für den Bereich der umgebungsabhängigen Anforderungen ist der Begriff der Ästhetik irrelevant. Der Schutz des Orts-, Straßen- und Landschaftbildes rechtfertigt Eigentumsbeschränkungen unabhängig davon, ob dies auch ein ästhetischer Belang ist oder nicht.

32. Es kann nicht davon ausgegangen werden, daß aus verfassungsrechtlichen Gründen ein über den Verunstaltungsschutz hinausgehendes Maß an umgebungsabhängigen baugestalterischen Anforderungen geboten ist.

33. Bei der Anwendung der umgebungsabhängigen Anforderungen in den Generalklauseln der Landesbauordnungen stellt sich vor allem die Frage der Bestimmtheit. Insoweit kann generalklauselartig nur das "harmonische Minimum" geschützt werden, also das, was von der überwiegenden Zahl der insofern aufgeschlossenen Betrachter als Mindestmaß an Rücksicht auf die Umgebung verlangt wird.

34. Gerichtliche Entscheidungen zum Komplex der umgebungsabhängigen Generalklauseln haben häufig einen Hauch von Willkür. Auch bei der Verwendung der hier vorgeschlagenen Formel ist eine rechtsstaatliche befriedigende Bestimmtheit kaum zu erreichen. Es ist insoweit ein sinnvoller und von den Bauordnungen zugelassener Anwendungsbereich für örtliche Bauvorschriften, den umgebungsabhängigen Maßstab der Generalklauseln zu konkretisieren.

35. Die in den Bauordnungen enthaltenen Klauseln zum Schutz der beabsichtigten Gestaltung des Orts-, Straßen- und Landschaftsbildes haben keinen eigenständigen Anwendungsbereich. Die von der Gemeinde beabsichtigte Gestaltung kann nur dann zu Beschränkungen der Eigentümerbefugnisse führen, wenn sie rechtssatzmäßig in einer örtlichen Bauvorschrift konkretisiert sind. Dann beschränkt aber schon die Satzung die Befugnisse der Eigentümer: auf die Generalklausel kommt es nicht mehr an.

36. Der in den baugestalterischen Generalklauseln vorgesehene Schutz der beabsichtigten Gestaltung gibt aber einen Hinweis auf die Zulässigkeit 
von gestalterischen Anforderungen, die über den Verunstaltungsmaßstab hinausgehen, soweit die Bauordnungen selbst eine Beschränkung örtlicher Bauvorschriften auf den Rahmen der Generalklauseln anordnen oder soweit eine solche Bindung als allgemeiner Grundsatz angenommen wird.

37. Art. 12 Abs. 3 BayBO stellt partiell über den Verunstaltungsschutz hinausgehende Anforderungen an die Baugestaltung.

38. Begriffsmäßig ist zu unterscheiden zwischen einer erweiterten Gebiets- und einer positiven Gestaltungspflege.

39. In örtlichen Bauvorschriften kann eine sog. erweiterte Gebietspflege betrieben werden, die ein Mehr an Rücksicht auf die Umgebung vorschreibt, als sich dies aus den Generalklauseln ergibt. Die eigentumsrechtliche Zulässigkeit ist in der Rechtsprechung seit langem zu Recht anerkannt.

40. Bei der positiven Gestaltungspflege hingegen definieren die Gemeinden nach eigenen Vorstellungen ihr Aussehen ("Image", "Bild"). Eine solche positive Gestaltungspflege ist nur durch Satzung möglich. Die eigentumsrechtliche Zulässigkeit ergibt sich aus dem Gedanken des gemeindlichen Selbstgestaltungsrechts.

41. Gegen eine so verstandene positive Gestaltungspflege bestehen auch sonst keine verfassungsrechtlichen Bedenken, weder im Hinblick auf das Identifikationsverbot, noch aus dem Bestimmtheitsgrundsatz.

\section{Zu E:}

42. § 9 Abs. 4 BauGB erhält eine materielle Ermächtigung an den Landesgesetzgeber, zwischen den im BauGB geregelten Festsetzungsmöglichkeiten und den auf Landesrecht beruhenden Festsetzungen einen Planungsund Planzusammenhang herzustellen.

43. Für den Erlaß der auf Landesrecht beruhenden Festsetzungen müssen im wesentlichen die Anforderungen eingehalten werden, die auch für das Aufstellen von Festsetzungen nach $\S 9$ Abs. 1 BauGB gelten. § 9 Abs. 4 2. HS BauGB erlaubt den Landesgesetzgebern im Grundsatz ein Abweichen von den Bestimmungen des BauGB nur insoweit, als es um die Rechtsfolgen einer getroffenen Festsetzung, nicht aber, soweit es um die Schaffung einer solchen geht.

44. Im Falle der Aufnahme einer örtlichen Bauvorschrift in den Bebauungsplan richtet sich die Statthaftigkeit des Normenkontrollverfahrens nach $\S 47$ Abs. 1 Nr. 1 VwGO. 
45. Nicht allen Landesbauordnungen ist es gelungen, die Ermächtigung des $\S 9$ Abs. 4 BauGB auch wirklich auszufüllen. Dies gilt vor allem für die NBauO, da nach deren $\$ \S 97,98$ örtliche Bauvorschriften im übertragenen Wirkungskreis zu erlassen sind. Unterschiedliche Kontrollmaßstäbe verhindern aber den von $\S 9$ Abs. 4 BauGB intendierten Planzusammenhang.

46. Art. 91 Abs. 3 S. 3 BayBO muß restriktiv interpretiert werden, soweit eine Aufnahme in den Bebauungsplan nach $\S 9$ Abs. 4 BauGB ermöglicht werden soll. Er kann eine Begründungspflicht für auf Landesrecht beruhenden Festsetzungen nur insoweit ausschließen, als eine Begründung von $\S 9$ Abs. 8 BauGB im Gesamtkontext des Bebauungsplanes auch nicht gefordert ist.

47. Ein wesentliches materielles Erfordernis für die Aufnahme nach § 9 Abs. 4 BauGB ist die Geltung des Abwägungsgebotes. Dieses ist jedoch in den Landesbauordnungen verankert und gilt sowohl für einfache Satzungen als auch bei Aufnahme in den Bebauungsplan.

48. Das aus den Landebauordnungen ableitbare einfachgesetzliche Abwägungsgebot hat je nach dem Inhalt der örtlichen Bauvorschrift eine unterschiedliche Struktur. Es ähnelt - soweit es um eine Konkretisierung des Verunstaltungsmaßstabes geht - weitgehend dem nachvollziehenden Abwägen entsprechend der Rechtsprechung des BVerwG zu §35 BBauG / BauGB. Unter Umständen liegt aber auch eine "Planung" und damit ein gestaltendes Abwägen im Sinne der Rechtsprechung des Gerichts zur Bauleitplanung und zum Planfeststellungsrecht vor.

49. Da nach Auffassung des BVerwG das planerische Abwägungsgebot im Bundesverfassungsrecht wurzelt, ist das einfachgesetzliche Abwägungsgebot bei örtlichen Bauvorschriften teilweise verfassungsrechtlich "unterlegt".

50. Auch wenn die Anforderungen des $\S 9$ Abs. 4 BauGB nicht erfüllt sind, ist der gemeinsame Einsatz von städtebaulichen und bauordnungsrechtlichen Plänen möglich. Die Anforderungen des Abwägungsgebotes führen jedoch tendentiell zu eingeschränkten Koppelungsmöglichkeiten. Vor allem ist eine en-bloc-Abstimmung über örtliche Bauvorschriften und den für dasselbe Gebiet zu erlassenen Bebauungsplan zu vermeiden.

51. Die Inbezugnahmen des BBauG in den Landesbauordnungen sind sog. dynamische (Fremd-)Verweisungen. Gegen die Zulässigkeit solcher Verweisungen gibt es keine grundsätzlichen Bedenken. Vor allem handelt es sich insofern nicht um eine Preisgabe von Gesetzgebungbefugnissen. Es 
wird vielmehr ein Normbefehl nur mittelbar erlassen, indem zunächst eine Norm eines anderen Gesetzgebers Gegenstand einer rechtlichen Normierung wird. Soweit sich daraus hinreichend deutlich ergibt, welche möglichen Änderungen des Verweisungsobjektes vom Normgeber mit gewollt sind, sind dynamische Fremdverweisungen verfassungsrechtlich zulässig.

52. Da das Ziel dieser Verweisungen darin besteht, die Ermächtigung des $\S 9$ Abs. 4 BauGB auszuschöpfen, hat der verweisende Gesetzgeber eine hinreichend konkretisierte Aussage getroffen. Nach dem Fortfall der generellen Genehmigungspflicht von Bebauungsplänen durch das BauGB (§ 11) ist danach in der Regel für aufzunehmende örtliche Bauvorschriften ebenfalls ein Anzeigeverfahren durchzuführen, und zwar auch, solange die Landesbauordnungen noch nicht an das BauGB angepaßt sind.

53. Soweit örtliche Bauvorschriften als einfache Satzungen erlassen werden, unterliegen sie nach verfassungsrechtlich nicht zu beanstandender einfachgesetzlicher Regelung in den meisten Landesbauordnungen keiner Begründungspflicht. De lege ferenda wäre eine Begründungspflicht zu begrüßen.

54. Aus der Entscheidung der meisten Landesgesetzgeber gegen eine Begründungspficht für einfache Satzungen über örtliche Bauvorschriften sind materiellrechtliche Folgen zu ziehen. Die planenden Gemeinden sind davon befreit, die Einhaltung des Abwägungsgebotes nachzuweisen. Die gerichtliche Plankontrolle beschränkt sich im wesentlichen auf eine Überprüfung des Planergebnisses.

55. Soweit sich aus einer solchen Stimmigkeitskontrolle eine Nichtigkeit des Planes nicht ablesen läßt, bleibt es den Planbetroffenen unbenommen, selbst Abwägungsfehler nachzuweisen. Es kommt insofern zu einer Umkehr der Beweislast.

56. Es ist zumindest terminologisch verfehlt, von einer Beschränkung der Kontrolle auf das Abwägungsergebnis zu sprechen. Es wird sonst begrifflich angeknüpft an eine Rechtsprechung des BVerwG zur Abwägungsvorgangsund Abwägungsergebniskontrolle, die jedoch anders gemeint und mittlerweile zudem konkludent weitgehend relativiert worden ist. Es gibt insoweit keine Abwägungsvorgangs- und Abwägungsergebniskontrolle, sondern nur eine Überprüfung des Abwägungsprozesses anhand des Planergebnisses und anhand dessen, was Rückschlüsse auf den Vorgang der Findung dieses Ergebnisses zuläßt. 
57. Örtliche Bauvorschriften, die als einfache Satzungen erlassen werden, können hinreichend wirksam auch nur anhand des Planergebnisses überprüft werden. Zumindest ist eine solche gesetzgeberische Entscheidung nicht sachwidrig.

58. Bei der Wahl zwischen der Aufnahme von örtlichen Bauvorschriften in den Bebauungsplan und dem Erlaß einer einfachen Satzung haben die Gemeinden einen gewissen Ermessensspielraum. Die einfache Satzung leidet an einem zur Nichtigkeit führenden Fehler, wenn diese Wahl pflichtwidrig getroffen wird.

59. Vor allem dann, wenn örtliche Bauvorschriften nach $\S 9$ Abs. 4 BauGB in einen Bebauungsplan aufgenommen worden sind, kann eine Änderung der auf Landesrecht beruhenden Festsetzungen in der Regel nur dadurch erfolgen, daß ein Verfahren zur Änderung des Bebauungsplanes mit allen damit verbundenen verfahrens- und materiellrechtlichen Anforderungen durchlaufen wird.

60. Die rechtsstaatlich notwendige Bestimmtheit von Satzungsbestimmungen steht in gewissem Gegensatz zu den Wünschen der Planungspraxis im Hinblick auf eine gewisse Flexibilität zur Lenkung der äußeren Gestaltung von Gebäuden. Ein teilweiser Ausweg ist die Aufnahme von Gestaltungswünschen der Gemeinde in privatrechtliche Kaufverträge, soweit die Gemeinde etwa über eine Entwicklungsgesellschaft vor der Bebauung Grundstückseigentümer ist.

61. Auch Gestaltungsabsichten, die auf diese Weise verwirklicht werden sollen, bedürfen einer satzungsmäßigen Grundlage, die die beabsichtigte Gestaltung in Grundzügen festlegt. 


\section{Literatur}

Abel, Gunther, Die Bedeutung der Lehre von den Einrichtungsgarantien für die Auslegung des Bonner Grundgesetzes, Berlin 1964.

Adrian, Hanns, Die kommunale Bauleitplanung - Stadtplanung heute, in: Püttner, Günter (Hrsg.), HbKWP Band 3, 2. Auflage, Berlin u. a. 1983, S. 357 ff.

Albers, Gerd, Die Einflußnahme auf das Grundeigentum als städtebauliches Anliegen, in: Westermann, Harry u. a. (Hrsg.): Raumplanung und Eigentumsordnung, Festschrift für Werner Ernst zum 70. Geburtstag, München 1980, S. 1 ff.

- Vom Fluchtlinienplan zum Stadtentwicklungsplan, Zum Wandel städtebaulicher Leitvorstellungen und Methoden in den letzten hundert Jahren, AfK 6 (1967), S. $192 \mathrm{ff}$.

- Stadtplanung, Eine praxisorientierte Einführung, Darmstadt 1988.

Alexy, Robert, Ermessensfehler, JZ 1986, S. 701 ff.

- Theorie der Grundrechte, Baden-Baden 1985.

Alte Städte - alte Dörfer, siehe Bayerisches Staatsministerium des Inneren.

Anschütz, Gerhard, Die Verfassung des Deutsches Reichs vom 11. August 1919, Ein Kommentar für Wissenschaft und Praxis, unveränderter Nachdruck der vierten Bearbeitung, 14. Auflage 1933, Bad Homburg v. d. H., 1965.

Arndt, Gottfried, Die dynamische Rechtsnormverweisung in verfassungsrechtlicher Sicht BVerfGE 47, 285, in: JuS 1979, S. 784 ff.

Arnim, Achim von, siehe Schlotterbeck, Karlheinz /von Arnim, Achim von.

Arnim, Hans Herbert von, Zur "Wesentlichkeitstheorie" des Bundesverfassungsgerichts, DVBI. 1987, S. $1241 \mathrm{ff}$.

Bachof, Otto, Rechtsnatur, zulässiger Inhalt und gerichtliche Anfechtung von Friedhofssatzungen, Ein Rechtsgutachten, AöR 78 (1952/53), S. 82 ff.

Baden, Eberhard, Dynamische Verweisungen und Verweisungen auf Nichtnormen, NJW 1979, S. 623 ff.

Badura, Peter, Das normative Ermessen beim Erlaß von Rechtsverordnungen und Satzungen, in: Gedächtsnisschrift für Wolfgang Martens, Berlin u.a. 1987, S. 25 ff.

- Das Planungsermessen und die rechtsstaatliche Funktion des Allgemeinen Verwaltungsrechts, in: Verfassung und Verfassungsrechtsprechung, Festschrift zum 25-jährigen Bestehen des Bayerischen Verfassungsgerichtshofes, München 1972, S. $157 \mathrm{ff}$.

- Rechtsetzung durch Gemeinden, DÖV 1963, S. 561 ff.

- Staatsrecht, Systemmatische Erläuterung des Grundgesetzes für die Bundesrepublik Deutschland, München 1986.

Bächer, Max, Gedanken zur Stadtgestaltung, in: Forum für Stadtentwicklung und Kommunalpraxis e. V. (Hrsg.), Gestaltungsqualität durch Regelungsmöglichkeiten?, Wege zur Erreichung städtebaulicher und architektonischer Gestaltungsqualität, Stuttgart u. a. 1981, S. $23 \mathrm{ff}$.

Bäck, Walter / Hoffmann, Egon / Janssen, Fritz / Volmer, Gerhard, Gewerbeordnung, Köln u. a. 1964.

Baltz, Constanz / Fischer, Friedrich Wilhelm, Preußisches Baupolizeirecht mit Anhang Baupolizeilicher Vorschriften, 6. Auflage 1934, unveränderter Nachdruck 1954. 
Battis, Ulrich, Grenzen der Einschränkung gerichtlicher Plankontrolle - Zur Auslegung der $\S 155$ a und b BBauG - , DÖV 1981, S. 433 ff.

- Novelliertes Bundesbaugesetz und Grundgesetz, DÖV 1978, S. 113 ff.

- Öffentliches Baurecht und Raumordnungsrecht, Stuttgart u. a., 2. Auflage 1987.

- Partizipation im Städtebaurecht, Berlin 1976.

- Stadterhaltung durch $\$ 39$ h?, in: difu, Baufreiheit und Stadtentwicklung, S. 203 ff., Berlin 1978.

Battis, Ulrich / Krautzberger, Michael / Löhr, Rolf-Peter, Baugesetzbuch - BauGB - 2. Auflage, München 1987.

Battis, Ulrich / Schmittat, Karl-Oskar, Rechtsfragen des Denkmalschutzes, NuR 1983, S. 102 ff.

Bauer, Daniela, Rechtliche und tatsächliche Bedeutung der Generalklausel im Bauordnungsrecht, München 1981.

Baumeister, Reinhard, Stadt-Erweiterungen in technischer, baupolizeilicher und wirtschaftlicher Beziehung, Berlin 1876.

Baur, Fritz, Rechtliche Schlußüberlegungen, in: Forum für Stadtentwicklung und Kommunalpraxis e. V. (Hrsg.), Gestaltungsqualität durch Regelungsmöglichkeiten?, Wege zur Erreichung städtebaulicher und architektonischer Gestaltungsqualität, Stuttgart u. a. 1981, S. $95 \mathrm{ff}$.

Bayerisches Staatsministerium des Inneren - Oberste Baubehörde, Stadtgestalt und Denkmalschutz im Städtebau, Eine Dokumentation des bayerischen Landeswettbewerbes 1977/78, München 1979.

Bayerisches Staatsministerium des Inneren - Oberste Baubehörde - / Bayerisches Staatsministerium für Wissenschaft und Kunst, Alte Städte - Alte Dörfer, Gestalten und Erhalten durch örtliche Bauvorschriften, München 1987.

Beckmann, Friedrich-Wilhelm, Grenzen für den Erlaß von örtlichen Bauvorschriften - Auswirkungen auf die Außenwerbung (Lichtwerbung), WRP 1978, S. 693 ff.

Berg, Wilfried, Die verwaltungsrechtliche Entscheidung bei ungewissem Sachverhalt, Berlin 1980.

- Die Stellung der Gemeinden im und zum Staat, Teil 2 B: Allzuständigkeit der Gemeinden und gesetzlich zugewiesene Aufgaben der Landkreise und Bezirke, in: Knemeyer (Hrsg.), Bayerische Gemeinden - Bayerischer Gemeindetag, Festschrift 75 Jahre Bayerischer Gemeindetag, München 1987, S. 135 ff.

- Grundsätze des verwaltungsgerichtlichen Verfahrens, in: Erichsen / Hoppe / von Mutius (Hrsg.), System des verwaltungsgerichtlichen Rechtsschutzes: Festschrift für ChristianFriedrich Menger zum 70. Geburtstag, Köln u. a. 1985, S. 537 ff.

- Wirtschaftsverwaltung einschließlich Bauwesen, in: Jeserich, Kurt G. A. / Pohl, Hans / von Unruh, Georg-Christoph, Deutsche Verwaltungsgeschichte, Band IV, Das Reich als Republik und in der Zeit des Nationalsozialismus, Stuttgart 1985, S. $421 \mathrm{ff}$.

Berner, Georg / Böhm, Werner-Hans, Art. 42 BayLStVG, in: Bayerisches Landesstraf- und Verordnungsgesetz mit weiteren einschlägigen Vorschriften und Hinweisen, erläutert von Karl Bengl, Georg Berner, Ernst Emmerig, unter Mitarbeit von Heinz Stöckel und Werner-Hans Böhm, Stand: Oktober 1987.

Bethge, Herbert, Aktuelle Aspekte der Verfassungsgarantie der kommunalen Selbstverwaltung, Die Verwaltung 15 (1982), S. 205 ff.

- Das Selbstverwaltungsrecht im Spannungsfeld zwischen institutioneller Garantie und grundrechtlicher Freiheit, in: von Mutius (Hrsg.), Selbstverwaltung im Staat der Industriegesellschaft, Festgabe zum 70. Geburtstag von G. C. von Unruh, S. 149 ff., Heidelberg 1983.

- Grundrechtsverwirklichung und Grundrechtssicherung durch Organisation und Verfahren, NJW 1982, S. 1 ff. 
- Parlamentsvorbehalt und Rechtsatzvorbehalt für die Kommunalverwaltung, NVwZ 1983, S. $577 \mathrm{ff}$.

Bettermann, Karl August, Über die Rechtswidrigkeit von Staatsakten, in: Recht als Prozeß und Gefüge, Festschrift für Hans Huber zum 80. Geburtstag, Bern 1981, S. 25 ff.

Bielenberg Walter, § 9 BBauG, Kommentierung, in: Ernst, Werner / Zinkahn, Willy / Bielenberg, Walter, u. a., Bundesbaugesetz, Kommentar, München, Bearbeitungsstand: August 1981

- §1 BauNVO, Kommentierung, in: Ernst, Werner / Zinkahn, Willy / Bielenberg, Walter, u. a., Baugesetzbuch, Kommentar, München, Bearbeitungsstand: weitgehend März 1988.

- $\$ 15$ BauNVO, Kommentierung, in: Ernst, Werner / Zinkahn, Willy / Bielenberg, Walter, u. a., Baugesetzbuch, Kommentar, München, Bearbeitungsstand: August 1986.

Birk, Hans-Jörg Grenzen staatlicher Gestaltungsregelungen nach der Rechtsprechung, in: Forum für Stadtentwicklung und Kommunalpraxis e. V. (Hrsg.), Gestaltungsqualität durch Regelungsmöglichkeiten?, Wege zur Erreichung städtebaulicher und architektonischer Gestaltungsqualität, Stuttgart u. a. 1981, S. 73 ff.

Bleckmann, Albert, Inhalt und Umfang des Gesetzesvorbehaltes bei Gemeindesatzungen, DVBI. 1987, S. 1085 ff.

Blümel, Willi, Das Selbstgestaltungsrecht der Städte und Gemeinden, in: Verwaltung im Rechtsstaat, Festschrift für Carl Hermann Ule, Köln u. a. 1987, S. 19 ff.

- Das verfassungsrechtliche Verhältnis der kreisangehörigen Gemeinden zu den Kreisen, VerwArchiv 77 (1984), S. 197 ff., 297 ff.

- Festsetzung von Lärmschutzbereichen und gemeindliche Selbstverwaltungsgarantie, VerwArchiv 75 (1982), S. 329 ff.

- Gemeinden und Kreise vor den öffentlichen Aufgaben der Gegenwart, VVDStRL 36 (1977), Berlin 1978, S. $171 \mathrm{ff}$.

- Grundrechtsschutz durch Verfahrensgestaltung, in: Blümel (Hrsg.), Frühzeitige Bürgerbeteiligung bei Planungen, Berlin 1982, S. $23 \mathrm{ff}$.

- Wesensgehalt und Schranken des kommunalen Selbstverwaltungsrechts, in: von Mutius (Hrsg.), Selbstverwaltung im Staat der Industriegesellschaft, Festgabe zum 70. Geburtstag von G. C. von Unruh, Heidelberg 1983, S. 265 ff.

Blumenberg, Hildegard, Neuere Entwicklungen zu Struktur und Inhalt des Abwägungsgebotes im Bauplanungsrecht, DVBI. 1989, S. 86 ff.

Böckenförde, Ernst-Wolfgang, Gesetz und gesetzgebende Gewalt, Von den Anfängen der deutschen Staatsrechtslehre bis zur Höhe des staatsrechtlichen Positivismus, 2. Auflage, Berlin 1981.

Boeddinghaus, Gerhard, Das Einfügungsgebot des $\$ 34$ Abs. 1 BBauG als Mittel zur Wahrung einer vorgegebenen städtebaulichen Ordnung, BauR 1986, S. 506 ff.

- Probleme mit schmalen Traufgassen, BauR 1987, S. 635 ff.

- Stadterhaltung - Stadtgestaltung, Aufgaben der gemeindlichen Selbstverwaltung nach dem Bundesbaugesetz, Köln u. a. 1982.

- Zu den Anforderungen an eine andere Festsetzung von Abstandsflächen in einem Bebauungsplan, BauR 1989, S. 4 ff.

Boeddinghaus, Gerhard / Hahn, Dittmar, Bauordnung für das Land Nordrhein-Westfalen Landesbauordnung - Stand: 1. Januar 1988.

Böhmer, Werner, Grundfragen der verfassungsrechtlichen Gwährleistung des Eigentums in der Rechtsprechung des Bundesverfassungsgerichts, NJW 1988, S. $2561 \mathrm{ff}$.

- Probleme der Dogmatik und Systematik der Eigentumsbestimmungen des Grundgesetzes, Beilage I/1984 in AgrarR 4/1984, S. 2 ff.

- Sondervotum zum Urteil des BVerfG vom 10.03.1981, E 56, $211 \mathrm{ff}$., in BVerfGE 56, $249 \mathrm{ff}$. 
Börger, Heinz, Der Begriff "sonstige öffentliche Belange" im Sinne des § 34 Bundesbaugesetz, Münster 1981.

Börger, Michael, Genehmigungs- und Planungsentscheidungen unter dem Gesichtspunkt des Gesetzesvorbehaltes, Grundtypen exekutivischer Handlungsformen im Hinblick auf mögliche Entscheidungsfreiräume der Verwaltung, Münster 1987.

Bork, Gundolf / Köster, Wolf, Landesbauordnung Nordrhein-Westfalen, BauO NW 1984, Kommentar, Die neue BauO mit Erläuterungen für die Praxis aus baurechtlicher und bautechnischer Sicht, Köln u. a. 1985.

Bosch, Jürgen, Die Aufstockung von Flachdachgebäuden, Nachbarschutz, gestalterische Vorschriften und Bebauungsplan, ZfBR 1987, S. $182 \mathrm{ff}$.

Breuer, Rüdiger, Die Bodennutzung im Konflikt zwischen Städtebau und Eigentumsgarantie, München 1976.

- Bauplanungsrechtliche Instrumente zum Schutz der Sozialstruktur, Schriftenreihe Nr. 02 "Stadtentwicklung" des Bundesministers für Raumordnung, Bauwesen und Städtebau, Heft Nr. 02.034, 1985.

- Der Niederschlag der Wohnungs- und Städtebaureform in der Gesetzgebung, insbesondere im Allgemeinen Baugesetz von 1900, in: Rodriguez-Lores / Fehl (Hrsg.), Städtebaureform 1865 - 1900, S. $507 \mathrm{ff}$.

- Die hoheitliche raumgestaltende Planung, Wirkungsbereich und Zusammentreffen von Planfeststellungen, fachlichen Nutzungsregelungen, Bauleitplänen und Plänen der Raumordnung, Bonn 1968.

- Entschädigungsrechtliche Konsequenzen von Eingriffen in die Baufreiheit, DÖV 1978. S. $189 \mathrm{ff}$.

- Kontrolle der Bauleitplanung - Analyse eines Dilemmas, NVwZ 1982, S. 273 ff.

Brohm, Winfried, Der Schutz privater Belange bei Bauplanungen, Antragsbefugnis, Abwägungsgebot, Plangewährleistungsrechte, insbesondere für gewerbliche Interessen, NJW 1981, S. 1689 ff.

- Die Eigenständigkeit der Gemeinden, DÖV 1986, S. 397 ff.

- Die Selbstverwaltung der Gemeinden im Verfassungssystem der Bundesrepublik, DVB1. 1984, S. 293 ff.

- Kompetenzüberschneidungen im Bundesstaat - Rechtsdogmatische Konsequenzen der Gondelbahnentscheidung des Bundesverfassungsgerichts -, DÖV 1983, S. 525 ff.

- Verkehrsberuhigung in Städten, Gestaltungs- und Rechtsfragen bei der Einführung von Wohnstraßen, Heidelberg 1985.

- Verwirklichung überörtlicher Planungsziele durch Bauleitplanung, DVBl. 1980, S. 653 ff.

Brugger, Winfried, Rechtsprobleme der Verweisung im Hinblick auf Publikation, Demokratie und Rechtsstaat, VerwArchiv 78 (1987), S. 1 ff.

Bryde, Brun-Otto, Art. 80 GG, in: von Münch, Ingo (Hrsg.), Grundgesetz-Kommentar, Band 3 (Art. 70 bis Art. 146 und Gesamtregister), 2. Auflage, München 1983.

Büchs, Heribert, Gestaltungssatzungen für schutzwürdige Bereiche, Der Landkreis 1978, S. $411 \mathrm{f}$.

Büge, Max / Zinkahn, Willy, Der Rechtsschutz gegen Verunstaltung, Ein Wegweiser durch das Recht der Baugestaltung und Außenwerbung, Düsseldorf 1952.

Bülow, Wolfgang, Rechtsfragen flächen- und bodenbezogenen Denkmalschutzes, Münster 1986.

Bull, Hans-Peter, Die Staatsaufgaben nach dem Grundgesetz, Kronsberg/Ts., 2. Auflage 1977.

Bundesminister für Wohnungsbau, Allgemeine Einführung in die Musterbauordnung, Teil A, Fassung April 1960, aufgestellt vom Begründungsausschuß der Musterbauordnungskommission. 
Burger, Bert / Gutschow, Niels / Krause, Karl-Jürgen, Bebauungspläne und Ortssatzungen, Instrumente zur gestalterhaltenden Erneuerung historischer Stadtgebiete, difu, Berlin 1977.

Burmeister, Joachim, Verfassungstheoretische Neukonzeption der kommunalen Selbstverwaltungsgarantie, München 1977.

Clemens, Thomas, Die Verfassungsgarantie der kommunalen Selbstverwaltung im Bild der Rechtsprechung des Bundesverfassungsgerichts, zugleich Bericht aus der Festgabe für G. C. von Unruh: "Selbstverwaltung im Staat der Industriegesellschaft", herausgegeben von Albert von Mutius; in: Der Städtetag 1986, S. 258 ff., 320 ff.

- Die Verweisung von einer Rechtsnorm auf andere Vorschriften - insbesondere ihre Verfassungsmäßigkeit - , AöR 111 (1986), S. 63 ff.

Conrad, Heinz, Gemeindliche Autonomie und Gesetzesvorbehalt, BayVBI. 1970, S. 384 ff.

Conrady, Hans-Peter, "Angelegenheiten der örtlichen Gemeinschaft" nach Art. 28 Abs. II Satz 1 GG?, DVBl. 1970, S. 408 ff.

Dannwitz, Thomas von, Die Gestaltungsfreiheit des Verordnungsgebers, Zur Kontrolldichte verordnungsgeberischer Entscheidungen, Berlin 1989.

Debold-Kritter, Astrid, Gestaltungsverordnungen im Altstadtbereich, Bauwelt 1977, S. 443 ff.

Dechsling, Rainer, Das Verhältnismäßigkeitsgebot, Eine Bestandsaufnahme der Literatur zur Verhältnismäßigkeit staatlichen Handelns, München 1989.

- Rechtsschutz und Begründungspflicht - Eine verfassungsrechtliche Analyse der $\S \S 39$ Abs. 2 Nr. 1 VwVfG und 35 Abs. 2 Nr. 1 SGB-VwVf - , DÔ 1985, S. 714 ff.

Degenharh, Christoph, Das Verwaltungsverfahren zwischen Verwaltungseffizienz und Rechtsschutzauftrag, DVBI. 1982, S. 872 ff.

Dehmel, Hans Hermann, Übertragener Wirkungskreis, Auftragsangelegenheiten und Pflichtaufgaben nach Weisung, Die Durchführung staatlicher Aufgaben durch die Gemeinde - Grundlagen und Wandlungen, Berlin 1970.

Dittus, Wilhelm, Baupolizei?, DVBI. 1956, S. 249 ff., 320 ff.

Dolde, Klaus-Peter, Grundrechtsschutz durch einfaches Verfahrensrecht?, NVwZ 1982, S. 65 ff.

Dolde, Klaus-Peter / Schlarmann, Hans, Zulässigkeit von Vergnügungsstätten im beplanten Gebiet, BauR 1984, S. 121 ff.

Dölker, Walter, Anforderungen an Ermächtigungsgrundlagen von Satzungen, Heidelberg 1984.

Dolzer, Rudolf, Zum Begründungsgebot im geltenden Verwaltungsrecht, DÖV 1985, S. 9 ff.

Domning, Heinz / Fuß, Leopold, Bauordnungsrecht Schleswig-Holstein, Kommentar, Kiel 1984.

Dürr, Hansjochen, Anmerkung zu BVerwG, Beschluß vom 11.11.1988, DVBI. 1989, S. 359 ff., in: DVBI. 1989, S. $360 \mathrm{ff}$.

- Die Antragsbefugnis bei der Normenkontrolle von Bebauungsplänen, Baden-Baden 1987.

Dyong, Hartmut, Außenwerbung und Bauplanungsrecht, Der Landkreis 1971, S. $87 \mathrm{ff}$.

- $\$ 34$ BauGB, in: Ernst, Werner / Zinkahn, Willy / Bielenberg, Walter, Baugesetzbuch, Kommentar, München, Bearbeitungsstand: März 1987.

Eberl, Wolfgang, Denkmalschutzgesetz und örtliche Bauvorschriften, Zur Abgrenzung von Denkmalerhaltung und Ortsbildpflege, BayVBI. 1987, S. 353 ff.

Eberl, Wolfgang / Martin, Dieter / Petzet, Michael, Bayerisches Denkmalschutzgesetz, Komentar unter besonderer Berücksichtigung finanz- und steuerrechtlicher Aspekte, München, 3. Auflage 1985.

Eberle, Carl-Eugen, Gesetzesvorbehalt und Parlamentsvorbehalt, DÖV 1984, S. 484 ff.

Ehlers, Dirk, Die Anpassung der Landesverwaltungsverfahrensgesetze an das Verwaltungsverfahrensgesetz des Bundes, DVBI. 1977, S. $693 \mathrm{ff}$. 
Eicher, Hermann, Der Machtverlust der Landesparlamente, Historischer Rückblick, Bestandsaufnahme, Reformabsichten, Berlin 1988.

Einsele, Martin, Gestaltung durch Bauleitplanung?, Stadtbauwelt 1974, S. 142 f.

Ekey, Friedrich L, Die Verminderung von Eigentümerrechten im Spannungsfeld zwischen Art. 14 I S. 1 GG und Art. 14 I S. 2 GG, München 1988.

Emmerich Volker / Steiner, Udo, Möglichkeiten und Grenzen der wirtschaftlichen Betätigung der öffentlich-rechtlichen Rundfunkanstalten, Berlin 1986.

Emmerig, Ernst, Ein Allgemeiner Teil des bayerischen Sicherheitsrechts, BayVBl. 1975, S. 285 ff.

Engel, Helmut, Zur Erhaltung des Stadtbildes, AfK 1975, S. $213 \mathrm{ff}$.

Engelmann, Gerhard, Der baurechtliche Verunstaltungsbegriff bei den Anlagen der Außenwerbung, Erlangen 1986.

Erbel, Günter, Inhalt und Auswirkungen der verfassungsrechtlichen Kunstfreiheitsgarantie, Berlin u. a., 1966.

- Eine verfassungstheoretische Neukonzeption der kommunalen Selbstverwaltungsgarantie, Bemerkungen zum Buch von Joachim Burmeister, in: Die Verwaltung 11 (1978), S. 499 ff.

Erbguth, Wilfried, Auswirkungen des Planfeststellungsverfahrens auf die Bauleitplanung, NVwZ 1989, S. 608 ff.

- Neue Aspekte zur planerischen Abwägungsfehlerlehre?, DVBl. 1986, S. 1230 ff.

- Rechtsstaatsprinzip und kommunales Selbstverwaltungsrecht - aktuelle Problemlagen, Jura 1988, S. $561 \mathrm{ff}$.

- Rechtssystemmatische Grundlagen des Umweltrechts, Berlin 1987.

- Zur verfassungsrechtlichen Eigentumsgarantie anhand eines praktischen Beispiels, JuS 1988, S. 699 ff.

Erichsen, Hans-Uwe, Der Schutz der Allgemeinheit und der individuellen Rechte durch die polizei- und ordnungsrechtlichen Handlungsvollmachten der Exekutive, VVDStRL 35 (1976), S. $171 \mathrm{ff}$.

- Kommunalrecht, in: Grimm, Dieter / Papier, Hans-Jürgen (Hrsg.), Nordrhein-westfälisches Staats- und Verwaltungsrecht, Frankfurt/Main 1986, S. 105 ff.

- Schule und Parlamentsvorbehalt, in: Wilke, Dieter (Hrsg.), Festschrift zum 125-jährigen Bestehen der Juristischen Gesellschaft zu Berlin, Berlin u. a. 1984, S. 113 ff.

Ernst, Werner, Die Bundeskompetenz für das Bau- und Bodenrecht, DVBl. 1955, S. $410 \mathrm{ff}$.

- Zur Geschichte des städtischen Bau- und Bodenrechts, BBauBl. 1953, S. 206 ff.

Ernst, Werner / Hoppe, Werner, Das öffentliche Bau- und Bodenrecht, Raumplanungsrecht, 2. Auflage 1981.

Evers, Hans-Ulrich, Die Regelung der "sonstigen Nutzung" durch Bebauungsplan, DVBI. 1968, S. $1 \mathrm{ff}$.

Faber, Heiko, Kommentierung Art. 28 GG, in: Wassermann, Rudolf (Hrsg.), Kommentar zum Grundgesetz für die Bundesrepublik Deutschland in zwei Bänden, Band 2, Art. 21 - 146, Neuwied u. a. 1984.

Fackler, Christian, Verfassungs- und verwaltungsrechtliche Aspekte eines Individualanspruchs auf Bauleitplanung, Berlin 1989.

Falkenberg, Dieter, Zum Vorbehalt des Gesetzes im Schulverhältnis, BayVBl. 1978, S. 166 ff.

Fehrmann, Wilderich, Zur Aufnahme baugestalterischer Festsetzungen in den Bebauungsplan ( 9 Abs. 2 BBauG), BauR 1971, S. 145 ff.

Fickert, Hans Carl / Fieseler, Herbert, Baunutzungsverordnung, Kommentar unter besonderer Berücksichtigung des Umweltschutzes mit ergänzenden Rechts- und Verwaltungsvorschriften, 5. Auflage 1985. 
Finkelnburg, Klaus, Zum Schutz von Baudenkmalen in Berlin, in: Wilke, Dieter (Hrsg.), Festschrift zum 125-jährigen Bestehen der Juristischen Gesellschaft zu Berlin, Berlin u. a. 1984, S. $129 \mathrm{ff}$.

Flagge, Ingeborg (Hrsg.), Gestaltung und Satzung: Baufreiheit oder verordnete Baugestaltung, München 1982.

Förster, Hans / Grundei, Albrecht H. / Steinhoff, Dietrich / Dageförde, Hans-Jürgen / Wilke, Dieter, Bauordnung für Berlin vom 28 . Februar 1985, Kommentar mit Rechtsverordnungen und Ausführungsvorschriften, 4. Auflage 1986.

Forsthoff, Ernst, Die öffentliche Körperschaft im Bundesstaat, Eine Untersuchung über die Bedeutung der institutionellen Garantie in den Artikeln 127 und 137 der Weimarer Verfassung, Tübingen 1931.

- Lehrbuch des Verwaltungsrechts, Erster Band, Allgemeiner Teil, 10. Auflage, München 1973.

Franßen, Everhardt, Das Städtebaurecht als Steuerungsinstrument der Stadtentwicklung, in: difu, Baufreiheit und Stadtentwicklung, S. 19 ff., Berlin 1978.

Frers, Dirk, Zum Verhältnis zwischen Gemeinde und Gemeindeverband nach Art. 28 Abs. 2 GG - Zugleich Anmerkung zum Beschluß des BVerfG vom 23. November 1988, 2 BvR 1619/83 und 2 BvR 1628/83, DVBI. 1989, S. 300 ff. - , in: DVBI. 1989, S. 449 ff.

Friauf, Karl-Heinrich, Bau- und Bodenrecht, in: von Münch (Hrsg.), Besonderes Verwaltungsrecht, 8. Auflage, Berlin u. a. 1988, S. $477 \mathrm{ff}$.

Friauf, Karl-Heinrich / Wendt, Rudolf, Zur Zulässigkeit eines baurechtlichen "Denkmalschutzes" für Arbeiterwohnsiedlungen, Essen 1980

Funke, Hans Friedrich, Die Lenkbarkeit von Abwägungsvorgang und Abwägungsergebnis zugunsten des Umweltschutzes, DVBI. 1987, S. $511 \mathrm{ff}$.

Funke, Hans F. / Schroer, Jochen, Selbstverwaltungsgarantie und gemeindliche Zusammenarbeit bei der Bauleitplanung, ZG 1986, S. 256 ff.

Fuss, Ernst-Werner, Zur Verweisung des deutschen Umsatzsteuergesetzes auf den gemeinsamen Zolltarif der Europäischen Gemeinschaften, in: Kruse, Heinrich Wilhelm (Hrsg.), Festschrift für Heinz Paulick zum 65. Geburtstag, 9. Mai 1973, Köln 1973, S. 293 ff.

Gädtke, Horst / Böckenförde, Dieter / Temme, Heinz-Georg, Landesbauordnung NordrheinWestfalen, Düsseldorf, 7. Auflage 1986.

Gaentzsch, Günter, BauGB Erster Teil: Bauleitplanung, Kommentierung in: Schlichter, Otto und Stich, Rudolf (Hrsg.), Berliner Kommentar zum Baugesetzbuch, Köln u. a. 1988, 1. Halbband S. 199 ff.

- Baugestaltung durch Gemeindesatzungen, Insbesondere zu gemeindlichen Außenwerbungssatzungen, DSt. 1969, S. 374 ff.

- Das geltende Planungsrecht, in: Püttner, Günter (Hrsg.), HbKWP Band 3, 2. Auflage, Berlin u. a. 1983, S. 364 ff.

- Denkmalpflege und kommunale Selbstverwaltung, ZSSD 1974, S. 273 ff.

- Denkmalschutz - eine Aufgabe der Gemeinden?, DSt. 1974, S. 484 ff.

- Möglichkeiten ortsrechtlicher Regelungen der Außenwerbung, in: Die Bauverwaltung 1973, S. $410 \mathrm{ff}$.

- Planungsrechtliche Fragen der Verkehrsberuhigung, in: Walprecht, Dieter (Hrsg.), Verkehrsberuhigung in Gemeinden, Band 2, Erfolge, Empfehlungen, neue Erkenntnisse, Köln u. a. 1987, S. $31 \mathrm{ff}$.

Gallwas, Hans-Ulrich, Verwaltungsgemeinschaft von Amts wegen, Ein Beitrag zum Selbstverwaltungsrecht der Gemeinden, BayVBI. 1973, S. 393 ff.

Gamber, Dieter, Die verfassungsrechtliche Problematik der dynamischen Verweisung von Landesrecht auf Bundesrecht, VBIBW 1983, S. 197 ff.

Geiger, Harald, Anmerkung zu BVerwG, Beschluß vom 7.9.1988 - 4 N 1.87 - , BayVBl. 1989, S. 86 f., in: BayVBI. 1989, S. 89 ff. 
Geimer, Richard, Anmerkungen zu $\S 155$ b Abs. 1 S. 1 Nr. 3, 5 und 6 BBauG, BauR 1980, S. $208 \mathrm{ff}$.

Geitmann, Roland, Bundesverfassungsgericht und "offene" Normen, Zur Bindung des Gesetzgebers an Bestimmtheitserfordernisse, Berlin 1971.

Gelzer, Konrad, Bauplanungsrecht, Bundesbaugesetz - Baunutzungsverordnung - Städtebauförderungsgesetz, Köln, 4. Auflage 1984.

Gestefeld, Rolf, Rechtsschutz im Städtebauförderungsgesetz, Klagemöglichkeiten - Ermessen Partizipation, Hamburg 1978.

Giegerich, Thomas, Die Planungshoheit der Gemeinde, JA 1988, S. 367 ff.

Giese, Friedrich, Die Bundeskompetenz zur Regelung des Bauwesens, AöR 80 (1955-56), S. $212 \mathrm{ff}$.

Glum, Friedrich, Das Recht der Selbstverwaltung der Gemeinden und Gemeindeverbände nach Art. 127 der Reichsverfassung, AöR 56 (1929), S. 379 ff.

Göbel, Ludwig, Gleitendes Verweisen als Rechtsetzungsform - Beitrag eines Praktikers der Gesetzgebungsberatung - , in: Schäffer, Heinz / Triffterer, Otto (Hrsg.), Rationalisierung der Gesetzgebung / Jürgen Rödig Gedächtnissymposion 28. - 30. Oktober 1986, SalzburgResidenz, Baden-Baden 1982, S. 64 ff.

Goodman, Nelson, Kunst und Erkenntnis, in: Henrich, Dieter und Iser, Wolfgang (Hrsg.), Theorien der Kunst, Frankfurt/Main, 2. Auflage 1984, S. 569 ff.

Gönnenwein, Otto, Gemeinderecht, Tübingen 1963.

Götz, Volkmar, Bauleitplanung und Eigentum, Frankfurt/Main u. a. 1969.

Grauvogel, Gustav, § 1 BBauG, Kommentierung, in: Brügelmann, Hermann, u. a., Bundesbaugesetz, Bearbeitungsstand: Februar 1986.

Grave, Helmut, § 155 b BBauG - mißglückt und verfassungswidrig !, BauR 1980, S. 199 ff.

Grawer, Rolf, Gemeinden und Kreise vor den öffentlichen Aufgaben der Gegenwart, VVDSt RL 36 (1977), S. 277 ff.

Grimm, Dieter, Kulturauftrag im staatlichen Gemeinwesen, VVDStRL 42 (1984), S. $46 \mathrm{ff}$.

Groeben, Klaus von der, Die Erfüllung von allgemeinen und besonderen polizeilichen Aufgaben, in: Deutsche Verwaltungsgeschichte, Band 3, herausgegeben von Kurt G. A. Jeserich, Hans Pohl, Georg Christoph von Unruh, Stuttgart 1984, S. 435 ff.

Groschupf, Otto, 75 Jahre Allgemeines Sächsisches Baugesetz, DVBl. 1975, S. 873 ff.

Grosse-Suchsdorf, Ulrich / Schmaltz, Hans Karsten / Wiechert, Reinald, Niedersächsische Bauordnung, Niedersächsisches Denkmalschutzgesetz, Kommentar, Hannover, 4. Auflage 1987.

Groth, Klaus-Martin, Berlin hat eine neue Bauordnung, GE 1985, S. $324 \mathrm{ff}$.

Gubelt, Manfred, Zwischenbilanz zum neuen Bauordnungsrecht, NWVBl. 1988, S. 129 ff.

Gutschow, Niels, Kommunale Stadtbildpflege mit Gestaltungssatzungen, in: Flagge, Ingeborg (Hrsg.), Gestaltung und Satzung: Baufreiheit oder verordnete Gestaltung, München 1982, S. 92 ff.

Hackelsberger, Christoph, Fruchtlose Häßlichkeit, Probleme gewerblicher Ansiedlung, in: Flagge, Ingeborg (Hrsg.), Gestaltung und Satzung: Baufreiheit oder verordnete Gestaltung, München 1982, S. $87 \mathrm{ff}$.

Häberle, Peter, Berufs"ständische" Satzungsautonomie und staatliche Gesetzgebung, Zur Facharztentscheidung des BVerfG vom 9.5.72, DVBI. 1972, S. 909 ff.

- Die Freiheit der Kunst im Verfassungsstaat, AöR 110 (1985), S. 577 ff.

Hain, Friedrich Wilhelm, Lübeck, Gestaltungssatzung in der Diskussion, in: Flagge, Ingeborg (Hrsg.), Gestaltung und Satzung: Baufreiheit oder verordnete Gestaltung, München 1982, S. 31 ff.

Hamann, Andreas, Autonome Satzungen und Verfassungsrecht, Heidelberg 1958. 
Hassel, Volker, Zur Stellung der Gemeinde innerhalb der Landesverwaltung - Anmerkungen zum "Rastede-Urteil" des Bundesverwaltungsgerichts, VerwRundschau 1984, S. 145 ff.

Hasskarl, Horst, Die Rechtsprechung des Bundesverfassungsgerichts zu Art. 80 Abs. 1 Satz 2 GG, AöR 94 (1969), S. 85 ff.

Haug, Winfried, Autonomie im öffentlichen Recht (Geschichte und allgemeine Dogmatik), Heidelberg 1961.

Hauth, Michael, Der Ausschluß bestimmter Arten von baulichen Nutzungen bzw. Anlagen durch (einfachen) Bebauungsplan gemäß $\S 1$ Abs. 5 und Abs. 9 BauNVO, BauR 1986, S. $648 \mathrm{ff}$.

Heide, Hans-Jürgen von der, Anwendung des Bau- und Planungsrechts des Bundes auf Anlagen der Außenwerbung, DSt. 1968, S. 515 ff.

Heide, Dirk von der, Der Abbau von Genehmigungsvorbehalten im Kommunal- und Baurecht, Stärkung kommunaler Selbstverwaltung und / oder Verwaltungsvereinfachung, Stuttgart u. a. 1987.

Heine, Hugo, Die Preußischen Baupolizeigesetze nebst den sonstigen einschlägigen Reichsund Landesgesetzen, Berlin u. a. 1928.

Heinz, Harald, Planungsrecht und Baugestalt, Vom Bebauungsplan zum Bauentwurf und vom angestrebten Haus- und Straßenbild zum Bebauungsplan, Wiesbaden u. a. 1985.

Heinze, Christian, Das planungsrechtliche Abwägungsgebot, NVwZ 1986, S. 87 ff.

- Keine Heilung der Nichtberücksichtigung relevanter Belange bei der planerischen Abwägung in gerichtlichen Verfahren?, NVwZ 1989, S. 121.

Hendler, Reinhard, Die bürgerschaftliche Mitwirkung an der städtebaulichen Planung, Göttingen 1977.

- Selbstverwaltung als Ordnungsprinzip, Zur politischen Willensbildung und Entscheidung im demokratischen Verfassungsstaat der Industriegesellschaft, Köln u. a. 1984.

Henke, Reginhard, Stadterhaltung als kommunale Aufgabe, Die Erhaltungssatzung und das flankierende städtebauliche Instrumentarium, Berlin 1985.

Hennecke, Frank, Anmerkung zu BayVerfGH Entsch. v. 27.05.81 - Vf.15-VII-80 u. a. - , DÖV 1982, S. 691 ff., in: DÖV 1982, S. 696 ff.

Henschel, Johann-Friedrich, Eigentumsgewährleistung und Mieterschutz, NJW 1989, S. 937 ff.

Herb, Martin, Zivilrechtliche Regelungsmöglichkeiten zur Erzielung städtebaulicher und architektonischer Gestaltungsqualität, in: Forum für Stadtentwicklung und Kommunalpraxis e. V. (Hrsg.), Gestaltungsqualität durch Regelungsmöglichkeiten?, Wege zur Erreichung städtebaulicher und architektonischer Gestaltungsqualität, Stuttgart u. a. 1981, S. 63 ff.

Hermann, Burkard, Öffentlich-rechtliche Antennenverbote: Erscheinungsformen und verfassungsrechtliche Probleme, Mainz 1988.

Hermes, Reinhard, Der Bereich des Parlamentsgesetzes, Berlin 1988.

Hesse, Konrad, Bestand und Bedeutung der Grundrechte in der Bundesrepublik Deutschland, EuGRZ 1978, S. 427 ff.

Herzog Roman, Kommentierung zu Art. 20 GG, in: Maunz, Thoedor u. a., Grundgesetz, Kommentar, Stand: September 1980.

Heussner, Hermann, Vorbehalt des Gesetzes und "Wesentlichkeitstheorie", Aus der neueren Rechtsprechung des Bundesverfassungsgerichts zum Schulrecht, in: Avenarius, Hermann / Engelhardt, Hanns / Heussner, Hermann / Zezschwitz, Friedrich von (Hrsg.), Festschrift für Erwin Stein zum 80. Geburtstag, Bad Homburg v.d.H. 1983, S. 111 ff.

Hieber, Ulrich, Gewerbepolitik als Aufgabe des Städtebaus, in: Schriftenreihe des Bundesministers für Raumordnung, Bauwesen und Städtebau, Heft Nr. 03.115, "Neue städtebauliche Aufgaben", 1986, S. 63 ff.

Hinkel, Karl Reinhard, Zur Situation der kommunalen Selbstverwaltung, NVwZ 1985, S. 225 ff. 
Hoek, Friedrich-Wilhelm, Lüneburg, Örtliche Bauvorschrift oder Vorsicht vor perfekten Gestaltungssatzungen, in: Flagge, Ingeborg (Hrsg.), Gestaltung und Satzung: Baufreiheit oder verordnete Gestaltung, München 1982, S. $51 \mathrm{ff}$.

Hönes, Ernst-Rainer, Die Unterschutzstellung von Kulturdenkmälern, Köln 1987.

Hörst, Bernhard, Einsatz örtlicher Bauvorschriften in der Planungspraxis, in: Städte- und Gemeinderat 1977, S. 185 ff.

Hofmann, Jochen, Bericht über die Diskussion in: Knemeyer / Hofmann (Hrsg.), Gemeinden und Kreise, Expertengespräch zur Selbstverwaltungsgarantie, Würzburg 1984.

Hoppe, Werner, Bauleitplanung und Eigentumsgarantie - Zum Abwägungsgebot des $\S 1$ Abs. 4 S. 2 Bundesbaugesetz - , DVBI. 1964, S. 165 ff.

- Die "Zusammenstellung des Abwägungsmaterials" und die "Einstellung der Belange" in die Abwägung "nach Lage der Dinge" bei der Planung, DVBl. 1977, S. 136 ff.

- Gerichtliche Kontrolldichte bei komplexen Verwaltungsentscheidungen, Ein Beitrag zu "zieldiktierten" Planungs- und komplexen Prognoseentscheidungen, in: Bachof, Otto / Heigl, Ludwig / Redeker, Konrad (Hrsg.), Verwaltungsrecht zwischen Freiheit, Teilhabe und Bindung, Festgabe aus AnlaB des 25jährigen Bestehens des Bundesverwaltungsgerichts, München 1978, S. 295 ff.

- Kommunale Selbstverwaltung und Planung, in: von Mutius (Hrsg.), Selbstverwaltung im Staat der Industriegesellschaft, Festgabe zum 70. Geburtstag von G. C. von Unruh, Heidelberg 1983, S. 555 ff.

- Planung, in: Isensee, Josef und Kirchhof, Paul (Hrsg.), Handbuch des Staatsrechts der Bundesrepublik Deutschland, Band III, Das Handeln des Staates, Heidelberg 1988, S. 653 ff.

- Rechtliche Aspekte beim Bauen in vorgeprägter Umgebung, in: Wilke, Dieter / Weber, Harald (Hrsg.), Gedächtnisschrift für Friedrich Klein, München 1977, S. 190 ff.

- Zur Struktur von Normen des Planungsrechts, Bemerkungen zu rechtstatsächlichen Anforderungen an die Begriffsbildung im Planungsrecht, DVBI. 1974, S. $641 \mathrm{ff}$.

Huber, Ernst-Rudolf, Selbstverwaltung der Wirtschaft, Stuttgart 1958.

- Zur Problematik des Kulturstaates, Tübingen 1958.

Huber, Peter-Michael, Grundrechtsschutz durch Organisation und Verfahren als Kompetenzproblem in der Gewaltenteilung und im Bundesstaat, München 1988.

Hüffer, Rolf, Verunstaltungsverbot und Einfügungsgebot, Zur Auslegung von Art. 12 Abs. 3 BayBO 1982, BayVBl. 1984, S.12 ff.

Hüttenbrink, Jost, Können die Gemeinden oder die Baugenehmigungsbehörden die Ansiedlung von nicht-großflächigen Einzelhandelsbetrieben oder Verbrauchermärkten in ausgewiesenen Misch-, Gewerbe- oder Industriegebieten verhindern?, DVBl. 1983, S. $530 \mathrm{ff}$.

Hufen, Friedhelm, Die Bedeutung gliedstaatlichen Verfassungsrechts in der Gegenwart, BayVBI. 1987, S. 513 ff.

- Die Freiheit der Kunst in staatlichen Institutionen: dargestellt am Beispiel der Kunst- und Musikhochschulen, Baden-Baden 1982.

- Fehler im Verwaltungsverfahren, 1. Auflage, Baden-Baden 1986.

- Heilung und Unbeachtlichkeit grundrechtsrelevanter Verfahrensfehler? Zur verfassungskonformen Auslegung der $\S \S 45$ und 46 VwVfG, NJW 1982, S. 2160 ff.

Hufen, Friedhelm / Leiß, Dieter, Ausgewählte Probleme beim Erlaß von Baumschutzverordnungen, BayVBl. 1987, S. 289 ff.

Ibler, Martin, Die Differenzierung zwischen Vorgangs- und Ergebniskontrolle bei planerischen Abwägungsentscheidungen, DVBI. 1988, S. 469 ff.

- Die Schranken planerischer Gestaltungsfreiheit im Planfeststellungsrecht, Berlin 1988.

Ipsen, Jörn, Niedersächsisches Kommunalrecht, Lehrbuch, Stuttgart u. a. 1989. 
Institut für Bauforschung e. V., Analyse von Gestaltungsfestsetzungen für neue Wohngebiete Potentielle Auswirkungen auf Kosten und Nutzen des Bauwerks - (Kurzbericht), BBauBl. 1987, S. $278 \mathrm{ff}$.

Iser, Wolfgang, Interpretationsperspektiven moderner Kunsttheorie, in: Henrich, Dieter und Iser, Wolfgang (Hrsg.), Theorien der Kunst, Frankfurt/Main, 2. Auflage 1984, S. 33 ff.

Isensee, Josef, Gemeinwohl und Staatsaufgaben im Verfassungsstaat, in: Isensee, Josef und Kirchhof, Paul (Hrsg.), Handbuch des Staatsrechts der Bundesrepublik Deutschland, Band III, Das Handeln des Staates, Heidelberg 1988, S. 3 ff.

Jacobi, Erwin, Die Rechtsverordnungen, in: Anschütz, Gerhard und Thoma, Richard (Hrsg.), Handbuch des Deutschen Staatsrechts, 2. Band, Tübingen 1972, S. $236 \mathrm{ff}$.

Jakobs, Michael Ch., Der Grundsatz der Verhältnismäßigkeit, Mit einer exemplarischen Darstellung seiner Geltung im Atomrecht, Köln u. a. 1985.

Jäde, Henning, Anmerkung zu BayVGH, Beschluß vom 20.11.1986, BayVB1. 1987, S. 337 ff., in: BayVBI. 1987, S. 338 ff.

- Verunstaltungsverbot und Einfügungsgebot, Zur Auslegung des Art. 12 Abs. 3 BayBO 1982, BayVBI. 1984, S. $10 \mathrm{ff}$.

Jaeger, Falk, Instrumente der Stadtgestaltung, ZSSD 1979, S. 297 ff.

Jahn, Ralf, Verbot bzw. Einschränkung von Einzelhandelsbetrieben durch qualifizierten Bebauungsplan gemäß $§ 1$ Abs. 5 und Abs. 9 BauNVO, BayVBl. 1988, S. 40 ff.

Jakob, Wolfgang, Eingriff kommunaler Satzungen in "Freiheit und Eigentum", DÖV 1970, S. $666 \mathrm{ff}$.

Jellinek, Walter, Verwaltungsrecht, Nachdruck der 3. Auflage von 1931, Bad Homburg v. d. H. 1966.

Jung, Otmar, Zum Kulturstaatsbegriff Johann Gottlieb Fichte - Verfassung des Freistaates Bayern - Godesberger Grundsatzprogramm der SPD, Meisenheim am Glan 1976.

Kabel, Erich, Baufreiheit und Raumordnung, Die Verflechtung von Baurecht und Bauentwicklung im deutschen Städtebau, Ravensburg 1949.

Kalusche, Bernd, Baurecht und Bauästhetik seit dem 15. Jahrhundert unter besonderer Berücksichtigung der süddeutschen Städte, Heidelberg 1976.

Karpen, Hans-Ulrich, Die Verweisung als Mittel der Gesetzgebungstechnik, Berlin 1970.

- Die Verweisungstechnik im System horizontaler und vertikaler Gewaltenteilung, in: Rödig, Jürgen (Hrsg.), Studien zu einer Theorie der Gesetzgebung, Berlin u. a. 1976, S. $221 \mathrm{ff}$.

- Gesetzesgestaltung und Gesetzesanwendung im Leistungsstaat, NJW 1988, S. 2512 ff.

Keller, Johann, Recht und Praxis der örtlichen Bauvorschriften nach Art. 91 BayBO, München 1985.

Kersting, Klaus, Zur baurechtlichen Einordnung von Werbeanlagen, VerwRundschau 1982, S. 84 ff.

Keßler, Hartmut, Die Abwertung der Verfahrensvorschriften im Bauplanungsrecht durch $\S 155$ a - c BBauG, Bonn 1980.

Kiess, Adolf, Rechtsverordnung und Satzung, Unterschiede und Stellung im geltenden Verfassungsrecht, Tübingen 1961.

Kilpper, Gerhart, Analyse und Lösungsansätze zur Frage der Regelbarkeit von Gestaltung, in: Forum für Stadtentwicklung und Kommunalpraxis e. V. (Hrsg.), Gestaltungsqualität durch Regelungsmöglichkeiten?, Wege zur Erreichung städtebaulicher und architektonischer Gestaltungsqualität, Stuttgart u. a. 1981, S. $31 \mathrm{ff}$.

Kimminich, Otto, Eigentum - Enteignung - Entschädigung, Eine Kommentierung des Art. 14 GG, Sonderausgabe aus dem Bonner Kommentar, Hamburg 1976.

Funktion und Ausgestaltung der Öffentlichkeitsbeteiligung im atomrechtlichen Genehmigungsverfahren, 4. Referat, in: Lukes, Rudolf (Hrsg.), Fünftes Deutsches AtomrechtsSymposium, Referate und Diskussionsberichte, Köln u. a. 1977, S. 263 ff. 
Kirchhof, Ferdinand, Die Baurechtsnovelle 1979 als Rechtswegsperre?, Zur Vereinbarkeit der $\S \S 155$ a und b BBauG mit Art. 19 IV GG, NJW 1981, S. 2382 ff.

Kirchhof, Paul, Rechtsquellen und Grundgesetz, in: Starck, Christian (Hrsg.), Bundesverfassungsgericht und Grundgesetz, Festgabe aus Anlaß des 25-jährigen Bestehens des Bundesverfassungsgerichts, Zweiter Band, Verfassungsauslegung, Tübingen 1976, S. 50 ff.

Kisker, Gunter, Anmerkung zu BVerfG, Beschluß des Ersten Senats vom 20.10.1981 - BvR 640/80 - ,(abgedruckt in DVBI. 1982, S. 401), in: DVBI. 1982, S. $886 \mathrm{ff}$.

- Neue Aspekte im Streit um den Vorbehalt des Gesetzes, NJW 1977, S. 1313 ff.

Klein, Hans H., Erwägungen der Enquete-Kommission Verfassungsreform des Deutschen Bundestages zu einer Neufassung des Art. 80 GG, DÖV 1975, S. $523 \mathrm{ff}$.

Kloepfer, Michael, Der Vorbehalt des Gesetzes im Wandel, JZ 1984, S. 685 ff.

Klüber, Hans, Handbuch der Kommunalpolitik, Göttingen 1971.

Knaup, Hans / Stange, Gustav-Adolf, Kommentar zur Baunutzungsverordnung, Düsseldorf, 7. Auflage 1983.

Knemeyer, Franz-Ludwig, Aufgabenkategorien im kommunalen Bereich - Mittelbare Staatsverwaltung? - Fremdverwaltung? - Zur Bedeutung der Organleihe, DÖV 1988, S. 397 ff.

- Bauplanungs- und Bauordnungsrecht, in: Maunz / Obermayer / Berg / Knemeyer, Staatsund Verwaltungsrecht in Bayern, 5. neubearbeitete Auflage 1988, S. 329 ff.

- Bayerisches Kommunalrecht, 6. Auflage, Stuttgart u. a. 1988.

- Das verfassungsrechtliche Verhältnis der Kommunen zueinander und zum Staat, Überlegungen zur Grundsatzentscheidung des Bundesverwaltungsgerichts vom 4.8.1983 in Sachen Abfallbeseitigung Rastede, DVBI. 1984, S. $23 \mathrm{ff}$.

- Die Entwicklung der Selbstverwaltungsgarantie, Interpretation vor dem Hintergrund sich wandelnder Verhältnisse, in: Knemeyer / Hofmann (Hrsg.), Gemeinden und Kreise, Expertengespräch zur Selbstverwaltungsgarantie, Würzburg 1984.

- Die Stellung der Gemeinden im und zum Staat, Teil 2 A,, Die Stellung der bayerischen Gemeinden nach Grundgesetz, Bayerischer Verfassung und bayerischen Landesgesetzen, in: Knemeyer (Hrsg.), Bayerische Gemeinden - Bayerischer Gemeindetag, Festschrift 75 Jahre Bayerischer Gemeindetag, München 1987, S. 95 ff.

- Die verfassungsrechtliche Gewährleistung des Selbstverwaltungsrechts der Gemeinden und Landkreise, in: von Mutius (Hrsg.), Selbstverwaltung im Staat der Industriegesellschaft, Festgabe zum 70. Geburtstag von G. C. von Unruh, Heidelberg 1983, S. 209 f.

- Gemeinden unter dem Einfluß von Fachbehörden, Forderungen zu einem partnerschaftlichen Miteinander, Stuttgart u. a. 1983.

- Gewährleistung des notwendigen Handlungs- und Entfaltungsspielraums der kommunalen Selbstverwaltung, NJW 1980, S. $1140 \mathrm{ff}$.

Knemeyer, Franz-Ludwig / Emmert, Rudolf, Die Verordnung über die Wasserversorgung (AVB-WasserV) ist wegen Verstoßes gegen das Selbstverwaltungsrecht verfassungswidrig zugleich Anmerkung zum Beschluß des Bundesverfassungsgerichts vom 02.11.81 - 2 BvR 671/81, JZ 1982, S. $284 \mathrm{ff}$.

Knies, Wolfgang, Freiheit der Kunst und Kulturstaat, in: Häberle, Peter (Hrsg.), Kulturstaatlichkeit und Kulturverfassungsrecht, Darmstadt 1982, S. 235 ff.

- Schranken der Kunstfreiheit als verfassungsrechtliches Problem, München 1967.

Koch, Hans / Molodovsky, Paul / Rahm, Wolfdietrich, Bayerische Bauordnung, Kommentar, Stand: 7.- 9. Auflage 1987.

Koch, Hans-Joachim, Abwägungsvorgang und Abwägungsergebnis als Gegenstände gerichtlicher Plankontrolle, DVBl. 1989, S. 399 ff.

- Das Abwägungsgebot im Planungsrecht - Einige Bemerkungen zur Intensität verwaltungsgerichtlicher Kontrolle, veranlaßt durch BVerwG, Urteil vom 21.8.1981 - DVBI. 1983, S. $1125 \mathrm{ff}$. 
- Recht der Landesplanung und des Städtebaus, in: Hoffmann-Riem, Wolfgang / Koch, Hans-Joachim (Hrsg.), Hamburgisches Staats- und Verwaltungsrecht, Frankfurt/Main 1988 , S. 258 ff.

Koch, Hans-Joachim / Hosch, Rüdiger, Baurecht, Raumordnungs- und Landesplanungsrecht, Stuttgart u. a. 1988.

König, Hans-Günter, Bayerisches Baurecht, Köln u. a., 2. Auflage 1988.

Köstering Heinz, Kommunale Selbstverwaltung und staatliche Planung, DÖV 1981, S. 689 ff.

Köttgen, Arnold, Die Gemeinde und der Bundesgesetzgeber, Stuttgart 1957.

- Gemeindliches Satzungsrecht und Grundgesetz, DVBI. 1955, S. 445 ff.

Kopp, Ferdinand, Verfassungsrecht und Verwaltungsverfahrensrecht, Eine Untersuchung über die verfassungsrechtlichen Voraussetzungen des Verwaltungsverfahrens in der Bundesrepublik und die Bedeutung der Grundentscheidungen der Verfassung für die Feststellung, Auslegung und Anwendung des geltenden Verwaltungsverfahrensrechts, München 1971.

- Verwaltungsverfahrensgesetz, 4. Auflage, München 1986.

Korte, Heinz W., Die Aufgabenverteilung zwischen Gemeinde und Staat unter besonderer Berücksichtigung des Subsidiaritätsprinzips, VerwArchiv 61 (1970), S. 3 ff., $141 \mathrm{ff}$.

Krämer, Fritz, Das Städtebaurecht als Steuerungsinstrument der Stadtentwicklung, in: difu, Bauf reiheit und Stadtentwicklung, Berlin 1978, S. 7 ff.

Krebs, Walter, Baurecht, in: Grimm, Dieter / Papier, Hans-Jürgen (Hrsg.), Nordrhein-westfälisches Staats- und Verwaltungsrecht, Frankfurt/Main 1986, S. $379 \mathrm{ff}$.

- Zum aktuellen Stand der Lehre vom Vorbehalt des Gesetzes, Jura 1979, S. 304 ff.

Krebsbach, Ulrich, Bauordnung und Bauaufsicht, in: Püttner, Günter (Hrsg.), HbKWP Band 4, 2. Auflage Berlin u. a. 1984, S. $549 \mathrm{ff}$.

Kreßel, Hans P., Was kann Inhalt gemeindlicher Satzungen sein?, BayVBI. 1967, S. $410 \mathrm{ff}$.

Kretschmer, Ernst, Nochmals: Der "gebildete Durchschnittsmensch", DVBI. 1970, S. 55 ff.

Kromik, Wolfgang, Gestaltungssatzungen aus verfassungs- und bauplanungsrechtlicher Sicht, in: Flagge, Ingeborg (Hrsg.), Gestaltung und Satzung: Baufreiheit oder verordnete Gestaltung, München 1982, S. 95 ff.

Krüger, Hartmut, Die Aufgabenallzuständigkeit der Gemeinden - ein verfassungsrechtliches Hindernis für eine leistungsfähige Verwaltungsorganisation?, NWVBI. 1987, S. $97 \mathrm{ff}$.

Krüger, Herbert, Allgemeine Staatslehre, 2. Auflage, Stuttgart u. a. 1966.

Kühling, Jürgen, Fachplanungsrecht, Düsseldorf 1988.

Kuhn, Gustav, Ästhetische Bevormundung durch Bebauungspläne?, DVBI. 1968, S. 497 ff.

Kummer, Michael, Anm. zu OVG Lüneburg, Urt. v. 19.12.79, DÖV 1980, S. 837 ff., in DÖV 1980, S. 839 ff.

Kunig, Philip, Das Rechtsstaatsprinzip, Überlegungen zu seiner Bedeutung für das Verfassungsrecht der Bundesrepublik Deutschland, Tübingen 1986.

Langer, Stephan, Gemeindliches Selbstgestaltungsrecht und überörtliche Raumplanung, VerwArchiv 80 (1989), S. 352 ff.

Langheinecken, Uwe, Der Grundsatz der Verhältnismäßigkeit in der Rechtsprechung des Bundesverfassungsgerichts, unter besonderer Berücksichtigung der Judikatur zu Art. 12 Abs. 1 S. 2 GG, Wiesbaden 1972.

Laubinger, Hans-Werner, Grundrechtsschutz durch Gestaltung des Verwaltungsverfahrens, VerwArchiv 75 (1982), S. 60 ff.

Leisner, Walter, Eigentum, in: Isensee, Josef / Kirchhof, Paul (Hrsg.), Handbuch des Staatsrechts der Bundesrepublik Deutschland, Band IV, Freiheitsrechte, Heidelberg 1989, S. $1023 \mathrm{ff}$.

- Privatinteressen als öffentliche Interessen, DÖV 1970, S. 217 ff. 
Lemmel, Hans Peter, BauGB, Zweites Kapitel Dritter Teil, Erhaltungssatzung und städtebauliche Gebote, in: Schlichter, Otto und Stich, Rudolf (Hrsg.), Berliner Kommentar zum Baugesetzbuch, Köln u. a. 1988, 2. Halbband, S. 1801 ff.

- Die Unbeachtlichkeit von Mängeln der Begründung des Bebauungsplans nach der Bundesbaugesetz-Novelle 1979, DVBI. 1981, S. $318 \mathrm{ff}$.

Lenz, Wolfgang, Anwendung von Bauwichvorschriften im nichtbeplanten Innenbereich, BauR 1972, S. $261 \mathrm{ff}$.

Lepa, Manfred, Verfassungsrechtliche Probleme der Rechtsetzung durch Rechtsverordnung, AöR 105 (1980), S. $337 \mathrm{ff}$.

Lerche, Peter, Bayerisches Schulrecht und Gesetzesvorbehalt, Rechtsgutachten erstattet im Auftrag des Bayer. Staatsministeriums für Unterricht und Kultus, München 1981.

- Ermächtigungsvorschriften für Außenwerbungs-Satzungen, Rechtsgutachten auf Anregung des Zentralausschusses der Werbewirtschaft e. V. erstattet, Beilage Nr. 6/69 zu Heft 11 von DB Jahrgang 1969.

- Grenzen der Wehrhaftigkeit kommunaler Planungshoheit, in: Maunz, Theodor (Hrsg.), Verwaltung und Rechtsbindung, Festschrift zum hundertjährigen Bestehen des Bayerischen Verwaltungsgerichtshofs, München u. a. 1979.

- Grundrechtsbegrenzungen "durch Gesetz" im Wandel des Verfassungsbildes, DVBI. 1958, S. $524 \mathrm{ff}$.

- Übermaß und Verfassungsrecht, Zur Bindung des Gesetzgebers an die Grundsätze der Verhältnismäßigkeit und der Erforderlichkeit, Köln u. a. 1961.

- Werbung und Verfassung, München u. a. 1967.

Ley, Richard, Die Fortschreibung des Bauordnungsrechts durch die neue Musterbauordnung, NVwZ 1983, S. 599 ff.

- Öffentliches Baurecht, in: Ley, Richard / Prümm, Hans-Paul (Hrsg.), Staats- und Verwaltungsrecht für Rheinland-Pfalz, Darmstadt u. a. 1986, S. 375 ff.

Lohr, Valentin, Satzungsgewalt und Staatsaufsicht, Eine kommunal- und sparkassenrechtliche Untersuchung, Stuttgart u. a. 1963.

Looks, Volker, Bauästhetische Vorschriften und Verfassungsrecht, Kiel 1969.

Loschelder, Wolfgang, Die Befugnis des Gesetzgebers zur Disposition zwischen Gemeinde und Kreisebene, Aufgabenverteilung und Aufsichtszuordnung nach dem Maßstab des Art. 28 Abs. 2 GG, Göttingen 1986.

- Kommunale Selbstverwaltungsgarantie und gemeindliche Gebietsgestaltung, Berlin 1976.

Lücke, Jörg, Begründungszwang und Verfassung, Zur Begründungspflicht der Gerichte, Behörden und Parlamente, Tübingen 1987.

Macher, Ludwig, Der Grundsatz des gemeindefreundlichen Verhaltens, Zur Aktualisierung der Garantie der kommunalen Selbstverwaltung, Berlin 1971.

Maier, Günter, Bauordnungsrechtliche Anforderungen an die Gestaltung von Bauwerken Zur Auslegung von Art. 11 der Bayerischen Bauordnung - , BayVBI. 1980, S. 5 ff.

Mainczyk, Lorenz, Baugesetzbuch (BauGB), Kommentar, Stuttgart 1987.

Marcks, Peter, § 33 i GewO, Kommentierung in: Landmann / Rohmer, Gewerbeordnung und ergänzende Vorschriften, Band I: Gewerbeordnung - Kommentar, Stand: Oktober 1987.

Martens, Wolfgang, Gefahrenabwehr, Allgemeines Polizeirecht (Ordnungsrecht) des Bundes und der Länder, Begründet unter dem Titel "Preußisches Polizeirecht" von Bill Drews. Fortgeführt mit dem Titel "Allgemeines Polizeirecht" von Gerhard Wacke. 9. Auflage von Klaus Vogel und Wolfgang Martens, Köln u. a. 1986.

- Öffentlich als Rechtsbegriff, Bad Homburg v. d. H. u. a. 1969.

- Wandlungen im Recht der Gefahrenabwehr, DÖV 1982, S. 89 ff. 
Masson, Christoph / Samper, Rudolf, Bayerische Kommunalgesetze, Gemeindeordnung, Landkreisordnung, Bezirksordnung, Verwaltungsgemeinschaftsordnung, Kommentar, München, Stand: August 1989.

Matthaei, Joachim, Gestaltung und Satzung, Einführung, in: Flagge, Ingeborg (Hrsg.), Gestaltung und Satzung: Baufreiheit oder verordnete Gestaltung, München 1982, S. 9 ff.

Matzerath, Horst / Thienel, Ingrid, Stadtentwicklung, Stadtplanung, Stadtentwicklungsplanung, Probleme im 19. und im 20. Jahrhundert am Beispiel der Stadt Berlin, in: Die Verwaltung 10 (1977), S. $173 \mathrm{ff}$.

Maué, Bernhard, Das ästhetische Empfinden des gebildeten Durchschnittsbetrachters als Beurteilungsmaßstab bei der Anwendung von $\S 1$ Baugestaltungsverordnung, BBauBl. 1957, S. 470 ff.

Maunz, Theodor, Art. 80 GG, Kommentierung in: Maunz u. a., Grundgesetz, Kommentar, Stand: Juni 1978.

- Bodenrecht vor den Schranken des Grundgesetzes, DÖV 1975, S. 1 ff.

- Die kommunale Allzuständigkeit, in: Festschrift für Wolfgang Zeidler, Band 2, Berlin u. a. 1987, S. $1157 \mathrm{ff}$.

Maurer, Hartmut, Allgemeines Verwaltungsrecht, 6. Auflage, München 1988.

Meder, Theodor, Die Verfassung des Freistaates Bayern, Handkommentar, 3. Auflage, Stuttgart u. a. 1985.

Mehlhorn, Dieter-Jürgen, Stadterhaltung als städtebauliche Aufgabe, Grundlage und Sicherung der Erhaltungsziele durch historisch-genetische Siedlungsanalyse und Bauleitplanung gem. BauGB, Düsseldorf 1988.

Mengelkoch, Heinz, Gemeinderecht, in: Ley, Richard / Prümm, Hans Paul (Hrsg.), Staatsund Verwaltungsrecht für Rheinland-Pfalz, Darmstadt u. a. 1986, S. $115 \mathrm{ff}$.

Meyer, Hans, Die Finanzverfassung der Gemeinden, Ein Beitrag zur Stellung der Gemeinden in der Finanzverfassung des Bundes, Stuttgart u. a. 1969.

- $\S 155$ b BBauG, Kommentierung, in: Kohlhammer Kommentare Bundesbaugesetz, Band 4, Stand: 45. Lieferung, Februar 1986.

Meyer, Otto / Saß, Karl, Gesetz betreffend die Anlegung von Straßen und Plätzen in Städten und ländlichen Ortschaften: Straßen- und Baufluchtengesetz vom 2. Juli 1875, Kommentar (vormals R. Friedrichs) von Hugo v. Strauß und Torney und Carl Saß, 7. Auflage, Berlin u. a. 1934.

Meyn, Karl-Ulrich, Autonome Satzung und demokratische Legitimation - Zur Rechtsprechung des BVerfG - , DVBI. 1977, S. $593 \mathrm{ff}$.

- Gesetzesvorbehalt und Rechtsetzungsbefugnis der Gemeinden, Göttingen 1977.

Meth, Rudolf, Denkmalpflege in der Kleinstadt - das Beispiel Königsberg in Bayern, BayBgm. 1988, S. 442 ff.

Michel, Klaus, Die Rechtsproblematik der Verunstaltungsbegriffe im Baugestaltungsrecht, Zugleich ein Beitrag zur Theorie der Gesetzesauslegung und Rechtsanwendung, Bonn 1967.

Mihatsch, Michael, Öffentliche Kunstsubventionierung, Verfassungs- und verwaltungsrechtliche Probleme, insbesondere bei der Einschaltung nicht-staatlicher Instanzen in das Subventionsverfahren, Berlin 1989.

Moench, Christoph, Denkmalschutzrecht, neuere Entwicklungen, Berührungspunkte mit dem Baurecht, ZfBR 1985, S. 113 ff., 163 ff.

Moench, Christoph / Schmidh, Thomas, Die Freiheit der Baugestaltung, Aktuelle Probleme im Recht des Denkmalschutzes und der Baugestaltung, dargestellt anhand der Rechtslage in Bayern, Düsseldorf 1989.

Moog, Wilfried / Schmidt, Franz-Josef, Landesbauordnung Rheinland-Pfalz, LBauO 1974. LBauO 1986 im Vergleich, Düsseldorf 1987. 
Morlok, Martin, Die Folgen von Verfahrensfehlern am Beispiel von kommunalen Satzungen, Berlin 1988.

von Münch, Ingo, Art. 5 GG, Kommentierung in: von Münch (Hrsg.), Grundgesetz-Kommentar, Band 1 (Präambel bis Art. 20), 3. Auflage, München 1985.

von Mutius, Albert, Das Selbstverwaltungsrecht der Gemeinden und Gemeindeverbände, Jura 1982, S. 28 ff.

- Grundrechtsschutz contra Verwaltungseffizienz im Verwaltungsverfahren?, NJW 1982, S. $2150 \mathrm{ff}$.

- Kommunalverwaltung und Kommunalpolitik, in: Jeserich, Kurt G. A. / Pohl, Hans / von Unruh, Georg-Christoph, Deutsche Verwaltungsgeschichte, Band 5, Stuttgart 1987, S. 312 ff.

- Örtliche Aufgabenerfüllung, Traditionelles, funktionales oder neues Selbstverwaltungsverständnis?, in: von Mutius (Hrsg.), Selbstverwaltung im Staat der Industriegesellschaft, Festgabe zum 70. Geburtstag von G. C. von Unruh, Heidelberg 1983, S. 227 ff.

- Sind weitere rechtliche Maßnahmen zu empfehlen, um den notwendigen Handlungs- und Entfaltungsspielraum der kommunalen Selbstverwaltung zu gewährleisten? Gutachten E für den 53. DJT, München 1980.

- Umweltverträglichkeitsprüfung im Raumordnungsverfahren - insbesondere zu den verfassungsrechtlichen Fragen der Einführung einer Öffentlichkeitsbeteiligung - , BayVB1. 1988, S. $641 \mathrm{ff}$, S. $678 \mathrm{ff}$.

von Mutius, Albert / Schoch, Friedrich K., Kommunale Selbstverwaltung und Stellenobergrenzen, DVBI. 1981, S. 1077 ff.

Nachreiner, Anton, Verbrauchermärkte in der städtebaulichen Ordnung, München 1986.

Namgalies, Johannes A, Das Grundrecht auf Stadtgestaltung, Speyer 1980.

Mick, Eberhard, Einzelheiten zur öffentlich-rechtlichen und zivilrechtlichen Regelung, in: Forum für Stadtentwicklung und Kommunalpraxis e. V. (Hrsg.), Gestaltungsqualität durch Regelungsmöglichkeiten?, Wege zur Erreichung städtebaulicher und architektonischer Gestaltungsqualität, Stuttgart u. a. 1981, S. 86 ff.

Niehues, Norbert, Nach welchen rechtlichen Grundsätzen sind das öffentliche Schulwesen und die Stellung der an ihm Beteiligten zu regeln?, Verhandlungen des 51. DJT 1976, Band II Teil M, S. 40 ff., München 1976.

Niemeier, Hans Bund und Gemeinden, Aktuelle Organisations-, Finanz- und Verfassungsprobleme, Berlin 1972.

Nierhaus, Michael, Die Verteilung der Beweislast im Verwaltungsprozeß - Dargestellt am Beispiel von Erstattungsfällen im Beamtenrecht -, BayVBI. 1978, S. 745 ff.

Obermayer, Klaus, Allgemeines Verwaltungsrecht, in: Maunz / Obermayer / Berg / Knemeyer, Staats- und Verwaltungsrecht in Bayern, Stuttgart u. a., 5. Auflage 1988, S. 85 ff.

- Der Plan als verwaltungsrechtliches Institut, VVDStRL 18 (1960), S. 144 ff., Berlin 1960.

Obernolte, Wolfgang / Danner, Wolfgang, Energiewirtschaftsrecht, Energiewirtschaftsgesetz mit den Durchführungsbestimmungen, Nebengesetzen, Verordnungen und Erlassen, Kommentar, Band I, Stand: Juni 1987.

Oebbecke, Janberend, Die Einheit der Verwaltung als Rechtsproblem, DVBl. 1987, S. 866 ff.

Oelker, Wilhelm, Bauaufsichtsrecht, Ein Leitfaden für die Praxis, Berlin u. a. 1954.

Oeter, Dietrich, Licht im Hoch- und Städtebau aus medizinischer Sicht, in: Institut für Landesund Stadtentwicklungsforschung des Landes Nordrhein-Westfalen (ILS) im Auftrag des Innenministers NW (Hrsg.), Licht im Hoch- und Städtebau, Dortmund 1979, S. 27 ff.

Ortlieb, Dieter, Skeptische Erfahrungen des Kommunalpolitikers über die Erreichbarkeit von Gestaltungsqualität im Städtebau, in: Forum für Stadtentwicklung und Kommunalpraxis e. V. (Hrsg.), Gestaltungsqualität durch Regelungsmöglichkeiten?, Wege zur Erreichung städtebaulicher und architektonischer Gestaltungsqualität, Stuttgart u. a. 1981, S. 16 ff. 
Oldiges, Martin, Baurecht, in: Steiner (Hrsg.), Besonderes Verwaltungsrecht, 3. Auflage 1988, S. $439 \mathrm{ff}$.

Ortloff, Karsten-Michael, Die Entwicklung des Bauordnungsrechts, NVwZ 1988, S. 399 ff.

- Die Entwicklung des Bauordnungsrechts, NVwZ 1989, S. 615 ff.

- Das Abstandsflächenrecht der Berliner Bauordnung - $\$ 6$ BauO BIn 1985, Nachbarschutz und Verfahrensrecht - , Kommentar, Berlin 1987.

- Öffentliches Baurecht, Band II: Bauordnungsrecht, Nachbarschutz, Rechtsschutz, München, 2. Auflage 1990.

- Recht und Technik - die Bedeutung der Regeln der Baukunst nach der Berliner Bauordnung, GE 1987, S. 426 ff.

Ossenbühl, Fritz, Der Vorbehalt des Gesetzes und seine Grenzen, in: Götz, Volkmar / Klein, Hans-Hugo / Starck, Christian (Hrsg.), Die öffentliche Verwaltung zwischen Gesetzgebung und richterlicher Kontrolle, Göttinger Symposion, München 1985, S. 9 ff.

- Die Quellen des Verwaltungsrechts, in: Erichsen, Hans-Uwe und Martens, Wolfgang (Hrsg.), Allgemeines Verwaltungsrecht, 8. Auflage 1988, S. 63 ff.

- Die verfassungsrechtliche Zulässigkeit der Verweisung als Mittel der Gesetzgebungstechnik, DVBI. 1967, S. 401 ff.

- Eine Fehlerlehre für untergesetzliche Normen, NJW 1986, S. 2805 ff.

- Kernenergie im Spiegel des Verfassungsrechts, DÖV 1981, S. 1 ff.

- Rechtsverordnung, in: Isensee, Josef und Kirchhof, Paul (Hrsg.), Handbuch des Staatsrechts der Bundesrepublik Deutschland, Band III, Das Handeln des Staates, Heidelberg 1988, S. $387 \mathrm{ff}$.

- Satzung, in: Isensee, Josef und Kirchhof, Paul (Hrsg.), Handbuch des Staatsrechts der Bundesrepublik Deutschland, Band III, Das Handeln des Staates, Heidelberg 1988, S. 463 ff.

- Richterliches Prüfungsrecht und Rechtsverordnungen, in: Recht als Proze $B$ und Gefüge, Festschrift für Hans Huber zum 80. Geburtstag, Bern 1981, S. 283 ff.

- Verwaltungsverfahren zwischen Verwaltungseffizienz und Rechtsschutzauftrag, NVwZ 1982, S. 465 ff.

- Welche normativen Anforderungen stellt der Verfassungsgrundsatz des demokratischen Rechtsstaates an die planende staatliche Tätigkeit?, dargestellt am Beispiel der Entwicklungsplanung, Gutachten für den 50. DJT, Band I Teil B, München 1974.

- Zur Bedeutung von Verfahrensmängeln im Atomrecht, NJW 1981, S. 375 ff.

- Zur Erziehungskompetenz des Staates, in: Habscheid, Walther J. / Gaul, Hans Friedhelm / Mikat, Paul: Festschrift für Friedrich Wilhelm Bosch zum 65. Geburtstag, 2. Dezember 1976, Bielefeld 1976, S. 751 ff.

Osthof, Alfred, Nutzungsgehalt und Ordnungsgehalt des Bebauungsplans, Pfaffenweiler 1987.

Papier, Hans-Jürgen, Aktuelle Probleme des Planungsschadenrechts nach $\S 44$ BBauG, BauR 1976, S. $297 \mathrm{ff}$.

- Art. 14 GG, Kommentierung in: Maunz u. a., Kommentar zum GG, Stand: September 1983.

- Der Vorbehalt des Gesetzes und seine Grenzen, in: Götz, Volkmar / Klein, Hans-Hugo / Starck, Christian (Hrsg.), Die öffentliche Verwaltung zwischen Gesetzgebung und richterlicher Kontrolle, Göttinger Symposion, München 1985, S. 37 ff.

- Die rechtlichen Grenzen der Bauleitplanung, DVBI. 1975, S. 461 ff.

- Interkommunaler Kompetenzkonflikt, DVBI. 1984, S. 453 ff.

- Rechtliche Bindung und gerichtliche Kontrolle planender Verwaltung im Bereich des Bodenrechts, NJW 1977, S. 1714 ff. 
Pappermann, Ernst, Zum Problem der Sonderstellung größerer Städte im Kreis, Neue Aspekte nach Durchführung der Gebietsreform, besonders aus nordrhein-westfälischer Sicht, VerwArchiv 65 (1974), S. 163 ff.

- Zur Einengung der kommunalen Selbstverwaltung durch staatliche Bürokratie, DVBI. 1981, S. 1040 ff.

- Zur Problematik der Kreisentwicklungsplanung, Bemerkungen zur derzeitigen Praxis und zur Diskussion um eine gesetzliche Regelung in Nordrhein-Westfalen, DÖV 1973, S. 505 ff.

- Verwaltungsverbund im kreisangehörigen Raum, Zur Funktionalreform in NordrheinWestfalen nach dem "Zuständigkeitsbericht Kreise / Gemeinden" der Projektgruppe des Innenministers, DÖV 1975, S. $181 \mathrm{ff}$.

Pernice, Dietrich, Stadtentwicklung und Stadtgestaltung mit oder gegen private Investoren, DSt. 1989, S. 383 ff.

Peschau, Hans-Hermann, Die Beweislast im Verwaltungsrecht, Zur Verteilung des Aufklärungsrisikos im Verwaltungsprozeß, Berlin 1983.

Pestalozza, Christian, Gesetzgebung im Rechtsstaat, NJW 1981, S. 2081 ff.

- Thesen zur kompetenzrechtlichen Qualifikation von Gesetzen im Bundesstaat, DÖV 1972, S. $181 \mathrm{ff}$.

Peters, Hans, Die Satzungsgewalt innerstaatlicher Verbände, in: Anschütz, Gerhard und Thoma, Richard (Hrsg.), HbDStR 2. Band, Tübingen 1932, S. 264 ff.

Petz, Helmut, Die Übertragung von Staatsaufgaben als Kreisverwaltungsaufgaben auf die kreisfreien Städte, BayVBI. 1989, S. 353 ff.

Pfaff, Richard, Die Gemeinden als legitime und legale Repräsentanten von Bürgerinteressen, VerwArchiv 72 (1979), S. $1 \mathrm{ff}$.

- Planungsrechtsprechung und ihre Funktionen, Ein Beitrag zur judiziellen Steuerung im pluralistischen Rechtsbildungsproze $B$ und zur rechtsprechungskonformen Verfassungsinterpretation, Königstein / Ts. 1982.

Pieroth, Bodo / Schlink, Bernhard, Grundrechte, Staatsrecht II, Heidelberg, 5. Auflage 1989.

Pietzcker, Jost, Änderung bestehender Bebauungspläne durch Änderung der Baunutzungsverordnung?, NVwZ 1989, S. $601 \mathrm{ff}$.

- Das Verwaltungsverfahren zwischen Verwaltungseffizienz und Rechtsschutzauftrag, VVDStRL 41 (1983), S. 193 ff.

- Vorrang und Vorbehalt des Gesetzes, JuS 1979, S. 710 ff.

Piltz, Volker, Grundzüge des Bauordnungsrechts, Stuttgart u. a. 1985.

Pitschas, Rainer, Der Verwaltungsstaat in der Krise: Vom Wandel des Verwaltungsverfahrens, in: Konrad, Hans-Joachim (Hrsg.), Grundrechtsschutz und Verwaltungsverfahren unter besonderer Berücksichtigung des Asylrechts, Referate der 23. Tagung der wissenschaftlichen Mitarbeiter der Fachrichtung "Öffentliches Recht", 22. - 26. Februar 1983 in Berlin, Berlin 1985, S. $23 \mathrm{ff}$.

Plate, Klaus, Neues Landesbauordnungsrecht, Göttingen 1972.

Prahl, Albert, Wann und wie oft muß ein Bebauungsplan begründet werden?, BauR 1975, S. $388 \mathrm{ff}$.

Proksch, Roland, Das Bauordnungsrecht in der Bundesrepublik Deutschland - Entwicklung, Stand, Regelungsprobleme - Berlin 1981.

Püttner, Günter, Überblick über die Planungsarbeit der Kommunen, in: Püttner, Günter (Hrsg.), HbKWP Band 3, 2. Auflage, Berlin u. a. 1983, S. 317 ff.

Rasch, Ernst / Schaetzell, Johannes, Hessische Bauordnung, Wiesbaden 1978, Stand: Juli 1986.

Rave, Jan, Berlin, Gestaltungsrichtlinien für die Villenkolonie Grunewald, in: Flagge, Ingeborg (Hrsg.), Gestaltung und Satzung: Baufreiheit oder verordnete Gestaltung, München 1982, S. 47 ff. 
- Berlin, Rettung der Onkel-Tom-Siedlung kontrovers, in: Flagge, Ingeborg (Hrsg.), Gestaltung und Satzung: Baufreiheit oder verordnete Gestaltung, München 1982, S. $41 \mathrm{ff}$.

Redeker, Konrad, Gründe für ein neues Städtebaurecht, in: Schuster, Franz (Hrsg.), Neues Städtebaurecht, Forschungsbericht 43, herausgegeben im Auftrag der Konrad-AdenauerStiftung, Melle 1984, S. 29 ff.

- Grundgesetzliche Rechte auf Verfahrensteilhabe, Bemerkungen zu einem status activus prozessualis, NJW 1980, S. $1593 \mathrm{ff}$.

Redeker, Konrad / Oertzen, Hans-Joachim von, Verwaltungsgerichtsordnung, Kommentar, 8. Auflage, Stuttgart u. a. 1985.

Reinhard, Rudolf / Scheuner, Ulrich, Verfassungsschutz des Eigentums, Zwei Abhandlungen, Tübingen 1954.

Rengeling, Hans-Werner, Das Grundeigentum als Schutzobjekt der Eigentumsgarantie (Art. 14 GG) und als Gegenstand verwaltungsrechtlicher Planung, Gestaltung und Schrankensetzung, AöR 105 (1980), S. 423 ff.

- Vorbehalt und Bestimmtheit des Atomgesetzes, Zur Verfassungsmäßigkeit des Schnellen Brüters von Kalkar, NJW 1978, S. 2217 ff.

Richter, Gerd-Jürgen, Verfassungsprobleme der kommunalen Funktionalreform, Köln 1977.

- Verfassungstheoretische Neukonzeption der kommunalen Selbstverwaltungsgarantie?, Besprechung der Arbeit von Joachim Burmeister, Verfassungstheoretische Neukonzeption der kommunalen Selbstverwaltungsgarantie, in: DVBI. 1978, S. $783 \mathrm{ff}$.

Rodriguez-Lores, Juan / Fehl, Gerhard (Hrsg.), Städtebaureform 1865 - 1900, Von Licht, Luft und Ordnung in der Stadt der Gründerzeit, Hamburg 1985.

Rodriguez-Lores, Juan, Stadthygiene und Städtebau, Zur Dialektik von Ordnung und Unordnung in den Auseinandersetzungen des Deutschen Vereins für öffentliche Gesundheitspflege 1868 - 1901, in: Rodriguez-Lores, Juan / Fehl, Gerhard (Hrsg.), Städtebaureform 1865 - 1900 , S. 19 ff.

Rößler, Hans-Günter, Beitrag zum Thema: Harmonisierung von Planungs-, Umwelt- und Bauordnungsrecht, in: Schuster, Franz (Hrsg.), Neues Städtebaurecht, Forschungsbericht 43, herausgegeben im Auftrag der Konrad-Adenauer-Stiftung, Melle 1984, S. $107 \mathrm{ff}$.

- Kommentar zur Bauordnung von Nordrhein-Westfalen, 3. Auflage, Köln u. a. 1985.

Roellecke, Gerd, Die Verwaltungsgerichtsbarkeit im Grenzbereich zur Gesetzgebung, NJW 1978, S. 1776 ff.

Ronellenfitsch Michael, Einführung in das Planungsrecht, Darmstadt 1986.

Roseneck, Reinhard / Mindak, Jochen, Altstadtsatzungen, Der Landkreis 1978, S. 181 ff.

Roters, Wolfgang, Art. 28 GG, Kommentierung in: von Münch, Ingo (Hrsg.), GrundgesetzKommentar Band 2 (Artikel 21 bis Artikel 69), München, 2. Auflage 1983.

- Kommunale Mitwirkung an höherstufigen Entscheidungsprozessen, Zur künftigen Rolle der kommunalen Selbstverwaltung im politisch-administrativen System der Bundesrepublik Deutschland, Köln u. a. 1975.

Roth, Joachim, 100 Jahre "Kreuzberg-Urteil" des PrOVG, NVwZ 1982, S. 363 ff.

Rubel, Rüdiger, Planungsermessen, Norm- und Begründungsstruktur, Frankfurt / Main 1982.

Rupp, Hans-Heinrich, Wohl der Allgemeinheit und öffentliches Interesse, Bedeutung der Begriffe im Verwaltungsrecht, in: Wohl der Allgemeinheit und öffentliche Interessen, Berlin 1968, S. 116 ff.

Ryu, Jee-Tai, Nachholen der Begründung, Nachschieben von Gründen und Konversion von Verwaltungsakten, Versuch einer Abgrenzung dieser Rechtsfiguren im Rahmen des Bundesverwaltungsverfahrensgesetzes, Regensburg 1989.

Sachs, Michael, Die dynamische Verweisung als Ermächtigungsnorm, NJW 1981, S. $1651 \mathrm{ff}$. 
Saran, Walter, Baufluchtliniengesetz, Gesetz, betreffend die Anlegung und Veränderung von Straßen und Plätzen in Städten und ländlichen Ortschaften vom 2. Juli 1875, 2. Auflage 1921, unveränderter Nachdruck, Berlin 1954.

Sauter, Helmut, Landesbauordnung für Baden-Württemberg, Kommentar, Stand: Januar 1984.

Schäfer, Rudolf / Schmidt-Eichstaedt, Gerd, Anwendungserfahrungen mit dem Städtebaurecht, in: Schuster, Franz (Hrsg.), Neues Städtebaurecht, Forschungsbericht 43, herausgegeben im Auftrag der Konrad-Adenauer-Stiftung, Melle 1984, S. 53 ff.

Scheerbarth, Walter, Das allgemeine Bauordnungsrecht unter besonderer Berücksichtigung der Landesbauordnungen, Köln, 2. Auflage 1966.

Scheffler, Hans-Herman, Die allgemeine Pflicht zur Begründung von Verwaltungsakten, DÖV 1977, S. 767 ff.

Schenke, Wolf-Rüdiger, Art. 19 Abs. 4 GG, Zweitbearbeitung, in: Kommentar zum Bonner Grundgesetz, Stand: Dezember 1982.

- Die verfassungsrechtliche Problematik dynamischer Verweisungen, NJW 1980, S. 743 ff.

- Verfassungsrechtliche Grenzen gesetzlicher Verweisungen, in: Oberndorfer, Peter und Schambeck, Herbert (Hrsg.), Verwaltung im Dienste von Wirtschaft und Gesellschaft, Festschrift für Ludwig Fröhler zum 60. Geburtstag, Berlin 1980, S. 87 f.

Scheuner, Ulrich, Zur Neubestimmung der kommunalen Selbstverwaltung, AfK 12 (1973), S. 1 ff.

Schink, Alexander, Gesetzliche Kreiszuständigkeiten und Subsidiaritätsprinzip, in: SchmidtJortzig, Edzard / Schink, Alexander, Subsidiaritätsprinzip und Kommunalordnung, Köln u. a. 1982.

- Zentralisierung kommunaler Aufgaben nach der Gebiets- und Funktionalreform, DVBI. 1983, S. 1165 ff.

Schlaich, Klaus, Neutralität als verfassungsrechtliches Prinzip, vornehmlich im Kulturverfassungs- und Staatskirchenrecht, Tübingen 1972.

Schlez, Georg, Landesbauordnung für Baden-Württemberg, München, 3. Auflage 1985.

- Neues Bauordnungsrecht, Kritische Bemerkungen zum Entwurf einer Novelle der Landesbauordnung für Baden-Württemberg, Düsseldorf 1972.

Schlichter, Otto, BauGB, Einführung, "Vom Bundesbaugesetz und Baugesetzbuch", in: Schlichter, Otto und Stich, Rudolf (Hrsg.), Berliner Kommentar zum Baugesetzbuch, Köln u. a. 1988,1 . Halbband, S. $179 \mathrm{ff}$.

- BauGB, Vorbemerkung zu den $\S 29$ - 38, in: Schlichter, Otto und Stich, Rudolf (Hrsg.), Berliner Kommentar zum Baugesetzbuch, Köln u. a. 1988, 1. Halbband, S. 561 ff.

Schlichter, Otto / Friedrich Klaus, Bauplanungsrechtliche Steuerung der Ansiedlung von Gewerbebetrieben, Überlegungen zur Bewältigung der durch Vergnügungsstätten und großflächige Einzelhandelsunternehmen verursachten städtebaulichen Probleme, WiVerw. 1988, S. $199 \mathrm{ff}$.

Schlichter, Otto / Stich, Rudolf / Tittel, Hans-Joachim, Bundesbaugesetz, Kommentar, 3. überarbeitete Auflage, (Novelle 1979), Köln u. a. 1979.

Schlotterbeck, Karl-Heinz / Amim, Achim von, Landesbauordnung für Baden-Württemberg LBO - , 3. Auflage, Stuttgart 1988.

Schlüter, Theo, Stadtgestalt und Stadtgestaltung, Stadtbauwelt 1975, S. 259 ff.

Schmaltz, Hans Karsten, Örtliche Bauvorschriften über Gestaltung, VuR 1983, S. 217 ff.

Schmidt, Reiner, Gesetz und Recht als Orientierung im Wertewandel, BayVBI. 1988, S. 1 ff.

Schmid, Walter, Organisierte Einwirkungen auf die Verwaltung, Zur Lage der zweiten Gewalt, VVDStRL 33 (1974), S. 183 ff.

Schmidt-Aßmann, Eberhard, Art. 19 IV, Kommentierung in: Maunz u. a., Grundgesetz, Kommentar, Band 2, Stand: Januar 1985. 
- Das bebauungsrechtliche Planungserfordernis bei §§ 34, 35 BBauG, Köln u. a. 1982.

- Die Berücksichtigung situationsbestimmter Abwägungselemente bei der Bauleitplanung, Beiträge zur planungsrechtlichen Behandlung städtebaulicher Gemengelagen, Köln u. a. 1981.

- Die kommunale Rechtsetzung im Gefüge der administrativen Handlungsformen und Rechtsquellen - Aufgaben, Verfahren, Rechtsschutz - , München 1981.

- Die kommunale Rechtssetzungsbefugnis, in: Püttner, Günter (Hrsg.), HbKWP Band 3, Berlin u. a., 2. Auflage 1983, S. $182 \mathrm{ff}$.

- Die Rechtsetzungsbefugnis der kommunalen Körperschaften, Zu einigen neueren Entwicklungen im Recht der normativen Handlungsformen, in: von Mutius (Hrsg.), Selbstverwaltung im Staat der Industriegesellschaft, Festgabe zum 70. Geburtstag von G. C. von Unruh, Heidelberg 1983, S. 607 ff.

- Grundfragen des Städtebaurechts, Göttingen 1972.

- Grundsätze der Bauleitplanung - Zur administrativen Funktion des neugefaßten $\$ 1$ Abs. 1 , 6 und 7 BBauG - , BauR 1978, S. 99 ff.

- Kommunen und örtliche Energieversorgung, in: Hüffer, Uwe / Ipsen, Knut / Tettinger, Peter J. (Hrsg.), Berg- und Energierecht vor den Fragen der Gegenwart, Festschrift für Fritz Fabricius zum 70. Geburtstag, Stuttgart u. a. 1989, S. 251 ff.

- Kommunalrecht, in: von Münch, Ingo, (Hrsg.), Besonderes Verwaltungsrecht, 8. Auflage 1988, S. $97 \mathrm{ff}$.

- §1 Abs. 6 BBauG, Kommentierung, in: Ernst, Werner / Zinkahn, Willy / Bielenberg, Walter, u. a., Bundesbaugesetz, Kommentar, München, Bearbeitungsstand: weitgehend Januar 1977.

- Probleme des modernen Städtebaus in verfassungsrechtlicher Sicht, DVBI. 1972, S. 627 ff.

- Zum staatsrechtlichen Prinzip der Selbstverwaltung, in: Gedächtnisschrift für Wolfgang Martens, Berlin u. a. 1987, S. $249 \mathrm{ff}$.

Schmidt-Eichstaedt, Gerd, Das System kommunaler Aufgaben, B. Die Rechtsqualität der Kommunalaufgaben, in: Püttner (Hrsg.), HbKWP Band 3, 2. Auflage 1983, S. 9 ff.

Schmidt-Jortzig, Edzard, Gemeindliche Selbstverwaltung und Entwicklungszusammenarbeit, DVBI. 1989, S. 142 ff.

- Die Einrichtungsgarantien der Verfassung, Dogmatischer Gehalt und Sicherungskraft einer umstrittenen Figur, Göttingen 1979.

- Kommunale Organisationshoheit, staatliche Organisationsgewalt und körperschaftliche Selbstverwaltung, Göttingen 1979.

- Kommunale Satzungen als Form materieller Rechtsetzung durch Selbstverwaltungskörperschaften, ZG 1987, S. 193 ff.

- Kommunalrecht, Stuttgart 1982.

Schmidt-Jortzig, Edzard / Schink, Alexander, Subsidiaritätsprinzip und Kommunalordnung, Köln 1982.

Schmidt-Tophoff, Alfons, Ist $§ 1$ Baugestaltungsverordnung nur mit Einschränkungen rechtsgültig?, Eine Auseinandersetzung mit der Rechtsprechung des Bundesverwaltungsgerichts, BBauBl. 1957, S. 232 ff.

- Kann das Baurecht des Bundes auch Regelungen für Anlagen der Außenwerbung treffen?, DVBI. 1968, S. 490 ff.

Schmitt, Carb, Freiheitsrechte und institutionelle Garantien der Reichsverfassung (1931), in: Verfassungsrechtliche Aufsätze aus den Jahren 1924 - 1954, Materialien zu einer Verfassungslehre, Unveränderter Nachdruck der 1958 erschienenen ersten Auflage, Berlin 1973, S. $141 \mathrm{ff}$.

- Verfassungslehre, Unveränderter Nachdruck der 1928 erschienenen ersten Auflage, Berlin 1965. 
Schmitt-Glaeser, Walter, Die Position der Bürger als Beteiligte im Entscheidungsverfahren gestaltender Verwaltung, in: Verfahren als staats- und verwaltungsrechtliche Kategorie, Heidelberg 1984, S. 35 ff.

- Verwaltungsprozeßrecht, Kurzlehrbuch mit Systematik zur Fallbearbeitung, Stuttgart u. a., 9. Auflage 1988.

Schneider, Hans, Autonome Satzung und Rechtsverordnung, Unterschiede und Übergänge, in: Hefermehl, Wolfgang und Nipperdey, Hans Carl (Hrsg.), Festschrift für Philipp Möhring zum 65. Geburtstag, München u. a. 1965, S. 521 ff.

- Gesetzgebung, Ein Lehrbuch, Heidelberg 1982.

- Zur Verhältnismäßigkeitskontrolle insbesondere bei Gesetzen, in: Starck, Christian (Hrsg.), Bundesverfassungsgericht und Grundgesetz, Festgabe aus Anlaß des 25jährigen Bestehens des Bundesverfassungsgerichts, Band II, Tübingen 1976, S. 390 ff.

Schneider, Oskar, Leitlinien für ein neues Baugesetzbuch, in: Schuster, Franz (Hrsg.), Neues Städtebaurecht, Forschungsbericht 43, herausgegeben im Auftrag der Konrad-AdenauerStiftung, Melle 1984, S. 19 ff.

Schoch Friedrich, Zur Situation der kommunalen Selbstverwaltung nach der Rastede-Entscheidung des BVerfG, VerwArchiv 81 (1990), S. 18 ff.

Schol, Rupert, Ausschließliche und konkurrierende Gesetzgebungskompetenz von Bund und Ländern in der Rechtsprechung des Bundesverfassungsgerichts, in: Festgabe aus Anlaß des 25-jährigen Bestehens des BVerfG, 2. Band, Tübingen 1976, S. 252 ff.

- Art. 5 Abs. 3 GG, Kommentierung in: Maunz u. a., Grundgesetz, Kommentar, Band 1, Stand: Mai 1977.

- Rechtsfragen zur Verweisung zwischen Gesetz und Tarifvertrag, in: Mayer-Maly, Theo / Richardi, Reinhard / Schambeck, Herbert / Zöllner, Wolfgang (Hrsg.), Arbeitsleben und Rechtspflege, Festschrift für Gerhard Müller, Berlin 1981, S. 509 ff.

Schomers, Manfred / Zlonicky, Marlene / Zlonicky, Peter, Zur Problematik gestalterischer Festsetzungen in Bebauungsplänen, BauR 1971, S. $158 \mathrm{ff}$

Schröcker, Sebastian, Die Übernahme von Bundesrecht als Landesrecht, NJW 1967, S. 2285 ff.

Schröder, Meinhard, Grundlagen und Anwendungsbereich des Parlamentsrechts, Zur Übertragbarkeit parlamentsrechtlicher Grundsätze auf Selbstverwaltungsorgane, insbesondere in der Kommunal- und Hochschulverwaltung, Baden-Baden 1979.

Schrödter, Hans, BBauG, Kommentar, 4. Auflage, München 1980.

- Vom Kreuzberg-Urteil zur Bauregelungsverordnung, Die Rechtsprechung des Preußischen Oberverwaltungsgerichts zum Städtebaurecht, DVBI. 1975, S. $846 \mathrm{ff}$.

Schuegraf, Elmar, Die Problematik kommunaler Entwicklungsgesellschaften im Städtebau, NJW 1964, S. 2088 ff.

Schulte, Bernhard, Rechtsgüterschutz durch Bauordnungsrecht, Berlin 1980.

Schulte, Hans, Buchbesprechung zu Joachim Burmeister, Verfassungstheoretische Neukonzeption der kommunalen Selbstverwaltungsgarantie, DVB1. 1978, S. 825 ff.

- Das Dogma Baufreiheit, DVBI. 1979, S. 133 ff.

Schultze, Harald, Raumordnungspläne und gemeindliche Selbstverwaltung, Die Anpassung der Bauleitpläne an die Ziele der Raumordnung und Landesplanung, Bonn 1970.

Schulze-Fielitz, Helmuth, Sozialplanung im Städtebaurecht - Am Beispiel der Stadterneuerung - , Königstein / Ts. 1978.

- Theorie und Praxis parlamentarischer Gesetzgebung - besonders des 9. Deutschen Bundestages (1980 - 1983) - , Berlin 1988.

Schweiger, Karl, Der "gebildete Durchschnittsmensch" und der unbestimmte Rechtsbegriff, DVBI. 1968, S. 481 ff.

Schwerdtfeger, Gunther, Die Rechtsfolgen von Abwägungsdefiziten in der Bauleitplanung BVerwGE 64, 33, in: JuS 1983, S. 270 ff. 
- Optimale Methodik der Gesetzgebung als Verfassungspflicht, in: Stödter, Rolf und Thieme, Werner (Hrsg.), Hamburg Deutschland Europa, Beiträge zum deutschen und europäischen Verfassungs-, Verwaltungs- und Wirtschaftsrecht, Festschrift für Hans Peter Ipsen zum siebzigsten Geburtstag, Tübingen 1977, S. $173 \mathrm{ff}$.

Schwerdtner, Eberhard, Einkaufszentren als Rechtsproblem, zugleich Anm. zu den inhaltlich übereinstimmenden Urteilen v. 20.03.85 - 3 S 309 / 84 - und - 3 S 2075 / 84 - des VGH Bd.W., BauR 1986, S. 253 ff.

Seewald, Otfried, Kommunalrecht, in: Steiner (Hrsg.), Besonderes Verwaltungsrecht, 3. Auflage 1988, S. $1 \mathrm{ff}$.

Sendler, Horst, Der Nachbarschutz im Städtebaurecht, Teil 1 - Nachbarschutz im Planbereich, BauR 1970, S. 4 ff.

- Die Zulässigkeit von Bauvorhaben, Die $\$ 29$ bis 34 Bundesbaugesetz, BBauBI. 1968, S. 12 ff., $63 \mathrm{ff}$.

Seybold, Eberhard, Bauästhetisches Ortsrecht, Hamburg 1987.

Simon, Alfons, Bayerische Bauordnung, Kommentar, Band I, Stand: November 1988.

- Die Außenwerbung in ihrer rechtlichen Ausgestaltung, WiVerw. 1980, S. 194 ff.

Simon, Helmut / Heußner, Hermann, Sondervotum zu BVerfG, Beschluß vom 20.12.1979 - 1 BvR 385/77 - NJW 1980, S. 759 ff., in: NJW 1980, S. 764 ff.

Soell, Hermann, Die Bedeutung der Sozialpflichtigkeit des Grundeigentums bei der Landschaftspflege und dem Naturschutz, DVBI. 1983, S. $241 \mathrm{ff}$.

- Landschaftsschutz, Kiesabbaurecht und Enteignung, Anm. zu den Urteilen des BGH vom 26.1.1984 III ZR 178 und 179 / 82, NuR 1984, S. 196 und 198, in: NuR 1984, S. 185 ff.

- Sind die Gemeinschaftsaufgaben nach Art. 91 a GG ein geeignetes Instrument zur Weiterentwicklung des föderalen Systems? in: Schnur, Roman (Hrsg.), Festschrift für Ernst Forsthoff zum 70. Geburtstag, München 1972, S. 397 ff.

- Umweltschutz, ein Grundrecht?, NuR 1985, S. 205 ff.

Sonntag, Andreas, Die Beweislast bei Drittbetroffenenklagen, Frankfurt/Main u. a. 1986.

Spanner, Hans, Grenzen des Rechts zum Erlaß von Verordnungen und Satzungen nach der Rechtsprechung des Bundesverfassungsgerichts, Ein Beitrag zur Fehlerlehre für untergesetzliche Normen, BayVBI. 1986, S. 225 ff.

Staats, Johann-Friedrich, Verweisung und Grundgesetz, in: Rödig, Jürgen (Hrsg.), Studien zu einer Theorie der Gesetzgebung, Berlin u. a. 1976, S. 244 ff.

Stabenow, Wolfgang, Hamburg Bau 78, Sackgasse oder neuer Weg? in: Flagge, Ingeborg (Hrsg.), Gestaltung und Satzung: Baufreiheit oder verordnete Gestaltung, München 1982, S. $15 \mathrm{ff}$.

Stadtler, Otto / Baumgartner, Robert / Wiebel, Emil, Das Bau- und Wohnungsrecht in Bayern, Sammlung der in Bayern geltenden Vorschriften mit Kommentaren zum Bundesbaugesetz, zur Bayerischen Bauordnung und zur Baunutzungsverordnung, München, Stand: Mai 1989.

Starck, Christian, Autonomie und Grundrechte, Zur Regelungsbefugnis öffentlich-rechtlicher Autonomieträger im Grundrechtsbereich, AöR 92 (1967), S. 449 ff.

- Das Bonner Grundgesetz, Kommentar, begründet von Hermann v. Mangold, fortgeführt von Friedrich Klein, vollständig neubearbeitete 3. Auflage, Band 1: Präambel, Art. 1 bis 5 , München 1985.

- Der Gesetzesbegriff des Grundgesetzes, Ein Beitrag zum juristischen Gesetzesbegriff, Baden-Baden 1970.

- Regelungskompetenzen im Bereich des Art. 12 Abs. 1 GG und ärztliches Berufsrecht, Bemerkungen zum Facharzt-Beschluß des BVerfG, NJW 1972, S. 1489 ff.

Staupe, Jürgen, Parlamentsvorbehalt und Delegationsbefugnis, Zur "Wesentlichtkeitstheorie" und zur Reichweite legislativer Regelungskompetenzen, insbesondere im Schulrecht, Berlin 1986. 
Steinberg, Rudolf, Baumschutzsatzungen und -verordnungen, Kompetenz- und Grundrechtsprobleme naturschutzrechtlicher Regelungen, NJW 1981, S. 550 ff.

- Baurecht, in: Meyer, Hans / Stolleis, Michael (Hrsg.), Hessisches Staats- und Verwaltungsrecht, 2. Auflage, Frankfurt/Main 1986, S. 264 ff.

- Das Nachbarrecht der öffentlichen Anlagen, Nachbarschutz gegen Planfeststellungen und sonstige Anlagen der öffentlichen Hand, Frankfurt / Main 1988.

- Die verfassungsrechtliche Gewährleistung der kommunalen Planungshoheit - BVerfG E 56, 298, in: JuS 1982, S. 578 ff.

Steiner, Udo, Anmerkung zu VGH Bad.-Württ., Urt. v. 25.06.81, DÖV 1982, S. 206 ff., in: DÖV 1982, S. 554 ff.

- Die Beschränkung von Luftverunreinigungen an Straßen in der straßenrechtlichen Planfeststellung, in: Blümel, Willi (Hrsg.), Bedarfsplanung - Planfeststellung - Immissionsschutz, Speyer 1988, S. 35 ff.

- Kommunen und Leistungssport - Mäzenatentum oder Daseinsvorsorge?, in: DVerwPr. 1987, S. $171 \mathrm{ff}$.

- Kulturauftrag im staatlichen Gemeinwesen, VVDStRL 42 (1984), S. 7 ff., Berlin 1984.

- Kulturpflege, in: Isensee, Josef und Kirchhof, Paul (Hrsg.), Handbuch des Staatsrechts der Bundesrepublik Deutschland, Band III, Das Handeln des Staates, Heidelberg 1988, S. 1235 ff.

- Öffentliche Verwaltung durch Private, Hamburg 1975.

- Rechtliche Aspekte einer städtebaulich orientierten Verkehrsplanung in den Gemeinden Untersuchung straßenverkehrsrechtlicher, straßenrechtlicher und entschädigungsrechtlicher Fragen zur Förderung verkehrsberuhigter Zonen durch verkehrsordnende Maßnahmen - herausgegeben vom Bundesminister für Verkehr, Bonn 1980.

- Rechtsfragen der Einrichtung von Zonen mit beschränkter Geschwindigkeit innerhalb geschlossener Ortschaften, DAR 1989, S. 401 ff.

- Staat, Sport und Verfassung, DÖV 1983, S. 173 ff.

- Straßen- und Wegerecht, in: Steiner, Udo (Hrsg.), Besonderes Verwaltungsrecht, 3. Auflage 1988, S. $601 \mathrm{ff}$.

Stern, Klaus, Das Staatsrecht der Bundesrepublik Deutschland, Band I, Grundbegriffe und Grundlagen des Staatsrechts, Strukturprinzipien der Verfassung, München, 2. Auflage 1984.

- Das Staatsrecht der Bundesrepublik Deutschland, Band III, Allgemeine Lehren der Grundrechte, 1. Halbband, München 1989.

- Die Verfassungsgarantie der kommunalen Selbstverwaltung, in: HbKWP Band 1, 2. Auflage 1981, S. 204 ff.

Stich Rudolf, Beitrag zum Thema: Harmonisierung von Planungs-, Umwelt- und Bauordnungsrecht, in: Schuster, Franz (Hrsg.), Neues Städtebaurecht, Forschungsbericht 43, herausgegeben im Auftrag der Konrad-Adenauer-Stiftung, Melle 1984, S. 113 ff.

- Die Möglichkeiten des Schutzes und der Erhaltung von geschichtlich, künstlerisch und städtebaulich bedeutsamen Bauten und Gesamtanlagen nach Städtebau- und Bauordnungsrecht, in: Verwaltung im Rechtsstaat, Festschrift für C. H. Ule, Köln u. a. 1987, S. 375 ff.

- Maßnahmen der Stadterhaltung und des Denkmalschutzes im Spannungsfeld zwischen Bundes- und Landesrecht sowie zwischen kommunaler Selbstverwaltung und staatlicher Einwirkung, ZfBR 1983, S. 61 ff.

- Verbote der Verwendung bestimmter Heizstoffe in Baugebieten - Zur umweltschutzbedeutsamen Wechselwirkung zwischen Städtebau-, Immissions-, Bauordnungs- und Gemeinderecht - , DÖV 1981, S. 645 ff. 
Stich, Rudolf / Gabelmann, Horst, Landesbauordnung Rheinland-Pfalz (LBauO) mit Architektengesetz und Ingenieurkammergesetz - Text- und Bildkommentar - mit juristischen und fachtechnischen Erläuterungen, ergänzenden Rechts- und Verwaltungsvorschriften sowie Gerichtsentscheidungen und Anmerkungen, Wiesbaden, Stand: März 1988.

Stich, Rudolf / Sayn, Volker / Gabelmann, Horst, Landesbauordnung für Rheinland Pfalz, Band II, Stand: Februar 1985.

Stier-Somlo, Fritz, Grund- und Zukunftsfragen deutscher Politik, Bonn 1917.

Stober, Rolf, Gewerbliche Wirtschaft und Baunutzungsrecht, WiVerw. 1984, S. $129 \mathrm{ff}$.

- Verwaltungsrecht II, Besonderes Organisations- und Dienstrecht, Ein Studienbuch, Begründet von Hans J. Wolff, Fortgeführt von Otto Bachof, 5. neubearbeitete Auflage, München 1987.

Ströhsel, Theodor A, Reger's Handausgabe der Gewerbeordnung für das Deutsche Reich, 1. Band, 8. Auflage 1929.

Stüer, Bernhard, Funktionalreform und kommunale Selbstverwaltung, Göttingen 1980.

Thiele, Willi, Allzuständigkeit im örtlichen Wirkungskreis - ein politisch hochstilisiertes, praktisch unbrauchbares Dogma?, DVBI. 1980, S. 10 ff.

Thoma, Richard, Die juristische Bedeutung der grundrechtlichen Sätze der deutschen Reichsverfassung im allgemeinen, in: Nipperdey, Hans Carl (Hrsg.), Die Grundrechte und Grundpflichten der Reichsverfassung, Kommentar zum zweiten Teil der Reichsverfassung, Erster Band: Allgemeine Bedeutung der Grundrechte und die Artikel 102 - 117, Berlin 1929, S. 1 ff.

Tietzsch Rainer, Bauordnungsrechtliche Bestandspflege, Erhaltungs- und Verbesserungspflichten für Mietwohnhäuser nach § 110 der Bauordnung für Berlin, Berlin 1985.

Timmermann, Franz Hubert, Der baurechtliche Nachbarschutz, Berlin 1968.

Trieb, Michael, Beitrag zum Thema: Anforderungen des Städtebaus an das Städtebaurecht, in: Schuster, Franz (Hrsg.), Neues Städtebaurecht, Forschungsbericht 43, herausgegeben im Auftrag der Konrad-Adenauer-Stiftung, Melle 1984, S. 147 ff.

- Stadtgestaltung, Theorie und Praxis, Düsseldorf 1974.

Trieb, Michael / Schmidt, Alexander / Paetow, Stefan / Buch Felicitas / Strobel, Richard, Erhaltung und Gestaltung des Ortsbildes, Denkmalpflege, Ortsbildplanung und Baurecht, 2. Auflage, Stuttgart u. a. 1988.

Trommer, Sigurd, Verordnete Gestaltung?, Bauwelt 1977, S. 585

Ule, Carl Hermann, Verwaltungsprozeßrecht, 9. Auflage, München 1987.

Umbach Dieter C., Das Wesentliche an der Wesentlichkeitstheorie, in: Zeidler, Wolfgang / Maunz, Theodor / Roellecke, Gerd (Hrsg.), Festschrift Hans Joachim Faller, München 1984, S. $111 \mathrm{ff}$.

Unruh, Georg-Christoph von, Wodurch unterscheiden sich kommunale von staatlichen Angelegenheiten?, DÖV 1977, S. 467 ff.

Vereinigung der Landesdenkmalpfleger in der Bundesrepublik Deutschland, Stellungnahme zu Erhaltungssatzungen und Gestaltungssatzungen in historischen Ortsteilen, Deutsche Kunst und Denkmalpflege 1981, S. 193 ff.

Veh Herbert Michael, Die dynamische Verknüpfung von Landes- und Bundesrecht, Zum Beschluß des Bayer. Obersten Landesgerichts vom 03. Juni 1986 (BayVBI. 1987, 27 ff.), BayVBI. 1987, S. 225 ff.

Vogel, Klaus, Beschränkung von Werbeanlagen durch Bebauungspläne zum Schutz des Straßenverkehrs?, BayVB1. 1978, S. 585 ff.

- Gefahrenabwehr, Allgemeines Polizeirecht (Ordnungsrecht) des Bundes und der Länder. Begründet unter dem Titel "Preußisches Polizeirecht" von Bill Drews. Fortgeführt mit dem Titel "Allgemeines Polizeirecht" von Gerhard Wacke, 9. Auflage von Klaus Vogel und Wolfgang Martens, Köln u. a. 1986.

Vollmer, Horst, Baugestaltungsrecht, ArchivPF 1980, S. $101 \mathrm{ff}$. 
Wagener, Frido, Einführung in die Diskussion, in: Knemeyer / Hofmann (Hrsg.), Gemeinden und Kreise, Expertengespräch zur Selbstverwaltungsgarantie, Würzburg 1984.

- Landkreise und Kreisfinanzen, in: Wagener, Frido (Hrsg.), Kreisfinanzen, Göttingen 1982.

Wahl, Rainer, Verwaltungsverfahren zwischen Verwaltungseffizienz und Rechtsschutzauftrag, VVDStRL 41 (1983), S. 151 ff.

Wallraven-Lindl, Marie-Luise, Die Anhörung der Straßenanlieger vor längerfristigen Straßenbauarbeiten, Konstanz 1987.

Watzke, Hans-Georg, Die Baugestaltung als Aufgabe der Baupolizei, Berlin 1972.

- Denkmalschutz- und Stadtplanungsrecht, difu, Berlin 1976.

- Zur Konkurrenz von Denkmalschutz- und städtebaulichem Erhaltungsrecht, ZfBR 1981, S. $10 \mathrm{ff} ., 57 \mathrm{ff}$.

Weber, Werner, Staats- und Selbstverwaltung in der Gegenwart, 2. Auflage, Göttingen 1967.

Weber, Wolf, Selbstverwaltung und Demokratie in den Gemeinden nach der Gebietsreform, Siegburg 1982.

Wendt, Rudolf, Der Garantiegehalt der Grundrechte und das Übermaßverbot, Zur maßstabsetzenden Kraft der Grundrechte in der Übermaßprüfung, AöR 104 (1979), S. 414 ff.

- Eigentum und Gesetzgebung, Hamburg 1985.

Wenzel, Werner / Bündgen, Günter, Hessische Bauordnung, Kommentar für die Praxis, 2. Auflage, Köln u. a. 1984.

Werner, Fritz, Das Problem der Kodifikation des Baurechts, DVB1. 1952, S. $261 \mathrm{ff}$.

- Die Zuständigkeit des Bundes für ein Bundesbaugesetz, DVBl. 1954, S. 481 ff.

Westbomke, Konrad, Der Anspruch auf Erlaß von Rechtsverordnungen und Satzungen, Berlin 1976.

Westermann, Harry, Das Baurecht im Rechtssystem, BBauBl. 1952, S. 137 ff.

- Flexible Bestimmung des Eigentumsinhalts durch Nachbarrecht und Bebauungsplan, in: Beiträge zur Raumplanung, herausgegeben vom Zentralinstitut für Raumplanung an der Universität Münster, Band 1, "Zur Theorie der allgemeinen und der regionalen Planung", S. 85 ff.

Weyreuther, Felix, Bauen im Außenbereich, Ein nach Stichwörtern gegliederter Kommentar zu den mit § 35 BBauG zusammenhängenden Fragen - unter besonderer Berücksichtigung der Rechtsprechung des Bundesverwaltungsgerichts - , Köln u. a. 1979.

- Bundes- und Landesbaurecht, BauR 1972, S. 1 ff.

- Die Bedeutung des Eigentums als abwägungserheblicher Belang bei der Planfeststellung nach dem Bundesfernstraßengesetz, DÖV 1977, S. 419 ff.

- Eigentum, öffentliche Ordnung und Baupolizei, Gedanken zum Kreuzbergurteil des Preußischen Oberverwaltungsgerichts, Köln u. a. 1972.

- Rechtliche Bindung und gerichtliche Kontrolle planender Verwaltung im Bereich des Bodenrechts, BauR 1977, S. 293 ff.

- Über die Erforderlichkeit von Bebauungsplänen, DVBI. 1981, S. 369 ff.

- Verwaltungsverantwortung und gerichtliche Kontrolle, UPR 1986, S. $121 \mathrm{ff}$.

Widera, Bernd, Zur verfassungsrechtlichen Gewährleistung gemeindlicher Planungshoheit, Berlin 1985.

Wiecherh, Reinald, Anm. zu OVG Lüneburg, Urt. v. 18.04.1974, DVB1. 1975, S. 954 ff.

- Baurecht, in: Faber, Heiko / Schneider, Hans-Peter (Hrsg.), Niedersächsisches Staats- und Verwaltungsrecht, Frankfurt / Main 1985, S. 278 ff.

- Gesetzgebungskompetenz für das Bau- und Bodenrecht, ZRP 1985, S. 239 ff.

Wiedenroth, Kurt-Ludwig, Das Ostertorviertel in Bremen, Ende der Gigantonomie, in: Flagge, Ingeborg (Hrsg.), Gestaltung und Satzung: Baufreiheit oder verordnete Gestaltung, München 1982, S. $24 \mathrm{ff}$. 
Wienands, Rudolf, Grundlagen der Gestaltung zu Bau und Stadtbau, Basel u. a. 1985.

- Stadt-Gestaltungsgutachten-Bochum, Hrsg.: Stadt Bochum, Presse- und Informationsamt.

Wilke, Dieter, Anmerkung zu BVerfG, BeschluB v. 20.10.1981 - 1 BvR 640/80, JZ 1982, S. 755 ff., in: JZ 1982, S. $758 \mathrm{ff}$.

- Bundesverfassungsgericht und Rechtsverordnungen, AöR 98 (1973), S. 196 ff.

Wolff, J., Zur baurechtlichen Beurteilung der Baugestaltung, BBauBI. 1957, S. $341 \mathrm{ff}$.

Würtenberger, Thomas, Der Rechtsschutz gegen Energiefreileitungen, BayVBI. 1982, S. $673 \mathrm{ff}$.

Zeitler, Herbert, Staat und Selbstverwaltung im Städtebaurecht, BayVBI. 1987, S. 682 ff.

Ziebill, Otto, Kommunale Selbstverwaltung und Politische Wissenschaft, AfK 3 (1964), S. 25 ff.

Ziegler, Jürgen, Ein formulierter Vorschlag zur Aufnahme des Bauordnungsrechts in ein (Bundes-)Baugesetzbuch, DVB1. 1984, S. 378 ff.

- Zum Dualismus Bodenrecht, Bauordnungsrecht, Einzelfragen, Gehalt des Bauordnungsrechts, (Bundes-)Baugesetzbuch, ZfBR 1980, S. 275 ff.

Ziegler, Wolfgang, Die Verkündung von Satzungen und Rechtsverordnungen der Gemeinden, Berlin 1976.

Zimmerli, Ulrich, Der Grundsatz der Verhältnismäßigkeit im öffentlichen Recht, Versuch einer Standortbestimmung, Basel 1978.

Zinkahn, Willy, Außenwerbung und Baugestaltungsverordnung, DÖV 1953, S. $161 \mathrm{ff}$.

- Einleitung, in: Ernst, Werner / Zinkahn, Willy / Bielenberg, Walter, u. a., Baugesetzbuch, Kommentar, München, Bearbeitungsstand: April 1985.

- Verunstaltungsrecht und Außenwerbung, DVBI. 1951, S. $368 \mathrm{ff}$.

Zippelius, Reinhold, Allgemeine Staatslehre (Politikwissenschaft), 9. Auflage, München 1985.

Zöllner, Dieter, Bauleitplanung im gemeindefreien Gebiet?, BayVBI. 1987, S. 549 ff.

Zoller, Wolfgang, Über die Bedeutung des Art. 80 GG, Gewaltenteilungsgrundsatz und Normensetzung durch die Verwaltung, Frankfurt / Main 1971.

Zuck, Rüdiger, Das Recht des Bebauungsplans, Verfahrensgang - Rechtsbindung - Plansicherung - Gerichtskontrolle, Stuttgart u. a. 1978.

Zwanzig, Günter W., Ortsrecht zur Baudenkmalpflege, Die Baugestaltungsverordnung einer Großen Kreisstadt, Der Landkreis 1975, S. 280 ff. 


\section{Stichwortregister}

Abstandsflächen

- Abweichende Festsetzungen in Bebauungsplänen $40 \mathrm{f}$.

- Allgemeines $37 \mathrm{ff}$.

- Bedeutung der Vorschriften im Innenbereich 99

- Bedeutung der Vorschriften im Planbereich $99 \mathrm{ff}$.

- Kompetenzrechtliche Einordnung 39, 54 f., 98 ff.

- Kritik 100

- Modifizierung in örtlichen Bauvorschriften $37 \mathrm{ff}$.

- und Bauplanungsrecht $37 \mathrm{ff} ., 97 \mathrm{ff}$.

- Vergrößerung in örtlichen Bauvorschriften $41 \mathrm{f}$.

- Verringerung in örtlichen Bauvorschriften $40,42 \mathrm{ff}$.

Abstimmungsgebot 233

Abwägung

- Arten 240

- bei Eigentumsgarantie 49, 50

- bei örtlichen Bauvorschriften 271 ff., $286 \mathrm{f}$.

- bei $\S 1$ Abs. 5, 6 BauGB 64

- Bindung an Abstandsflächenvorschriften 106

- Fehler bei 230

- Nachweis $260 \mathrm{ff}$.

- und Begründung 262

- zwischen öffentlichen und privaten Belangen 76

Abwägungsdefizit 275

Abwägungsdisproportionalität 275, 277, 280

Abwägungsergebnis $74 \mathrm{f} ., 271 \mathrm{ff}$.

Abwägungsfehler 73, 275 ff., 285

- bei nachvollziehender Abwägung 241

Abwägungsfehlgewichtung 275

Abwägungsgebot 71,100

- Ableitung $239 \mathrm{ff}$.

- als materiell-rechtliche Anforderung 276

- Beweislast $283 \mathrm{ff}$.

- beim Erlaß örtlicher Bauvorschriften 233, 235, $239 \mathrm{ff}$.

- rechtsstaatliches 74, 272 f., $284 \mathrm{f}$.

- und Ziele der Bauleitplanung 74

-Abwägungskontrolle $271 \mathrm{ff}$.
- bei örtlichen Bauvorschriften 282 ff.

- Doppelprüfung $275 \mathrm{ff}$.

- Rechtsprechung des BVerwG 273 ff.

- wissenschaftliche Diskussion $278 \mathrm{ff}$.

Abwägungsvorgang $271 \mathrm{ff}$.

- "innere" und "äußere" Seite 274, 285

Ästhetik 92, 198

- Förderung als öffentliche Aufgabe 178 ff.,191

- "höhere" 181, 220

- Konsensfragen 169, $170 \mathrm{ff}$.

- wissenschaftliche 172 (siehe auch "Bauästhetik")

Ästhetische Erfahrung 172

Ästhetisches Empfinden 170, 172

Ästhetisches Minimum 169, 179, 185 ff., 199

Allgemeines Baugesetz für das Königreich Sachsen $84 \mathrm{f}$.

Allzuständigkeit 132

Altstadtkern 44, 50

Amtspflichten 292

Anerkannte Regeln der Baukunst 166

Anerkannte Regeln der Technik 166

Angelegenheiten der örtlichen Gemeinschaft 117

- als kompetenzbegrenzendes Merkmal $130 \mathrm{f}$.

- Definition $130 \mathrm{ff}$.

- Verteidigungspolitik als 130, 133

Anlagen

- funktionswidrige $218 \mathrm{f}$.

Anständige Baugesinnung 167 f., 171, 199

Antennenverbote (siehe "Dachantennen")

Anzeigeverfahren 245, 259, 288

Arbeitersiedlung 192

Architektonische Harmonie 170

Art der baulichen Nutzung 56, 104, 204

- funktionswidrige Anlagen $218 \mathrm{f}$.

- geschichtliche Entwicklung 83

Aufenthaltsräume 54

Aufgaben

- gemeindliche $143 \mathrm{f}$.

- staatliche $143 \mathrm{f}$.

Aufgabenerfüllung

- Eingriffe $128 \mathrm{ff}$.

- "Ob" und "Wie" $128 \mathrm{ff}$.

Aufgabenkatalog 120

Aufgabenqualifikation 115, 131 ff., 143 
Aufgabensysteme $107 \mathrm{ff}$.

- und gemeindliche Individualität 144 ff.

Aufnahme in den Bebauungsplan $22 \mathrm{f}$., 40, 203, 211, 226

- Anforderungen $231 \mathrm{ff}$.

- Ermessensgesichtspunkte $288 \mathrm{f}$.

- nach \$9 Abs. 2 BBauG a. F. 226

Aufsicht (siehe "Rechtmäßigkeitskontrolle", "Zweckmäßigkeitskontrolle")

Auftragsangelegenheiten

- sog. Überschwemmung mit 126

Ausnahmen 231

Ausschöpfung der Ermächtigung des $\S 9$ Abs. 4 BauGB $237 \mathrm{ff}$.

Außenanstrich 66, 104, 175, 223, 270, 290

Außenbereich 55, 99, 240

Bad-Dürkheimer-Gondelbahnfall 51

Bauästhetik 24

- und Kulturgestaltungsmacht 180 ff.

- und umgebungsabhängige

Anforderungen $190 \mathrm{ff}$., 198

- und umgebungsunabhängige Anforderungen $176 \mathrm{ff}$.

(siehe auch "Ästhetik")

Bauästhetisches Ortsrecht 24 f., 193

Bauaufsichtsrecht 53 (siehe auch "Bauordnungsrecht")

Baufreiheit $77 \mathrm{f}$.

- als Ursache für Fehlentwicklungen $82 \mathrm{f}$.

- Berücksichtigung bei Abwägung $291 \mathrm{ff}$.

- und Einvernehmenserfordernisse 224

Baugebietsarten 218, 221 (siehe auch "Art der baulichen Nutzung")

Baugenehmigung

- als gebundener Verwaltungsakt $223 \mathrm{f}$.

Baugenehmigungsbehörde

- Gemeinde als 43

Baugestalterische Absichten 25, 26 ff., $91 \mathrm{f}$.

Baugestalterische Anforderungen $165 \mathrm{ff}$.

- grundrechtlicher Prüfungsmaßstab $173 \mathrm{ff}$.

- verfassungsrechtliche Determinierung $193 \mathrm{ff}$.

(siehe auch "umgebungsabhängige Anforderungen", "umgebungsunabhängige Anforderungen")

Baugestalterische Generalklausel 24, 34, $165 \mathrm{ff}$.

- Einfluß der BaugestaltungsVO $167 \mathrm{ff}$.

- Übersicht 165 ff.

- Umgebungsabhängige Anforderungen $190 \mathrm{ff}$.
- Umgebungsunabhängige Anforderungen $176 \mathrm{ff}$.

Baugestalterische Vorschriften

- Begriff $24 \mathrm{ff}$.

- Begründungspflicht 270

- und Eigentumsgarantie $176 \mathrm{ff}$.

- und Festsetzungen nach $\$ 9$ Abs. 1 BauGB 28 ff., $91 \mathrm{ff}$.

- Unterschiede zu Schutzvorschriften 32

Baugestaltungsverordnung 29, 190, 197, 206, 212

- Bedeutung für heutige Kompetenzaufteilung 52

- "positive Anforderungen" $214 \mathrm{ff}$.

- Rechtsprechung 167 ff., 206

- und Rechtsform für VorschriftenerlaB 110

- und "städtebauliche Absicht" 27

- Weitergeltung $167 \mathrm{f}$.

Baugrenzen 30, 39, 42, 94

Bauhistorische Gründe 43

Baukörper

- asymmetrische 201

Baukultur 169

Baukunst 166

Bauleitpläne

- Planrechtfertigung 68, 75

- Erforderlichkeit 68

Bauleitplanung

- als Nichtfachplanung 74

- Anspruch auf 79

- Kongruenz von Rechten und Pflichten 75

- individuelle Ansprüche 79

- institutionelle Vorrangstellung $106 \mathrm{f}$.

- "Passivseite" 74

- und Abstandsflächen 97 ff.

- und Grundstücksgrenzen 107

- Zweck 81 (siehe auch "Bauplanungsrecht")

Bauliche Anlage 21 f., 54, 65, 220

Baulinien 30, 39, 42, 94

- zur Absicherung von Traufgassen 43

Baumaterialien 220

Bauordnungsrecht 19 ff., 111

- Abgrenzung zum Bauplanungsrecht $47 \mathrm{ff}$.

Bauordnungsrechtliche Generalklausel

- Bedeutung bei Änderung von Flachdachbauweise 25

Bauplanungsrecht $19 \mathrm{ff}$.

- Abgrenzung zum Bauplanungsrecht $47 \mathrm{ff}$.

- Kodifizierung 84

- und Abstandsflächenrecht 38 ff.

- Sperrwirkung zulasten Landesgesetzgebung $105 \mathrm{ff}$. (siehe auch "Bauleitplanung") 
Baupolizei 52, 57 ff.

Baurechtsvollzug 126

BauregelungsVO 85

Baurecht

- Gesamtkompetenz 52

- Kodifikation 47

- Kompetenzaufteilung $47 \mathrm{ff}$.

Baurechtsgutachten 47, $51 \mathrm{ff}$.

- Inhalt $51 \mathrm{ff}$.

- Kritik 53 ff.

- Wirkungen $51 \mathrm{ff}$.

Baustile 220

Bauweise

- geschlossene 39, 43, 103

- offene 43

- Traufgassen 43

Bauwich 37, 54

Bauzonenpläne 83

Bayerischer Senat 137

Beabsichtigte Gestaltung 167, 202 ff.

- rechtssatzmäßige Konkretisierung $203 \mathrm{ff}$.

- und positive Gestaltungspflege $208 \mathrm{ff}$.

Bebauungsbefugnis $77 \mathrm{ff}$.

Bebauungsplan 120

- Aufnahme von örtlichen Bauvorschriften 22 f., $226 \mathrm{ff}$., $287 \mathrm{ff}$.

- Beschlußfassung $230 \mathrm{f}$.

- Festlegung von Abstandsvorschriften 40

- Festsetzungen 228

- Konkretisierung der beabsichtigten Gestaltung 204

- Verfahren $229 \mathrm{ff}$.

- Vorrang gegen Abstandsflächenbestimmungen $39 \mathrm{f}$.

Beeinträchtigung der beabsichtigten $\mathrm{Ge}$ staltung 203

Befreiung 231, 269

Begründbarkeitskontrolle 279

Begründung

- Bedeutung für Abwägungskontrolle $260 \mathrm{ff}$.

- des Satzungsentwurfs 235

- "externe" $263 \mathrm{f}$.

- "interne" $264 \mathrm{f}$.

- von örtl. Bauvorschriften 239, $260 \mathrm{ff}$.

- von Satzungen 98, 233

Begründungspflicht

- Ableitung aus Art. 19 Abs. 4 GG $265 \mathrm{f}$

- Ableitung aus Eigentumsgarantie 269 ff.

- Ableitung aus Grundrechten $266 \mathrm{ff}$.

- Ableitung aus Rechtsstaatsprinzip $263 \mathrm{ff}$.

- als Verfahrenspflicht 262
- bei baugestalterischen Vorschriften $270 \mathrm{f}$.

- bei Schutzvorschriften $269 \mathrm{f}$.

- de lege ferenda $270 \mathrm{f}$.

Bekanntgabe $259 \mathrm{f}$.

Beratung bei Gestaltung 223

Berufsfreiheit 174

Beschlußfassung im Gemeinderat $230 \mathrm{f}$.

Beseitigung von Teilen baulicher Anlagen

- durch örtliche Bauvorschriften 35

- durch Stadterhaltungssatzungen 35

Besondere Anforderungen 31, $201 \mathrm{f}$.

Bestandsgarantie 173

Bestandskraft 239

Bestimmtheit

- der Verweisungen auf das BBauG $258 \mathrm{ff}$.

- von Rechtsverordnungsermächtigungen 162

Bestimmtheitsgrundsatz 167, 170, 179, $184,290 \mathrm{ff}$.

- als Grenze für umgebungsunabhängige Anforderungen 179, 184

- und Einfügungserfordernis 211

- und positive Gestaltungspflege $222 \mathrm{ff}$.

- von Ermächtigungsgrundlagen $224 \mathrm{f}$

- von Satzungsbestimmungen $222 \mathrm{ff}$.

- und Verweisungen $250 \mathrm{ff}$.

- und Wesentlichkeitstheorie $156 \mathrm{ff}$.

Beteiligungsgesellschaft 291

Beweislast $283 \mathrm{ff}$.

- Modifikation $284 \mathrm{f}$.

Bodenrecht

- Abstandsflächen 37 ff., 98 ff.

- als Planungsrecht 86 ff., 211

- finale Kompetenzabgrenzung $80 \mathrm{ff}$.

- geschichtliche Entwicklung $81 \mathrm{ff}$.

- Inanspruchnahme der Kompetenz durch Bund 38

- Umgrenzung im Baurechtsgutachten 52

- Umschlag in das 65

- und Denkmalschutzrecht $35 \mathrm{f}$.

- und Städtebaurecht 27

- Vergleich mit WRV 57

Bodenrechtliche Relevanz 35

Brückenwerbungsgesetz 191, 217

Bundesgesetzblatt 251

Bundesrechtskonforme Auslegung 238

Bundesstaatsprinzip 252

Dach

- Formen 53 f., 88

- geneigtes 24,88

Dachantennen

- Beschränkung 24, 31 
- aus anderen als gestalterischen Gründen 92

Dachaufbauten $172 \mathrm{f}$.

Dachausbauten $172 \mathrm{f}$.

Dachdeckung 287

Dachgauben 173 ff., 188

Dachgescho $B 103$

Dachgestaltung 103, 172, 241, 287, 289

- Begründung 270

- Berücksichtigung nachbarlicher Belange 109

- Rückwirkungen auf GFZ 109

- und Einfügungserfordernis 213

- und spezifischer Bodenbezug 88 (siehe auch "Flachdachbauweise")

Dachlandschaft 173, 287

Dachneigung 29, 175

Dekonzentration 154

Delegation 157

Demokratieprinzip 155

- und Verweisungen $251 \mathrm{ff}$.

Denkmalschutz

- Abgrenzung zum Städtebaurecht 48

- als Angelegenheit der Länder 34

- als gemeindliche Aufgabe 75

- als Ziel der Bauleitplanung 35

- durch Bauleitpläne 71, 81

- durch örtliche Bauvorschriften 32 ff., $95 \mathrm{ff}$.

- durch Stadterhaltungssatzungen $59 \mathrm{ff}$.

- Ensembleschutz 33,60

- Kompetenzfragen 59 ff., $95 \mathrm{ff}$.

- städtebaulicher 61 f., 96

- und gemeindliches Satzungsrecht $33 \mathrm{f}$.

- und Festsetzungen in Bebauungsplänen 35, 102

Denkmalschützende Vorschriften $31 \mathrm{ff}$., $95 \mathrm{ff}$.

Dispens

- von Abstandsflächenbestimmungen 39,42

Dokumentationsobliegenheit $260 \mathrm{f}$.

Doppelzuständigkeiten 49

Dualistisches System 107 ff.

- angebliche Verfassungswidrigkeit 118

- angebliches Verschwinden 150

Dynamische Verweisung 245

- Bedenken aus Demokratieprinzip 251 ff.

- und Internationales Privatrecht 253

- und Verkündung $250 \mathrm{f}$.

Dynamische Anknüpfung $249 \mathrm{f}$.

Effektiver Rechtsschutz 265 f.

Eigener Wirkungskreis 23, $108 \mathrm{ff}$., $139 \mathrm{ff}$.

- Pflichtaufgaben 129

- Regelungen im BauGB 111
- bei Aufnahme von örtl. Bauvorschriften in den Bebauungsplan 238

Eigentum

- Eingriff 135

- Privatnützigkeit $173 \mathrm{ff}$.

Eigentumsgarantie 224

- als Grenze für baugestalterische Anforderungen 179

- Bedeutung für Kompetenzaufteilung 49

- Inhalts- und Schrankenbestimmungen 49

- staatliche Schutzpflicht 98

- und Abstandsflächen 107

- und Baufreiheit 77

- und Bauleitplanung $76 \mathrm{f}$.

- und Begründungspflicht $269 \mathrm{ff}$

- und positive Gestaltungspflege $217 \mathrm{ff}$.

- und Schutzvorschriften 32

- und umgebungsabhängige Anforderungen 191

- und umgebungsunabhängige Anforderungen $177 \mathrm{ff}$.

- Wertentscheidung 76 (siehe auch "Grundeigentum")

Eigenverantwortlichkeit 114, 128

Einfriedungen 44, 111, 219, 270

Einfügungserfordernis $166,169 \mathrm{f}$.

- nach \$34 BauGB 99, 169, 211

- nach § 12 BayBO $210 \mathrm{ff}$.

Einsichtsrecht 262

Einvernehmenserfordernisse $223 \mathrm{f}$.

Einzelhandelsbetriebe

- großflächige 72

Energieversorgung 124

Ensemble 33, 60

Enteignung 51

Entwicklungsgebot 233

Erhaltung von Teilen baulicher Anlagen 35,102

Erhaltungssatzungen (siehe "Stadterhaltungssatzungen")

Erläuterung 261, 265

Ermessen 68

- des Landesgesetzgebers 232

- für die Wahl zwischen einfacher Satzung und Bebauungsplan 98, $287 \mathrm{ff}$.

- und Abwägung 238 ff., 276

Ermöglichungsfunktion von örtlichen Bauvorschriften $98 \mathrm{ff}$.

Erosion der kommununalen Selbstverwaltung $122 \mathrm{f}$.

Ersatzbauleitplanung 50

- bei Abstandsflächenbestimmungen 42, $97 \mathrm{f}$.

- bei Garagen und Stellplätzen 45

Erschließungsanlagen 82

Erweiterter Ungebungsschutz 214 ff., 290 
Exekutive 162

Exekutiventscheidungen 157

Facharztbeschluß 137

Fachaufsicht 108, 131

- als Eingriff in kommununale Selbstverwaltungsgarantie 134

- und kommununale Individualität 145

Fachplanung $79 \mathrm{f}$.

Fernwärme 124

Festsetzungen in Bebauungsplänen 228

- kompetenzrechtliche Anforderungen $87 \mathrm{ff}$.

- Überschneidungsprobleme $93 \mathrm{ff}$.

- und baugestalterische Vorschriften $28 \mathrm{ff}$.

Finanzhoheit $141 \mathrm{f}$.

Firstrichtung 223

- Festlegung in baugestalterischen Vorschriften 29 f., $93 \mathrm{ff}$.

- Festsetzung in Bebauungsplänen $29 \mathrm{f}$., $93 \mathrm{ff}$.

- Festlegung in denkmalschützenden Vorschriften 35, $95 \mathrm{ff}$.

Flachdachbauweise 92 ff., 213, 219, 229

- Änderung der 24 f., 234, 289

- öffentliches oder privates Interesse 77

Flachdachgarage $200 \mathrm{f}$.

Flächennutzungsplan

- Konkretisierung der beabsichtigten Gestaltung 204

- Rechtmäßigkeitskontrolle 111

- und Kernbereich der kommun. Selbstverwaltungsgarantie 120

Floatglas-Entscheidung $273 \mathrm{ff}$.

Fluchtlinienfestsetzungen 82 ff.

Flughafen München-II 277, 279

Formenverbot 162

Fremdverwaltung 109

Fremdverweisungen $250,252 \mathrm{ff}$.

Frühzeitige Bürgerbeteiligung 234

Fügen

- additives und divisives 66

Funktionelle Aufgaben 119, 124 ff.

Funktionelles Selbstverwaltungsverständnis $114 \mathrm{f}$.

\section{Garagen}

- Einschränkung von $45 \mathrm{f}$.

Garantie des effektiven Rechtsschutzes $265 \mathrm{f}$.

Gebäudehöhe 97

- und Abstandsflächen 39

- Festlegung nach Bauplanungsrecht 30 f., 95
- Festlegung in baugestalterischen Vorschriften $30 \mathrm{f}$., 101

Gebäudetiefe 97

- Festlegung nach Bauplanungsrecht 30, 95

- Festlegung in baugestalterischen Vorschriften 30,95

Gebietsbezogene Gestaltungspflege 24

Gebildeter Durchschnittsbetrachter 168 f., 183 ff., 199

- Versuch einer Konkretsierung 185 ff.

Gefälligkeitsbebauungsplan 80

Gefahrenabwehr 210

Gemeinderat

- Beschlußfassung 230 f., 244

- Geschäftsgang 259

Gemeindeparlament 136

Gemeindevolk 136

Gemeindliche Belange 144

Gemeindliche Individualität (siehe "kommunale Individualität")

Genehmigungspflicht 36, 56, $60 \mathrm{ff}$., 258 f.

- von örtlichen Bauvorschriften in Bebauungsplänen $245 \mathrm{ff}$.

Generalklauseln 22, 25, 32, 209 (siehe auch "Baugestalterische Generalklauseln")

Genuin gemeindliche Aufgaben 142 ff., 163,219

Geordnete städtebauliche Entwicklung 67 ff., 79, 81 (siehe auch

"städtebauliche Entwicklung und Ordnung")

Gesamtplanung 79

Geschoßflächenzahl 53, 94, 103

Geschoßhöhe 29, 103

Geschoßzahl 39, 53 f., 66, 103, 229

Gesetzesdeliberation 252

Gesetzesvorbehalt

- bei Art. 28 Abs. 2 S. 1 GG 114, 128 ff.

- demokratischer 135 ff., 293

- rechtsstaatlicher $135 \mathrm{ff}$.

Gesetzgebungskompetenz $47 \mathrm{ff}$.

Gesetzmäßigkeit der Verwaltung 122

Gestaltung 209

- einwandfreie166

- "globale" 64 ff., 99

Gestaltungsabsichten

- privatrechtliche Durchsetzung $291 \mathrm{ff}$.

Gestaltungskonzept 286

Gesundheitsschutz 92, 292

Gewerbepolitik

- durch Bauleitpläne 72

Gleichheitssatz 34

Grabgestaltung 178

Grundeigentum $49 \mathrm{ff}$.

- Planabhängigkeit 135 
Grundflächenzahl 53, 94 ff.

Grundrecht auf Umweltschutz 195

Grundrechte 219

- Ableitung von Verfahrensrechten $266 \mathrm{ff}$.

- auf Stadtgestaltung $194 \mathrm{f}$.

- und Art. 19 Abs. 2 GG

- und Baugestaltung 173 ff.

Grundschuld 256

Grundstücksfreiflächen 44

Grundstücksgrenze 38, 54, 98, 101

Gute Sitten 186

Harmonisches Minimum 200, 202

Hochzonung 124

Hypothekenrecht 256

Identifikationsverbot 182

- und positive Gestaltungspflege $220 \mathrm{ff}$.

Identität zwischen Regierenden und Regierten 252

Immunität 136

Indemnität 136

Informationsfreiheit 92

Inkrafttreten 233, $236 \mathrm{ff}$.

Innenbereich 39, 43, 90, $211 \mathrm{f}$.

Institutionelle Garantie $126 \mathrm{f}$.

- der kommunalen Selbstverwaltung $113,121,135$

- geschichtliche Entwicklung $121 \mathrm{f}$.

- und Kernbereich $126 \mathrm{f}$.

Integrationstheorie $156 \mathrm{ff}$.

Interessenausgleich 74

- bei Abwägung $241 \mathrm{ff}$.

- bei Festlegung der Firstrichtung 95

- bei örtlichen Bauvorschriften 103 ff., 235

- planerischer $87 \mathrm{ff}$.

Interessenkonflikte 74

Jugendstilfassade 188

Kernbereich der kommunalen Selbstverwaltung 113

- historische Betrachtungsweise 119

- Rechtsprechung des BVerfG $118 \mathrm{ff}$.

- und Bauleitplanung 119 ff., 127

- und örtliche Bauvorschriften $118 \mathrm{ff}$., $127 \mathrm{f}$.

- und Übermaßverbot 122

Kodifikation 47

Kompetenzblock $129 \mathrm{ff}$.

Kompetenzfragen 19 ff.

Körperliche Unversehrtheit 98
Kommunale Identität 140, $144 \mathrm{ff}$.

Kommunale Individualität 140

- und übertragener Wirkungskreis 145

- und kommunales Aufgabensystem 144

Kommunale Rechtssetzung

- und Gleichheitssatz 34

Kommunale Selbstverwaltung (siehe "Selbstverwaltungsgarantie")

Kompensationsmodell $126 \mathrm{f}$.

Kompetenzabgrenzung im Baurecht

- Problemfälle $26 \mathrm{ff}$., $36 \mathrm{f}$.

Kompetenzüberschneidungen 49

Kontrollverfahren 229, 236

Kontrollmaßstäbe 229

Kostentragung 263, 266

Kreise 133

Kreuzberg-Urteil 58, 83, 210

Kulturauftrag $180 \mathrm{ff}$.

Kulturgestaltungsmacht $180 \mathrm{ff}$.

Kulturstaatszielbestimmung $181 \mathrm{f}$.

Kumulierungstheorie $157 \mathrm{f}$.

Kunst 172, 221

- Staatsfreiheit 180

Kunstförderung $180 \mathrm{ff}$.

Kunstfreiheitsgarantie 174 ff., 182

Länder

- Aufgabenverlust 48

- Staatlichkeit 48

Länderkompetenzen $57 \mathrm{ff}$.

Landschaftsbildschutz, siehe Ortsbildschutz

Landschaftsschutz

- funktioneller 55

- optischer $55 \mathrm{f}$.

Legislative 162

Legitimation

- von Gemeinderäten 136

- von Parlamenten 136

Leistungsverbund $114 \mathrm{f}$.

Maß der baulichen Nutzung

- geschichtliche Entwicklung 83

- und Dachgestaltung 289

Menschenwürde 268

Memmingen-Beschluß $119 \mathrm{f}$.

Mietskasernen $82 \mathrm{ff}$.

Mitbestimmungsurteil 177

Mittelbare Entscheidungserheblichkeit 158

Mittelbare Staatsverwaltung 143

Monistisches System 107 ff., 150

Mülheim-Kärlich-Entscheidung $266 \mathrm{ff}$.

Musterbauordnung

- Abstandsflächenrecht 37

- Anforderungen an Baugestaltung 169 
- Kommission 52

- und Wirkungskreis 110

Nachbarliche Interessen 30, 94, 103, $235 \mathrm{ff}$.

Nachbarschutz

- durch Festlegungen in örtlichen Bauvorschriften 103

- bei Aufnahme von Bauvorschriften in den Bebauungsplan $235 \mathrm{f}$.

Negativplanung 69

Neukonzeption der kommununalen Selbstverwaltungsgarantie $114 \mathrm{ff}$.

Nichtbauliche Anlage 44

Nichtfachplanung 73

Nichtstörung des Ortsbildes 167

Non-liquet-Situation 284

Normbegünstigungstheorie 283

Normenerlaßverfahren $226 \mathrm{ff}$.

Normenkontrollklage 206, 283

- Statthaftigkeit 236 f., 244, 288

Öffentliche Belange $69 \mathrm{ff}$.

Öfentliche Sicherheit und Ordnung 22, $25,63,90,209 \mathrm{f}$.

Öffentliches Interesse $71 \mathrm{ff}$., $191 \mathrm{ff}$.

- an Eigentumsbindung $177 \mathrm{ff}$.

- bei positiver Gestaltungspflege $217 \mathrm{ff}$.

- Definitionsbefugnis $177 \mathrm{f}$.

Örtliche Bauvorschriften

- Abwägung $271 \mathrm{ff}$.

- als einfache Satzungen 259 ff.

- Aufnahme in den Bebauungsplan $22 \mathrm{f}$., $226 \mathrm{ff}$.

- Begriff 19

- Bekanntgabe $259 \mathrm{f}$.

- Beschlußfassung $230 \mathrm{f}$.

- Darstellung $259 \mathrm{f}$.

- historische Vorläufer 22

- kompetenzrechtliche Einordnung $102 \mathrm{ff}$.

- materiellrechtliche Anforderungen 271 ff.

- Normenerlaßverfahren 226 ff.

- Regelungsbereiche $24 \mathrm{ff}$.

- und Kernbereich der kommunalen Selbstverwaltungsgarantie $118 \mathrm{ff}$.

- und kommunale Aufgabensysteme $107 \mathrm{ff}$.

- und umgebungsunabhängige Anforderungen $187 \mathrm{ff}$.

- Verhältnis zu Stadterhaltungssatzungen 64

Örtliche Radizierung 138

Örtliche Situation 87

Örtlichkeitsmerkmal 131 ff.
Organleihe 152

Ortsbildgestaltung

- als abwägungserheblicher Belang 28

Ortsbildschutz 32, 104, 144, 199, 215

- für beabsichtigte Gestaltung $202 \mathrm{ff}$.

- durch Generalklauseln 197 ff.

- durch Stadterhaltungssatzungen 35

- durch Bauleitpläne 64

- durch Generalklauseln 166, 190

- gemeinsame Verantwortung 48

- im Bauplanungsrecht 96

- nach MBauO 169

Parallelgesetzgebung 252

Parlamentsentscheidungen 157

Parlamentsgesetz 256

Parlamentsvorbehalt 156 (siehe auch "Wesentlichkeitstheorie")

Persönlichkeitsrecht 174

Personalhoheit $141 \mathrm{f}$.

Pflichtaufgaben nach Weisung $108 \mathrm{f}$.

Planeinheit 234

Planerischer Interessenausgleich 87 ff., $110 \mathrm{ff}$.

Planersatzmaßstäbe 90

Planklarheit 228

Planrechtfertigung

- bei Bebauungsplänen 69 ff., 75

- Begründung des Erfordernisses $78 \mathrm{f}$.

- durch öffentliche Belange $69 \mathrm{ff}$.

- durch private Belange 76 ff., 79

Planung $88 \mathrm{ff}$., $242 \mathrm{f}$.

- beim Erlaß örtlicher Bauvorschriften 242,272

- nach bauordnungsrechtlichen Grundlagen $105 \mathrm{f}$.

- und Abwägung $272 \mathrm{f}$.

Planungsbedürfnis $212 \mathrm{f}$.

Planungsermessen 72

Planungshoheit 113, 126

- und Kernbereich der kommunalen Selbstverwaltung 119

- und Selbstgestaltungsrecht 141

Planungsinstrumentarium

- geschichtliche Entwicklung $82 \mathrm{ff}$.

Planungsrecht

- geschichtliche Entwicklung $81 \mathrm{ff}$.

- und Abstandsflächen 37

Planungszusammenhang 229, 231, 238

Planzusammenhang 229, 231

Politische Entscheidung

- über Örtlichkeit einer Aufgabe 132

Polizeibegriff 57 ff., 150

Polizeiliche Generalklausel 84

Polizeirecht 23 (siehe auch "Sicherheitsrecht")

Polizeiverordnung 150 
Positive Gestaltungspflege 203, 208 ff., 290

- Begriff $214 \mathrm{ff}$.

- Begründungspflicht 270

- durch baugestalterische Vorschriften $214 \mathrm{ff}$.

- durch Schutzvorschriften $216 \mathrm{ff}$.

- und Bestimmtheitsgrundsatz 222

- und Identifikationsverbot $220 \mathrm{ff}$.

- verfassungsrechtliche Zulässigkeit $217 \mathrm{ff}$.

Präambeln $269 \mathrm{f}$.

Preußische Verunstaltungsgesetze $57 \mathrm{ff}$., 190 f., 210

PreuBisches Fluchtliniengesetz 82

Preußisches Wohnungsgesetz 85

Private Belange $76 \mathrm{ff}$.

Privatrechtliche Durchsetzung von Gestaltungsabsichten $291 \mathrm{ff}$.

- verfahrensrechtliche Sicherungen $292 \mathrm{ff}$.

Programmiermaßstäbe 155

Proportionalitätsprüfung 242

ProzeB risiko 263, 266

Prüfungsmaßstab 112

Qualifikationsfehler 114, $130 \mathrm{f}$.

Raumbedeutsamkeit 87

Rechtmäßigkeitskontrolle 138, 146, 229 , 236

Rechtsstaatsprinzip 155, 204, 239

- Ableitung des Ubermaßverbotes $116 \mathrm{f}$.

- Ableitung einer Begründungspflicht $263 \mathrm{ff}$.

- und Abwägung 74

- und dynamische Verweisungen $247 \mathrm{ff}$.

Rechtsverordnung 111, $146 \mathrm{ff}$.

- als Instrument gemeindlicher Selbstgestaltung $146 \mathrm{ff}$.

- Bund und Länder 254

- Geltungsgrund 152

- im eigenen Wirkungskreis 150

- Unterscheidung zur Satzung $152 \mathrm{ff}$.

Rechtsverordnungsermächtigung

- Abgrenzung zum Bereich des formellen Gesetzes $156 \mathrm{ff}$.

- Bestimmtheit 158 ff., 163

- in der Weimarer Republik $161 \mathrm{f}$.

- Umwandlung in Satzungsermächtigung 112, $147 \mathrm{f} ., 149$

- und formelles Gesetz

- Verwendung in der Rechtsordnung $148 \mathrm{ff}$.

Regelungsziele

- im Bauordnungsrecht 36, 74 ff., 93 ff.
- im Bauplanungsrecht 36, 61, 74 ff., 93 ff., 102

Rücksichtnahmeklauseln 167, 198

Sächsisches Baugesetzbuch (siehe "Allgemeines Baugesetz")

Satteldach 200

Satzung $146 \mathrm{ff}$., $259 \mathrm{ff}$.

- als Instrument der Regelung eigener Angelegenheiten 110

- als Instrument gemeindlicher Selbstgestaltung $146 \mathrm{ff}$.

- Begründung $260 \mathrm{ff}$.

- Bekanntgabe $259 \mathrm{f}$.

- Definition 147

- Geltungsgrund 152

- im übertragenen Wirkungskreis 112, 147 f., 149

- ohne rechtsverbindliche Festsetzung $290 \mathrm{ff}$.

- und Daseinsvorsorge 148

- Unterscheidung zur Rechtsverordnung $152 \mathrm{ff}$.

- Verfahren $259 \mathrm{ff}$.

Satzungsautonomie 151, 155

Satzungsermächtigung

- Bestimmtheit 158 ff.

- Nichtanwendung des Art. 80 GG 160

- Verwendung in der Rechtsordnung $148 \mathrm{ff}$.

Satzungshoheit 142

Schubladenpläne $205 \mathrm{ff}$.

Schutzvorschriften $95 \mathrm{ff}$.

- Begriff $31 \mathrm{ff}$.

- für Gebäude unter Denkmalschutz 34

- und baugestalterische Vorschriften $31 \mathrm{ff}$.

- und Bauplanungsrecht $34 \mathrm{ff}$.

- und Begründungspflicht $269 \mathrm{f}$.

- und Denkmalschutz 32

- Unterschiede zu baugestalterischen Vorschriften 32

Sekundärwirkungen 72

Selbstgestaltungsrecht 116, $139 \mathrm{ff}$.

- Definition 141

- Einordnung 141

- gesetzliche Beschränkungen $144 \mathrm{f}$.

- und Grundrechtseinsch ränkungen 219

Selbstkontrolle $263 \mathrm{ff}$.

Selbstverwaltungsaufgaben 107

Selbstverwaltungsgarantie $107 \mathrm{ff}$.

- alternative Konzeptionen $114 \mathrm{ff}$.

- Stärkung der 116

Sicherheitsrecht 38 (siehe auch "Polizeirecht")

Siedlungswesen 52

Situationsgebundenheit 49 
Sozialbindung des Eigentums

- und umgebungsunabhängige Anforderungen $176 \mathrm{ff}$.

Sozialpflichtigkeit des Eigentums 49

Sozialstaatsprinzip 196

Sperrwirkung des $\$ 9$ Abs. 1 BauGB 227

Spielhallen 72 f., 88

Staatsaufgaben 107

Staatsaufsicht 108

Staatszielbestimmungen 195

Stadtästhetik 92

Stadtbildanalyse $269 \mathrm{f}$.

Stadtbildpflege 170, 196

Stadterhaltungsssatzungen $35 \mathrm{ff}$., $95 \mathrm{ff}$., 196

- kompetenzrechtliche Rechtfertigung $59 \mathrm{ff}, 88 \mathrm{f}$.

- verfassungsrechtliche Verpflichtung zum ErlaB 196

Stadterweiterungen 82

Stadtgestalt

- psychische Wirkungen 98

- verfassungsrechtliche Absicherung $193 \mathrm{ff}$.

Stadtgestaltung $193 \mathrm{f}$.

- als einheitliche Aufgabe $108 \mathrm{f}$.

- Gesamtkonzept 241, 286 f.

- mit bauplanungsrechtlichen Instrumenten 64

Stadtplanung

- als künstlerische Aufgabe 98

Stadtsilhouette 75

Stadtstaaten 21

Städtebauliche Absichten

- als Kompetenzproblem 26 ff., $91 \mathrm{ff}$.

- bei Stadterhaltungssatzungen $62 \mathrm{f}$.

- und Bauästhetik 26

- und baugestalterische Absichten $27 \mathrm{f}$.

- und Flachdachfälle 76

- verfassungskonforme Interpretation 27

Städtebauliche Entwicklung und Ordnung $62 \mathrm{ff}$.

- als einheitliche Aufgabe $84 \mathrm{ff}$.

- bei Stadterhaltungssatzungen $62 \mathrm{f}$.

- Konkretisierung $68 \mathrm{ff}$. (siehe auch "geordnete städtebauliche Entwicklung")

Städtebauliche Gründe

- Einsatz bauordnungsrechtlicher Instrumente 46

- für die Verringerung von Abstandsflächen $42 \mathrm{f}$.

Städtebauliche Mißstände 84

Städtebauliche Planung 52

Städtebauliche Qualität 65, 66, 71

Städtebaulicher Bezug $59 \mathrm{ff}$.

- und Bodenrecht $86 \mathrm{ff}$.
Städtebaulicher Denkmalschutz $61 \mathrm{ff}$.

Städtebaurecht 27, $97 \mathrm{ff}$.

- Abgrenzung zum Denkmaischutzrecht 48

- und sondergesetzliche Materien 47 (siehe auch "Bodenrecht")

Statische Verweisung (siehe "Verweisung")

Statuarische Bestimmungen 149

Status negativus 182

Stellplätze

- Einschränkung von 45 f., 94

Stellung der baulichen Anlage 30

Straßen

- Planung von 82

Straßenbildschutz (siehe "Ortsbildschutz")

Straßenrecht 56, 62, 79

Straßenunterhaltung 149

Straßenverkehrsrecht 56, 62

Subjektiv-öffentliches Recht 77

- auf Stadtgestaltung 194

Subsidiaritätsprinzip 145

Substraktionstheorie 123

Teile baulicher Anlagen 35, 96

Teilhaberechte 194

Teilungsgenehmigung 56, 63, 90

Traufgassen $43 \mathrm{ff}$.

Traufhöhe 103

Übermaßverbot 241, 271, 287

- Ableitung $116 \mathrm{f}$.

- bei Baubeseitigungsanordnung $290 \mathrm{f}$.

- bei gestalterischen Anforderungen 194

- bei Eingriffen in Art. 28 Abs. 2

S. 1 GG 116 f., 121, 123, 132

- und Abwägung $241 \mathrm{f}$.

- und Baufreiheit 78

- und Kernbereich der kommunalen Selbstverwaltungsgarantie $122 \mathrm{f}$.

- unter der WRV 122

Übertragene Angelegenheiten 109

Übertragener Wirkungskreis $108 \mathrm{ff}$.

- Aufwertung 146

- und Aufnahme von örtl. Bauvorschriften in den Bebauungsplan 235, 238

- und Selbstgestaltung $139 \mathrm{ff}$.

Uferbauverbot 55

Umgebungsabhängige Anforderungen $166 \mathrm{ff}$.

- Konkretisierung durch örtliche Bauvorschriften $200 \mathrm{ff}$.

- Reichweite $197 \mathrm{ff}$.

- Vergleich mit umgebungsunabhängigen Anforderungen $198 \mathrm{ff}$. 
Umgebungsunabhängige Anforderungen $166,176 \mathrm{ff}$.

- Rechtsprechung 188

- Relevanz für örtliche Bauvorschriften $188 \mathrm{f}$.

(siehe auch "Baugestalterische Anforderungen")

Unmittelbarkeitsformel 53 ff., 97

Verfahren

- bei Aufnahme von örtlichen Bauvorschriften $231 \mathrm{ff}$.

- beim Erlaß örtlicher Bauvorschriften $259 \mathrm{ff}$.

Verfahrensgestaltung $266 \mathrm{ff} ., 292 \mathrm{ff}$.

Verfassungskonforme Auslegung 187

- der Baugestaltungsverordnung 168

- der BayBO 27, 91 f.

Verkündung $250 \mathrm{f}$.

Verordnung (siehe "Rechtsverordnung")

Verteidigungspolitik 133

Verunstaltung

- Begriff 168

- der beabsichtigten Gestaltung 202 ff.

- Konkretisierung 240 f., 243

- Maßstab 183 ff.

Verunstaltungsschutz

- Beschränkung örtlicher Bauvorschriften auf den 25

- durch Bebauungspläne 70

- durch Generalklauseln 165 ff.

- für Straßen- und Ortsbild 166 f. (siehe auch unter "Baugestalterische Anforderungen")

Verwaltungsakt 223, 240, 267

Verweisung $237 \mathrm{f}$., $244 \mathrm{ff}$.

- Arten $245 \mathrm{ff}$.

- echte oder unechte $247 \mathrm{f}$.

- im engeren Sinn $247 \mathrm{f}$.

- Rechtsprechung des BVerfG 250
Verweisungsanalogie $248 \mathrm{f}$.

Vier-Augen-Prinzip 264

Vollgeschoß 103

Vorbehalt der Satzung 293

Vorbehalt des Gesetzes 155

Wanderungsprozesse $124 \mathrm{f}$.

Weinheimer Entwurf 108

Werbeanlagen $104 \mathrm{ff}$.

- als baugebietswidrige Anlagen 205, $218 \mathrm{f}$.

- Allgemeine Problcmatik 21

- Anforderungen in örtlichen Bauvorschriften $21 \mathrm{f}$.

- Anforderungen in baugestalterischen Vorschriften 29

- AusschluB in Schutzvorschriften 32

- Beschränkung der Ausrichtung auf Bundesstraßen 24

- Kompetenzfragen 62, 64

Wände 54

Werkgerechte Durchbildung 166, 167, 199)

Wertvorstellungen 171

Wesensgehalt (siehe "Kernbercich")

Wesentlichkeitstheorie 135, $155 \mathrm{ff}$., $224 \mathrm{f}$.

- bei Verweisungen 258

- im Gemeinderecht 293

- und Art. 80 GG 156 ff.

Wohlfahrtspflege 57 f., 209 ff.

Wohnungswesen 52,58

Zeichnerische Darstcllung 260

Zusammenwirkung von Entscheidungsträgern 264

Zuständigkeitsvermutung 133

Zweckmäßigkeitskont rollc 10\%, 129) (f., $145,229,235 \mathrm{f}$.

Zweckprogrammicrung 81,145

Zweitwohnungssteuer 137 


\section{Lebenslauf}

12.09.1959

1966-1969

1969-1978

Mai 1978

$1978-1980$

Nov. 1980

Okt. 1982 -

Juni 1983

Januar 1985

Januar 1986

April 1986 -

März 1989

März 1989

April 1989

Februar 1990

Seit 28.12.1987
Geboren in Leer /Ostfriesland, Deutscher Staatsangehöriger

Besuch der Hoheellernschule in Leer

Besuch des Ubbo-Emmius-Gymnasiums in Leer

Reifeprüfung

Ausbildung zum Bankkaufmann bei der Deutschen Bank AG, Filiale Leer

Beginn des Jurastudiums an der Universität Regensburg

Studium an der Universität Genf

Beginn der Beschäftigung am Lehrstuhl für Öffentliches Recht, insbesondere Deutsches und Bayerisches Staats- und Verwaltungsrecht (Prof. Dr. Steiner)

Ablegung des Ersten Juristischen Staatsexamens in Regensburg

Referendarzeit in Regensburg und beim Bayerischen Verwaltungsgerichtshof in München

Ablegung des Zweiten Juristischen Staatsexamens

Ernennung zum Wissenschaftlichen Assistenten a. Z.

Promotion zum Dr. jur.

verheiratet mit Heike Manssen geb. Jungeblut, ein Kind (Lena, geb. 12.03.1989) 